\title{
DISPOSIÇÃO DE LODO DE ESGOTO E COMPOSTO DE LIXO URBANO NUM LATOSSOLO VERMELHO-AMARELO CULTIVADO COM CANA-DË-AÇÚCAR
}

\author{
FERNANDO CARVALHO OLIVEIRA \\ Engenheiro Agrônomo
}

Orientador: Prof ${ }^{\mathfrak{a}}$ Dr $^{\mathrm{a}}$ MARIA EMILIA MATTIAZZO-PREZOTTO

Tese apresentada à Escola Superior de Agricultura "Luiz de Queiroz", Universidade de São Paulo, para obtenção do título de Doutor em Agronomia. Área de Concentração: Solos e Nutrição de Plantas.

PIRACICABA

Estado de São Paulo - Brasil

Janeiro - 2000 


\section{Dados Internacionais de Cotalogação na Publicação (CIP) DIVISÃo DE BIBLIOTECA E DOCUMENTAÇÃo - Compus "Luiz de Queiroz"/USP}

\section{Oliveira, Fernando Carvalho}

Disposição de lodo de esgoto e composto de lixo urbano num latossolo vermelhoamarelo cultivado com cana-de-açúcar / Fernando Carvalho Oliveira. - - Piracicaba, 2000.

247 p.: il.

Tese (doutorado) - Escola Superior de Agricultura Luiz de Queiroz, 2000.

Bibliografia.

1. Cana-de-açúcar 2. Efeito residual 3. Latossolo vermelho-amarelo 4. Lixo doméstico 5. Lodo de esgoto 6. Metal pesado 7. Química do solo I. Título

CDD 631.41

Permitida a cópia total ou parcial deste documento, desde que citada a fonte - 0 autor" 
À minha esposa Lenita e ao meu filho Gabriel, Dedico 


\section{AGRADECIMENTOS}

À Prof ${ }^{\mathrm{a}} \mathrm{Dr}^{\mathrm{a}}$ Maria Emilia Mattiazzo-Prezotto, pela orientação, amizade e apoio em todas as decisões tomadas durante o curso de pós graduação;

À Fundação de Amparo à Pesquisa do Estado de São Paulo (FAPESP), pela bolsa de estudos concedida e pelo auxílio pesquisa que viabilizou este trabalho;

Ao Dr. Cláudio Roberto Marciano, grande amigo e parceiro na realização deste trabalho, pelo convívio saudável durante os cursos de mestrado e doutorado e pela inestimável contribuição em todas as etapas de execução do experimento;

À $\operatorname{Dr}^{\mathrm{a}}$ Raffaella Rossetto e ao Dr. Léo Zimback, pesquisadores da Estação Experimental de Agronomia do IAC em Piracicaba, pelo apoio e concessão da área experimental;

À todos os funcionários da Estação Experimental de Agronomia do IAC em Piracicaba, especialmente ao técnico Marcelo Alex Gil, pela atenção e apoio dispensados à execução das atividades de campo;

Ao Prof. Dr. Sérgio Oliveira Moraes, pelo suporte dado a este trabalho;

Ao Prof. Dr. Arnaldo Antonio Rodella, pelos ensinamentos em Química Analítica e pela orientação na montagem do sistema FIA;

Ao Prof. Dr. Marcos Omir Marques (FCAV/UNESP) pelas sugestões na redação desta tese;

Aos Profs. Drs. Nadir Almeida da Glória, José Carlos Chitolina, Edgar G. F. de Beauclair, José Carlos Alcarde e Arquimedes Lavorenti pela amizade e o convívio desses anos;

À todos os funcionários do Setor de Química do Departamento de Ciências Exatas, especialmente aos técnicos Lenita M. de C. Pacheco e Oliveira, Carlos Rubini Júnior, Janaína Truffi, e às secretárias Maria Angélica P. Bernardino e Armelinda T. Assef, pela ótima convivência de todos esses anos e principalmente por estarem sempre dispostos a colaborar;

Ao técnico Francisco Bernardo Dias, pertencente ao Laboratório de Física do Solo do Departamento de Ciências Exatas, pela colaboração nas atividades de campo;

Aos colegas pós-graduandos do setor de Química do Departamento de Ciências Exatas;

Enfim, a todos que direta ou indiretamente colaboraram para a realização deste trabalho. 


\section{SUMÁRIO}

Página

LISTA DE FIGURAS........................................................................................ vii

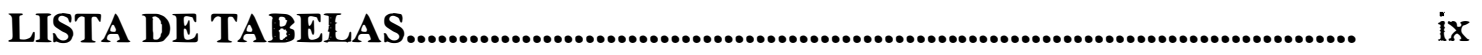

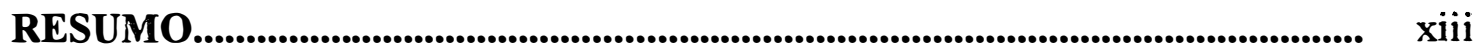

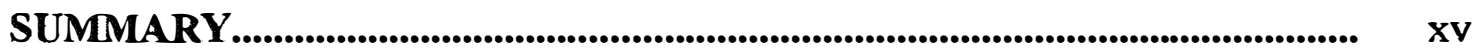

1 INTRODUÇÃ

2 REVISÃO DE LITERATURA............................................................................ 3

2.1 Geração de resíduos nos centros urbanos............................................................. 3

2.2 Conceitos, caracterização e potencial agronômico dos resíduos............................... 5

2.3 Critérios para aplicação de resíduos orgânicos urbanos em solos agrícolas............. 13

2.4 Efeitos da aplicação de resíduos urbanos em atributos do solo.............................. 18

2.4.1 Carbono orgânico............................................................................... 18

2.4.1.1 Degradação da carga orgânica dos resíduos no solo................................ 20

2.4.1.2 Cinética da degradação da carga orgânica de resíduos............................ 25

2.4.2 Condutividade elétrica e $\mathrm{pH}$................................................................... 26

2.4.3 Capacidade de troca de cátions............................................................. 31

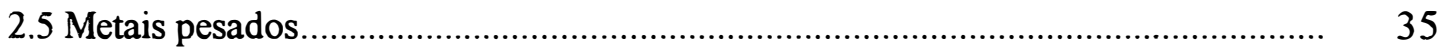

2.5.1 Fatores que interferem no comportamento dos metais pesados no solo......... 35

2.5.2 Acúmulo de metais pesados nos solos e nas plantas.................................. 37

2.5.3 Mobilidade dos metais pesados no solo..................................................... 43

2.5.4 Avaliação da fitodisponibilidade de metais pesados.................................... 54

2.6 Dinâmica, no solo, do nitrogênio aplicado via resíduos urbanos........................... 60

3 MATERIAL E MÉTODOS.............................................................. 73

3.1 Caracterização da área experimental........................................................... 73

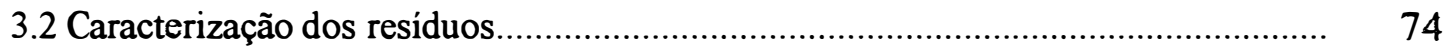

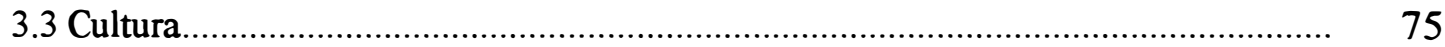

3.4 Delineamento experimental e tratamentos.................................................... 76 


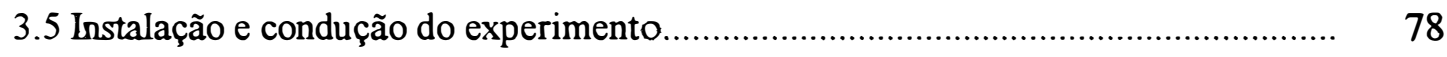

3.5.1 Instalação dos tensiômetros e extratores de solução do solo............................. 83

3.5.2 Coleta e preparo das amostras de solo ........................................................... 84

3.5.3 Coleta e preparo das amostras de planta..................................................... 85

3.5.4 Extração e preparo das amostras de solução do solo......................................... $\quad 86$

3.6 Cronograma das atividades realizadas no campo................................................. 86

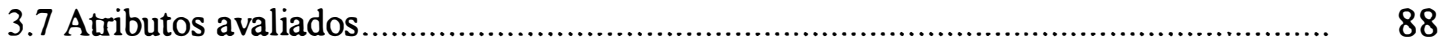

3.7.1 Produtividade da cana-de-açúcar.................................................................. 88

3.7.2 Carbono orgânico ................................................................................. 88

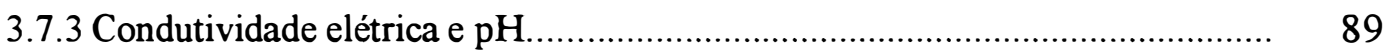

3.7.4 Capacidade de troca de cátions................................................................... 90

3.7.5 Metais pesados no solo e nas plantas......................................................... $\quad 90$

3.7.5.1 Avaliação da fitodisponibilidade de metais pesados................................... 91

3.7.6 Mobilidade de metais pesados no solo.......................................................... 91

3.7.7 Lixiviação de nitrato e amônio ...................................................................... 91

3.7.7.1 Determinação dos teores de $\mathrm{N}$-total e $\mathrm{N}-\mathrm{NO}_{3}{ }^{-}+\mathrm{N}^{-} \mathrm{NH}_{4}{ }^{+}$no solo.............. 92

3.7.7.2 Determinação dos teores de $\mathrm{N}-\mathrm{NO}_{3}{ }^{-}$e N-NH${ }_{4}^{+}$na solução do solo........... 92

3.7.7.3 Fluxo de água no solo............................................................................ 94

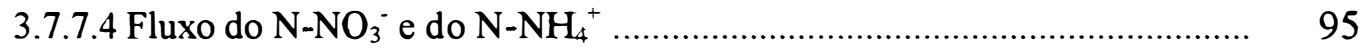

3.8 Tratamento estatístico dos dados..................................................................... 95

4 RESULTADOS E DISCUSSÃO_.............................................................. 99

4.1 Lodo de esgoto................................................................................................. 99

4.1.1 Produtividade da cana-de-açúcar ................................................................... 99

4.1.2 Carbono orgânico................................................................................ 102

4.1.3 Condutividade elétrica e pH.................................................................... 109

4.1.4 Capacidade de troca de cátions .................................................................. 117

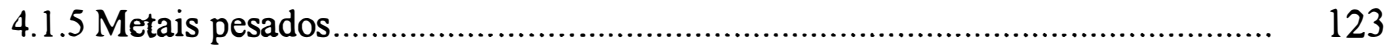

4.1.5.1 Acúmulo de metais pesados no solo e nas plantas.................................... 123

4.1.5.2 Mobilidade de metais pesados no solo .................................................... 133

4.1.5.3 Avaliação da fitodisponibilidade de metais pesados.................................. 139 


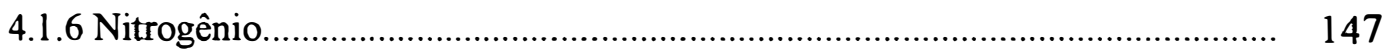

4.1.6.1 Lixiviação de nitrato e amônio.................................................................. 147

4.1.6.2 Acúmulo de nitrogênio no solo............................................................ 159

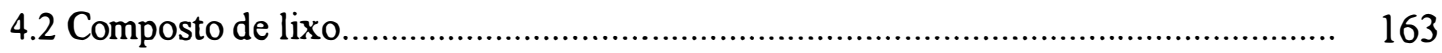

4.2.1 Produtividade da cana-de-açúcar................................................................... 163

4.2.2 Carbono orgânico................................................................................ 165

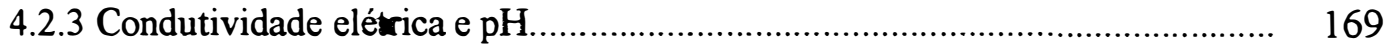

4.2.4 Capacidade de troca de cátions................................................................... 176

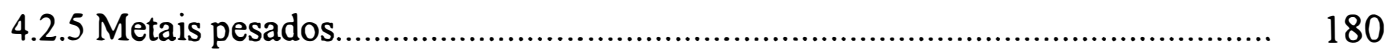

4.2.5.1 Acúmulo de metais pesados no solo e nas plantas................................... 180

4.2.5.2 Mobilidade de metais pesados no solo.................................................... 188

4.2.5.3 Avaliação da fitodisponibilidade de metais pesados................................... 191

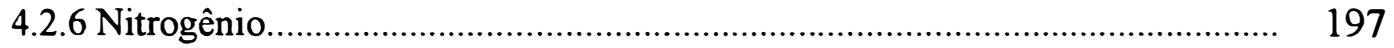

4.2.6.1 Lixiviação de nitrato e amônio................................................................... 197

4.2.6.2 Acúmulo de nitrogênio no solo............................................................. 205

5 APRECIAÇÃO GERAL DOS RESULTADOS OBTIDOS............................. 208

6 CONCLUSÕES.................................................................................................... 212

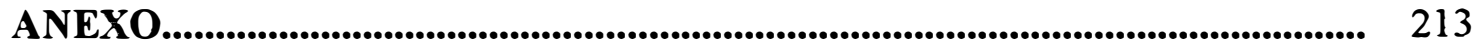

REFERÊNCIAS BIBLIOGRÁFICAS..................................................... 216

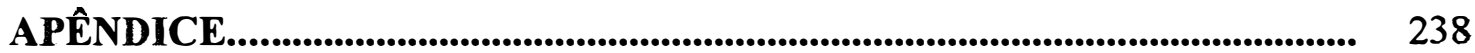




\section{LISTA DE FIGURAS}

Página

1 Principais processos de transformação, no solo, do nitrogênio orgânico contido em resíduos.

2 Croqui da área experimental.

3 Transporte, aplicação e distribuição manual dos resíduos nas parcelas experimentais, no ano agrícola 1996/97

4 Qualidade da distribuição dos resíduos nas parcelas experimentais no ano agrícola 1996/97.

5 Aspecto do lodo de esgoto após período de pré-secagem, sistema de incorporação dos resíduos e homogeneidade da incorporação no ano agrícola $1996 / 97$.

6 Aspecto geral dos extratores de solução do solo e tensiômetros instalados na área experimental no ano agrícola 1997/98.

7 Sistema de pesagem dos colmos de cana-de-açúcar, dentro da área útil de cada parcela, para determinação da produtividade

8 Sistema de análise em fluxo contínuo utilizado para determinação de $\mathrm{N}^{-\mathrm{NO}_{3}{ }^{-} .}$

9 Sistema de análise em fluxo contínuo utilizado para determinação de $\mathrm{N}-\mathrm{NH}_{4}^{+}$.

10 Produtividades da cana-de-açúcar $\left(\mathrm{Mg} \mathrm{ha}^{-1}\right)$ obtidas nos anos agrícolas 1996/97 e 1997/98 para o experimento com lodo de esgoto.

11 Comparação entre precipitações mensais ocorridas na área experimental nos anos agrícolas 1996/97 e 1997/98 com as médias ocorridas em Piracicaba, SP considerando-se um período de retorno de 82 anos.

12 Decréscimo do carbono orgânico adicionado ao solo via lodo de esgoto, nos anos agrícolas de 1996/97 e 1997/98, ajustado a um modelo de cinética de primeira ordem.

13 Capacidade de troca de cátions do solo no decorrer dos anos agrícolas 1996/97 e 1997/98 para os tratamentos com doses de lodo de esgoto e calagem + adubação mineral

14 Relações entre CTC e pH, CTC e teores de carbono orgânico do solo no experimento com lodo de esgoto. 
15 Relações entre teores de cobre nas amostras de folha, colmo e caldo da cana-de-açúcar e teores totais determinados no solo no experimento com lodo de esgoto

16 Relações entre teores de zinco nas amostras de folha, colmo e caldo da cana-de-açúcar e teores totais determinados no solo no experimento com lodo de esgoto

17 Concentração média e desvio padrão de $\mathrm{N}-\mathrm{NO}_{3}{ }^{-}$na solução do solo determinados a $0,3,0,6$ e $0,9 \mathrm{~m}$ de profundidade, para os tratamentos com doses de lodo de esgoto e ad. mineral, no decorrer do ano agricola 1997/98.

18 Teores de $\mathrm{N}$-total, $\mathrm{N}$-orgânico e $\mathrm{N}-\mathrm{NO}_{3}{ }^{-}+\mathrm{N}-\mathrm{NH}_{4}{ }^{+}$determinados no solo, em profundidade, ao final dos anos agrícolas 1996/97 e 1997/98, no experimento com lodo de esgoto

19 Produtividades da cana-de-açúcar $\left(\mathrm{Mg} \mathrm{ha}^{-1}\right)$ obtidas nos anos agrícolas 1996/97 e 1997/98 para o experimento com composto de lixo.

20 Decréscimo do carbono orgânico adicionado ao solo via composto de lixo, nos anos agrícolas de 1996/97 e 1997/98, ajustado a um modelo de cinética de primeira ordem

21 Capacidade de troca de cátions do solo no decorrer dos anos agrícolas 1996/97 e 1997/98 para o tratamentos com doses de composto de lixo e calagem + adubação mineral.

22 Relações entre CTC e pH, CTC e teores de carbono orgânico do solo no experimento com composto de lixo.

23 Relações entre teores de cobre nas amostras de folha, colmo e caldo da cana-de-açúcar e teores totais determinados no solo no experimento com composto de lixo.

24 Relações entre teores de zinco nas amostras de folha, colmo e caldo da cana-de-açúcar e teores totais determinados no solo no experimento com composto de lixo

25 Concentração média e desvio padrão de $\mathrm{N}_{-} \mathrm{NO}_{3}{ }^{-}$na solução do solo determinados a $0,3,0,6$ e $0,9 \mathrm{~m}$ de profundidade, para os tratamentos com doses de composto de lixo e ad. mineral, no decorrer do ano agrícola 1997/98

26 Teores de $\mathrm{N}$-total, $\mathrm{N}$-orgânico e $\mathrm{N}-\mathrm{NO}_{3}{ }^{-}+\mathrm{N}_{-} \mathrm{NH}_{4}{ }^{+}$determinados no solo, em profundidade, ao final dos anos agricolas 1996/97 e 1997/98, no experimento com composto de lixo. 


\section{LISTA DE TABELAS}

Página

1 Critérios para aplicação de lodo de esgoto em solos agrícolas, baseados na presença de metais pesados, preconizados pela USEPA (1993) e adotados pela CETESB (1998).....

2 Principais caracteristicas químicas e fisicas do Latossolo Vermelho-Amarelo..

3 Composição química parcial das duas remessas de lodo de esgoto e composto de lixo utilizadas no experimento

4 Doses dos residuos empregadas em cada tratamento, dentro de cada ano experimental, e seus valores equivalentes em carbono orgânico, nitrogênio total e nitrogênio inorgânico $\left(\mathrm{N}-\mathrm{NO}_{3}{ }^{-}+\mathrm{N}-\mathrm{NH}_{4}^{+}\right)$.

5 Cronograma das atividades realizadas no campo nos dois anos agricolas.

6 Esquema da análise de variância utilizado para a variável produtividade da cana-de-açúcar em cada experimento.

7 Esquema da análise de variância utilizado para as variáveis carbono orgânico, gradiente de carbono, condutividade elétrica, $\mathrm{pH}$ e CTC do solo e seus respectivos graus de liberdade.

8 Esquema da análise de variância utilizado para as variáveis condutividade elétrica, $\mathrm{pH}$, metais pesados, nitrogênio (total e inorgânico) avaliados em função da profundidade de coleta da amostra e seus respectivos graus de liberdade

9 Teores de carbono orgânico do solo $\left(\mathrm{g} \mathrm{kg}^{-1}\right)$ determinados para doses de lodo de esgoto em diversas épocas de amostragem, dentro dos anos agrícolas $1996 / 97$ e $1997 / 98$

10 Condutividade elétrica do solo $\left(\mu \mathrm{S} \mathrm{cm}^{-1}\right)$ determinada, na camada de 0 - 0,2 m, para doses de lodo de esgoto em diversas épocas de amostragem, dentro dos anos agrícolas 1996/97 e 1997/98.

11 Condutividade elétrica do solo $\left(\mu \mathrm{S} \mathrm{cm}^{-1}\right)$ determinada nas camadas de $0-0,2$, $0,2-0,4,0,4-0,6$ e $0,6-0,8 \mathrm{~m}$, aos 360 dias após incorporação de doses de lodo de esgoto nos anos agrícolas 1996/97 e 1997/98.

12 Valores pH do solo determinados para doses de lodo de esgoto em diversas épocas de amostragem, dentro dos anos agrícolas 1996/97 e 1997/98. 
13 Valores $\mathrm{pH}$ do solo determinados nas camadas de $0-0,2,0,2-0,4,0,4-0,6$ e $0,6-0,8 \mathrm{~m}$, aos 360 dias após incorporação de doses de lodo de esgoto nos anos agrícolas 1996/97 e 1997/98

14 Teores totais de $\mathrm{Cu}, \mathrm{Cr}, \mathrm{Ni}$ e $\mathrm{Zn}$ recuperados do solo na camada $0-0,2 \mathrm{~m}$, nos anos agrícolas 1996/97 e 1997/98, para os tratamentos com doses de lodo de esgoto.

15 Quantidades de metais pesados adicionadas ao solo $\left(\mathrm{mg} \mathrm{kg}^{-1}\right)$, na camada de 0 - 0,2 m, pela aplicação de lodo de esgoto nos anos agnícolas 1996/97 e $1997 / 98$ e valores acumulados no período.

16 Teores totais de $\mathrm{Cu}, \mathrm{Cr}$ e $\mathrm{Zn}$ detectados no solo, nas várias profundidades, em função da disposição de doses crescentes de lodo de esgoto nos anos agrícolas 1996/97 e 1997/98.

17 Teores de $\mathrm{Cu}, \mathrm{Ni}$ e $\mathrm{Zn}$ avaliados no solo pelos extratores DTPA-TEA,

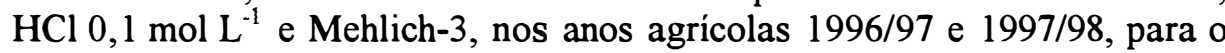
experimento com lodo de esgoto.

18 Coeficientes de correlação linear simples para os teores avaliados de $\mathrm{Cu}, \mathrm{Ni}$ e

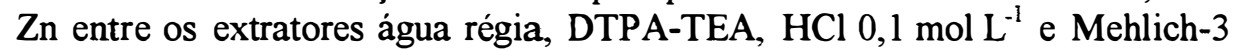
(M-3), nos anos agrícolas 1996/97 e 1997/98, para o experimento com lodo de esgoto

19 Correlações lineares entre a concentração de cobre e zinco nas plantas de cana-de-açúcar e os teores avaliados no solo pelos vários extratores químicos, considerando todos os tratamentos do experimento com lodo de esgoto

20 Correlações lineares entre a concentração de cobre e zinco nas plantas de cana-de-açúcar e os teores avaliados no solo pelos vários extratores químicos, considerando apenas os tratamentos com doses A, B e C de lodo de esgoto.

21 Balanço hídrico estimado no ano agrícola $1997 / 98$ para as camadas de $0-0,3$, $0-0,6,0-0,9 \mathrm{~m}$, nos tratamentos que compõem o experimento com lodo de esgoto.

22 Fluxo de água, concentração média de $\mathrm{N}-\mathrm{NO}_{3}{ }^{-}$na solução do solo e lixiviação

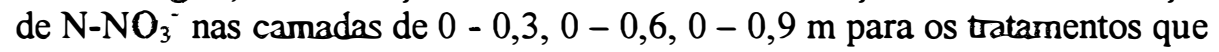
compõem o experimento com lodo de esgoto

23 Fluxo de água, concentração média de $\mathrm{N}-\mathrm{NH}_{4}{ }^{+}$na solução do solo e lixiviação de $\mathrm{N}_{-} \mathrm{NH}_{4}{ }^{+}$nas camadas de $0-0,3,0-0,6,0-0,9 \mathrm{~m}$ para os tratamentos que compõem o experimento com lodo de esgoto.

24 Teores de Carbono orgânico do solo $\left(\mathrm{g} \mathrm{kg}^{-1}\right)$ determinados para doses de composto de lixo em diversas épocas de amostragem, dentro dos anos agrícolas 1996/97 e 1997/98. 
25 Condutividade elétrica do solo $\left(\mu \mathrm{S} \mathrm{cm}^{-1}\right)$ determinada, na camada de 0 - 0,2 m, para doses de composto de lixo em diversas épocas de amostragem, dentro dos anos agrícolas 1996/97 e 1997/98

26 Condutividade elétrica do solo $\left(\mu \mathrm{S} \mathrm{cm} \mathrm{cm}^{-1}\right)$ determinada nas camadas de $0-0,2$, $0,2-0,4,0,4-0,6$ e $0,6-0,8 \mathrm{~m}$, aos 360 dias após incorporação de doses de composto de lixo nos anos agrícolas 1996/97 e 1997/98.

27 Valores $\mathrm{pH}$ do solo determinados para o doses de composto delixo em diversas épocas de amostragem, dentro dos anos agrícolas 1996/97 e 1997/98.

28 Valores $\mathrm{pH}$ do solo determinados nas camadas de $0-0,2,0,2-0,4,0,4-0,6$ e $0,6-0,8 \mathrm{~m}$, aos 360 dias após incorporação de doses de composto de lixo nos anos agrícolas 1996/97 e 1997/98.

29 Teores totais de $\mathrm{Cu}, \mathrm{Cr}$ e $\mathrm{Zn}$ recuperados do solo na camada $0-0,2 \mathrm{~m}$, nos anos agrícolas 1996/97 e 1997/98, para os tratamentos com doses de composto de lixo

30 Quantidades de metais pesados adicionadas ao solo $\left(\mathrm{mg} \mathrm{kg}^{-1}\right)$, na camada de 0 - 0,2 m, pela aplicação de composto de lixo nos anos agrícolas 1996/97 e $1997 / 98$ e os valores acumulados no período.

31 Teores totais de $\mathrm{Cu}, \mathrm{Cr}$ e $\mathrm{Zn}$ detectados no solo, nas várias profundidades, em função da disposição de doses crescentes de composto de lixo nos anos agricolas 1996/97 e 1997/98

32 Teores de $\mathrm{Cu}$, Ni e $\mathrm{Zn}$ avaliados no solo pelos extratores DTPA-TEA,

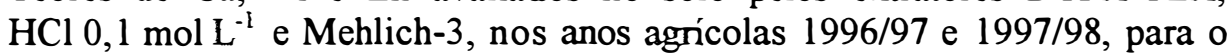
experimento com composto de lixo.

33 Coeficientes de correlação linear simples para os teores avaliados de $\mathrm{Cu}, \mathrm{Ni}$ e $\mathrm{Zn}$ entre os extratores água régia, DTPA-TEA, $\mathrm{HCl} 0,1 \mathrm{~mol} \mathrm{~L}^{-1}$ e Mehlich-3 (M-3), nos anos agrícolas 1996/97 e 1997/98, para o experimento com composto de lixo.

34 Correlações lineares entre a concentração de cobre e zinco nas plantas de cana-de-açúcar e os teores avaliados no solo pelos vários extratores químicos, considerando todos os tratamentos do experimento com composto de lixo.

35 Correlações lineares entre a concentração de cobre e zinco nas plantas de cana-de-açúcar e os teores avaliados no solo pelos vários extratores químicos, considerando apenas os tratamentos com doses A, B e C de composto de lixo

36 Balanço hídrico estimado no ano agrícola $1997 / 98$ para as camadas de $0-0,3$, $0-0,6,0-0,9 \mathrm{~m}$, nos tratamentos que compõem o experimento com composto de lixo. 


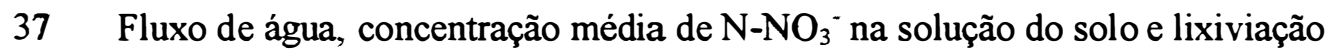
de $\mathrm{N}_{-} \mathrm{NO}_{3}$ nas camadas de $0-0,3,0-0,6,0-0,9 \mathrm{~m}$ para os tratamentos que compõem o experimento com composto de lixo.

38 Fluxo de água, concentração média de $\mathrm{N}_{-} \mathrm{NH}_{4}{ }^{+}$na solução do solo e lixiviação de $\mathrm{N}-\mathrm{NH}_{4}{ }^{+}$nas camadas de $0-0,3,0-0,6,0-0,9 \mathrm{~m}$ para os tratamentos que compõem o experimento com composto de lixo. 


\title{
DISPOSIÇÃO DE LODO DE ESGOTO E COMPOSTO DE LIXO URBANO NUM LATOSSOLO VERMELHO-AMARELO CULTIVADO COM CANA-DE-AÇÚCAR
}

\author{
Autor: Fernando Carvalho Oliveira \\ Orientador: Prof Dr $^{\mathrm{a}}$ Maria Emilia Mattiazzo-Prezotto
}

\section{RESUMO}

Nos anos agrícolas 1996/97 e 1997/98 foi conduzido, em área da Estação Experimental do Instituto Agronômico de Campinas em Piracicaba, SP, um experimento a campo com lodo de esgoto e composto de lixo urbano tendo por objetivo, a avaliação da extensão e severidade dos efeitos causados pela disposição desses resíduos num Latossolo Vermelho-Amarelo cultivado com cana-de-açúcar. As variáveis avaliadas foram: produtividade; teor de carbono-orgânico do solo e estimativa da degradação da carga orgânica adicionada via resíduos; condutividade elétrica, $\mathrm{pH}$ e capacidade de troca de cátions do solo; metais pesados no solo, nas plantas e sua disponibilidade avaliada através de extratores químicos; mobilidade de metais pesados no solo; lixiviação de $\mathrm{N}-\mathrm{NO}_{3}{ }^{-}$e $\mathrm{N}-\mathrm{NH}_{4}{ }^{+}$e o acúmulo de nitrogênio no solo.

Foram estabelecidos 9 tratamentos com 4 repetições, distribuídos num delineamento em blocos casualizados com parcelas experimentais de $100 \mathrm{~m}^{2}$ sendo a área útil, os $25 \mathrm{~m}^{2}$ centrais. Os tratamentos foram: calagem + adubação mineral; testemunhas (uma para tratamentos com lodo de esgoto e uma para composto de lixo urbano); três doses de lodo de esgoto denominadas A, B e C (respectivamente, em base seca, 33; 66 e $99 \mathrm{Mg} \mathrm{ha}^{-1}$, em 1996/97 e 37; 74; e $110 \mathrm{Mg} \mathrm{ha}^{-1}$, em 1997/98); três doses de composto de lixo urbano (respectivamente, em base seca, 20, 40 e $60 \mathrm{Mg} \mathrm{ha}^{-1}$, em 
1996/97 e 24, 48 e $72 \mathrm{Mg} \mathrm{ha}^{-1}$, em 1997/98). Os resíduos foram aplicados superficialmente em área total, com distribuição manual dentro das parcelas e incorporados ao solo, na camada de 0 - 0,2 m, com enxada rotativa. Em 1996/97 os resíduos foram incorporados em área total e em 1997/98, nas entre-linhas da cultura.

Os resultados mostraram que com o uso de ambos os resíduos a produtividade de cana-de-açúcar foi equivalente a adubação mineral convencional. As disposições de lodo de esgoto e composto de lixo também promoveram aumentos nos teores de carbono orgânico, no pH, na condutividade elétrica e na CTC do solo. Aumentos da CTC, nos tratamentos com lodo de esgoto, foram melhor explicados pelas alterações no $\mathrm{pH}$ do solo ao passo que, nos tratamentos com composto de lixo, estes aumentos foram atribuídos tanto as alterações de $\mathrm{pH}$ quanto as dos teores de C-orgânico do solo. Dos metais pesados considerados, foram detectados, no solo, nos tratamentos com lodo de esgoto, acúmulos de $\mathrm{Cu}, \mathrm{Cr}$, $\mathrm{Ni}$ e $\mathrm{Zn}$ e de $\mathrm{Cu}, \mathrm{Cr}$ e $\mathrm{Zn}$ nos tratamentos com composto de lixo. Nas plantas foram detectados apenas $\mathrm{Cu}$ e $\mathrm{Zn}$ uma vez que, $\mathrm{Cd}, \mathrm{Cr}$, $\mathrm{Ni}$ e $\mathrm{Pb}$ estiveram abaixo do limite de determinação do método analítico utilizado. Os extratores químicos empregados mostraram-se pouco eficientes na avaliação da fitodisponibilidade de $\mathrm{Cu}$ e $\mathrm{Zn}$. Quanto a mobilidade dos metais pesados, o $\mathrm{Cu}$ e $\mathrm{Cr}$ mostraram-se imóveis e Zn móvel, atingindo ao final de 1997/98, a camada de 0,4-0,6 m. A disposição dos resíduos urbanos apresentou elevado potencial para promover a contaminação de aqüíferos subterrâneos através da lixiviação de formas nitrogenadas inorgânicas. Os resíduos contribuíram também para o acúmulo de $\mathrm{N}$-orgânico na superficie do solo. Os resultados mostraram que na definição das taxas e freqüências de disposições do resíduo, pelo menos a curto prazo, o nitrogênio deve ser um fator mais restritivo do que os metais pesados. 


\title{
SEWAGE SLUDGE AND MUNICIPAL COMPOST WASTE DISPOSAL IN AN ACID SOIL CULTIVATED WITH SUGAR CANE
}

\author{
Author: Fernando Carvalho Oliveira \\ Adviser: Prof Dr ${ }^{\mathrm{a}}$ Maria Emilia Mattiazzo-Prezotto
}

\section{SUMMARY}

The aim of this paper is to present data of an experiment on sewage sludge and municipal compost waste disposal in soil cultivated with sugarcane. It was conducted in the years of 1996/97 and 1997/98, at the Sugarcane Research Station of IAC Agronomic Institute of Campinas, located in Piracicaba, São Paulo State- Brazil. It was also the aim of this study to evaluate the extension and severity of the disposal of large amounts of sewage sludge and municipal waste compost into soil and its effects on sugar cane plants.

The statistic design adopted was randomized blocks with nine treatments and four replications, each parcel had a $100 \mathrm{~m}^{2}$ size and an available area of $25 \mathrm{~m}^{2}$. The treatments established were: lime plus mineral fertilizer; control (one for the treatments with sewage sludge and one for treatments with municipal compost waste); sewage sludge in three levels (respectively 33; 66 and $99 \mathrm{Mg} \mathrm{ha}^{-1}$ in the $96 / 97$ experiment and 37; 74 and $110 \mathrm{Mg} \mathrm{ha}^{-1}$ in 97/98, considering dry weight basis); and three levels of municipal waste compost (respectively $20 ; 40$ and $60 \mathrm{Mg} \mathrm{ha}^{-1}$ in $96 / 97$ and 24,48 and $72 \mathrm{Mg} \mathrm{ha}^{-1}$ in 97/98). The wastes were applied manually to surface soil in each parcel and incorporated to $0-0.2 \mathrm{~m}$ with rotary tiller. In the first farm year the wastes were incorporated to total surface soil and in the following year only into plants interrows. 
The following parameters were evaluated: sugarcane yield; changes in soil organic carbon and its degradation; electric conductivity, $\mathrm{pH}$ and $\mathrm{CEC}$; heavy metals in soil, in plants and its availability by chemical extractants; heavy metals mobility through soil; nitrate and ammonium leaching and $\mathrm{N}$ accumulation in soil.

The results showed that the sugarcane yield in the soil plus waste treatment was not different from those observed in lime + fertilizer treatment. There was an increase on soil organic carbon, $\mathrm{pH}$ and electric conductivity, and CEC due to waste addition. The increase of CEC on soil in the sludge treatments was due to $\mathrm{pH}$ effect while in the compost treatment it was due mainly to the carbon addition. There was an increase of $\mathrm{Cu}, \mathrm{Cr}, \mathrm{Ni}$ and $\mathrm{Zn}$ in the soil sludge treatments and of $\mathrm{Cu}, \mathrm{Cr}$ and $\mathrm{Zn}$ in the soil compost treatment. However, in the sugar cane only $\mathrm{Cu}$ and $\mathrm{Zn}$ was detected. The chemical extractants used to preview plant availability of heavy metals were not effective. Among the metals $\mathrm{Zn}$ was the only one that presented soil mobility, accumulating it in the $0.4-0.6 \mathrm{~m}$ soil layer. The contamination of groundwater can occur due to the nitrate leaching observed in the waste treatments. It was also observed an organic $\mathrm{N}$ accumulation on the topsoil.

The sewage sludge and municipal waste compost disposal must be ruled by the $\mathrm{N}$ waste rather than heavy metal content at least in the coming future. 


\section{INTRODUÇÃO}

O crescimento populacional, sua concentração nos centros urbanos e as facilidades proporcionadas pela chamada "vida moderna", tem incrementado sobremaneira o consumo de alimentos e de produtos industrializados. Em conseqüência, crescem cada vez mais as quantidades geradas de resíduos, a uma taxa de produção maior do que àquela que exprime a capacidade do ambiente degradar, ocasionando os inúmeros problemas circunstanciados ao seu acúmulo. Entre os resíduos gerados, os esgotos e o lixo urbano são os que mais se destacam, seja pelas grandes quantidades produzidas, seja pelo potencial poluidor.

No que concerne aos esgotos, atualmente a maior parte é lançada "in natura" nos cursos d'água, o que compromete a quantidade e a qualidade dos recursos hídricos das regiões densamente habitadas. O lixo urbano é depositado, na maioria das cidades brasileiras, a céu aberto ou na melhor das hipóteses em aterros sanitários.

Sem tratamento e disposição final adequados, esses resíduos urbanos são responsáveis por sérios problemas de ordem sanitária e ambiental ocasionados através da proliferação de vetores biológicos transmissores de doenças (insetos, aves e ratos), da contaminação do solo e das águas de superficie e subsuperficie ou até mesmo do ar pela liberação de odores desagradáveis e gases tóxicos. Nos últimos anos, esses problemas vem causando grandes preocupações aos orgãos públicos competentes que, aliados as pressões sociais ocasionadas por uma nova consciência política e ambiental, vem procurando soluções técnica e economicamente viáveis.

As alternativas atualmente utilizadas para o tratamento de ambos resíduos não resolvem totalmente o problema, uma vez que são gerados novos resíduos. Assim, no final do tratamento dos esgotos é gerado, em grande escala, um outro resíduo: o lodo de esgoto. Dentre as alternativas para sua destinação final podem ser citadas: disposição em oceanos, aterro misto com lixo urbano, incineração, produção de agregado leve para a 
construção civil e utilização e ou disposição em solos agrícolas. No caso do lixo, dentre as alternativas para redução do volume a ser descartado, destacam-se: incineração, reciclagem de materiais reprocessáveis e compostagem da fração orgânica com destinação para a agricultura.

A destinação do lodo de esgoto e do composto de lixo para agricultura é a alternativa que merece maior destaque pelas seguintes razões: pode ser viabilizada tecnicamente através da pesquisa, apresenta os menores custos, utiliza o solo como um meio favorável ao consumo da carga orgânica potencialmente poluidora, pode trazer os beneficios inerentes da matéria orgânica além de proporcionar a reciclagem de nutrientes. Entretanto, dependendo das suas origens, esses resíduos podem apresentar características que venham limitar seu emprego na agricultura. Dentre estas, destacam-se: presença de patógenos, compostos orgânicos persistentes e tóxicos, compostos nitrogenados e metais pesados.

Neste contexto, são de extrema importância as pesquisas sobre a ocorrência e a severidade dos efeitos ocasionados pela adição desses resíduos no sistema solo-planta-água. É a partir destes estudos que serão desenvolvidas as técnicas de manejo visando aumentar os beneficios desta prática e minimizar os possíveis efeitos adversos. Cabe ressaltar que, nas condições de clima e solos brasileiros, estudos dessa natureza são escassos, especialmente aqueles realizados a campo.

Diante do exposto, idealizou-se um projeto abrangente, conduzido em condições de campo, objetivando-se avaliar a extensão dos efeitos causados pela disposição de elevadas doses de lodo de esgoto e composto de lixo, por dois anos sucessivos, num Latossolo Vermelho-Amarelo cultivado com cana-de-açúcar. Incluiu-se neste projeto, um estudo desenvolvido por Marciano (1999), sobre as alterações nas propriedades fisico-hídricas do solo, tal como retenção de água e a condutividade hidráulica do solo saturado e não saturado.

No presente trabalho, foram analisadas as seguintes variáveis: produtividade da cana-de-açúcar; teor de carbono-orgânico do solo e a estimativa da degradação da carga orgânica adicionada via resíduos; condutividade elétrica e $\mathrm{pH}$ do solo; capacidade de troca de cátions do solo; metais pesados no solo, nas plantas e sua fitodisponibilidade avaliada através de extratores químicos; mobilidade de metais pesados no solo; lixiviação de $\mathrm{N}_{-} \mathrm{NO}_{3}{ }^{-}$e $\mathrm{N}-\mathrm{NH}_{4}{ }^{+}$e o acúmulo de nitrogênio no solo. 


\section{REVISÃO DE LITERATURA}

\subsection{Geração de resíduos nos centros urbanos}

Os esgotos e o lixo urbano certamente se apresentam como dois dos maiores problemas ambientais a serem enfrentados pelo homem no século XXI. As quantidades geradas são assustadoras, o que vem acelerando o ritmo de degradação dos recursos naturais.

Dados da Secretaria de Planejamento do governo brasileiro, citados por Luduvice (1998), dão conta de que até o ano de 1996 apenas 30\% dos esgotos produzidos em cidades brasileiras eram coletados sendo que, deste total, cerca de $8 \%$ recebiam algum tipo de tratamento. Andreoli \& Pegorini (1998) reportaram que 10 milhões de $\mathrm{m}^{3}$ de esgotos são coletados e despejados diariamente nos cursos d'água sem nenhum tratamento, situação que deve ser agravada pela inclusão de mais 70 milhões de habitantes nas redes de coletas nos próximos 15 anos.

Esta situação faz do tratamento dos esgotos uma prática indispensável para a preservação dos recursos hídricos. No entanto, desse tratamento resulta o lodo de esgoto, cuja disposição final é problemática e pode representar $60 \%$ dos custos de operação de uma estação de tratamento (Centro Nacional de Referência em Gestão Ambiental Urbana, 1998). Embora atualmente uma fração muito pequena dos esgotos seja tratada, quantidades significativas e crescentes de lodo de esgoto vem sendo geradas. Apenas na região metropolitana de São Paulo, SP, com a capacidade de tratamento instalada e em operação, gera-se diariamente em torno de 100 toneladas de lodo de esgoto seco, com uma previsão para o ano de 2015 de 766 toneladas diárias (Santos \& Tsutiya, s.d.; CEEJ, 1996). No Estado do Paraná a produção atual está em torno de 29 toneladas diárias de lodo de esgoto seco, destacando-se a cidade de Curitiba, PR, com 20 toneladas diárias (Andreoli \& Pegorini, 1998). 
Somando-se aos problemas dos esgotos, no Brasil são produzidos cerca de 100 mil toneladas diárias de lixo urbano (Canabarro, 1995), o que para Lima et al. (1998) deve chegar a 170 mil toneladas diárias nos próximos 75 anos. Os problemas causados pela geração de grandes quantidades de lixo se tornam ainda mais graves diante do descaso com que é tratado pelas autoridades públicas. Para se ter uma idéia, 59\% do lixo gerado no Brasil são simplesmente dispostos em lixões a céu aberto, sem o mínimo critério técnico, $1 \%$ é jogado em cursos d'água, $13 \%$ são dispostos em aterros controlados, $25 \%$ em aterros sanitários e o restante se divide em incineração e compostagem (Grossi, 1993). No Estado de São Paulo, cerca de $87 \%$ do lixo gerado são dispostos em lixões a céu aberto, $8 \%$ são dispostos em aterros controlados e $5 \%$ em aterros sanitários (Ferro Neto, 1994).

O tratamento do lixo consiste basicamente na separação da sua fração orgânica dos materiais inertes recicláveis como vidro, papel, papelão, material ferroso e plástico. A fração orgânica pode ser tratada através da compostagem, tendo como produto final um resíduo orgânico humificado com potencial de utilização na agricultura. Embora haja esta alternativa, o tratamento do lixo no Brasil ainda é incipiente. Dados do IBGE (1983) apontaram para menos de $1 \%$ a quantidade tratada e compostada, o que não deve ter mudado muito nestes últimos anos, considerando-se que na cidade de São Paulo por exemplo, até o ano de 1995, das 12 mil toneladas de lixo geradas diariamente, apenas $1,5 \%$ eram processadas em usinas de reciclagem e compostagem (Melo et al. 1997).

A atenuação ou até mesmo as soluções dos problemas causados pelos esgotos e lixos urbanos passam necessariamente por dois caminhos: o primeiro deles é a educação dos povos ou seja, não basta tratar resíduos, é imprescindível combater o desperdício e reduzir os volumes gerados; o segundo é a implementação de políticas ambientais e de saneamento básico que visem ampliar a capacidade de tratamento desses resíduos. $\mathrm{O}$ sucesso das estações ou usinas de tratamento por sua vez, depende da viabilização técnica e econômica de alternativas para a disposição final do lodo de esgoto e do composto de lixo e neste contexto, o potencial de utilização desses resíduos na agricultura, assume grande importância. 


\subsection{Conceitos, caracterização e potencial agronômico dos resíduos}

Lodo de esgoto é um resíduo semi-sólido resultante do tratamento dos esgotos ou águas servidas cuja composição, predominantemente orgânica, varia em função da sua origem. O composto de lixo ou composto de resíduos sólidos urbanos também é um resíduo de composição predominantemente orgânica, resultante de processos de decomposição aeróbica e termofilica da fração orgânica do lixo doméstico por comunidades microbianas quimiorganotróficas existentes no próprio lixo.

A caracterização química desses resíduos é de fundamental importância para tomada de decisões quanto a conveniência ou não da disposição em solos agrícolas, para o estabelecimento das taxas de aplicação e principalmente para o monitoramento dos seus efeitos no sistema solo-planta-água.

Para Sommers et al. (1976), os fatores determinantes da composição química do lodo de esgoto são as características, o método de tratamento, a variabilidade sazonal e o tipo e o grau de industrialização da região onde são gerados os esgotos. Sommers (1977) caracterizou mais de 250 amostras de lodo de esgoto provenientes de 150 estações de tratamentos situadas em oito Estados americanos. As espécies encontradas e suas concentrações mínimas, máximas e médias, expressas no material seco, obtidas para lodos digeridos anaerobicamente foram: C-orgânico $=180$ a 390,268 ; $\mathrm{N}$-total $=5$ a 176,$42 ; \quad \mathrm{N}_{-} \mathrm{NH}_{4}^{+}=0,1$ a $67,6, \quad 1,6 ; \quad \mathrm{N}-\mathrm{NO}_{3}{ }^{-}=0$ a $4,9, \quad 0,1$; P-total $=5$ a 143, 30; $\mathrm{K}=0,2$ a 26,4,3,0; $\mathrm{Ca}=19$ a 200, 49; $\mathrm{Mg}=0,3$ a 19,2, 4,8; S-total $=8$ a 15,$11 ; \mathrm{Na}=0,1$ a $21,9,7,3 ; \mathrm{Al}=1$ a 135,$5 ; \mathrm{Ba}=0$ a $9,0,5 \mathrm{~g} \mathrm{~kg}^{-1}$ e As $=10$ a 230, 116; $\mathrm{B}=12$ a 760, 36; $\mathrm{Cd}=3$ a 3410, 16; $\mathrm{Co}=3$ a 18, 7,0; $\mathrm{Cr}=24$ a 28850, 1350; $\mathrm{Cu}=85$ a 10100, 1000; $\mathrm{Fe}=1000$ a 153000, 12000; $\mathrm{Hg}=0,5$ a 10600,$5 ; \mathrm{Mn}=58$ a 7100, 280; $\mathrm{Mo}=24$ a 39,$30 ; \mathrm{Ni}=2$ a 3520,$85 ;$ $\mathrm{Pb}=58 \mathrm{a} 19730,540 ; \mathrm{Zn}=108$ a 27800, $1890 \mathrm{mg} \mathrm{kg}^{-1}$; para lodos digeridos aerobicamente foram: C-orgânico $=270$ a 370, 295; N-total $=5$ a 76, 48; $\mathrm{N}-\mathrm{NH}_{4}{ }^{+}=0,03$ a $11,3,0,4 ; \mathrm{N}^{-} \mathrm{NO}_{3}{ }^{-}=0,01$ a $0,83,0,2 ;$ P-total $=11$ a 55, 27; $\mathrm{K}=0,8$ a 11, 3,8; $\mathrm{Ca}=6$ a 135, 30; $\mathrm{Mg}=0,3$ a $11,4,1 ;$ S-total $=6$ a 11, 8; $\mathrm{Na}=0,3$ a 30,7, 7,7; $\mathrm{Al}=1$ a 23, 4,0; $\mathrm{Ba}=0$ a 0,3, 0,2 $\mathrm{g} \mathrm{kg}^{-1}$ e As=traços; $\mathrm{B}=17$ a 74, 33; $\mathrm{Cd}=5$ a 2170, 16; Co $=$ traços; $\mathrm{Cr}=10$ a 13600, 260; 
$\mathrm{Cu}=85$ a 2.900, 970; $\mathrm{Fe}=1000$ a 40000, 10000; $\mathrm{Hg}=1$ a 22, 5; $\mathrm{Mn}=55$ a 1120, 340; $\mathrm{Mo}=30$ a 30, 30; $\mathrm{Ni}=2$ a 1700, 31; $\mathrm{Pb}=13$ a 15000, 300; $\mathrm{Zn}=108$ a 14900, $1800 \mathrm{mg} \mathrm{kg}^{-1}$.

$\mathrm{Na}$ literatura nacional não foram encontrados trabalhos científicos específicos sobre a caracterização química de lodo de esgoto gerado em diferentes localidades e métodos de tratamento. Alguns dados da composição parcial desses resíduos são encontrados em trabalhos que objetivaram estudar aspectos relacionados ao seu uso agrícola. Dessa forma, reunindo-se os dados apresentados por Bettiol \& Carvalho (1982a); Bataglia et al. (1983); Bettiol et al. (1983); Carvalho (1983); Berton et al. (1989); Marques (1990); André (1994); Melo et al. (1994); Barreto (1995); Oliveira (1995); Marques (1996); Berton et al. (1997) e Bertoncini (1997), realizou-se uma aproximação da amplitude de variação na composição de lodos, mais precisamente da região metropolitana de São Paulo, SP. As concentrações mínimas e máximas para matéria orgânica e algumas espécies químicas, expressas no material seco foram: Matéria orgânica $=313$ a 722; C-orgânico $=132$ a 299; $\quad$-total $=7,2$ a 30,7; P-total $=0,5$ a 21,0; $\mathrm{K}=0,8$ a 14,6; $\mathrm{Ca}=13,5$ a 162,$7 ; \mathrm{Mg}=2,1$ a 27,3; S-total $=7,2$ a 19,2 $\mathrm{g} \mathrm{kg}^{-1}$ e $\mathrm{Cd}=4$ a $35 ; \quad \mathrm{Co}=30$ a 41; $\mathrm{Cr}=545$ a 2.227; $\mathrm{Cu}=379$ a 2404; $\mathrm{Fe}=34954$ a 170955; $\mathrm{Ni}=378$ a 1.331; $\mathrm{Mn}=54$ a $820 ;$ $\mathrm{Pb}=119$ a $835 ; \mathrm{Zn}=683$ a $4.327 \mathrm{mg} \mathrm{kg}^{-1}$. Ressalta-se que esses valores foram obtidos por diferentes métodos analíticos, caracterizando mais uma fonte de variação.

Os resultados da caracterização química de amostras de lodo de esgoto apresentados pelos diversos autores brasileiros demonstram, quando comparados com aqueles apresentados Sommers (1977), que não existem grandes diferenças em espécies na composição do lodo porém, quando se consideram os aspectos quantitativos, verifica-se grande variabilidade. No entanto, deve-se ressaltar que as faixas de variações para N, P e K são sensivelmente menores do que aquelas para metais pesados. A grande variação nos teores de $\mathrm{Cu}, \mathrm{Cd}, \mathrm{Cr}, \mathrm{Ni}, \mathrm{Pb}$ e $\mathrm{Zn}$ são concordantes com os dados apresentados por Kabata-Pendias \& Pendias (1984), MaCcalla et al. (1986) e Kuchenrither \& McMillan (1990). Esta variabilidade é atribuída ao perfil industrial de cada região de origem das amostras e aos fatores de sazonalidade. 
A composição química de compostos de lixo varia amplamente conforme as regiões onde são produzidos, refletindo o nível sócio-econômico das comunidades geradoras do lixo, o tipo de coleta (seletiva ou generalizada), a eficiência nos processos de separação adotados pelas usinas de tratamento e compostagem e com o grau de maturação do composto (Xin et al., 1992).

Xin et al. (1992) realizaram um amplo estudo sobre a composição química de compostos de lixo gerados nos Estados Unidos e em países da Europa. As espécies químicas encontradas e suas amplitudes de variação, representadas por concentrações mínimas e máximas expressas no material seco foram: C-orgânico $=270$ a 400; $\mathrm{N}$-total $=9,0$ a 17,8; P-total $=1,5$ a 6,$0 ; \mathrm{K}=0,7$ a 9,$7 ; \mathrm{Ca}=12,0$ a 75,$7 ; \mathrm{Mg}=0,8$ a 6,$0 ;$ S-total $=2,0$ a 6,$0 ; \mathrm{Cl}=3,2$ a 5,$0 ; \mathrm{Na}=2,0$ a $6,7 \mathrm{~g} \mathrm{~kg}^{-1}$ e $\mathrm{Cd}=0$ a $100 ; \mathrm{Cr}=2$ a 270 ; $\mathrm{Cu}=100$ a $630 ; \mathrm{Hg}=4$ a $5 ; \mathrm{Ni}=0,76$ a $190 ; \mathrm{Mn}=300$ a $600 ; \mathrm{Pb}=5$ a $900 ;$ $\mathrm{Zn}=500$ a $1650 \mathrm{mg} \mathrm{kg}^{-1}$.

No Brasil, Berton \& Valadares (1991) encontraram, para compostos de lixo gerados na cidade de São Paulo, SP, praticamente as mesmas espécies químicas em faixas de concentrações próximas àquelas apresentadas por Xin et al.(1992). Resultados semelhantes foram encontrados em estudo realizado por Cravo (1995). Esse autor caracterizou amostras de composto de lixo provenientes de seis capitais brasileiras obtendo as seguintes faixas de concentrações, expressas no material seco: Matéria orgânica $=160$ a 474; C-orgânico $=93$ a 275; $\mathrm{N}$-total $=7,7$ a 14,5; P-total $=1,8$ a 4,2; $\mathrm{K}=3,3$ a 10,$9 ; \mathrm{Ca}=18,3$ a 36,$1 ; \mathrm{Mg}=2,2$ a $4,7 \mathrm{~g} \mathrm{~kg}^{-1}$ e $\mathrm{Cd}=1$ a $5 ; \mathrm{Co}=7$ a 21 ; $\mathrm{Cr}=29$ a $168 ; \mathrm{Cu}=45$ a $815 ; \mathrm{Fe}=12782$ a $52145 ; \mathrm{Mn}=154$ a $536 ; \mathrm{Mo}=16$ a $38 ;$ $\mathrm{Ni}=11$ a $91 ; \mathrm{Pb}=92$ a $599 ; \mathrm{Zn}=111$ a $1007 \mathrm{mg} \mathrm{kg}^{-1}$.

A análise conjunta dos resultados obtidos nos diversos trabalhos de caracterização química de compostos de lixo, seja no exterior ou no Brasil evidencia que, de maneira semelhante ao lodo de esgoto, as maiores amplitudes de variação ocorrem para os metais pesados.

Além de nutrientes e metais pesados, tanto lodo de esgoto quanto composto de lixo podem conter patógenos e compostos orgânicos tóxicos. 
Bactérias, vírus, protozoários e vermes parasitas são alguns dos organismos patogênicos que inevitavelmente estarão presentes nesses resíduos (Hue, 1995). Entretanto, as quantidades e as espécies de patógenos variam amplamente com as condições sócio-econômicas da população, hábitos sanitários e com a eficiência dos processos de tratamento dos resíduos. No caso do lodo de esgoto, processos de tratamento como digestão aeróbia, anaeróbia e calagem até $\mathrm{pH} 12,5$ reduzem mas não eliminam completamente a presença desses organismos (Soccol, 1998). Para o composto de lixo, em processos de compostagem bem conduzidos, a quase totalidade dos patógenos pode ser eliminada na fase termofilica, onde as temperaturas atingem 55 a $60^{\circ} \mathrm{C}$ (Pereira Neto, 1988).

Quando se considera a utilização desses resíduos na agricultura, o conhecimento do destino dos patógenos no solo é de fundamental importância. Sorber \& Moore ${ }^{1}$, citados por Hue (1995), numa ampla revisão bibliográfica sobre o assunto, concluíram que: o número de Salmonella spp. no solo é reduzido em $90 \%$ após 3 semanas da aplicação de lodo de esgoto; em média $90 \%$ das viroses são eliminadas em 3 dias quando lodo é aplicado superficialmente em solos sob clima quente ao passo que, em áreas de clima mais frio a sobrevivência aumenta para 30 dias; entre os parasitas, os maiores índices de sobrevivência são para Ascaris, apresentando redução média de $90 \%$ após 77 dias da aplicação. Escosteguy et al. (1993) estudaram o destino de bactérias enteropatogênicas num solo tratado com doses equivalentes a 40,80 e $120 \mathrm{Mg} \mathrm{ha}^{-1}$ (base seca) de composto de lixo. Os autores não verificaram a presença de Salmonella spp e Estreptococcus sp. no composto utilizado, atribuindo este fato à ação da temperatura observada no processo de compostagem, cujos valores foram superiores a $60^{\circ} \mathrm{C}$; após 54 dias da adição do composto ao solo, verificaram que a população de coliformes totais reduziu em 200 vezes, não diferindo daquela encontrada no solo testemunha. No Brasil esse assunto ainda precisa ser melhor estudado, no entanto espera-se que, em virtude do clima quente e com técnicas de manejo a serem definidas, os problemas relacionados a patógenos venham ser facilmente contornados.

\footnotetext{
SORBER.C.A.; MOORE, B.E. Survival and transport of pathogens in sludge-amended soils. A critical literature review. NTIS. \#PB87-180337. Washington. 1987.
} 
Com relação aos compostos orgânicos tóxicos, as maiores fontes para lodo de esgoto são os esgotos industriais, produtos químicos domésticos e pesticidas. Bifenilas Policloradas (PCBs) e Hidrocarbonetos Aromáticos Policíclicos (PAHs) são os dois principais grupos presentes no lodo de esgoto (Hue, 1995). O primeiro grupo são substâncias organocloradas apolares, facilmente absorvidas pelas plantas, acumulativas na cadeia alimentar, extremamente persistentes no solo; o segundo são substâncias cancerígenas resultante da queima incompleta de substâncias orgânicas e também persistentes no solo (Grossi, 1993).

Essas substâncias também são motivos de preocupação no composto de lixo. Grossi (1993) analisou 61 amostras de composto de lixo provenientes de 21 usinas de tratamento e compostagem brasileiras. $\mathrm{O}$ autor encontrou compostos orgânicos tóxicos do grupo das dibenzeno-p-dioxinas policloradas (PCDD), dibenzenofuranas policloradas (PCDF), bifenilas policloradas (PCBs) e dos hidrocarbonetos aromáticos policíclicos (PAHs). Na maioria das amostras analisadas as concentrações desses compostos estiveram acima dos limites de tolerância adotados pela legislação alemã. Isto mostra que, a exemplo dos microrganismos patogênicos, o destino desses compostos no solo deve ser melhor estudado.

O potencial agronômico do lodo de esgoto e do composto de lixo esta fundamentado basicamente nos elevados teores de carbono orgânico presentes na sua composição. Aumentar o teor de C-orgânico de um solo, pode significar melhorias nas suas propriedades fisicas, químicas e biológicas. Além disso, esses resíduos encerram em suas composições, apreciáveis quantidades de nutrientes, com destaque para nitrogênio e fósforo no lodo de esgoto e nitrogênio e potássio no composto de lixo.

De acordo com Kirkham (1982), estudos sobre o poder fertilizante do lodo de esgoto são descritos nos Estados Unidos desde 1925. Efeitos benéficos às produtividades das culturas, avaliados a curto prazo, foram apresentados em vários trabalhos, entre eles Leslie (1970), Hinesly et al. (1972), Mays et al. (1973), Cunningham et al. (1975), Sabey et al. (1977), Reed et al. (1991) e Cripps et al. (1992).

No Brasil, estudos dessa natureza são tão recentes quanto a preocupação com o tratamento dos esgotos. Por aqui, os primeiros trabalhos exaltando o potencial de uso 
agrícola desse resíduo foram realizados por Santos (1979), Carvalho \& Barral (1981), Bettiol \& Carvalho (1982a), Bettiol \& Carvalho (1982b) e Carvalho (1983). Daí para frente um número maior de trabalhos científicos interessados em estudar 0 comportamento agronômico do lodo de esgoto foram realizados sendo os mais relevantes, descritos na seqüência .

Berton et al.(1989), em casa de vegetação, avaliaram a produção de matéria seca e a absorção de nutrientes por plantas de milho em função da adição, a cinco solos paulistas, de doses de lodo de esgoto equivalentes a 0, 40 e $80 \mathrm{Mg} \mathrm{ha}^{-1}$ (base seca). Foram verificados aumentos significativos na produção de matéria seca e na absorção de $\mathrm{N}, \mathrm{P}, \mathrm{Ca}, \mathrm{Mg}$, e $\mathrm{Zn}$ de acordo com as doses aplicadas. Em doses de até $80 \mathrm{Mg} \mathrm{ha}^{-1}$, apesar dos elevados teores de $\mathrm{Cu}$ e $\mathrm{Zn}$ no lodo, não foi observada redução na produção de matéria seca nos cinco solos utilizados.

Em estudo conduzido a campo num Latossolo Vermelho-Amarelo, Marques (1990) comparou, por dois anos consecutivos, os efeitos da fertilização mineral e da aplicação anual de doses crescentes de lodo de esgoto $\left(4,8,16\right.$ e $32 \mathrm{Mg} \mathrm{ha}^{-1} \mathrm{com}$ $72 \%$ de umidade), complementadas com potássio, sobre a produtividade e a qualidade industrial da cana-de-açúcar. $\mathrm{O}$ autor concluiu que é possivel a utilização do resíduo na cultura uma vez que não foram observadas diferenças significativas, entre os tratamentos, para produtividade e características tecnológias da cana-de-açúcar.

$\mathrm{O}$ efeito imediato e o poder residual de doses crescentes de lodo de esgoto (equivalentes a $0,20,40,80$ e $160 \mathrm{Mg} \mathrm{ha}^{-1}$ com $92 \%$ de umidade) foram estudados por Da Ros et al (1993) a campo num solo Podzólico Vermelho-Amarelo. De maneira geral, a aplicação de lodo de esgoto aumentou significativamente, em função das doses, o rendimento de matéria seca, tanto da cultura do milheto (efeito imediato) quanto da associação aveia-ervilhaca (efeito residual) e além disso, foram aumentados no solo os teores de N-total e P-disponivel evidenciando a contribuição do lodo em fornecer nutrientes às plantas.

Silva (1995) avaliou o poder fertilizante do lodo de esgoto através de um estudo a campo num Podzólico Vermelho-Amarelo cultivado com cana-de-açúcar. Foram utilizadas três doses de lodo $\left(0,20\right.$ e $40 \mathrm{Mg} \mathrm{ha}^{-1}$ com $62 \%$ de umidade) combinadas com 
adubação NP, NK, PK e NPK (dosagens de 60, 80 e $100 \mathrm{~kg} \mathrm{ha}^{-1}$ respectivamente para N, $\mathrm{P}_{2} \mathrm{O}_{5}$ e $\mathrm{K}_{2} \mathrm{O}$ ) e sem adubação. $\mathrm{O}$ autor verificou que o lodo de esgoto atuou como corretivo do complexo coloidal do solo e como fertilizante para a cultura, essencialmente como fonte de $\mathrm{Ca}, \mathrm{P}, \mathrm{S}$ e $\mathrm{Zn}$. Esses beneficios proporcionaram aumentos lineares da produtividade de biomassa e açúcar. Salientou-se que os citados benefícios foram de curta duração, se restringindo a apenas 1 ano agrícola.

-Em outro estudo a campo, Marques (1996) combinou quatro doses de lodo de esgoto $\left(0,40,80\right.$ e $160 \mathrm{Mg} \mathrm{ha}^{-1}$ com $74 \%$ de umidade) com dois níveis de fertilização mineral (50 ou $100 \%$ do NPK recomendado para a cultura da cana-de-açúcar). Observou-se que o lodo proporcionou melhoria nas condições gerais de fertilidade do solo como $\mathrm{pH}$, matéria orgânica e nutrientes. Além disso, o autor verificou que mesmo na menor dose aplicada do resíduo, a redução de $50 \%$ da aplicação de fertilizantes não exerceu efeitos significativos sobre a produtividade da cultura, indicando que a utilização do lodo pode significar economia de recursos com fertilizantes minerais.

A aplicação de composto de lixo bem maturado em solos cultivados tem apresentado efeitos desejáveis do ponto de vista agronômico. Aumentos na fitodisponibilidade de $\mathrm{P}, \mathrm{K}, \mathrm{Ca}$ e $\mathrm{Mg}$, elevação do $\mathrm{pH}$ e redução da acidez potencial são os principais efeitos desses resíduos no solo (Hortenstine \& Rothwell, 1972 Bengtson \& Cornette, 1973; Giordano et al., 1975; Mazur et al., 1983a; Mazur et al., 1983b; Kiehl, 1985; Peixoto et al. 1987; Ferreira \& Cruz, 1992).

Num experimento conduzido em casa-de-vegetação, Mazur et al. (1983a) aplicaram num Latossolo Amarelo, doses equivalentes a $30 \mathrm{Mg} \mathrm{ha}^{-1}$ (base seca) de composto de lixo. Foram verificados aumentos de $57 \%$ no teor de fósforo assimilável do solo, aumentos na absorção de fósforo por plantas de milho e o conseqüente acréscimo na produção de matéria seca. Dando seqüência a este trabalho, Mazur et al. (1983b) observaram que a utilização de composto de lixo elevou o pH do solo e reduziu o teor Al trocável. $\mathrm{Na}$ associação de composto de lixo com calcário, tais efeitos foram ainda mais pronunciados.

Backes \& Kämpf (1991) avaliaram o potencial de utilização do composto de lixo como substrato para produção de plantas ornamentais. Os autores atestam a 
viabilidade da utilização desse resíduo para tal finalidade no entanto, afirmam que composto de lixo só é recomendado como componente do substrato, devendo ser misturado a outros materiais. Por outro lado, Alves \& Passoni (1997) demonstraram que a utilização do composto, até mesmo como substrato único, não apresentou prejuízos ao desenvolvimento de mudas de oiti (Licania tomentosa - Benth). A divergência entre esses resultados está obviamente ligada a origem do composto utilizado em cada caso e também ao comportamento diferenciado entre as várias espécies vegetais.

Trindade et al. (1996) observaram que a aplicação, num Latossolo Vermelho-Amarelo, de doses de composto de lixo equivalentes a $0,10,20,40 \mathrm{e}$ $60 \mathrm{Mg} \mathrm{ha}^{-1}$ (base seca) aumentou linearmente os teores de P-disponivel. Verificaram também o maior crescimento de plantas de milho em função das doses, assim como um efeito residual positivo em cultivos sucessivos.

De maneira geral, resultados mais satisfatórios têm sido encontrados com a utilização do composto de lixo complementado com fertilizantes minerais. Dessa forma, Cravo (1995) obteve maiores produtividades de alface em tratamentos que associavam doses de composto de lixo de até $120 \mathrm{Mg} \mathrm{ha}^{-1}$ (base seca) com fertilizantes minerais e calcário. Lopes et al. (1996) encontraram maior rendimento de matéria seca de caupi quando associaram doses de composto de lixo com fertilizantes nitrogenados. Por fim, de maneira concordante com esses autores, Abreu Junior (1999) verificou aumento na produção de matéria seca de plantas de arroz, por dois cultivos, quando associou composto de lixo, fertilizante mineral e calcário. Todavia, esses efeitos não foram superiores aos da calagem com fertilizantes minerais.

A aplicação de resíduos urbanos ao solo cujo objetivo básico era 0 fornecimento de nutrientes às plantas, mudou de enfoque a partir da década de 70 , passando a existir um interesse cada vez maior em dispor desses resíduos em doses muito além daquelas de recomendação agronômica (Khaleel et al., 1981). Neste contexto, o solo também estaria sendo utilizado como um meio depurador da carga orgânica presente nos resíduos (Glória, 1992). Este fato deve-se principalmente, ao número cada vez maior de projetos implantados para tratamento de esgoto e lixo urbano o que por sua vez, tem aumentado vertiginosamente as quantidades de lodo de esgoto e 
composto de lixo geradas e com isso, a pressão para disposição final desses resíduos a baixo custo.

Embora a disposição de lodo de esgoto e composto de lixo possa trazer inúmeros beneficios aos solos agrícolas, a adoção desta prática por anos sucessivos traz grandes preocupações no que diz respeito à persistência desses resíduos e seus efeitos nas características fisicas e químicas do solo, além das possibilidades de poluição do solo e da água com metais pesados e nitrogênio inorgânico. Na seqüência é realizada uma breve discussão sobre alguns desses aspectos, especialmente àqueles que são de interesse para este trabalho.

\subsection{Critérios para aplicação de resíduos orgânicos urbanos em solos agrícolas}

Nos paises desenvolvidos, os quais apresentam legislações bem definidas para disposição final de resíduos com potencial poluente, os critérios adotados para aplicação de lodo de esgoto e ou composto de lixo em solos agrícolas são extremamente variáveis, o que reflete as dificuldades em se estabelecer normas a respeito deste assunto, mesmo contando com um considerável volume de resultados de pesquisa (Rodella \& Alcarde, 1999). No Brasil, a necessidade de se regulamentar a aplicação desses resíduos em solos é emergente e neste sentido, os Estados do Paraná e de São Paulo já deram passo a frente. No Paraná, através da SANEPAR, foram propóstas normas, com alguns critérios adaptados da legislação da Espanha, regulamentando a utilização agrícola do lodo de esgoto produzido naquele Estado (Companhia de Saneamento do Paraná, 1997). Para São Paulo, a CETESB através da Norma P. 4.230 de outubro de 1998 (documento não homologado), dispõe de critérios e procedimentos para a aplicação de lodo de esgoto em áreas agrícolas (Companhia de Tecnologia e Saneamento Ambiental, 1998). Esta norma por sua vez, foi basicamente uma adaptação da norma 40 CFR (Code of Federal Regulations) Part 503 da USEPA - United States Environmental Protection Agency (1993). Para o composto de lixo ainda não existe no Brasil nenhum tipo de regulamentação no entanto, acredita-se que no futuro esta deverá seguir, em linhas gerais, os critérios estabelecidos para o lodo de esgoto. 
De maneira geral, as legislações são fundamentadas em aspectos comuns como àqueles que dizem respeito às características químicas e microbiológicas dos resíduos, à escolha das áreas aptas aos receberem e naqueles que determinam as taxas e freqüências de aplicações. As grandes diferenças ficam por conta do grau de exigência ou tolerância preconizado em cada legislação.

Neste item será dada ênfase a a lguns tópicos da norma que está sendo preparada pela CETESB e aos critérios que esta agência vem adotando da USEPA. Para o Estado de São Paulo está previsto que não será permitida a aplicação, em solos agrícolas, de lodo de esgoto contendo metais pesados em concentrações superiores aos limites apresentados na primeira coluna da Tabela 1. Com relação aos patógenos, somente será aceita a aplicação de lodos que se enquadrem nas classes A ou B, descritas com maiores detalhes na Norma P. 4.230 já citada anteriormente. Na escolha das áreas aptas a receberem aplicações do resíduo deverão ser levadas em consideração as facilidades de acesso durante o período de aplicação, sua distância de áreas residenciais, a direção predominante dos ventos e os seguintes fatores de restrição: a) a declividade da área não deverá ultrapassar $10 \%$ para aplicação superficial e 18\% para aplicação subsuperficial; b) deverão ser mantidas zonas de proteção de modo a não causar incômodos à vizinhança pela possível emissão de odores; c) deverão ser mantidas distâncias de 15 (quinze) metros de vias públicas, 10 (dez) metros de drenos interceptores e divisores de águas superficiais de jusante e de trincheiras drenantes de águas superficiais e subterrâneas; d) a distância entre a superfície do terreno e o nível do lençol freático deverá ser superior a 1,2 m na época da aplicação.

As taxas de aplicação do lodo de esgoto serão definidas com base no mais restritivo dos seguintes critérios: nitrogênio disponivel para a cultura; poder de neutralização; teor de metais pesados no resíduo e no solo. $\mathrm{O}$ critério do nitrogênio disponível é definido em função da capacidade do lodo de esgoto disponibilizar tal nutriente para as plantas, num determinado período de tempo. A CETESB recomenda na Norma P. 4.230 alguns ensaios para se verificar a taxa de mineralização do $\mathrm{N}$-orgânico presente no resíduo. De posse da taxa de mineralização e do conhecimento das 
concentrações de formas orgânicas e inorgânicas do elemento presentes no lodo de esgoto, procede-se ao seguinte cálculo para o nitrogênio disponivel em base seca:

Nitrogênio disponível $\left(\mathrm{g} \mathrm{kg}^{-1}\right)$ para aplicações superficiais do resíduo;

$$
\mathrm{N}_{\text {disp }}=(\mathrm{Tm} / 100) \times\left(\mathrm{N} \text {-total }-\mathrm{N}-\mathrm{NH}_{3}\right)+0,5 \times\left(\mathrm{N}^{-\mathrm{NH}_{3}}\right)+\left(\mathrm{N}^{-\mathrm{NO}_{3}}{ }^{-}+\mathrm{N}-\mathrm{NO}_{2}{ }^{-}\right)
$$

Nitrogênio disponível $\left(\mathrm{g} \mathrm{kg}^{-1}\right)$ para aplicações subsuperficiais do resíduo;

$$
\mathrm{N}_{\text {disp }}=(\mathrm{Tm} / 100) \times\left(\mathrm{N}-\text { total }-\mathrm{N}-\mathrm{NH}_{3}\right)+\left(\mathrm{N}-\mathrm{NH}_{3}\right)+\left(\mathrm{N}^{-\mathrm{NO}_{3}}{ }^{-}+\mathrm{N}-\mathrm{NO}_{2}{ }^{-}\right)
$$

onde: $\mathrm{Tm}=$ taxa de mineralização do $\mathrm{N}$-orgânico do lodo; $\mathrm{N}$-total $\left(\mathrm{g} \mathrm{kg}^{-1}\right)$ é o nitrogênio Kjeldahl; $\mathrm{N}-\mathrm{NH}_{3}\left(\mathrm{~g} \mathrm{~kg}^{-1}\right)$ é o nitrogênio amoniacal; $\mathrm{N}^{-\mathrm{NO}_{3}^{-}}+\mathrm{N}-\mathrm{NO}_{2}^{-}\left(\mathrm{g} \mathrm{kg}^{-1}\right)$ é a somatória de nitrogênio nítrico presente no resíduo no momento da aplicação.

A taxa de aplicação do lodo de esgoto em $\mathrm{Mg} \mathrm{ha}^{-1}$ é então definida pelo quociente entre a quantidade de nitrogênio recomendada para a cultura em $\mathrm{kg} \mathrm{ha}^{-1}$ e teor estimado de nitrogênio disponível $\mathrm{em} \mathrm{kg}^{-1}$. Provavelmente, para lodos de estações de tratamento onde predominam os esgotos domésticos, este critério será o mais restritivo na definição das taxas de aplicação; considerando as quantidades médias de $\mathrm{N}$ recomendadas para a maioria das culturas e as quantidades médias de nitrogênio disponível no lodo, as taxas devem variar, de acordo com este critério, de 5 a $20 \mathrm{Mg} \mathrm{ha}^{-1}$ (base seca) de lodo de esgoto (Wallace \& Wallace, 1994).

Com relação ao poder de neutralização do resíduo, aplica-se esse critério essencialmente a lodos de esgoto estabilizados com cal. Nesses casos, a definição das taxas de aplicação deverá considerar resultados de ensaios com misturas lodo-solo de forma a garantir que o $\mathrm{pH}$ final da mistura não ultrapasse o valor máximo de 7,0 (determinado em água, relação solo:água 1:2,5). A taxa anual máxima de aplicação do resíduo não poderá resultar em quantidades de metais pesados superiores aos limites estabelecidos na coluna 2, enquanto que a carga cumulativa desses metais, resultante de sucessivas aplicações, não deverá ultrapassar os valores apresentados na coluna 3 da Tabela 1. 
Tabela 1. Critérios para aplicação de lodo de esgoto em solos agrícolas, baseados na presença de metais pesados, preconizados pela USEPA (1993) e adotados pela CETESB (1998) ${ }^{1}$.

\begin{tabular}{cccc}
\hline & Coluna 1 & Coluna 2 & Coluna 3 \\
\hline Metais pesados & $\begin{array}{c}\text { Concentração máxima } \\
\text { permissivel no lodo }\end{array}$ & $\begin{array}{c}\text { Taxa anual máxima de } \\
\text { aplicação no solo }\end{array}$ & $\begin{array}{c}\text { Carga cumulativa } \\
\text { máxima permitida pela } \\
\text { aplicação de lodo } \\
\mathrm{kg} \mathrm{ha}^{-1}\end{array}$ \\
\hline Arsênio & $\mathrm{mg} \mathrm{kg}^{-1}$ & $\mathrm{Kg} \mathrm{ha}^{-1}$ & 41 \\
Cádmio & 75 & 2,0 & 39 \\
Cobre & 85 & 1,9 & 1500 \\
Chumbo & 4300 & 75 & 300 \\
Mercúrio & 840 & 15 & 17 \\
Níquel & 57 & 0,85 & 420 \\
Selênio & 420 & 21 & 100 \\
Zinco & 100 & 5,0 & 2800 \\
\hline
\end{tabular}

TValores estabelecidos com base no material seco.

A simples adoção dos critérios estabelecidos nas legislações não torna segura, por tempo indeterminado, a utilização agrícola de resíduos. É imprescindível o monitoramento periódico de todos os componentes do ambiente agrícola como o solo, a água e as plantas. Este fato reflete uma certa fragilidade que existe nas legislações o que por sua vez, é conseqüência da complexidade que envolve o comportamento dos diversos resíduos no ambiente. Um exemplo disto, são as críticas contundentes recebidas pela USEPA devido aos limites estabelecidos para metais pesados.

De acordo com Wallace \& Wallace (1994) as novas normas da USEPA são bem vindas por permitir a aplicação de maiores taxas de lodo de esgoto do que a versão anterior, de 1989, principalmente por promover aumentos significativos nos teores de carbono orgânico dos solos cultivados. No entanto, os níveis críticos preconizados para metais pesados foram estabelecidos com base em estudos da fitotoxicidade de cada elemento considerado isoladamente, negligenciando possíveis interações entre vários metais e principalmente os efeitos sinergísticos. Nesse caso, combinações de metais a certos níveis podem trazer sérios problemas, os quais podem não se manifestarem se o elemento ocorrer na mesma concentração porém, sozinho. Mcbride (1995) apresentou uma visão extremamente crítica e muito bem fundamentada sobre esse assunto. Segundo o autor, os limites preconizados pela USEPA são extremamente permissíveis e foram 
definidos por métodos inadequados. Além disso, não existiam na época experimentos de campo cujos níveis máximos de metais pesados estabelecidos na norma tivessem sido alcançados, permanecendo a ser provada a segurança de tais níveis. Destacou-se ainda que a questão mais importante a ser respondida antes que os limites da USEPA possam ser considerados aceitáveis, em termos de agricultura e ambiente, diz respeito ao destino dos metais pesados acumulados no solo após um longo prazo da interrupção de aplicações sucessivas de lodo de esgoto.

As recentes iniciativas de alguns Estados brasileiros em regulamentar a utilização agrícola do lodo de esgoto é de importância incontestável. No entanto, é preciso ressaltar os grandes riscos envolvidos na adoção dos critérios de países de clima temperado o que, por hora, são justificáveis pela falta de melhores alternativas. Isto significa que as normas que estão sendo implantadas deverão evoluir com o tempo atribuindo à pesquisa científica, a responsabilidade de fornecer subsídios para melhorias ou elaboração de novos critérios que sejam mais adequados a realidade dos trópicos.

Diante do exposto, cabe aqui um esclarecimento. $\mathrm{O}$ enfoque principal dado a este trabalho partiu do princípio de que a disposição de resíduos urbanos em solos cultivados deve ser tão mais intensa enquanto resultar em mínima agressão ao ambiente e ao mesmo tempo ofereça beneficios aos solos e às plantas. Para tanto, utilizou-se do critério mais permissivo, que no presente caso foi o dos metais pesados. As elevadas doses dos resíduos empregadas neste estudo, especialmente para o lodo de esgoto, objetivaram em primeira instância obter informações sobre a pertinência dos critérios da USEPA para metais pesados, aplicados num caso de solo e clima tropicais. Além disso, buscou-se através do estudo e acompanhamento de outras variáveis do sistema solo-planta-água, uma avaliação segura da ocorrência e severidade dos efeitos causados pela aplicaçãao de elevadas doses dos resíduos. A hipótese de viabilidade econômica desta prática aqui foi desconsiderada pois, acredita-se que a necessidade do tratamento e destinação final dos resíduos produzidos pela atividade humana já é uma realidade e que os esforços empregados na resolução desses problemas devem ser enfrentados, pelo menos a luz dos conhecimentos atuais, como um custo social. 


\subsection{Efeitos da aplicação de resíduos urbanos em atributos do solo}

\subsubsection{Carbono orgânico}

Alguns dos efeitos causados pela disposição de lodo de esgoto e composto de lixo em solos agrícolas, estão diretamente relacionados com a persistência de suas cargas orgânicas nestes solos. Se pelo menos parte do carbono orgânico presente nesses resíduos for resistente a degradação, seus teores no solo aumentarão ao longo de sucessivas aplicações proporcionando assim, alterações significativas em algumas propriedades químicas e fisicas desse solo (Clapp et al., 1986; Metzger \& Yaron, 1987).

Os incrementos e a conservação nos teores de C-orgânico dos solos, em decorrência dessa prática, são devidos às taxas de degradação dos resíduos e seus fatores determinantes. Dessa forma, é provável que exista diferenças entre o comportamento desses resíduos quando dispostos em solos de regiões de clima temperado e tropical.

Em solos sob clima temperado, tais incrementos são possíveis e tem sido comprovados por diversos trabalhos (Bengtson \& Cornette, 1973; Epstein et al., 1976; Hohla et al., 1978; Giusquiani et al., 1995; Logan et al., 1997).

Epstein et al. (1976), em condições campo, verificaram que após 18 meses da aplicação de um lodo de esgoto anaeróbio, os teores de carbono orgânico num solo siltoso aumentaram 50 e $100 \%$ em áreas que receberam respectivamente 160 e $240 \mathrm{Mg} \mathrm{ha}^{-1}$ (base seca). Hohla et al. (1978), num solo semelhante, aplicaram por 6 anos uma carga acumulada de $297,5 \mathrm{Mg} \mathrm{ha}^{-1}$ (base seca) de lodo de esgoto anaeróbio. Os teores de carbono orgânico do solo aumentaram, neste período, de 9,5 para $22,9 \mathrm{~g} \mathrm{~kg}^{-1}$. No entanto, estudos de fracionamento revelaram que do C-orgânico presente no solo tratado com lodo de esgoto, $10,9 \%$ era C-carboidrato e $11,9 \%$ era de óleos e graxas enquanto que, no solo testemunha estas frações eram respectivamente de 18,9 e 1,67\%. Isto mostra que as alterações no carbono dos solos podem não ser apenas quantitativas e que por ocasião de aplicações sucessivas do resíduo, a concentração de substâncias recalcitrantes no solo pode aumentar demasiadamente com conseqüências desconhecidas. Logan et al. (1997) fizeram uma única aplicação de lodo de esgoto anaeróbio nas doses equivalentes a $0,7,5,15,30,60,120,150,188,225$ e $300 \mathrm{Mg} \mathrm{ha}^{-1}$ (base seca) e acompanharam os teores de C-total do solo por 5 anos consecutivos. 
Observaram que os teores de C-total aumentaram linearmente com as doses aplicadas. Os maiores decréscimos nesses teores foram observados nos três primeiros anos após a aplicação, sugerindo maiores taxas de degradação neste período. Nos dois últimos anos, houveram pouquíssimas variações em tal atributo, estacionando os teores de carbono em valores crescentes com as doses e significativamente maiores do que na testemunha.

Bengtson \& Cornette (1973) verificaram em experimento de campo que, após 28 meses da aplicação de composto de lixo (relação $\mathrm{C} / \mathrm{N}=66$ ) nas doses equivalentes a 0, 4,4 e $44 \mathrm{Mg} \mathrm{ha}^{-1}$ (base seca), os teores de C-orgânico do solo haviam aumentado linearmente com as doses, sendo que da testemunha para a maior dose o aumento foi de $31,5 \%$. Efeitos semelhantes foram encontrados por Giusquiani et al. (1995), os quais aplicaram anualmente 10,30 e $90 \mathrm{Mg} \mathrm{ha}^{-1}$ de composto de lixo (relação $\mathrm{C} / \mathrm{N}=14$ ) por 4 anos sucessivos.

Os resultados obtidos pelos diversos autores citados acima, podem não ser totalmente aplicáveis quando são consideradas as regiões sob clima tropical. Nestas regiões, devido às condições de temperatura, os resíduos podem apresentar maiores taxas de degradação e portanto, apenas efeitos temporários sobre o atributo em questão. Neste contexto, a taxa e a frequência de aplicação dos resíduos são aspectos importantes a serem considerados.

No caso do lodo de esgoto, trabalhos conduzidos a campo no Brasil mostraram que quando ocorrem seus efeitos sobre o carbono orgânico dos solos, estes podem ser temporários. Melo et al. (1994) aplicaram, num Latossolo Vermelho escuro distrófico, 0,4, 8, 16 e $32 \mathrm{Mg} \mathrm{ha}^{-1}$ (com 39,3\% de umidade) de lodo de esgoto anaeróbio e observaram que até os 77 dias após a aplicação do lodo todos os tratamentos diferiram em relação à testemunha quanto ao teor de C-orgânico. Desse momento até 230 dias após a aplicação, apenas o tratamento que recebeu $32 \mathrm{Mg} \mathrm{ha}^{-1}$ de lodo de esgoto foi superior à testemunha. De acordo com os autores, isto significa que o C-orgânico adicionado com o lodo foi rapidamente degradado, apresentando um tempo de residência no solo muito curto. Este fato é reforçado por Silva (1995), o qual não detectou nenhum acréscimo significativo de C-orgânico no solo após 146 dias da aplicação de 20 e $40 \mathrm{Mg} \mathrm{ha}^{-1}$ (com 62\% de umidade) de lodo de esgoto anaeróbio num Podzólico Vermelho-Amarelo. 
Em casos de taxas de aplicações de lodo de esgoto mais elevadas, mesmo nas condições dos trópicos, um acréscimo nos teores de carbono do solo pode ser possível conforme sugeriu o trabalho de Marques (1996). O autor verificou que aproximadamente um ano depois da aplicação de 0, 40, 80 e $160 \mathrm{Mg} \mathrm{ha}^{-1}$ (com 74\% de umidade) de lodo de esgoto havia um efeito crescente e linear sobre os teores de C-orgânico de um Latossolo Vermelho escuro.

Um dos poucos trabalhos realizados no Brasil que abordou os efeitos do composto de lixo sobre os teores de C-orgânico de solos foi o de Abreu Junior (1999). Este autor verificou, em condições de casa de vegetação, que após 90 dias da aplicação de $60 \mathrm{Mg} \mathrm{ha}^{-1}$ (base seca) de composto de lixo foi possível detectar acréscimos nos teores de C-orgânico de 21 tipos diferentes de solos ácidos e 5 tipos de solos alcalinos, todos de ocorrência no Brasil. Para os solos ácidos os incrementos de carbono variaram entre 4 e $35 \%$ e para os solos alcalinos esses valores variaram entre 8,6 e $34 \%$.

\subsubsection{Degradação da carga orgânica dos resíduos no solo}

Os conhecimentos relativos a degradação da carga orgânica de resíduos em solos são de grande importância. Além de fornecerem informações essenciais para orientar o seu manejo, permitem um melhor entendimento no balanço do $\mathrm{C}$-orgânico dos solos e possibilitam uma prévia avaliação do potencial dos diversos tipos de resíduos orgânicos, em proporcionarem incrementos à fertilidade do solo (Levi-Minzi et al. 1990; Barreto, 1995).

Para se avaliar a degradação dessa carga orgânica em função do tempo de incubação, pode-se obter os dados experimentais tanto em condições de campo como em condições de laboratório ou estufas (Rodella, 1996). Experimentos a campo podem apresentar limitações na avaliação de efeitos específicos como àqueles causados por temperatura, umidade e doses de aplicação, mas por outro lado, permitem estimar um comportamento geral em condições mais próximas da realidade. Esses estudos normalmente se baseiam em determinações químicas do decréscimo do material orgânico remanescente no solo, o que é feito através de determinações periódicas do carbono orgânico (Tester, 1990; Hyun et al., 1998). Estudos realizados em laboratório 
permitem avaliações mais exatas e mais rápidas uma vez que nestes casos, as variáveis que interferem nos processos de degradação são controladas e via de regra, ideais para a ocorrência de tais processos. Os métodos mais usados nesses casos, baseiam-se na intensidade da respiração microbiológica através de medidas das emanações de $\mathrm{CO}_{2}$ de amostras de terra incubadas com materiais orgânicos (Stotzky, 1965; Jenkinson \& Powlson, 1976). No entanto, embora esses experimentos de respirometria sejam amplamente considerados por refletirem com acuracidade o grau de mineralização de materiais orgânicos, deve se considerar que estudos de curto prazo, freqüentemente usados nestas condições, são severamente limitados quando se quer extrapolar seus resultados para as condições naturais de campo (Hsieh et al., 1981) e neste caso, eles podem apenas dar um indicativo do potencial máximo do solo para degradação de determinados materiais orgânicos (Rodella, 1996).

A intensidade da degradação da carga orgânica do lodo de esgoto e do composto de lixo, uma vez aplicados ao solo, pode variar em função das características dos resíduos (tipo de tratamento, grau de estabilização e composição), da textura e pH do solo, da umidade e temperatura do ambiente e das taxas e métodos de aplicação.

Utilizando-se de técnicas para medida da respiração de microrganismos, em condições de laboratório, Miller (1974) estudou a degradação de um lodo de esgoto anaeróbio. Para tanto, o autor utilizou 3 solos de texturas distintas com dois niveis de umidade (saturado e 1/3 bar), 2 doses de lodo (equivalentes a 90 e $224 \mathrm{Mg} \mathrm{ha}^{-1}$-base seca), 3 períodos de incubação (1, 3 e 6 meses) e 4 niveis de temperatura simulando as estações do ano na cidade de Columbus - Ohio State (USA). O autor observou que a matéria orgânica do lodo foi bastante resistente a degradação uma vez que, a taxa máxima do carbono adicionado emanado como $\mathrm{CO}_{2}$ foi de 20 e $18 \%$ respectivamente para a menor e a maior dose aplicada, em 6 meses de incubação. Os niveis de umidade não afetaram a degradação do lodo no solo arenoso mas em condições de saturação, as taxas de degradação foram moderadamente reduzidas no solo siltoso e completamente inibidas no solo argiloso. No entanto, dentro dos mesmos níveis de umidade, não houveram diferenças atribuídas ao tipo de solo. A temperatura foi o fator que mais influenciou a degradação do lodo de esgoto. 
Agbin et al. (1977) verificaram que a taxa de degradação de um lodo de esgoto digerido anaerobicamente foi reduzida em função da dose aplicada. Para doses de $22,4 \mathrm{e}$ $224 \mathrm{Mg} \mathrm{ha}^{-1}$ (base seca) eles determinaram respectivamente 28,5 e $19,6 \%$ do carbono orgânico do lodo de esgoto emanado como $\mathrm{CO}_{2}$, num período de 12 meses de incubação. Por outro lado, Tester et al (1977) aplicaram 4 doses de composto a base lodo de esgoto $(0,2,4$ e $6 \%$ do peso seco do solo) e observaram que $16 \%$ do C-orgânico do resíduo, independentemente das doses, foi emanado $\mathrm{como}^{\mathrm{CO}_{2}}$ em 54 dias de incubação.

Para lodos similares gerados em 4 diferentes localidades, Terry et al. (1979a) encontram taxas de degradação variando de 26 a $42 \%$ em 4 meses de incubação. Esses autores afirmaram que uma fração dos resíduos é rapidamente decomponível em solos aeróbios entretanto, de 55 a $80 \%$ do C-orgânico presente no lodo parece ser recalcitrante. Os autores salientaram que as taxas de degradação encontradas podem estar superestimadas, devido ao aumento da degradação do C-orgânico nativo dos solos em função da adição do lodo de esgoto ("efeito priming") e também pela possível liberação, em solos ácidos, do C-inorgânico do lodo (íons carbonatos por exemplo) como $\mathrm{CO}_{2}$. Considerando o "efeito priming", Terry et al. (1979b) sintetizaram em laboratório com ${ }^{14} \mathrm{C}$, um lodo de esgoto anaeróbio semelhante a lodos de ocorrência natural. Foram estudados os efeitos do tipo de solo, níveis de umidade, níveis de $\mathrm{pH}$, temperatura de incubação, taxas e métodos de aplicação sobre a intensidade de degradação no solo, do C-orgânico do lodo. Os autores observaram rápida degradação apenas nos primeiros 28 dias de incubação. Ao final de 336 dias, apenas $46 \%$ do ${ }^{14} \mathrm{C}$-orgânico do lodo foi emanado como $\mathrm{CO}_{2}$, sugerindo que a maior parte da matéria orgânica do resíduo foi resistente a degradação. Fatores como textura, $\mathrm{pH}$ e umidade do solo não exerceram efeitos significativos sobre a degradação do material. Quanto aos métodos de aplicação, foram verificadas maiores taxas para aqueles solos que receberam lodo em superfície e incubados a $30^{\circ} \mathrm{C}$ quando comparados com solos onde o lodo foi incorporado e incubado a $21^{\circ} \mathrm{C}$.

O efeito da composição de diferentes resíduos orgânicos sobre sua degradabilidade em solos foi estudado por Levi-Minzi et al. (1990). Num rápido experimento de respirometria em condições de laboratório, os autores avaliaram o 
potencial de degradação de seis diferentes resíduos relativamente estabilizados: esterco de gado, esterco de suínos, cama de frango, lodo de esgoto aeróbio, composto de lixo urbano e palha de centeio. Foram utilizadas 4 doses $(0,0,5,1$ e $2 \%$ base peso seco) e 3 temperaturas de incubação $\left(8,22\right.$ e $\left.30^{\circ} \mathrm{C}\right)$. Nas avaliações da primeira semana de incubação foram obtidas as maiores taxas de degradação para todos os resíduos, o que segundo os autores, se deve a maior presença, neste momento, de substâncias orgânicas facilmente degradáveis pelos microrganismos como por exemplo, aminoácidos, proteínas e carboidratos. Na sequência, uma redução brusca da atividade respiratória foi explicada pela maior presença de complexos lignino-celulósicos. Os autores relataram que a degradação da carga orgânica dos resíduos aumentou linearmente com a temperatura, no entanto só apresentaram os dados obtidos para $22^{\circ} \mathrm{C}$. Nesta temperatura, as taxas de degradação encontradas após 21 dias de incubação para as doses 1,2 e 3 dos vários resíduos foram respectivamente 46,48 e $49 \%$ para esterco de porco; 50, 46 e $45 \%$ para cama de frango; 22, 20 e 19\% para lodo de esgoto aeróbio; 29, 19 e 13\% para palha de centeio; 7, 7 e 7\% para esterco de gado; 7, 6 e 5\% para composto de lixo urbano. Em alguns casos parece ter ocorrido uma leve tendência de queda na taxa de degradação em função do aumento das doses. Diante da relativa persistência no solo, esterco de gado e composto de lixo urbano foram destacados como os resíduos de maior potencial em aumentar e manter teores elevados de carbono orgânico em solos.

Barreto (1995) comparou em condições de laboratório, através de técnicas de respirometria, as taxas de degradação de 4 diferentes resíduos: torta de filtro da agroindústria canavieira, composto de lixo urbano estabilizado, lodo de esgoto anaeróbio e lodo aeróbio de indústria petroquímica. O autor utilizou-se de 2 doses de cada resíduo, equivalentes em carbono orgânico (4 e $8 \mathrm{Mg} \mathrm{ha}^{-1}$ - base seca), aplicadas em amostras de dois solos, um Latossolo Vermelho escuro e uma Areia Quartzosa. Os resultados não evidenciaram diferenças entre solos, porém uma tendência de queda nas taxas de degradação do carbono foi observada da menor para a maior dose. Ao final de 60 dias de incubação, a porcentagem média do carbono degradado nos dois solos para cada resíduo nas doses 1 e 2 foram respectivamente 26 e $24 \%$ para torta de filtro; 15 e $14 \%$ para o composto de lixo; 15 e 13\% para o lodo de esgoto; 11 e $9 \%$ para o lodo petroquímico. Resultados semelhantes para composto de lixo foram obtidos por 
Hadas \& Portnoy (1997), os quais observaram através de ensaios de laboratório, as taxas de degradação de duas doses do resíduo (5 e 15\% em peso seco) aplicadas em amostras de um solo argiloso e outro arenoso. Não foram observados efeitos significativos do tipo de solo no entanto, em 230 dias de incubação verificaram-se taxas de 13 a $15 \%$ para a menor dose e de $8 \%$ para a maior dose aplicada.

Um aspecto relevante quando se considera a degradabilidade de resíduos orgânicos que são tratados por processos de compostagem é o grau de maturação no qual se encontra o resíduo quando ele é aplicado ao solo. Neste contexto, Bernal et al. (1998) estudaram a degradação de sete diferentes misturas de resíduos orgânicos aplicados a um solo calcário em 4 diferentes fases de maturação. Entre os compostos formados, destacam-se aqueles preparados com lodo de esgoto ( $79 \%$ lodo $+21 \%$ palha de milho) e composto de lixo urbano ( $95 \%$ lixo urbano $+5 \%$ de bagaço de sorgo sacarino). Amostras desses compostos foram coletadas em cada uma das seguintes fases: (I)-composto crú, (II)-fase termofilica, (III)-final da fase ativa, (IV) composto maturado; na sequência foram incubadas no solo por 70 dias, na dose equivalente a $48 \mathrm{Mg} \mathrm{ha}^{-1}$ (base seca), com umidade do solo em $60 \%$ da capacidade de retenção de água, a uma temperatura de $28^{\circ} \mathrm{C}$. Os resultados mostraram que as taxas de degradação dos resíduos no solo são reduzidas drasticamente a medida que aumenta o grau de maturação dos compostos. No caso do composto a base de lodo de esgoto, quando aplicado ao solo na fase (I), apresentou uma taxa de degradação de $93,2 \%$ do carbono orgânico total aplicado, taxas estas que diminuíram para 77,40 e $24 \%$ quando o composto foi aplicado respectivamente nas fases (II), (III) e (IV). Para o composto a base de lixo urbano, as taxas encontradas para os resíduos aplicados nas fases (I), (II), (III) e (IV) foram respectivamente $80,12,7$ e $9 \%$. Os autores concluíram pela importância do tempo de compostagem desses materiais, tendo em vista duas razões principais: eliminar o risco de efeitos prejudiciais às culturas em decorrência da aplicação de materiais orgânicos não estabilizados e aumentar a eficiência desta prática no sentido de recuperar e conservar o C-orgânico dos solos. Resultados concordantes com Bernal et al. (1998) foram obtidos por Pascual et al. (1998a) e Pascual et al. (1998b), os quais verificaram a maior degradabilidade de composto de lixo fresco quando comparado com composto estabilizados e lodo de esgoto anaeróbio. 
De uma maneira geral, os trabalhos consultados revelaram ser o lodo de esgoto anaeróbio e o composto de lixo devidamente maturado, resíduos que oferecem certa resistência para serem degradados no solo. No caso do lodo de esgoto, esta resistência tem sido atribuída principalmente ao tratamento de estabilização que tais lodos recebem (Demuynck et al., 1985) o que por sua vez, se traduz num aumento significativo da presença, em sua fração orgânica, de compostos orgânicos estáveis como lignina, celulose, lipídeos, substâncias húmicas, graxas, ceras, óleos e resinas (Pagliai et al., 1981; Clapp et al., 1986). O composto de lixo urbano por sua vez, quando eficientemente compostado, apresenta grandes alterações em sua composição, maior estabilidade biológica e principalmente, menor proporção de substâncias orgânicas facilmente mineralizáveis.

É importante salientar que todos os trabalhos consultados foram realizados com base em experimentos de laboratório sendo a maioria, conduzidos por muito pouco tempo. Dessa forma, todos os resultados ou tendências observadas nessas condições necessitam ser reforçados por estudos de longo prazo e em condições de campo.

\subsubsection{Cinética da degradação da carga orgânica de resíduos}

Diversos trabalhos têm demonstrado que, quando adicionado aos solos, o carbono orgânico presente no lodo de esgoto e no composto de lixo apresenta uma fase inicial de rápida degradação seguida por outras de estabilização progressiva (Miller, 1974; Terry et al., 1979a; Terry et al., 1979b; Levi-Minzi et al., 1990). O estudo da cinética das reações envolvidas nesse processo pode ser uma ótima ferramenta para o seu entendimento, além de possibilitar previsões sobre o comportamento desses materiais orgânicos no solo (Rodella, 1996).

Gilmour et al. (1977) demonstraram que as diversas fases de degradação do C-orgânico no solo podem ser descritas por uma equação cinética de primeira ordem. Esta equação, de acordo com Rodella (1996), baseia-se no princípio de que a velocidade de degradação das substâncias orgânicas diminui em proporção direta com a quantidade de substrato remanescente, podendo ser traduzido entre outras, pelas equações apresentadas na seqüência: 
Equação diferencial:

Equação na forma integrada:

Equação na forma integrada linearizada:

$$
\begin{aligned}
-\mathrm{dC}_{\mathrm{R}} / \mathrm{dt} & =\mathrm{kC}_{\mathrm{R}} \\
\mathrm{C}_{\mathrm{R}} & =\mathrm{C}_{0} \mathrm{e}^{-\mathrm{kt}} \\
\ln \mathrm{C}_{\mathrm{R}} & =\ln \mathrm{C}_{0}-\mathrm{k} . \mathrm{t}
\end{aligned}
$$

onde: $\mathrm{k}$ é a constante de velocidade de primeira ordem expressa em tempo ${ }^{-1}$, quanto maior o valor desta constante, maior é a velocidade de degradação do $\mathrm{C}$-orgânico; $\mathrm{C}_{\mathrm{R}}$ é a quantidade de carbono remanescente no tempo t e $\mathrm{C}_{0}$ a quantidade inicial de carbono orgânico incorporado ao solo.

Esses modelos matemáticos normalmente são aplicados a dados experimentais obtidos em condições controladas de laboratório. No entanto, nada impede que o ajuste destes modelos em dados coletados a campo, apesar de todas fontes de variações envolvidas nestas condições experimentais, venham trazer informações importantes sobre o comportamento desses resíduos no solo. Neste trabalho buscou-se aplicar um modelo de cinética de primeira ordem aos dados de $\mathrm{C}$-orgânico do solo coletados no decorrer de 2 anos experimentais. Os objetivos principais foram estimar a taxa de decréscimo do carbono em cada ano agrícola e verificar se haveria alguma alteração na constante de velocidade de degradação em decorrência da $2^{\underline{a}}$ aplicação dos resíduos.

\subsubsection{Condutividade elétrica e pH}

Medidas da condutividade elétrica são freqüentemente utilizadas para avaliar a concentração de sais solúveis no solo. De acordo com a Sociedade Americana de Ciência do Solo (Richards ${ }^{2}$, citado por Lopes, 1989), valores de condutividade elétrica, no extrato de saturação, maiores que $2000 \mu \mathrm{S} \mathrm{cm}^{-1}$ caracterizam solos salinos. Nesses casos, o crescimento e desenvolvimento das plantas são diretamente afetados pela ocorrência de toxicidade de alguns íons, desequilíbrios nutricionais e principalmente pelas dificuldades na absorção de água e nutrientes devidas ao aumento da pressão osmótica da solução do solo (Allison, 1964; Fageria, 1984, Marschner, 1995).

\footnotetext{
${ }^{2}$ RICHARDS, L.A. Diagnosis Improvements of Saline and Alcaline Soils. Washington: Departament of Agriculture. 1954. 160p.
} 
A disposição de lodo de esgoto ou composto de lixo em solos agrícolas pode aumentar a condutividade elétrica desses solos devido aos altos teores de sais presentes nos resíduos (Hortenstine \& Rothwell, 1972, 1973; Epstein et al., 1976).

Epstein et al. (1976) verificaram, num experimento a campo, que após um mês da aplicação de lodo de esgoto anaeróbio a condutividade elétrica do solo, determinada em pasta de saturação, aumentou de $410 \mu \mathrm{S} \mathrm{cm}^{-1}$ na testemunha para $2500 \mathrm{e}$ $5450 \mu \mathrm{S} \mathrm{cm}^{-1}$ respectivamente nos tratamentos com 40 e $240 \mathrm{Mg} \mathrm{ha}^{-1}$ (base seca). Após quatro meses da aplicação esses valores eram $1310 \mu \mathrm{S} \mathrm{cm}^{-1}$ na testemunha, $2150 \mathrm{e}$ $3850 \mu \mathrm{S} \mathrm{cm}^{-1}$ nos tratamentos com lodo. Somente após 15 meses da aplicação dos resíduos é que foram observados valores tolerados pela maioria das culturas ou seja, $660 \mu \mathrm{S} \mathrm{cm}^{-1}$ na testemunha, $1100 \mathrm{e} 1500 \mu \mathrm{S} \mathrm{cm}^{-1}$ para os tratamentos com lodo de esgoto. Os autores atribuíram o aumento inicial da condutividade elétrica à grande concentração de íons $\mathrm{Ca}^{+2}, \mathrm{Mg}^{+2}$ e $\mathrm{Cl}^{-}$presentes na camada superficial do solo, ao passo que o decréscimo desses valores foi função da lixiviação desses íons causados pela ocorrência de chuvas no período estudado. Embora não mencionado, é possível que a presença de ions $\mathrm{NO}_{3}{ }^{-}$e $\mathrm{NH}_{4}{ }^{+}$tenham contribuído significativamente para elevar a condutividade elétrica do solo uma vez que, a mineralização do N-orgânico poderia estar ocorrendo, naquele momento, com maior intensidade.

Stark \& Clapp (1980) avaliaram a condutividade elétrica de um solo arenoso (suspensão solo:água 1:2,5) que recebeu cinco aplicações de lodo de esgoto anaeróbio em quatro diferentes doses, distribuídas num período de três anos. As quantidades acumuladas no período foram 0,119, 237 e $466 \mathrm{Mg} \mathrm{ha}^{-1}$ (base seca). Um ano após a última aplicação de lodo, os autores verificaram que os valores de condutividade elétrica variavam, de 80 a $1100 \mu \mathrm{S} \mathrm{cm}^{-1}$, linearmente com as doses. Neste mesmo experimento, cinco anos depois da última aplicação de lodo de esgoto, Harding et al. (1985) verificaram que a condutividade elétrica dos solos tratados com o resíduo apresentou valor médio de $490 \mu \mathrm{S} \mathrm{cm}^{-1}$, enquanto que no solo testemunha este valor aumentou para $300 \mu \mathrm{S} \mathrm{cm}^{-1}$ devido as adições anuais de fertilizantes nitrogenados. Durante todo o 
período experimental, os autores cultivaram milho e não observaram danos causados pelo aumento na concentração salina do solo.

Por outro lado, Bevacqua \& Mellano (1994) destacaram a necessidade de constante monitoramento da conduvidade elétrica de solos tratados com composto a base de lodo de esgoto. Eles observaram que a aplicação acumulada, durante dois anos, de $74 \mathrm{Mg} \mathrm{ha}^{-1}$ (base seca) deste resíduo aumentou a condutividade (extrato de saturação) de $1520 \mu \mathrm{S} \mathrm{cm}^{-1}$ na testemunha para $2440 \mu \mathrm{S} \mathrm{cm}^{-1}$ no solo tratado. Estes níveis foram considerados prejudiciais para as culturas do alho e alface. Logan et al. (1997) acompanharam o comportamento dos valores de condutividade elétrica do solo (suspensão solo:água 1:5) durante cinco anos após a aplicação de elevadas doses de lodo de esgoto. Verificaram que a condutividade elétrica aumentou linearmente com as doses aplicadas. Os maiores valores foram observados no segundo ano após a aplicação, o que foi associado a uma combinação de maiores taxas de mineralização do C-orgânico do lodo com os efeitos climáticos. Neste ano, a condutividade elétrica do solo nos tratamentos que receberam doses equivalentes a $150,188,225$ e $300 \mathrm{Mg} \mathrm{ha}^{-1}$ atingiram valores acima $900 \mu \mathrm{S} \mathrm{cm}^{-1}$ prejudicando o crescimento de plantas de milho e alface.

Utilizando-se de composto de lixo na recuperação de solos degradados pela mineração, Hortenstine \& Rothwell (1972) observaram ao final de dois anos, aumentos na condutividade elétrica (extrato de saturação) de 47 e 105\% devidos a aplicação anual de respectivamente 35 e $70 \mathrm{Mg} \mathrm{ha}^{-1}$ (base seca) do resíduo. Convém salientar que esses aumentos tiveram como referência uma testemunha adubada com $1 \mathrm{Mgha}^{-1} \mathrm{de}$ fertilizantes minerais. Num experimento em vasos, Hortenstine \& Rothwell (1973), trabalhando com um composto de lixo peletizado nas doses equivalentes a $0,16,32,64$ e $128 \mathrm{Mg} \mathrm{ha}^{-1}$ (base seca), verificaram efeitos crescentes sobre o atributo em questão, chegando a obter valores de $1730 \mu \mathrm{Sm}^{-1}$ para a maior dose, porém em nenhum dos trabalhos os autores observaram efeitos fitotóxicos às culturas da aveia e do sorgo granifero.

Abreu Junior (1999) num experimento com vasos (sistema fechado, sem lixiviação) observou que a adição de composto de lixo na dose de $60 \mathrm{Mg} \mathrm{ha}^{-1}$ (base seca) a 26 solos de ocorrência no Brasil, mesmo quando combinado com calagem ou gessagem e fertilização mineral, não elevou a concentração salina (CE - suspensão solo:água 1:1) a níveis preocupantes. Nos solos ácidos os valores 
mínimos observados para àqueles tratados com resíduo e sua testemunha foram respectivamente 67 e $13 \mu \mathrm{S} \mathrm{cm}^{-1}$ (Terra Roxa Estruturada sem calagem e fertlizantes minerais) enquanto que os valores máximos foram de 357 e $53 \mu \mathrm{S} \mathrm{cm}^{-1}$ (Latossolo Amarelo álico com calagem e fertilizantes minerais). Em solos alcalinos os valores foram um pouco mais elevados, devido a própria natureza desses solos. Os valores mínimos encontrados para os solos tratados com resíduo e sua testemunha foram respectivamente 127 e $52 \mu \mathrm{S} \mathrm{cm}^{-1}$ (Cambissolo Latossólico sem gessagem e fertlizantes minerais) sendo que os valores máximos foram de 442 e $214 \mu \mathrm{S} \mathrm{cm}^{-1}$ (Solo salino sódico com gessagem e fertilizantes minerais). As diferenças verificadas entre os diversos solos provavelmente estão relacionadas aos seus diferentes potenciais para mineralização do carbono e do nitrogênio orgânico presente no resíduo.

Através dos resultados de pesquisas aqui apresentados, evidencia-se o potencial do lodo de esgoto e do composto de lixo em proporcionar, mesmo que temporariamente, condições de salinidade nos solos. Os trabalhos sugeriram de maneira geral, que a intensidade dos efeitos causados sobre a condutividade elétrica desses solos é função da composição, taxas e freqüência de aplicação dos resíduos, do regime pluviométrico da localidade e da capacidade de drenagem dos solos. Além disso, há de se considerar que as conseqüências dessas alterações no solo são variáveis com a capacidade de tolerância de cada espécie vegetal. Por fim, verificou-se que o potencial de salinização dos resíduos é mais um fator de preocupação quando da disposição dos mesmos em solos agrícolas e que isto deve ser considerado em estratégias de manejo desses resíduos. "

Outro aspecto importante quando da utilização agrícola de resíduos urbanos são seus efeitos sobre o $\mathrm{pH}$ dos solos. A extensão de tais efeitos são dependentes da matéria orgânica presente nos resíduos, das propriedades do solo como textura e capacidade de tamponamento e do tempo e taxa de aplicação dos resíduos (Clapp et al.,1986).

Aplicando lodo de esgoto nas doses de 40 e $240 \mathrm{Mg} \mathrm{ha}^{-1}$ (base seca), Epstein et al. (1976) verificaram efeitos sobre o $\mathrm{pH}$ do solo somente para a maior dose. Ainda sim, esses efeitos foram temporários sendo que, aos 30 dias após a aplicação do resíduo os valores observados para a testemunha e para as parcelas tratadas foram respectivamente 5,7 e 7,5, aos 120 dias foram 4,7 e 6,3 e ao final do experimento ( \pm 500 dias após a aplicação) os valores obtidos foram 6,2 e 6,3. Stark \& Clapp (1980), 
após um ano da última de sucessivas aplicações de lodo de esgoto, verificaram que o pH de um solo arenoso atingiu valor 6,0 independentemente da dose aplicada, contra um valor de 5,6 na testemunha. Neste mesmo experimento, cinco anos mais tarde, Harding et al. (1985) verificaram que os solos tratados com lodo de esgoto continuavam apresentando valores próximos a 6,0 enquanto a testemunha apresentou $\mathrm{pH} 5,0$. Os autores atribuíram este fato a um possivel poder de tamponamento ocasionado pela contínua degradação da matéria orgânica do resíduo. Logan et al. (1997) trabalhando com solo derivado de rochas calcárias e várias doses de lodo de esgoto, observaram imediatamente após a aplicação do resíduo, para as menores doses $\left(7,5\right.$ e $\left.15 \mathrm{Mg} \mathrm{ha}^{-1}\right)$, um decréscimo no valor $\mathrm{pH}$. Este decréscimo estava associado as reações de nitrificação. Nas demais doses houveram aumentos de até duas unidades, em função da dose aplicada. A partir do segundo ano da aplicação do lodo não foram mais observados efeitos significativos sobre o $\mathrm{pH}$ do solo.

Outros trabalhos como o de King \& Morris (1972), Simeoni et al. (1984) Pietz et al. (1989) e Dowdy et al. (1991) verificaram que alguns lodos de esgoto podem acidificar o solo. De acordo com estes autores, esta acidificação é atribuída às reações de nitrificação do nitrogênio amoniacal, a provável oxidação de sulfitos e a produção de ácidos orgânicos durante a degradação do resíduo.

Aumentos no pH de solos devido a aplicação de composto de lixo tem sido demonstrados por vários trabalhos científicos (Hortenstine \& Rothwell, 1972, Bengtson \& Cornette, 1973; Mazur et al., 1983b, Maynard \& Hill, 1994 Trindade et al., 1996). Num trabalho mais abrangente, Abreu Júnior (1999) verificou que a aplicação de composto de lixo $\left(60 \mathrm{Mg} \mathrm{ha}^{-1}\right)$, sem nenhum outro aditivo, foi capaz de elevar o pH de 21 solos ácidos brasileiros, avaliados 90 dias após a incubação com o resíduo.

Algumas explicações tem sido utilizadas para justificar os fenômenos responsáveis pela elevação do $\mathrm{pH}$ de solos tratados com resíduos orgânicos. A primeira delas é dada por Hoyt \& Turner (1975), os quais atribuíram a elevação do pH de um solo ácido, a complexação do alumínio presente na sua solução, por substâncias orgânicas produzidas durante a decomposição de resíduos de alfafa. Por outro lado, Mattiazzo \& Glória (1987) explicaram a elevação do pH de solos tratados com vinhaça, 
pela produção de íons $\mathrm{OH}^{-}$quando o oxigênio atua como receptor final de elétrons da oxidação microbiana do carbono orgânico do resíduo. Hue (1992) afirmou que a elevação de $\mathrm{pH}$ num solo altamente intemperizado estava associada a produção de $\mathrm{OH}$ em função da adição de esterco de galinha e lodo de esgoto. De acordo com o autor, a produção de hidroxilas foi devida a dois processos. Primeiro por reações de troca de ligantes entre ânions orgânicos e terminais hidroxilas de óxidos de $\mathrm{Fe}$ e $\mathrm{Al}$; reações semelhantes a adsorção de fosfatos, onde os ânions orgânicos (p.e. tartarato e ftalato) são adsorvidos aos óxidos em troca do lançamento de $\mathrm{OH}$ na solução do solo. Segundo, a redução de óxidos de $\mathrm{Fe}$ e $\mathrm{Mn}$ (predominantemente goetita) que deve ocorrer em ambiente rico em elétrons derivados da rápida oxidação do carbono orgânico dos resíduos, conforme a reação abaixo.

$$
\mathrm{FeO}(\mathrm{OH})+\mathrm{e}^{-}+\mathrm{H}_{2} \mathrm{O} \leftrightarrow \mathrm{Fe}^{2+}+3 \mathrm{OH}
$$

Convém salientar que existem casos em que o efeito alcalinizante de resíduos urbanos é promovido essencialmente por fatores não relacionados com as reações de degradação da matéria orgânica. É o caso típico dos lodos de esgoto que recebem $\mathrm{CaO}$ no tratamento para redução das populações de microrganismos patogênicos. Aumentos de $\mathrm{pH}$ em solos tratados com lodos dessa natureza podem ser observados nos trabalhos de Oliveira (1995), Silva (1995), Sloan \& Basta (1995) e Bertoncini (1997).

\subsubsection{Capacidade de troca de cátions}

Nos solos de ocorrência em regiões tropicais, a matéria orgânica se apresenta como a principal componente do complexo de cargas negativas, tendo em vista a menor reatividade dos óxidos de ferro e alumínio e dos minerais de argila predominantes, como a caulinita. Sua capacidade em gerar cargas negativas se deve fundamentalmente aos grupos funcionais carboxílicos $(-\mathrm{COOH})$, fenólicos $(-\mathrm{OH})$, álcoois $(-\mathrm{OH})$ e metoxílicos $\left(-\mathrm{OCH}_{3}\right)$ que se encontram na periferia das moléculas dos ácidos orgânicos presentes no húmus (Fassbender, 1975). Dessa forma, é notório que a manifestação dessas cargas é determinada essencialmente pelas condições de acidez ou alcalinidade do meio (Helling et al., 1964), o que permite afirmar que grande parte da capacidade de troca de cátions dos solos tropicais é dependente do seu $\mathrm{pH}$. 
A influência de resíduos urbanos sobre a CTC de solos tem sido verificada por diversos autores. Hortenstine \& Rothwell (1972) observaram que duas aplicações de composto de lixo (35 e $70 \mathrm{Mg} \mathrm{ha}^{-1} \mathrm{ano}^{-1}$ ), num solo degradado por mineração, foi capaz de aumentar a CTC desse solo de 8,4 para 13,0 e 20,1 $\mathrm{mmol}_{\mathrm{c}} \mathrm{kg}^{-1}$. Num solo arenoso sob floresta de pínus, Bengtson \& Cornette (1973) verificaram que mesmo após 28 meses da aplicação de $44 \mathrm{Mg} \mathrm{ha}^{-1}$ de composto de lixo a CTC do solo apresentou-se $18 \%$ maior do que nas áreas não tratadas. Epstein et al. (1976), mostraram que elevadas doses de lodo de esgoto anaeróbio também podem causar aumentos na CTC de solos. Esses autores observaram que enquanto no solo não tratado com o resíduo a CTC variou de 55 a $64 \mathrm{mmol}_{\mathrm{c}} \mathrm{kg}^{-1}$, seu valor chegou a $154 \mathrm{mmol}_{\mathrm{c}} \mathrm{kg}^{-1}$ nos tratamentos com doses de $240 \mathrm{Mg} \mathrm{ha}^{-1}$. No entanto, após 18 meses da aplicação houve um decréscimo para $87 \mathrm{mmol}_{\mathrm{c}} \mathrm{kg}^{-1}$, o que foi atribuído a degradação da matéria orgânica. Em todos esses trabalhos, os autores atribuíram o aumento da CTC dos solos ao acréscimo de cargas negativas provenientes da matéria orgânica dos resíduos. Nem poderia ser diferente, uma vez que possíveis efeitos do $\mathrm{pH}$ do solo teriam sido mascarados devido ao fato da CTC ter sido determinada com a utilização de soluções alcalinas tamponadas.

Em estudo conduzido em casa de vegetação por Simeoni et al. (1984), utilizando-se de amostras de um solo arenoso com pH inicial 5,4, foram aplicadas 0,60 , 120 e $240 \mathrm{Mg} \mathrm{ha}^{-1}$ (base seca) de um lodo de esgoto anaeróbio. Os resultados de $\mathrm{pH}$ e CTC determinada em $\mathrm{pH} 8,2$, obtidos para a testemunha e doses de lodo, foram respectivamente os seguintes: $\mathrm{pH}, 5,1,5,0,5,0$ e 4,7 ; CTC, 17,7 , 19,5 , 21,3 e $25,7 \mathrm{mmol}_{\mathrm{c}} \mathrm{kg}^{-1}$. Os autores explicaram que o aumento da CTC foi devido ao aumento de C-orgânico do solo, embora esses resultados não tenham sido apresentados. $\mathrm{O}$ que chamou a atenção, é que o lodo de esgoto praticamente não elevou o pH do solo, apresentando decréscimo na maior dose do resíduo. Se considerarmos que a manifestação das cargas negativas da matéria orgânica é dependente do $\mathrm{pH}$, os valores de CTC obtidos pelo autor não seriam reais e sim valores potenciais.

Nas determinações da CTC do solo, em linhas gerais, assume-se que um cátion presente numa solução salina é capaz de ocupar os sítios de troca iônica da amostra sendo sua quantidade adsorvida, determinada na seqüência. Essas determinações eram 
realizadas tradicionalmente com a utilização de soluções tamponadas em pH 7,0 ou 8,2 (Bache, 1976). Gillman \& Sumpter (1986) propuseram um método, modificado de Gillman (1979), para determinação da CTC ao pH atual dos solos no qual se utiliza solução de $\mathrm{BaCl}_{2}$ para saturar as amostras, deslocando em seguida o $\mathrm{Ba}^{2+}$ adsorvido com solução de $\mathrm{MgSO}_{4}$. Atualmente este método tem sido recomendado pela American Society of Agronomy (Sumner \& Miller, 1996) por possibilitar a quantificação da CTC na forma mais próxima das condições naturais do campo. Além disso, tal procedimento é tido como o mais adequado para os solos intemperizados das regiões tropicais, onde a CTC é altamente dependente do $\mathrm{pH}$ (Rodella, 1996).

Cavallaro et al. (1993) determinaram, em condições de campo, os efeitos da aplicação de $0,8,16$ e $24 \mathrm{Mg} \mathrm{ha}^{-1}$ (base seca) de lodo de esgoto sobre a CTC $\left(\mathrm{BaCl}_{2}-\mathrm{MgSO}_{4}\right)$ ao $\mathrm{pH}$ atual, de um solo Podzólico ácido de Porto Rico. Os resultados obtidos para carbono do solo, $\mathrm{pH}$ em água e CTC, para a testemunha e a maior dose de lodo foram respectivamente: carbono, 15,9 e 21,0 $\mathrm{g} \mathrm{kg}^{-1}$; $\mathrm{pH}, 5,08$ e 5,17; CTC, 73,2 e $85,8 \mathrm{mmol}_{\mathrm{c}} \mathrm{kg}^{-1}$. Os autores atribuíram o aumento significativo da CTC do solo a elevação no seu teor de carbono orgânico e seus efeitos sobre a complexação do Al que estaria ocupando sítios de troca. No entanto, apesar do considerável aumento no teor de matéria orgânica, o acréscimo na CTC ocorreu em nível abaixo do esperado, provavelmente devido ao inexpressivo efeito do resíduo sobre o $\mathrm{pH}$ do solo. Giusquiani et al. (1995), após aplicação de composto de lixo $\left(0,10,30\right.$ e $90 \mathrm{Mg} \mathrm{ha}^{-1}$ base seca) num solo calcário com $\mathrm{pH}$ inicial 8,2 , também verificaram que os acréscimos na CTC ao $\mathrm{pH}$ atual foram abaixo dos esperados. Considerando que o $\mathrm{pH}$ do solo esteve acima de 7,0, os autores atribuíram este fato aa decréscimo na contribuição das cargas negativas das substâncias orgânicas devido à complexação de metais pesados adicionados ao solo através do resíduo.

A contribuição de diferentes materiais orgânicos para a CTC de um Latossolo Vermelho-Amarelo foi avaliada, em casa de vegetação, por Rodella et al. (1995). Foram aplicados e incubados por 90 dias, $10 \mathrm{Mg} \mathrm{ha}^{-1}$ de carbono orgânico, através de diferentes materiais, em amostras de solo com pH inicial de 4,9 e 6,4. Turfa, bagaço de cana, torta de filtro, cama de frango, esterco de gado, composto de lixo, vermicomposto e lodo de 
esgoto foram os materiais utilizados. Os autores relacionaram a CTC a $\mathrm{pH} 7,0$ do material orgânico com a CTC do solo determinada ao $\mathrm{pH}$ atual e verificaram que apenas $32 \%$ da CTC do solo podia ser explicada pela CTC do material orgânico adicionado. Esta proporção aumentou para $78 \%$ quando $\mathrm{opH}$ do solo foi incluído na análise de regressão. Isto significa que, embora os diversos materiais tenham apresentado diferentes quantidades de cargas negativas, suas eficiências em elevar a CTC do solo foram determinadas pelos seus efeitos sobre o $\mathrm{pH}$ desse solo. Por exemplo, a turfa foi o material que apresentou maior CTC a pH 7,0 mas promoveu uma reação ácida no solo e por isso foi um dos materiais que menos contribuiu para o aumento do atributo em questão. De maneira semelhante, Barreto (1995) apontou o efeito do lodo de esgoto e do composto de lixo sobre o $\mathrm{pH}$ de uma Areia Quartzosa, como a principal variável que influenciou o aumento da CTC determinada ao $\mathrm{pH}$ atual.

No Brasil, poucos autores tem se preocupado em verificar os efeitos desses resíduos na CTC dos solos entre eles, Melo et al. (1994) e Silva (1995). No entanto, tais trabalhos estimaram a CTC pela soma de bases (Raij et al., 1987), o que pode levar, dependendo da taxa de aplicação, a superestimativas devido as elevadas concentrações de cálcio e magnésio que freqüentemente ocorrem no lodo de esgoto e no composto de lixo. Melo et al. (1994) observaram que a aplicação de lodo de esgoto (32 $\mathrm{Mg} \mathrm{ha}^{-1}$ - 39\% de água) promoveu um aumento significativo na CTC de um Latossolo Vermelho escuro distrófico avaliada até 473 dias após a aplicação do resíduo. Os autores encontraram correlação positiva e significativa da CTC com o teor de C-orgânico do solo e da CTC com a fração humina deste carbono. No trabalho de Silva (1995) a aplicação de doses crescentes de lodo de esgoto (0, 20 e $40 \mathrm{Mg} \mathrm{ha}^{-1}-$ $62 \%$ de água) aumentou substancialmente a CTC de um Podzólico Vermelho-Amarelo porém, esses efeitos foram temporários. $\mathrm{O}$ autor explicou que a queda no valor estimado de CTC a partir dos 250 dias após a aplicação do resíduo foi devida a rápida decomposição e aos processos de polimerização da fração húmica liberada pela matéria orgânica do solo. Foi ressaltado também, que na análise de carbono orgânico do solo não se constatou variações que justificassem as alterações na CTC. Os valores da CTC evidentemente apresentaram o mesmo comportamento dos teores de cálcio, magnésio e 
potássio do solo. Devido a grande quantidade aplicada desses cátions, (p.e $175 \mathrm{~kg} \mathrm{ha}^{-1}$ de Ca) parece razoável supor que a queda no valor estimado da CTC seria melhor justificada por uma provável lixiviação das chamadas "bases" trocáveis.

\subsection{Metais pesados}

\subsubsection{Fatores que interferem no comportamento dos metais pesados no solo}

Conhecer o comportamento dos metais pesados no solo é essencial para avaliar o impacto ambiental provocado pela disposição em solos agrícolas, de resíduos contendo esses elementos (Sposito et al., 1982). A extensão deste impacto está diretamente relacionada com a habilidade do solo em reter esses metais (Elliott et al., 1986).

Quando adicionados aos solos, os metais pesados contidos em resíduos passam por inúmeras reações, as quais são responsáveis pelas várias espécies químicas e físicas que serão difundidas neste ambiente (Essington \& Mattigod, 1991). De maneira geral, tais reações ocorrem por processos de precipitação e dissolução, complexação com compostos orgânicos e ou inorgânicos e adsorção e desorção (Alloway, 1990). A intensidade desses processos é influenciada pelos vários atributos dos solos incluindo o valor $\mathrm{pH}$, textura e composição mineral (teor e tipos de argilas, teor de óxidos de ferro, alumínio e manganês), teor de matéria orgânica, capacidade de troca de cátions (CTC), potencial redox, composição da solução do solo e a temperatura ambiente (Kabata-Pendias \& Pendias, 1984; Alloway, 1990).

Precipitação é o processo pelo qual um íon metálico reage com outros íons solúveis para formar um produto sólido e a dissolução é o processo inverso. A composição da solução, o pH e o potencial redox do solo são os atributos que mais interferem nesses processos. Os metais pesados podem ser precipitados como hidróxidos, sulfatos, sulfitos, fosfatos e carbonatos sendo que, alguns desses precipitados são muito estáveis e portanto, apresentam dissolução mais dificil, outros podem se dissolverem mais facilmente quando expostos a determinadas condições de solo, como a acidez. Existem casos em que o precipitado é formado por partículas pouco densas e por isso permanecem em suspensão na solução do solo, sujeitas portanto, a movimentação por fluxo de massa (Kabata-Pendias \& Pendias, 1984; Adriano, 1986). 
Nos processos de complexação, os metais pesados são quelados por compostos orgânicos ou inorgânicos, conhecidos como ligantes. Os ligantes orgânicos típicos são os ácidos fúlvicos e húmicos derivados da matéria orgânica. Alguns metais pesados como $\mathrm{Cu}, \mathrm{Mn}, \mathrm{Ni}, \mathrm{Pb}$ e $\mathrm{Zn}$ apresentam grande afinidade com esses ligantes, caracterizando uma importante via de redução da disponibilidade desses elementos às plantas tendo em vista que, esses complexos são pouco solúveis em água (Adriano, 1986). A tendência dos cátions metálicos interagir com ligantes inorgânicos e formar complexos solúveis é explicada pelas regras da química de coordenação (Kabata-Pendias \& Pendias, 1984). De acordo com a teoria de Pearson (1963), baseada numa sistemática de classificação dos elementos químicos em ácidos e bases, os pares de íons ou complexos formados em solução ocorrem preferencialmente entre ácidos fortes e bases fortes e entre ácidos fracos e bases fracas. Pode-se citar por exemplo, que $\mathrm{Ba}^{2+}, \mathrm{Cr}^{3+}, \mathrm{Fe}^{3+}, \mathrm{Mn}^{2+}, \mathrm{Mn}^{7+} \mathrm{e} \mathrm{Al}^{3+}$ reagem prontamente com os ligantes $\mathrm{CO}_{3}{ }^{2-}, \mathrm{F}^{-}, \mathrm{NO}_{3}{ }^{-}, \mathrm{PO}_{4}{ }^{3-}$ e $\mathrm{SO}_{4}{ }^{2-} ; \mathrm{Cd}^{2+}, \mathrm{Cu}^{2+}, \mathrm{Fe}^{2+}$, $\mathrm{Ni}^{2+}, \mathrm{Pb}^{2+}$ e $\mathrm{Sn}^{2+}$ são complexados preferencialmente por $\mathrm{Cl}, \mathrm{Br}^{-}, \mathrm{SO}_{3}{ }^{2-}, \mathrm{NH}_{3}$ e $\mathrm{NO}_{2}{ }^{-}$; enquanto que $\mathrm{Hg}^{2+}$ e $\mathrm{Ag}^{+}$apresentam maior probabilidade de formar complexos com $\mathrm{r}$, $\mathrm{CN}^{\circ}, \mathrm{S}^{2 *}, \mathrm{SH}, \mathrm{P}$ e N orgânicos.

Através dos processos de adsorção, os metais pesados nas formas iônicas ou complexas podem ser retidos, predominantemente por forças eletrostáticas, na superfície de partículas sólidas do solo. A habilidade desta fase sólida em reter os cátions, denominada capacidade de troca de cátions ou simplesmente CTC, é uma das mais importantes propriedades que governam a presença desses elementos na solução do solo (Alloway, 1990). A maior ou menor CTC é função dos tipos e teores de minerais de argila, dos teores de óxidos de ferro e alumínio, dos teores de matéria orgânica e do $\mathrm{pH}$ do solo. A capacidade do solo em reter metais geralmente, é aumentada com a elevação do pH. De acordo com Adriano (1986), exceções são feitas para o As, Mo, Se e alguns estados de valência do $\mathrm{Cr}$, que são mais comumente removidos em solos alcalinos. A relativa solubilidade de alguns metais pesados em função do $\mathrm{pH}$ do solo foi assim sumarizada por Fuller ${ }^{3}$ et al., citados por Adriano (1986): em solos ácidos ( $\mathrm{pH} 4,2$ a 6,6), $\mathrm{Cd}, \mathrm{Hg}$, Ni e $\mathrm{Zn}$ são relativamente solúveis, As, Be e $\mathrm{Cr}$ são moderadamente solúveis, e

\footnotetext{
${ }^{3}$ FULLER, W.H.; KORTE, N.E.; NIEBLA, E.E.;ALESIJ, B.A. Contribuiton of soil to the migration of certain common and trace elements. Soil Science. v.122, p. 223-235, 1977.
} 
$\mathrm{Cu}, \mathrm{Pb}$ e Se são pouco solúveis; em solos neutros a alcalinos ( $\mathrm{pH}$ 6,7 a 7,8), As e Cr são relativamente solúveis, $\mathrm{Be}, \mathrm{Cd}, \mathrm{Hg}$ e $\mathrm{Zn}$ são moderadamente solúveis, e $\mathrm{Cu}, \mathrm{Pb}$ e $\mathrm{Ni}$ são pouco solúveis.

\subsubsection{Acúmulo de metais pesados nos solos e nas plantas}

A presença de metais pesados em concentrações relativamente elevadas, constitui um dos maiores entraves para a disposição de resíduos urbanos em solos agrícolas. Esses elementos podem expressar seu potencial poluente diretamente sobre os organismos dos solos, pela disponibilidade às plantas em níveis fitotóxicos além da possibilidade de transferência para a cadeia alimentar através das próprias plantas ou pela contaminação das águas de superficie e subsuperficie (Logan \& Chaney, 1983; Chang et al., 1987, Levine et al., 1989).

O acúmulo desses elementos no solo, em decorrência da disposição de lodo de esgoto ou composto de lixo, vem sendo apontado nos EUA desde a década de 70 (King \& Morris, 1972; Hortenstine \& Rothwell, 1972; Bengtson \& Cornette, 1973; Cunningham etal., 1975; Galloway \& Jacobs, 1977; Baxter et al., 1983; Chang et al., 1984; Sommers et al., 1987; Williams et al., 1980, 1984 e 1987). No Brasil, este potencial de acúmulo foi verificado nos trabalhos de Berton et al. (1989), Oliveira (1992), Vanzolini (1994), Oliveira (1995), Barreto (1995), Marques (1996), Abreu Júnior (1999) entre outros. No entanto, devido aos vários fatores que influenciam o comportamento desses elementos nos ecossistemas (Sommers, 1977), existem grandes dificuldades na interpretação e na reprodução ou aplicação dos resultados de pesquisa (Singh \& Keefer, 1989), principalmente no que diz respeito a intensidade de absorção dos metais pesados pelas plantas e as possibilidades desses elementos alcançarem concentrações fitotóxicas avaliadas nos solos e ou nas plantas.

Embora ainda exista a necessidade de muitos estudos, a serem realizados por longo prazo e em condições de campo, sobre a disposição de resíduos urbanos em solos agrícolas, Page et al. (1987) já apontaram num trabalho de revisão, algumas informações importantes sobre o comportamento, no sistema solo-planta, dos metais pesados adicionados via lodo de esgoto. De acordo com os autores, dois aspectos foram 
relevantes: o primeiro é que o lodo de esgoto desempenhou ao mesmo tempo no solo, o papel de fonte e agente imobilizador dos metais pesados; o segundo é que a absorção de metais pesados pelas plantas em função das taxas de aplicação do resíduo, tem apresentado diferentes tipos de respostas incluindo comportamentos lineares, assintóticos, respostas negativas ou simplesmente nenhum tipo de resposta.

Neste contexto, com base em observações de dados referentes a absorção de metais pesados por diversas culturas, obtidos em diferentes experimentos de campo, Corey et al. (1987) perceberam que, na maioria dos casos, a absorção desses elementos não aumentava linearmente com as taxas de aplicação de lodo de esgoto e sim, a partir de determinadas doses do resíduo, atingia e se estabelecia num valor máximo. Os autores denominaram este comportamento de "resposta platô" surgindo daí, a chamada "teoria do platô" ou do original "plateau theory". De acordo com esta teoria, a capacidade de adsorção específica dos metais pesados adicionados ao solo, via lodo de esgoto, persistirá enquanto esses elementos estiverem no solo sugerindo portanto, que os metais não permaneceriam em formas prontamente disponiveis às plantas e que o resíduo, que é a fonte de contaminação de metais pesados, tem em sua carga orgânica uma forma de aumentar a capacidade dos solos em reter esses elementos. Neste sentido, após as concentrações de metais no tecido vegetal terem alcançado o chamado platô, após sucessivas aplicações de lodo de esgoto, estas permanecerão nestes níveis até mesmo depois da interrupção das aplicações do resíduo (Chang et al., 1997; Logan et al.,1997).

Logan et al. (1997) ressaltaram que as taxas de degradação da carga orgânica do lodo de esgoto e seus efeitos sobre o $\mathrm{pH}$ do solo constituem dois fatores de confundimento para a teoria do platô. Esta afirmação foi baseada em McBride (1995), o qual argumentou que a lenta degradação da matéria orgânica do lodo poderia liberar metais em formas mais solúveis, atribuindo a este fenômeno a chamada "hipótese da bomba relógio" ou do original "sludge time bomb hypothesis". Esta hipótese postula que a capacidade do solo em adsorver metais pesados é aumentada pela matéria orgânica adicionada via lodo de esgoto no entanto, com o tempo seguido da interrupção das aplicações, esta capacidade tende a voltar ao seu valor original, liberando metais pesados 
para a solução do solo. De forma mais detalhada, McBride (1995) explicou que devido a capacidade finita do solo para imobilizar metais, sem a contribuição adsortiva da matéria orgânica do lodo, uma relação do tipo Langmuir pode ocorrer. Sobre este argumento, Chang et al. (1997) esclareceram que ocorrendo um fenômeno de adsorção explicado pelas isotermas de Langmuir, a concentração de equilibrio aumentará rapidamente a medida que a capacidade de adsorção do solo diminuir com a degradação da matéria orgânica do lodo, aumentando assim, a disponibilidade de metais às plantas. Acrescentaram ainda que, conforme o solo for passando pelos processos naturais de acidificação, a solubilidade e atividade desses metais tendem aumentar ainda mais.

É importante salientar que, por enquanto, não existe consenso a respeito dessas teorias. Os poucos trabalhos científicos que descreveram a fitodisponibilidade de metais pesados em solos tratados com lodo de esgoto e buscaram explicações através de tais teorias, apresentaram resultados discordantes e algumas vezes, pouco conclusivos. Dessa forma, foi possivel notar nesses trabalhos que as respostas variam com as espécies vegetais e com os próprios metais pesados, além de existir grandes discussões a respeito do tempo de estudo necessário para se obter resultados não equivocados. São exemplos disto os trabalhos de Barbarick et al. (1995), Chang et al.(1997) e Logan et al. (1997).

Barbarick et al. (1995) conduziram por 11 anos, dois experimentos com lodo de esgoto em duas localidades geográficas com solos semelhantes e de textura "barrenta". No local ora denominado A, os autores realizaram seis aplicações alternadas do resíduo, ano sim e ano não, nas doses equivalentes a $0,6,7,13,4$ e 26,8 $\mathrm{Mg} \mathrm{ha}^{-1}$ (base seca) e no local B foram cinco aplicações nas mesmas doses e periodicidade. Em todos os anos e nas duas localidades eles cultivaram trigo com o objetivo de avaliar as concentrações de $\mathrm{Cd}, \mathrm{Cu}, \mathrm{Mo}, \mathrm{Ni}, \mathrm{Pb}$ e $\mathrm{Zn}$ nos grãos da cultura e tentar ajustar o modelo de fitodisponibilidade de metais pesados descrito pela teoria do platô. Ressalta-se que neste estudo foram combinados os dados dos dois experimentos, totalizando 88 pontos de dados médios amostrais ( 2 locais $\times 11$ anos $\times 4$ doses de lodo de esgoto). Para os metais $\mathrm{Cd}$ e $\mathrm{Pb}$ não foi possivel nenhum tipo de consideração uma vez que a concentração desses elementos nos grãos estiveram abaixo dos limites de determinação $\left(<0,1 \mathrm{mg} \mathrm{kg}^{-1}\right.$ para $\mathrm{Cd} \mathrm{e}<0,3 \mathrm{mg} \mathrm{kg}^{-1}$ para $\mathrm{Pb}$ ) em todas as amostras coletadas. As concentrações de $\mathrm{Cu}$ e $\mathrm{Zn}$ apresentaram uma resposta do tipo platô e não foram verificados sintomas de 
fitoxicidade. Os niveis de $\mathrm{Cu}$ aproximaram-se de uma concentração platô em torno de $6,86 \mathrm{mg} \mathrm{kg}^{-1}$, cerca de $1,75 \mathrm{mg} \mathrm{kg}^{-1}$ acima dos valores obtidos nos grãos produzidos nos solos testemunha. Para o $\mathrm{Zn}$, a concentração platô, calculada pelo modelo matemático ajustado, foi de $52,5 \mathrm{mg} \mathrm{kg}^{-1}$, cerca de $26,9 \mathrm{mg} \mathrm{kg}^{-1}$ maior do que as testemunhas. As concentrações de Ni nos grãos apresentaram um comportamento linear em função das aplicações cumulativas do elemento via resíduo. Com relação ao Mo, os autores não verificaram nenhum tipo de resposta.

Trabalhando com dados obtidos durante 10 anos em experimentos de campo, Chang et al. (1997) estabeleceram todas as condições necessárias para uma possível comprovação das teorias do platô e da "bomba relógio". Neste estudo, foram aplicados anualmente, lodo de esgoto nas doses de 0, 22,5, 45, 90 e $180 \mathrm{Mg} \mathrm{ha}^{-1}$ (base seca). Ao final de seis anos de aplicações, as parcelas experimentais foram divididas ao meio sendo que, numa primeira metade as aplicações de lodo foram interrompidas e na outra parte, as aplicações seguiram nas mesmas doses por mais 10 anos. Por ocasião da divisão das parcelas, os autores passaram a cultivar beterradas duas vezes por ano, apresentando neste artigo, apenas análises dos dados obtidos acerca das concentrações de $\mathrm{Cd}$ nos tecidos vegetais. Embora tenham sido observadas pequenas indicações de que a concentração platô era eminente, os autores consideraram que tal teoria não poderia ser comprovada inequivocamente. Por outro lado, o fenômeno da "bomba relógio" não pôde ser desconsiderado por completo tendo em vista que, curiosamente, os dados também apontaram para a possibilidade de que a concentração platô de $\mathrm{Cd}$ na beterraba nunca seria alcançada. Além disso, a falta de uma resposta do tipo Langmuir, seguida da interrupção nas aplicações de lodo, pode ter sido devida a uma baixa taxa de mineralização da matéria orgânica do resíduo e por isso não teria sido possível, durante 10 anos, a volta da capacidade de adsorção do solo aos seus valores originais. $\mathrm{O}$ parecer final dos autores diz que os fenômenos postulados por ambas as teorias não foram evidenciados com os dados experimentais, nem mesmo nos tratamentos que receberam aplicações contínuas do resíduo, haja visto que as quantidades de lodo de esgoto acumuladas, em todo período de estudo, chegaram a $2880 \mathrm{Mg} \mathrm{ha}^{-1}$, o equivalente a $176 \mathrm{~kg} \mathrm{ha}^{-1} \mathrm{de} \mathrm{Cd}$. 
Logan et al. (1997) cultivaram milho e alface durante dois e cinco anos respectivamente, num solo derivado de rochas calcárias tratado uma única vez, com doses crescentes de lodo de esgoto $\left(0,7,5,15,30,60,120,150,188,225\right.$ e $300 \mathrm{Mg} \mathrm{ha}^{-1}$ - base seca). Objetivaram, entre outras coisas, verificar a absorção e o tipo de resposta das plantas aos metais $\mathrm{Cd}, \mathrm{Cu}, \mathrm{Ni}, \mathrm{Pb}$ e $\mathrm{Zn}$ cujas concentrações no lodo eram respectivamente de $46,433,67,185$ e $2334 \mathrm{mg} \mathrm{kg}^{-1}$. Nas plantas de milho verificaram que a absorção de $\mathrm{Cd}$, $\mathrm{Cu}$ e $\mathrm{Zn}$ aumentou significativamente com as taxas aplicadas de lodo de esgoto ao passo que, para $\mathrm{Ni}$ e $\mathrm{Pb}$ os teores absorvidos foram comparáveis com a testemunha. Tanto os teores encontrados nas folhas como na biomassa da parte aérea exibiram, para os metais $\mathrm{Cd}, \mathrm{Cu}$ e $\mathrm{Zn}$, uma resposta do tipo platô. Para as plantas de alface, as concentrações desses metais apresentaram aumentos lineares nos cultivos de todos os anos. De forma semelhante ao milho, não foram obtidas respostas para $\mathrm{Ni}$ e $\mathrm{Pb}$. Embora tenham sido verificadas respostas lineares para alguns metais absorvidos pela alface, os autores ressaltaram que os dados não confirmam a teoria proposta por McBride (1995). As razões para esta afirmação podem ser exemplificadas pelos resultados obtidos para o $\mathrm{Cu}$, o qual mostrou que o efeito da degradação da matéria orgânica do lodo sobre a absorção desse elemento alcançou um valor máximo após o segundo cultivo, reduzindo-se nos cultivos subsequentes.

Relatos sobre fitotoxicidade provocada pela presença de metais pesados em solos tratados com lodo de esgoto ou composto de lixo são escassos e de maneira geral, apresentam resultados discordantes, demonstrando a necessidade de mais estudos sobre o assunto. A exemplo disso, pode-se citar os trabalhos de Davis \& Beckett (1978) e Davis \& Carton-Smith (1984), os quais estimaram as concentrações foliares fitotóxicas de $\mathrm{Cu}$, Ni e $\mathrm{Zn}$ para plantas de centeio cultivadas em solos tratados com lodo de esgoto enriquecido com metais pesados em níveis crescentes. Os primeiros autores encontraram, respectivamente para $\mathrm{Cu}, \mathrm{Ni}$ e $\mathrm{Zn}$, as concentrações tóxicas de 21,14 e $201 \mathrm{mg} \mathrm{kg}^{-1}$. No estudo conduzido por Davis \& Carton-Smith (1984), as concentrações em plantas com sintomas de fitotoxicidade foram, para os respectivos metais, 22, 90 e $140 \mathrm{mg} \mathrm{kg}^{-1}$. 
De acordo com Logan \& Chaney (1983) e Chang et al. (1987) a toxicidade por metais pesados em plantas foi demonstrada somente em casos em que a aplicação dos metais pesados ao solo foi realizada na forma de sais solúveis ou quando da aplicação de doses excessivamente elevadas de lodo de esgoto. Chang et al. (1987) verificaram que as quantidades de metais absorvidas por plantas cultivadas em solos tratados com lodo, correspondem de uma maneira geral, a menos de $1 \%$ do total adicionado. Cabe salientar que, as afirmações desses autores foram baseadas numa extensa revisão feita em trabalhos sobre a disposição de lodo de esgoto em solos agrícolas.

Berti \& Jacobs (1993) estudaram, em condições de campo, as conseqüências da aplicação de altas taxas de metais pesados, via lodo de esgoto, para as culturas de milho, sorgo e soja. Os autores aplicaram em 10 anos, as quantidades acumuladas de 0, 240, 690 e $870 \mathrm{Mg} \mathrm{ha}^{-1}$ (base seca) de lodo de esgoto de diversas origens. Essas quantidades foram equivalentes a $0,44,17$ e $21 \mathrm{~kg} \mathrm{ha}^{-1}$ de Cd; 0, 1120, 2700 e $3000 \mathrm{~kg} \mathrm{ha}^{-1} \mathrm{de} \mathrm{Cr}$; $0,350,1870$ e $1800 \mathrm{~kg} \mathrm{ha}^{-1}$ de $\mathrm{Cu} ; 0,280,1730$ e $2100 \mathrm{~kg} \mathrm{ha}^{-1}$ de Ni; 0, 1430, $2670 \mathrm{e}$ $11300 \mathrm{~kg} \mathrm{ha}^{-1} \mathrm{de} \mathrm{Zn}$. Depois da última aplicação de lodo, os solos foram cultivados por um periodo de 6 anos. As médias de produtividade de grãos, obtidas nos cultivos realizados neste período, indicaram alguns acréscimos somente nas duas menores doses, para as culturas de milho e sorgo. Para a cultura da soja, não houveram incrementos em nenhuma das doses. Por outro lado, nas doses que receberam $870 \mathrm{Mg} \mathrm{ha}^{-1}$ de lodo, foram observadas sensiveis quedas nas produtividades de milho e sorgo, salientando-se que nestas condições as plantas de soja nem mesmo germinaram. A queda de produtividade do milho e do sorgo foi atribuida a uma provável fitotoxicidade de $\mathrm{Ni}$ e $\mathrm{Zn}$. No caso do

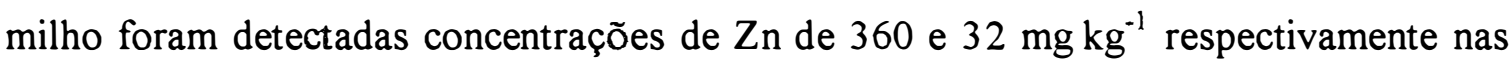
folhas e nos grãos, ao passo que nas parcelas testemunha estas concentrações foram respectivamente de 81 e $22 \mathrm{mg} \mathrm{kg}^{-1}$; para o $\mathrm{Ni}$, as plantas cultivadas nas parcelas tratadas com lodo, apresentaram teores de 4,6 e $4,3 \mathrm{mg} \mathrm{kg}^{-1}$ respectivamente nas folhas $\mathrm{e}$ nos grãos enquanto que na testemunha, essas concentrações foram respectivamente de 0,29 e $0,42 \mathrm{mg} \mathrm{kg}^{-1}$. As plantas de sorgo apresentaram teores foliares de $\mathrm{Zn}$ de $280 \mathrm{e}$ $90 \mathrm{mg} \mathrm{kg}^{-1}$ respectivamente nas parcelas tratadas com lodo (maior dose) e na testemunha enquanto que, os teores foliares de $\mathrm{Ni}$ foram respectivamente de 11 e $3,2 \mathrm{mg} \mathrm{kg}^{-1}$. 
Neste mesmo estudo, testes de fracionamento no solo, das espécies químicas de metais, indicaram que $\mathrm{Cd}$, Ni e $\mathrm{Zn}$ são, do ponto de vista ambiental, mais problemáticos do que $\mathrm{Cr}, \mathrm{Cu}$ e $\mathrm{Pb}$ tendo em vista que foram encontrados em maiores proporções, nas frações disponiveis às plantas.

Wallace \& Wallace (1994) relataram que, em Los Angeles, EUA, tem sido comercializados compostos orgânicos a base de lodo de esgoto, para utilização em áreas destinadas a parques e jardins. Em algumas dessas áreas, nas quais esses produtos vem sendo aplicados por mais de 40 anos, as plantas tem mostrado sintomas de toxicidade comprovado por análises químicas. Os metais freqüentemente encontrados em maiores concentrações nesses solo foram $\mathrm{Cd}, \mathrm{Cu}, \mathrm{Ni}, \mathrm{Pb}$ e $\mathrm{Zn}$. No entanto, segundo os autores, foram observados sintomas de toxidez sempre que os teores de $\mathrm{Cu}$ e $\mathrm{Zn}$, extraídos do solo por DTPA-TEA, excederam respectivamente 20 e $80 \mathrm{mg} \mathrm{kg}^{-1}$. Porém, na maioria dos casos de fitotoxicidade, os autores encontraram serem devidas ao $\mathrm{Zn}$.

A possibilidade da interação tóxica entre os metais pesados, potencializando seus efeitos sobre as plantas, mesmo em baixas concentrações, tem sido verificada por alguns autores (Wallace, 1982; Wallace \& Berry, 1989). Smilde et al. (1992), por exemplo, em solos coletados próximos à áreas de fundições estudaram possíveis interações entre $\mathrm{Cd}$ e $\mathrm{Zn}$. A análise de folhas de alface, espinafre, trigo e milho cultivados nos solos argilosos mostraram que a relação normal $\mathrm{Cd}: \mathrm{Zn}$ é antagônica. De forma contrária, uma possível interação sinergística entre os metais considerados foi observada nos solos arenosos, onde a absorção de $\mathrm{Cd}$ foi aumentada pela presença do $\mathrm{Zn}$. Neste caso, a hipótese de sinergismo foi reforçada pela baixa produtividade das culturas nesses solos.

\subsubsection{Mobilidade dos metais pesados no solo}

O movimento vertical e descendente de contaminantes pelo perfil dos solos agrícolas, pode significar um grande problema para a sociedade contemporânea. Neste sentido, em decorrência do crescente interesse pela utilização de determinados resíduos urbanos na agricultura, este tema vem recebendo nos últimos anos, uma maior atenção 
de pesquisadores, principalmente no que se refere a mobilidade de metais pesados (Lund et al., 1976; Ritter et al., 1978; Willians et al., 1980; McBride et al., 1997).

Embora seja o solo uma barreira natural de proteção aos aquíferos subterrâneos, os fatores que governam sua capacidade em reter metais pesados são extremamente complexos, o que dificulta sobremaneira o seu entendimento e as possibilidades de previsões acerca do comportamento desses elementos, principalmente a longo prazo. Sabe-se que, conforme foi comentado brevemente no item 2.5.1, a maior ou menor mobilidade dos metais pesados através do solo será determinada por seus atributos como teores e tipos de argila, $\mathrm{pH}$, capacidade de troca de cátions, matéria orgânica entre outros, influenciados por reações de adsorção/dessorção, precipitação/dissolução, complexação e oxirredução.

A mobilidade de metais pesados em solos tratados com lodo de esgoto, tem sido apontada como nula ou muito baixa por diversos trabalhos científicos (Emmerich et al., 1982; Baxter et al., 1983; Chang et al., 1984; Williams et al., 1980 e 1987). No entanto, a persistência da capacidade do solo em reter tais elementos, em função do tempo e dos níveis de ocorrência da contaminação, dos fatores climáticos envolvidos e das taxas de degradação da carga orgânica dos diferentes resíduos contaminantes, vem sendo muito questionada por alguns autores (McBride et al., 1995; Camobreco et al., 1996; McBride et al., 1997).

Williams et al. (1980) estudaram a mobilidade dos metais $\mathrm{Cd}, \mathrm{Cr}, \mathrm{Cu}, \mathrm{Fe}, \mathrm{Hg}$, $\mathrm{Mn}, \mathrm{Ni}, \mathrm{Pb}$ e $\mathrm{Zn}$ num solo ácido de textura "barrenta" tratado com lodo de esgoto gerado numa região industrializada. Foram aplicadas e incorporadas, na camada de $0-0,20 \mathrm{~m}$, doses anuais de 0 e $180 \mathrm{Mg} \mathrm{ha}^{-1}$ (base seca) de lodo de esgoto. Após 3 anos de sucessivas aplicações do resíduo, os solos foram amostrados nas camadas de $0-0,20$, $0,20-0,225, \quad 0,225-0,25, \quad 0,25-0,30, \quad 0,30-0,40, \quad 0,40-0,50, \quad 0,50-0,75$, $0,75-1,0 \mathrm{~m}$ e analisados para teores totais dos referidos elementos. De maneira geral, os resultados obtidos mostraram decréscimos nos teores de metais com o aumento da profundidade de coleta das amostras. Dessa forma, para $\mathrm{Cd}, \mathrm{Cu}$ e $\mathrm{Hg}$ os teores encontrados nos solos tratados com lodo praticamente se igualaram a testemunha nas amostras coletadas a $0,225-0,25 \mathrm{~m}$ de profundidade $(0,025-0,05 \mathrm{~m}$ abaixo da camada 
de incorporação do resíduo). Os metais $\mathrm{Cr}, \mathrm{Fe}, \mathrm{Mn}$ e $\mathrm{Ni}$ não foram detectados, em teores maiores do que na testemunha, abaixo da camada de incorporação do lodo de esgoto. $\mathrm{Para} \mathrm{o} \mathrm{Pb}$, foram encontrados teores maiores do que nas testemunhas até a profundidade de 0,30 - 0,40 m e para o $\mathrm{Zn}$ até 0,25 - 0,30 m. Os dados sugeriram portanto, pequeno ou nenhum movimento dos metais abaixo da camada $0-0,30 \mathrm{~m}, 0,10 \mathrm{~m}$ da camada de incorporação. No entanto, os autores comentaram que apesar da possibilidade de $\mathrm{Zn} \mathrm{e} \mathrm{Pb}$ terem lixiviados para profundidades maiores que 0,20 e $0,30 \mathrm{~m}$, os dados não foram consistentes o suficiente para tal afirmação tendo em vista, a grande possibilidade de erro e ou contaminação das amostras do solo. Neste contexto, os autores consideraram todos os metais praticamente imóveis no perfil do solo, atribuindo este fato às possíveis reações de retenção desses elementos. Assim, nas condições do experimento, sugeriram que o $\mathrm{Fe}$ e o $\mathrm{Cr}$, na forma de íons trivalentes, teriam sido precipitados como óxidos e hidróxidos insolúveis; $\mathrm{Cu}$ e $\mathrm{Ni}$ teriam formado complexos organo-metálicos relativamente estáveis; $\mathrm{Mn}$ teria sido oxidado a formas insolúveis e $\mathrm{Hg}$ estaria fortemente adsorvido ao solo. De todos os elementos, acreditaram os autores, $\mathrm{Zn}$ e $\mathrm{Cd}$ não seriam fortemente imobilizados, e por isso apresentariam potencial para entrarem na cadeia alimentar e neste caso, somente o $\mathrm{Cd}$ representaria real perigo a saúde. Williams et al. (1987) deram seqüência a este estudo com aplicações anuais de lodo de esgoto por mais 5 anos nas mesmas taxas anteriores, obtendo parcelas experimentais com histórico de 8 aplicações do resíduo, conferindo o acúmulo de $1440 \mathrm{Mg} \mathrm{ha}^{-1}$. Convém salientar que os autores seguiram os mesmos procedimentos, para aplicação e incorporação do lodo e para as amostragens do solo, adotados em Williams et al. (1980). No decorrer de 9 anos de monitoramento desta área experimental, foram realizadas quatro avaliações dos teores totais de metais presentes nas amostras de solo coletadas em profundidade. Uma apreciação geral dos resultados demonstrou que os metais $\mathrm{Cd}, \mathrm{Cu}$, $\mathrm{Zn}$ e $\mathrm{Hg}$ moveram-se, ainda que em pequenas quantidades, para as profundidades de 0,05 a $0,10 \mathrm{~m}$ abaixo da camada de incorporação do lodo $(0-0,20 \mathrm{~m})$. No entanto, os autores ressaltaram que estes resultados podem ter sido influenciados, parcialmente, por uma eventual contaminação durante a amostragem ou ainda, uma variação na profundidade de coleta da amostra resultante de um significativo decréscimo na 
densidade aparente do solo. A presença do $\mathrm{Cr}$ e do $\mathrm{Pb}$ se restringiram a camada de incorporação do resíduo. A relativa imobilidade dos metais pesados foi atribuída ao pH do solo e mais uma vez, às reações de adsorção a óxidos e hidróxidos, de troca de cátions e de complexação com a matéria orgânica. No entanto, é importante esclarecer que neste estudo, em função da aplicação do lodo de esgoto, o $\mathrm{pH}\left(\mathrm{H}_{2} \mathrm{O}\right)$ do solo abaixou de 5,4 para 4,5 .

Dowdy et al. (1991) amostraram um solo argilo-siltoso após 14 anos de sucessivas adições de lodo de esgoto, com o objetivo de verificar a distribuição dos metais $\mathrm{Cd}, \mathrm{Cu}$ e $\mathrm{Zn}$ em seus horizontes "genéticos" até $1,0 \mathrm{~m}$ de profundidade. Foram aplicadas neste período, $765 \mathrm{Mg} \mathrm{ha}^{-1}$ (base seca) acumuladas de lodo de esgoto, o que correspondeu a aplicação de 192, 1070 e $3660 \mathrm{~kg} \mathrm{ha}^{-1}$ de Cd, Cu e Zn, respectivamente. $\mathrm{O} \mathrm{pH}\left(\mathrm{H}_{2} \mathrm{O}\right)$ do solo foi reduzido de 6,3 na testemunha para 5,4 nos solos tratados com o resíduo. Os resultados evidenciaram a imobilidade do $\mathrm{Cu}$ tendo em vista que, teores maiores que a testemunha foram encontrados somente nos horizontes Ap $(0-0,27 \mathrm{~m})$. As concentrações de $\mathrm{Cd}$ foram significativamente maiores no subsolo das áreas tratadas com lodo de esgoto (horizonte $2 \mathrm{C}_{1}-0,83-1,0 \mathrm{~m}$ ), cerca de $0,4 \mathrm{mg} \mathrm{kg}^{-1}$ maiores do que os niveis apresentados no solo testemunha. Para o $\mathrm{Zn}$ foram verificados teores mais elevados do que no solo testemunha até no horizonte $\mathrm{Bt}_{1}(0,32-0,51 \mathrm{~m})$, com acréscimos de aproximadamente $12 \mathrm{mg} \mathrm{kg}^{-1}$ nas áreas tratadas com lodo. Os autores estimaram, com base na quantidade de metais extraidos por $\mathrm{HNO}_{3} 4,0 \mathrm{~mol} \mathrm{~L}-1$, que $4,1 \%$ do $\mathrm{Cd}$ e $4,8 \%$ do $\mathrm{Zn}$ adicionados via lodo de esgoto, se moveram da camada de incorporação do resíduo para as camadas compreendidas entre os horizontes $2 \mathrm{Bt}_{2}$ e $2 \mathrm{C}_{1}$ $(0,51-1,0 \mathrm{~m})$. Cabe lembrar que o método analítico empregado foi capaz de recuperar apenas $48 \%$ das quantidades totais adicionadas dos metais $\mathrm{Cd}$ e $\mathrm{Zn}$. Foi explicado que esta baixa recuperação do metais pelo $\mathrm{HNO}_{3} 4,0 \mathrm{~mol} \mathrm{~L}^{-1}$ é devido a possivel oclusão desses elementos no interior de minerais de argila e ou pela sorção a sítios específicos sugerindo portanto, que os metais estavam fortemente retidos no solo. Acrescentaram ainda, que na região onde foi conduzido o experimento, ocorreram severos déficits hídricos que aliados a elevada densidade das camadas superficiais do solo e a ação das raizes vegetais, provocaram grandes rachaduras na camada de cultivo. Esses fenômenos 
foram seguidos de elevadas precipitações aumentando a quantidade de água livre no sistema. Baseados nesses aspectos os autores concluíram que a relativa movimentação desses metais foi devida essencialmente, além dos fatores químicos, aos fatores físicos e morfológicos do solo.

A mobilidade de $\mathrm{Cu}$ e $\mathrm{Zn}$ também foi estudada por Chino et al. (1992) num solo ácido, formado por cinzas vulcânicas, tratado com lodo de esgoto estabilizado com cal. Durante quatro anos foram aplicadas doses do resíduo que resultaram na quantidade acumulada de $1039 \mathrm{Mg} \mathrm{ha}^{-1}$ (base seca) o que correspondeu ao acúmulo de 449 e $3346 \mathrm{~kg} \mathrm{ha}^{-1}$ de $\mathrm{Cu}$ e $\mathrm{Zn}$, respectivamente. Amostras de solos foram coletadas, nas camadas de incorporação do resíduo $(0-0,10 \mathrm{~m})$ e nas camadas de $0,20-0,30 \mathrm{~m}$, nas seguintes épocas: antes da primeira aplicação de lodo, em seguida da última aplicação (quatro anos após a primeira aplicação), quatro anos após a última aplicação e depois, anualmente por mais quatro anos; totalizando um período de 12 anos de acompanhamento dos teores totais desses metais no solo. Todas as evidências indicaram que não houve movimentação do $\mathrm{Cu}$ para baixo da camada de incorporação do lodo. $\mathrm{A}$ concentração de Zn-total encontrada na camada de incorporação aumentou de $137 \mathrm{mg} \mathrm{kg}^{-1}$ na primeira amostragem (antes da aplicação de lodo) para $277 \mathrm{mg} \mathrm{kg}^{-1}$ na sequêencia da última aplicação do resíduo. Esta concentração praticamente se manteve constante até última amostragem ( 8 anos após a última aplicação de lodo). Os autores salientaram que estes dados não indicam perdas de $\mathrm{Zn}$ da camada superior, seja por lixiviação ou seja por absorção pelas plantas no entanto, a concentração do elemento aumentou na camada de $0,20-0,30 \mathrm{~m}$ de $119 \mathrm{mg} \mathrm{kg}^{-1}$, antes da aplicação do resíduo, para $144 \mathrm{mg} \mathrm{kg}^{-1}$, a partir dos 6 anos após a última aplicação de lodo. Concluíram que nas condições do experimento, o $\mathrm{Zn}$ pode levar ao menos 10 anos para se deslocar 0,20 m abaixo da camada de incorporação do lodo porém, não foi descartada a hipótese do elemento ter atingido as camadas inferiores através de operações mecânicas de cultivo.

Em colunas de solos tratados com composto de lixo, Giusquiani et al. (1992) estudaram a influência da fração solúvel em água, da matéria orgânica do resíduo, sobre a mobilidade de metais pesados. Foram utilizadas amostras de um solo argiloso e um 
solo arenoso, sendo ambos alcalinos $\left(\mathrm{pH}\left(\mathrm{H}_{2} \mathrm{O}\right)=8,0\right)$, os quais foram dispostos em colunas de PVC de $0,50 \mathrm{~m}$ com disposição superficial do equivalente a $90 \mathrm{Mg} \mathrm{ha}^{-1}$ (base seca) de composto de lixo. Os resultados apresentados pelos autores demonstraram que a adição de composto aumentou significativamente as concentrações de $\mathrm{Cr}, \mathrm{Cu}, \mathrm{Ni}$ e Zn na água lixiviada das colunas. Estes aumentos foram maiores no solo arenoso do que no argiloso, como um reflexo da menor capacidade de retenção química e física do primeiro solo. No entanto, embora tenha sido notada uma elevada capacidade de complexação dos metais pelas substâncias orgânicas solúveis, ácidos fúlvicos principalmente, a lixiviação dos referidos metais foi principalmente atribuída ao aumento na presença desses elementos em solução, em decorrência da própria adição do resíduo. Isto foi concluído uma vez que, os solos apresentaram grande capacidade para adsorção das substâncias orgânicas hidrossolúveis. Análises no perfil dos solos indicaram que cerca de 70 a $80 \%$ da referida fração orgânica foi retida na camada de $0-0,10 \mathrm{~m}$ das colunas de lixiviação e que apenas 5 e $10 \%$ dessa fração foram detectadas nos totais de água lixiviada nas colunas de solo arenoso e argiloso, respectivamente. Ressaltaram-se que o $\mathrm{pH}\left(\mathrm{H}_{2} \mathrm{O}\right)$ dos solos tratados com composto e dos solos testemunha mantiveram-se em valores próximos a 7,5, eliminando qualquer diferença de comportamento dos metais em virtude da reação do solo.

Estudos conduzidos a campo e laboratório por Lamy et al. (1993) apontaram para os riscos de contaminação, por $\mathrm{Cd}$, de águas subterrâneas. Foram monitorados os teores de $\mathrm{Cd}$ e matéria orgânica solúvel nas águas de drenagem de um solo hidromórfico, de textura argilosa, tratado com lodo de esgoto, líquido e digerido, em dose equivalente a $11 \mathrm{Mg} \mathrm{ha}^{-1} \mathrm{em}$ base seca. Os autores verificaram que nas águas drenadas da área tratada com lodo, haviam elevadas quantidades de substâncias orgânicas solúveis e que a concentração de $\mathrm{Cd}$ era duas vezes maior do que nas águas da área testemunha. Os estudos de laboratório demonstraram que a formação de complexos orgânicos com o $\mathrm{Cd}$ é favorecida em faixas de $\mathrm{pH}$ variando de 5 a 7 , onde sua retenção pelo solo seria menor. Esta observação, segundo os autores, ilustra a possibilidade de sérias conseqüências ambientais devidas a lixiviação do $\mathrm{Cd}$ pois, em áreas agrícolas 
tratadas com lodo de esgoto o $\mathrm{pH}$ do solo é mantido, normalmente, a valores próximos de 6,5 .

Bertoncini (1997) verificou a possibilidade de lixiviação de $\mathrm{Cd}, \mathrm{Cr}, \mathrm{Cu}, \mathrm{Ni}$ e $\mathrm{Zn}$ através de um experimento conduzido em tubos de percolação $(0,25 \mathrm{~m})$ utilizando-se de três solos tropicais, Areia Quartzosa (AQ), Latossolo Vermelho-Amarelo (LV) e Latossolo Vermelho escuro (LE), aos quais foram incorporadas sucessivas quantidades de lodo de esgoto. No total foram aplicadas $156 \mathrm{Mg} \mathrm{ha}^{-1}$ (base seca) do resíduo, num período de 310 dias. Após este período, as colunas de solo foram lixiviadas com água destilada em quantidade equivalente a 4 vezes a capacidade de retenção dos solos. A presença de $\mathrm{Cd}, \mathrm{Cr}$ e $\mathrm{Zn}$ não foi detectada em nenhum dos lixiviados coletados, sugerindo a pequena mobilidade desses metais nos solos testados. Em faixa de $\mathrm{pH}\left(\mathrm{CaCl}_{2}\right)$ 6,5 a 7,5, observada em todos tratamentos com lodo de esgoto, o autor salienta que os processos de precipitação de $\mathrm{Fe}$ e $\mathrm{Al}$ ocorrem com grande intensidade em função da baixa solubilidade desses cátions nas referidas condições de acidez. Considerando que tais processos de precipitação ocorrem, inicialmente, pela formação de núcleos primários seguido de crescimento dos cristais pela adsorção de cátions aos sítios livres da superficie da micela, acreditou-se que a imobilidade de $\mathrm{Cd}$ e $\mathrm{Zn}$ pode ter sido devida a processos de coprecipitação desses elementos junto a óxidos de $\mathrm{Fe}$ e $\mathrm{Al}$ sem portanto, desconsiderar a hipótese da adsorção de tais metais aos ácidos húmicos, que são pouco solúveis. A imobilidade do $\mathrm{Cr}$ sugeriu a maior presença deste elemento na forma trivalente $\left(\mathrm{Cr}^{3+}\right)$, menos móvel e menos tóxica que a forma hexavalente. Na forma trivalente o $\mathrm{Cr}$ pode ter sido precipitado como hidróxidos de fómulas genéricas $\mathrm{Cr}(\mathrm{OH})_{3}$ ou $\mathrm{Fe}_{\mathrm{x}} \mathrm{Cr}_{1-\mathrm{x}}(\mathrm{OH})_{3}$ em condições alcalinas ou pouco ácidas. Pode também ter sido complexado junto a moléculas orgânicas pouco solúveis ou adsorvido à superficie de minerais, tornando-se pouco móvel num sistema equilibrado. A perda de $\mathrm{Cu}$ por lixiviação foi verificada nos solos $\mathrm{AQ}$ e $\mathrm{LV}$. Em ambos os casos, a lixiviação do $\mathrm{Cu}$ esteve relacionada com o arraste de substâncias orgânicas dissolvidas na água, o que foi evidenciado pela coloração escura dos lixiviados. No entanto, a quantidade de $\mathrm{Cu}$ perdido por lixiviação não passou de $1 \%$ do total adicionado. A lixiviação de Ni ocorreu somente no solo $\mathrm{AQ}$, provavelmente devido a baixa capacidade de retenção desses solos 
e também as grandes quantidades de substâncias orgânicas lixiviadas. $\mathrm{O}$ autor explica com base na literatura, que o $\mathrm{Ni}$ tem sido encontrado predominantemente nas frações residual e ocluído aos óxidos de $\mathrm{Fe}$ e $\mathrm{Al}$, o que pode explicar a ausência desse metal nos lixiviados coletados nos solos LV e LE, que são de textura fina e possuem elevados teores de óxidos.

McBride et al. (1997) avaliaram a mobilidade de alguns metais pesados numa área de solo argilo-siltoso que recebeu uma disposição de $240 \mathrm{Mg} \mathrm{ha}^{-1}$ (base seca) de lodo de esgoto. Tal avaliação foi realizada após 15 anos da aplicação do resíduo e teve como testemunha uma área próxima, com mesmo tipo de solo e $\mathrm{pH}$ (6,5 a 7,0 em água). Observaram que, aproximadamente $40 \%$ do $\mathrm{Cu}$ e $\mathrm{Zn}$ e menos de $30 \%$ do $\mathrm{Cd}$ aplicados via lodo, foram perdidos da camada de incorporação do resíduo $(0-0,20 \mathrm{~m})$. No entanto, quando foram determinados os teores desses metais nas camadas mais profundas, não foram observadas evidências da movimentação desses elementos. Por outro lado, análises mais recentes da água do lençol freático, que era pouco profundo, demonstraram que a lixiviação de $\mathrm{Cu}, \mathrm{Zn}, \mathrm{Ni}$ e $\mathrm{Hg}$ poderia estar ocorrendo, mas as concentrações encontradas na água foram extremamente baixas para explicar as perdas aparentes de metais no passado. Diante da complexidade dos resultados, os autores salientaram que aspectos físicos e biológicos devem ser considerados como colaboradores na migração dos metais pesados das camadas superficiais. Foram citados o caminhamento preferencial de água e partículas, seja do resíduo contaminante ou do solo contaminado, por rachas estruturais do solo, canais feitos por raizes e organismos vivos (minhocas por exemplo) e até mesmo a ocorrência e lixiviação de formas de metais desconhecidas que não são complexadas e nem adsorvidas.

Todos os trabalhos consultados sugeriram que a maior parte dos metais pesados, presentes nos solos tratados com lodo de esgoto ou composto de lixo, ocorreram na fase sólida desses solos o que por sua vez, poderiam estar assim distribuídos, nas mais variadas formas químicas. Dessa forma, o fracionamento dos metais pesados em solos contaminados, seja através desses resíduos orgânicos ou de fontes inorgânicas, é uma importante ferramenta para o melhor entendimento da mobilidade ou não, desses elementos no seu perfil. Taylor et al. (1995) realizaram o 
fracionamento de $\mathrm{Cd}, \mathrm{Cu}, \mathrm{Ni}, \mathrm{Pb}$ e $\mathrm{Zn}$ presentes num solo argiloso tratado com lodo de esgoto anaeróbio. Foram aplicadas anualmente $20 \mathrm{Mg} \mathrm{ha}^{-1}$ (base seca) de lodo, durante 5 anos, totalizando uma aplicação média de $21,114,72,114$ e $425 \mathrm{~kg} \mathrm{ha}^{-1}$ dos respectivos metais pesados. Após 10 anos da aplicação inicial de lodo, análises realizadas em amostras de solo da camada de incorporação do resíduo $(0-0,15 \mathrm{~m})$ revelaram que, menos de $1 \%$ do total aplicado de todos os metais foi extraído por $\mathrm{KNO}_{3}$ (formas trocáveis) e $\mathrm{H}_{2} \mathrm{O}$ (formas solúveis), sugerindo que no decorrer do tempo, estas formas de metais podem ter sido removidas por plantas, lixiviadas e principalmente transformadas em outras frações. No solo tratado com lodo de esgoto o $\mathrm{Cu}$ foi encontrado, em maior quantidade, na fração orgânica $(\mathrm{NaOH})$ enquanto que, $\mathrm{Cd}, \mathrm{Ni}, \mathrm{Pb}$ e $\mathrm{Zn}$ estiveram em maiores concentrações na fração carbonatada (EDTA). Os resultados indicaram um baixo potencial para lixiviação dos metais mas por outro lado, os autores consideraram que as frações carbonatadas e orgânicas podem manter esses elementos em forma lábil e portanto, mais disponiveis às plantas e mais sujeitos a lixiviação do que no solo testemunha. No entanto, tendo em vista que a ocorrência do ânion $\mathrm{CO}_{3}{ }^{2-}$ se faz na solução do solo somente em condições de $\mathrm{pH}>8,0$, parece estranho que neste estudo as frações carbonatadas dos metais considerados tenham sido tão significativas uma vez que, o $\mathrm{pH}\left(\mathrm{H}_{2} \mathrm{O}\right)$ do solo após o tratamento com lodo foi de 6,9.

Com o objetivo de avaliar a mobilidade e as principais formas de retenção dos metais $\mathrm{Cd}, \mathrm{Cu}, \mathrm{Pb}$ e $\mathrm{Zn}$, Matos et al. (1996) constituíram colunas de solo em condições de laboratório, representando, individualmente, os horizontes $\mathrm{A}, \mathrm{B}$ e $\mathrm{C}$ de um Latossolo Vermelho-Amarelo. A influência do $\mathrm{pH}$ sobre a mobilidade dos metais foi verificada através de um tratamento com calagem, definido por curva de neutralização para atingir $\mathrm{pH}\left(\mathrm{H}_{2} \mathrm{O}\right) 7,0$, em amostras do horizonte A. Foram utilizados tubos de PVC com $0,15 \mathrm{~m}$ de diâmetro e $0,25 \mathrm{~m}$ de comprimento seccionados longitudinalmente para facilitar a retirada de amostras de solo, nas profundidades de 0,025, 0,10 e 0,175 m, para o procedimento da extração seqüencial dos metais. A contaminação do solo foi realizada na superficie dos tubos pela disposição de uma camada de $0,01 \mathrm{~m}$ de areia lavada (200 g), previamente contaminada com sais de $\mathrm{Cd}, \mathrm{Cu}, \mathrm{Pb}$ e $\mathrm{Zn}$. A concentração dos metais no substrato foram, com exceção do $\mathrm{Cd}$, baseadas nos teores médios encontrados 
em amostras de composto de lixo quais sejam: 20, 200, 300 e $700 \mathrm{mg} \mathrm{kg}^{-1}$ dos respectivos metais. Os tubos foram lixiviados com $11 \mathrm{~L}$ de água destilada durante 11 dias, tomando uma série de precauções para uma distribuição homogênea da água na coluna. De maneira geral, a análise da água lixiviada permitiu as observações descritas na seqüência. $\mathrm{O}$ metal $\mathrm{Cu}$ esteve ausente nos efluentes de todos os tratamentos, o que demonstrou sua forte retenção pelo solo. Sua ausência nos efluentes das colunas com amostras do horizonte $C$, que apresentou teores muito menores de matéria orgânica, sugeriu que o $\mathrm{Cu}$ também tem afinidade com outros componentes do solo, mesmo aqueles considerados inertes. Os metais $\mathrm{Cd}, \mathrm{Pb}$ e $\mathrm{Zn}$ foram detectados na maioria dos efluentes, apresentando relativa mobilidade. Para as colunas com horizonte A, com e sem calagem, foi observada menor mobilidade do $\mathrm{Cd}$ e $\mathrm{Zn}$ do que no horizonte $\mathrm{B}$. Isto foi atribuído a maior presença de sítios de troca no horizonte $A$, proporcionado provavelmente pelos maiores teores de matéria orgânica. $\mathrm{O} \mathrm{Pb}$ não apresentou comportamento semelhante, o que foi atribuído à sua possivel interação com a caulinita e ou com a fração oxídica do solo. A calagem não afetou significativamente a mobilidade dos metais no horizonte A. Os autores explicaram que a elevação da CTC do solo, com a criação de novos sítios de adsorção pH-dependentes, e o abaixamento da solubilidade dos sais adicionados, não foram suficientes para promoverem uma queda significativa na taxa de lixiviação desses metais. As colunas com amostras do horizonte $\mathrm{C}$, caracterizados também pelos menores teores de argila, óxidos de Fe e menor CTC, apresentaram em seu lixiviado maior concentração de $\mathrm{Cd}$ quando comparados com os horizontes A e B. Segundo os autores, isto evidenciou que a principal forma de retenção do $\mathrm{Cd}$ é através da atração eletrostática nos sítios de troca da matriz do solo. Esta tendência não foi verificada para $\mathrm{Pb}$ e $\mathrm{Zn}$, deixando transparecer que, para estes metais, outras formas de retenção assumem maior importância. A relativa eficiência do horizonte $\mathrm{C}$ em reter os metais, a despeito da baixa atividade físico-química da matriz (baixo teor de argila) foi associada à baixa condutividade hidráulica desse horizonte. Isto deve ter possibilitado um maior tempo para interação dos metais com as frações mais grosseiras do solo, por serem essas constituídas por hematita, muscovita e caulinita pseudomorfa. A marcha de extração seqüencial dos metais pesados revelou que o $\mathrm{Cd}$ foi 
o metal que apresentou maior percentual de retenção na fase trocável do solo, principalmente na camada superficial $(0,025 \mathrm{~m})$ dos horizontes A e B. No horizonte $\mathrm{C}$ este fenômeno se distribuiu por toda sua extensão, evidenciando uma maior participação de ligações menos energéticas, tornando o metal mais móvel. O $\mathrm{Zn}$ também apresentou grande retenção na fase trocável do solo principalmente nos horizontes A e C. A fração oxídica também assumiu importância na retenção do $\mathrm{Zn}$ para todos horizontes. A calagem no horizonte $\mathrm{A}$ apresentou significativo efeito na redução da retenção de $\mathrm{Cd} \mathrm{e}$ $\mathrm{Zn}$ na fase trocável, o que foi explicada pela precipitação desses metais (fase residual) e pela maior retenção em sitios específicos da matriz do solo. $\mathrm{Na}$ retenção do $\mathrm{Pb}$, a fração oxídica se destacou, principalmente nos horizontes A e B, mesmo em condições de acidez $(\mathrm{pH}<5,0)$. Os autores atribuíram este fato a ligações do tipo adsorção específica, o que leva a crer que mesmo em condições de acidez, o $\mathrm{Pb}$ é fortemente retido e portanto, com menor potencial para lixiviação e disponibilidade às plantas. Para o $\mathrm{Cu}$ houve predomínio da fração residual, o que indicou uma forte ligação deste metal à matriz e ou uma forte complexação nas condições do estudo. A fase orgânica das camadas superficiais dos horizontes também se destacou na retenção do $\mathrm{Cu}$. A retenção preferencial do $\mathrm{Cu}$ e do $\mathrm{Pb}$ nas frações não trocáveis, segundo os autores, indica que em condições de competição iônica com $\mathrm{Cd}$ e $\mathrm{Zn}$, esses metais são adsorvidos primeiramente, ocupando sítios de maior energia, restando ao $\mathrm{Cd}$ e ao $\mathrm{Zn}$ a ocupação de sítios de menor energia. Dessa forma, o $\mathrm{Zn}$ e o $\mathrm{Cd}$ sobressairam como os elementos mais móveis, seguidos pelo $\mathrm{Pb}$ com baixa mobilidade, e pelo $\mathrm{Cu}$, que foi considerado imóvel neste solo. Foi concluido portanto, que o $\mathrm{Cd}$ e o $\mathrm{Zn}$ oferecem maior risco potencial à contaminação de águas subterrâneas.

De uma maneira geral, as pesquisas têm demonstrado que os metais $\mathrm{Cr}, \mathrm{Cu}, \mathrm{Ni}$ $\mathrm{e} \mathrm{Pb}$ apresentam baixa mobilidade, acumulando-se na camada do solo onde os resíduos contaminantes são incorporados, enquanto que $\mathrm{Zn}$ e principalmente o $\mathrm{Cd}$ são relativamente móveis e portanto, apresentam maior potencial para contaminar o subsolo e as águas subterrâneas. Por outro lado, observou-se também que muitas dúvidas a respeito desta questão ainda são pertinentes, o que se justifica pela existência de poucos trabalhos de longo prazo e que levem em consideração as mais diversas condições de 
ambiente e de solos. Nas regiões tropicais por exemplo, existe uma carência muito grande de estudos desta natureza pois, não se pode desconsiderar o fato de que, a mobilidade dos metais pesados pode ser maior em condições de solos altamente intemperizados sob regime de temperaturas e precipitações pluviométricas mais elevadas do que nas regiões temperadas.

\subsubsection{Avaliação da fitodisponibilidade de metais pesados}

A contaminação causada por metais pesados, em solos tratados com resíduos urbanos é avaliada, freqüentemente, pelos teores totais desses elementos no solo. Por outro lado, para se avaliar a extensão dessa contaminação, no que se refere aos efeitos causados sobre as plantas e a cadeia alimentar, são necessários conhecimentos acerca das concentrações disponíveis às plantas (Leschber et al., 1985).

Para avaliação dessa fitodisponibilidade, vem sendo estudados diversos extratores químicos cuja eficiência é atribuída de acordo com o grau de correlação estabelecido entre quantidades extraídas do solo e quantidades absorvidas pelas plantas (Kiekens \& Cottenie, 1985). Nesse sentido, os extratores químicos que mais tem se destacado são as soluções de ácidos, de substâncias quelantes e suas combinações (Singh \& Narwal, 1984; Dang et al., 1990; King \& Hajjar, 1990).

Os extratores ácidos apresentam maior capacidade de extração que os demais, principalmente devido ao seu potencial em dissolver, mesmo que parcialmente, as estruturas que retém metais pesados. Porém, deve-se ressaltar que isto não implica, necessariamente, em eficiência para predizer a fitodisponibilidade. São exemplos deste grupo as soluções de Mehlich-1, Mehlich-3, $\mathrm{HCl} 0,1 \mathrm{~mol} \mathrm{~L}^{-1}$ e $\mathrm{HNO}_{3} 0,1 \mathrm{~mol} \mathrm{~L}^{-1}$. A solução de Mehlich-3 $\left(\mathrm{CH}_{3} \mathrm{COOH} 0,2 \mathrm{~mol} \mathrm{~L}^{-1}+\mathrm{NH}_{4} \mathrm{NO}_{3} 0,25 \mathrm{~mol} \mathrm{~L}^{-1}+\mathrm{NH}_{4} \mathrm{~F} 0,015\right.$ $\mathrm{mol} \mathrm{L}^{-1}+\mathrm{HNO}_{3} 0,013 \mathrm{~mol} \mathrm{~L}^{-1}+$ EDTA $0,001 \mathrm{~mol} \mathrm{~L}^{-1}$ ), proposta por Mehlich (1984), foi desenvolvida, inicialmente, para avaliação da disponibilidade de macro e micronutrientes em solos do sudeste dos EUA. Esta solução incluiu também, o EDTA (ácido etileno diamino tetraacético), um agente quelante que extrai, preferencialmente, os metais complexados (Reed \& Martens, 1996). A solução de $\mathrm{HCl} 0,1 \mathrm{~mol} \mathrm{~L}^{-1}$, foi 
proposta originalmente por Wear \& Sommer (1948), passando posteriormente por diversas modificações. Extratores mais enérgicos, como por exemplo a "água régia" $\left(\mathrm{HCl}+\mathrm{HNO}_{3}-3: 1\right)$ proposta em Van-Loon (1985), podem ser utilizados para quantificação dos teores totais de metais nos solos porém, é pouco comum sua inclusão em estudos de fitodisponibilidade (Singh \& Narwal, 1984; Roca \& Pomares, 1991).

O emprego de substâncias complexantes como extratores químicos decorre basicamente da sua capacidade em extrair metais pesados complexados à matéria orgânica. Entre estes ligantes, o EDTA e o DTPA (ácido dietileno triamino pentaacético) tem sido os mais utilizados em trabalhos de pesquisa com diferentes elementos e tipos de solos (Latterell et al., 1978; Ribeiro \& Tucunango-Sarabia, 1984; Bataglia \& Raij, 1989; Roca \& Pomares, 1991). Destaca-se aqui, o extrator DTPA-TEA (DTPA $0,005 \mathrm{~mol} \mathrm{~L}^{-1}+$ trietanolamina $\left.0,1 \mathrm{~mol} \mathrm{~L}^{-1}+\mathrm{CaCl}_{2} \quad 0,01 \mathrm{~mol} \mathrm{~L}^{-1}\right)$ desenvolvido por Lindsay \& Norvell (1978) para extração de $\mathrm{Cu}, \mathrm{Fe}, \mathrm{Mn}$ e $\mathrm{Zn}$ em solos calcários. O princípio desse método é fundamentado na capacidade do DTPA formar complexos estáveis e hidrosolúveis com metais, diminuindo a atividade iônica dos mesmos no extrato. Em resposta, metais são desorvidos das superficies das partículas do solo (metais trocáveis) no sentido de restabelecer o equilibrio solo - solução sendo assim, complexados sucessivamente. Considera-se dessa forma, o princípio de que a absorção desses elementos pelas plantas é tão maior quanto for as quantidades de metais em solução que por sua vez, variam diretamente em função da capacidade da fase sólida do solo em repor esses elementos.

Baxter et al. (1983) estudaram a disponibilidade de $\mathrm{Cd}, \mathrm{Cu}, \mathrm{Ni}, \mathrm{Pb}$ e $\mathrm{Zn}$ para plantas forrageiras cultivadas numa área de solos calcários onde foram dispostos, aproximadamente, $300 \mathrm{Mg} \mathrm{ha}^{-1}$ (base seca) de lodo de esgoto, distribuídos num período de sete anos. Verificaram que as concentrações de $\mathrm{Cd}, \mathrm{Cu}, \mathrm{Ni}$ e $\mathrm{Zn}$ no tecido vegetal aumentaram significativamente com a aplicação do resíduo ao passo que para $\circ \mathrm{Pb}$, foram detectados aumentos apenas no solo. $\mathrm{Na}$ avaliação da fitodisponibilidade desses metais, os autores não encontraram correlações significativas entre as concentrações determinadas no solo, por DTPA-TEA e $\mathrm{HNO}_{3}$ concentrado, e àquelas verificadas no tecido vegetal. Entretanto, quando foram correlacionados os dados obtidos por ambos 
extratores, obtiveram-se elevados coeficientes de correlação. Segundo os autores, os resultados sugeriram que o extrator DTPA-TEA poderia ser utilizado seguramente, como um índice para estimativa dos teores totais presentes no solo, mas de forma alguma como um extrator capaz de predizer a disponibilidade de metais pesados às plantas. Por outro lado, contrariando as conclusões de Baxter et al. (1983), Singh \& Narwal (1984) consideraram o DTPA-TEA como o melhor extrator químico, comparado com $\mathrm{HNO}_{3}$, "água régia", $\mathrm{HCl} \mathrm{0,2} \mathrm{mol} \mathrm{L}^{-1}$ e $\mathrm{NH}_{4} \mathrm{Oac}-\mathrm{pH} 4,8$, para avaliar a disponibilidade de $\mathrm{Cd}, \mathrm{Pb}$ e $\mathrm{Zn}$ para plantas de nabo comestivel. Trabalhando com solo arenoso em três diferentes valores $\mathrm{pH}(5,6,6,0$ e 7,5) e com aplicação de três doses de lodo de esgoto $\left(0,50\right.$ e $100 \mathrm{Mg} \mathrm{ha}^{-1}$ - base seca), observaram que o $\mathrm{pH}$ não influenciou a ação dos extratores químicos, porém as quantidades de metais absorvidas pelas plantas aumentaram nas condições de maior acidez. A "água-régia", $\mathrm{HCl} 0,2 \mathrm{~mol} \mathrm{~L}^{-1}$ e o $\mathrm{NH}_{4} \mathrm{Oac}-\mathrm{pH} 4,8$ apresentaram correlações significativas para os metais $\mathrm{Cd}$ e $\mathrm{Pb}$, enquanto que $\mathrm{OHNO}_{3}$ só foi eficiente para $\mathrm{Cd}$. Para $\mathrm{Ni}$ e Co nenhum dos extratores testados apresentaram resultados satisfatórios.

Num experimento de campo, com três solos ácidos de diferentes texturas, Rappaport et al. (1988) avaliaram a disponibilidade, para plantas de milho, de elevadas quantidades $\mathrm{Cd}, \mathrm{Cu}, \mathrm{Ni}$ e $\mathrm{Zn}$ devidas a aplicação de um lodo de esgoto indústrial nas doses de $0,42,84,126,168$ e $210 \mathrm{Mg} \mathrm{ha}^{-1}$ (base seca). Análises de correlação simples, realizadas para metais extraídos por DTPA-TEA em cada tipo de solo, revelaram de maneira geral, baixos coeficientes. O maior coeficiente de correlação positiva ocorreu entre $\mathrm{Zn}$ extraído do solo siltoso e $\mathrm{Zn}$ presente nas folhas do milho $(\mathrm{r}=0,65)$. Para os solos argiloso e arenoso foram encontrados para $\mathrm{Cd}$ e $\mathrm{Ni}$, coeficientes de correlação negativos. Esta relação inversa foi explicada como sendo um reflexo da diluição dos teores desses metais na planta devido ao maior crescimento proporcionado pelas maiores taxas de nitrogênio aplicadas através das doses crescentes do lodo de esgoto. Quando foram correlacionados o conjunto de dados obtidos para os três solos e os teores dos metais nas folhas de milho, não foram obtidos resultados significativos para nenhum dos elementos estudados. Os autores explicaram que os baixos coeficientes de correlação obtidos e até mesmo os casos em que não houveram correlações entre metais extraídos 
do solo e seus teores absorvidos por plantas de milho, foram devidos ao fato de que as doses crescentes de lodo de esgoto praticamente não promoveram aumentos nas concentrações de metais pesados do tecido vegetal.

Dang et al. (1990) verificaram que o DTPA-TEA foi adequado para avaliar a disponibilidade de $\mathrm{Cd}, \mathrm{Ni}, \mathrm{Pb}$ e $\mathrm{Zn}$ para plantas de cebola e feno grego (Trigonella poenum-graceum). Neste trabalho, amostras de um solo calcário $(\mathrm{pH}=8,3)$ foram contaminadas com os referidos metais em níveis de $0,50,100,200 \mathrm{e}^{2} 00 \mathrm{mg} \mathrm{kg}^{-1}$ na forma de sais altamente solúveis. Todas as correlações obtidas foram significativas $(r \geq 0,95)$ no entanto, esses resultados dificilmente seriam extrapoláveis para situações onde os metais pesados se apresentam em frações menos solúveis, combinados com as mais variadas espécies químicas ou complexados com a matéria orgânica, como no caso do lodo de esgoto e do composto de lixo.

King \& Hajjar (1990) serviram-se dos extratores DTPA-TEA e Mehlich-3 para estudar, em casa de vegetação, o efeito residual de lodo de esgoto sobre a disponibilidade de $\mathrm{Cd}, \mathrm{Cr}, \mathrm{Cu}, \mathrm{Ni}, \mathrm{Pb}$ e $\mathrm{Zn}$ para plantas de fumo e amendoim. Utilizaram-se de um solo podzólico de textura média com três diferentes valores $\mathrm{pH}$ $(5,2 ; 5,8$ e 6,4$)$ procedente de uma área que recebeu lodo de esgoto nas doses equivalentes a $0,9,18$ e $27 \mathrm{Mg} \mathrm{ha}^{-1}$ ano $^{-1}$, durante três anos. Os resultados de análises de correlações múltiplas, considerando os níveis de $\mathrm{pH}$ do solo, sugeriram que o DTPA-TEA foi um extrator mais eficiente que o Mehlich-3 na predição da fitodisponibilidade dos metais $\mathrm{Cd}, \mathrm{Cu}, \mathrm{Ni}$ e $\mathrm{Zn}$. Para o $\mathrm{Cr}$ e o $\mathrm{Pb}$, os resultados não foram conclusivos devida a baixa concentração nas plantas. Mulchi et al. (1991) verificaram que as soluções de Mehlich-1, Mehlich-3 e DTPA-TEA foram adequadas para determinar a disponibilidade de $\mathrm{Cd}, \mathrm{Cu}, \mathrm{Ni}$ e $\mathrm{Zn}$ para plantas de fumo cultivadas em solos ácidos acrescidos de lodo de esgoto. Também observaram que nenhum dos três extratores foram eficientes para $\mathrm{Fe}$ e $\mathrm{Pb}$ e que o Mehlich-3 não foi adequado para $\mathrm{Mn}$.

Em solo calcário, Roca \& Pomares (1991) aplicaram doses equivalentes a 400, 800 e $1200 \mathrm{~kg} \mathrm{ha}^{-1} \mathrm{ano}^{-1}$ de nitrogênio (N-total) na forma de lodo de esgoto, em cultivos seqüenciais de batata - milho, batata - alface e batata, no primeiro, segundo e terceiro ano, respectivamente. A eficiência de diferentes extratores químicos na avaliação da 
disponibilidade de metais pesados às plantas foi afetada pela espécie vegetal em questão. Dessa forma, quando foram consideradas as plantas de batata observaram-se boas correlações para $\mathrm{Zn}, \mathrm{Cu}$ e $\mathrm{Ni}$ extraídos por DTPA-TEA e "água-régia", e para $\mathrm{Zn}$ e Ni quando extraídos por $\mathrm{HCl} 0,1 \mathrm{~mol} \mathrm{~L}^{-1}$. Nenhum dos extratores apresentaram correlações para os teores de metais pesados presentes nas folhas de milho porém para os grãos, foram obtidas correlações para o $\mathrm{Cd}$ extraído por $\mathrm{HCl} 0,1 \mathrm{~mol} \mathrm{~L}^{-1}$ e $\mathrm{Pb}$ extraído por DTPA-TEA e "água-régia". Quando a espécie foi a alface, foram obtidas correlações para $\mathrm{Zn}$ e $\mathrm{Cd}$ extraídos por DTPA-TEA e "água-régia" e para $\mathrm{Cd}$ e $\mathrm{Ni}$ extraídos por

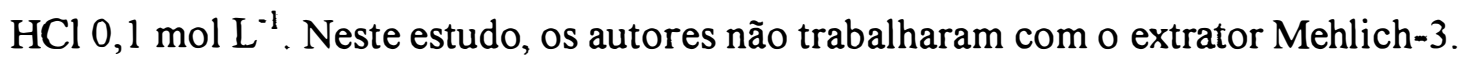

Abreu et al. (1995) compararam a eficiência dos extratores Mehlich-1, Mehlich-3 e DTPA-TEA na avaliação da disponibilidade de $\mathrm{Cd}, \mathrm{Cr}, \mathrm{Ni}$ e $\mathrm{Pb}$ para plantas de trigo e feijão cultivadas sucessivamente em 31 a mostras de solos paulistas. O extrator Mehlich-3 apresentou a maior capacidade de extração seguido pelo Mehlich-1 e DTPA-TEA. Os métodos utilizados foram ineficientes para avaliar a disponibilidade dos metais $\mathrm{Cd}, \mathrm{Cr}$, $\mathrm{Ni}$ e $\mathrm{Pb}$ para o trigo e $\mathrm{Pb}$ e $\mathrm{Cd}$ para o feijão. Correlações significativas e positivas foram obtidas para o $\mathrm{Cr}$ extraído por Mehlich-1 e Mehlich-3 e para o $\mathrm{Ni}$ extraído por Mehlich-3 e DTPA-TEA sendo o feijão em todos os casos, a planta teste. Para os autores, os resultados pouco satisfatórios foram atribuídos às baixas concentrações de metais pesados em todas as amostras de solos. Diante disto, resolveram proceder uma análise de regressão multivariada incluindo algumas características dos solos, teor de argila, matéria orgânica e $\mathrm{pH}$, como variáveis independentes. As características que mais contribuíram para o modelo foram o teor de argila, quando foi considerado o $\mathrm{Cr}$, e o $\mathrm{pH}$, no caso do $\mathrm{Ni}$. Os resultados mostraram que a predição da concentração desses metais na parte aérea do feijão tem sua eficácia aumentada se a análise do solo for acompanhada, principalmente, pelas determinações de $\mathrm{pH}$ e argila.

Em 21 amostras de solos ácidos e 5 amostras de solos alcalinos, todos de ocorrência no Brasil, Abreu Junior (1999) estudou a eficiência de diversos extratores químicos na predição da disponibilidade de $\mathrm{Cd}, \mathrm{Cr}, \mathrm{Cu}, \mathrm{Ni}, \mathrm{Pb}$ e $\mathrm{Zn}$, adicionados aos solos via composto de lixo $\left(60 \mathrm{Mg} \mathrm{ha}^{-1}\right)$, para plantas de arroz. Foram realizadas 
correlações considerando três conjuntos de dados: o primeiro com as médias de todos os solos, o segundo apenas com as médias dos solos ácidos e o último, com os solos alcalinos. De maneira geral, em todas as combinações analisadas os coeficientes de correlação para os extratores DTPA-TEA e Mehlich-3 foram, quando significativos, relativamente baixos $(r \leq 0,63)$. Quando foi considerado o conjunto de todos os solos, determinou-se correlações significativas para $\mathrm{Cd}, \mathrm{Cu}$ e $\mathrm{Zn}$ em ambos extratores. Para os solos ácidos, foram obtidas correlações significativas para $\mathrm{Cd}, \mathrm{Cr}, \mathrm{Cu}$ e $\mathrm{Zn}$ e para os solos alcalinos apenas os metais $\mathrm{Pb}$ e $\mathrm{Zn}$, também para ambos os extratores. Os maiores coeficientes de correlação foram obtidos para o $\mathrm{Cd}$ extraído por DTPA-TEA, no conjunto de todos os solos e para os solos ácidos. Para o $\mathrm{Zn}$ destacou-se o DTPA-TEA quando foram considerados apenas os solos ácidos. Nas condições deste trabalho, uma análise global dos dados sugeriu a impossibilidade de se apontar um extrator eficiente, ao mesmo tempo, para todos os metais considerados e nas variadas condições de solos. Isto sem contar as dificuldades adicionais, caso fossem consideradas outras espécies como plantas indicadoras.

Diante do exposto, fica evidente que existem grandes dificuldades para a definição de um extrator multielementar que inclua vários metais pesados e que ao mesmo tempo, seja eficiente para diagnosticar a disponibilidade desses elementos às várias espécies vegetais cultivadas nos vários tipos de solos. Além disso, uma outra variável pode ser apontada. Em solos contaminados com metais pesados, principalmente naqueles casos que esta contaminação é devida a aplicação de resíduos orgânicos, diversos trabalhos tem demonstrado que a absorção desses elementos, com freqüência, não se comporta linearmente com as quantidades de metais aplicadas ou presentes nos solos (Barbarick et al., 1995; Logan et al., 1997). Este comportamento, além dos fatores ligados às espécies vegetais, provavelmente é devido a série de reações no solo que indisponibilizam estes elementos às plantas, o que diga-se de passagem, é mais um fenômeno natural a ser simulado por um extrator artificial, o que sem dúvida é outra dificuldade. Dessa forma, fica clara a necessidade de pesquisas nesta área do conhecimento, principalmente nas condições brasileiras onde estudos desta natureza, em solos contaminados, são incipientes. 


\subsection{Dinâmica, no solo, do nitrogênio aplicado via resíduos urbanos}

Considerando-se que em média, mais de $90 \%$ do nitrogênio total presente em lodo de esgoto e composto de lixo, é nitrogênio orgânico (Sommers et al., 1977; Xin et al., 1992), o conhecimento dos principais processos envolvidos nas transformações deste elemento, quando tais resíduos são dispostos no solo, é de grande importância não só do ponto de vista agronômico mas principalmente, para a avaliação dos riscos de poluição ambiental. Tais processos, ilustrados na Figura 1, são brevemente comentados com base nos textos de Victoria et al. (1992) e Hue (1995).

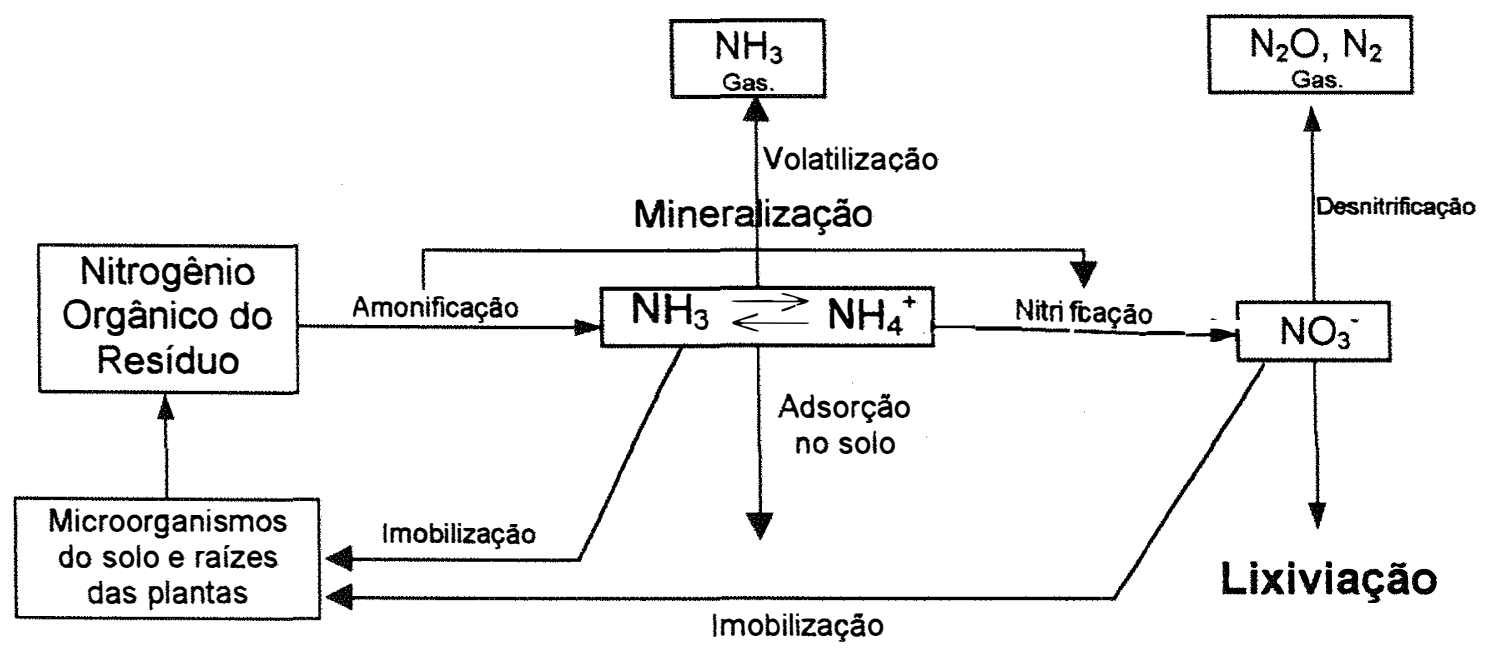

Figura 1. Principais processos de transformação, no solo, do nitrogênio orgânico contido em resíduos. Fonte: Adaptado de Hue (1995).

A transformação do N-orgânico em N-inorgânico, chamada de mineralização, é compreendida por dois processos biológicos: amonificação e nitrificação. Amonificação é um processo mediado por microrganismos quimiorganotróficos, pelo qual o $\mathrm{N}$-orgânico é transformado em amônio e amônia (aquosa). Trata-se de um processo relativamente lento, que não requer microrganismos específicos podendo ocorrer tanto em condições aeróbias quanto anaeróbias. É fortemente favorecida quando a relação $\mathrm{C} / \mathrm{N}$ do resíduo e da mistura solo-resíduo, resulta em valores menores que 15 (Hue, 1995). Uma vez disponível no solo, $\mathrm{O}_{\mathrm{NH}_{4}}^{+}$poderá seguir diversos caminhos como: ser imobilizado por microrganismos; absorvido pelas plantas; adsorvido ao complexo de troca iônica do solo; fixado no solo pela inclusão entre as lâminas dos 
minerais de argila do tipo 2:1; ser perdido por volatilização da $\mathrm{NH}_{3}$ em condições de $\mathrm{pH}>8,0$. Porém, em solos bem drenados com predomínio de condições aeróbias, a maior parte do $\mathrm{NH}_{4}{ }^{+}$é rapidamente oxidada a nitrato através do processo de nitrificação. Tal processo é mediado por bactérias quimiolitotróficas e ocorre em duas etapas: a) nitritação: que é a oxidação do amônio a nitrito, levada a efeito por bactérias do gênero Nitrosomonas; b) nitratação: que é a oxidação do nitrito a nitrato, levada a efeito por bactérias do gênero Nitrobacter. A exemplo do ín $\mathrm{NH}_{4}{ }^{+}$, o destino do $\mathrm{NO}_{3}{ }^{-}$no solo também se divide em vários caminhos: pode ser novamente imobilizado por microrganismos caso haja condições favoráveis (p.e. aumento da relação $\mathrm{C} / \mathrm{N}$ do solo); pode ser absorvido pelas plantas; pode ser perdido para a atmosfera na forma de $\mathrm{N}_{2}$ ou $\mathrm{N}_{2} \mathrm{O}$ através de um processo chamado desnitrificação, caso haja necessariamente condições de anaerobiose ou baixa concentração de oxigênio; poderá ser facilmente lixiviado em condições de umidade e fluxo descendente de água.

Dentre os processos envolvidos nas perdas de nitrogênio do sistema solo-planta, a possibilidade de lixiviação de nitratos é o que tem causado maior preocupação a diversos segmentos da sociedade, sejam agricultores, pesquisadores ou ambientalistas (Stratton et al., 1995). A grande mobilidade deste ín no solo aliada a crescente utilização de fertilizantes nitrogenados e a necessidade cada vez maior de disposição de residuos urbanos, principalmente lodo de esgoto, estão contribuindo para o agravamento, em diversas regiões do planeta, dos problemas de eutrofização de águas de superfície, como lagos e rios, e de contaminação de águas subterrâneas, as quais muitas vezes são a principal ou a única fonte de água potável de grandes populações (Aschmann et al., 1992; Muchovej \& Rechcigl, 1995; Hue, 1995).

De acordo com Muchovej \& Rechcigl (1995) águas com concentrações de $\mathrm{N}-\mathrm{NO}_{3}{ }^{-}$maiores que $3 \mathrm{mg} \mathrm{L}^{-1}$ já são consideradas contaminadas. Segundo esses autores, a Organização Mundial da Saúde (OMS) recomenda que a água potável não deve apresentar concentrações de $\mathrm{N}-\mathrm{NO}_{3}{ }^{-}$maiores do que $10 \mathrm{mg} \mathrm{L}^{-1}$, padrão também adotado no Brasil pelo Ministério da Saúde, através da Comissão Nacional de Normas e Padrões para Alimentos (Brasil, 1990). Hue (1995) salientaram que o consumo de águas com teores de $\mathrm{N}_{-} \mathrm{NO}_{3}{ }^{-}$acima dos limites recomendados pela OMS pode causar sérios 
problemas de saúde aos seres humanos, principalmente em crianças menores de três meses. Além da possibilidade de efeitos carcinógenos, é comum a ocorrência de um problema conhecido como metahemoglobinemia causada quando um agente oxidante, no caso o nitrito, oxida o Fe da hemoglobina e forma metahemoglobina (metHb), reduzindo a capacidade do sangue em transportar oxigênio. Crianças recém nascidas são altamente susceptíveis ao envenenamento com $\mathrm{NO}_{3}{ }^{-}$porque determinadas bactérias presentes em seu trato digestivo (com reação alcalina) são capazes de reduzi-lo a $\mathrm{NO}_{2}$, possibilitando a transformação da hemoglobina em metHb. Como o transporte de oxigênio pelo sangue fica comprometido, a criança fica sufocada e com o corpo azulado. Assim, é comum a metahemoglobinemia ser chamada de "sindrome do bebê azul". Animais domésticos como ruminantes, eqüinos e suínos apresentam maior tolerância a niveis de nitrato na água de consumo. No entanto, concentrações de $\mathrm{N}_{-} \mathrm{NO}_{3}{ }^{-}$acima de $40 \mathrm{mg} \mathrm{L}^{-1}$ já oferecem grandes riscos.

$\mathrm{O}$ potencial de lixiviação de $\mathrm{N}^{-} \mathrm{NO}_{3}{ }^{-}$devido a disposição e ou utilização agronômica de lodo de esgoto não tem sido avaliado nas condições brasileiras. Este fato é justificado por serem relativamente recentes no Brasil, as necessidades de destinação final deste resíduo para áreas agrícolas. Além disso, a grande maioria dos trabalhos publicados enfatizaram os aspectos relacionados com a poluição do solo por metais pesados. Porém, nos Estados Unidos e em diversos países da Europa, onde a prática de se destinar lodo de esgoto para solos agrícolas é bem mais antiga, este problema tem sido alvo de inúmeros trabalhos cientificos.

Kelling et al. (1977) avaliaram os efeitos da disposição de lodo de esgoto anaeróbio, sobre a lixiviação do nitrogênio inorgânico pelo perfil de dois solos, um siltoso (experimento A) e outro arenoso (experimento B). Foram aplicadas doses de lodo de $0,3,75,7,5,15,30$ e $60 \mathrm{Mg} \mathrm{ha}^{-1}$ (base seca), o equivalente a $0,340,680,1360,2720$ e $5440 \mathrm{~kg} \mathrm{ha}^{-1}$ de nitrogênio total. Os experimentos foram instalados a campo com avaliações periódicas do solo e da solução do solo até 26 meses após a aplicação do resíduo. Os resultados mostraram que apenas nos tratamentos com as duas maiores doses de lodo ocorreram, em ambos os solos, perdas significativas de nitrogênio por lixiviação. Tanto as análises de solo como de sua solução, no experimento A, apontaram maiores 
perdas de $\mathrm{N}_{-} \mathrm{NO}_{3}{ }^{-}$no período de 10 a 15 meses da aplicação do resíduo. Neste período, as amostras de solução do solo, coletadas na camada de 1,2 a 1,5 m, apresentaram teores de $\mathrm{N}_{-} \mathrm{NO}_{3}{ }^{-}$, nos tratamentos com $30 \mathrm{Mg} \mathrm{ha}^{-1}$ de lodo de esgoto, variando de 78 a $93 \mathrm{mg} \mathrm{L}^{-1}$ acima dos teores obtidos no tratamento testemunha, e de 136 a $225 \mathrm{mg} \mathrm{L}^{-1}$ nos tratamentos com a maior dose do resíduo. No experimento B as perdas de nitrogênio por lixiviação foram maiores e principalmente, mais rápidas. Os autores verificaram por

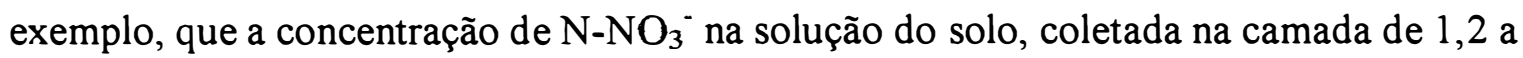
1,5 m, após 3 semanas da aplicação do resíduo, apresentou para a maior dose de lodo no experimento $\mathrm{A}$, um teor de $7 \mathrm{mg} \mathrm{L}^{-1}$ maior que a testemunha enquanto que, no experimento $\mathrm{B}$ este teor foi $104 \mathrm{mg} \mathrm{L}^{-1}$ maior, tendência que persistiu até os 4 meses após a aplicação do lodo de esgoto. Após 26 meses as concentrações de $\mathrm{N}_{-} \mathrm{NO}_{3}{ }^{-}$nas amostras de solução do solo praticamente se igualaram a testemunha, para todos os tratamentos em ambos os solos. Convém salientar que de 20 a $50 \%$ do nitrogênio total aplicado era na forma $\mathrm{N}^{-\mathrm{NH}_{4}}{ }^{+}$e devido a reação levemente alcalina do lodo, os dados sinalizaram para uma grande perda de nitrogênio por volatilização. Além disso, este estudo foi realizado no Estado de Wisconsin - USA, que apresenta invernos rigorosos. Embora os autores não tenham mencionado os índices pluviométricos ocorridos durante o período experimental, acredita-se que tanto os fatores climáticos como as perdas de nitrogênio por volatilização foram os responsáveis pela menor lixiviação de nitrato nos tratamentos com doses abaixo de $30 \mathrm{Mg} \mathrm{ha}^{-1}$ de lodo de esgoto. Num contexto geral, foram destacados neste trabalho, dois importantes fatores os quais influenciaram a intensidade das perdas de nitrogênio, através da lixiviação de $\mathrm{N}^{-\mathrm{NO}_{3}}{ }^{-} \mathrm{O}$ primeiro deles é o tipo de solo, ficando evidenciado que solos mais arenosos, com maior condutividade hidráulica, perdem mais rapidamente por lixiviação, o nitrogênio das camadas cultivadas, o que também foi verificado mais tarde por Gaines \& Gaines (1994). O segundo fator foi devido as taxas de mineralização do nitrogênio orgânico. Sobre este aspecto, os autores consideraram para definição das doses de lodo a serem aplicadas, taxas de 15,6 e $4 \%$ respectivamente para o $1^{\circ}, 2^{\circ}$ e $3^{\circ}$ ano de experimentação, o que resultaria durante os 3 anos em doses de 95, 190, 380, 760 e $1520 \mathrm{~kg} \mathrm{ha}^{-1}$ de nitrogênio "disponível" às culturas. Porém verificaram que nas condições do experimento, essas 
taxas atingiram valores bem maiores e correspondentes a mais de $50 \%$ apenas nas três primeiras semanas após a aplicação do lodo.

A mineralização do nitrogênio orgânico contido nos residuos, assim como muitos outros processos bioquímicos, é diretamente influenciada pelas propriedades químicas e físicas do solo, pelas origens e características dos resíduos, pelas taxas de aplicação e pelos fatores climáticos (Cassman \& Munns, 1980; Barbarika et al., 1985). A exemplo disto, verifica-se em estudos de incubação de lodo de esgoto digerido as mais variadas taxas de mineralização do nitrogênio orgânico; de 4 a $48 \%$ em 16 semanas (Ryan et al. 1973), de 40 a $42 \%$ em 15 semanas (Epstein et al., 1978), de 19 a $37 \%$ em 32 semanas (Lindemann \& Cardenas, 1984), de 1 a $58 \%$ em 26 semanas (Chae \& Tabatabai, 1986). Para composto de lixo não foram encontrados na literatura dados a este respeito no entanto, de acordo com Stratton et al. (1995) a mineralização do nitrogênio orgânico contido nesses materiais é altamente dependente da relação $\mathrm{C} / \mathrm{N}$ do mesmo. Dessa forma, pode-se concluir que processos de mineralização vão predominar apenas em situações em haja um composto maturado e uma conseqüente relação C/N baixa $(<15)$ (Hue, 1995).

Em solos siltosos sob florestas, Sidle \& Kardos (1979) aplicaram lodo de esgoto, parcelado em duas vezes, dentro de um período de sete meses. Os totais aplicados foram 0, 13 e $27 \mathrm{Mg} \mathrm{ha}^{-1}$ (base seca) do resíduo ou 0, 1417 e $3034 \mathrm{~kg} \mathrm{ha}^{-1}$ de nitrogênio total. Amostras de solução do solo, coletadas com extratores de cápsula porosa, apresentaram a $0,15 \mathrm{~m}$ de profundidade, concentrações máximas de $\mathrm{N}-\mathrm{NO}_{3}{ }^{-}$de 194 e $290 \mathrm{mg} \mathrm{L}^{-1}$ respectivamente para os tratamentos com a menor e maior dose, um mês após a segunda parcela de aplicação do lodo de esgoto. Neste período predominaram fluxos ascendentes de água no solo devido a baixa precipitação e a elevada evapotranspiração. Somente após 14 meses da aplicação da segunda parcela do lodo, em ambas as doses, a concentração de $\mathrm{N}^{-\mathrm{NO}_{3}}{ }^{*}$ na solução do solo a $0,15 \mathrm{~m}$ de profundidade foi menor que $10 \mathrm{mg} \mathrm{L}^{-1}$. As amostras coletadas a $1,2 \mathrm{~m}$ de profundidade apresentaram os maiores picos de concentração de $\mathrm{N}_{-} \mathrm{NO}_{3}{ }^{-}$seis meses após àqueles da profundidade de $0,15 \mathrm{~m}$. Com a maior ocorrência de chuvas neste período, as concentrações chegaram atingir $66 \mathrm{e} 180 \mathrm{mg} \mathrm{L}^{-1}$ para as respectivas doses de lodo de 
esgoto. Passados oito meses da ocorrência desses picos ou 14 meses da aplicação da

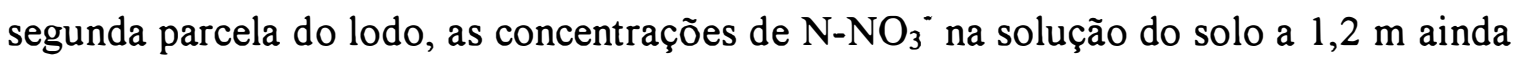
eram de 22 e mais de $100 \mathrm{mg} \mathrm{L}^{-1}$ respectivamente para as doses de 13 e $27 \mathrm{Mg} \mathrm{ha}^{-1}$ de lodo, bem acima dos limites de segurança recomendados pela OMS. Convém salientar que no tratamento testemunha, para as duas profundidades consideradas, as concentrações de $\mathrm{N}^{-\mathrm{NO}_{3}}{ }^{*}$ na solução do solo, durante todo o período de estudo, estiveram em níveis abaixo do limite de determinação do método analítico empregado. Através de modelos matemáticos de simulação, os autores encontraram uma estreita relação entre o movimento da água de chuvas intensas e a lixiviação do $\mathrm{N}^{-\mathrm{NO}_{3}}{ }^{-}$. Eles chamaram o fenômeno de canalização do lixiviado por macroporos interconectados. Para florestas, foi concluído que a disposição de lodo de esgoto nas doses experimentadas oferecem grandes riscos de contaminação das águas de subsuperficie tendo em vista que, os solos nestas condições são largamente dotados de macroporos formados por pequenos canais de raízes mortas e macrorganismos, rachaduras provocadas pelo congelamento e descongelamento da superfície e tocas de pequenos animais o que, segundo os autores, tem mostrado grande contribuição no movimento da água pelo perfil do solo.

Em determinadas condições de ambiente e dependendo da origem do lodo de esgoto utilizado, podem ocorrer casos em que a mineralização do nitrogênio e as possiveis perdas por lixiviação sejam processos relativamente mais lentos (Tester et al., 1977). Nestes casos, aplicações anuais e sucessivas desses resíduos, mesmo que em pequenas doses, podem levar ao acúmulo de nitrogênio orgânico, tornando com o tempo, mesmo com baixas taxas de mineralização, quantitativamente significativas a presença de $\mathrm{N}^{-\mathrm{NO}_{3}}{ }^{-}$no solo e portanto passível de lixiviação. Este fenômeno foi observado parcialmente no trabalho de Inman et al. (1982). Eles aplicaram num solo siltoso 0, 150 e $300 \mathrm{Mg} \mathrm{ha}^{-1}$ (base seca) de um composto a base de lodo de esgoto ( $65 \%$ lodo $+35 \%$ serragem de madeira), o equivalente a 0,2040 e $4080 \mathrm{~kg} \mathrm{ha}^{-1}$ de nitrogênio total. Foram cultivados mudas de duas espécies arbóreas por um período de 30 meses. Amostras de solução do solo coletadas durante o período de estudo

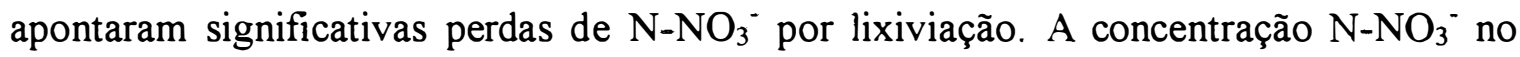


horizonte $\mathrm{C}$ do solo (1,0 m de profundidade) chegou a $70-80 \mathrm{mg} \mathrm{L}^{-1}$ nos tratamentos com $300 \mathrm{Mg} \mathrm{ha}^{-1}$ de composto, contra $11-12 \mathrm{mg} \mathrm{L}^{-1}$ no tratamento testemunha. Os autores salientaram que estas concentrações devem ter ocorridos em níveis mais elevados visto que, a primeira coleta de solução do solo foi realizada apenas depois de 267 dias da aplicação do resíduo. O que chamou a atenção é que, apesar da significativa lixiviação de $\mathrm{N}^{-\mathrm{NO}_{3}}{ }^{-}$, as concentrações de $\mathrm{N}$-total no solo da camada de $0-0,15 \mathrm{~m}$, para os tratamentos com 150 e $300 \mathrm{Mg} \mathrm{ha}^{-1}$ de composto, após 30 meses da aplicação, apresentaram uma redução de apenas 3 a $6 \%$ de N-total determinado logo após a aplicação do composto. Somados a isso, ao final dos 30 meses da aplicação do resíduo, as concentrações de $\mathrm{N}$-total encontradas nos tratamentos com composto apresentaram valores duas a três vezes maiores, quando comparadas com a testemunha. Isto foi um indicativo de baixa taxa de mineralização e portanto, um potencial de acúmulo do $\mathrm{N}$-orgânico caso haja novas aplicações do resíduo.

Em algumas regiões dos Estados Unidos, lodo de esgoto e resíduos orgânicos industriais são freqüentemente dispostos em elevadas quantidades nas chamadas áreas de "landfarming" (utilização do solo como meio depurador da carga orgânica) ou em áreas degradadas, onde tais disposições objetivam a recuperação da biota do solo. Preocupados com o crescimento desta prática, Jones \& Hinesly (1988) alertaram sobre o potencial de contaminação das águas de superficie e subsuperficie, pelo excesso de nitrogênio que estaria sendo carreado dessas áreas de disposição, tanto pelo escorrimento superficial ("runoff") como principalmente pela lixiviação de $\mathrm{N}^{-\mathrm{NO}_{3}}$ ". Para tanto, eles conduziram um experimento em macro lisímetros $(3 \times 15 \mathrm{~m})$ de um solo siltoso, com declividade de $0,015 \mathrm{~m} \mathrm{~m}^{-1}$, onde foram monitoradas por dois anos sucessivos, as perdas de nitrogênio inorgânico devidas a disposição de elevadas doses de lodo de esgoto anaeróbio líquido. Foram aplicadas doses do resíduo equivalentes a 2292 e $3286 \mathrm{~kg} \mathrm{ha}^{-1}$ de nitrogênio total, respectivamente para primeiro e segundo ano de experimentação. Num outro lisímetro, como termo de comparação, foram aplicados $336 \mathrm{~kg} \mathrm{ha}^{-1}$ ano ${ }^{-1}$ de nitrogênio na forma de $\mathrm{NH}_{4} \mathrm{NO}_{3}$, fertilização recomendada para $\mathrm{o}$ milho, que foi cultivado em todos os lisimetros. Os resultados indicaram para os lisímetros tratados com lodo de esgoto, perdas anuais de $\mathrm{N}_{-} \mathrm{NO}_{3}{ }^{\circ}$ por "runoff" de 
5,1 e $0,9 \mathrm{~kg} \mathrm{ha}^{-1}$ enquanto que por lixiviação a $0,9 \mathrm{~m}$ de profundidade, tais perdas foram de 663 e $371 \mathrm{~kg} \mathrm{ha}^{-1}$ respectivamente para o primeiro e segundo ano de monitoramento. Nos lisímetros fertilizados com $\mathrm{NH}_{4} \mathrm{NO}_{3}$, as perdas anuais por "runoff" foram respectivamente, para o primeiro e segundo ano, de 3,3 e $1,1 \mathrm{~kg} \mathrm{ha}^{-1}$ e por lixiviação foram de 79 e $31 \mathrm{~kg} \mathrm{ha}^{-1}$. A concentração média de $\mathrm{N}_{-} \mathrm{NO}_{3}^{-}$nas águas lixiviadas dos lisímetros com lodo foram de 223 e $148 \mathrm{mg} \mathrm{L}^{-1}$ ao passo que, para os lisímetros com $\mathrm{NH}_{4} \mathrm{NO}_{3}$, tais concentrações foram de 24 e $44 \mathrm{mg} \mathrm{L}^{-1}$, para os respectivos anos de monitoramento. Convém salientar que mesmo nos tratamentos com fertilizante mineral,

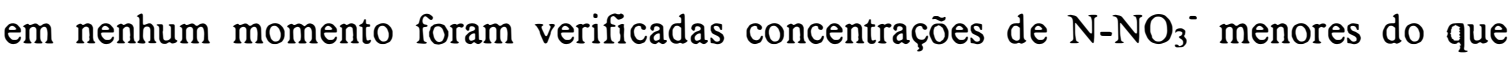
$10 \mathrm{mg} \mathrm{L}^{-1}$. As maiores perdas de $\mathrm{N}^{-\mathrm{NO}_{3}}{ }^{-}$ocorridas no primeiro ano de monitoramento foram justificadas pela ocorrência de um maior volume de precipitações quando comparado com as do ano seguinte. Além disso, verificaram-se que de 70 a $80 \%$ das perdas ocorreram no período dos meses de novembro a abril, período de concentração das chuvas. Por fim, com base nos resultados obtidos, os autores salientaram que em áreas de "landfarming" deveriam ser incorporados sistemas de filtragem ou retenção do $\mathrm{N}-\mathrm{NO}_{3}{ }^{-}$, antes que a qualidade das águas sejam comprometidas.

Aschmann et al. (1992) afirmaram que o interesse pela disposição de elevadas doses de lodo de esgoto em áreas florestais na região de Maryland - USA vem aumentando devido a crescente produção do resíduo e a indisponibilidade de áreas agrícolas suficientes para atender a demanda. Diante desse fato, eles conduziram um estudo buscando contribuir para a determinação de taxas de aplicação seguras para o ambiente, essencialmente no que diz respeito ao potencial de contaminação por nitratos. Dessa forma, foram aplicadas num solo siltoso, doses crescentes de lodo de esgoto anaeróbio (0, 3, 6 e $12 \mathrm{Mg} \mathrm{ha}^{-1}$ - base seca) equivalentes a 0, 200, 400 e $800 \mathrm{~kg} \mathrm{ha}^{-1} \mathrm{de}$ nitrogênio total. Amostras de solução do solo foram coletadas, através de extratores de cápsulas porosas, a $0,8 \mathrm{~m}$ de profundidade, por um período de 18 meses, iniciando-se 6 meses após a aplicação dos resíduos. No tratamento com $200 \mathrm{~kg} \mathrm{ha}^{-1}$ de $\mathrm{N}$, a solução do solo atingiu picos de concentração de $\mathrm{N}^{-N_{3}}{ }_{3}^{-}$de $30 \mathrm{mg} \mathrm{L}^{-1} 7$ meses após a aplicação do lodo no entanto, com a ocorrência de chuvas tais concentrações abaixaram rapidamente para os níveis da testemunha ou seja, próximo de zero. Para os tratamentos 
com 400 e $800 \mathrm{~kg} \mathrm{ha}^{-1}$ de $\mathrm{N}$, a concentração média de $\mathrm{N}^{-\mathrm{NO}_{3}}{ }^{-}$flutuou em torno de $40 \mathrm{mg} \mathrm{L}^{-1}$ durante um ano após a aplicação do resíduo. A relação entre as doses de

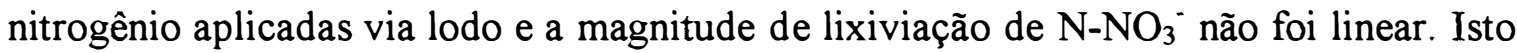
ocorreu principalmente por que não houveram aumentos proporcionais nas concentrações de $\mathrm{N}^{-\mathrm{NO}_{3}}{ }^{-}$presentes nas várias amostragens de solução do solo, a medida que se aumentaram as doses aplicadas de 400 para $800 \mathrm{~kg} \mathrm{ha}^{-1}$ de N. O que ocorreu foi justamente o contrário ou seja, os maiores picos de $\mathrm{N}_{-} \mathrm{NO}_{3}{ }^{-}$, foram observados para os tratamentos com $400 \mathrm{~kg} \mathrm{ha}^{-1}$ de $\mathrm{N}$. Os autores acreditaram que para a maior dose de lodo deve ter ocorrido algum tipo de inibição aos processos de mineralização ou nitrificação, possivelmente devidos a salinidade e a presença em maiores níveis, de substâncias orgânicas tóxicas. Amostras de solo coletadas ao final de dois anos da aplicação do lodo, mostraram para as duas maiores doses, um grande incremento nos teores de $\mathrm{N}-\mathrm{NO}_{3}{ }^{-}$ entre 0,25 e $1,75 \mathrm{~m}$ de profundidade, apresentando picos de concentração (20 a $40 \mathrm{mg} \mathrm{kg}^{-1}$ ) entre 0,75 e 1,10 m. Tendo em vista que as precipitações ocorridas no período de estudo foram abaixo da média (considerando um período de retorno de 30 anos), os autores salientaram que por conseqüência, os padrões de lixiviação ocorridos podem ter sido abaixo do potencial máximo. Eles acreditaram que as baixas precipitações durante o período tenham reduzido a nitrificação potencial em todos os tratamentos, além de ter possibilitado a presença de altos teores de $\mathrm{N}-\mathrm{NO}_{3}^{-}$, particularmente na maior dose de lodo, nas amostras de solução do solo coletadas ao final de dois anos da aplicação do resíduo. Ainda sim, os autores atestaram que doses anuais de até $200 \mathrm{~kg} \mathrm{ha}^{-1}$ de $\mathrm{N}$-lodo de esgoto não devem oferecer riscos de contaminação de águas subsuperficiais.

A densidade populacional de plantas de uma determinada área e a intensidade de absorção de nutrientes, própria de cada espécie vegetal, podem limitar significativamente o movimento de $\mathrm{N}^{-\mathrm{NO}_{3}}{ }^{-}$pelo perfil do solo. Com base nesta hipótese, Medalie et al. (1994) conduziram um experimento a campo, em área de solo areno-siltoso sob floresta, com objetivo de avaliar a lixiviação de nutrientes ocasionada pela disposição de lodo de esgoto aeróbio. As parcelas experimentais constaram de áreas densamente vegetadas (subparcelas A - com atividade de absorção pelas raízes das 
plantas) e áreas mantidas no limpo (subparcelas B - sem interferência nenhuma de raizes) as quais foram tratadas com doses crescentes do resíduo $(0,3,3,6,9$ e 14,5 $\mathrm{Mg} \mathrm{ha}^{-1}$ - base seca) equivalentes a 0, 199, 396 e $740 \mathrm{~kg} \mathrm{ha}^{-1}$ de N-total. Extratores de solução do solo com cápsulas porosas foram instalados em todos tratamentos, a aproximadamente $0,6 \mathrm{~m}$ de profundidade. Nitrato foi o íon dominante nas amostras de solução do solo coletadas nas subparcelas B. Após 3 meses da aplicação do lodo, período de maior ocorrência de chuvas, as concentrações de $\mathrm{N}-\mathrm{NO}_{3}{ }^{-}$na solução do solo aumentaram nitidamente em cada uma das subparcelas B tratadas com o resíduo. Nestas subparcelas, nos tratamentos com 396 e $740 \mathrm{~kg} \mathrm{ha}^{-1}$ de $\mathrm{N}$-total, foram atingidos respectivamente, picos de concentração de 13 e $32 \mathrm{mg} \mathrm{L}^{-1}$ de $\mathrm{N}-\mathrm{NO}_{3}{ }^{-}$, enquanto que na testemunha esses valores não ultrapassaram $3 \mathrm{mg} \mathrm{L}^{-1}$. Diante destes dados, os autores concluíram sobre o potencial de lixiviação do $\mathrm{N}_{-} \mathrm{NO}_{3}{ }^{-}$para o lençol freático, que neste local variava sazonalmente de 1 a $4 \mathrm{~m}$ de profundidade. Por outro lado, para todos os tratamentos das subparcelas A não foram detectadas concentrações de $\mathrm{N}-\mathrm{NO}_{3}{ }^{-}$maiores que $3 \mathrm{mg} \mathrm{L}^{-1}$, fato que provavelmente esteve ligado a intensa absorção de nitrato pela vegetação herbácea e arbórea contidas nestas áreas. De maneira geral, os resultados obtidos para estas subparcelas sugeriram que taxas de aplicação de lodo de esgoto de até $14,5 \mathrm{Mg} \mathrm{ha}^{-1}$ (740 $\mathrm{kg} \mathrm{ha}^{-1}$ de N-total) não apresentariam riscos de contaminação das águas subterrâneas. Segundo os autores isto foi possível devido a uma combinação de efeitos físicos, químicos e biológicos, notadamente a absorção de $\mathrm{NO}_{3}{ }^{-}$pelas plantas. $\mathrm{Em}$ outros experimentos realizados em áreas florestadas, como o de Aschmann et al. (1992), foram observadas maiores perdas de $\mathrm{N}_{-} \mathrm{NO}_{3}^{-}$. Embora este estudo tenha sido realizado em local diferente, o solo, a vegetação típica e as precipitações foram muito semelhantes ao passo que, o lodo de esgoto utilizado apresentou importantes diferenças. Uma comparação entre estes estudos evidenciou que o potencial de perdas de $\mathrm{N}_{-} \mathrm{NO}_{3}{ }^{-}$por lixiviação não só depende do clima, do tipo de solo e vegetação, mas também das características do lodo, principalmente àquelas determinadas pelo processo de tratamento.

Os efeitos do tipo de lodo de esgoto, da época e método de aplicação no solo sobre a lixiviação de nitratos foram destacados no trabalho de Shepherd (1996). Nas 
condições da Inglaterra foram comparados três tipos de lodo de esgoto (líquido crú, líquido digerido e digerido semi desidratado) aplicados em doses equivalentes a $250 \mathrm{~kg} \mathrm{ha}^{-1}$ de $\mathrm{N}$-total, três épocas (setembro, novembro e janeiro) e dois métodos de aplicação (injetado em subsuperficie e espalhamento superficial) num experimento de campo com solo arenoso. Os resultados mostraram que o tipo de lodo teve uma grande

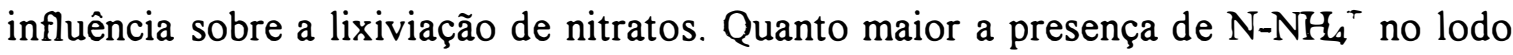
maior foi o potencial de perdas por lixiviação, particularmente devido a rápida nitrificação. Desta forma, as maiores taxas de lixiviação de $\mathrm{N}-\mathrm{NO}_{3}{ }^{-}$foram encontradas para os tratamentos com lodo digerido líquido seguido pelo lodo líquido crú e por último, o lodo digerido semi desidratado. Com relação as épocas de aplicação do resíduo, as maiores perdas foram encontradas para as aplicações de setembro e novembro. Este fato foi diretamente relacionado as maiores temperaturas ocorridas no período o que favoreceram os processos de nitrificação, além disso somou-se as intensas chuvas que ocorrem nesta época e as conseqüentes maiores taxas de drenagem. $\mathrm{O}$ autor salientou que até mesmo o surpreendente desenvolvimento da cevada cultivada na época, não foi suficiente para evitar o caminhamento do nitrato para as camadas subsuperficiais do solo. A aplicação do lodo por injeção em subsuperficie facilitou sobremaneira as perdas por lixiviação, principalmente do lodo digerido líquido. Dois aspectos relacionados a este fato foram bem explorados pelo autor. O primeiro relacionou as maiores perdas por lixiviação devido ao fato do nitrogênio já ter sido aplicado em profundidade e de maneira concentrada em linhas de injeção, o que teria exigido menor volume de drenagem para caminhar no perfil, além de ter sido menos exposto as raízes das plantas, seja pela profundidade como pela localização pontual. Por outro lado, o segundo aspecto estaria relacionado com as menores perdas por volatilização de $\mathrm{NH}_{3}$ ocorridas devidas a este método de aplicação o que foi reforçado pelos fortes indícios, relatados pelo autor, de que ocorreram grandes perdas por volatilização quando o lodo foi aplicado em superficie, principalmente o lodo digerido semi-desidratado. Foi concluído portanto, que nas condições da Inglaterra não há necessidade de se fazer restrições quanto ao tipo de lodo, desde que estes não sejam 
aplicados antes do final de dezembro (fim da temporada de chuvas intensas) e pelo método injeção.

Com objetivos semelhantes aos de Shepherd (1996), Misselbrook et al. (1996) conduziram um experimento em duas localidades da Inglaterra de solos areno-argilosos semelhantes porém, com regime pluviométrico diferenciado. O primeiro local, ora denominado $\mathrm{A}$, apresentou médias anuais de precipitação de $800 \mathrm{~mm}$ enquanto que o segundo, local B, apresentou médias de $1200 \mathrm{~mm}$. A lixiviação de nitrato, medida com extratores de cápsula porosa a $0,9 \mathrm{~m}$ de profundidade, foi comparada nas duas localidades com aplicações de lodo de esgoto crú e lodo anaeróbio líquido, nas épocas de outono (outubro/novembro) e inverno (Dezembro/janeiro), pelos métodos de injeção em subsuperficie e espalhamento superficial. Os experimentos foram conduzidos por dois anos, recebendo aplicações anuais de aproximadamente $300 \mathrm{~kg} \mathrm{ha}^{-1}$ de N-total via lodo de esgoto. Os resultados mostraram que a concentração de $\mathrm{N}_{-} \mathrm{NO}_{3}{ }^{-}$no lixiviado excedeu os limites de potabilidade apenas nos tratamentos do local A, com lodo de esgoto digerido, aplicado por injeção na época de outono, apresentando médias de $12 \mathrm{e}$ $19 \mathrm{mg} \mathrm{L}^{-1}$ respectivamente para o primeiro e segundo ano de avaliações. Os autores explicaram que devido a menor quantidade de chuvas neste local, os lixiviados foram mais concentrados em nitratos. Com relação a época de aplicação do lodo, dentro do local A, a justificativa são as maiores taxas de mineralização do nitrogênio que ocorrem no outono devido as temperaturas mais favoráveis do que as do inverno. Considerando todos experimentos, as perdas de $\mathrm{N}^{-\mathrm{NO}_{3}}{ }^{\circ} \mathrm{em} \mathrm{kg} \mathrm{ha}{ }^{-1}$ chegaram ao máximo de $24,19 \mathrm{e}$ $6 \%$ do aplicado, respectivamente para os tratamentos com lodo anaeróbio líquido injetado no local A, lodo anaeróbio aplicado em superficie no local B e lodo crú aplicado nos dois locais, todos na época do outono justificados pelas maiores taxas de mineralização do nitrogênio orgânico e de chuvas. Ao contrário do que se esperava, as maiores perdas de nitrogênio ocorreram no local A, com menor média anual de precipitações. Os autores mostraram que isto se deu, devido ao maior aproveitamento do nitrogênio aplicado pelas gramíneas plantadas no local $\mathrm{B}$, evidenciando os efeitos da cobertura vegetal no sentido de limitar as perdas de nitrogênio por lixiviação. 
Extratores de solução com cápsula porosa tem sido largamente empregados em avaliações de lixiviação de nitratos em solos tratados com lodo de esgoto ou composto a base de lodo (Sidle \& Kardos, 1979; Aschmann et al., 1992; Medalie et al., 1994; Shepherd, 1996; Misselbrook et al., 1996). Estes equipamentos, conforme descrito por Reichardt et al. (1977), constam essencialmente de uma cápsula porosa fixada à extremidade de um tubo de PVC de 0,5 polegada de diâmetro e comprimento variável de acordo com a profundidade de solo da qual se deseja extrair a solução. Internamente a este PVC encontram-se três tubos de nylon de $3 \mathrm{~mm}$ de diâmetro, um deles partindo da extremidade da cápsula até um recipiente coletor da solução (tubo de ensaio), os demais apenas penetram poucos centímetros no tubo PVC sendo que, um é ligado a uma bomba de vácuo e o outro a uma coluna de mercúrio pela qual se controla a tensão aplicada assim como, se identifica possiveis vazamentos no sistema. A solução do solo é obtida fazendo-se vácuo em todo o sistema. Ainda de acordo com Reichardt et al. (1977), este método de extração da solução do solo é plenamente válido nos estudos da movimentação do íon $\mathrm{NO}_{3}{ }^{-}$, apresentando a grande vantagem de não ser destrutivo, permitindo a verificação das variações da concentração do íon em função do tempo e do espaço. Lord \& Shepherd (1993) acrescentaram que tais extratores além de permitirem quantificar a lixiviação de nitratos em condições reais de campo, são fáceis de usar e possibilitam amostrar a solução sempre no mesmo ponto o que minimiza os efeitos da variabilidade espacial sobre a interpretação dos dados.

Este equipamento foi muito utilizado no Brasil em estudos para a quantificação das perdas de $\mathrm{N}^{-\mathrm{NO}_{3}}{ }^{-}$decorrentes da fertilização mineral de culturas como feijão e milho (Libardi \& Reichardt, 1978; Reichardt et al., 1979; Meirelles et al., 1980; Bassoi \& Carvalho, 1992; Bassoi \& Reichardt, 1995). Os resultados obtidos nesses trabalhos de maneira geral, variaram de acordo com a cultura, com a quantidade de nitrogênio utilizada na adubação e principalmente com o volume de água drenada pelo perfil do solo, sugerindo uma estreita relação entre o movimento da água e do $\mathrm{N}-\mathrm{NO}_{3}$. As quantidades de $\mathrm{N}^{-\mathrm{NO}_{3}}{ }^{-}$perdidas para profundidades maiores do que $1,0 \mathrm{~m}$ variaram de 0,4 a $7,0 \mathrm{~kg} \mathrm{ha}^{-1}$ em prazos de 3 a 12 meses de estudo. 


\section{MATERIAL E MÉTODOS}

\subsection{Caracterização da área experimental}

O presente experimento foi conduzido nos anos agrícolas 1996/97 e 1997/98, em condições de campo, numa área plana de Latossolo Vermelho-Amarelo selecionada no setor mais elevado da paisagem da Estação Experimental do Instituto Agronômico de Campinas, em Piracicaba, SP. A localização geográfica da Estação é $22^{\circ} 41^{\prime} 00^{\prime \prime}$ de latitude sul e $47^{\circ} 39^{\prime} 00^{\prime \prime}$ de longitude oeste, com altitude de $554 \mathrm{~m}$ acima do nível do mar e relevo suave ondulado. O clima, de acordo com a classificação de Köppen, é do tipo Cwa: subtropical com inverno seco, apresentando temperatura média do mês mais frio inferior a $18^{\circ} \mathrm{C}$ e do mês mais quente superior a $22^{\circ} \mathrm{C}$ (Setzer, 1966). Os parâmetros climáticos apresentam as seguintes médias anuais: a) precipitação: $1253 \mathrm{~mm}$; b) temperatura: $21,1^{\circ} \mathrm{C}$; c) umidade relativa do ar: $74 \%$; d) velocidade do vento: $2,2 \mathrm{~m} \mathrm{~s}^{-1}$. $\mathrm{Na}$ Tabela 2 são apresentadas as principais características químicas e físicas do solo da área experimental.

Tabela 2. Principais características químicas e físicas do Latossolo Vermelho-Amarelo.

\begin{tabular}{|c|c|c|c|c|c|c|c|c|c|c|c|c|}
\hline $\begin{array}{l}\text { Prof. } \\
(\mathrm{m})\end{array}$ & $\begin{array}{c}\mathrm{pH} \\
\left(\mathrm{CaCl}_{2}\right)\end{array}$ & $\begin{array}{l}\text { C-org } \\
\mathrm{g} \mathrm{kg}^{-1}\end{array}$ & $\begin{array}{c}\mathrm{P} \\
\mathrm{mg} \mathrm{dm} \\
\end{array}$ & $\mathrm{K}$ & $\mathrm{Ca}$ & $\mathrm{Mg}$ & $\begin{array}{r}\mathrm{H}+\mathrm{A} \\
\mathrm{mmol}_{\mathrm{c}}\end{array}$ & $\mathrm{dm}^{-3}$ & $\mathrm{Al}$ & SB & $\mathrm{T}$ & $\begin{array}{l}\mathrm{V} \\
\%\end{array}$ \\
\hline $0-0,20$ & 4,1 & 9,29 & 3 & 0,3 & 11 & 5 & 47 & & 10 & 16,3 & 63,3 & 27,7 \\
\hline $0,20-0,40$ & 4,1 & 8,13 & 2 & $0 ; 3$ & 14 & 5 & 47 & & 10 & 19,3 & 66,3 & 29,1 \\
\hline $0,40-0,60$ & 4,1 & 6,38 & 1 & 0,1 & 11 & 3 & 47 & & 12 & 14,1 & 61,1 & 23,1 \\
\hline $\begin{array}{l}\text { Prof: } \\
\text { (m) }\end{array}$ & $\mathrm{Al}_{2} \mathrm{O}_{3}$ & $\begin{aligned} & \mathrm{Fe}_{2} \mathrm{O}_{3} \\
= & \mathrm{g} \mathrm{kg}^{-1}\end{aligned}$ & $\mathrm{SiO}_{2}$ & \multicolumn{2}{|c|}{ Areia grossa } & \multicolumn{2}{|c|}{$\begin{array}{l}\text { Areia fina } \\
-\mathrm{g} \mathrm{kg}^{-1}\end{array}$} & Silte & & Argila & \multicolumn{2}{|c|}{$\begin{array}{c}\text { Densidade } \\
\mathrm{kg} \mathrm{m}^{-3}\end{array}$} \\
\hline $0-0,20$ & 108 & 71,5 & 121 & 1 & & 329 & & 141 & & 335 & & 1316 \\
\hline $0,20-0,40$ & 144 & 85,8 & 148 & 1 & & 248 & & 116 & & 442 & & 1292 \\
\hline $0,40-0,60$ & 150 & 88,7 & 155 & 2 & & 218 & & 90 & & 481 & & 1277 \\
\hline
\end{tabular}

$2 \mathrm{~mm} \geq$ Areia grossa $>0,5 \mathrm{~mm} \geq$ Areia fina $>0,05 \mathrm{~mm} \geq$ Silte $>0,002 \mathrm{~mm} \geq$ Argila; 


\subsection{Caracterização dos resíduos}

Foram utilizadas duas remessas (1 $1^{a}$ aplicação-1996/97 e $2^{2}$ aplicação-1997/98) de dois diferentes resíduos de origem urbana: lodo de esgoto e composto de lixo. O lodo de esgoto, resultante de digestão anaeróbia, foi obtido junto a Estação de Tratamento de Esgotos de Barueri - SABESP, Barueri, SP e o composto de lixo junto a Usina de Tratamento de Lixo da Cidade de São Jorge - Prefeitura Municipal de Santo André, Santo André, SP. Ambos resíduos tiveram sua composição química parcial determinada no laboratório de Química Ambiental do Departamento de Ciências Exatas da ESALQ/USP. Os resultados obtidos para as duas remessas dos resíduos são apresentados na Tabela 3.

Tabela 3. Composição química parcial das duas remessas de lodo de esgoto e composto de lixo utilizadas no experimento ${ }^{(1)}$.

\begin{tabular}{|c|c|c|c|c|c|}
\hline \multicolumn{2}{|c|}{ Atributos analisados } & \multicolumn{2}{|c|}{ Lodo de esgoto } & \multicolumn{2}{|c|}{ Composto de lixo } \\
\hline & & 1996 & 1997 & 1996 & 1997 \\
\hline Umidade & $\left(\mathrm{g} \mathrm{kg}^{-1}\right)$ & 668,90 & 633,84 & 485,39 & 497,48 \\
\hline $\mathrm{pH}\left(\mathrm{H}_{2} \mathrm{O}, 1: 2,5\right)$ & & 12,25 & 8,50 & 4,77 & 8,00 \\
\hline Poder de neutralização & ( $\% \mathrm{CaCO}_{3}$ eq. $)$ & 40,36 & 31,44 & n.r. & 1,66 \\
\hline Carbono orgânico & $\left(\mathrm{g} \mathrm{kg}^{-1}\right)$ & 207,88 & 184,85 & 341,99 & 281,63 \\
\hline Matéria orgânica & $\left(\mathrm{g} \mathrm{kg}^{-1}\right)$ & 368,92 & 331,85 & 637,80 & 600,99 \\
\hline N-total & $\left(\mathrm{g} \mathrm{kg}^{-1}\right)$ & 25,58 & 21,71 & 10,12 & 12,71 \\
\hline $\mathrm{N}-\mathrm{NH}_{4}^{+}+\mathrm{N}-\mathrm{NO}_{3}^{-}$ & $\left(\mathrm{g} \mathrm{kg}^{-1}\right)$ & 3,19 & 2,60 & 1,15 & 2,53 \\
\hline Relação C/N-total & & 8,13 & 8,51 & 33,79 & 22,15 \\
\hline CTC a pH 7,0 & $\left(\mathrm{mmol}_{\mathrm{c}} \mathrm{kg}^{-1}\right)$ & 436,55 & 375,25 & 147,96 & 228,78 \\
\hline P-total & $\left(\mathrm{g} \mathrm{kg}^{-1}\right)$ & 11,20 & 11,16 & 1,63 & 4,46 \\
\hline K-total & $\left(\mathrm{g} \mathrm{kg}^{-1}\right)$ & 1,06 & 0,97 & 5,28 & 4,90 \\
\hline Ca-total & $\left(\mathrm{g} \mathrm{kg}^{-1}\right)$ & 170,31 & 132,10 & 21,26 & 18,40 \\
\hline Mg-total & $\left(\mathrm{g} \mathrm{kg}^{-1}\right)$ & 10,63 & 2,70 & 2,66 & 1,60 \\
\hline S-total & $\left(\mathrm{g} \mathrm{kg}^{-1}\right)$ & 8,49 & 10,77 & 3,01 & 3,78 \\
\hline Na-total & $\left(\mathrm{g} \mathrm{kg}^{-1}\right)$ & 0,76 & 0,71 & 5,46 & 5,20 \\
\hline Cd-total & $\left(\mathrm{mg} \mathrm{kg}^{-1}\right)$ & 28,4 & 16,0 & n.d. & n.d. \\
\hline Cr-total & $\left(\mathrm{mg} \mathrm{kg}^{-1}\right)$ & 385,0 & 386,0 & 41,4 & 81,0 \\
\hline Cu-total & $\left(\mathrm{mg} \mathrm{kg}^{-1}\right)$ & 784,3 & 534,0 & 222,7 & 403,0 \\
\hline Ni-total & $\left(\mathrm{mg} \mathrm{kg}^{-1}\right)$ & 238,6 & 286,0 & 26,2 & 34,0 \\
\hline Pb-total & $\left(\mathrm{mg} \mathrm{kg}^{-1}\right)$ & 152,8 & 171,0 & 91,6 & 196,0 \\
\hline Zn-total & $\left(\mathrm{mg} \mathrm{kg}^{-1}\right)$ & 1568,5 & 1649,0 & 386,9 & 496,0 \\
\hline
\end{tabular}

\footnotetext{
(n) Resultados para umidade e pH expressos com base no material original e os demais são expressos com base no material seco a $65^{\circ} \mathrm{C}$; n.r.: análise não realizada: n.d.: não detectado, valores abaixo do limite de determinação do método analítico empregado $\left(<9 \mathrm{mg} \mathrm{kg}^{-1}\right.$ na amostra).
} 
Para caracterização química parcial dos resíduos foram utilizados diversos métodos. Nas determinações de umidade, matéria orgânica e nitrogênio total foram empregados os métodos oficiais para fertilizantes orgânicos e nas determinações do poder de neutralização foi empregado o método oficial para calcários e corretivos (Brasil, 1988). As determinações dos teores de carbono orgânico basearam-se na oxidação do mesmo por dicromato de potássio por via úmida, na presença de ácido sulfúrico e com aquecimento externo (Rodella, 1996). Os teores de nitrogênio inorgânico $\left(\mathrm{N}-\mathrm{NO}_{3}{ }^{-}+\mathrm{N}-\mathrm{NH}_{4}{ }^{+}\right)$foram determinados através de extração prévia com solução $0,02 \mathrm{~mol} \mathrm{~L}^{-1}$ de ácido tricloroacético (relação resíduo:solução de 1:100) seguido por destilação do filtrado em meio alcalino. Cabe ressaltar que o ácido tricloroacético tem a função de precipitar as formas protéicas de nitrogênio, eliminando por conseguinte a interferência dessas formas no resultado final. A CTC dos resíduos foi determinada através da saturação das amostras com solução de $\mathrm{HCl}$, seguida do deslocamento do $\mathrm{H}^{+}$ adsorvido pelo ín $\mathrm{Ca}^{2+}$ fornecido por solução de acetato de cálcio a $\mathrm{pH} 7,0$, conforme metodologia descrita em Williams (1984), modificado por Rodella \& Alcarde (1994). Os teores totais de fósforo, potássio, cálcio, magnésio, enxofre, sódio e metais pesados foram determinados em extratos nítrico-perclórico de amostras secas e moídas. $O$ fósforo foi determinado pelo método espectrofotométrico do ácido molibdovanadofosfórico. O potássio e o sódio foram determinados por fotometria de chama de emissão. $\mathrm{O}$ enxofre foi precipitado com adição de $\mathrm{BaCl}_{2}$ e determinado por método gravimétrico. Cálcio, magnésio e os metais pesados foram determinados por espectrometria de absorção atômica com chama convencional ar/acetileno.

\subsection{Cultura}

Foi empregada, como planta-teste, a cana-de-açúcar (Saccharum officinarum) variedade RB-78-5148, cultivada em ciclo anual como "cana-planta" no ano agrícola 1996/97 e como $1^{\underline{a}}$ soqueira no ano agrícola 1997/98. Na escolha desta cultura consideraram-se os seguintes fatores: a) não está necessariamente destinada a alimentação direta, podendo ser utilizada para fins energéticos, evitando-se assim, a entrada na cadeia alimentar de metais pesados que porventura sejam absorvidos pelas 
plantas; b) apresenta alto interesse econômico pelo seu grande aproveitamento; c) ocupa extensas áreas no Estado de São Paulo com relativa proximidade a grandes centros urbanos potencialmente produtores de lodo de esgoto e composto de lixo.

\subsection{Delineamento experimental e tratamentos}

O experimento foi conduzido num delineamento em blocos casualizados, com quatro repetições e 9 tratamentos:

1. Calagem + Adubação Mineral

2. Testemunha (lodo de esgoto)

6. Testemunha (composto de lixo)

3. Lodo de esgoto dose A

7. Composto de lixo dose A

4. Lodo de esgoto dose B

8. Composto de lixo dose B

5. Lodo de esgoto dose $\mathrm{C}$

9. Composto de lixo dose $\mathrm{C}$

O tratamento 1 , constituído por calagem e adubação mineral, foi estabelecido de acordo com as recomendações técnicas para a cultura da cana-de-açúcar apresentadas na $2^{\underline{a}}$ edição do Boletim Técnico nº 100 do IAC (Spironello et al. 1996).

As doses $\mathrm{A}, \mathrm{B}$ e $\mathrm{C}$ de ambos os resíduos foram definidas com base nos resultados da composição química parcial dos mesmos. Para o lodo de esgoto o critério adotado no estabelecimento dessas doses foi função da quantidade máxima de metais pesados possível de ser adicionada anualmente em solos agrícolas, conforme os parâmetros preconizados pela norma 40 CFR (Code of Federal Regulations) Part 503 da USEPA - United States Environmental Protection Agency (1993). Com base neste critério foi estabelecida a dose anual máxima (dose B). Objetivando-se um maior contraste entre doses e a verificação da pertinência do critério adotado em condições tropicais, estabeleceram-se as doses $\mathrm{A}$ e $\mathrm{C}$, sendo a primeira a metade e a segunda 1,5 vezes a dose B. Assim, na primeira aplicação de lodo de esgoto (ano agrícola 1996/97) verificou-se que o metal pesado cádmio limitou a dose máxima em $202,1 \mathrm{Mg}^{\text {ha }}{ }^{-1}$ (material original). Por se tratar de um experimento de campo e principalmente devido as dificuldades na manipulação do lodo de esgoto, considerou-se impraticável a aplicação desta dose com o devido grau de exatidão, optando-se pelo valor inteiro e 
próximo de $200 \mathrm{Mg} \mathrm{ha}^{-1}$. Portanto, as doses de lodo de esgoto para a primeira aplicação ficaram estabelecidas nos seguintes valores expressos com base no material original: dose $\mathrm{A}=100 \mathrm{Mg} \mathrm{ha}^{-1}$; dose $\mathrm{B}=200 \mathrm{Mg} \mathrm{ha}^{-1}$ e dose $\mathrm{C}=300 \mathrm{Mg} \mathrm{ha}^{-1}$ (respectivamente 33, 66 e $99 \mathrm{Mg} \mathrm{ha}^{-1}$ expressos com base no lodo seco). Por ocasião da segunda aplicação (ano agrícola 1997/98) e considerando-se os mesmos critérios da aplicação anterior, o elemento níquel limitou a dose máxima em 200,6 $\mathrm{Mg} \mathrm{ha}^{-1}$ (material original) e pelas mesmas razões da aplicação anterior, tal dose foi estabelecida em $200 \mathrm{Mg} \mathrm{ha}^{-1}$. Dessa forma, as doses de lodo de esgoto para a segunda aplicação ficaram estabelecidas nos seguintes valores expressos com base no material original: dose $\mathrm{A}=100 \mathrm{Mg} \mathrm{ha}^{-1}$; dose $\mathrm{B}=200 \mathrm{Mg} \mathrm{ha}^{-1}$ e dose $\mathrm{C}=300 \mathrm{Mg} \mathrm{ha}^{-1}$ (respectivamente, 37,74 e $110 \mathrm{Mg} \mathrm{ha}^{-1}$ expressos com base no lodo seco).

Com relação aos tratamentos com composto de lixo, estava previsto inicialmente a adoção do mesmo critério utilizado para a definição das doses de lodo de esgoto. No entanto, os metais pesados considerados neste estudo se apresentaram em concentrações muito menores no composto de lixo do que àquelas encontradas no lodo de esgoto (Tabela 3) o que resultaria em doses elevadíssimas e operacionalmente inviáveis de serem transportadas e aplicadas ao solo. Optou-se portanto, em adotar o conteúdo de carbono orgânico aplicado ao solo via lodo como parâmetro de referência para o estabelecimento das doses de composto de lixo. Este critério possibilitou que Marciano (1999) comparasse as alterações ocasionadas pelos dois resíduos sobre as propriedades físico-hídricas do Latossolo Vermelho-Amarelo, tendo em vista que o carbono orgânico é reconhecidamente o principal responsável por tais alterações.

Na primeira aplicação, as doses de composto de lixo ficaram estabelecidas nos seguintes valores expressos com base no material original: dose $\mathrm{A}=39 \mathrm{Mg} \mathrm{ha}^{-1}$; dose $\mathrm{B}=78 \mathrm{Mg} \mathrm{ha}^{-1}$ e dose $\mathrm{C}=117 \mathrm{Mg} \mathrm{ha}^{-1}$ (respectivamente 20, 40 e $60 \mathrm{Mg} \mathrm{ha}^{-1}$ expressos com base no composto seco). A segunda aplicação seguiu os mesmos critérios da primeira ficando as doses estabelecidas nos seguintes valores expressos com base no material original: dose $\mathrm{A}=48 \mathrm{Mg} \mathrm{ha}^{-1}$; dose $\mathrm{B}=96 \mathrm{Mg} \mathrm{ha}^{-1}$; dose $\mathrm{C}=144 \mathrm{Mg} \mathrm{ha}^{-1}$ (respectivamente 24,48 e $72 \mathrm{Mg} \mathrm{ha}^{-1}$ expressos com base no composto seco). 
As doses dos resíduos empregadas para cada tratamento nos dois anos experimentais bem como, as doses equivalentes em carbono orgânico, nitrogênio total e nitrogênio inorgânico $\left(\mathrm{N}-\mathrm{NO}_{3}{ }^{-}+\mathrm{N}-\mathrm{NH}_{4}{ }^{+}\right)$são apresentadas na Tabela 4.

Tabela 4. Doses dos resíduos empregadas em cada tratamento, dentro de cada ano experimental, e seus valores equivalentes em carbono orgânico, nitrogênio total e nitrogênio inorgânico $\left(\mathrm{N}-\mathrm{NO}_{3}{ }^{-}+\mathrm{N}_{-} \mathrm{NH}_{4}{ }^{+}\right)^{(1)}$.

\begin{tabular}{|c|c|c|c|c|c|c|c|c|}
\hline \multirow{3}{*}{ Tratamentos } & \multicolumn{2}{|c|}{ Resíduos } & \multicolumn{2}{|c|}{ C - orgânico } & \multicolumn{2}{|c|}{$\mathrm{N}-$ total } & \multicolumn{2}{|c|}{$\mathrm{N}-\mathrm{NO}_{3}{ }^{-}+\mathrm{N}-\mathrm{NH}_{4}{ }^{+}$} \\
\hline & 1996 & 1997 & 1996 & 1997 & 1996 & 1997 & 1996 & 1997 \\
\hline & \multicolumn{2}{|c|}{$--\mathrm{Mg} \mathrm{ha}^{-1}-\cdots$} & \multicolumn{2}{|c|}{$\cdots \mathrm{Mg} \mathrm{ha}^{-1}-\cdots$} & \multicolumn{4}{|c|}{ - $\mathrm{kg} \mathrm{ha}^{-1} \ldots \ldots$} \\
\hline 1. Ad. Mineral ${ }^{*}$ & 0 & 0 & 0 & 0 & $70^{* *}$ & $120^{* * *}$ & 70 & 120 \\
\hline 2. Testemunha & 0 & 0 & 0 & 0 & 0 & 0 & 0 & 0 \\
\hline 3. Lodo d. A & 33 & 37 & 6,8 & 6,8 & 844 & 803 & 105 & 96 \\
\hline 4. Lodo d. B & 66 & 74 & 13,7 & 13,6 & 1688 & 1607 & 211 & 192 \\
\hline 5. Lodo d. C & 99 & 110 & 20,6 & 20,4 & 2532 & 2388 & 316 & 286 \\
\hline 6. Testemunha & 0 & 0 & 0 & 0 & 0 & 0 & 0 & 0 \\
\hline 7. Composto d. A & 20 & 24 & 6,8 & 6,8 & 202 & 305 & 23 & 61 \\
\hline 8. Composto d. B & 40 & 48 & 13,7 & 13,6 & 405 & 610 & 46 & 121 \\
\hline 9. Composto d. C & 60 & 72 & 20,5 & 20,4 & 607 & 915 & 69 & 182 \\
\hline
\end{tabular}

(i) Doses expressas com base nos resíduos secos;

* Adubação nitrogenada (plantio + cobertura) realizada com uréia:

** Adubação nitrogenada total (plantio + cobertura) na cana-planta;

*** Adubação nitrogenada total em cobertura na $1^{\mathrm{a}}$ soqueira.

\subsection{Instalação e condução do experimento}

Seguindo-se a definição dos tratamentos iniciou-se o preparo da área para instalação do experimento. Tal preparo constou inicialmente de sub-solagem para rompimento de uma camada compactada localizada entre 0,20 e $0,30 \mathrm{~m}$ de profundidade. Após isto, operações de aração e gradagem de nivelamento foram realizadas. Na sequência, foram demarcadas as parcelas com $10 \mathrm{~m}$ de largura e $10 \mathrm{~m}$ de comprimento onde, no momento oportuno, foram plantadas 7 linhas de cana-de-açúcar espaçadas de 1,4 m. Dessa forma, a área total de cada parcela foi de $100 \mathrm{~m}^{2}$, sendo as estações para amostragens os $25,2 \mathrm{~m}^{2}$ centrais $(6,0 \times 4,2 \mathrm{~m})$. Na Figura 2 é apresentado um croqui da área experimental. 


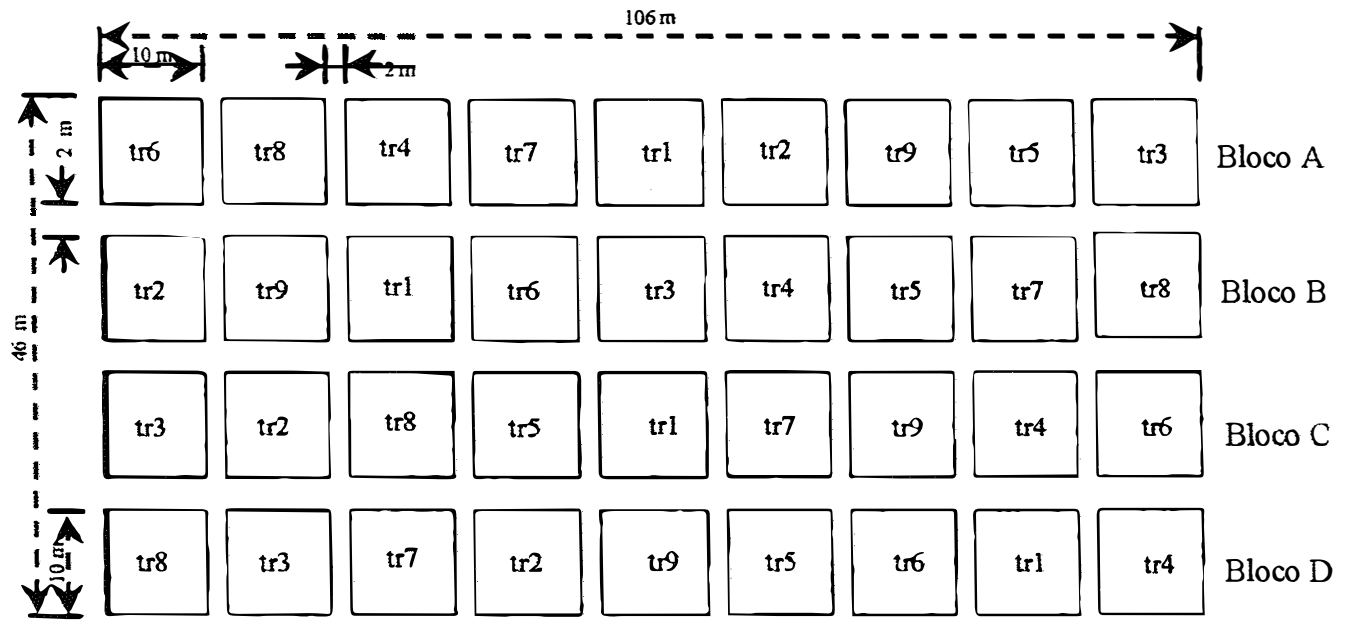

Figura 2. Croqui da área experimental.

No primeiro ano de experimentação, os resíduos foram aplicados superficialmente em área total e em pré-plantio, com distribuição manual dentro das parcelas e incorporação ao solo na camada de $0-0,2 \mathrm{~m}$ através da utilização de enxada rotativa. As doses equivalentes aos respectivos tratamentos foram quantificadas com auxílio de tambores com capacidade de $100 \mathrm{~L}$, os quais eram cheios com os resíduos e pesados no próprio local. Em seguida eram despejados numa carreta basculante tracionada por trator e transportados até as parcelas experimentais. Convém salientar que a aplicação do lodo de esgoto foi realizada com alguns dias de antecedência à aplicação do composto de lixo. Esta operação se fez necessária diante da impossibilidade da incorporação imediata do lodo de esgoto o que por sua vez, tornou imprescindível um período de pré-secagem após sua distribuição na área. Após tal período foram aplicadas as doses equivalentes de composto de lixo nos tratamentos correspondentes e realizada a calagem nas parcelas do tratamento 1. Finalizando estas operações, na sequência foi realizada a incorporação dos resíduos e do calcário em toda área experimental, obtendose um ótimo grau de homogeneização e uniformidade. Detalhes sobre o transporte, aplicação, distribuição manual, qualidade de distribuição e incorporação dos resíduos nas parcelas podem ser observados nas Figuras 3, 4 e 5. 

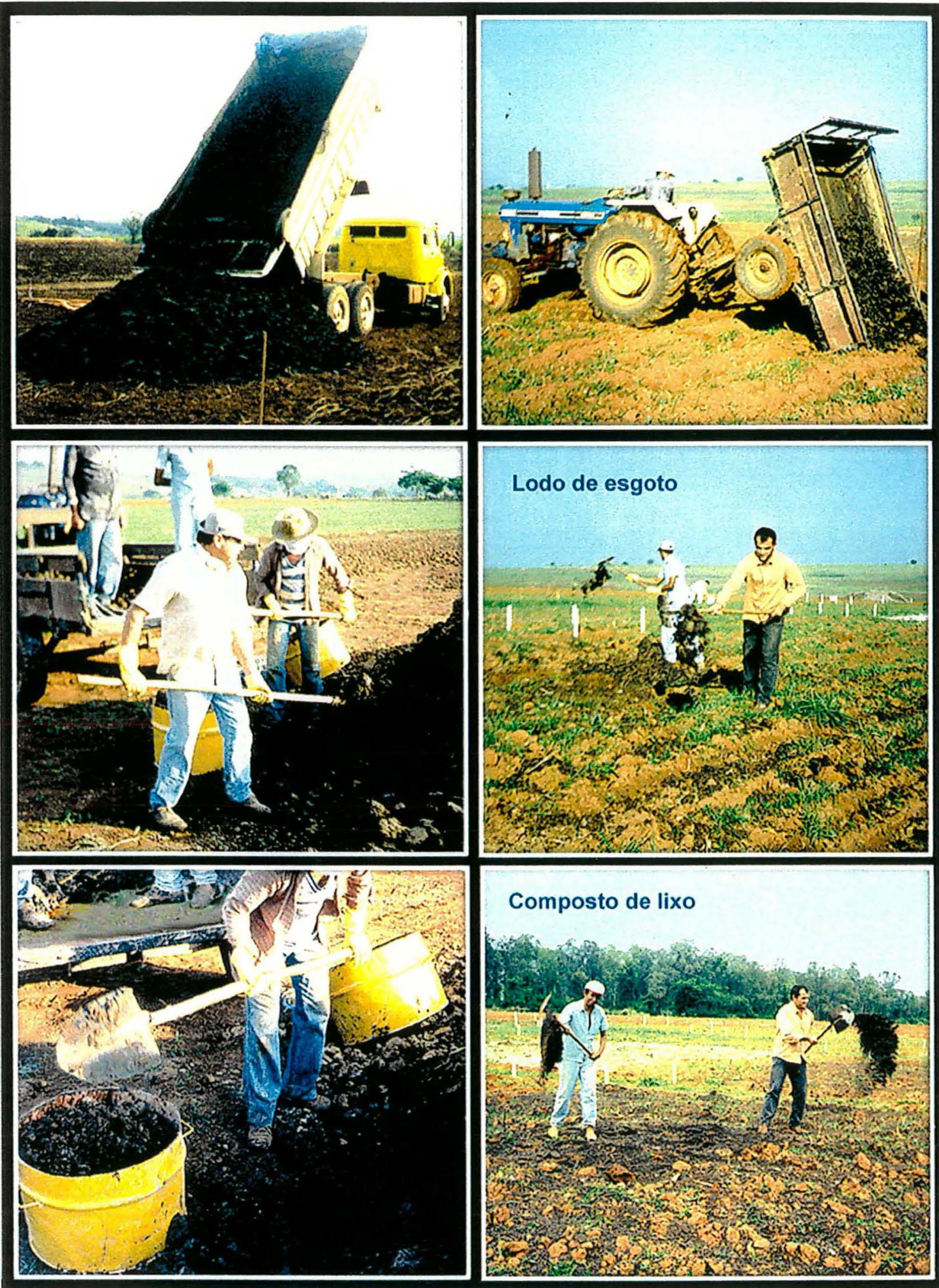

Composto de lixo

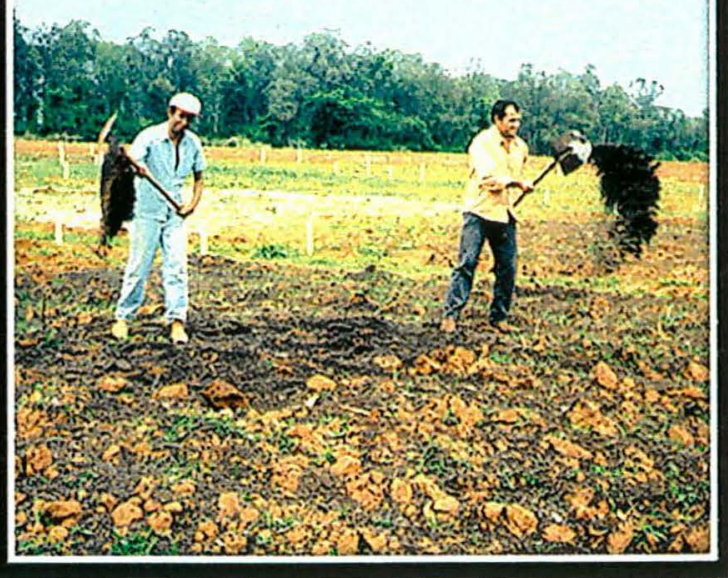

Figura 3. Transporte, aplicação e distribuição manual dos resíduos nas parcelas experimentais, no ano agrícola 1996/97. 

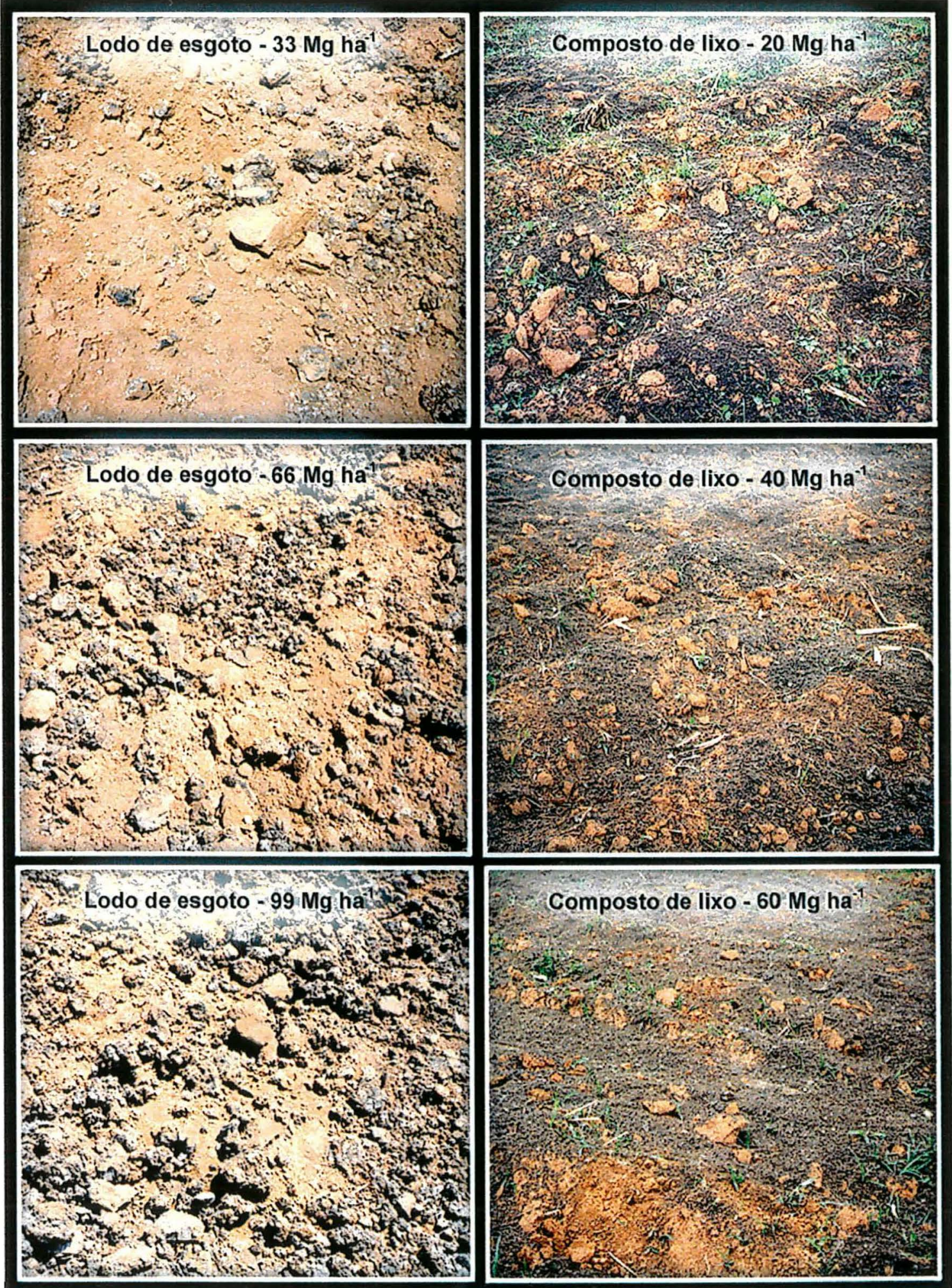

Figura 4. Qualidade da distribuição dos resíduos nas parcelas experimentais no ano agrícola 1996/97. 


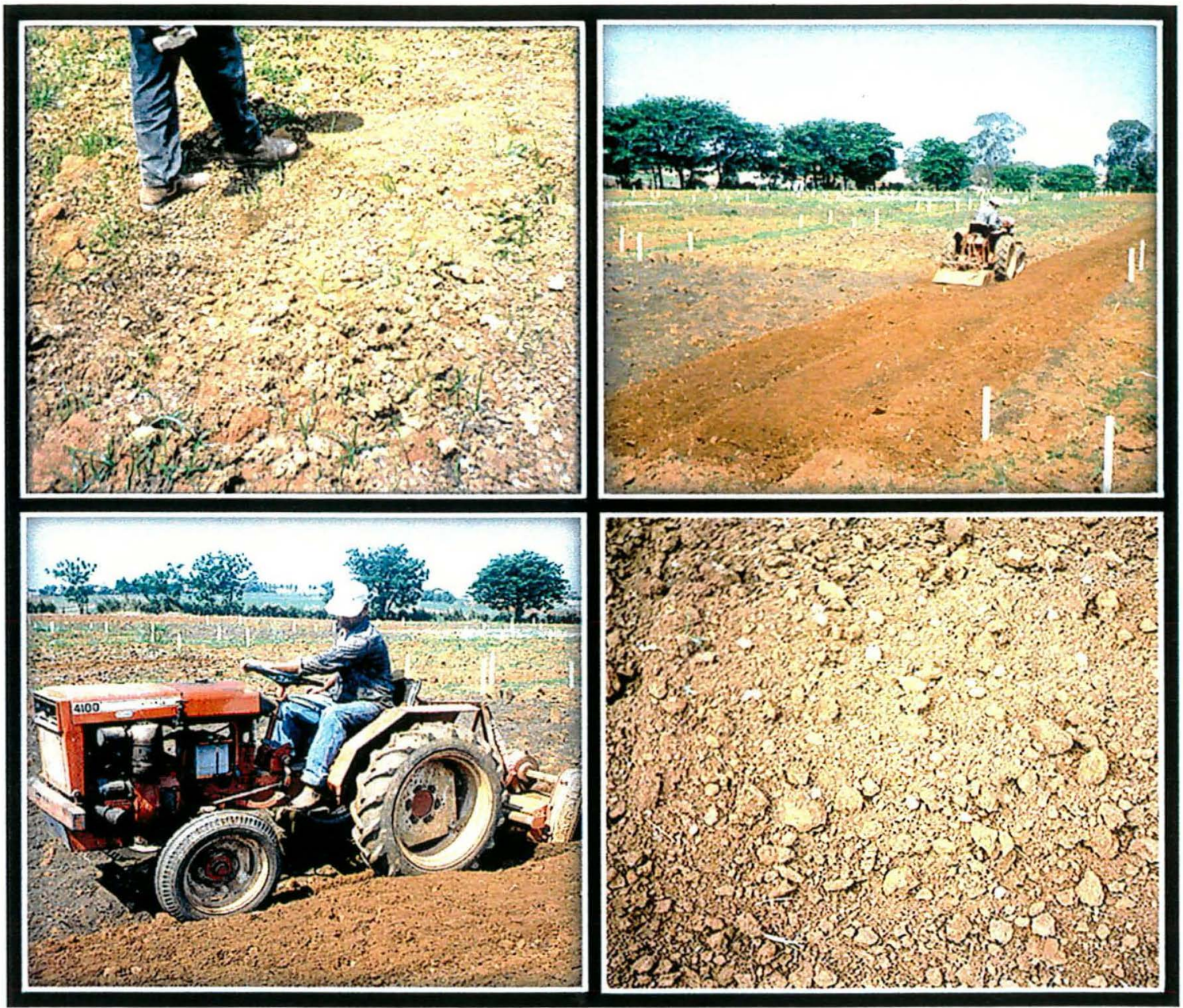

Figura 5. Aspecto do lodo de esgoto após período de pré-secagem, sistema de incorporação dos resíduos e homogeneidade da incorporação no ano agrícola 1996/97.

O plantio da cana-de-açúcar foi realizado após um período de incubação dos tratamentos de aproximadamente 60 dias. No decorrer de todo período experimental foram realizados os tratos culturais necessários: aplicação de herbicidas e cultivo manual ou mecânico em todas as parcelas e adubação de cobertura nas parcelas do tratamento 1 .

No segundo ano de experimentação foram adotados, basicamente, os mesmos procedimentos do primeiro. Os resíduos foram aplicados superficialmente em área total sobre a $1^{\underline{a}}$ soqueira, com distribuição manual dentro das parcelas e incorporação ao solo, nas entre-linhas de plantio, na camada de $0-0,2 \mathrm{~m}$, com a utilização da enxada rotativa. 
Foram instalados na área experimental tensiômetros e extratores de solução do solo, procedimentos e objetivos que são descritos com detalhes no ítem 3.5.1.

Amostragens de solo, plantas e solução do solo, realizadas no período experimental, são detalhadas respectivamente nos ítens 3.5.2, 3.5.3 e 3.5.4.

\subsubsection{Instalação dos tensiômetros e extratores de solução do solo}

Após a segunda aplicação dos resíduos, foram instaladas na área experimental nove baterias de quatro tensiômetros, uma em cada parcela do Bloco $\mathrm{D}$, nas profundidades de $0,20,0,45,0,75$ e $0,95 \mathrm{~m}$ a $0,40 \mathrm{~m}$ da linha central das parcelas. Leituras em dias alternados das colunas de $\mathrm{Hg}$ dos tensiômetros serviram como ferramenta indispensável no fornecimento de dados para os cálculos de armazenagem de água no perfil do solo.

$\mathrm{Na}$ sequência, após a incorporação dos resíduos, foram instaladas 36 baterias de três unidades extratoras de solução do solo, uma por parcela experimental, a $0,40 \mathrm{~m}$ da linha central e nas profundidades de 0,3,0,6 e 0,9 m. A unidade extratora de solução do solo é essencialmente a mesma descrita por Reichardt et al. (1977), exceto pela presença de uma coluna de $\mathrm{Hg}$ pela qual se controla a tensão aplicada e se identifica possiveis vazamentos no sistema.

O procedimento de instalação dos tensiômetros e dos extratores de solução foi o mesmo. Consistiu basicamente, na abertura de orificio no solo de diâmetro milimetricamente maior do que aquele do equipamento uma vez que, sua cápsula porosa deve estar em íntimo contato com o solo. Para tanto, utilizou-se de um trado especial e um bastão de aço que teve por finalidade acertar as saliências da parede interna do orifício. Também foram colocados discos de borracha nos extratores, junto a superfície do solo, com objetivo de impedir o caminhamento preferencial da água pela parede externa dos mesmos. O procedimento foi demorado e exigiu muito cuidado devido a fragilidade das peças. Uma observação geral dos equipamentos instalados no campo pode ser feita na Figura 6. 


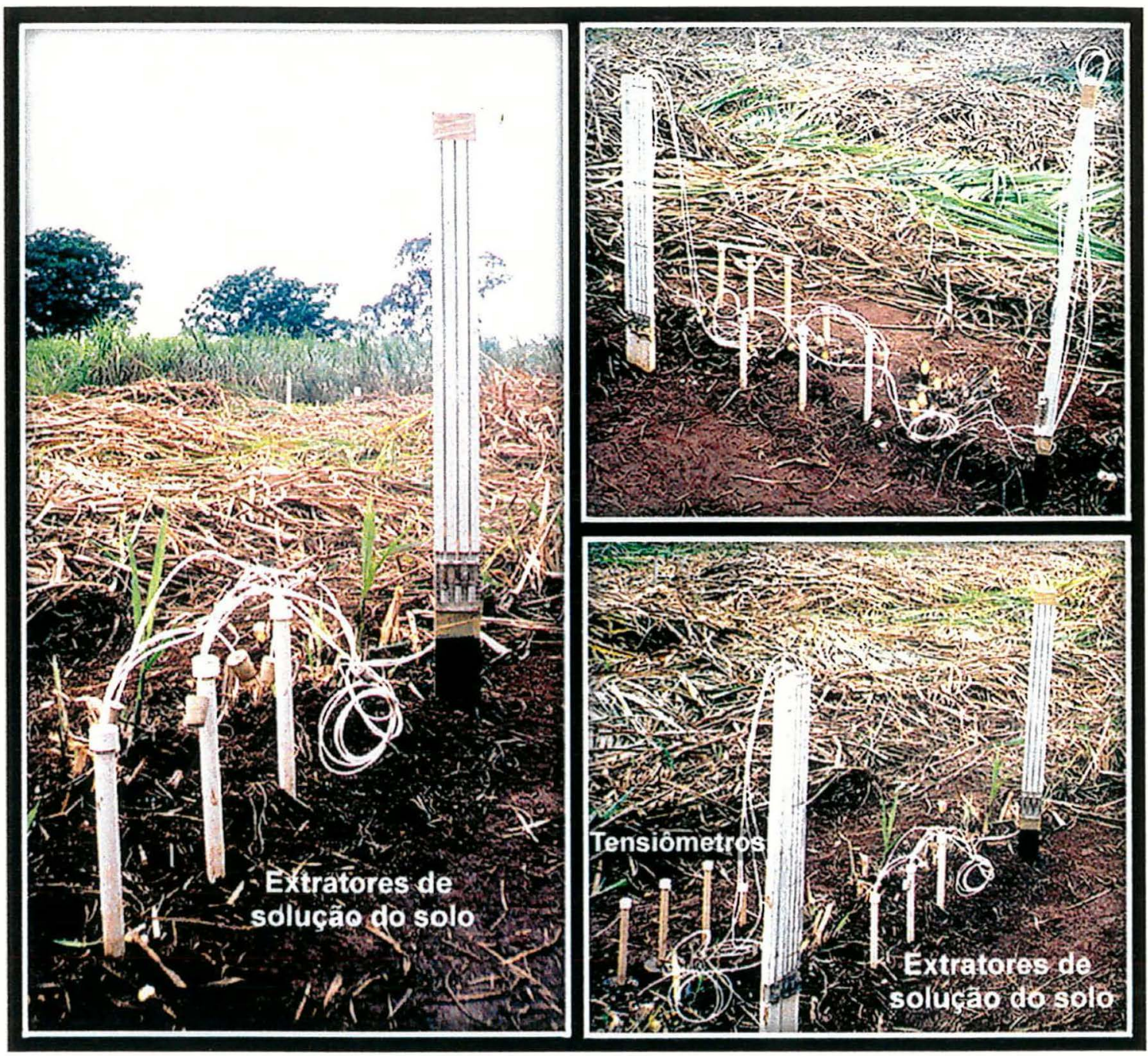

Figura 6. Aspecto geral dos extratores de solução do solo e tensiômetros instalados na área experimental no ano agrícola 1997/98.

\subsubsection{Coleta e preparo das amostras de solo}

Diversas coletas de amostras de solo foram realizadas durante o período experimental. As amostras representativas das parcelas experimentais, coletadas na camada superficial de $0-0,2 \mathrm{~m}$, foram compostas por 5 amostras simples retiradas nas entre-linhas da cultura, dentro das estações de amostragens $\left(25,2 \mathrm{~m}^{2}\right.$ centrais das parcelas). Àquelas coletadas em outras profundidades seguiram o mesmo procedimento, com a diferença de que foram representadas pela composição de 3 amostras simples. 
$\mathrm{Na}$ camada superficial do solo $(0-0,2 \mathrm{~m})$ foram coletadas amostras aos 0,30 , $60,90,150,210,270$ e 360 dias após a incorporação de cada uma das aplicações dos resíduos. Aos 360 dias após a incorporação dos resíduos, nos dois anos de experimentação, também foram coletadas amostras representativas das camadas de $0,2-0,4,0,4-0,6$ e $0,6-0,8 \mathrm{~m}$.

Essas amostras foram secas em estufa de circulação forçada de ar a $60^{\circ} \mathrm{C}$, destorroadas e passadas por peneira $A B N T n^{\circ} 16$ (1,19 mm de malha) com objetivo principal de eliminar, ao máximo, a presença de pequenas raízes.

Amostras diferenciadas foram coletadas aos 380 dias após a incorporação dos resíduos da primeira aplicação (ano agricola 1996/97) e aos 400 dias após a incorporação dos resíduos da segunda aplicação (ano agrícola 1997/98). No primeiro caso as amostras foram coletadas nas camadas de $0-0,3,0,3-0,6,0,6-0,9 \mathrm{~m}$ e no segundo, nas camadas de $0-0,3,0,3-0,6,0,6-0,9$ e $0,9-1,2 \mathrm{~m}$. Tais amostras foram congeladas para serem analisadas oportunamente.

\subsubsection{Coleta e preparo das amostras de plantas}

Ao final de cada ano agrícola, por ocasião da colheita das plantas de cana-de-açúcar, foram realizadas amostragens de folhas, colmos e caldo das plantas. Após o corte das plantas da bordadura, isolou-se apenas as plantas localizadas nas estações de amostragens das parcelas, o que facilitou sobremaneira os trabalhos.

Nestas estações, foram coletadas 15 folhas "+1" das plantas de cana-de-açúcar, identificadas com base no sistema de ordenação de Kuijper (Clements, 1980). Este material foi encaminhado ao laboratório onde foi lavado seqüencialmente com água destilada, solução $0,1 \mathrm{~mol} \mathrm{~L}^{-1}$ de $\mathrm{HCl}$ e água deionizada. Após a lavagem, selecionou-se o terço médio dessas folhas, retirou-se a nervura central e colocou-se os limbos foliares para secar em estufa de circulação forçada de ar a $60^{\circ} \mathrm{C}$. Estes limbos foliares foram moídos e constituíram as amostras de folhas analisadas. Após a amostragem de folhas, foram coletados aleatóriamente 10 colmos por estação de amostragem. Tais colmos 
imediatamente foram lavados e desfibrados. As amostras dos colmos desfibrados foram secas e moídas da mesma forma que as amostras de folhas. Porções de colmos desfibrados, representativas de cada parcela experimental, foram encaminhadas para prensa onde se extraíram as amostras de caldo. Estas amostras foram congeladas e analisadas oportunamente.

\subsubsection{Extração e preparo das amostras de solução do solo}

As extrações de solução do solo foram realizadas ao longo do segundo ano agricola em função da ocorrência das chuvas. $\mathrm{O}$ volume extraído variou com a umidade do solo e por esta razão as amostras analisadas foram formadas por duas ou três extrações seqüenciais. Num periodo de 408 dias de monitoramento, contados a partir da incorporação dos residuos, foram consideradas as 7 amostragens descritas abaixo.

$\begin{array}{lcr}1^{\mathbf{a}} \text { amostragem } & \text { dezembro/97 } & \text { extrações dos dias } 16,17 \text { e } 28 \\ 2^{\underline{\mathbf{a}} \text { amostragem }} & \text { fevereiro/98 } & \text { extrações dos dias } 12,16 \text { e } 17 \\ 3^{\mathbf{a}} \text { amostragem } & \text { maio/98 } & \text { extrações dos dias } 06 \text { e } 07 \\ 4^{\mathbf{a}} \text { amostragem } & \text { junho/98 } & \text { extrações dos dias } 09 \text { e } 10 \\ 5^{\mathbf{a}} \text { amostragem } & \text { setembro/98 } & \text { extrações dos dias } 21 \text { e } 22 \\ 6^{\underline{\mathbf{a}}} \text { amostragem } & \text { outubro/98 } & \text { extrações dos dias } 20 \text { e } 21 \\ 7^{\mathbf{a}} \text { amostragem } & \text { dezembro/98 } & \text { extrações dos dias } 14 \text { e } 15\end{array}$

As amostras de solução do solo não passaram por nenhum tipo de preparo ou seja, foram coletadas, congeladas e depois analisadas.

\subsection{Cronograma das atividades realizadas no campo}

Para um melhor entendimento de todas as atividades realizadas no campo, relacionou-se na Tabela 5, a sequência cronológica das mesmas no decorrer dos dois anos agrícolas. 
Tabela 5. Cronograma das atividades realizadas no campo nos dois anos agrícolas

\begin{tabular}{|c|c|c|}
\hline Atividades & $\operatorname{Dia}(\mathbf{s})$ & Mês/Ano \\
\hline Seleção e demarcação da área experimental & - & Junho/1996 \\
\hline Preparo inicial do solo (subsolagem) & - & Julho/1996 \\
\hline Aração e gradagem do solo & - & Agosto/1996 \\
\hline $1^{\mathfrak{a}}$ aplicação dos resíduos & 26,27 e 28 & Setembro/1996 \\
\hline Incorporação dos resíduos & 16 & Outubro/1996 \\
\hline $1^{\text {a }}$ amostragem do solo ( 0 ddi* $)$ & 16 & Outubro/1996 \\
\hline Operação de cultivo mecânico & 09 & Novembro/1996 \\
\hline $2^{\mathrm{a}}$ amostragem do solo ( $30 \mathrm{ddi}^{*}$ ) & 14 & Novembro/1996 \\
\hline Plantio da cana-de-açúcar & 07 & Dezembro/1996 \\
\hline $3^{\natural}$ amostragem do solo ( $\left.60 \mathrm{ddi}\right)$ & 16 & Dezembro/1996 \\
\hline Operação de cultivo mecânico & 10 & Janeiro/1997 \\
\hline $4^{a}$ amostragem do solo (90 ddi) & 16 & Janeiro/1997 \\
\hline $\begin{array}{l}\text { Adubação de cobertura }\left(40 \mathrm{~kg} \mathrm{ha}^{-1} \text { de } \mathrm{N} \text { e de } \mathrm{K}_{2} \mathrm{O}\right) \text { nas } \\
\text { parcelas do tratamento } 1\end{array}$ & 05 & Fevereiro/1997 \\
\hline Operação de cultivo mecânico & $25^{\circ}$ & Fevereiro/1997 \\
\hline $5^{\mathrm{z}}$ amostragem do solo (150 ddi) & 12 & Março/1997 \\
\hline $6^{\mathrm{a}}$ amostragem do solo (210 ddi) & 09 & Maio/1997 \\
\hline $7^{\mathrm{a}}$ amostragem do solo ( $\left.270 \mathrm{ddi}\right)$ & 10 & Julho/1997 \\
\hline $8^{a}$ amostragem do solo ( $\left.360 \mathrm{ddi}\right)$ & 07 & Outubro/1997 \\
\hline Colheita da cana-planta & 18 & Outubro/1997 \\
\hline $1^{\mathrm{a}}$ amostragem de folhas, colmos e caldo & 18 & Outubro/1997 \\
\hline $\begin{array}{l}1^{\mathrm{a}} \text { amostragem diferenciada** do solo } \\
\text { (camadas } 0-0,3,0,3-0,6 \text { e } 0,6-0,9 \mathrm{~m} \text { ) }\end{array}$ & 01 & Novembro/1997 \\
\hline $2^{\mathrm{a}}$ aplicação dos resíduos & 03,04 e 05 & Novembro/1997 \\
\hline Instalação dos tensiômetros & 11 e 12 & Novembro/1997 \\
\hline Incorporação dos residuos & 13 & Novembro/1997 \\
\hline $1^{\mathrm{a}}$ amostragem do solo (0 ddi) & 13 & Novembro/1997 \\
\hline $\begin{array}{l}\text { Adubação de cobertura }\left(120,30 \text { e } 150 \mathrm{~kg} \mathrm{ha}^{-1} \text { respectivamente }\right. \\
\left.\text { de } \mathrm{N}, \mathrm{P}_{2} \mathrm{O}_{5} \text { e } \mathrm{K}_{2} \mathrm{O}\right) \text { nas parcelas do tratamento } 1\end{array}$ & 29 & Novembro/1997 \\
\hline Instalação dos extratores de solução & 01 a 12 & Dezembro/1997 \\
\hline $2^{a}$ amostragem do solo ( $\left.30 \mathrm{ddi}\right)$ & 13 & Dezembro/1997 \\
\hline $1^{\mathrm{a}}$ amostragem da solução do solo & 16,17 e 28 & Dezembro/1997 \\
\hline $3^{\mathrm{a}}$ amostragem do solo $(60 \mathrm{ddi})$ & 12 & Janeiro/1998 \\
\hline $4^{\mathrm{a}}$ amostragem do solo (90 ddi) & 11 & Fevereiro/1998 \\
\hline $2^{\mathrm{a}}$ amostragem da solução do solo & 12,16 e 17 & Fevereiro/1998 \\
\hline $5^{\mathrm{a}}$ amostragem do solo (150 ddi) & 13 & Abril/1998 \\
\hline $3^{\mathrm{a}}$ amostragem da solução do solo & 06 e 07 & Maio/1998 \\
\hline $4^{\mathrm{a}}$ amostragem da solução do solo & 09 e 10 & Junho/1998 \\
\hline $6^{\mathrm{a}}$ amostragem do solo $(210 \mathrm{ddi})$ & 11 & Junho/1998 \\
\hline $7^{\mathrm{a}}$ amostragem do solo ( $\left.270 \mathrm{ddi}\right)$ & 11 & Agosto/1998 \\
\hline $5^{\mathrm{a}}$ amostragem da solução do solo & 21 e 22 & Setembro/1998 \\
\hline $6^{\mathrm{a}}$ amostragem da solução do solo & 20 e 21 & Outubro/1998 \\
\hline Colheita da $1^{\mathrm{a}}$ soqueira & 24 & Outubro/1998 \\
\hline $2^{\mathrm{a}}$ Amostragem de folhas, colmos e caldo & 24 & Outubro/1998 \\
\hline $8^{\mathrm{a}}$ amostragem do solo (360 ddi) & 09 & Novembro/1998 \\
\hline $7^{\mathrm{a}}$ amostragem da solução do solo & 14 e 15 & Dezembro/1998 \\
\hline $\begin{array}{l}2^{\underline{a}} \text { amostragem diferenciada do solo } \\
\text { (camadas } 0-0,3,0,3-0,6 \text { e } 0,6-0,9,0,9-1,2 \mathrm{~m} \text { ) }\end{array}$ & 22 e 23 & Dezembro/1998 \\
\hline
\end{tabular}

* ddi = dias depois da incorporação dos resíduos; ${ }^{* *}$ amostras coletadas e analisadas, sem secagem prévia, para teores de nitrogênio total e nitrogênio nítrico + amoniacal. 


\subsection{Atributos avaliados}

A extensão dos efeitos causados por duas aplicações sucessivas dos resíduos urbanos ao solo foi avaliada através de atributos das plantas, do próprio solo e da solução do solo.

\subsubsection{Produtividade da cana-de-açúcar}

A produtividade da cana de açúcar foi avaliada, ao final de cada ano agrícola, pela pesagem das plantas, diretamente no campo, através de uma balança acoplada a uma carregadeira (Figura 7). As plantas foram colhidas crúa (sem queima prévia), com despalhamento e desponte manual, dentro da área útil de cada parcela.
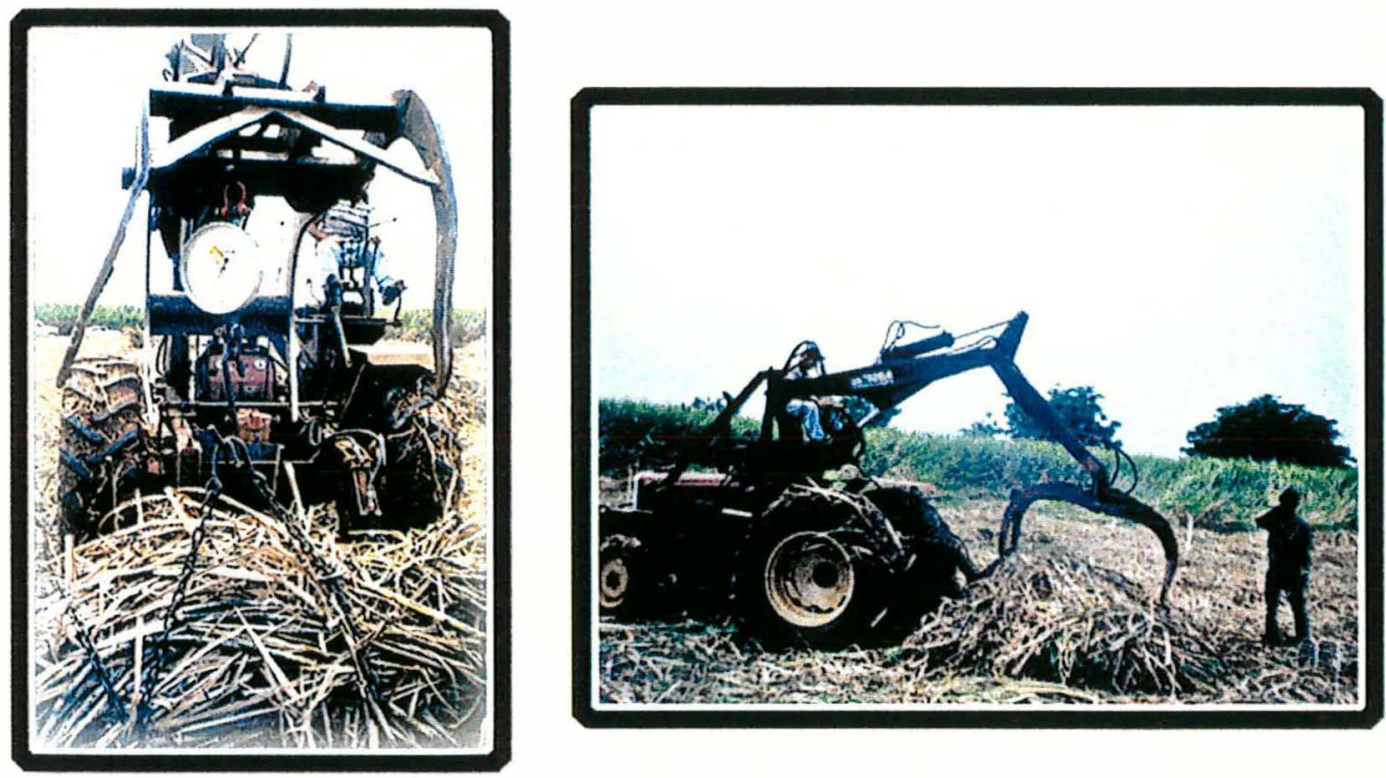

Figura 7. Sistema de pesagem dos colmos de cana-de-açúcar, dentro da área útil de cada parcela, para determinação da produtividade.

\subsubsection{Carbono orgânico}

Foram avaliados os efeitos da aplicação dos resíduos sobre o teor de carbono orgânico do solo ao longo do período experimental. Em cada ano foi estimada a taxa de degradação da carga orgânica adicionada via lodo de esgoto e composto de lixo. Para tanto, determinações de carbono orgânico foram realizadas nas amostras de solo 
coletadas, na camada $0-0,2 \mathrm{~m}$, aos $0,30,60,90,150,210,270$ e 360 dias após incorporação de cada aplicação dos resíduos. Tais determinações foram realizadas por método volumétrico de oxi-redução (dicromatometria) em amostras de 3,00 g de solo, seguindo em linhas gerais a metodologia proposta por Walkley \& Black (1934).

A taxa de degradação da carga orgânica foi estimada através da determinação química do decréscimo de carbono orgânico presente no solo. Este decréscimo foi determinado através da aplicação de um modelo cinético de primeira ordem aos dados médios dos chamados gradientes de carbono. A variável gradiente de carbono expressa o teor de carbono orgânico remanescente no solo devido ao tratamento e foi obtida ao longo do período estudado, pela diferença entre o teor de C-orgânico nas parcelas tratadas com resíduos e o teor daquelas não tratadas (testemunhas). Tal procedimento pode ser resumido pela seguinte expressão:

$$
g C=\mathrm{C}_{\text {trat }}-\mathrm{C}_{\text {test }}
$$

onde:
$\mathbf{g C}=$ gradiente de carbono $\mathrm{em}^{\mathrm{g} \mathrm{kg}}{ }^{-1}$;
$\mathbf{C}_{\text {trat }}=$ teor de carbono orgânico nas parcelas tratadas com resíduo;
$\mathrm{C}_{\text {test }}=$ teor de carbono orgânico nas parcelas testemunha.

\subsubsection{Condutividade elétrica e $\mathrm{pH}$}

As determinações de condutividade elétrica e $\mathrm{pH}$ do solo foram realizadas nas amostras coletadas na camada de $0-0,2 \mathrm{~m}$ aos $30,60,90,150,210,270$ e 360 dias após incorporação de cada aplicação dos resíduos. Aos 360 dias após a incorporação dos resíduos, para ambos os anos agrícolas, tais determinações também foram realizadas nas amostras das camadas de $0,2-0,4,0,4-0,6$ e $0,6-0,8 \mathrm{~m}$.

A condutividade elétrica das amostras foi determinada em extrato solo - água (relação 1:1) com leitura direta em condutivímetro DIGIMED DM-31. As determinações de $\mathrm{pH}$ foram realizadas potenciométricamente em extratos solo - solução $0,01 \mathrm{~mol} \mathrm{~L}^{-1}$ de $\mathrm{CaCl}_{2}$ (relação 1:2,5). 


\subsubsection{Capacidade de troca de cátions}

A capacidade de troca de cátions do solo foi determinada nas amostras coletadas, na camada de $0-0,2 \mathrm{~m}$, aos $30,90,150,270$ e 360 dias após incorporação de cada aplicação dos resíduos. A CTC foi determinada ao $\mathrm{pH}$ atual do solo pelo método proposto por Gillman \& Sumpter (1986), utilizando soluções não tamponadas. Este método consiste essencialmente na saturação dos sítios de troca do solo com íons $\mathrm{Ba}^{2+}$ fornecido por soluções de $\mathrm{BaCl}_{2}$. Em seguida os íons $\mathrm{Ba}^{2+}$ retidos são trocados por íons $\mathrm{Mg}^{2+}$ fornecidos por uma solução de $\mathrm{MgSO}_{4}$ de concentração exatamente conhecida. A CTC é calculada com base no decréscimo da concentração de íons $\mathrm{Mg}^{2+}$ presentes nesta última solução.

\subsubsection{Metais pesados no solo e nas plantas}

Os teores totais dos metais pesados $\mathrm{Cd}, \mathrm{Cr}, \mathrm{Cu}, \mathrm{Ni}, \mathrm{Pb}$ e $\mathrm{Zn}$ foram avaliados no solo e nas plantas ao final de cada ano agrícola. Para o solo, as determinações foram realizadas nas amostras coletadas na camada de $0-0,2 \mathrm{~m}$ aos 360 dias após a incorporação dos resíduos. Os metais foram extraídos em "água-régia" através de um sistema de digestão em forno de microondas (CEM - modelo MDS-2000) conforme metodologia proposta por Nieuwenhuize et al. (1991). Convém salientar que foram utilizadas $500 \mathrm{mg}$ de amostra de solo, sendo o extrato recuperado em $50 \mathrm{~mL}$.

Nas plantas, as determinações foram realizadas nas amostras de folhas, colmos desfibrados e caldo. Os extratos obtidos por digestão nítrico-perclórica foram concentrados tendo em vista que, alguns metais pesados freqüentemente se apresentam em concentrações extremamente baixas. Desta forma, para as amostras de folhas e colmos desfibrados foram digeridas $2000 \mathrm{mg}$ do material com recuperação do extrato em volume final de $15 \mathrm{~mL}$. Para o caldo, foram digeridos $50 \mathrm{~mL}$ da amostra com recuperação do extrato em volume final de $10 \mathrm{~mL}$.

Em ambos os casos, as determinações analíticas dos metais foram feitas por espectrometria de absorção atômica com chama convencional ar/acetileno. 


\subsubsection{Avaliação da fitodisponibilidade de metais pesados}

Foram avaliadas três soluções extratoras no estudo da fitodisponibilidade de metais pesados. Tais avaliações foram baseadas em correlações lineares entre os teores de metais nas amostras de plantas e os de metais no solo. As soluções extratoras foram empregadas nas amostras de solo coletadas ao final de cada ano agrícola, na camada de $0-0,2 \mathrm{~m}, 360$ dias após incorporação dos resíduos. Os metais pesados foram analisados por extração com solução $0,1 \mathrm{~mol} \mathrm{~L}^{-1}$ de $\mathrm{HCl}$, solução de Mehlich-3 e DTPA-TEA. A extração com $0,1 \mathrm{~mol} \mathrm{~L}^{-1}$ de $\mathrm{HCl}$ se fez agitando $10,00 \mathrm{~g}$ de solo com $50 \mathrm{~mL}$ de solução (Reed \& Martens, 1996). A solução de Mehlich 3 foi empregada na proporção de $50 \mathrm{~mL}$ para 5,00 g de solo, agitando-se 5 minutos (Mehlich, 1984). A extração com DTPA-TEA consistiu em agitar $25,00 \mathrm{~g}$ de solo com $50 \mathrm{~mL}$ da solução extratora, por 2 horas (Lindsay \& Norvell, 1978). Em todos os métodos, após a agitação, os extratos foram filtrados através de processos de filtração lenta, procedendo-se a seguir, à determinação dos metais por espectrometria de absorção atômica com chama convencional ar/acetileno.

\subsubsection{Mobilidade de metais pesados no solo}

A possibilidade de movimentação de metais pesados pelo perfil do solo foi avaliada através de dois procedimentos. No primeiro deles utilizou-se da determinação direta desses elementos, nas amostras coletadas de solução do solo, por espectrometria de absorção atômica com chama convencional ar/acetileno. O segundo procedimento foi a determinação dos teores totais dos metais pesados nas amostras de solo coletadas aos 360 dias, nas camadas de $0-0,2,0,2-0,4,0,4-0,6$ e 0,6-0,8 m. A metodologia para extração e determinação dos metais foi a mesma descrita no ítem 3.6.5.

\subsubsection{Lixiviação de nitrato e amônio}

A lixiviação de $\mathrm{N}^{-\mathrm{NO}_{3}}{ }^{-}$e de $\mathrm{N}-\mathrm{NH}_{4}{ }^{+}$foi estimada, para o ano agrícola 1997/98, através da determinação dos teores desses íons nas amostras coletadas de solução do solo e do cálculo do fluxo de água pelo perfil estudado. Análises de $\mathrm{N}$-total e $\mathrm{N}-\mathrm{NO}_{3}{ }^{-}+\mathrm{N}-\mathrm{NH}_{4}{ }^{+}$no solo também foram realizadas ao final de cada ano experimental. 


\subsubsection{Determinação dos teores de $\mathrm{N}$-total e $\mathrm{N}-\mathrm{NO}_{3}{ }^{-}+\mathrm{N}-\mathrm{NH}_{4}{ }^{+}$no solo}

Os teores de $\mathrm{N}$-total e $\mathrm{N}-\mathrm{NO}_{3}{ }^{-}+\mathrm{N}_{-}-\mathrm{NH}_{4}{ }^{+}$foram determinados nas amostras de solo, com umidade natural, coletadas aos 380 e 400 dias após, respectivamente, a primeira e a segunda incorporação dos resíduos. Com base nestas determinações foram estimados, por diferença, os teores de N-orgânico. Para o final do primeiro ano agrícola, as amostras utilizadas foram representativas das camadas $0-0,3,0,3-0,6,0,6-0,9 \mathrm{~m} \mathrm{e}$ para o final do segundo ano acrescentou-se amostras da camada de 0,9-1,2 m.

A determinação do $\mathrm{N}$-total foi feita de acordo com a metodologia proposta por Alcarde \& Chitolina (1991). Os teores de $\mathrm{N}^{-\mathrm{NO}_{3}}{ }^{-}+\mathrm{N}^{-} \mathrm{NH}_{4}{ }^{+}$foram determinados por extração com solução $2 \mathrm{~mol} \mathrm{~L}^{-1}$ de $\mathrm{KCl}$ seguido de destilação em meio alcalino com liga de Devarda (Bremner, 1965). Paralelamente foi determinada a umidade das amostras analisadas e os resultados de nitrogênio foram expressos com base no solo seco.

\subsubsection{Determinação dos teores de $\mathrm{N}-\mathrm{NO}_{3}{ }^{-}$e $\mathrm{N}-\mathrm{NH}_{4}{ }^{+}$na solução do solo}

As determinações do $\mathrm{N}^{-\mathrm{NO}_{3}}{ }^{-}$e do $\mathrm{N}-\mathrm{NH}_{4}{ }^{+}$foram realizadas por espectroscopia de absorção molecular num sistema de análise de injeção em fluxo contínuo - marca ASIA-Ismatec. A utilização deste método justificou-se pela alta sensibilidade e pelo reduzido volume gasto de amostra. O limite mínimo de determinação do método é de $0,01 \mathrm{mg} \mathrm{L}^{-1}$ para $\mathrm{N}_{-\mathrm{NO}_{3}}^{-}$e de $0,005 \mathrm{mg} \mathrm{L}^{-1}$ para N-NH${ }_{4}^{+}$.

$\mathrm{O}$ procedimento para determinação de $\mathrm{N}^{-\mathrm{NO}_{3}}{ }^{-}$, que seguiu em linhas gerais o

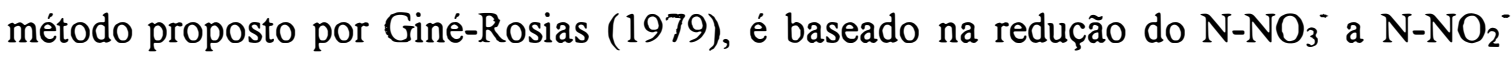
através de um reator (coluna) de $\mathrm{Cd}^{\circ}$. Os íons $\mathrm{NO}_{2}{ }^{-}$formam com sulfanilamida, em meio ácido, um composto chamado diazônio. Este composto combinado com $\mathrm{N}$-(1-naphthyl)ethylenodiamina dicloridrato forma outro composto de coloração vermelho/violeta. A intensidade da cor, diretamente proporcional a concentração de $\mathrm{N}-\mathrm{NO}_{3}{ }^{-}$na amostra, é medida ao comprimento de ondas de $555 \mathrm{~nm}$. Cabe ressaltar que na hipótese da presença de $\mathrm{N}-\mathrm{NO}_{2}^{-}$na amostra, estas também são quantificadas. Um diagrama do sistema de análise de $\mathrm{N}-\mathrm{NO}_{3}{ }^{-}$é apresentado na Figura 8.

Para determinação de $\mathrm{N}-\mathrm{NH}_{4}{ }^{+}$, o procedimento é baseado na sua conversão para $\mathrm{N}-\mathrm{NH}_{3}$ livre após alcalinização da amostra com solução $0,1 \mathrm{~mol} \mathrm{~L}^{-1}$ de hidróxido de sódio. As formas $\mathrm{N}-\mathrm{NH}_{3}$ difundem através de uma membrana de polipropileno dentro de uma solução indicadora (púrpura de bromocresol), formando um composto colorido, cuja intensidade de cor é medida ao comprimento de ondas de $605 \mathrm{~nm}$. O diagrama do sistema de análise de $\mathrm{N}-\mathrm{NH}_{4}{ }^{+}$é apresentado na Figura 9. 
Bomba Peristaltica $50 \%$

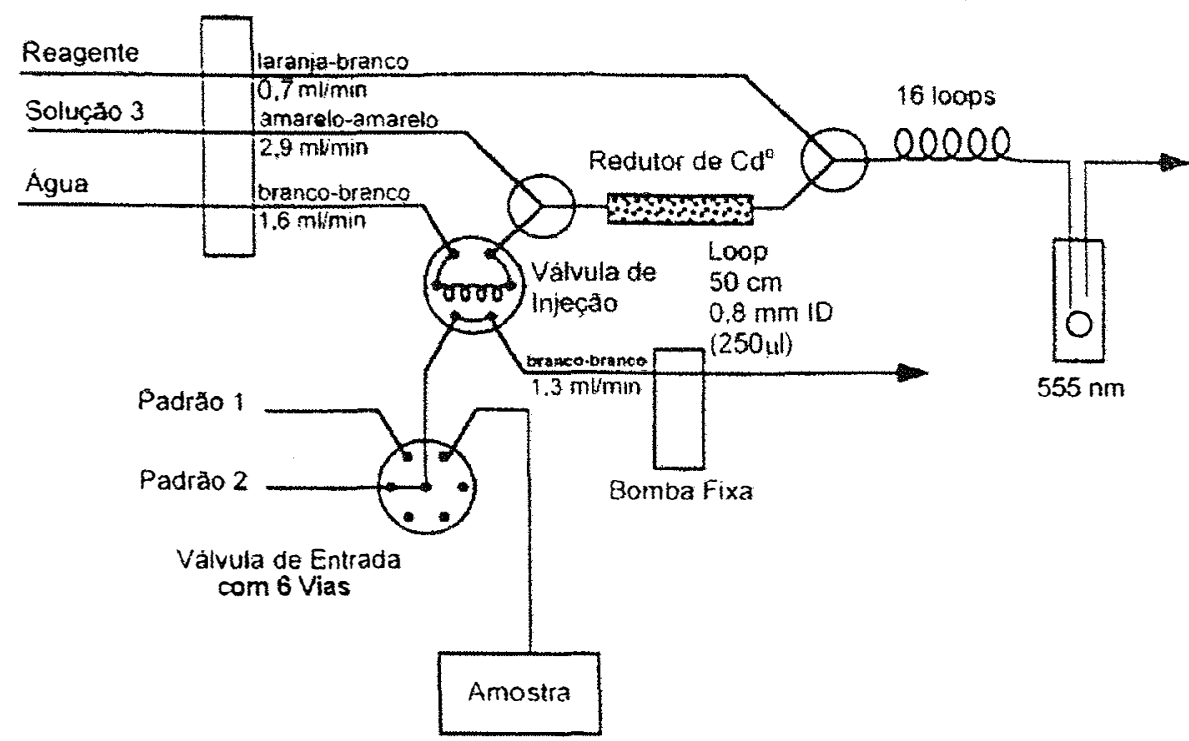

Figura 8. Sistema de análise em fluxo contínuo utilizado para determinação de $\mathrm{N}-\mathrm{NO}_{3}{ }^{-}$.

Bomba Peristáltica $50 \%$

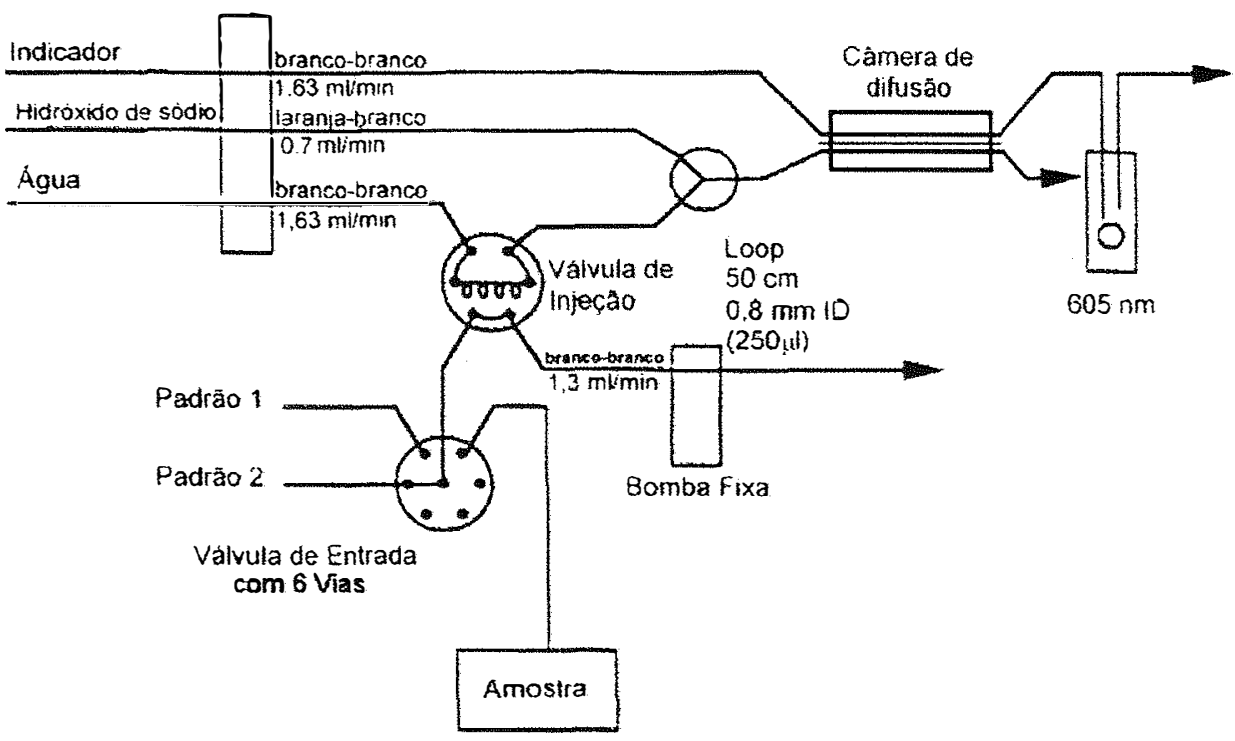

Figura 9. Sistema de análise em fluxo contínuo utilizado para determinação de $\mathrm{N}^{-} \mathrm{NH}_{4}{ }^{\dagger}$. 


\subsubsection{Fluxo de água no solo}

O fluxo de água no solo q $(\mathrm{mm})$ foi estimado através da equação do balanço hídrico:

$$
\mathrm{P}+\mathrm{I}+\mathrm{ETr}+\mathrm{q}+\mathrm{ES}-\Delta \mathrm{A}=0
$$

onde:

P é a precipitação pluvial $(\mathrm{mm})$; I seria a irrigação $(\mathrm{mm})$, neste caso nula; ETr é a evapotranspiração real da cultura da cana-de-açúcar $(\mathrm{mm})$; ES, o escoamento superficial $(\mathrm{mm})$, considerado nulo devido a baixa declividade da área experimental $\left(<0,03 \mathrm{~m} \mathrm{~m}^{-1}\right)$; $\Delta \mathrm{A}$, a variação de armazenamento de água no solo na camada considerada. Nesta equação, a convenção dos sinais das variáveis é feita de modo que àquelas que impliquem no aumento do armazenamento de água no solo sejam consideradas positivas e aquelas que impliquem na diminuição sejam consideradas negativas. Assim, P e I são positivas, ETr é negativa, e ES, q e $\Delta \mathrm{A}$ podem ser negativas ou positivas, dependendo de cada situação.

Os dados de precipitação foram coletados no posto meteorológico próximo a área experimental. A ETr da cultura foi considerada igual a evapotranspiração máxima (ETm) quando o armazenamento de água no solo estava acima dos limites críticos citados por Doorenbos et al.(1979). Quando ficaram abaixo desses limites considerou-se que a ETr variou linearmente com o armazenamento. A ETm da cultura foi calculada como o produto da evapotranspiração potencial da grama $\left(\mathrm{ET}_{0}\right)$ pelos coeficientes de cultura (kc) descritos por Doorenbos \& Pruit (1975). Para o cálculo de $E_{0}$ utilizou-se o método de Penman, sugerido por Doorenbos \& Pruit (1975), sendo que os dados necessários foram obtidos junto ao posto meteorológico do Departamento de Ciências Exatas da ESALQ/USP.

A variação de armazenamento de água no solo foi obtida através das leituras periódicas dos tensiômetros instalados na área experimental e das curvas de retenção de água no solo. Estas curvas foram determinadas em laboratório por Ghiberto (1999), a 
partir de amostras indeformadas coletadas numa trincheira na área experimental, nas mesmas profundidades de instalação dos tensiômetros.

Os períodos para a estimativa do fluxo de água foram definidos arbitrariamente levando em conta a data de amostragem da solução do solo e a ocorrência e distribuição das precipitações pluviais. Dessa forma, foram utilizadas como limites a ocorrência de estiagens mais longas, procurando manter dentro de cada período as maiores precipitações que ocorreram próximas às datas de coleta de solução do solo.

\subsubsection{Fluxo do $\mathrm{N}-\mathrm{NO}_{3}{ }^{-}$e do $\mathrm{N}-\mathrm{NH}_{4}{ }^{+}$}

Considerando-se que as perdas por lixiviação de $\mathrm{N}_{-} \mathrm{NO}_{3}{ }^{-}$e $\mathrm{N}-\mathrm{NH}_{4}{ }^{-}$ocorreram apenas por fluxo de massa sua estimativa foi obtida, para cada período e profundidade estudada, pelas equações:

$$
\begin{aligned}
\mathrm{q} \mathrm{N}-\mathrm{NO}_{3}{ }^{-} & =\underset{\mathrm{q} \mathrm{H}}{\mathrm{H}} \mathrm{O} \cdot\left[\mathrm{N}-\mathrm{NO}_{3}{ }^{-}\right] \\
\mathrm{e} & \\
\mathrm{q} \mathrm{N}-\mathrm{NH}_{4}{ }^{+} & =\mathrm{q} \mathrm{H}_{2} \mathrm{O} \cdot\left[\mathrm{N}-\mathrm{NH}_{4}{ }^{+}\right]
\end{aligned}
$$

onde:

- q $\mathrm{N}-\mathrm{NO}_{3}{ }^{-}$e q $\mathrm{N}-\mathrm{NH}_{4}{ }^{+}$são respectivamente o fluxo de nitrogênio nítrico e nitrogênio amoniacal no solo $\left(\mathrm{mg} \mathrm{m}^{-2}\right)$;

- $\mathrm{q}_{2} \mathrm{O}$ é o fluxo de água no solo $\left(\mathrm{mm} \mathrm{ou} \mathrm{L} \mathrm{m}^{-2}\right)$;

- $\left[\mathrm{N}-\mathrm{NO}_{3}{ }^{-}\right]$e $\left[\mathrm{N}-\mathrm{NH}_{4}{ }^{+}\right]$são respectivamente a concentração média de nitrogênio nítrico e nitrogênio amoniacal na solução do solo $\left(\mathrm{mg} \mathrm{L}^{-1}\right)$.

\subsection{Tratamento estatístico dos dados}

Conforme comentado no item 3.4 deste capítulo, o plano de pesquisa inicial previa a adoção do mesmo critério para estabelecimento das doses a serem empregadas, de lodo de esgoto e composto de lixo. No entanto, diante das limitações impostas pela composição diferenciada desses materiais, não foi possível a realização de tal procedimento. Considerou-se dessa forma, imprópria a comparação entre os resultados 
obtidos para os tratamentos com cada um dos resíduos, o que fez com que se optasse pela análise e interpretação dos dados considerando-se dois experimentos distintos: o primeiro com doses de lodo de esgoto e outro com doses de composto de lixo. Neste caso, foi considerado para cada experimento como tratamento testemunha, as médias entre os tratamentos 2 e 6 . O tratamento 1 (Calagem + Adubação Mineral) foi empregado na análise de cada experimento, a medida que houvesse interesse nos seus possiveis efeitos sobre a variável em questão.

As análises estatísticas foram realizadas separadamente para cada ano experimental. $\mathrm{O}$ detalhamento do esquema de análise de cada variável se fez necessário devido as diferenças na maneira como foram estudadas neste trabalho, diferenças estas que envolveram números, épocas e profundidades de coletas de amostras e a própria natureza da variável.

Para a variável produtividade da cana-de-açúcar, em cada experimento, fez-se a análise de variância de acordo com o esquema apresentado na Tabela 5, aplicando-se 0 teste F. Os tratamentos (Calagem+Ad. Mineral e Doses 0, A, B e C do resíduo) foram desdobrados num contraste ortogonal de interesse (Calagem+Ad. Mineral x Doses A, B e C) e estudo de regressão polinomial de $1^{\underline{0}}$ e $2^{\underline{0}}$ grau para doses do resíduo.

Tabela 6. Esquema da análise de variância utilizado para a variável produtividade da cana-de-açúcar em cada experimento.

\begin{tabular}{cc}
\hline Causas da variação & Graus de liberdade \\
\hline Blocos & 3 \\
Tratamentos & $(4)$ \\
\hline Calagem+Ad. Mineral x Doses A, B e C & 1 \\
Regressões para doses do resíduo & 3 \\
\hline Resíduo & 12 \\
\hline Total & 19 \\
\hline
\end{tabular}

As variáveis carbono orgânico, gradiente de carbono, condutividade elétrica, $\mathrm{pH}$ e CTC do solo foram analisadas em delineamento com parcelas subdivididas, sendo as parcelas constituídas pelos tratamentos (Doses $0, \mathrm{~A}, \mathrm{~B}$ e $\mathrm{C}$ do resíduo) e as subparcelas, pelas épocas de coleta das amostras de solo (dias após a incorporação do 
resíduo). Foi feita a aplicação do teste $\mathrm{F}$ de acordo com o esquema de análise de variância apresentado na Tabela 6. Quando constatada interação significativa, as médias das variáveis carbono orgânico, condutividade elétrica, $\mathrm{pH}$ e CTC foram testadas, dentro de épocas de amostragem e tratamentos, por modelos de regressão polinomial de $1^{\circ}$ e $2^{\circ}$ grau. Para a variável gradiente de carbono, verificando-se efeitos significativos das causas de variação, foram realizados ajustes de funções exponenciais do tipo $y=a e^{-b x}$.

Tabela 7. Esquema da análise de variância utilizado para as variáveis carbono orgânico, gradiente de carbono, condutividade elétrica, pH e CTC do solo e seus respectivos graus de liberdade.

\begin{tabular}{lcccc}
\hline Causas da variação & \multicolumn{4}{c}{ Graus de liberdade } \\
& C-org. & Grad. C & Condut. e pH & CTC \\
\hline Blocos & 3 & 3 & 3 & 3 \\
Tratamentos & 3 & 2 & 3 & 3 \\
Resíduo (A) & 9 & 6 & 9 & 9 \\
\hline Parcelas) & $(15)$ & $(11)$ & $(15)$ & $(15)$ \\
Épocas de amostragem & 7 & 7 & 6 & 4 \\
Tratamentos x Épocas de amostragem & 21 & 14 & 18 & 12 \\
Resíduo (B) & 84 & 63 & 72 & 48 \\
\hline Total & 127 & 95 & 111 & 79 \\
\hline
\end{tabular}

Para a variável CTC do solo também empregou-se a análise de correlação linear simples entre seus valores e $\mathrm{pH}$ e entre seus valores e teores de carbono orgânico do solo. O tratamento 1 (Calagem + Ad. Mineral) foi considerado apenas nas correlações da CTC com o $\mathrm{pH}$.

Algumas variáveis como, condutividade elétrica, $\mathrm{pH}$, metais pesados, nitrogênio total, orgânico e inorgânico foram avaliadas no solo, ao final de cada ano experimental, em função da profundidade de coleta das amostras. Nestes casos, também foram analisadas em delineamento com parcelas subdivididas, sendo os tratamentos (Doses $\mathrm{O}, \mathrm{A}, \mathrm{B}$ e $\mathrm{C}$ ) as parcelas e as profundidades, as subparcelas. $\mathrm{O}$ teste $\mathrm{F}$ foi aplicado de acordo com o esquema de análise de variância apresentado na Tabela 7. Quando constatada interação significativa, as médias foram testadas dentro de profundidades, por modelos de regressão polinomial de $1^{\circ}$ e $2^{\circ}$ grau e dentro de tratamentos através do teste de Tukey a $P \leq 0,05$. 
Tabela 8. Esquema da análise de variância utilizado para as variáveis condutividade elétrica, $\mathrm{pH}$, metais pesados e nitrogênio (total, orgânico e inorgânico), avaliados em função da profundidade de coleta da amostra e seus respectivos graus de liberdade.

\begin{tabular}{lcc}
\hline Causas da variação & \multicolumn{2}{c}{ Graus de liberdade } \\
& Condut., $\mathrm{pH}$, Metais e N (ano2) & N (ano1) \\
\cline { 2 - 3 } Blocos & 3 & 3 \\
Tratamentos & 3 & 3 \\
Residuo (A) & 9 & 9 \\
\hline (Parcelas) & $(15)$ & $(15)$ \\
Profundidade da amostra & 3 & 2 \\
Tratamentos x Profundidade da amostra & 9 & 6 \\
Resíduo (B) & 36 & 24 \\
\hline Total & 63 & 47 \\
\hline \hline
\end{tabular}

As concentrações de metais pesados determinadas nas amostras de planta foram relacionadas para todos os tratamentos considerados em cada experimento, dentro de cada ano experimental, com os teores totais dos metais extraídos do solo. Aos dados foram testados modelos de regressão polinomial de $1^{0}$ e $2^{\circ}$ grau e um modelo exponencial do tipo $\mathrm{y}=\mathrm{a}\left(1-\mathrm{e}^{-\mathrm{bx}}\right)$. Na possibilidade de todos os modelos serem significativos, optou-se pelo modelo exponencial, caso este tenha apresentado coeficiente de determinação próximo ou maior que os modelos de regressão polinomial.

A eficiência dos extratores químicos na predição da disponibilidade de metais pesados às plantas foi avaliada através da análise de correlação linear simples entre os teores determinados nas amostras de planta e os teores recuperados do solo pelos vários extratores utilizados.

Para os teores de $\mathrm{N}-\mathrm{NO}_{3}{ }^{-}$e $\mathrm{N}-\mathrm{NH}_{4}{ }^{+}$, determinados periodicamente na solução do solo, foram apresentadas graficamente suas médias com os respectivos desvios padrões.

As análises de variância, testes de médias, correlações lineares simples e regressões polinomiais foram realizadas através do programa estatístico SANEST (Zonta et al., 1987) e os ajustes de modelos exponenciais foram testados através do programa estatístico SAS (SAS Institute Inc., 1998). 


\section{RESULTADOS E DISCUSSÃO}

São apresentados e discutidos, separadamente, os resultados obtidos para os tratamentos com lodo de esgoto e com composto de lixo. Os registros diários das precipitações pluviométricas ocorridas no período experimental constam do Apêndice 1. Os resultados das análises de variância e respectivos coeficientes de variação constam do Apêndice 2.

\subsection{Lodo de esgoto}

\subsubsection{Produtividade da cana-de-açúcar}

Os valores de produtividade obtidos para a cana-de-açúcar nos anos agrícolas 1996/97 e 1997/98 são apresentados na Figura 10. Para a "cana-planta", ano agrícola 1996/97, foram obtidas baixas produtividades em todos os tratamentos. Este fato está diretamente relacionado com alguns imprevistos que surgiram no decorrer dos trabalhos de campo; o primeiro deles ficou por conta da má distribuição das chuvas na área experimental. Observando-se a Figura 11, que compara os totais mensais de precipitações ocorridas durante o período experimental com a distribuição média em Piracicaba, SP (periodo de retorno de $82 \operatorname{anos}^{4}$ ), verifica-se que nos meses de setembro, outubro e novembro /96 ocorreram chuvas excessivas forçando um atraso no plantio da cana-de-açúcar, devido as dificuldades de operação na área. Dessa forma, o plantio que estava previsto para outubro foi realizado em dezembro/96. Não obstante a este atraso, nos meses de fevereiro, março e abril de 1997 a ocorrência de chuvas esteve abaixo da média local, sugerindo déficit hídrico. Este período coincidiu com a fase exponencial de crescimento da cultura, o que teria prejudicado sobremaneira o seu desenvolvimento.

\footnotetext{
${ }^{4}$ Dados extraídos da Home Page do Setor de Física e Meteorologia do Departamento de Ciências Exatas ESALQ/USP - http://www.ciagri.usp.br/-emdabreu/MEDIAS.TXT
} 
Ademais, optou-se por antecipar a colheita das plantas, que foi realizada com 316 dias $(\approx 11$ meses - outubro/97) para não comprometer o desenvolvimento da cultura para 0 $2^{\underline{a}}$ ano. Todos estes fatos somados, reafirmam uma das principais desvantagens econômicas no plantio da chamada cana-de-ano, que segundo Coleti (1987) apresenta produtividade extremamente dependente de um rápido desenvolvimento, dificultado em solos que não sejam de alta fertilidade além da sensibilidade a períodos de estiagem.

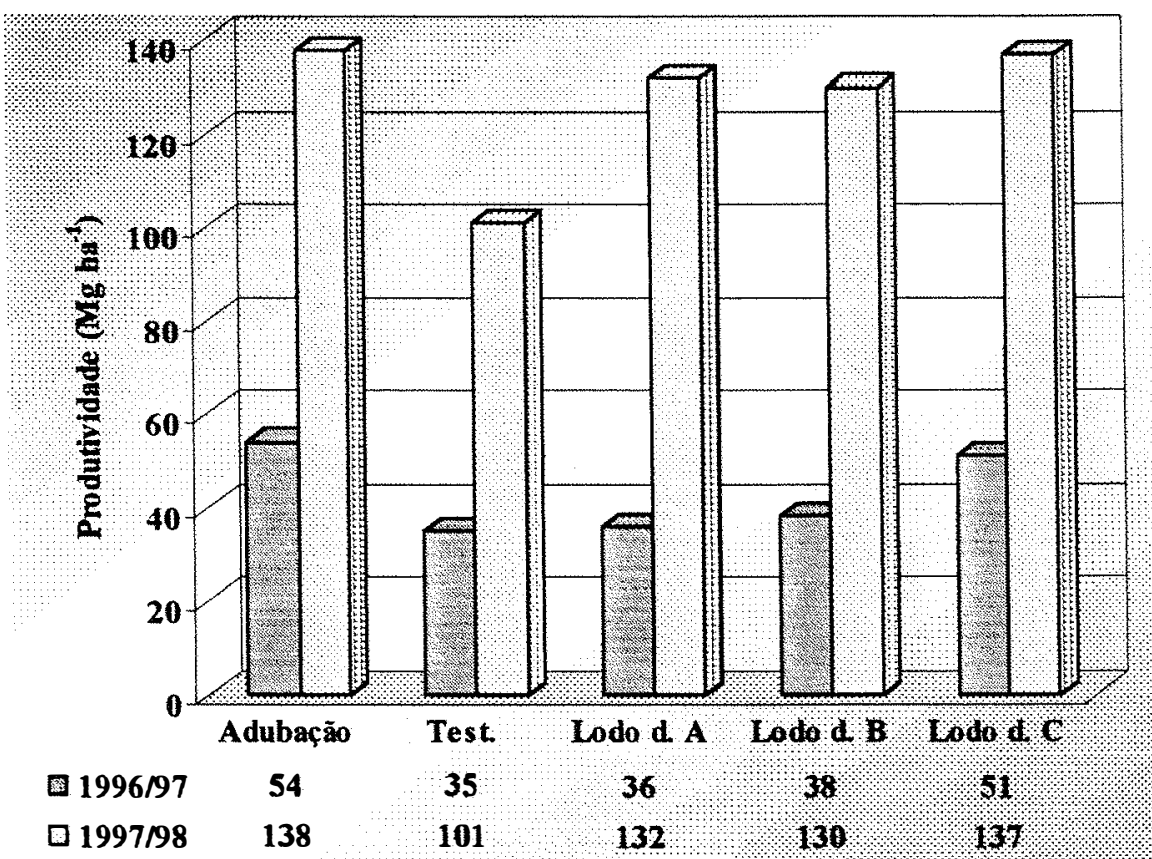

Figura 10. Produtividades da cana-de-açúcar $\left(\mathrm{Mg} \mathrm{ha}^{-1}\right)$ obtidas nos anos agrícolas 1996/97 e 1997/98 para o experimento com lodo de esgoto.

A análise estatística dos dados permite afirmar que, apesar da baixa produtividade, houve um efeito linear e significativo $\left(\mathrm{R}^{2}=0,72^{* *}\right)$ do lodo de esgoto em relação a testemunha absoluta. Por outro lado, pela análise de contrastes verifica-se a superioridade do tratamento calagem + adubação mineral em relação a média da produtividade para as doses 33,66 e $99 \mathrm{Mg} \mathrm{ha}^{-1}$ de lodo de esgoto. Considerando-se as quantidades de macronutrientes adicionados via lodo, verifica-se que o potássio foi o elemento adicionado em menor quantidade, principalmente nas doses A e B $(\approx 35$ e $70 \mathrm{~kg} \mathrm{ha}^{-1}$ respectivamente). Convém salientar que o teor original de $\mathrm{K}$ disponível no solo da área experimental (Tabela 2) é considerado extremamente baixo (Raij et al., 1996). Estas observações sugerem, além das razões discutidas anteriormente, 
que as baixas produtividades nestes tratamentos podem ter sido intensificadas pela insuficiência de potássio disponivel às plantas. Acrescenta-se a isto o fato de ter sido observado no campo, excesso de folhas velhas secas, secando das pontas e das margens para o centro do limbo foliar, sintomas típicos da deficiência de $\mathrm{K}$.

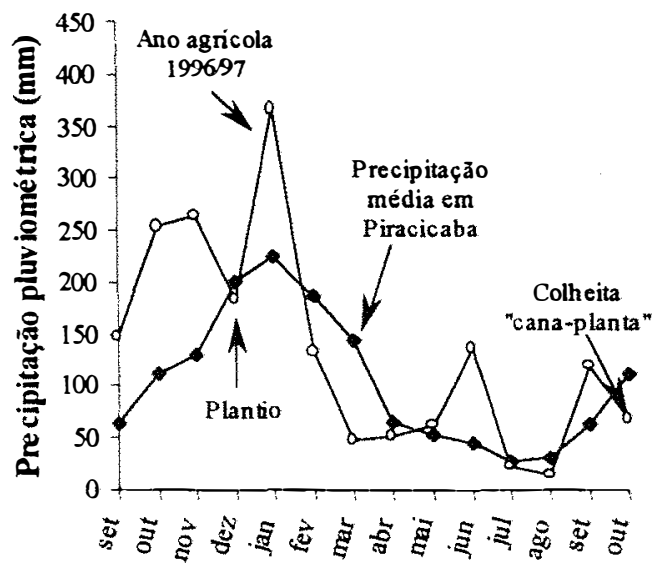

Periodo em meses

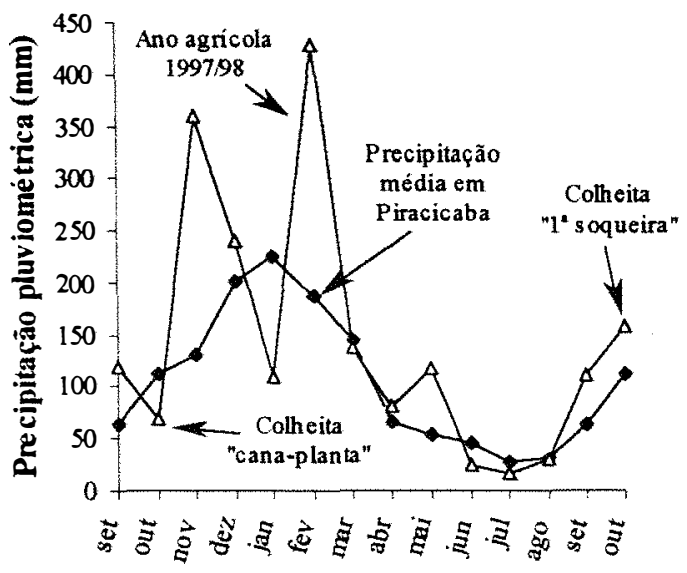

Periodo e m meses

Figura 11. Comparação entre as precipitações mensais ocorridas na área experimental nos anos agrícolas 1996/97 e 1997/98 com as médias mensais ocorridas em Piracicaba, SP considerando-se um período de retorno de 82 anos.

A necessidade de suplementar o lodo de esgoto com potássio para um desenvolvimento satisfatório de culturas, tem sido relatada em trabalhos com menores taxas de aplicação do resíduo. Como exemplos pode-se citar os trabalhos de Oliveira (1992) com a cultura do sorgo granífero, Da Ros et al. (1990) com aveia e ervilhaca, Marques (1990) e Marques (1996) com a cana-de-açúcar.

As produtividades obtidas na primeira soqueira, no ano agrícola de 1997/98, foram bastante superiores a "cana-planta". Neste caso a cultura, colhida com 12 meses, foi beneficiada possivelmente por um efeito residual da primeira aplicação do resíduo além de ter sido favorecida por quantidades elevadas e bem distribuídas de chuvas (Figura 11) durante seu crescimento. Somando-se a estes fatores, com base na experiência do ano anterior, procedeu-se a suplementação potássica das testemunhas e dos tratamentos com doses A e B de lodo de esgoto, de acordo com as recomendações de Spironello et al. (1996). 
A análise estatística para produtividades da primeira soqueira mostrou um efeito quadrático $\left(\mathrm{R}^{2}=0,89^{*}\right)$ para doses do resíduo. Para os tratamentos com doses

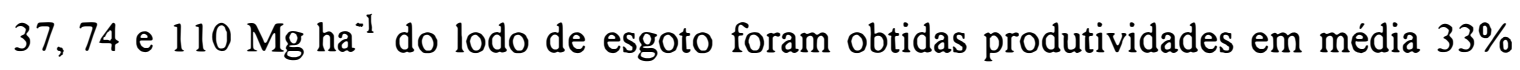
superiores a testemunha absoluta. A produtividade média para estas doses, quando comparada pela análise de contrastes com o tratamento calagem + adubação mineral não revelou diferença significativa. Isto posto, verifica-se que o emprego do lodo de esgoto mesmo em doses de $110 \mathrm{Mg} \mathrm{ha}^{-1}$, não ofereceu ganhos de produtividade quando comparado a adubação mineral convencional. Por outro lado, tendo em vista que este trabalho foi realizado sob a ótica da disposição do resíduo, convém salientar que as elevadas doses aplicadas também não causaram efeitos deletérios a esta variável.

Efeitos benéficos às produtividades das culturas devidos a aplicação de lodo de esgoto também foram verificados por Reed et al. (1991), Cripps et al. (1992), Berton et al. (1989), Da Ros et al. (1993) entre outros. Silva (1995) e Marques (1996) mostraram em seus trabalhos que o lodo de esgoto em associação com fertilizantes minerais apresenta efeitos satisfatórios sobre a produtividade da cana-de-açúcar o que pode significar economia de recursos com fertilizantes.

Para a maior dose aplicada de lodo de esgoto não foi necessário suplementar o potássio mas neste caso, foram adicionados ao solo quantidades elevadas de outros macronutrientes como por exemplo $\mathrm{N}\left(2388 \mathrm{~kg} \mathrm{ha}^{-1}\right)$ e $\mathrm{Ca}\left(14,5 \mathrm{Mg} \mathrm{ha}^{-1}\right)$. Este fato evidencia o quanto o lodo de esgoto é desbalanceado do ponto de vista agronômico, o que sem dúvida nenhuma configura mais um aspecto a ser considerado no seu manejo.

\subsubsection{Carbono orgânico}

Os teores de carbono orgânico do solo apresentaram em todas as épocas de amostragem, nos dois anos agrícolas, aumentos lineares em função das doses aplicadas de lodo de esgoto (Tabela 9). Tomando-se como base a testemunha absoluta, verifica-se que aos 360 dias após a incorporação do resíduo, no ano agrícola 1996/97, houveram aumentos de 13, 14 e 15\% nos teores de carbono proporcionados respectivamente, pelas doses de 33, 66 e $99 \mathrm{Mg} \mathrm{ha}^{-1}$ de lodo de esgoto. Aos 360 dias após a incorporação da segunda aplicação, ano agrícola 1997/98, tais aumentos foram de 17, 25 e 43\% respectivamente para as doses de 37,74 e $110 \mathrm{Mg} \mathrm{ha}^{-1}$, cerca de 10,17 e $33 \%$ de acúmulo em relação aos teores de carbono observados ao final do ano anterior. 
Tabela 9. Teores de Carbono orgânico do solo $\left(\mathrm{g} \mathrm{kg}^{-1}\right)$ determinados para doses de lodo de esgoto em diversas épocas de amostragem, dentro dos anos agrícolas 1996/97 e 1997/98.

Ano agrícola 1996/97

\begin{tabular}{cccccccc} 
Dias $^{1}$ & \multicolumn{3}{c}{ Doses de lodo de esgoto $\left(\mathrm{Mg} \mathrm{ha}^{-1}\right)$} & \multicolumn{2}{c}{ Termo de Regressão $\left(\mathrm{R}^{2}\right)$} \\
\cline { 2 - 5 } & 0 & 33 & 66 & 99 & Linear & Quadrático \\
\hline 0 & 7,16 & 9,12 & 10,67 & 12,37 & $0,99^{* *}$ & ns \\
30 & 7,09 & 8,48 & 9,14 & 9,90 & $0,97^{* *}$ & ns \\
60 & 6,94 & 8,29 & 8,84 & 9,61 & $0,96^{* *}$ & ns \\
90 & 7,58 & 8,77 & 9,61 & 10,67 & $0,99^{* *}$ & ns \\
150 & 8,74 & 10,03 & 10,49 & 11,70 & $0,97^{* *}$ & ns \\
210 & 8,39 & 9,89 & 9,99 & 10,34 & $0,79^{* *}$ & ns \\
270 & 8,86 & 9,95 & 9,98 & 10,41 & $0,83^{* *}$ & ns \\
360 & 8,86 & 10,04 & 10,07 & 10,19 & $0,69 *$ & ns \\
Termo de & & & & & & \\
Regressão $\left(\mathrm{R}^{2}\right)$ & & & & & & \\
Linear & $0,79^{* *}$ & $0,63^{* *}$ & ns & ns & & - \\
Quadrático & $0,85^{*}$ & ns & ns & ns & - & -
\end{tabular}

Ano agrícola $1997 / 98$

\begin{tabular}{|c|c|c|c|c|c|c|}
\hline \multirow[t]{2}{*}{ Dias } & \multicolumn{4}{|c|}{ Doses de lodo de esgoto $\left(\mathrm{Mg} \mathrm{ha}^{-1}\right)$} & \multicolumn{2}{|c|}{ Termo de Regressão $\left(\mathrm{R}^{2}\right)$} \\
\hline & 0 & 37 & 74 & 110 & Linear & Quadrático \\
\hline 0 & 8,57 & 11,79 & 12,88 & 15,95 & $0,97^{* *}$ & ns \\
\hline 30 & 8,86 & 11,83 & 12,81 & 14,97 & $0,97^{=*}$ & ns \\
\hline 60 & 8,72 & 11,00 & 11,68 & 14,10 & $0,96 *$ & ns \\
\hline 90 & 8,87 & 11,06 & 11,85 & 14,00 & $0,97^{* *}$ & ns \\
\hline 150 & 8,98 & 11,33 & 11.65 & 14,01 & $0,94^{* *}$ & ns \\
\hline 210 & 8,99 & 11,03 & 11,72 & 14,33 & $0,96^{* *}$ & ns \\
\hline 270 & 9,42 & 11,37 & 12,05 & 13,82 & $0,97^{* *}$ & ns \\
\hline 360 & 9,48 & 11,06 & 11,84 & 13,53 & $0,98^{* *}$ & ns \\
\hline \multicolumn{7}{|c|}{$\begin{array}{c}\text { Termo de } \\
\text { Regressão }\left(\mathrm{R}^{2}\right)\end{array}$} \\
\hline Linear & $0,87^{*}$ & ns & $0,28^{*}$ & $0,56^{* *}$ & - & - \\
\hline Quadrático & ns & ns & $0,62^{*}$ & $0,68^{\circ}$ & - & - \\
\hline
\end{tabular}

Tias após a incorporação do lodo de esgoto;

${ }^{*},{ }^{* *}$, ns Indicam respectivamente, que os termos de regressão linear ou quadrática foram significativos a $\mathrm{P} \leq 0,05$, $P \leq 0,01$ ou não significativos pelo teste $F$.

Estes dados revelam de uma maneira geral, que o lodo de esgoto foi capaz de proporcionar aumentos significativos nos teores de carbono orgânico do solo, sugerindo a possibilidade de incrementos crescentes por ocasião de aplicações sucessivas do resíduo. Tais incrementos também foram observados por autores que desenvolveram 
seus experimentos em solos sob clima temperado. Epstein et al. (1976) verificaram em condições de campo, que mesmo após 18 meses da aplicação de 160 e $240 \mathrm{Mg} \mathrm{ha}^{-1}$ de lodo de esgoto anaeróbio, os teores de carbono orgânico num solo siltoso apresentaram-se respectivamente, 50 e 100\% maior que a testemunha. De maneira semelhante, Logan et al. (1997) observaram durante 5 anos, aumentos lineares no carbono total do solo em decorrência de uma única aplicação de doses crescentes do resíduo.

Por outro lado, trabalhos conduzidos no Brasil, portanto em regiões tropicais, mostraram que quando ocorrem efeitos do lodo de esgoto sobre o carbono orgânico dos solos, estes são temporários. Melo et al. (1994) verificaram que a aplicação de lodo de esgoto anaeróbio em doses de até $16 \mathrm{Mg} \mathrm{ha}^{-1}$ (com 39,3\% de umidade), proporcionaram efeitos sobre o teor de C-orgânico de um Latossolo Vermelho escuro distrófico até 77 dias após aplicação do resíduo. Desse periodo até 230 dias, somente a dose de $32 \mathrm{Mg} \mathrm{ha}^{-1}$ foi suficiente para manter alguma alteração sobre a variável considerada. Resultados concordantes foram observados por Silva (1995) o qual não detectou nenhum acréscimo significativo de C-orgânico no solo, após 146 dias da aplicação de 20 e $40 \mathrm{Mg} \mathrm{ha}^{-1}$ (62\% de umidade) de lodo de esgoto anaeróbio num Podzólico Vermelho-Amarelo. Segundo os autores, teria ocorrido uma rápida e total degradação do lodo de esgoto nas taxas e condições de clima em que foi aplicado.

Comparado com os dados de Melo et al. (1994) e Silva (1995), os resultados obtidos por Marques(1996) sugerem que somente em taxas elevadas de aplicações, seria possivel um efeito mais prolongado do lodo de esgoto sobre os teores de carbono orgânico dos solos. Dessa forma, é possivel que no presente trabalho tais efeitos só tenham ocorrido devido as elevadas doses e a freqüência anual das aplicações. Porém, em doses menores que $33-37 \mathrm{Mg} \mathrm{ha}^{-1}$ (6,8 $\mathrm{Mg} \mathrm{ha}^{-1}$ de C-orgânico) provavelmente seriam necessárias várias aplicações anuais e sucessivas até que seus efeitos sobre o carbono orgânico do solo fossem detectados num periodo maior ou igual a um ano das aplicações.

Os teores de carbono orgânico foram influenciados pela interação entre tratamentos e épocas de amostragem do solo. Esperava-se que esta interação fosse 
devida ao decréscimo dos teores de carbono determinados nas várias amostragens, o que foi verdadeiro apenas para as doses B e C, no ano agrícola 1997/98. No entanto, pode-se observar na Tabela 9, no decorrer das épocas de amostragem do solo, um comportamento crescente dos teores de C-orgânico da testemunha absoluta. Tais acréscimos foram mais expressivos para o primeiro ano agrícola. O teor de carbono orgânico apresentado originalmente pelo Latossolo Vermelho-Amarelo, antes da instalação do experimento, era de $9,29 \mathrm{~g} \mathrm{~kg}^{-1}$ (Tabela 2). Dessa forma, o sensivel decréscimo observado para esta variável no tempo zero do ano agrícola 1996/97 é justificado pelas operações de preparo do solo antes da aplicação do resíduo. Tais operações que constaram de subsolagem, aração e gradagem promoveram uma inversão de camadas, aflorando o solo da camada abaixo de 0,2 m com menor teor de C-orgânico (Tabela 2). Outra possibilidade a ser considerada é o estímulo a degradação de parte do C-orgânico nativo do solo pela aeração proporcionada por tais operações. É importante notar que os teores de C-orgânico da testemunha retornaram aos seus valores originais somente aos 24 meses do preparo inicial do solo.

Em virtude destes fatos, a melhor maneira encontrada para se quantificar o decréscimo do carbono orgânico do solo ao longo de todo o período experimental, daí estimando-se a sua taxa de degradação, foi subtraindo-se dos tratamentos com aplicação do resíduo, o efeito da testemunha nas respectivas épocas de amostragem do solo criando-se assim, a variável denominada gradiente de carbono. Este procedimento permitiu uma comparação mais detalhada entre os decréscimos do carbono nos dois anos agrícolas, além de fornecer indicativos sobre o potencial de seu acúmulo no solo.

A análise de variância para gradiente de carbono apontou no ano agrícola 1996/97, interação significativa entre doses de lodo de esgoto e épocas de amostragem, evidenciando um comportamento diferenciado entre doses. Para o segundo ano, foram verificados efeitos significativos de doses e épocas de amostragem, não havendo interação entre estes fatores. Desta forma, obteve-se um comportamento médio válido para as três doses do resíduo.

De maneira geral, para os dois anos agrícolas, verificou-se que o decréscimo do carbono orgânico aplicado ao solo através do lodo de esgoto, ajustou-se a um modelo de cinética de primeira ordem (Figura 12). Com base neste modelo matemático, pode-se 
inferir que o lodo de esgoto teria apresentado uma fase inicial de degradação mais rápida seguida por outras de estabilização progressiva. A maior velocidade de degradação no período inicial seria explicada pelo ataque microbiano àquelas substâncias orgânicas mais facilmente degradáveis que restaram do tratamento biológico do lodo de esgoto, como proteínas celulares e carboidratos, ao passo que para a fase final a menor velocidade de degradação seria atribuída às substâncias mais recalcitrantes. Miller (1974), Terry et al. (1979a) e Terry et al. (1979b) observaram este mesmo comportamento para lodos anaeróbios em ensaios de respirometria conduzidos em condições de laboratório. Em condições de campo, através de metodologia semelhante à utilizada no presente trabalho, esse comportamento também foi verificado por Logan et al. (1997).

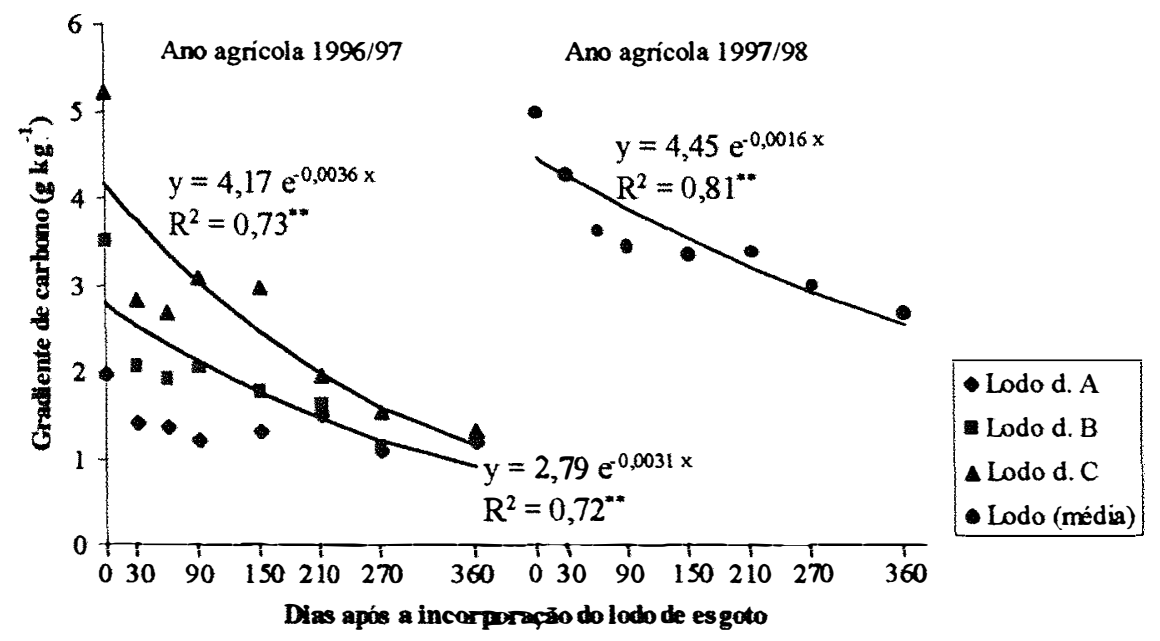

Figura 12. Decréscimo do carbono orgânico adicionado ao solo via lodo de esgoto, nos anos agrícolas de 1996/97 e 1997/98, ajustado a um modelo de cinética de primeira ordem. ("* significativo a $\mathrm{P} \leq 0,01$ pelo teste $\mathrm{F}$ )

Os valores estimados para as constantes de velocidade praticamente não variaram entre as doses aplicadas no ano agrícola 1996/97. No entanto, tais valores foram o dobro da constante média estimada no ano agrícola 1997/98. Estas constantes refletiram diretamente sobre as taxas globais de decréscimo do carbono orgânico do solo nos períodos estudados. 
Para o primeiro ano agrícola as taxas de decréscimo foram estimadas em $65 \mathrm{e}$ $73 \%$ respectivamente, para as doses de 66 e $99 \mathrm{Mg} \mathrm{ha}^{-1}$. Estas taxas podem ser consideradas como uma estimativa da taxa de degradação da carga orgânica do lodo de esgoto. Para a menor dose do resíduo não houve ajuste significativo do modelo matemático adotado. Neste caso é possível que o método analítico utilizado na determinação do carbono orgânico não tenha sido suficientemente sensível para superar a variabilidade dos resultados. É importante salientar que neste ano, para diminuir ao máximo a interferência de plantas invasoras, foram necessárias três operações de cultivo mecânico. Assim, as altas taxas de degradação estimadas para o lodo de esgoto podem ser justificadas por um aumento na oxidação do carbono orgânico, estimulado pelo revolvimento e conseqüente oxigenação do solo na camada superficial.

Após a segunda aplicação do resíduo, ano agricola 1997/98, a taxa média de decréscimo do carbono foi estimada em $44 \%$. Entretanto, não é possivel afirmar que houve uma queda na taxa de degradação do resíduo uma vez que, a taxa de decréscimo obtida nesta ocasião incluiu o carbono recalcitrante acumulado no solo devido a aplicação anterior. O fato de não ter havido neste ano, nenhuma operação mecânica que revolvesse o solo, certamente colaborou no sentido de diminuir o decréscimo do carbono. Entretanto, não devem ser descartadas as possibilidades da ocorrência de efeitos inibitórios sobre microorganismos organotróficos, causado pelo possível acúmulo de metais pesados e substâncias orgânicas recalcitrantes e tóxicas presentes no lodo de esgoto. Tais possibilidades devem ser avaliadas cuidadosamente em outros estudos.

As taxas de decréscimo do carbono encontradas no presente trabalho podem estar superestimadas, o que teria ocorrido basicamente por duas razões: devido a possibilidade da perdas através da lixiviação de substâncias orgânicas solúveis da camada de incorporação do resíduo; devido ao aumento da degradação do carbono orgânico nativo do solo em função da aplicação do lodo de esgoto, fenômeno conhecido como "efeito priming" observado por diversos autores, entre eles Terry et al. (1979a).

Nas condições em que foi realizado o presente trabalho, considerando-se as taxas e a freqüência de aplicações do resíduo, evidenciou-se que parte do carbono orgânico presente no lodo de esgoto foi resistente a degradação Estes resultados são concordantes com diversos estudos realizados em condições controladas de laboratório, 
os quais evidenciaram a relativa resistência a degradação no solo, da carga orgânica de lodos anaeróbios. Miller (1974) obteve taxas máximas de degradação de 20 e 18\%, em 180 dias de incubação de doses equivalentes a 90 e $224 \mathrm{Mg} \mathrm{ha}^{-1}$ (base seca). Por um período de 365 dias, Agbin et al.(1977) observaram taxas de 28,5 e 19,6\% respectivamente, para doses equivalentes a 22,4 e $224 \mathrm{Mg} \mathrm{ha}^{-1}$ (base seca). Terry et al. (1979a) afirmaram que uma fração do lodo de esgoto é rapidamente decomponível em solos aeróbios entretanto, de 55 a $80 \%$ do seu C-orgânico parece ser recalcitrante.

A persistência do carbono orgânico presente no lodo esgoto quando adicionado ao solo, é atribuída essencialmente ao tratamento de estabilização biológica que esses resíduos recebem nas estações de tratamento de esgotos (Demuynck et al., 1985). Tal persistência por sua vez, é conferida pela presença significativa na fração orgânica do lodo, de compostos orgânicos estáveis como lignina, celulose, lipídeos, substâncias húmicas, graxas, ceras, óleos e resinas (Pagliai et al., 1981; Clapp et al. 1986).

Considerando-se as evidencias do acúmulo de carbono orgânico no solo, algumas alterações em suas propriedades químicas e físicas são esperadas (Clapp et al., 1986 e Metzger \& Yaron, 1987). Neste contexto, estudando algumas propriedades físicas do Latossolo Vermelho-Amarelo da área experimental, Marciano (1999) verificou após a segunda aplicação de lodo de esgoto, alterações na densidade do solo, na porosidade total e na condutividade hidráulica determinada para a faixa de potencial mátrico de 0 a $1 \mathrm{kPa}$.

É preciso considerar que o simples aumento no teor de carbono pode não significar apenas beneficios ao sistema solo-planta. Hohla et al. (1978) verificaram um importante fenômeno num solo que recebeu aplicações sucessivas de lodo de esgoto anaeróbio por 6 anos. Observaram que os teores de carbono orgânico neste solo aumentaram de 9,5 para $22,9 \mathrm{~g} \mathrm{~kg}^{-1}$ entretanto, estudos de fracionamento revelaram que do C-orgânico presente no solo tratado com lodo, 10,9\% era de C-carboidrato e 11,9\% era óleos e graxas enquanto que, no solo testemunha estas frações eram respectivamente de $18,9 \%$ e $1,67 \%$. Isto demonstra que é preciso conhecer melhor a qualidade do carbono orgânico persistente e principalmente seus efeitos a longo prazo sobre as características químicas e físicas do solo que são de interesse para fins agronômicos e ambientais. 


\subsubsection{Condutividade elétrica e $\mathrm{pH}$}

Para os dois anos agrícolas, a condutividade elétrica do solo foi influenciada significativamente pela interação entre tratamentos com lodo de esgoto e épocas de amostragem (Tabela 10).

De maneira geral, o lodo de esgoto aumentou a condutividade elétrica do solo. No ano agrícola 1996/97, verifica-se na maioria das épocas de amostragem, que as doses empregadas do resíduo proporcionaram efeito quadrático sobre a variável em questão. Para o ano seguinte, após a segunda aplicação, com exceção apenas dos valores determinados aos 30 dias, foi constatado que a condutividade aumentou linearmente com as doses empregadas. Este comportamento diferenciado entre os dois anos agrícolas deve estar relacionado com a dinâmica da degradação da carga orgânica do lodo de esgoto e principalmente com a distribuição das precipitações pluviométricas ocorridas dentro de cada ano, nas respectivas épocas de amostragem do solo.

Os maiores acréscimos observados para esta variável foram, no ano agrícola 1996/97, aos 30 dias após a incorporação do lodo de esgoto e no ano agrícola 1997/98, aos 150 dias. Para o primeiro ano, nas parcelas tratadas com as doses $\mathrm{A}$ e $\mathrm{C}$ do resíduo, os respectivos acréscimos na condutividade elétrica foram de 995 e $1153 \%$ em relação a testemunha. Em 1997/98, tais acréscimo variaram de 393 a 768\%. Aumentos na condutividade elétrica de solos tratados com lodo de esgoto também foram observados por Epstein et al. (1976), Stark \& Clapp (1980), Bevacqua \& Mellano (1994), Logan et al. (1997) e Anjos (1999).

O lodo de esgoto utilizado no presente trabalho foi condicionado, no seu processo de tratamento, com $\mathrm{FeCl}_{3}$ e cal hidratada. Dessa forma, apresentou em sua composição elevados teores de íons $\mathrm{Ca}^{2+}$. Isto posto, considerando-se que foram adicionadas ao solo via lodo de esgoto, quantidades anuais de $\mathrm{Ca}^{2+}$ variando de 4,8 a $16,9 \mathrm{Mg} \mathrm{ha}^{-1}$, parece razoável atribuir os aumentos na conduvidade elétrica a presença deste íon no solo. Entretanto, a contribuição de íons $\mathrm{NO}_{3}{ }^{-}$não deve ser desconsiderada. 
Tabela 10. Condutividade elétrica do solo $\left(\mu \mathrm{S} \mathrm{cm}^{-1}\right)$ determinada, na camada de $0-0,2 \mathrm{~m}$, para doses de lodo de esgoto em diversas épocas de amostragem, dentro dos anos agrícolas 1996/97 e 1997/98.

\begin{tabular}{|c|c|c|c|c|c|c|}
\hline \multirow{3}{*}{$\operatorname{Dias}^{1}$} & \multicolumn{4}{|c|}{ Ano agrícola 1996/97 } & \multirow{2}{*}{\multicolumn{2}{|c|}{ Termo de Regressão $\left(\mathrm{R}^{2}\right)$}} \\
\hline & \multicolumn{4}{|c|}{ Doses de lodo de esgoto $\left(\mathrm{Mg} \mathrm{ha}^{-1}\right)$} & & \\
\hline & 0 & 33 & 66 & 99 & Linear & Quadrático \\
\hline 30 & 101,6 & 1112,5 & 1022,0 & 1272,8 & $0,70^{* *}$ & $0,88^{* *}$ \\
\hline 60 & 79,4 & 464,3 & 516,0 & 606,0 & $0,82^{* *}$ & 0,96 \\
\hline 90 & 115,4 & 670,5 & 586,8 & 749,0 & $0,68^{* *}$ & $0,84^{* *}$ \\
\hline 150 & 107,0 & 517,0 & 484,8 & 600,8 & $0,73^{* *}$ & $0,88^{* *}$ \\
\hline 210 & 116,9 & 497,3 & 407,0 & 556,3 & $0,66^{* *}$ & $0,78^{* *}$ \\
\hline 270 & 62,9 & 246,0 & 280,5 & 368,3 & $0,91^{* *}$ & ns \\
\hline 360 & 73,9 & 294,8 & 336,0 & 370,5 & $0,81^{* *}$ & $0,97^{* *}$ \\
\hline \multicolumn{7}{|l|}{$\begin{array}{c}\text { Termo de } \\
\text { Regressão }\left(\mathrm{R}^{2}\right)\end{array}$} \\
\hline Linear & ns & $0.59^{* *}$ & $0,61^{* *}$ & $0,62^{* *}$ & - & - \\
\hline \multirow[t]{2}{*}{ Quadrático } & ns & $0,67^{* *}$ & $0,78^{* *}$ & $0,73^{* *}$ & - & - \\
\hline & \multicolumn{4}{|c|}{ Ano agrícola 1997/98 } & & \\
\hline \multirow[t]{2}{*}{ Dias } & \multicolumn{4}{|c|}{ Doses de lodo de esgoto $\left(\mathrm{Mg} \mathrm{ha}^{-1}\right)$} & \multicolumn{2}{|c|}{ Termo de Regressão $\left(\mathrm{R}^{2}\right)$} \\
\hline & 0 & 37 & 74 & 110 & Linear & Quadrático \\
\hline 30 & 127,3 & 530,5 & 569,5 & 716,3 & $0,86^{* *}$ & 0,94 " \\
\hline 60 & 79,7 & 309,0 & 336,0 & 454,0 & $0,90^{* *}$ & ns \\
\hline 90 & 89,8 & 468,5 & 555,8 & 712,8 & $0,91^{m *}$ & ns \\
\hline 150 & 92,2 & 454,8 & 499,3 & 800,0 & $0,93^{* *}$ & ns \\
\hline 210 & 61,8 & 289,5 & 280,0 & 534,8 & 0,96 "* & ns \\
\hline 270 & 80,0 & 379,5 & 472,8 & 672,8 & $0,96^{* *}$ & ns \\
\hline 360 & 70,8 & 156,3 & 252,6 & 301,1 & $0,99^{* *}$ & ns \\
\hline \multicolumn{7}{|c|}{$\begin{array}{c}\text { Termo de } \\
\text { Regressão }\left(\mathrm{R}^{2}\right)\end{array}$} \\
\hline Linear & ns & $0,55^{* *}$ & $0,35^{* *}$ & $0,27^{* *}$ & - & - \\
\hline Quadrático & ns & $0,59^{*}$ & ns & $0,52^{* *}$ & - & - \\
\hline
\end{tabular}

Dias após a incorporação do Iodo de esgoto;

${ }^{*},{ }^{* *}$, ns Indicam respectivamente, que os termos de regressão linear ou quadrática foram significarivos a $\mathrm{P} \leq 0,05$, $P \leq 0,01$ ou não significativo pelo teste $F$.

Epstein et al. (1976) atribuíram os aumentos na condutividade elétrica de solos tratados com lodo de esgoto à grande concentração de íons $\mathrm{Ca}^{2+}, \mathrm{Mg}^{2+} \mathrm{e} \mathrm{Cl}^{-}$presentes na camada de incorporação do resíduo. De forma concordante, Anjos (1999) encontrou correlações significativas entre a conduvidade elétrica de solos, tratados sucessivamente com elevadas taxas do resíduo, e seus teores de $\mathrm{Ca}^{2+}, \mathrm{Mg}^{2+}$ e $\mathrm{K}^{+}$. 
Considerando-se o comportamento da condutividade elétrica dentro das doses de lodo de esgoto no decorrer das amostragens, verifica-se para os dois anos agrícolas a medida que aumenta o tempo da incorporação do resíduo, uma tendência significativa de queda em seus valores (Tabela 10). Este decréscimo na concentração salina da superficie do solo provavelmente é devido a lavagem de íns solúveis ou em suspensão, proporcionado pelo movimento descendente da água de precipitações pluviométricas.

Comportamentos semelhantes foram obtidos por Epstein et al. (1976) e Harding et al. (1985). Ao aplicarem $240 \mathrm{Mg} \mathrm{ha}^{-1}$ de lodo de esgoto, Epstein et al. (1976) verificaram que a condutividade elétrica (pasta de saturação) aumentou, após um mês, de $410 \mu \mathrm{S} \mathrm{cm}^{-1}$ na testemunha para $5450 \mu \mathrm{S} \mathrm{cm}^{-1}$ na área tratada. Depois de quatro meses os valores encontrados foram $1310 \mu \mathrm{S} \mathrm{cm}^{-1}$ na testemunha e $3850 \mu \mathrm{S} \mathrm{cm}^{-1}$ na área tratada. Somente após 15 meses da aplicação é que foram observados valores tolerados pela maioria das culturas ou seja, $660 \mu \mathrm{S} \mathrm{cm}^{-1}$ na testemunha e $1500 \mu \mathrm{S} \mathrm{cm}^{-1}$ na área tratada. Os autores explicaram que este decréscimo verificado no decorrer do tempo foi devido a lixiviação de íons $\mathrm{Ca}^{2+}, \mathrm{Mg}^{2+}$ e $\mathrm{Cl}^{-}$causada pela ocorrência de chuvas no período de estudo. Harding et al. (1985) verificaram que após três anos de aplicações acumuladas de 119, 237 e $466 \mathrm{Mg} \mathrm{ha}^{-1}$ (base seca) de lodo de esgoto anaeróbio, a condutividade elétrica (suspensão solo:água 1:2,5)que atingiu valores máximos de até $1100 \mu \mathrm{S} \mathrm{cm}^{-1}$ logo após a última aplicação do resíduo, diminuiu após cinco anos do encerramento das aplicações, para um valor médio de $490 \mu \mathrm{S} \mathrm{cm}^{-1}$.

A hipótese da lixiviação de íons é comprovada neste trabalho, pelas determinações realizadas em amostras de solo coletadas em profundidade, 360 dias após a incorporação do resíduo, nos dois anos agrícolas (Tabela 11). Com base nestes dados, verifica-se que as doses empregadas de lodo de esgoto proporcionaram aumentos significativos da condutividade elétrica até $0,8 \mathrm{~m}$ de profundidade, evidenciando a lixiviação de íons pelo perfil do solo. Comparando-se a condutividade elétrica para profundidades, dentro de cada dose do resíduo, observa-se que ao final de 1996/97 os maiores valores foram para as camadas superficiais de $0-0,2$ e $0,2-0,4 \mathrm{~m}$ e para $1997 / 98$ estes ocorreram na camada de 0,2-0,4 m. No entanto, os valores observados comparados à testemunha, sugerem a movimentação de íons para as camadas abaixo de 
0,8 m possibilitando assim, aumentos prováveis e expressivos na condutividade elétrica de camadas mais profundas.

A lixiviação de íons $\mathrm{Ca}^{2+}, \mathrm{Mg}^{2+}, \mathrm{K}^{+}, \mathrm{Cl}^{-}, \mathrm{NH}_{4}^{+}$e $\mathrm{NO}_{3}{ }^{-}$devida a disposição de lodo de esgoto e que apresenta potencial para aumentar a condutividade elétrica em subsuperficie foi verificada por Medalie et al. (1994) e Anjos (1999).

A possibilidade de acúmulo de sais na camada de incorporação do resíduo em decorrência da segunda aplicação não foi evidenciada. Quando são comparados os dados de condutividade elétrica obtidos aos 360 dias após cada incorporação de lodo de esgoto, verifica-se no ano agrícola 1997/98, que os valores determinados foram sensivelmente menores do àqueles apresentados no ano anterior. Esta observação é reforçada pela proximidade verificada entre os demais valores de cada ano agrícola, nas respectivas épocas de amostragem (Tabela 10). É preciso salientar que a não ocorrência de efeito cumulativo pode ser devida ao fato de que no ano agrícola 1997/98, houveram precipitações acumuladas em $1655 \mathrm{~mm}$ ao passo que, no ano anterior estas foram acumuladas em $1480 \mathrm{~mm}$. Considerando-se a média local de $1275 \mathrm{~mm}$ anuais (periodo de retorno de 82 anos) verifica-se também que as quantidades de chuvas ocorridas no período experimental foram atípicas. O efeito das precipitações sobre a condutividade elétrica do solo pode ser exemplificado pela comparação entre os valores obtidos aos 30 dias após cada incorporação de lodo de esgoto. Em 1996/97, nos tratamentos com doses do resíduo, foram detectados valores aproximadamente 2 vezes maiores do àqueles verificados em 1997/98. Assim, enquanto que no primeiro ano a precipitação acumulada no período foi de $107,4 \mathrm{~mm}$, no ano seguinte foi observado um total de $386,7 \mathrm{~mm}$.

Embora a condutividade elétrica do solo, para todas as doses de lodo de esgoto e durante todo o período experimental, tenha se apresentado abaixo de $2000 \mu \mathrm{S} \mathrm{cm}^{-1}$, valor acima do qual os solos são considerados salinos (Richards, citado por Lopes, 1989), deve-se ressaltar que a adoção deste parâmetro não fornece uma indicação segura quanto ao grau de salinização do solo experimental, haja visto que este critério foi elaborado com base em determinações da condutividade em extratos de saturação.

Não obstante a isto, dependendo do tipo de solo e do regime pluviométrico do local, existe a possibilidade das doses do resíduo empregadas no presente trabalho ocasionar, mesmo que temporariamente, problemas de salinidade e seus conseqüentes efeitos ao desenvolvimento das plantas. Ademais, de acordo com os dados apresentados 
na Tabela 11, é possível afirmar que em condições de déficit hídrico, onde predominariam movimentos ascendentes da água do solo, haveria o afloramento dos sais que se encontram nas camadas subsuperficiais podendo assim, causar situações de salinidade agravando ainda mais os problemas de deficiência hídrica. Bevacqua \& Mellano (1994) encontraram efeitos sazonais do lodo de esgoto, sobre a condutividade elétrica do solo, que foram prejudiciais às culturas do alho e alface. Convém salientar que eles aplicaram durante dois anos, o total acumulado de $74 \mathrm{Mg} \mathrm{ha}^{-1}$ de um composto a base do resíduo, taxas e frequência de aplicações bem menores que no presente trabalho, e devido a combinação com os efeitos climáticos a condutividade elétrica em extrato de saturação chegou a picos temporários de $2440 \mu \mathrm{S} \mathrm{cm}^{-1}$.

Tabela 11. Condutividade elétrica do solo $\left(\mu \mathrm{S} \mathrm{cm}^{-1}\right)$ determinada nas camadas de $0-0,2$, $0,2-0,4,0,4-0,6$ e 0,6-0,8 m, aos 360 dias após incorporação de doses de lodo de esgoto nos anos agrícolas 1996/97 e 1997/98.

\section{Ano agrícola 1996/97}

Profundidade Doses de lodo de esgoto $\left(\mathrm{Mg} \mathrm{ha}^{-1}\right)$ Termo de Regressão $\left(R^{2}\right)$

( m )

\begin{tabular}{|c|c|c|c|c|c|c|}
\hline$(\mathrm{m})$ & 0 & 33 & 66 & 99 & Linear & Quadrático \\
\hline $0-0,2$ & 73,9 a & 294,8 a & 336,0 a & 370,5 a & $0,81^{* *}$ & $0.97^{*}$ \\
\hline $0,2-0,4$ & 73,8 a & 250,9 a & 376,0 a & 309,0 a & $0,68^{* *}$ & $0,98^{* *}$ \\
\hline $0,4-0,6$ & $68,8 \mathrm{a}$ & $160,6 \quad b$ & $196,8 \quad b$ & $207,8 \quad b$ & $0,86^{*}$ & ns \\
\hline $0,6-0,8$ & $61,2 \mathrm{a}$ & 153,2 & 199,7 & 218,6 & $0,91^{* *}$ & ns \\
\hline
\end{tabular}

\section{Ano agrícola 1997/98}

Profundidade

Doses de lodo de esgoto $\left(\mathrm{Mg} \mathrm{ha}^{-1}\right)$

Termo de Regressão $\left(\mathrm{R}^{2}\right)$

Doses de lodo de esgoto $\left(\mathrm{Mg} \mathrm{ha}^{-1}\right)$

\begin{tabular}{rrrrrrrrrrr} 
& 0 & \multicolumn{2}{c}{37} & & 74 & & 110 & Linear & Quadrático \\
\cline { 2 - 8 } $0-0,2$ & 70,7 & a & 156,3 & b & 252,6 & b & 301,1 & c & $0,98^{* *}$ & ns \\
$0,2-0,4$ & 54,1 & a & 231,0 & a & 330,3 & a & 460,8 & a & $0,99^{* *}$ & ns \\
$0,4-0,6$ & 46,5 & a & 144,2 & b & 227,5 & b & 387,0 & b & $0,98^{* *}$ & ns \\
$0,6-0,8$ & 53,7 & a & 128,9 & b & 228,2 & b & 283,1 & c & $0,99^{* *}$ & ns
\end{tabular}

$*^{* *}$, ns Indicam respectivamente, que os termos de regressão linear ou quadrática foram significativos a $\mathrm{P} \leq 0,05$,
$\mathrm{P} \leq 0,01$ ou não significativo pelo teste $\mathrm{F}$; Médias seguidas por letras distintas, em colunas, diferem entre si a $\mathrm{P} \leq 0,05$ pelo teste de Tukey - D.M.S. $5 \%=63,3$ (ano agrícola 1996/97) D.M.S. 5\% =69,9 (ano agrícola 1997/98).

Diante dos resultados aqui observados é importante destacar que a possibilidade de salinização dos solos, devido a utilização pouco cuidadosa do lodo de esgoto, é real. Dessa forma, é imprescindivel que esta variável seja monitorada e considerada em estratégias de manejo. 
Os resultados da aplicação de doses crescentes de lodo de esgoto sobre o $\mathrm{pH}$ do solo (Tabela 12) mostraram interação significativa entre tratamentos e épocas de aplicação para 1996/97 e efeito de épocas para 1997/98. As variações do pH em função das épocas de amostragem do solo foram pouco expressivas e apresentaram baixos coeficientes de determinação. Por outro lado, em função das doses aplicadas do resíduo, a variável apresentou aumentos de acordo com modelo quadrático, para ambos os anos.

Tabela 12. Valores $\mathrm{pH}$ do solo determinados para doses de lodo de esgoto em diversas épocas de amostragem, dentro dos anos agrícolas 1996/97 e 1997/98.

\begin{tabular}{|c|c|c|c|c|c|c|c|c|c|}
\hline \multirow{3}{*}{$\operatorname{Dias}^{1}$} & \multicolumn{7}{|c|}{ Ano agrícola 1996/97 } & \multirow{2}{*}{\multicolumn{2}{|c|}{ Termo de Regressão $\left(\mathrm{R}^{2}\right)$}} \\
\hline & \multicolumn{7}{|c|}{ Doses de lodo de esgoto $\left(\mathrm{Mg} \mathrm{ha}^{-1}\right)$} & & \\
\hline & 0 & \multicolumn{2}{|c|}{33} & \multicolumn{2}{|r|}{66} & \multicolumn{2}{|r|}{99} & Linear & Quadrático \\
\hline 30 & 4,3 & & 5,8 & & 6,5 & & 6,7 & $0,89^{* *}$ & $0,99^{\prime *}$ \\
\hline 60 & 4,2 & & 5,5 & & 6,7 & & 6,9 & $0,94^{* *}$ & $0,99^{* *}$ \\
\hline 90 & 4,2 & & 6,7 & & 7,0 & & 7,4 & $0,79^{* *}$ & $0,95^{* *}$ \\
\hline 150 & 4,3 & & 6,2 & & 6,7 & & 6,9 & $0,82^{* *}$ & $0,99^{* *}$ \\
\hline 210 & 4,2 & & 6,2 & & 6,6 & & 7,0 & $0,84=$ & $0,97^{* *}$ \\
\hline 270 & 4,2 & & 6,0 & & 6,7 & & 6,8 & $0,83^{* *}$ & $0,99^{\text {\#*}}$ \\
\hline 360 & 4,1 & & 6,5 & & 6,7 & & 6,5 & $0,61^{* *}$ & $0,96^{* *}$ \\
\hline \multicolumn{10}{|l|}{$\begin{array}{c}\text { Termo de } \\
\text { Regressão }\left(\mathrm{R}^{2}\right)\end{array}$} \\
\hline Linear & ns & & $0,21^{*}$ & & ns & & $0,22^{*}$ & - & - \\
\hline Quadrático & ns & & ns & & ns & & $0,57^{* *}$ & - & - \\
\hline \multicolumn{8}{|c|}{ Ano agrícola 1997/98 } & & \\
\hline \multirow[t]{2}{*}{ Dias } & \multicolumn{7}{|c|}{ Doses de lodo de esgoto ( $\left.\mathrm{Mg} \mathrm{ha}^{-1}\right)$} & \multicolumn{2}{|c|}{ Termo de Regressão $\left(\mathrm{R}^{2}\right)$} \\
\hline & 0 & & 37 & & 74 & & 110 & Linear & Quadrático \\
\hline 30 & 4,3 & & 6,9 & & 7,1 & & 7,4 & - & - \\
\hline 60 & 4,3 & & 6,6 & & 6,9 & & 7,0 & - & - \\
\hline 90 & 4,2 & & 6,4 & & 7,1 & & 7,3 & - & - \\
\hline 150 & 4,2 & & 6,8 & & 7,2 & & 7,4 & - & - \\
\hline 210 & 4,2 & & 6,8 & & 7,3 & & 7,5 & - & - \\
\hline 270 & 4,2 & & 7,0 & & 7,2 & & 7,5 & - & - \\
\hline 360 & 4,1 & & 6,8 & & 7,2 & & 7,5 & - & - \\
\hline \multirow{3}{*}{$\begin{array}{l}\text { Regressão para níveis } \\
\text { de Tratamentos }\end{array}$} & 4,2 & & 6,8 & & 7,1 & & 7,4 & $0,77^{* *}$ & $0,97^{* *}$ \\
\hline & \multicolumn{7}{|c|}{ Dias } & & \\
\hline & 30 & 60 & 90 & 150 & 210 & 270 & 360 & & \\
\hline $\begin{array}{c}\text { Regressão para níveis } \\
\text { de Dias }\end{array}$ & 6,3 & 6,3 & 6,3 & 6,4 & 6,4 & 6,4 & 6,5 & - & $0,20^{*}$ \\
\hline
\end{tabular}

** Indica que os termos de regressão linear ou quadrática foram significativos a $\mathrm{P} \leq 0,01$ pelo teste $\mathrm{F}$. 
No ano agrícola 1996/97 o pH apresentou acréscimos médios, em relação a testemunha, de 1,9, 2,5 e 2,7 unidades respectivamente para as doses de 33, 66 e $99 \mathrm{Mg} \mathrm{ha}^{-1}$ de lodo de esgoto. Em $1997 / 98$ tais acréscimos foram de 2,6, 2,9 e 3,2 unidades, observados após a reaplicação de 37,74 e $110 \mathrm{Mg} \mathrm{ha}^{-1}$ do resíduo. Para as três doses aplicadas, os acréscimos de $\mathrm{pH}$ em decorrência da segunda aplicação foram de 0,7, 0,4 e 0,5 unidade. Dessa forma, observa-se que a reaplicação do resíduo proporcionou aumentos relativamente pequenos quando comparado àqueles do primeiro ano, o que sugere o efeito de tamponamento do solo.

A ação neutralizante do lodo de esgoto empregado no presente trabalho é essencialmente devida a sua alcalinidade intrínseca ( $\mathrm{pH}$ em média $>10$ ). Cabe lembrar que no processo de tratamento foram adicionadas elevadas quantidades de $\mathrm{CaO}$, uma base forte, com o objetivo de eliminar patógenos e facilitar o processo de desidratação. Trabalhos como de Barreto (1995), Oliveira (1995), Silva (1995), Sloan \& Basta (1995), Bertoncini (1997) e Anjos (1999) mostraram resultados semelhantes, os quais também foram atribuídos a alcalinidade do material.

Ao final de cada ano agrícola foram realizadas avaliações de $\mathrm{pH}$ em amostras de solos coletadas em profundidade. De acordo com os dados apresentados na Tabela 13, observa-se para o ano 1996/97, aumentos significativos de $\mathrm{pH}$ até a profundidade de $0,4 \mathrm{~m}$. Esses aumentos seguiram um comportamento quadrático em função das doses aplicadas do resíduo. De maneira geral, dentro de cada dose, os maiores valores de $\mathrm{pH}$ foram observados na camada de incorporação. Para o ano agrícola 1997/98 foram observados aumentos lineares do $\mathrm{pH}$ até a camada de 0,8 m, sendo os maiores valores, verificados nas camadas superiores. Esses acréscimos no $\mathrm{pH}$ do solo em profundidade, certamente estão relacionados com o caminhamento, junto a água da chuva, de substância alcalizantes presentes no lodo de esgoto.

Os efeitos neutralizantes do lodo de esgoto utilizado no presente trabalho devem ser tratados como um caso particular, principalmente porque a ação mais pronunciada é devida a cal e não ao material orgânico. Neste caso, conforme sugerem os dados deste trabalho, pode-se esperar com a seqüência das aplicações do lodo de esgoto, a quebra da capacidade de tamponamento do solo e com isso a ascensão do $\mathrm{pH}$ a valores 
acima de 7,5. Este fenômeno não seria desejável uma vez que, proporcionaria condições favoráveis a ocorrência de indisponibilidade de micronutrientes às plantas, como $\mathrm{Cu}, \mathrm{Fe}$, Mn e Zn (Malavolta, 1980).

Tabela 13. Valores pH do solo determinados nas camadas de $0-0,2,0,2-0,4,0,4-0,6$ e $0,6-0,8 \mathrm{~m}$, aos 360 dias após incorporação de doses de lodo de esgoto nos anos agrícolas 1996/97 e 1997/98.

\begin{tabular}{|c|c|c|c|c|c|c|}
\hline \multirow{3}{*}{$\begin{array}{c}\text { Profundidade } \\
\text { (m) }\end{array}$} & \multicolumn{4}{|c|}{ Ano agrícola 1996/97 } & \multirow{2}{*}{\multicolumn{2}{|c|}{ Termo de Regressão $\left(\mathrm{R}^{2}\right)$}} \\
\hline & \multicolumn{4}{|c|}{ Doses de lodo de esgoto $\left(\mathrm{Mg} \mathrm{ha}^{-1}\right)$} & & \\
\hline & 0 & 33 & 66 & 99 & Linear & Quadrático \\
\hline $0-0,2$ & 4,1 a & $6.5 \mathrm{a}$ & $6,7 \mathrm{a}$ & $6.5 \mathrm{a}$ & $0.61^{* *}$ & $0,96^{* *}$ \\
\hline $0,2-0,4$ & $4,2 \mathrm{a}$ & $4,9 \quad b$ & $5,8 \quad b$ & 5,4 b & $0,69^{* *}$ & $0,90^{=}$ \\
\hline $0,4-0,6$ & 4,2 a & 4,4 & 4,4 & 4,6 & ns & ns \\
\hline $0,6-0,8$ & 4,2 a & $4,3 \quad c$ & 4,4 & 4.6 & ns & ns \\
\hline
\end{tabular}

Ano agrícola 1997/98

Profundidade Doses de lodo de esgoto $\left(\mathrm{Mg} \mathrm{ha}^{-1}\right)$ Termo de Regressão $\left(\mathrm{R}^{2}\right)$

\begin{tabular}{|c|c|c|c|c|c|c|c|c|}
\hline & 0 & 37 & & 74 & & 110 & Linear & Quadrático \\
\hline $0-0,2$ & 4,1 a & & a & & a & 7,5 a & $0,79^{=*}$ & $0,97^{* *}$ \\
\hline $0,2-0,4$ & $4,1 \quad \mathrm{a}$ & 4,3 & b & & $b$ & $4,8 \quad b$ & $0,99^{* *}$ & ns \\
\hline $0,4-0,6$ & 4,1 a & 4,2 & b & 4,3 & b & 4,5 & $0,99^{* *}$ & ns \\
\hline $0,6-0,8$ & 4,1 a & 4,2 & b & 4,3 & $\mathrm{~b}$ & 4,5 & $0,95^{* *}$ & ns \\
\hline
\end{tabular}

${ }^{*},{ }^{* *}$, ns Indicam respectivamente, que os termos de regressão linear ou quadrática foram significativos a $\mathrm{P} \leq 0,05$, $\mathrm{P} \leq 0,01$ ou não significativo pelo teste $\mathrm{F}$;

Médias seguidas por letras distintas, em colunas, diferem entre si a $\mathrm{P} \leq 0,05$ pelo teste de Tukey - D.M.S. $5 \%=0,53$ (ano agrícola 1996/97), D.M.S. 5\% =0,29 (ano agricola 1997/98).

Frente a estas observações cabe aqui um comentário. A adição da cal ao lodo de esgoto constitui uma dificuldade a mais no manejo racional da disposição desse resíduo em solos agrícolas. Além dos efeitos sobre $\mathrm{opH}$ e a condutividade elétrica, são agravados os problemas relacionados com o desbalanço de nutrientes no solo, principalmente com relação ao $\mathrm{Ca}^{+2}, \mathrm{Mg}^{2+}$ e $\mathrm{K}^{+}$. Somados a desproporção quantitativa destes elementos no próprio lodo de esgoto, considerando-se a série liotrópica pela qual os cátions são retidos no solo (Raij, 1991), a ocupação dos sítios de trocas pelos íons $\mathrm{Ca}^{2+}$ deverá agravar ainda mais o problema de desbalanço devido a maior suscetibilidade a lixiviação do $\mathrm{Mg}^{2+}$ e $\mathrm{K}^{+}$. Os efeitos do excesso de $\mathrm{Ca}^{+2}$ sobre a lixiviação de $\mathrm{Mg}^{2+}$ e $\mathrm{K}^{+}$ em solos tratados com lodo de esgoto foram comprovados por Anjos (1999). 
Convém salientar que a literatura científica apresenta diversos trabalhos que demonstram a capacidade de lodos de esgoto, sem tratamento prévio com cal, em elevar o pH de solos (Epstein et al., 1976; Stark \& Clapp, 1980; Logan et al., 1997). Nestes casos os autores atribuíram o efeito neutralizante às reações envolvidas na degradação da carga orgânica do resíduo. Por outro lado, trabalhos conduzidos por King \& Morris (1972), Simeoni et al. (1984), Pietz et al. (1989) e Dowdy et al. (1991) encontraram, em solos cultivados, efeitos acidificantes desses resíduos, os quais foram atribuídos às reações de nitrificação, a provável oxidação de sulfitos e a produção de ácidos orgânicos durante a degradação do resíduo.

De maneira geral, pode-se inferir que a retirada da cal do sistema de tratamento do lodo de esgoto é desejável sob os aspectos considerados no presente estudo, e neste caso, outros testes para a determinação dos efeitos dos novos resíduos serão necessários. Contudo, é importante reconhecer que os efeitos neutralizantes da cal contribuem no solo, para reduzir a disponibilidade dos metais $\mathrm{Cd}, \mathrm{Cr}, \mathrm{Ni}$ e $\mathrm{Pb}$ às plantas (Kabata-Pendias \& Pendias, 1984; Alloway, 1990), o que seria um aspecto positivo.

\subsubsection{Capacidade de troca de cátions}

Através da análise de variância foram verificados, para os dois anos agrícolas, sobre a CTC do solo, efeitos significativos de doses de lodo de esgoto e épocas de amostragem porém, não houve interação entre estes fatores (Apêndice 2). $\mathrm{O}$ aumento da CTC em função das doses do resíduo seguiu, dentro de todas as amostragens nos dois anos agrícolas, um comportamento quadrático $\left(\mathrm{R}^{2}=0,92^{* *}\right)$. Análises de regressão apontaram uma tendência crescente nos valores desta variável em função das épocas de amostragem do solo. Embora este comportamento tenha apresentado significância estatística, devido essencialmente a precisão alcançada nas determinações da CTC, as diferenças verificadas para as médias da variável, no decorrer das amostragens em cada ano agrícola, foram extremamente pequenas, de alguns décimos, e por isso não serão consideradas na interpretação e discussão dos resultados.

Examinando-se o comportamento da CTC no decorrer do período experimental (Figura 13) verifica-se, durante os dois anos agrícolas, uma proximidade muito grande 
entre os valores determinados para os tratamentos com doses $\mathrm{A}, \mathrm{B}$ e $\mathrm{C}$ de lodo de esgoto. No ano agrícola 1996/97, obteve-se entre doses, um valor médio de CTC de 44,62 $\pm 0,17 \mathrm{mmol}_{\mathrm{c}} \mathrm{kg}^{-1}$ ao passo que, para 1997/98, tal valor foi de $44,78 \pm 0,16 \mathrm{mmol}_{\mathrm{c}} \mathrm{kg}^{-1}$. O acréscimo médio proporcionado pelo lodo de esgoto em relação a testemunha absoluta, foi em 1996/97, de $12,91 \pm 0,19 \mathrm{mmol}_{\mathrm{c}} \mathrm{kg}^{-1}$ e em $1997 / 98$, de $13,52 \pm 0,10 \mathrm{mmol}_{\mathrm{c}} \mathrm{kg}^{-1}$. Portanto, após a segunda aplicação do resíduo obteve-se um incremento de apenas $0,60 \pm 0,23 \mathrm{mmol}_{\mathrm{c}} \mathrm{kg}^{-1}$, o que pode ser considerado desprezível. Diante destas constatações, é interessante ressaltar que os efeitos do lodo de esgoto sobre a CTC a pH atual do solo, os quais se manifestaram logo aos 30 dias após a incorporação da primeira aplicação, não refletiram nenhuma alteração expressiva, mesmo depois de 360 dias da reaplicação do resíduo, no ano agrícola 1997/98.

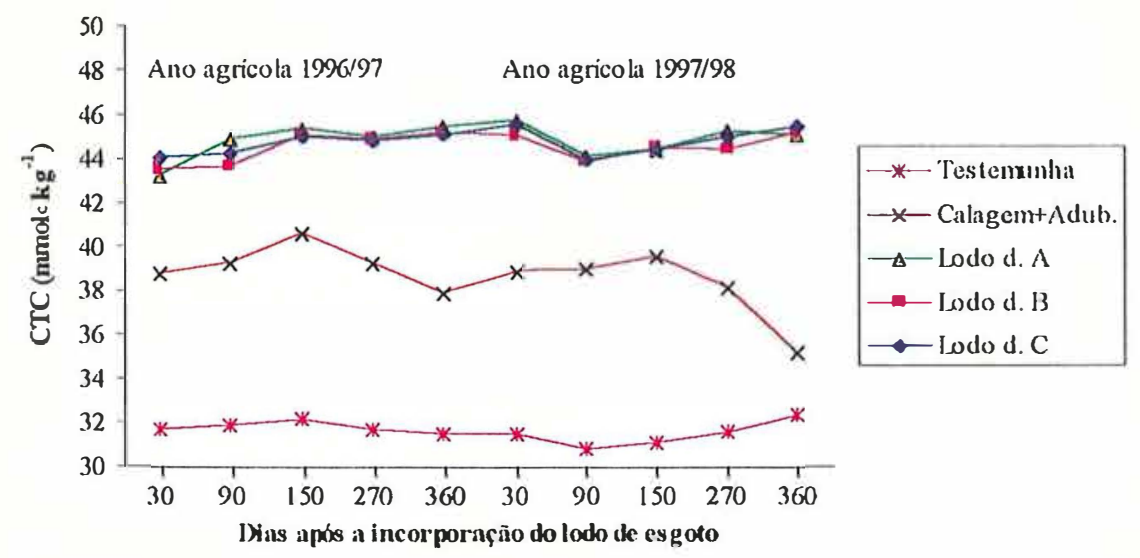

Figura 13. Capacidade de troca de cátions do solo no decorrer dos anos agrícolas 1996/97 e 1997/98 para os tratamentos com doses de lodo de esgoto e calagem + adubação mineral.

Um outro aspecto importante a ser considerado diz respeito a CTC a pH 7,0 do próprio lodo de esgoto (Tabela 3). Estimativas de acréscimos a CTC do solo, realizadas em função desses valores, da taxa de aplicação do resíduo e da densidade do solo na camada de incorporação revelam acréscimos potenciais ao redor de 5,4, 10,8 e $16,1 \mathrm{mmol}_{\mathrm{c}} \mathrm{kg}^{-1}$ respectivamente, em cada ano agrícola, para as doses A, B e C. Tendo em vista que os valores $\mathrm{pH}$ observados nos tratamentos com lodo de esgoto variaram, na 
maior parte do periodo experimental, entre 6,0 e 7,4 (Tabela 12), verifica-se em função das doses, que a estimativa crescente de incrementos para CTC não foi determinada no solo em nenhum momento (Figura 13). Portanto, considerando que a CTC a pH 7,0 do lodo de esgoto é devida essencialmente a sua carga orgânica, é possível que esta não seja a principal responsável pelas alterações determinadas na $\mathrm{CTC}$ a pH atual do solo.

De maneira geral, os resultados observados no presente trabalho não são concordantes com àqueles verificados por Epstein et al. (1976), Simeoni et al. (1984) e Cavallaro et al. (1993). Esses autores encontraram um comportamento crescente da CTC em função da aplicação de lodo de esgoto em doses que variaram de 0 a $240 \mathrm{Mg} \mathrm{ha}^{-1}$ (base seca). Em todos esses trabalhos, o comportamento da CTC foi atribuído aos acréscimos de carbono orgânico nos solos proporcionados pelas aplicações do resíduo.

Porém, é necessário ponderar que Epstein et al. (1976) estimou a CTC através da soma de bases, o que pode ter ocasionado superestimativas, essencialmente porque o

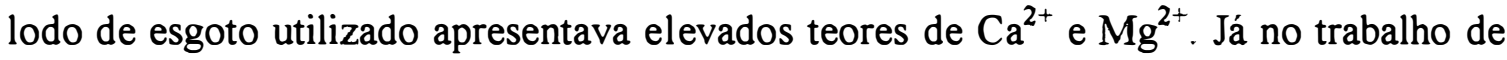
Simeoni et al. (1984) verificou-se que o resíduo empregado não proporcionou alterações significativas no $\mathrm{pH}$ do solo e além disso as determinações da CTC foram realizadas com solução alcalina tamponada $(\mathrm{pH}=8,2)$ assim, é provável que os resultados observados não sejam reais e sim, potenciais. Cavallaro et al. (1993) determinaram os valores CTC a pH atual, utilizando-se do mesmo método empregado no presente trabalho. Dessa forma, a discordância observada entre os resultados pode ser atribuída às diferenças existentes entre lodos de esgoto de diferentes origens, as quais são devidas aos processos de tratamento e principalmente a origem dos esgotos. Esta por sua vez, define os tipos de compostos orgânicos que prevalecerão na composição do resíduo.

Sabe-se que em solos tropicais o complexo de cargas negativas é essencialmente pH-dependente (Helling et al. 1964) e a matéria orgânica é a componente principal desse complexo (Fassbender, 1975). Assim, na tentativa de esclarecer melhor a participação das principais variáveis envolvidas na geração de cargas negativas no solo, foram estabelecidas relações entre a CTC e $\mathrm{pH}\left(\mathrm{CaCl}_{2}\right)$, e entre CTC e teores de carbono orgânico do solo (Figura 14). 


\section{Ano agrícola 1996/97}
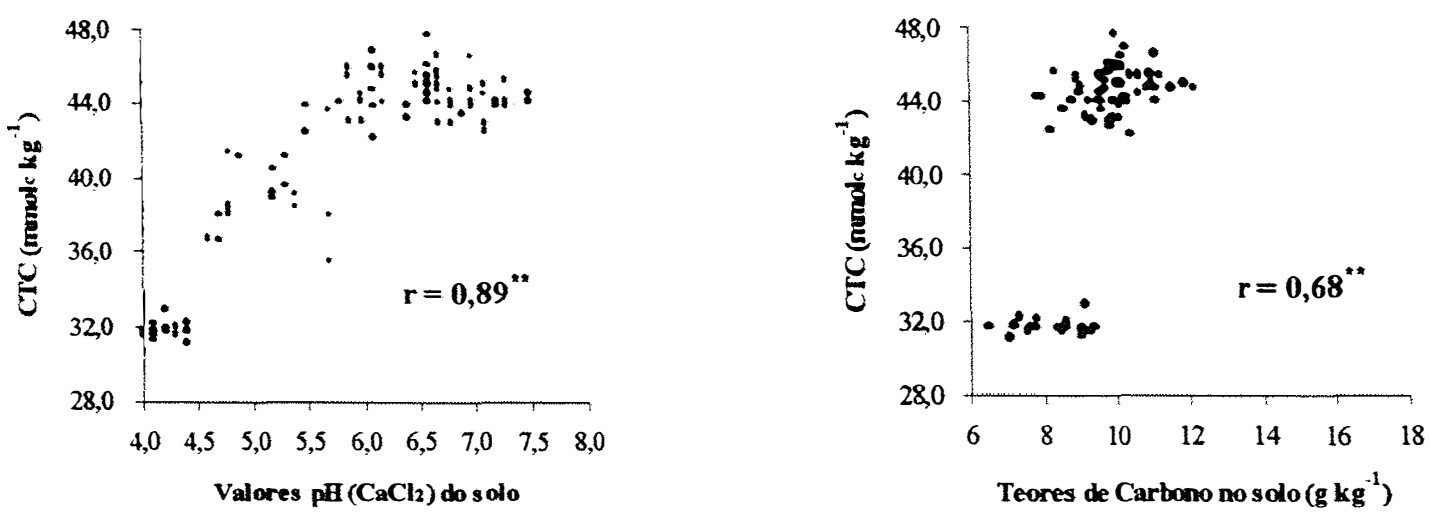

Ano agrícola $1997 / 98$
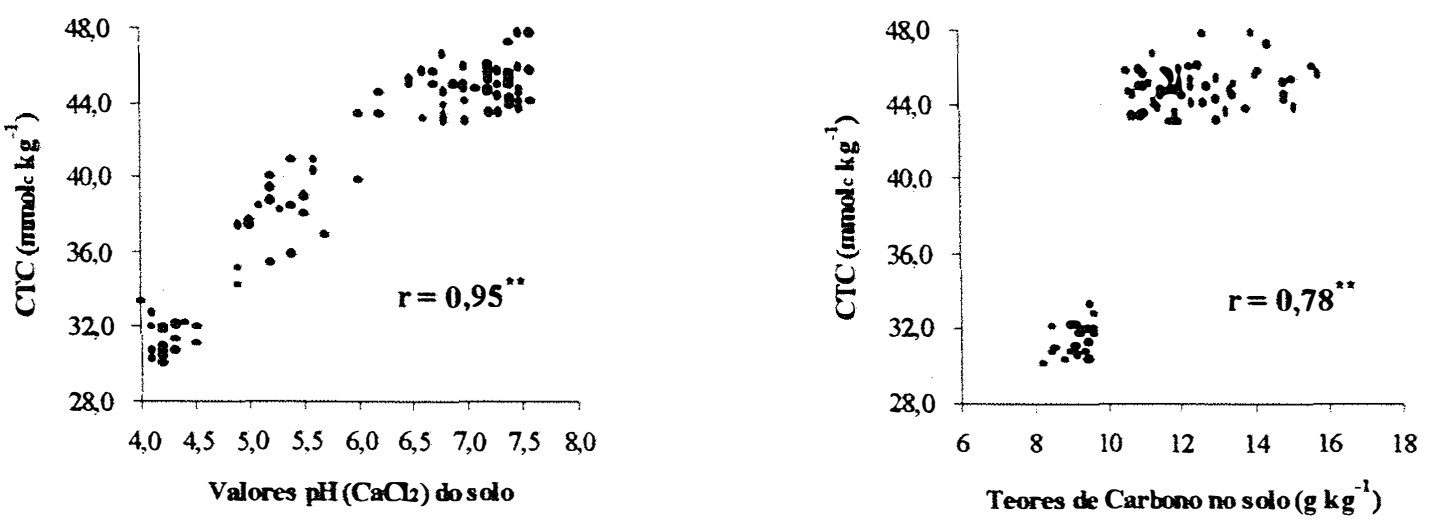

Anos agrícolas 1996/97 e 1997/98
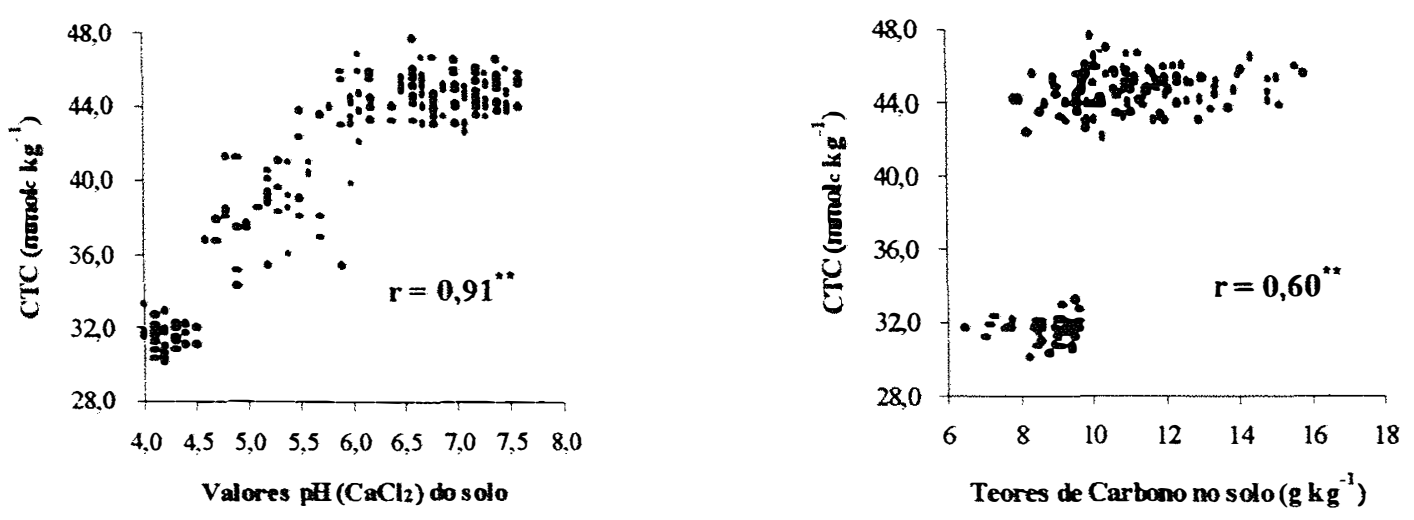

Figura 14. Relações entre CTC e pH, CTC e teores de carbono orgânico do solo no experimento com lodo de esgoto. (" Coeficientes de correlação significativos a $P \leq 0,01$ pelo teste $t)$. 
Para tanto, foram realizadas análises de correlação entre os valores de CTC ao $\mathrm{pH}$ atual e valores $\mathrm{pH}$ do solo considerando as determinações efetuadas separadamente, dentro de cada ano agrícola e para todo o período experimental. Incluiu-se nestas análises, os tratamentos com doses de lodo de esgoto e o tratamento calagem + adubação mineral. Pelo exame da Figura 14, verifica-se que as alterações na CTC apresentaram de maneira geral, uma elevada correlação positiva $\left(r=0,91^{* *}\right)$ com as alterações de $\mathrm{pH}$ do solo. Este fenômeno já era esperado uma vez que, conforme comentado anteriormente, a quase totalidade das cargas negativas em solos tropicais é dependente do $\mathrm{pH}$. No entanto, este comportamento só foi evidenciado porque o método utilizado para determinar a CTC o fez ao $\mathrm{pH}$ natural do solo.

As correlações entre CTC e carbono orgânico do solo foram positivas embora com coeficientes bem menores do que àqueles verificados com relação ao $\mathrm{pH}$. Convém salientar que neste caso, não foi considerado o tratamento calagem + adubação mineral já que este não causou alterações nos teores originais de carbono orgânico.

Esses resultados são concordantes com Barreto (1995) o qual verificou que os efeitos de doses de lodo de esgoto sobre a CTC determinada a $\mathrm{pH}$ atual de uma Areia Quartzosa foram melhores explicados pelas alterações no $\mathrm{pH}$ desse solo.

Diante das relações estabelecidas para o conjunto de dados obtidos, nos anos agrícolas de 1996/97 e 1997/98 (Figura 14), é possível verificar alguns fenômenos interessantes. O primeiro deles evidencia que os valores de CTC atingiram um patamar máximo a partir de valores $\mathrm{pH}$ próximos a 6,0 e não apresentaram variações expressivas acima deste valor. Ressalta-se que logo no primeiro ano agrícola, mesmo para a menor dose aplicada de lodo de esgoto, a maioria dos valores de $\mathrm{pH}$ observados foram próximos ou maiores do que 6,0 , o que sugere que tenha ocorrido a manifestação do potencial máximo de geração de cargas negativas variáveis do solo.

Com relação ao carbono orgânico, é fundamental observar que seus teores nas parcelas tratadas com as doses $\mathrm{A}, \mathrm{B}$ e $\mathrm{C}$ de lodo de esgoto variaram, no decorrer dos dois anos agrícolas, de 8,0 a $16,0 \mathrm{~g} \mathrm{~kg}^{-1}$, uma variação portanto, de $100 \%$. Apesar desta variação, considerando-se que os valores de $\mathrm{pH}$ do solo foram favoráveis a intensa manifestação de cargas variáveis da matéria orgânica, é estranho que nenhuma alteração expressiva na CTC tenha sido determinada. Diante dessas observações fica evidente que os aumentos de CTC, verificados nos tratamentos com lodo de esgoto, não foram 
predominantemente proporcionados pela carga orgânica do resíduo e sim por quaisquer outras formas diretamente relacionadas ao $\mathrm{pH}$ do solo.

Neste contexto, algumas hipóteses podem ser consideradas para explicar os fenômenos observados. A primeira delas parte do princípio de que a contribuição de resíduos orgânicos à CTC dos solos depende primariamente da natureza dos compostos orgânicos que os constituem (Rodella, 1996). Assim, conforme discutido no ítem 4.1.2, sabe-se que o lodo de esgoto contém uma gama variada de substâncias orgânicas que são recalcitrantes, sendo várias delas, substâncias apolares como óleos, graxas, resinas e ceras que conseqüentemente, por serem insolúveis em água, não geram cargas. Ademais, existem estudos que confirmam o acúmulo dessas substâncias no solo em decorrência de aplicações sucessivas do lodo de esgoto (Hohla et al. 1978). É possível também que a CTC a pH 7,0 determinada no resíduo seja devida a uma pequena fração orgânica degradável rapidamente no solo. Dessa forma, considerando que a degradação da carga orgânica do lodo de esgoto ocorre de acordo com um modelo cinético de primeira ordem, tal fração teria sido rapidamente degradada, antes mesmo das primeiras amostragens do solo.

Outra possível explicação está diretamente relacionada com o efeito neutralizante do lodo de esgoto. Neste caso, a maior parte do aumento manifestado pela CTC poderia ser atribuído as cargas variáveis da matéria orgânica nativa e da fração mineral do solo. Através da difratometria de raio X, verificou-se que a fração argila do Latossolo Vermelho-Amarelo da área experimental apresenta-se constituída basicamente por caulinita, goethita e hematita (dados não apresentados). Dessa forma, os incrementos de cargas negativas observados com o aumento do $\mathrm{pH}$ ocorreram provavelmente, devido a desprotonação de grupamentos silanol e aluminol da caulinita e de grupamentos hidroxila das superficies dos óxidos.

Destaca-se aqui que o tratamento com calagem, apresentou valores médios de CTC, durante os dois anos agrícolas, de $38,62 \pm 0,45 \mathrm{mmolc} \mathrm{kg}^{-1}$ o que representou um acréscimo em relação a testemunha, de $7,06 \pm 0,52 \mathrm{mmolc} \mathrm{kg}^{-1}$ (Figura 13 ). $\mathrm{O}$ valor $\mathrm{pH}$ médio nos dois anos foi de 5,2 nos tratamentos com calagem e de 4,2 nas testemunhas. Considerando-se que nenhuma fonte de carbono orgânico foi adicionada a este tratamento, verifica-se que apenas a elevação do valor $\mathrm{pH}$ do solo foi capaz de aumentar sua CTC. 


\subsubsection{Metais pesados}

\subsubsection{Acúmulo de metais pesados no solo e nas plantas}

O acúmulo de metais pesados em solos devido a disposições sucessivas de lodo de esgoto é um dos aspectos que causa preocupações com relação a segurança ambiental necessária para a viabilização desta prática. Sabe-se que, uma vez presentes na composição do resíduo, esses elementos podem seguir diversos caminhos quando são aplicados ao solo, sejam acumulados na camada onde são incorporados, absorvidos pelas plantas, lixiviados para camadas subsuperficiais ou arrastados pela erosão laminar.

Neste contexto, verifica-se na Tabela 14 que a disposição de doses crescentes de lodo de esgoto proporcionou, nos dois anos agricolas, aumentos lineares nos teores totais de $\mathrm{Cu}, \mathrm{Cr}$ e $\mathrm{Zn}$, avaliados após 360 dias da incorporação do resíduo. O elemento níquel foi detectado somente em 1997/98, para as duas maiores doses aplicadas. Os metais $\mathrm{Cu}$ e $\mathrm{Zn}$ foram os que apresentaram os maiores teores acumulados no solo, o que se explica pelas suas concentrações no resíduo. Para o $\mathrm{Cu}$, ao final do segundo ano agrícola, foram observados acréscimos médios em relação a testemunha, variando da menor para a maior dose aplicada, de 55 a $154 \%$. No caso do $\mathrm{Zn}$, esses acréscimos variaram de 148 a $381 \%$.

Os elementos $\mathrm{Cd}$ e $\mathrm{Pb}$ não foram detectados por apresentarem-se em concentrações abaixo do limite de determinação do método analítico empregado. No entanto, isto não significa que os mesmos estiveram ausentes e sim que suas concentrações foram respectivamente, menores que 18 e $76 \mathrm{mg} \mathrm{kg}^{-1}$. Situação semelhante foi observada para o $\mathrm{Ni}$ em todas as doses aplicadas em 1996/97 e para a dose A aplicada em 1997/98, as quais ocorreram em concentrações abaixo de $10 \mathrm{mg} \mathrm{kg}^{-1}$. De fato, quando são consideradas as quantidades $\left(\mathrm{mg} \mathrm{kg}^{-1}\right)$ de metais aplicadas ao solo via lodo de esgoto (Tabela 15 ), as quais teriam proporcionado um acúmulo máximo de $\mathrm{Cd}, \mathrm{Pb}$ e $\mathrm{Ni}$ de respectivamente, 1,74 , 12,91 e $8,97 \mathrm{mg} \mathrm{kg}^{-1}$, pode se verificar que estes teores não alcançaram os limites de determinação. 
Tabela 14. Teores totais de $\mathrm{Cu}, \mathrm{Cr}, \mathrm{Ni}$ e $\mathrm{Zn}$ recuperados do solo na camada $0-0,2 \mathrm{~m}$, nos anos agrícolas 1996/97 e 1997/98, para os tratamentos com doses de lodo de esgoto.

\begin{tabular}{|c|c|c|c|c|c|c|}
\hline \multirow[t]{2}{*}{ Ano agrícola } & \multicolumn{4}{|c|}{ Doses de lodo de esgoto $\left(\mathrm{Mg} \mathrm{ha}^{-1}\right)$} & \multicolumn{2}{|c|}{ Termo de Regressão $\left(\mathrm{R}^{2}\right)$} \\
\hline & 0 & $33(37)$ & $66(74)$ & $99(110)$ & Linear & Quadrático \\
\hline \multirow{4}{*}{$\begin{array}{l}1996 / 97 \\
1997 / 98\end{array}$} & \multicolumn{4}{|c|}{ Cobre $\left(\mathrm{mg} \mathrm{kg}^{-1}\right)$} & & \\
\hline & 17,86 & 19,47 & 27,90 & 30,97 & $0,93^{* *}$ & ns \\
\hline & 16,87 & 26,17 & 36,39 & 42,85 & $0,99^{* *}$ & ns \\
\hline & \multicolumn{4}{|c|}{ Cromo $\left(\mathrm{mg} \mathrm{kg}^{-1}\right)$} & & \\
\hline $1996 / 97$ & 16,57 & 21,56 & 25,30 & 25,59 & $0,89^{* *}$ & ns \\
\hline \multirow[t]{2}{*}{$1997 / 98$} & 15,55 & 18,14 & 25,21 & 27,19 & $0,95^{* *}$ & ns \\
\hline & \multicolumn{4}{|c|}{ Níquel (mg kg-1) } & & \\
\hline $1996 / 97$ & n.d. ${ }^{2}$ & n.d. & n.d. & n.d. & - & - \\
\hline \multirow[t]{2}{*}{$1997 / 98$} & n.d. & n.d. & 10,65 & 14,63 & - & - \\
\hline & \multicolumn{4}{|c|}{ Zinco (mg kg $\left.{ }^{-1}\right)$} & & \\
\hline $1996 / 97$ & 21,14 & 39,22 & 40,41 & 41,27 & $0,68^{* *}$ & $0,95^{* *}$ \\
\hline $1997 / 98$ & 20,19 & 50,03 & 77,11 & 97,21 & $0,99^{* *}$ & ns \\
\hline
\end{tabular}

Doses entre parênteses referem-se ao ano agrícola 1997/98;

${ }^{2}$ n.d. - não detectado, valor abaixo do limite de determinação do método analítico;

${ }^{*},{ }^{* *},{ }^{\text {ns }}$ Indicam respectivamente, que os termos de regressão linear ou quadrática foram significativos a $\mathrm{P} \leq 0,05$, $P \leq 0,01$ ou não significativo pelo teste $F$;

O potencial de acúmulo de metais pesados em solos, devido a disposição de lodo de esgoto, vem sendo extensivamente apontado nos EUA desde a década de 70 (King \& Morris, 1972; Cunningham et al., 1975; Galloway \& Jacobs, 1977; Baxter et al., 1983, Chang et al., 1984; Williams et al., 1980, 1984 e 1987). No Brasil, em trabalhos com solos de regiões tropicais, este potencial foi verificado por Berton et al. (1989), Oliveira (1992), Vanzolini (1994), Oliveira (1995), Barreto (1995), Silva (1995), Marques (1996), Anjos (1999) entre outros.

É importante salientar que os teores de $\mathrm{Cu}, \mathrm{Cr}$, Ni e $\mathrm{Zn}$ presentes no solo podem ser maiores do que àqueles recuperados pelo extrator "água régia". Considerando-se a somatória dos teores nativos dos metais extraídos pela "água régia" e as aplicações acumuladas desses mesmos metais pesados (Tabela 15), observa-se que os teores recuperados nos tratamentos com lodo de esgoto foram predominantemente inferiores. Este fato pode ser atribuído a problemas de amostragem do solo o que refletiria heterogeneidade na incorporação e na composição do resíduo, ao método de extração 
que nem sempre apresenta $100 \%$ de eficiência (Keller \& Védy, 1994) e a possibilidade desses elementos estarem sendo lixiviados para camadas abaixo de $0,2 \mathrm{~m}$.

Tabela 15. Quantidades de metais pesados adicionadas ao solo $\left(\mathrm{mg} \mathrm{kg}^{-1}\right)$, na camada de $0-0,2 \mathrm{~m}$, pela aplicação de lodo de esgoto nos anos agrícolas $1996 / 97 \mathrm{e}$ $1997 / 98$ e valores acumulados no período'.

\begin{tabular}{|c|c|c|c|c|c|c|c|c|c|}
\hline \multirow{3}{*}{ Metal } & \multicolumn{9}{|c|}{ Doses de lodo de esgoto ( $\left.\mathrm{Mg} \mathrm{ha}^{-1}\right)$} \\
\hline & \multicolumn{3}{|c|}{ Ano agrícola 1996/97 } & \multicolumn{3}{|c|}{ Ano agrícola 1997/98 } & \multicolumn{3}{|c|}{ Valores acumulados } \\
\hline & 33 & 66 & 99 & 37 & 74 & 110 & 70 & 140 & 209 \\
\hline & $:$ & & & & & & & & \\
\hline Cádmio & 0,36 & 0,71 & 1,07 & 0,22 & 0,45 & 0,67 & 0,58 & 1,16 & 1,74 \\
\hline Cobre & 9,83 & 19,67 & 29,50 & 7,51 & 15,01 & 22,52 & 17,34 & 34,68 & 52,02 \\
\hline Cromo & 4,83 & 9,65 & 14,48 & 5,43 & 10,85 & 16,13 & 10,26 & 20,50 & 30,61 \\
\hline Niquel & 2,99 & 5,98 & 8,97 & 4,02 & 8,04 & 11,95 & 7,01 & 14,02 & 20,92 \\
\hline Chumbo & 1,92 & 3,84 & 5,76 & 2,40 & 4,81 & 7,15 & 4,32 & 8,65 & 12,91 \\
\hline Zinco & 19,67 & 39,34 & 59,01 & 23,18 & 46,36 & 69,92 & 42,85 & 85,70 & 128,93 \\
\hline
\end{tabular}

Valores calculados com base no teor do metal presente no resíduo, com a dose aplicada e considerando a camada de incorporação no solo (0-0,2 m) cuja densidade de $1316 \mathrm{~kg} \mathrm{~m}^{-3}$ foi determinada por Marciano (1999).

A comparação dos teores totais determinados em 1996/97 com àqueles de $1997 / 98$ (Tabela 14) evidencia que aplicações sucessivas de lodo de esgoto, nas doses utilizadas neste trabalho, certamente levarão a um acúmulo desses metais na camada superficial do solo. Considerando-se a carga cumulativa máxima de metais pesados permitida pela aplicação de lodo de esgoto (USEPA, 1993 - Tabela 1) e com base nas concentrações médias apresentadas pelo resíduo empregado no presente trabalho (Tabela 3), estima-se que o elemento Ni seria o primeiro a atingir o limite máximo permitido, o que levaria de 15 a 46 anos no caso de aplicações anuais e sucessivas de doses médias variando entre 105 e $35 \mathrm{Mg} \mathrm{ha}^{-1}$ (base seca).

Dessa forma, observa-se que mesmo com elevadas taxas de aplicação, quando são considerados apenas os aspectos relacionados com metais pesados, as normas da USEPA, as quais foram adotadas pela CETESB (1998), são relativamente permissíveis. No entanto, cabe lembrar que estas normas tem sido alvo de criticas contundentes por parte de alguns autores. Wallace \& Wallace (1994) e McBride (1995) chamaram a atenção para vários fatores que não foram considerados pela USEPA na elaboração das normas. Destacaram entre outros, aspectos relacionados com a possibilidade de interação fitotóxica entre os metais pesados, a falta de pesquisas a longo prazo que 
comprovem a segurança dos limites estabelecidos e o desconhecimento do destino desses elementos no solo após os limites de acúmulo serem alcançados.

A possibilidade de incrementos na absorção de $\mathrm{Cd}, \mathrm{Cu}, \mathrm{Cr}, \mathrm{Ni}, \mathrm{Pb}$ e $\mathrm{Zn}$ pelas plantas de cana-de-açúcar foi avaliada através da determinação dos seus teores em amostras de folhas, colmo e caldo coletadas ao final dos anos agrícolas 1996/97 e 1997/98. Para os metais Cd, Cr, Ni e Pb não foram possíveis maiores considerações tendo em vista que suas concentrações, em todas as amostras analisadas, estiveram abaixo do limite de determinação do método analítico utilizado. Contudo, é possível assegurar que, caso as plantas tenham absorvido tais elementos, essas teriam apresentado concentrações abaixo dos seguintes valores: amostras de folhas e colmo desfibrado $\mathrm{Cd}<1,35 \mathrm{mg} \mathrm{kg}^{-1}, \mathrm{Cre} \mathrm{Ni}<0,75 \mathrm{mg} \mathrm{kg}^{-1}, \mathrm{~Pb}<5,70 \mathrm{mg} \mathrm{kg}^{-1}$; amostras de caldo $\mathrm{Cd}<0,04 \mathrm{mg} \mathrm{kg}^{-1}$; $\mathrm{Cr}$ e $\mathrm{Ni}<0,02 \mathrm{mg} \mathrm{kg}^{-1}, \mathrm{~Pb}<0,15 \mathrm{mg} \mathrm{kg}^{-1}$.

Os menores limites obtidos para determinação desses metais nas amostras de caldo foram devidos a possibilidade de concentração do extrato da amostra. Tais limites podem ser considerados satisfatórios, sugerindo que praticamente não ocorreram efeitos das doses de lodo de esgoto sobre as concentrações dos metais no caldo da cana-de-açúcar. Estes resultados são de grande relevância já que, não sendo verificados efeitos tóxicos às plantas, o caldo é o produto industrial da cana-de-açúcar onde o acúmulo de metais pesados poderia causar problemas a curto prazo.

Embora tenha havido uma preocupação em concentrar ao máximo os extratos das amostras de folhas e colmos, observa-se que estas não foram suficientes para a obtenção de limites de determinação aceitáveis. Dessa forma, fica evidente que a determinação desses elementos em concentrações baixas, sem pré-concentração, é praticamente impossível pelo método da espectrometria de absorção atômica com chama convencional ar/acetileno. Isto significa que em estudos futuros envolvendo metais pesados, resíduos urbanos e plantas, devem haver antes de qualquer coisa, preocupações em se buscar métodos analíticos alternativos, associados ou não com a espectrometria de absorção atômica, que possibilitem maior sensibilidade nestas determinações. Caso contrário, corre-se o grande risco de se obter novamente, resultados limitados que não permitam conclusões em termos quantitativos.

Existem na literatura científica informações de que as quantidades absorvidas de metais pesados pelas plantas são de uma maneira geral, menores do que $1 \%$ do total 
acumulado no solo e que esta absorção não é proporcional aos teores totais presentes (Chang et al., 1987). Assim, é possível que o lodo de esgoto não tenha proporcionado incremento algum na absorção de $\mathrm{Cd}$ e $\mathrm{Pb}$, haja visto que os acréscimos promovidos no solo pelas doses do resíduo foram relativamente pequenos (Tabela 15). Além disso, os teores de carbono orgânico e óxidos de $\mathrm{Fe}$ e $\mathrm{Al}$ do solo bem como seus valores $\mathrm{pH}$, foram favoráveis às reações de precipitação, complexação e adsorção que atuariam no sentido de reduzir a disponibilidade desses elementos às plantas (Kabata-Pendias \& Pendias, 1984; Adriano, 1986). Observações estas, válidas também para $\mathrm{Cr}$ e Ni.

Alguns resultados de pesquisa obtidos no Brasil, produzidos também com a cultura da cana-de-açúcar, corroboram com as inferências feitas anteriormente. Deve-se ressaltar porém, que a maioria das doses de lodo de esgoto empregadas pelos autores foram menores que as utilizadas no presente trabalho, além de serem aplicadas apenas por um ano agrícola. Silva (1995) verificou concentrações traços de Cd, Cr, Ni e Pb em amostras de colmos + folhas e de colmos de plantas cultivadas em áreas tratadas com doses crescentes de lodo de esgoto $\left(0,20\right.$ e $40 \mathrm{Mg} \mathrm{ha}^{-1}$ com $62 \%$ de umidade) porém, foi categórico em afirmar que os tratamentos não conferiram nenhum efeito sobre as variáveis em questão. De acordo com autor, as baixas concentrações encontradas nas amostras poderiam ser devidas a um mecanismo qualquer de retenção desses metais nas raízes da cultura ou até mesmo por um possível antagonismo desses elementos com cátions divalentes, como $\mathrm{Ca}^{2+}, \mathrm{Mn}^{2+}$ e $\mathrm{Zn}^{2+}$, presentes em maiores quantidades no solo. Marques (1996) também não detectou a presença de $\mathrm{Cd}, \mathrm{Cr}$ e $\mathrm{Pb}$ em amostras de folhas, colmo e caldo de plantas cultivadas com a utilização de doses de lodo de esgoto que variaram de 0 a $160 \mathrm{Mg} \mathrm{ha}^{-1}$ (com 74\% de umidade).

Com relação a $\mathrm{Cu}$ e $\mathrm{Zn}$, lembre-se que além de serem metais pesados, estes são micronutrientes de plantas. Assim, quando se considera os efeitos da disposição de resíduos urbanos contendo esses metais, as preocupações no que diz respeito às plantas, recaem sobre as possibilidades dos mesmos serem absorvidos em quantidades que venham causar desequilíbrios nutricionais e até mesmo efeitos fitotóxicos. Ademais, no caso da cana-de-açúcar existe a possibilidade de acréscimos nos teores desses elementos no caldo, o que poderia causar problemas no processo de industrialização da cultura, essencialmente na fermentação alcoólica. 
Os teores de $\mathrm{Cu}$ variaram, entre as amostras analisadas em todos tratamentos, para os anos 1996/97 e 1997/98, respectivamente entre os seguintes valores (Figura 15): folha - 5,04 a 6,65 $\mathrm{mg} \mathrm{kg}^{-1}, 4,59$ a $6,09 \mathrm{mg} \mathrm{kg}^{-1}$; colmo - 2,20 a 3,54 $\mathrm{mg} \mathrm{kg}^{-1}$, 1,94 a $2,95 \mathrm{mg} \mathrm{kg}^{-1}$; caldo - 0,25 a $0,60 \mathrm{mg} \mathrm{kg}^{-1}, 0,41$ a $0,88 \mathrm{mg} \mathrm{kg}^{-1}$. Para o $\mathrm{Zn}$ os intervalos de variação encontrados foram (Figura 16): folha - 13,58 a $21,10 \mathrm{mg} \mathrm{kg}^{-1}$, 13,40 a $21,00 \mathrm{mg} \mathrm{kg}^{-1}$; colmo-4,16 a $8,46 \mathrm{mg} \mathrm{kg}^{-1}, 5,23$ a $9,58 \mathrm{mg} \mathrm{kg}^{-1}$; caldo 0,56 a $1,14 \mathrm{mg} \mathrm{kg}^{-1}, 1,05$ a $1,41 \mathrm{mg} \mathrm{kg}^{-1}$.

De acordo com Sobral \& Weber (1983), os teores de micronutrientes nas diversas partes das plantas de cana-de-açúcar variam em função da variedade, de "cana-planta" para "cana-soca", com a idade das plantas e com o tipo de solo onde é cultivada. No entanto, considerando apenas como uma referência os dados apresentados para teores de $\mathrm{Cu}$ (Orlando Filho et al., 1980a) e teores de $\mathrm{Zn}$ (Orlando Filho et al., 1980b) obtidos para a variedade CB41-76, cultivadas em diversos tipos de solo e avaliadas em várias idades, pode-se afirmar que os teores obtidos no presente trabalho, nos colmos e na folha "+1", ocorreram dentro das variações encontradas por estes autores.

Os efeitos da disposição de lodo de esgoto sobre a absorção de $\mathrm{Cu}$ e $\mathrm{Zn}$ pelas plantas de cana-de-açúcar foram avaliados através de relações estabelecidas entre os teores determinados nas diferentes amostras de plantas e os teores totais recuperados do solo, para todos os tratamentos estabelecidos (Figuras 15 e 16). Nestas relações verificou-se a possibilidade de ajustes matemáticos buscando explicar o fenômeno ocorrido. Além dos tradicionais modelos de regressão linear e quadrática, aplicou-se um modelo exponencial modificado a partir da chamada equação do platô proposta por Logan \& Chaney ${ }^{5}$, citados por Logan et al. (1997). Este último pressupõe uma resposta do tipo assintótica para a absorção de metais pesados em função de seu acúmulo no solo. A descrição do modelo é a seguinte:

$$
\mathrm{y}=\mathrm{A}\left(1-\mathrm{e}^{-\mathrm{Bx}}\right)
$$

onde y é a concentração do metal na amostra de planta $\left(\mathrm{mg} \mathrm{kg}^{-1}\right)$, x é o teor total do metal recuperado do solo $\left(\mathrm{mg} \mathrm{kg}^{-1}\right)$, A é a concentração assintótica (platô) do metal na amostra de planta, B é a constante que define as alterações nos teores de metais da amostra em função do acréscimo do metal no solo.

\footnotetext{
${ }^{5}$ LOGAN. T.J.; CHANEY, R.L. Nonlinear rate response and relative crop uptake of sludge cadmium for land application of sludge risk assessment. In: LINDBERG, S.E.; HUTCHINSON, T.C. (Ed.) Proc. $^{\text {th }}$ International Conference Heavy Metals in the Environment. Edinburgh: CEP Consultants. 1987.p.387-388.
} 
Ano agrícola 1996/97
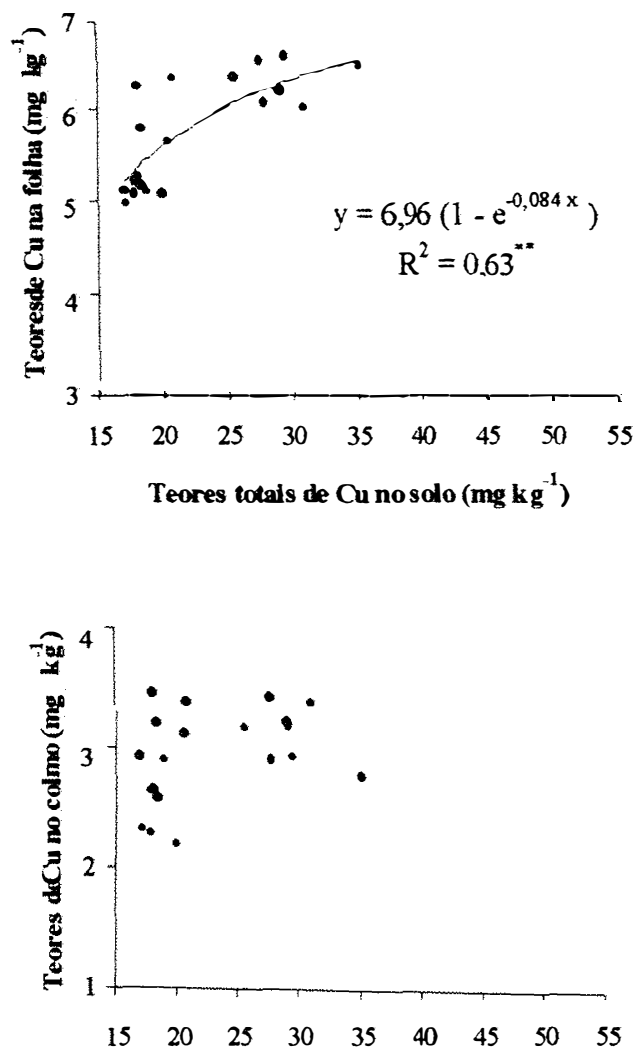

Teores totais de Cu no solo ( $\mathrm{mg} \mathrm{kg}^{-1}$ )

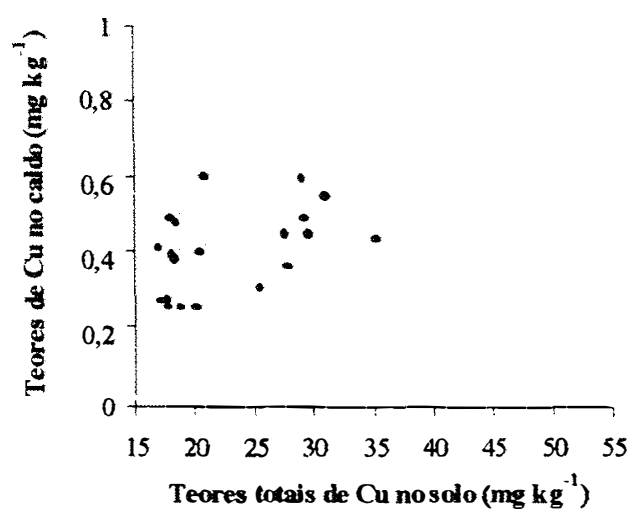

Ano agrícola 1997/98
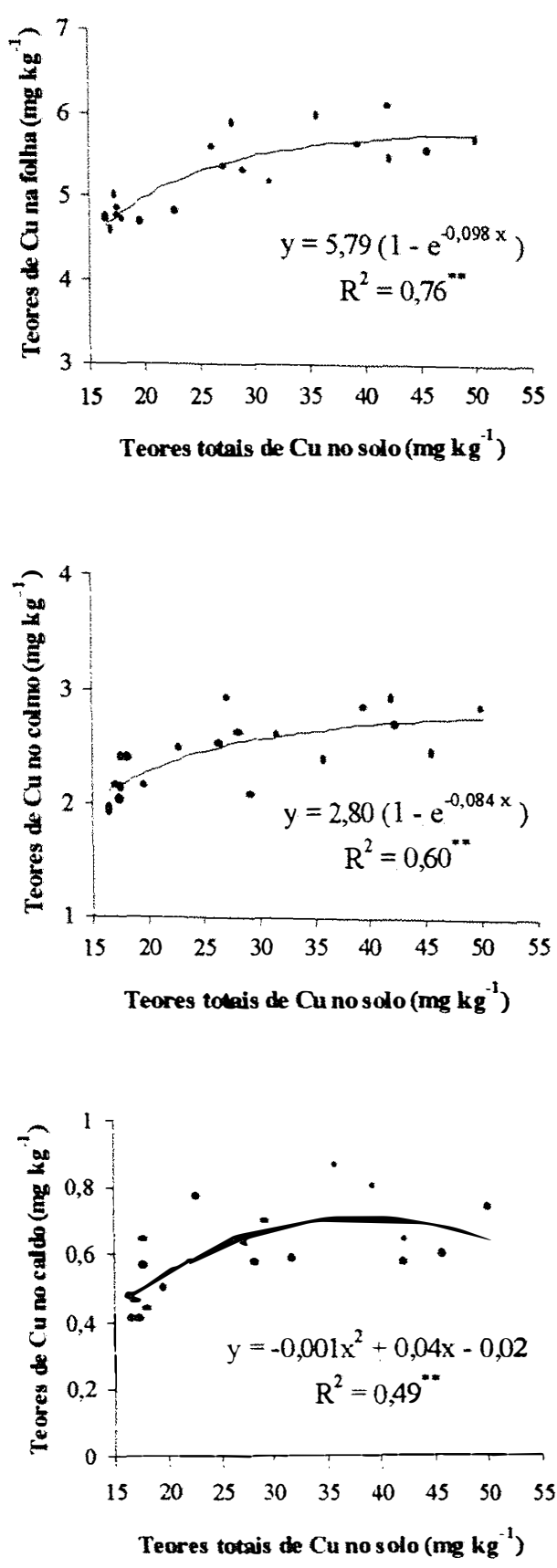

Figura 15. Relações entre teores de cobre nas amostras de folha, colmo e caldo da cana-de-açúcar e teores totais determinados no solo no experimento com lodo de esgoto. ("*Modelo ajustado significativo a $\mathrm{P} \leq 0,01$ pelo teste $\mathrm{F}$ ) 
Ano agrícola 1996/97
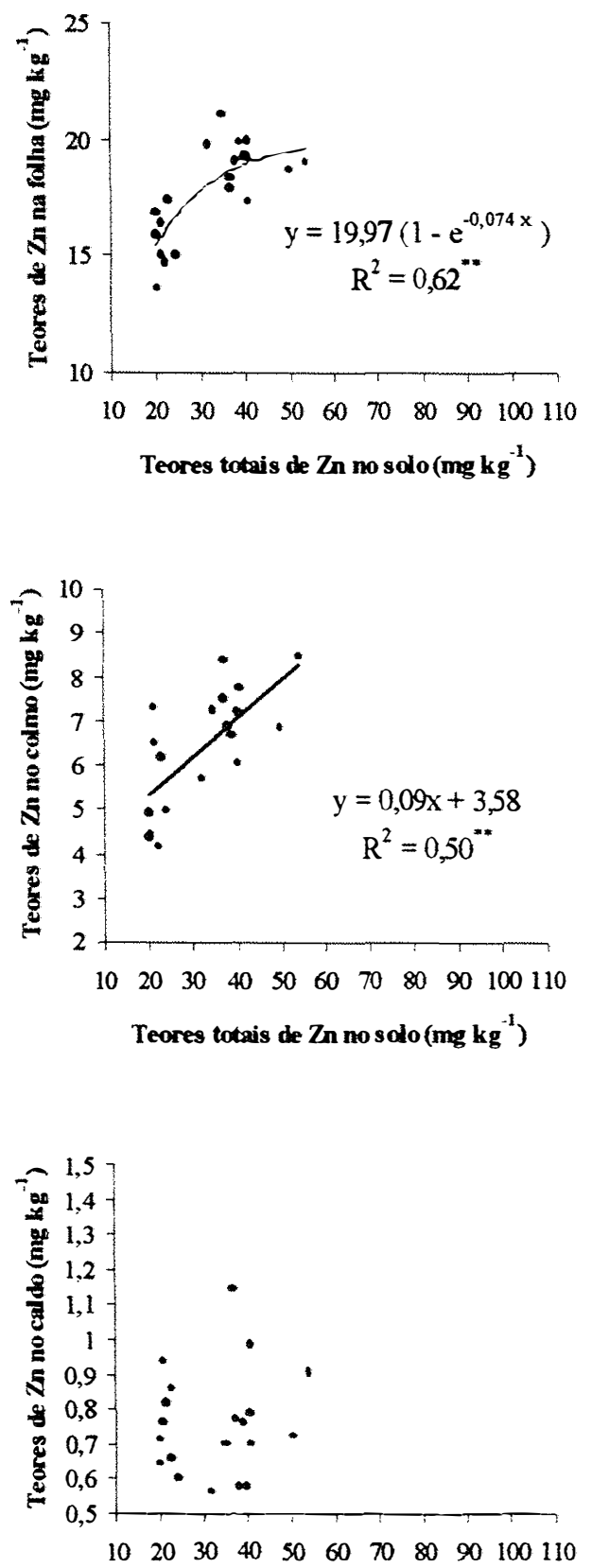

Teores totais de $\mathrm{Zn}$ no solo ( $\mathrm{mg} \mathrm{kg}^{-1}$ )
Ano agrícola 1997/98
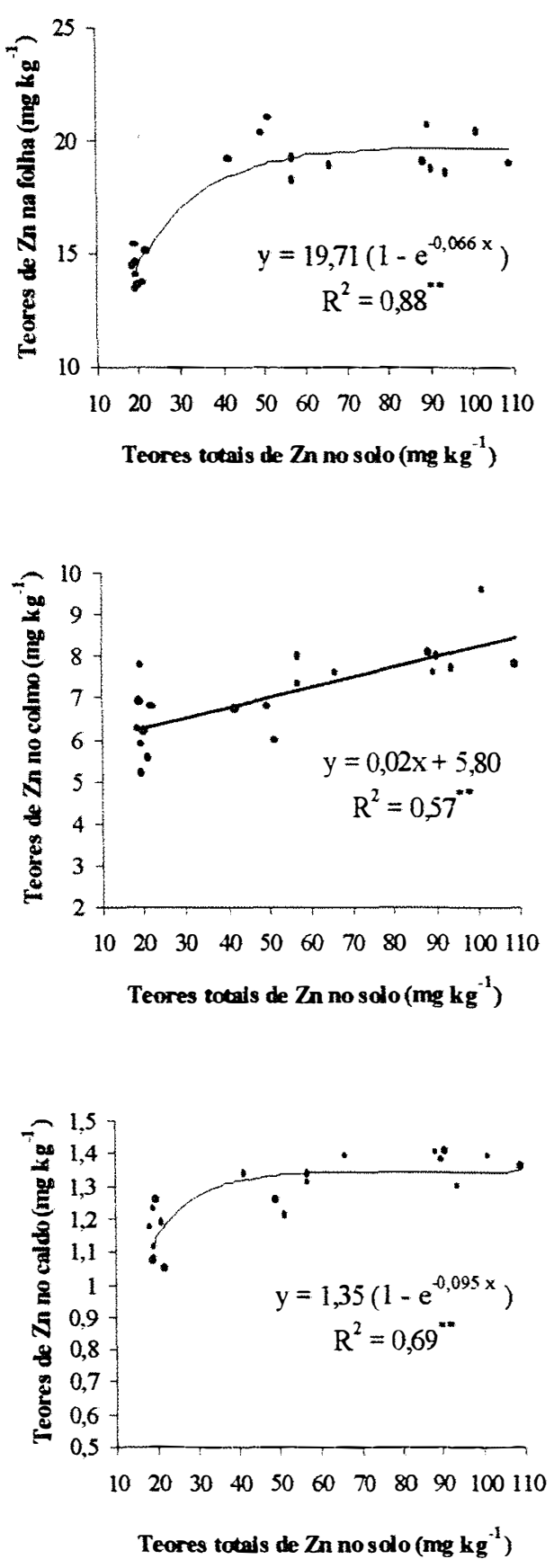

Figura 16. Relações entre teores de zinco nas amostras de folha, colmo e caldo da cana-de-açúcar e teores totais determinados no solo no experimento com lodo de esgoto. ("* Modelo ajustado significativo a $\mathrm{P} \leq 0,01$ pelo teste $F$ ) 
$\mathrm{Na}$ Figura 15, observa-se no ano agrícola 1996/97, aumentos dos teores de $\mathrm{Cu}$ na folha " +1 " em função dos acréscimos nos teores totais do solo. Nesta relação, o modelo matemático que melhor se ajustou foi o exponencial, sugerindo uma concentração platô de $\mathrm{Cu}$ de $6,96 \mathrm{mg} \mathrm{kg}^{-1}$ em média, $1,68 \mathrm{mg} \mathrm{kg}^{-1}$ acima dos teores obtidos para as folhas dos tratamentos sem lodo de esgoto (tratamentos 1 e 2). Para as amostras de colmo e caldo, não houveram evidencias de efeitos dos tratamentos com lodo de esgoto.

Nas amostras relativas a primeira soqueira, ano agrícola 1997/98, foram verificados efeitos significativos em todos os casos. Nas folhas observou-se novamente, um comportamento assintótico em relação aos acréscimos nos teores de $\mathrm{Cu}$ do solo. Enquanto esses teores variaram nos tratamentos com lodo de esgoto entre 25 e $50 \mathrm{mg} \mathrm{kg}^{-1}$, as folhas apresentaram uma concentração platô estimada em $5,79 \mathrm{mg} \mathrm{kg}^{-1}, 1,04 \mathrm{mg} \mathrm{kg}^{-1}$ em média, acima dos teores obtidos para as amostras dos tratamentos 1 e 2 . Comportamento semelhante é observado nas amostras de colmo, as quais apresentaram para a mesma variação de $\mathrm{Cu}$ no solo, uma concentração platô de $2,80 \mathrm{mg} \mathrm{kg}^{-1}$, em média $0,64 \mathrm{mg} \mathrm{kg}^{-1}$ maior do que os tratamentos 1 e 2. Nas amostras de caldo, o comportamento observado foi quadrático.

Com relação ao Zn, observa-se na Figura 16, para o ano agrícola 1996/97, efeitos significativos sobre seus teores na folha “+1" e no colmo, em função do acréscimo verificado nos teores totais do solo. Para as amostras de folha, observa-se uma concentração platô estimada em $19,97 \mathrm{mg} \mathrm{kg}^{-1}$, cerca de $4,10 \mathrm{mg} \mathrm{kg}^{-1}$ de acréscimo em relação aos teores verificados nos tratamentos 1 e 2 . Os teores no colmo aumentaram linearmente com os teores do solo e no caldo não foram verificados efeitos significativos.

Em 1997/98 foi observado um comportamento assintótico para os teores de $\mathrm{Zn}$ na folha e no caldo. As folhas "+1" apresentaram concentração platô de $19,71 \mathrm{mg} \mathrm{kg}^{-1}$, o que representa um acréscimo médio de $5,27 \mathrm{mg} \mathrm{kg}^{-1}$ em relação aos tratamentos sem lodo de esgoto. No caldo a concentração platô foi estimada em $1,35 \mathrm{mg} \mathrm{kg}^{-1}$, cerca de $0,20 \mathrm{mg} \mathrm{kg}^{-1}$ maior em relação as testemunhas. Os teores de $\mathrm{Zn}$ nas amostras de colmo aumentaram linearmente com o acréscimo nos teores totais do elemento no solo. 
A absorção de $\mathrm{Cu}$ e $\mathrm{Zn}$ por plantas cultivadas em solos tratados com lodo de esgoto, caracterizando respostas do tipo platô, também foi encontrada em estudos de longo prazo realizados por Barbarick et al. (1995) com a cultura do trigo e por Logan et al. (1997), com a cultura do milho. Por outro lado, Marques (1996) observou que a aplicação de até $160 \mathrm{Mg} \mathrm{ha}^{-1}$ (com $74 \%$ de umidade) de lodo de esgoto não alterou, quando comparado com as testemunhas, as concentrações de $\mathrm{Cu}$ e $\mathrm{Zn}$ no caldo da cana-de-açúcar (var. SP 70-1143); as médias verificadas foram respectivamente, 0,51 e $1,76 \mathrm{mg} \mathrm{kg}^{-1}$. Nos colmos, os teores de Cu praticamente não foram alterados pelos tratamentos, apresentando teor médio de $7,11 \mathrm{mg} \mathrm{kg}^{-1}$, já os teores de $\mathrm{Zn}$ não apresentaram comportamento definido. Nas folhas, os teores de $\mathrm{Zn}$ oscilaram entre 20 e $23 \mathrm{mg} \mathrm{kg}^{-1}$ sem deixar claro a influencia do resíduo e os teores de $\mathrm{Cu}$ aumentaram linearmente com as doses, chegando a atingir teores de $52,00 \mathrm{mg} \mathrm{kg}^{-1}$. Convém lembrar que, o trabalho de Marques (1996) foi conduzido por apenas 1 ano.

Os incrementos nos teores de $\mathrm{Cu}$ e $\mathrm{Zn}$ verificados em algumas amostras de plantas não foram de maneira geral, proporcionais aos aumentos que houveram nos teores totais desses metais, no solo. Dessa forma, nos casos em que foram observados comportamentos assintóticos é possível que seja um indicativo de que a partir de determinados teores acumulados no solo os teores absorvidos pelas plantas atinjam e se estabeleçam num valor máximo. Esta possibilidade foi defendida pela chamada "teoria do platô" proposta por Corey et al. (1987).

Porém, no presente trabalho não foi objetivo comprovar ou não a citada teoria, mesmo porque a forma e o tempo, pelos quais foi conduzido o experimento, não foram adequados para isso. Além disso, é importante considerar que os teores de C-orgânico nos solos tratados com lodo de esgoto, mantiveram-se elevados e os valores $\mathrm{pH}$ apresentaram-se próximos a 7,0. Para Logan et al. (1997) estas variáveis são os principais fatores de confundimento de tal teoria. De acordo com McBride (1995) e Chang et al. (1997), após o cessamento das aplicações de lodo de esgoto, com os processos da degradação do C-orgânico e a acidificação natural do solo, os metais pesados ora indisponíveis, passariam a formas solúveis e disponíveis às plantas. Esta 
seria de forma simplificada, uma definição da chamada "teoria da bomba relógio" McBride (1995).

Essas teorias ainda são objetos de estudo, de forma que não existe um consenso a este respeito. É fato que, os destinos desses elementos após a paralisação das aplicações do resíduo, são questões em aberto. É necessária portanto, a continuidade do estudo para verificar se as tendências observadas nos anos agrícolas 1996/97 e 1997/98 são válidas a longo prazo.

De qualquer maneira, é recomendável cautela na disposição desses resíduos no solo, que seja sempre acompanhada de monitoramento do sistema solo-planta-água enquanto que, trabalhos de pesquisa conduzidos a longo prazo procurem definir parâmetros e uma sistemática de aplicação comprovadamente adequada para as condições dos trópicos.

\subsubsection{Mobilidade de metais pesados no solo}

Os teores dos metais $\mathrm{Cd}^{2+}, \mathrm{Cr}, \mathrm{Cu}^{2+}, \mathrm{Ni}^{2+}, \mathrm{Pb}^{2+}$ e $\mathrm{Zn}^{2+}$ avaliados em todas as amostras de solução do solo, coletadas nas profundidades de 0,3,0,6 e 0,9 m, estiveram abaixo do limite de determinação do método analítico empregado, o que significa dizer que os teores de $\mathrm{Cd}^{2+}$ foram $<0,18 \mathrm{mg} \mathrm{L}^{-1}, \mathrm{Cr} \mathrm{e} \mathrm{Ni}^{2+}<0,10 \mathrm{mg} \mathrm{L}^{-1}, \mathrm{Cu}^{2+}$ e $\mathrm{Zn}^{2+}$

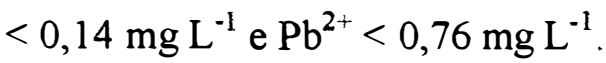

Diante do exposto, algumas considerações sobre o método de obtenção das amostras de solução do solo não podem deixar de serem feitas. De acordo com Suarez (1987), a extração por meio de vácuo pode levar a erros uma vez que neste processo, ocorre a eliminação de $\mathrm{CO}_{2}$ e outros compostos voláteis, propiciando aumentos no $\mathrm{pH}$ da amostra. De fato, não se sabe se apenas por esta razão, os valores de $\mathrm{pH}$ das amostras de solução do solo, coletadas na $1^{\underline{a}}$ e $7^{\underline{a}}$ amostragens, apresentaram respectivamente, médias de 7,6 $\pm 0,1$ e $8,2 \pm 0,02$, independentemente dos tratamentos e profundidades de coleta estabelecidos. Moraes \& Dynia (1990), verificaram durante a coleta de solução do solo através de extratores, uma progressiva obstrução dos poros das cápsulas com partículas coloidais do solo e a conseqüente diminuição na taxa de infiltração da solução. Também observaram a formação de uma capa coloidal de alta 
reatividade na superficie das cápsulas que, frente a elevação do $\mathrm{pH}$ da amostra, tornaria possível a precipitação de óxidos/hidróxidos de ferro na sua superfície interna, ocasionando um ambiente propício para ocorrência de processos de sorção e coprecipitação podendo modificar assim, a concentração de outros cátions metálicos.

Isto posto, é possível que a eventual presença dos metais em solução tenha sido afetada por estes fenômenos no entanto, deve-se considerar também que nas condições de condutividade elétrica (força iônica) e pH do solo nos tratamentos com lodo de esgoto, a atividade iônica dos cátions metálicos deve ser bastante reduzida. Para citar um exemplo, em solos com pH acima de 6,0, a atividade iônica dos metais $\mathrm{Cu}^{2+}$ e $\mathrm{Zn}^{2+}$ na solução, apresenta-se respectivamente, menores que $6,3 \times 10^{-5}$ e $6,5 \times 10^{-2} \mathrm{mg} \mathrm{L}^{-1}$ (Lindsay, 1981), concentrações bem menores que os limites de determinação do método analítico empregado.

Resultados semelhantes foram obtidos por Bertoncini (1997) em lixiviados de tubos de percolação contendo solos tratados com $156 \mathrm{Mg} \mathrm{ha}^{-1}$ (base seca) de lodo de esgoto. Exceções feitas apenas para o $\mathrm{Cu}^{2+}$ nos lixiviados obtidos da Areia Quatzosa e Latossolo Vermelho escuro e para o $\mathrm{Ni}$, detectado apenas nos lixiviados da Areia Quartzosa. Nesses casos o autor atribuiu a lixiviação dos metais ao arraste de substâncias orgânicas. Anjos (1999) também verificou que a eventual presença desses metais, na água lixiviada de vasos contendo $0,5 \mathrm{~m}^{3}$ de amostras de LV e LR tratadas com $388 \mathrm{Mg} \mathrm{ha}^{-1}$ (base seca) de lodo de esgoto, esteve durante 12 meses de avaliações, abaixo dos mesmos limites de determinação empregados no presente trabalho.

Nas amostras de solo coletadas em profundidade, não foram detectados os metais $\mathrm{Cd}, \mathrm{Ni}$ e $\mathrm{Pb}$ por estarem abaixo do limite de determinação do método analítico utilizado. Os limites de determinação foram os mesmos apresentados no ítem 4.1.5.1.

Entretanto, vários trabalhos nos quais esses metais foram adicionados ao solo, em elevadas quantidades, apontaram o $\mathrm{Cd}$ como um elemento de relativa mobilidade, representando riscos à qualidade das águas subterrâneas (Dowdy et al., 1991; Lamy et al., 1993, Matos et al. 1996). Para Lamy et al. (1993), a mobilidade do Cd em áreas tratadas com lodo de esgoto deve-se essencialmente, a complexação do metal por substâncias orgânicas que apresentam baixa capacidade de retenção em solos com pH na faixa de 5 a 7. Matos et al. (1996) e Amaral Sobrinho et al. (1997) encontraram, em 
condições de laboratório, que grande parte da retenção do $\mathrm{Cd}$ ocorre na fase trocável do solo, caracterizada por ligações menos energéticas (eletrostática) tornando o portanto, mais exposto a lixiviação. De qualquer maneira, com base nestas informações, é possivel que no presente trabalho tenha ocorrido a movimentação do $\mathrm{Cd}$ no entanto, esta seria pouco expressiva devido as baixas quantidades adicionadas pelo resíduo. Por outro lado, Amaral Sobrinho et al. (1997) destacaram com base na literatura, que a elevação do pH, também observada nos tratamentos com lodo de esgoto, pode favorecer a coprecipitação do $\mathrm{Cd}$ junto aos óxidos de $\mathrm{Fe}, \mathrm{Mn}$ e $\mathrm{Al}$, o que reduziria as possibilidades de lixiviação.

Com relação aos metais $\mathrm{Ni}$ e $\mathrm{Pb}$, resultados de trabalhos com lodo de esgoto, conduzidos a campo e por longo prazo, sugeriram o acúmulo desses elementos na camada superficial do solo, indicando que os mesmos são fortemente retidos (Williams et al., 1980; 1987; McBride, 1997). Amaral Sobrinho et al. (1997) verificaram em ensaios de laboratório, simulando a disposição de resíduos siderúrgicos num Podzólico Vermelho-Amarelo, que esses metais são preferencialmente ligados a fração residual e ocluídos junto aos óxidos de $\mathrm{Fe}$ e $\mathrm{Mn}$, o que segundo os autores confere alta retenção e baixa mobilidade. Verificaram também que a retenção dos metais tende a ser maior com o aumento do período de incubação no solo. Diante do exposto, mesmo não tendo sido detectados no presente trabalho, é provável que tais elementos não tenham se movimentado em profundidade, considerando-se os altos teores de óxidos de $\mathrm{Fe}$ contidos no Latossolo Vermelho-Amarelo, a elevação dos valores $\mathrm{pH}$ bem como, as pequenas quantidades aplicadas durante os dois anos experimentais.

Os teores totais de $\mathrm{Cu}, \mathrm{Cr}$ e $\mathrm{Zn}$ determinados nas diversas camadas de solo, ao final dos anos agrícolas 1996/97 e 1997/98, são apresentados na Tabela 16. Para o metal $\mathrm{Cu}$, a aplicação de doses crescentes de lodo de esgoto não proporcionou incrementos em seus teores nas camadas abaixo de $0-0,2 \mathrm{~m}$, em ambos os anos agrícolas. Pela comparação dos teores médios em profundidade, dentro de cada dose do resíduo, observa-se que nas doses $\mathrm{B}$ e $\mathrm{C}$ para os dois anos agrícolas, somente os teores da camada de incorporação foram diferentes e maiores do que àqueles determinados em profundidade. Para a dose A, esta diferença só foi verificada no ano agrícola 1997/98. Portanto, não houve nenhuma evidência da mobilidade do $\mathrm{Cu}$ ao final dos dois anos experimentais. 
A imobilidade do $\mathrm{Cu}$ também foi observada por Williams et al. (1987), Dowdy et al. (1991) e Chino et al. (1992) em experimentos de campo com a disposição de elevadas doses de lodo de esgoto, monitorados por períodos de respectivamente, 9, 14 e 12 anos. Esta imobilidade geralmente é atribuída a formação de complexos organo-metálicos estáveis (Williams et al., 1980; Taylor et al., 1995) e de baixa solubilidade. Além da complexação com substâncias orgânicas, Matos et al. (1996) salientaram que a imobilidade do $\mathrm{Cu}$ pode ser devida também a sua ligação a frações não trocáveis do solo o que foi comprovado por Amaral Sobrinho et al. (1997), os quais verificaram num Podzólico Vermelho-Amarelo com baixos teores de matéria orgânica, que o $\mathrm{Cu}$ adicionado via resíduo siderúrgico estava quase que totalmente ligado a fração residual e a óxidos de Fe e $\mathrm{Mn}$.

Com relação ao Cr, verifica-se para o ano agrícola 1996/97, que não houveram indícios de sua movimentação abaixo da camada de incorporação do lodo de esgoto. Porém, para o ano seguinte, observa-se efeito linear das doses do resíduo sobre seus teores no solo até a camada de 0,2-0,4 m. É importante notar o aumento nos teores naturais do solo, em função da profundidade. Considerando-se que os acréscimos nos teores de $\mathrm{Cr}$ na camada $0,2-0,4 \mathrm{~m}$ foram relativamente pequenos e que quando comparados com àqueles das camadas inferiores foram iguais ou até menores, é possível que tenha ocorrido alguma contaminação por ocasião da amostragem do solo. Dessa forma, acredita-se que os resultados não foram suficientemente claros para atestar a movimentação do $\mathrm{Cr}$ em profundidade.

Williams et al. (1980) e Williams et al. (1987) concluíram através de estudos a campo, pela imobilidade do $\mathrm{Cr}$ em solos tratados com lodo de esgoto. Resultados concordantes são apresentados por Bertoncini (1997) num estudo em tubos de percolação. Todos esses autores atribuíram a imobilidade do $\mathrm{Cr}$ a sua presença na forma trivalente $\left(\mathrm{Cr}^{3+}\right)$, a qual poderia ter sido precipitada como hidróxidos de fórmulas genéricas $\mathrm{Cr}(\mathrm{OH})_{3}$ ou $\mathrm{Fe}_{\mathrm{x}} \mathrm{Cr}_{1-x}(\mathrm{OH})_{3}$ em meio alcalino ou pouco ácido, ter sido complexado junto a moléculas orgânicas pouco solúveis ou adsorvido à superficie dos minerais. 
Tabela 16. Teores totais de $\mathrm{Cu}, \mathrm{Cr}$ e $\mathrm{Zn}$ determinados no solo, nas várias profundidades, em função da disposição de doses crescentes de lodo de esgoto nos anos agrícolas 1996/97 e 1997/98.

\begin{tabular}{|c|c|c|c|c|c|c|}
\hline \multirow{2}{*}{$\begin{array}{c}\text { Profundidade } \\
\text { (m) }\end{array}$} & \multicolumn{4}{|c|}{ Doses de lodo de esgoto $\left(\mathrm{Mg} \mathrm{ha}^{-1}\right)$} & \multicolumn{2}{|c|}{ Termo de Regressão $\left(\mathrm{R}^{2}\right)$} \\
\hline & 0 & $33(34)$ & $66(74)$ & $99(110)$ & Linear & Quadrático \\
\hline & \multicolumn{4}{|c|}{ Cobre (mg kg $\left.{ }^{-1}\right)$ - Ano agrícola 1996/97 } & & \\
\hline $0-0,2$ & 17,86 & 19,47 a & 27,90 a & 30,97 a & $0,93^{* *}$ & ns \\
\hline $0,2-0,4$ & 19,07 bc & 20,62 a & $22,09 \quad \mathrm{~b}$ & $21,48 \quad b$ & ns & ns \\
\hline $0,4-0,6$ & 21,77 a & 21,17 a & $20,62 \quad b$ & 19.55 & ns & ns \\
\hline \multirow[t]{2}{*}{$0,6-0,8$} & $21,49 a b$ & 21,48 a & $21,70 \quad b$ & 21,54 & ns & ns \\
\hline & \multicolumn{4}{|c|}{ Cobre $\left(\mathrm{mg} \mathrm{kg}^{-1}\right)$-Ano agricola 1997/98 } & & \\
\hline $0-0,2$ & $16,87 \quad b$ & 26,17 a & 36,39 a & 42.85 a & $0,99^{* *}$ & ns \\
\hline $0,2-0,4$ & $19,06 \mathrm{ab}$ & 21,58 a & $20,71 \quad b$ & $20.86 \quad b$ & ns & ns \\
\hline $0,4-0,6$ & 22,73 a & 24,84 a & $24,09 \quad b$ & 24.04 & ns & ns \\
\hline \multirow[t]{2}{*}{$0,6-0,8$} & 22,87 a & 22,36 a & $21,82 \quad b$ & 21,38 & ns & ns \\
\hline & \multicolumn{4}{|c|}{ Cromo $\left(\mathrm{mg} \mathrm{kg}^{-1}\right)$-Ano agrícola 1996/97 } & & \\
\hline $0-0,2$ & 16,57 & $21,56 \mathrm{ab}$ & 25,30 a & 25.59 a & $0,89^{\prime \prime *}$ & ns \\
\hline $0,2-0,4$ & 19,98 bc & $19,30 \quad b$ & $19,87 \quad b$ & $21.64 \mathrm{a}$ & ns & ns \\
\hline $0,4-0,6$ & $22,64 \mathrm{ab}$ & 23,51 a & $21,97 \mathrm{ab}$ & $22.70 \mathrm{a}$ & ns & ns \\
\hline \multirow[t]{2}{*}{$0,6-0,8$} & 24,16 a & 24,58 a & 25,66 a & 24,84 a & ns & ns \\
\hline & \multicolumn{4}{|c|}{ Cromo (mg kg ${ }^{-1}$ ) - Ano agrícola 1997/98 } & & \\
\hline $0-0,2$ & 15,55 & $18,14 \quad b$ & $25,21 \mathrm{a}$ & 27,19 a & $0,95^{* *}$ & ns \\
\hline $0,2-0,4$ & $18,79 \quad b$ & $19,89 \quad b$ & 23,11 a & $21,89 \quad b$ & $0,70^{* *}$ & ns \\
\hline $0,4-0,6$ & 23,13 a & 24,38 a & 23,55 a & $23.03 \quad b$ & ns & ns \\
\hline \multirow[t]{2}{*}{$0,6-0,8$} & 25,57 a & $25,10 \mathrm{a}$ & 25,15 a & $24.80 \mathrm{ab}$ & ns & ns \\
\hline & \multicolumn{4}{|c|}{ Zinco (mg kg $\left.{ }^{-1}\right)$ - Ano agrícola 1996/97 } & & \\
\hline $0-0,2$ & $21,14 a b$ & 39,22 a & 40,41 a & 41,27 a & $0,68^{* *}$ & $0,95^{* *}$ \\
\hline $0,2-0,4$ & $19,72 \quad b$ & $28,94 \quad b$ & $30,25 \quad b$ & $27,20 \quad b$ & $0,42^{*}$ & $0,99^{*}$ \\
\hline $0,4-0,6$ & $22,79 a b$ & $25.04 \quad b$ & $24,84 \quad c$ & $27.15 \quad b$ & ns & ns \\
\hline \multirow[t]{2}{*}{$0,6-0,8$} & 25,46 a & $26,72 \quad b$ & $26,78 \quad b c$ & $27.13 \quad b$ & ns & ns \\
\hline & \multicolumn{4}{|c|}{ Zinco $\left(\mathrm{mg} \mathrm{kg}^{-1}\right)$ - Ano agrícola $1997 / 98$} & & \\
\hline $0-0,2$ & 20,19 a & 50,03 a & 77,11 a & 97,21 a & $0,99^{* *}$ & ns \\
\hline $0,2-0,4$ & 19,59 a & $28,29 \quad b$ & $29,51 \quad b$ & $30.41 \quad b$ & $0,76^{* *}$ & ns \\
\hline $0,4-0,6$ & 22,09 a & $31,62 \quad b$ & $34,16 \quad b$ & 32.07 & 0,61 & 0,99 \\
\hline $0,6-0,8$ & 26,24 a & $27,49 \quad b$ & $27,94 \quad b$ & 27.50 & ns & ns \\
\hline
\end{tabular}


Foram observados aumentos nos teores totais de $\mathrm{Zn}$ do solo em função das doses de lodo de esgoto, no ano agrícola 1996/97, até a camada de 0,2-0,4 m. Em 1997/98, esses aumentos foram observados até a camada de 0,4-0,6 m, evidenciando uma progressão dos teores em profundidade, de um ano para o outro. Pela comparação dos teores de $\mathrm{Zn}$ entre camadas do solo, dentro das doses $\mathrm{A}, \mathrm{B}$ e $\mathrm{C}$ do resíduo, observa-se que os maiores valores foram determinados na camada de incorporação e que abaixo de 0,2 m, os teores foram praticamente iguais. Embora tenham sido observados aumentos nos teores naturais de $\mathrm{Zn}$ do solo em função da profundidade de coleta de amostra, pode-se verificar, para o ano agrícola 1997/98, que os acréscimos nos teores de $\mathrm{Zn}$, proporcionados pela aplicação de lodo de esgoto, nas camadas de 0,2 a 0,6 m, giraram em torno de $50 \%$ quando comparado com a testemunha. Dessa forma, a movimentação do $\mathrm{Zn}$ pelo perfil do solo tornou-se evidente. Estes resultados vão de encontro as observações feitas por Hue (1995) numa ampla revisão bibliográfica, de que o $\mathrm{Zn}$, entre os metais pesados, é o que apresentou maior potencial de lixiviação.

Welch \& Lund (1989) e Amaral Sobrinho et al. (1998) também verificaram a movimentação do $\mathrm{Zn}$ em profundidade. Os primeiros autores observaram, em colunas de solo tratadas com lodo de esgoto, que a lixiviação do metal aumentou em função da acidez do meio. Em colunas de um Podzólico Vermelho-Amarelo tratadas com resíduo siderúrgico ácido, Amaral Sobrinho et al. (1998) detectaram perdas de até 52\% do Zn-total adicionado à camada de incorporação. Os autores verificaram que do total lixiviado, $50 \%$ estava na forma trocável e $25 \%$ ligado a óxidos de Fe e Mn.

Baseados em diversos trabalhos científicos, Kabata-Pendias \& Adriano (1995) verificaram que, em solos ratados com elevadas taxas de lodo de esgoto, mais de $50 \%$ do $\mathrm{Zn}$ estava nas formas trocáveis e facilmente solúveis, aproximadamente $30 \%$ associado com óxidos ou hidróxidos de $\mathrm{Fe}$ e $\mathrm{Mn}$ e o restante dividindo-se entre as formas orgânicas e residual, observações que podem explicar a mobilidade do elemento.

Considerando-se que no presente trabalho, os valores de $\mathrm{pH}$ na camada de incorporação do lodo de esgoto estiveram próximos a neutralidade, a verificação de acréscimos nos teores de $\mathrm{Zn}$ em profundidade contrariaram alguns trabalhos constantes na literatura (Chino et al., 1992, Bertoncini, 1997) uma vez que, em condições de pouca 
ou nenhuma acidez e elevados teores de matéria orgânica, a presença do $\mathrm{Zn}$ em solução e outras formas facilmente lixiviáveis é bastante reduzida (Williams et al., 1987). Nestas condições, o metal pode ser facilmente coprecipitado junto aos óxidos de $\mathrm{Fe}$ e $\mathrm{Al}$ (Ross, 1994), formar complexos pouco solúveis com a matéria orgânica (Adriano, 1986) ou serem fortemente retidos por processos de adsorção específica (Kalbasi et al., 1978).

No entanto, diante das elevadas quantidades aplicadas deste metal através do lodo de esgoto e das quantidades de chuvas ocorridas nos dois anos experimentais (Figura 11), é provável que além de uma pequena fração solúvel, o arraste para as camadas abaixo de 0,2 $\mathrm{m}$, de formas pouco solúveis de $\mathrm{Zn}$ tenha sido significativo. Neste caso, a acidez verificada em profundidade para todos os tratamentos (Tabela 13), pode ter facilitado sua lixiviação para as camadas inferiores. Estas hipóteses também podem ser atribuídas a significativa movimentação de $\mathrm{Zn}$, observada por Andrade (1999), em áreas cultivadas com eucalipto e tratadas com elevadas doses de lodo de esgoto (40 $\mathrm{Mg} \mathrm{ha}^{-1}$ - base seca).

Diante da complexidade dos fatores envolvidos na mobilidade dos metais pesados, Dowdy et al. (1991), Hue (1995) e McBride et al. (1997) salientaram que, nos estudos a campo relativos a estas questões, não podem ser desconsiderados os aspectos físicos e biológicos do solo. Neste contexto, eles destacaram que tais elementos também podem atingir as camadas subsuperficiais do solo através do caminhamento preferencial de água e partículas, seja do resíduo contaminante ou do solo contaminado, por rachas estruturais do solo, canais feitos por raizes e organismos vivos e até mesmo a lixiviação de formas de metais desconhecidas que não são complexadas e nem adsorvidas.

Assim, novos estudos visando o fracionamento desses elementos, através de procedimentos de extrações seqüenciais, são necessários e podem trazer explicações conclusivas para situações específicas.

\subsubsection{Avaliação da fitodisponibilidade de metais pesados}

As quantidades de $\mathrm{Cd}, \mathrm{Cr}$ e $\mathrm{Pb}$ eventualmente removidas do solo pelas soluções

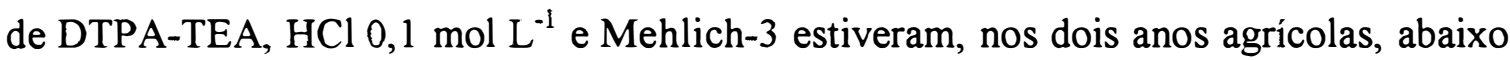
do limite de determinação do método analítico empregado. Dessa forma, para o extrator 
DTPA-TEA as quantidades desses metais nas amostras de solo foram respectivamente, $<0,3,<0,2 \mathrm{e}<1,5 \mathrm{mg} \mathrm{kg}^{-1}$. Para a solução de $\mathrm{HCl} 0,1 \mathrm{~mol} \mathrm{~L}^{-1}$ tais quantidades foram $<0,9,<0,5 \mathrm{e}<3,8 \mathrm{mg} \mathrm{kg}^{-1}$ ao passo que, para Mehlich-3 as quantidades foram $<1,8$, $<1,0 \mathrm{e}<7,6 \mathrm{mg} \mathrm{kg}^{-1}$. Estas observações somadas a não deteç̧ão dos referidos metais pesados nas amostras de plantas, mais uma vez ilustram as limitações do método analítico empregado não permitindo portanto, maiores considerações sobre esses elementos.

Anjos (1999), trabalhando com Latossolo Vermelho-Amarelo e Latossolo Roxo tratados com $388 \mathrm{Mg} \mathrm{ha}^{-1}$ (base seca) de lodo de esgoto proveniente da ETE-Barueri, verificou que os teores de $\mathrm{Cd}$ e $\mathrm{Pb}$ avaliados pelos extratores DTPA-TEA, $\mathrm{HCl}$ 0,1 mol L $\mathrm{m}^{-1}$ e Mehlich-3, também estiveram abaixo dos limites de determinação empregados no presente trabalho. Para o $\mathrm{Cr}$, o autor observou que os extratores $\mathrm{HCl} 0,1 \mathrm{~mol} \mathrm{~L}^{-1}$ e Mehlich-3 foram capazes de extrair respectivamente, 9 e $3 \%$ do total adicionado através do resíduo, no $\mathrm{LV}$ ao passo que para o $\mathrm{LR}$, somente a solução de Mehlich-3 extraiu $\mathrm{Cr}$, aproximadamente $2 \%$ do total adicionado. Convém salientar que não foi possivel avaliar a eficiência dos extratores na previsão da fitodisponibilidade desses elementos, já que os mesmos não foram detectados nas diversas partes das plantas de milho.

$\mathrm{Na}$ Tabela 17 são apresentados os teores de $\mathrm{Cu}, \mathrm{Ni}$ e $\mathrm{Zn}$ avaliados pelas soluções extratoras nos anos agrícolas 1996/97 e 1997/98. Considerando-se as quantidades aplicadas acumuladas desses metais no solo ao final do segundo ano agrícola (Tabela 15), é possivel estimar que a extração média de $\mathrm{Cu}$, nos tratamentos com doses A, B e C de lodo de esgoto foi de 17, 24 e $31 \%$ respectivamente para os

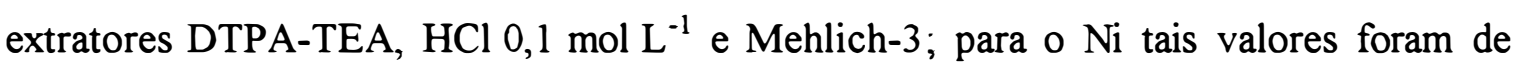
8, 28 e $23 \%$ e para o $\mathrm{Zn}$ esses valores foram de 13,33 e $35 \%$. Dessa forma, com relação a capacidade de extração dos métodos, verifica-se que àqueles que empregaram soluções ácidas $\left(\mathrm{HCl} \mathrm{0,1} \mathrm{mol} \mathrm{L}^{-1}\right.$ e Mehlich-3) extraíram quantidades maiores que DTPA-TEA. Esses resultados, de acordo com Abreu et al. (1995) são, até certo ponto, esperados, já que os ácidos dissolvem parcialmente diversas estruturas que contêm os metais pesados. 
Tabela 17. Teores de $\mathrm{Cu}, \mathrm{Ni}$ e $\mathrm{Zn}$ avaliados no solo pelos extratores DTPA-TEA, $\mathrm{HCl} 0,1 \mathrm{~mol} \mathrm{~L}^{-1}$ e Mehlich-3, nos anos agrícolas 1996/97 e 1997/98, para o experimento com lodo de esgoto.

\begin{tabular}{|c|c|c|c|c|c|c|c|}
\hline \multirow[t]{2}{*}{ Ano Agrícola } & \multirow[t]{2}{*}{ Extrator } & \multicolumn{4}{|c|}{ Doses de lodo de esgoto ${ }^{1}\left(\mathrm{Mg} \mathrm{ha}^{-1}\right)$} & \multicolumn{2}{|c|}{ Termo de Regressão $\left(\mathrm{R}^{2}\right)$} \\
\hline & & 0 & $33(34)$ & $66(74)$ & $99(110)$ & Linear & Quadrático \\
\hline & & \multicolumn{4}{|c|}{ Cobre (mg kg $\left.{ }^{-1}\right)$} & & \\
\hline $1996 / 97$ & DTPA-TEA & 0,70 & 2,97 & 3,86 & 3,86 & $0,80^{* *}$ & $0,99^{*}$ \\
\hline $1997 / 98$ & DTPA-TEA & 0,85 & 3,67 & 6,64 & 10,70 & $0,99^{* *}$ & ns \\
\hline $1996 / 97$ & $\mathrm{HCl} 0,1 \mathrm{~mol} \mathrm{~L}^{-1}$ & 0,90 & 5,23 & 5,35 & 6,64 & $0,80^{* * *}$ & ns \\
\hline $1997 / 98$ & $\mathrm{HCl} 0,1 \mathrm{~mol} \mathrm{~L}^{-1}$ & 0,98 & 5,43 & 10,39 & 11,66 & $0,96 *$ & ns \\
\hline $1996 / 97$ & Mehlich 3 & 1,22 & 6,05 & 8,48 & 7,70 & $0,75^{* * *}$ & ns \\
\hline $1997 / 98$ & Mehlich 3 & 1,17 & 7,25 & 10,35 & 17,33 & $0,98^{* *}$ & ns \\
\hline & & \multicolumn{4}{|c|}{ Niquel (mg kg ${ }^{-1}$ ) } & & \\
\hline $1996 / 97$ & DTPA-TEA & n.d. ${ }^{2}$ & 0,47 & 0,70 & 0,65 & ns & - \\
\hline $1997 / 98$ & DTPA-TEA & n.d. & 0,51 & 1,11 & 1,90 & $0,99^{* *}$ & - \\
\hline $1996 / 97$ & $\mathrm{HCl} 0,1 \mathrm{~mol} \mathrm{~L}^{-1}$ & n.d. & 1,41 & 2,33 & 1,98 & ns & - \\
\hline $1997 / 98$ & $\mathrm{HCl} 0,1 \mathrm{~mol} \mathrm{~L}^{-1}$ & n.d. & 1,78 & 4,09 & 5,93 & $0,99^{* *}$ & - \\
\hline $1996 / 97$ & Mehlich 3 & n.d. & 1,02 & 2,03 & 2,23 & ns & - \\
\hline \multirow[t]{2}{*}{$1997 / 98$} & Mehlich 3 & nd. & 1,50 & 3,68 & 4,45 & $0,78^{*}$ & - \\
\hline & & \multicolumn{4}{|c|}{ Zinco (mg kg $\left.{ }^{-1}\right)$} & & \\
\hline 1996/97 & DTPA-TEA & 0,62 & 4,76 & 6,34 & 6,71 & $0,84^{* *}$ & ns \\
\hline $1997 / 98$ & DTPA-TEA & 0,75 & 6,43 & 10,27 & 19,12 & $0,97^{* *}$ & ns \\
\hline $1996 / 97$ & $\mathrm{HCl} 0 ; 1 \mathrm{~mol} \mathrm{~L}^{-1}$ & 0,94 & 12,23 & 11,23 & 13,35 & $0,67^{* *}$ & $0,88^{* *}$ \\
\hline $1997 / 98$ & $\mathrm{HCl} 0,1 \mathrm{~mol} \mathrm{~L}^{-1}$ & 0,90 & 14,09 & 24,86 & 52,05 & $0,95^{* *}$ & ns \\
\hline $1996 / 97$ & Mehlich 3 & 1,25 & 12,28 & 13,95 & 16,90 & $0,84^{\prime *}$ & $0,96^{* *}$ \\
\hline $1997 / 98$ & Mehlich 3 & 1,23 & 16,85 & 30,95 & 44,95 & $0,99^{* * *}$ & ns \\
\hline
\end{tabular}

Doses entre parênteses referem-se ao ano agrícola $1997 / 98$;

${ }^{2}$ n.d. - não detectado, valor abaixo do limite de detenninação do método analítico. $0,20,0,50$ e $1,00 \mathrm{mg} \mathrm{kg}^{-1} \mathrm{na}$

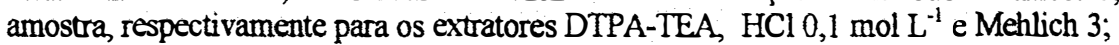

${ }^{*}, * *,{ }^{\text {ns }}$ Indicam respectivamente, que os termos de regressão linear ou quadrática foram significativos a $\mathrm{P} \leq 0,05$, $\mathrm{P} \leq 0,01$ ou não significativo pelo teste $\mathrm{F}$;

Dentre as soluções ácidas, a de Mehlich-3 apresentou a maior capacidade de extração para os metais $\mathrm{Cu}$ e $\mathrm{Zn}$ enquanto que, $\mathrm{HCl} 0,1 \mathrm{~mol} \mathrm{~L}^{-1}$ foi superior na extração do Ni. Assim, considerando-se que a solução de Mehlich-3 é composta, além dos ácidos acético e nítrico, pelo complexante EDTA, é possível inferir que para os metais $\mathrm{Cu}$ e $\mathrm{Zn}$,

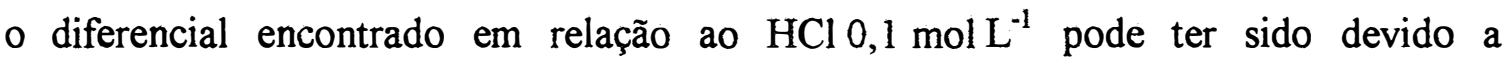
significativa presença desses elementos na fração orgânica do solo. Já para o $\mathrm{Ni}$ esta fração teria sido menos representativa.

As quantidades removidas de $\mathrm{Cu}$ e $\mathrm{Zn}$ pelas várias soluções extratoras, nos dois anos agrícolas, foram crescentes em função das doses aplicadas de lodo de esgoto. Para 
o $\mathrm{Ni}$, este comportamento foi evidente apenas no segundo ano agrícola. De maneira geral, as quantidades extraídas ocorreram na seguinte ordem: $\mathrm{Zn}>\mathrm{Cu}>\mathrm{Ni}$; resultados que refletem os teores presentes no lodo de esgoto e as taxas em que foram aplicados no solo. Tais resultados também sugerem que a fitodisponibilidade desses elementos seria supostamente crescente. Comportamentos semelhantes foram observados por Rappaport et al. (1988), King \& Hajjar (1990) e Roca \& Pomares (1991), em solos tratados com lodo de esgoto, respectivamente para os extratores DTPA-TEA, DTPA-TEA e Mehlich-3 e DTPA-TEA, $\mathrm{HCl} \mathrm{0,1} \mathrm{mol} \mathrm{L}{ }^{-1}$ e "água régia".

Tabela 18. Coeficientes de correlação linear simples para os teores avaliados de $\mathrm{Cu}, \mathrm{Ni}$ e $\mathrm{Zn}$ entre os extratores água régia, DTPA-TEA, $\mathrm{HCl} 0,1 \mathrm{~mol} \mathrm{~L}^{-1}$ e Mehlich-3 (M-3), nos anos agrícolas de 1996/97 e 1997/98, para o experimento com lodo de esgoto.

\begin{tabular}{|c|c|c|c|c|c|c|c|c|c|}
\hline \multirow[t]{2}{*}{ Extrator } & \multicolumn{3}{|c|}{ Cobre } & \multicolumn{3}{|c|}{ Níquel } & \multicolumn{3}{|c|}{ Zinco } \\
\hline & DTPA & $\mathrm{HCl}$ & M-3 & DTPA & $\mathrm{HCl}$ & M-3 & DTPA & $\mathrm{HCl}$ & M-3 \\
\hline
\end{tabular}

Ano agrícola 1996/97 (considerando os tratamentos 1, 2, 3, 4 e 5)

$\begin{array}{lccccccccc}\text { água régia } & 0,75^{* *} & 0,71^{* *} & 0,68^{* *} & - & - & - & 0,88^{* *} & 0,86^{* *} & 0,90^{* *} \\ \text { DTPA } & - & 0,97^{* *} & 0,97^{* *} & - & - & - & - & 0,93^{* *} & 0,93^{* *} \\ \text { HCl } & - & - & 0,93^{* *} & - & - & - & - & - & 0,96^{* *}\end{array}$

Ano agrícola 1996/97 (considerando os tratamentos 3, 4 e 5)

$\begin{array}{lccccccccc}\text { água régia } & 0,46^{\text {ns }} & 0,33^{n s} & 0,35^{n s} & - & - & - & 0,48^{\text {ns }} & 0,10^{n s} & 0,36^{\text {ns }} \\ \text { DTPA } & - & 0,86^{* *} & 0,95^{* *} & - & 0,89^{* *} & 0,84^{* *} & - & 0,70^{*} & 0,70^{*} \\ \mathrm{HCl} & - & - & 0,80^{* *} & - & - & 0,85^{* *} & - & - & 0,47^{\text {ns }}\end{array}$

Ano agrícola 1997/98 (considerando os tratamentos 1, 2,3,4 e 5)

$\begin{array}{lccccccccc}\text { água régia } & 0,98^{* *} & 0,91^{* *} & 0,95^{* *} & - & - & - & 0,95^{* *} & 0,94^{* *} & 0,98^{* *} \\ \text { DTPA } & - & 0,90^{* *} & 0,96^{* *} & - & - & - & - & 0,98^{* *} & 0,96^{* *} \\ \mathrm{HCl} & - & - & 0,91^{* *} & - & - & - & - & - & 0,97^{* *}\end{array}$

Ano agrícola $1997 / 98$ (considerando os tratamentos 3,4 e 5)

$\begin{array}{lccccccccc}\text { água régia } & 0,96^{* *} & 0,75^{* *} & 0,85^{* *} & - & - & - & 0,88^{* *} & 0,87^{* *} & 0,93^{* *} \\ \text { DTPA } & - & 0,75^{* *} & 0,91^{* *} & - & 0,98^{* *} & 0,87^{* *} & - & 0,96^{* *} & 0,911^{* *} \\ \text { HCl } & - & - & 0,71^{* *} & - & - & 0,92 & - & - & 0,95^{* *}\end{array}$
pelo teste $t$.
ns Indicam respectivamente, que as correlações foram significativas a $\mathrm{P} \leq 0,05, \mathrm{P} \leq 0,01$ ou não significativas

Embora tenham sido observadas diferenças na capacidade de extração das soluções utilizadas, verifica-se de maneira geral, correlações significativas entre todos os métodos, incluindo a "água régia", para os elementos $\mathrm{Cu}$ e $\mathrm{Zn}$ (Tabela 18). Exceção 
deve ser feita apenas para o ano agrícola 1996/97, quando foram considerados os teores avaliados pela "água régia" nos tratamentos 3, 4 e 5 (doses A, B e C do resíduo). Para o $\mathrm{Ni}$, as correlações não foram realizadas com o referido extrator tendo em vista que, seus teores estiveram abaixo do limite de determinação do método analítico. Porém, para as doses $\mathrm{A}, \mathrm{B}$ e $\mathrm{C}$ do lodo de esgoto, houveram correlações entre os teores de $\mathrm{Ni}$ extraídos por DTPA-TEA, $\mathrm{HCl} 0,1 \mathrm{~mol} \mathrm{~L}^{-1}$ e Mehlich-3. Verifica-se portanto, que todas as soluções empregadas fornecem indicações semelhantes para $\mathrm{Cu}$ e $\mathrm{Zn}$, enquanto que para $\mathrm{Ni}$, esta inferência não poderia ser feita apenas para a "água régia". Esses resultados vão de encontro àqueles obtidos por Roca \& Pomares (1991), os quais encontraram correlações significativas entre os teores de $\mathrm{Cu}$ e $\mathrm{Zn}$ extraídos por DTPA-TEA,

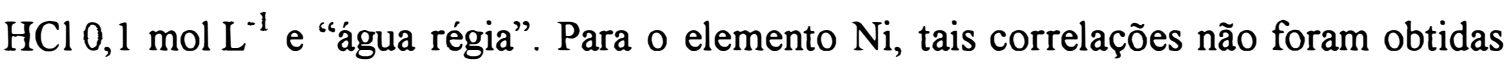
para a "água régia". Abreu et al. (1995) observaram correlações significativas entre os teores de Ni extraídos por DTPA-TEA e Mehlich-3.

A eficiência dos extratores químicos na previsão da disponibilidade dos metais pesados às plantas de cana-de-açúcar foi avaliada apenas para $\mathrm{Cu}$ e $\mathrm{Zn}$ tendo em vista que o $\mathrm{Ni}$ não foi detectado nas amostras de plantas (4.1.5.1). Dessa forma, são apresentados na Tabela 19 os coeficientes de correlação linear obtidos entre as concentrações desses metais nas diversas amostras de plantas e no solo, considerando todos os tratamentos empregados.

Verifica-se de maneira geral, que todas as soluções extratoras foram eficientes na avaliação da disponibilidade de $\mathrm{Cu}$ e $\mathrm{Zn}$ utilizando-se como índice os teores presentes na folha " +1 ", no colmo desfibrado e no caldo. Exceções são feitas apenas no primeiro ano agrícola, entre os teores de $\mathrm{Cu}$ no colmo e caldo e àqueles extraídos do solo por "água régia" e entre os teores de $\mathrm{Zn}$ no caldo e àqueles extraídos do solo, por todos extratores químicos. Neste ano porém, convém lembrar que a cana-de-açúcar foi colhida com aproximadamente 11 meses e apresentou um crescimento prejudicado e diferenciado em função dos tratamentos (4.1.1). Além disso, os aumentos dos teores desses elementos no solo não proporcionaram acréscimos nos teores presentes no colmo e no caldo. 
Tabela 19. Correlações lineares entre a concentração de cobre e zinco nas plantas de cana-de-açúcar e os teores avaliados no solo pelos vários extratores químicos, considerando todos os tratamentos do experimento com lodo de esgoto.

\begin{tabular}{|c|c|c|c|c|}
\hline Metais pesados & Água-régia & DTPA-TEA & $\mathrm{HCl} 0,1 \mathrm{~mol} \mathrm{~L}^{-1}$ & Mehlich-3 \\
\hline & \multicolumn{4}{|c|}{ Ano agrícola 1996/97 } \\
\hline & \multicolumn{4}{|c|}{ Folha "+1" } \\
\hline Cobre & $0,73^{* *}$ & $0,83^{* *}$ & $0,84^{* *}$ & $0,74^{* *}$ \\
\hline \multirow[t]{2}{*}{ Zinco } & $0,69^{* *}$ & $0,65^{* *}$ & $0,78^{* *}$ & $0,77^{* *}$ \\
\hline & \multicolumn{4}{|c|}{ Colmo } \\
\hline Cobre & $0,38^{\text {ns }}$ & $0,64^{* *}$ & $0,65^{* *}$ & $0,60^{* *}$ \\
\hline \multirow[t]{2}{*}{ Zinco } & $0,69^{* *}$ & $0,64^{* *}$ & $0,63^{* *}$ & $0,59^{* *}$ \\
\hline & \multicolumn{4}{|c|}{ Caldo } \\
\hline Cobre & $0,43^{\text {ns }}$ & $0,67^{* *}$ & $0,67^{* *}$ & $0,69^{* *}$ \\
\hline \multirow[t]{3}{*}{ Zinco } & $0,14^{\mathrm{ns}}$ & $0,25^{\mathrm{ns}}$ & $0,22^{\mathrm{ns}}$ & $0,08^{\mathrm{ns}}$ \\
\hline & \multicolumn{4}{|c|}{ Ano agrícola 1997/98 } \\
\hline & \multicolumn{4}{|c|}{ Folha "+1" } \\
\hline Cobre & $0,84^{* *}$ & $0,80^{n=}$ & $0,84^{* *}$ & $0,83^{* *}$ \\
\hline \multirow[t]{2}{*}{ Zinco } & $0,79^{* *}$ & $0,75^{* *}$ & $0,73^{* *}$ & $0,78^{* *}$ \\
\hline & \multicolumn{4}{|c|}{ Colmo } \\
\hline Cobre & $0,73^{* *}$ & $0,68^{* *}$ & $0,66^{* *}$ & $0,66^{* *}$ \\
\hline \multirow[t]{2}{*}{ Zinco } & $0,75^{* *}$ & $0,78^{* *}$ & $0,74^{* *}$ & $0,78^{* *}$ \\
\hline & \multicolumn{4}{|c|}{ Caldo } \\
\hline Cobre & $0,59^{* *}$ & $0,62^{* *}$ & $0,65^{* *}$ & $0,74^{* *}$ \\
\hline Zinco & $0,82^{* *}$ & $0,80^{* *}$ & $0,77^{* *}$ & $0,83^{* *}$ \\
\hline
\end{tabular}

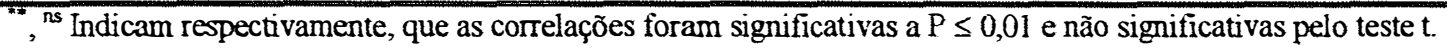

Resultados satisfatórios para DTPA-TEA e Mehlich-3, na previsão da disponibilidade de $\mathrm{Cu}$ e $\mathrm{Zn}$ para plantas cultivadas em solos acrescidos de lodo de esgoto, tem sido encontrados por diversos autores (Singh \& Narwal, 1984; King \& Hajjar, 1990; Mulchi et al., 1991, Anjos, 1999) porém, existem grandes variações no comportamento dos extratores em função das espécies vegetais consideradas (Roca \& Pomares, 1991).

Analisando-se as relações entre as quantidades totais de $\mathrm{Cu}$ e $\mathrm{Zn}$ recuperadas do solo, nos dois anos agrícolas, e seus teores nas várias amostras de plantas 
(Figuras 15 e 16) e considerando-se que houveram correlações significativas entre os chamados teores totais (extraídos por "água régia") e àqueles avaliados pelos demais extratores químicos, é importante notar que, na maioria dos casos em que foram verificados efeitos significativos dos teores de metais do solo sobre a concentração nas amostras de plantas, foram definidos dois grupos distintos de concentrações nas plantas; o primeiro referente à testemunha e ao tratamento com calagem + adubação mineral e o segundo, referente às doses $\mathrm{A}, \mathrm{B}$ e $\mathrm{C}$ de lodo de esgoto. Este fato evidenciou em alguns casos, a não variação entre os teores de $\mathrm{Cu}$ e $\mathrm{Zn}$ nas plantas cultivadas nos tratamentos com doses $\mathrm{A}, \mathrm{B}$ e $\mathrm{C}$ de lodo de esgoto, o que poderia tornar tendenciosa a validação da eficiência dos extratores químicos testados.

Diante disto, procederam-se correlações entre os teores recuperados do solo, somente nos tratamentos 3,4 e 5 , e os teores presentes nas amostras de plantas cultivadas nestes tratamentos (Tabela 20).

Neste caso, todos os extratores foram ineficientes para avaliar a disponibilidade de $\mathrm{Cu}$ através das amostras de folhas " +1 ", colmo e caldo das plantas de cana-de-açúcar. A não ocorrência de correlações significativas foi devida a falta de resposta das plantas aos acréscimos de $\mathrm{Cu}$ no solo proporcionados pelas aplicações de taxas crescentes de lodo de esgoto, enquanto que os extratores químicos extraíram quantidades lineares e crescentes em função dessas taxas. Em situação semelhante, Rappaport et al. (1988) verificaram que a ineficiência do extrator DTPA-TEA em prever a disponibilidade de $\mathrm{Cd}, \mathrm{Cu}, \mathrm{Ni}$ e $\mathrm{Zn}$ foi devida ao fato de que doses crescentes de lodo de esgoto $(0,42,84$, 126, 168 e $210 \mathrm{Mg} \mathrm{ha}^{-1}$ - base seca) praticamente não promoveram aumentos na absorção, por plantas de milho, desses metais pesados.

Para o $\mathrm{Zn}$, a utilização de folhas "+1" não foi um bom índice na avaliação de sua disponibilidade para todas as soluções extratoras. Certamente este fato esteve relacionado ao comportamento assintótico observado para as concentrações do elemento nestas amostras. Por outro lado, quando foram consideradas as amostras de colmo e caldo no ano agrícola 1997/98, foram obtidas correlações significativas e positivas com todos os extratores, destacando-se com os maiores coeficientes as soluções de Mehlich-3 para o colmo e DTPA-TEA e Mehlich-3 para o caldo. As correlações com as amostras 
de colmo apresentaram de forma geral, coeficientes sensivelmente maiores do que àqueles encontrados com as amostras de caldo. Isto se justifica, provavelmente, pelo comportamento linear crescente apresentado pelo elemento no colmo, em função dos acréscimos do metal no solo.

Tabela 20. Correlações lineares entre a concentração de cobre e zinco nas plantas de cana-de-açúcar e os teores avaliados no solo pelos vários extratores químicos, considerando apenas os tratamentos com doses $\mathrm{A}, \mathrm{B}$ e $\mathrm{C}$ de lodo de esgoto.

\begin{tabular}{|c|c|c|c|c|}
\hline Metais pesados & água-régia & DTPA-TEA & $\mathrm{HCl} 0,1 \mathrm{~mol} \mathrm{~L}^{-1}$ & Mehlich-3 \\
\hline & \multicolumn{4}{|c|}{ Ano agrícola 1996/97 } \\
\hline & \multicolumn{4}{|c|}{ Folha " $+1 "$} \\
\hline Cobre & $0,49^{\text {ns }}$ & $0,10^{\text {ns }}$ & $0,06^{\mathrm{ns}}$ & $0,04^{\text {ns }}$ \\
\hline \multirow[t]{2}{*}{ Zinco } & $-0,40^{n s}$ & $-0,50^{\mathrm{ns}}$ & $-0,26^{\mathrm{ns}}$ & $-0,13^{\text {ns }}$ \\
\hline & \multicolumn{4}{|c|}{ Colmo } \\
\hline Cobre & $-0,52^{\mathrm{ns}}$ & $-0,25^{\mathrm{ns}}$ & $-0,29^{\text {ns }}$ & $-0,12^{\text {ns }}$ \\
\hline \multirow[t]{2}{*}{ Zinco } & $0,45^{\text {ns }}$ & $0,31^{\mathrm{ns}}$ & $0,15^{\text {ns }}$ & $-0,13^{\text {ns }}$ \\
\hline & \multicolumn{4}{|c|}{ Caldo } \\
\hline Cobre & $-0,06^{\mathrm{ns}}$ & $0,31^{\mathrm{ns}}$ & $0,29^{\text {ns }}$ & $0,45^{\mathrm{ns}}$ \\
\hline \multirow[t]{3}{*}{ Zinco } & $0,24^{n s}$ & $0,47^{\mathrm{ns}}$ & $0,66^{*}$ & $0,11^{\mathrm{ns}}$ \\
\hline & \multicolumn{4}{|c|}{ Ano agrícola 1997/98 } \\
\hline & \multicolumn{4}{|c|}{ Folha "+1" } \\
\hline Cobre & $0,56^{\text {ns }}$ & $0,50^{\mathrm{ns}}$ & $0,50^{\mathrm{ns}}$ & $0,48^{\mathrm{ns}}$ \\
\hline \multirow[t]{2}{*}{ Zinco } & $-0,12^{\mathrm{ns}}$ & $0,06^{\mathrm{ns}}$ & $0,08^{\mathrm{ns}}$ & $-0,16^{\mathrm{ns}}$ \\
\hline & \multicolumn{4}{|c|}{ Colmo } \\
\hline Cobre & $0,37^{\mathrm{ns}}$ & $0,29^{n s}$ & $0,13^{\text {ns }}$ & $0,13^{\text {ns }}$ \\
\hline \multirow[t]{2}{*}{ Zinco } & $0,71^{* *}$ & $0,76^{* *}$ & $0,68^{*}$ & $0,80^{* *}$ \\
\hline & \multicolumn{4}{|c|}{ Caldo } \\
\hline Cobre & $0,02^{\text {ns }}$ & $0,16^{\mathrm{ns}}$ & $0,10^{\text {ns }}$ & $0,42^{\mathrm{ns}}$ \\
\hline Zinco & $0,57^{*}$ & $0,65^{*}$ & $0,59^{*}$ & $0,63^{*}$ \\
\hline
\end{tabular}

${ }^{3},{ }^{n}$ Indicam respectivamente, que as correlações foram significativas a $\mathrm{P} \leq 0,05, \mathrm{P} \leq 0,01$ ou não significativas pelo teste $t$.

Bidwell \& Dowdy (1987) trabalhando com um solo siltoso tratado com doses crescentes de lodo de esgoto $\left(0,60,120\right.$ e $180 \mathrm{Mg} \mathrm{ha}^{-1}$ - base seca) observaram que as elevadas correlações obtidas entre os teores de $\mathrm{Cd}$ e $\mathrm{Zn}$ avaliados por DTPA-TEA e 
àqueles absorvidos por plantas de milho, deveriam ser vistas com cautela. Eles verificaram que para níveis constantes de metais avaliados no solo, houveram diminuições nos teores absorvidos pelas plantas cultivadas seqüencialmente.

Com base no exposto, todos os resultados obtidos no presente trabalho também devem ser vistos com reservas uma vez que, a disponibilidade dos metais às plantas esteve provavelmente, influenciada pelos elevados valores de $\mathrm{pH}$ e carbono orgânico verificados no solo dos tratamentos com lodo de esgoto. Dessa forma, na hipótese da interrupção das aplicações do resíduo ficam dúvidas a respeito da disponibilidade desses elementos a medida em que a carga orgânica do lodo for se degradando e a acidez do solo aumentando. Neste contexto, insere-se também o comportamento característico de cada espécie vegetal, já que existem trabalhos na literatura que demonstram que plantas cultivadas em solos, cuja contaminação por metais pesados é devida a disposição de resíduos orgânicos, nem sempre absorvem esses elementos de forma crescente e linear em função das quantidades aplicadas (Corey et al., 1987; Barbarick et al., 1995; Logan et al., 1997).

\subsubsection{Nitrogênio}

\subsubsection{Lixiviação de nitrato e amônio}

$\mathrm{Na}$ Tabela 21 são apresentados os componentes do balanço hídrico e a estimativa do fluxo de água (q) nos vários tratamentos. Cabe lembrar que os fluxos com sinal negativo são descendentes e os com sinal positivo, ascendentes.

Pode-se observar que dentro de cada período e profundidade, os valores estimados para fluxo de água foram próximos entre tratamentos pois, evidentemente, todos receberam a mesma quantidade de chuvas. No entanto, para os tratamentos com doses $\mathrm{A}, \mathrm{B}$ e $\mathrm{C}$ de lodo de esgoto verifica-se em três dos quatro períodos em que houveram fluxos descendentes, que embora próxima, a movimentação de água foi sempre superior nestes tratamentos. Dessa forma, é possivel que esta tendência tenha relação com os efeitos do lodo sobre a condutividade hidráulica da camada superficial do solo haja visto que, Marciano (1999) encontrou nestes mesmos tratamentos, resultados que indicaram aumentos neste atributo devido a aplicação do resíduo. 


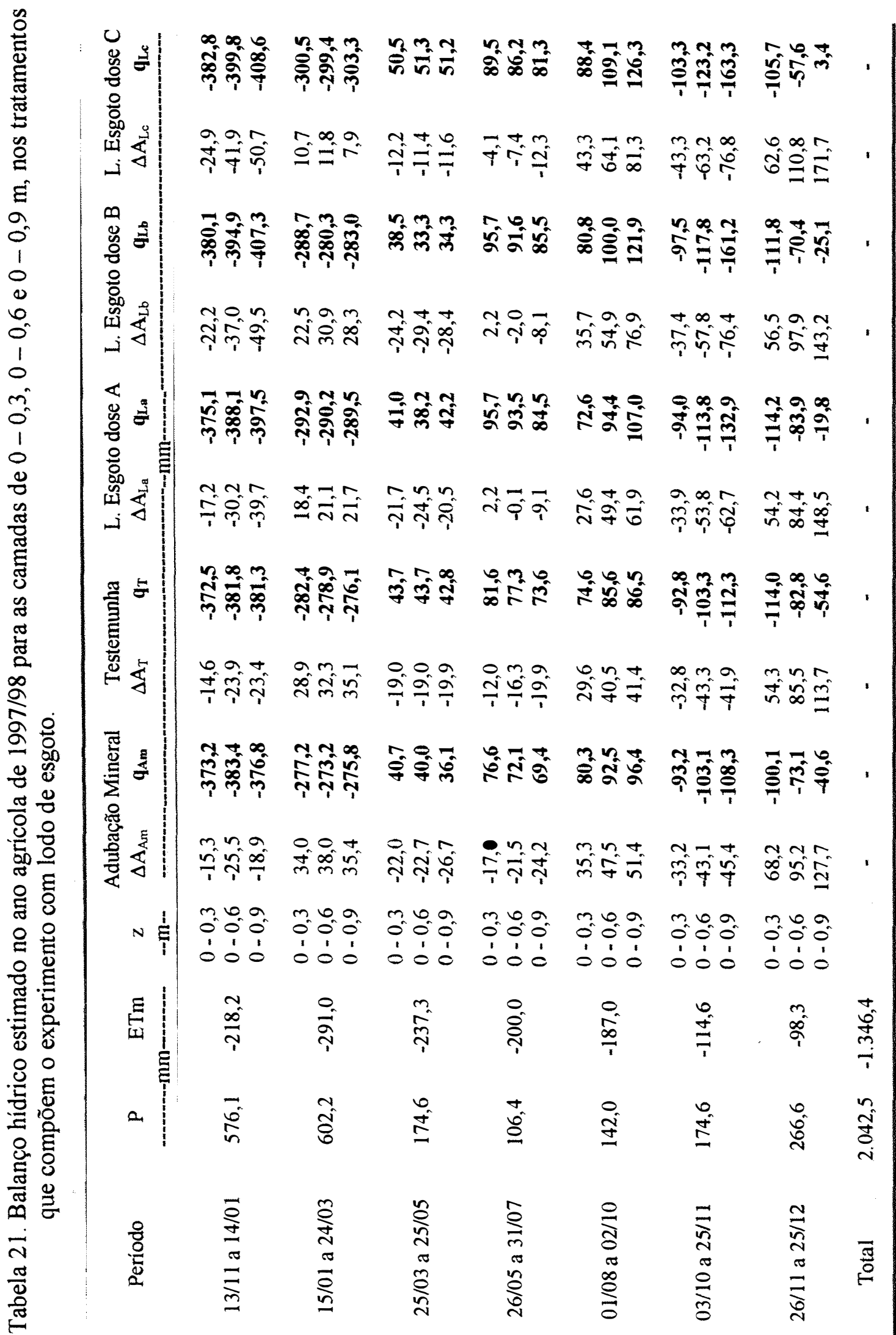


Os maiores fluxos descendentes de água foram verificados nos dois primeiros períodos estabelecidos, de 13/11/1997 a 14/01/98 e de 15/01 a 24/03/98, onde ocorreram as maiores quantidades de precipitações. É importante ressaltar que tais fluxos foram extremamente elevados, ocasionados por precipitações de ocorrência atípica e acima das médias regionais. Para se ter uma idéia, enquanto o acúmulo de chuvas no primeiro período foi de $576,1 \mathrm{~mm}$, a soma média dos meses completos de novembro, dezembro e janeiro, para a cidade de Piracicaba, SP (período de retorno de 82 anos $^{4}$ ), foi menor, cerca de 554,3 mm. Para o segundo período, a soma média dos meses completos de janeiro, fevereiro e março foi de $552,6 \mathrm{~mm}$, menor portanto, do que o ocorrido na área experimental $(602,2 \mathrm{~mm})$.

Nos períodos compreendidos entre $25 / 03$ a $02 / 10 / 1998$ foram verificados fluxos ascendentes de água. Nesta época a ocorrência de chuvas foi baixa e as perdas de água por evapotranspiração foram elevadas devido, além dos fatores climáticos, ao estágio de desenvolvimento da cultura, a qual apresentava bom crescimento e por conseguinte uma maior absorção e transpiração de água ocasionada essencialmente, pela grande área foliar.

No final do ano de 1998, com a volta das chuvas de primavera-verão na região de Piracicaba, SP, novamente foram verificados fluxos descendentes de água. Estes ocorreram nos períodos de 03/10 a 25/1 1/98 e 26/11 a 25/12/98.

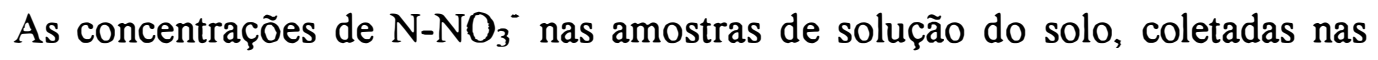
profundidades de 0,3,0,6 e 0,9 m, durante todo o período experimental, são apresentadas na Figura 17. De maneira geral, verifica-se que tais concentrações variaram com tratamentos e épocas de amostragens. Aumentos nos teores de $\mathrm{N}-\mathrm{NO}_{3}{ }^{-}$ocorreram, em todas as profundidades, em função das doses crescentes de lodo de esgoto, o que evidentemente foi devido aos acréscimos proporcionais nas quantidades de nitrogênio aplicadas através do resíduo. Considerando-se as épocas de amostragens, observam-se comportamentos diferenciados para cada profundidade, os quais foram provavelmente, devidos aos efeitos da percolação das águas de chuvas e a ação do sistema radicular das plantas de cana-de-açúcar na absorção do nitrogênio. 

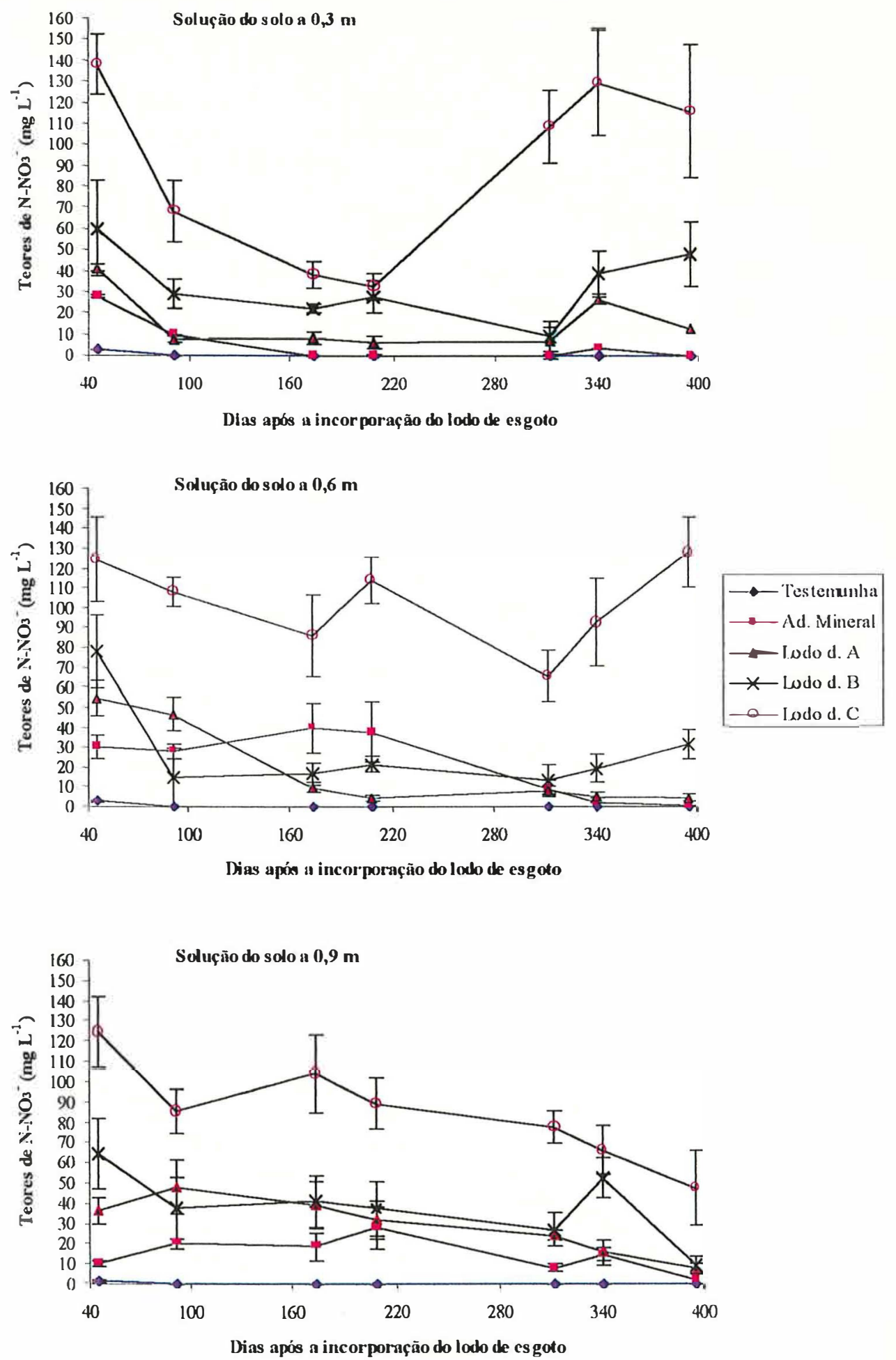

Figura 17. Concentração média e desvio padrão de $\mathrm{N}_{-} \mathrm{NO}_{3}{ }^{-}$na solução do solo determinados a 0,3, 0,6 e 0,9 m de profundidade, para os tratamentos com doses de lodo de esgoto e ad. mineral, no decorrer do ano agrícola 1997/98. 
Na profundidade de $0,3 \mathrm{~m}$, para todos os tratamentos, as maiores concentrações médias de $\mathrm{N}_{-} \mathrm{NO}_{3}{ }^{-}$foram observadas na $1^{\text {a }}$ amostragem de solução do solo ( \pm 45 dias após a incorporação do lodo de esgoto) onde os teores médios encontrados e os respectivos valores de desvio padrão foram de $2,75 \mathrm{mg} \mathrm{L}^{-1}\left(0,81 \mathrm{mg} \mathrm{L}^{-1}\right)$ para testemunha, 27,67 $\mathrm{mg} \mathrm{L}^{-1}\left(5,09 \mathrm{mg} \mathrm{L}^{-1}\right)$ para adubação mineral, 41,17 $\mathrm{mg} \mathrm{L}^{-1}$ $\left(13,13 \mathrm{mg} \mathrm{L}^{-1}\right)$ para dose A, 59,98 $\mathrm{mg} \mathrm{L}^{-1}\left(22,67 \mathrm{mg} \mathrm{L}^{-1}\right)$ para dose B e $137,87 \mathrm{mg} \mathrm{L}^{-1}$ $\left(14,24 \mathrm{mg} \mathrm{L}^{-1}\right)$ para dose $\mathrm{C}$ de lodo de esgoto. Para o tratamento com adubação mineral, este fato pode ser explicado pela adição, até então recente, do nitrogênio na forma de uréia enquanto que, nos tratamentos com lodo de esgoto, estas concentrações foram provavelmente, proporcionadas pelas elevadas quantidades de nitrogênio inorgânico aplicadas via resíduo (Tabela 4) e também pela rápida mineralização de parte do nitrogênio orgânico.

Nos tratamentos testemunha e adubação mineral, as concentrações caíram para praticamente zero a partir da $3^{\underline{a}}$ amostragem de solução ( \pm 174 dias) e assim permaneceram até o final das avaliações. Nos tratamentos com doses A, B e C de lodo de esgoto, de maneira geral, foram observados decréscimos até a $3^{\underline{a}}$ e $4^{\underline{a}}$ amostragens ( \pm 174 e 208 dias) sendo que, nas coletas seguintes, os teores de $\mathrm{N}_{-} \mathrm{NO}_{3}{ }^{-}$na solução do solo voltaram aumentar, atingindo aos 395 dias, concentrações próximas àquelas observadas na $1^{\underline{a}}$ amostragem. Os decréscimos verificados para a variável, até a $3^{\underline{a}}$ e $4^{\underline{a}}$ amostragens, em todos os tratamentos, podem ser explicados pelo elevado índice de precipitações ocorrido no período das extrações de solução, cerca de $1350 \mathrm{~mm}$ em aproximados 6 meses, o que teria proporcionado a movimentação $\mathrm{N}_{-} \mathrm{NO}_{3}{ }^{-}$para as camadas subsuperficiais do solo. Somado às chuvas, destaca-se também a possibilidade dos efeitos da absorção do $\mathrm{N}$ pela cana-de-açúcar já que no período citado, a cultura passou por sua fase exponencial de crescimento, onde a absorção de nutrientes é máxima. Para os tratamentos com lodo de esgoto, pode ser acrescentada às explicações anteriores, a possibilidade de queda na taxa de mineralização do N-orgânico do resíduo tendo em vista que, em se tratando de um processo microbiológico, este teria sido desfavorecido pelo inverno, época da $3^{\underline{a}}$ e $4^{\underline{a}}$ amostragens de solução, onde normalmente são observadas temperaturas mais amenas e a baixa ocorrência de chuvas. Por outro lado, os acréscimos nos teores de $\mathrm{N}^{-\mathrm{NO}_{3}}{ }^{-}$para estes mesmos tratamentos, nas amostragens de setembro, outubro e novembro ( $\pm 312,340$ e 395 dias, respectivamente), 
foram devidos provavelmente, ao aumento na taxa de mineralização do N-orgânico do resíduo, promovido pela ascensão da temperatura média do ambiente e pela volta da temporada de chuvas.

A movimentação do $\mathrm{N}-\mathrm{NO}_{3}^{-}$para as camadas subsuperficiais do solo foi evidenciada pelos teores encontrados nas amostras de solução, coletadas nas profundidades de 0,6 e $0,9 \mathrm{~m}$. $\grave{A}$ exemplo do que foi observado a $0,3 \mathrm{~m}$, as maiores concentrações de $\mathrm{N}^{-\mathrm{NO}_{3}}{ }^{-}$nestas profundidades também ocorreram, em todos os tratamentos, na $1^{\underline{a}}$ amostragem de solução ( \pm 45 dias), indicando a rápida movimentação do $\mathrm{N}$ até $0,9 \mathrm{~m}$, propiciada pelas precipitações ocorridas no período que antecedeu a coleta das amostras.

As concentrações verificadas a $0,6 \mathrm{~m}$ para os tratamentos testemunha, adubação mineral e dose A de lodo de esgoto apresentaram um comportamento decrescente no decorrer das amostragens de solução do solo. Para a testemunha os valores médios encontrados foram de $2,74 \mathrm{mg} \mathrm{L}^{-1}$ na $1^{1}$ amostragem e praticamente zero ( $\left.\leq 0,04 \mathrm{mg} \mathrm{L}^{-1}\right)$ nas demais coletas. No tratamento com adubação mineral as concentrações de $\mathrm{N}_{-\mathrm{NO}_{3}}^{-}$variaram entre 27,75 e $39,73 \mathrm{mg} \mathrm{L}^{-1}$ da $1^{\underline{a}}$ a $4^{\underline{a}}$ amostragem, declinando na seqüência para $0,45 \mathrm{mg} \mathrm{L}^{-1}$. Para a menor dose de lodo de esgoto (dose A), foram verificados nas duas primeiras amostragens, valores médios de 54,15 e $46,59 \mathrm{mg} \mathrm{L}^{-1}$, os quais foram reduzidos para valores $\leq 9,45 \mathrm{mg} \mathrm{L}^{-1}$ nas demais coletas.

Nos tratamentos com doses B e C de lodo de esgoto, as concentrações de

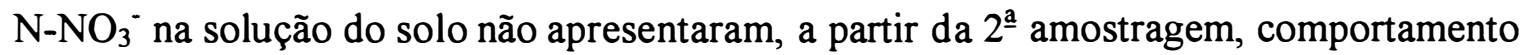
decrescente no decorrer do período experimental. Para a dose $\mathrm{B}$ do resíduo os valores oscilaram, neste período, de 13,48 a $31,49 \mathrm{mg} \mathrm{L}^{-1}$ e para a dose $\mathrm{C}$ tais variações foram de 65,62 a $127,46 \mathrm{mg} \mathrm{L}^{-1}$. Considerando que, neste estudo, $0,6 \mathrm{~m}$ foi uma profundidade de transição entre 0,3 e $0,9 \mathrm{~m}$, é provável que estas observações sejam explicadas pelas maiores quantidades de nitrogênio aplicadas nestes tratamentos sugerindo, mesmo ao final das avaliações, a presença de grandes quantidades de $\mathrm{N}_{-} \mathrm{NO}_{3}{ }^{-}$passíveis de movimentação para maiores profundidades.

Tendo em vista que a cultura da cana-de-açúcar apresenta cerca de $80 \%$ do seu sistema radicular distribuídos na camada de solo de 0 a $0,6 \mathrm{~m}$ e que a quase totalidade das raizes absorventes são distribuidas de 0 a 0,3 m (Bacchi, 1983), pode-se considerar que o $\mathrm{N}-\mathrm{NO}_{3}{ }^{-}$presente abaixo de $0,6 \mathrm{~m}$ de profundidade está praticamente perdido para 
o aproveitamento da cultura, significando portanto, um risco potencial de contaminação de águas subterrâneas.

Em todos os tratamentos, análises das amostras de solução do solo coletadas a 0,9 m revelaram, quando comparadas com a testemunha, elevadas concentrações de ${\mathrm{N}-\mathrm{NO}_{3}}^{-}$(Figura 17). Enquanto as referidas concentrações apresentaram na testemunha valores $\leq 1,47 \mathrm{mg} \mathrm{L}^{-1}$, no tratamento com adubação mineral tais valores oscilaram, até a $6^{\text {a }}$ amostragem ( \pm 340 dapi), entre 28,02 e $8,08 \mathrm{mg} \mathrm{L}^{-1}$, caindo para $2,5 \mathrm{mg} \mathrm{L}^{-1}$ por ocasião da $7^{\underline{a}}$ amostragem. Para as doses $\mathrm{A}, \mathrm{B}$ e $\mathrm{C}$ de lodo de esgoto, as concentrações máximas e mínimas, observadas entre a $1^{\underline{a}}$ e $7^{\underline{a}}$ amostragens, foram respectivamente, 48,10 e $7,68 \mathrm{mg} \mathrm{L}^{-1}, 64,16$ e $9,75 \mathrm{mg} \mathrm{L}^{-1}, 124,52$ e $47,40 \mathrm{mg} \mathrm{L}^{-1}$. De maneira geral, essas concentrações apresentaram um comportamento decrescente em função do tempo, sugerindo a movimentação do nitrogênio para profundidades maiores do que $0,9 \mathrm{~m}$. No entanto, os acréscimos verificados a 0,3 e 0,6 m, nas três últimas amostragens de solução nos tratamentos com doses do resíduo, indicaram que após o encerramento das avaliações, poderão haver aumentos nas concentrações de nitrogênio a $0,9 \mathrm{~m}$.

Convém salientar que as concentrações de $\mathrm{N}^{-\mathrm{NO}_{3}}{ }^{-}$a $0,9 \mathrm{~m}$ estiveram, durante a maior parte do período experimental, nos tratamentos adubação mineral e doses $\mathrm{A}$ e B de lodo de esgoto, bem acima de $10 \mathrm{mg} \mathrm{L}^{-1}$, padrão máximo adotado pela Organização Mundial da Saúde (OMS) para qualidade da água potável (Muchovej \& Rechcigl, 1995). Para a dose $\mathrm{C}$, tais concentrações estiveram acima dos limites de segurança da OMS em todas as avaliações da solução do solo, indicando que para maiores taxas de aplicações do resíduo, maior e mais prolongado é o seu efeito poluente devido a nitratos.

Diversos estudos conduzidos nas mais variadas condições de clima, solos e taxas de aplicação de lodo de esgoto, tem mostrado que a disposição deste resíduo em solos agrícolas pode proporcionar rapidamente, em profundidades maiores que $0,9 \mathrm{~m}$, concentrações de $\mathrm{N}_{-} \mathrm{NO}_{3}{ }^{-}$acima de $10 \mathrm{mg} \mathrm{L}^{-1}$ traduzindo-se portanto, num elevado risco à potabilidade das águas subterrâneas (Kelling et al., 1977; Sidle \& Kardos, 1979; Inman et al., 1982; Jones \& Hinesly, 1988). No caso dos fertilizantes nitrogenados, dependendo da intensidade de cultivo das áreas agrícolas e dos critérios de sua utilização, os riscos de contaminação também são elevados (Jones \& Hinesly, 1988; Muchovej \& Rechcigl, 1995).

As estimativas da lixiviação de $\mathrm{N}-\mathrm{NO}_{3}{ }^{-}$, nas camadas do solo de $0-0,3,0-0,6$ e $0-0,9 \mathrm{~m}$, para todos os tratamentos, encontram-se na Tabela 22. Os sinais negativos e 
positivos, a exemplo do fluxo de água, representam respectivamente, movimentos descendentes e ascendentes.

Houveram grandes perdas de $\mathrm{N}_{-} \mathrm{NO}_{3} \cdot$ nos tratamentos adubação mineral e doses $\mathrm{A}, \mathrm{B}$ e $\mathrm{C}$ de lodo de esgoto, em todas as camadas consideradas. As maiores quantidades lixiviadas de $\mathrm{N}^{-\mathrm{NO}_{3}}{ }^{-}$ocorreram, para todos os tratamentos e camadas do solo, nos dois primeiros períodos de avaliação (13/11/1997 a 14/01/98 e 15/01 a 24/03/98). Essas perdas, as quais representaram de 74 a $98 \%$ dos totais lixiviados, se deram pela

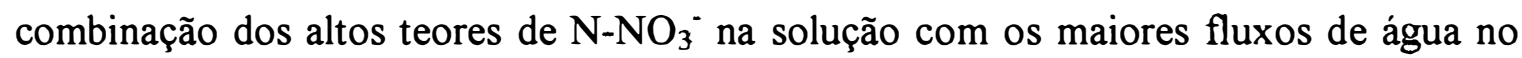
solo, o que evidencia a estreita relação entre o movimento da água e a lixiviação de nitratos, conforme relatado por Libardi \& Reichardt (1978), Reichardt et al. (1979) e Sidle \& Kardos (1979).

Para o tratamento testemunha, as perdas totais estimadas de $\mathrm{N}_{-} \mathrm{NO}_{3}{ }^{-}$nas camadas de $0-0,3,0-0,6$ e $0-0,9 \mathrm{~m}$ foram respectivamente, de 10,5, 10,5 e $5,6 \mathrm{~kg} \mathrm{ha}^{-1}$, sendo que praticamente $100 \%$ destas perdas, ocorreram no primeiro período considerado.

No tratamento adubação mineral, camada de $0-0,3 \mathrm{~m}$, a quase totalidade das perdas de nitrogênio ocorreram nos dois primeiros períodos sendo que, apenas no primeiro, estas representaram $77,3 \%$ do total lixiviado durante o experimento. Considerando-se que foram aplicados $120 \mathrm{~kg} \mathrm{ha}^{-1}$ de $\mathrm{N}$ por ocasião da adubação e levando-se em conta as perdas de $\mathrm{N}_{-} \mathrm{NO}_{3}{ }^{-}$da testemunha, verifica-se que praticamente todo o nitrogênio aplicado foi lixiviado para as camadas subsuperficiais nos dois primeiros períodos, sugerindo a rápida perda do $\mathrm{N}$ da camada onde se situa a maior parte das raízes absorventes das plantas de cana-de-açúcar. Nas camadas de 0-0,6 e $0-0,9 \mathrm{~m}$, foram verificados movimentos ascendentes de $\mathrm{N}_{-} \mathrm{NO}_{3}{ }^{-}$nos períodos compreendidos entre $25 / 03$ a $02 / 10 / 98$ porém, para a camada de $0-0,6 \mathrm{~m}$ o balanço final sugeriu que as perdas foram equivalentes ao total do $\mathrm{N}$ aplicado via fertilizante. $\mathrm{A}$ quantidade total lixiviada da camada $0-0,9 \mathrm{~m}$ foi de $76 \mathrm{~kg} \mathrm{ha}^{-1}$ e descontando-se a quantidade movimentada no tratamento testemunha, este valor representou cerca de $59 \%$ do total aplicado ao solo. Bassoi \& Carvalho (1992) encontraram perdas de nitrogênio a $0,3 \mathrm{~m}$ bem menores do que no presente trabalho no entanto, é preciso considerar que o período de avaliações e os fluxos descendentes de água no solo foram menores e principalmente, que a aplicação do fertilizante nitrogenado foi parcelada. 


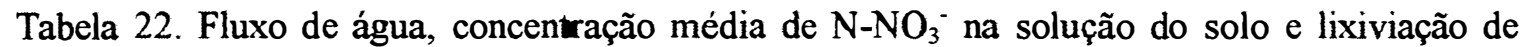
$\mathrm{N}-\mathrm{NO}_{3}{ }^{-}$nas camadas de $0-0,3,0-0,6$ e $0-0,9 \mathrm{~m}$ para os tratamentos que compõem o experimento com lodo de esgoto.

\begin{tabular}{|c|c|c|c|c|c|c|c|c|c|}
\hline \multirow[b]{2}{*}{ Período } & \multicolumn{3}{|c|}{ Fluxo de água } & \multicolumn{3}{|c|}{ Conc. média de $\mathrm{N}-\mathrm{NO}_{3}^{-}$} & \multicolumn{3}{|c|}{ Lixiviação de $\mathrm{N}-\mathrm{NO}_{3}^{-}$} \\
\hline & 90-0,3 & $\begin{array}{r}\mathbf{q}_{0-0,6} \\
-\mathbf{m m}\end{array}$ & Q00,9 & $\mathrm{C}_{0,3}$ & $\mathrm{C}_{0,6}$ & $\mathbf{C}_{0,9}$ & $\mathrm{~L}_{0.03}$ & $\begin{array}{r}\mathbf{L}_{0,0,6} \\
-\mathrm{kg} \mathrm{ha}^{-1}\end{array}$ & $\mathbf{L}_{0,9,9}$ \\
\hline & \multicolumn{9}{|c|}{ Adubação Mineral } \\
\hline $13 / 11$ a $14 / 01$ & $-373,2$ & $-383,4$ & $-376,8$ & 27,66 & 30,16 & 10,08 & $-103,2$ & $-115,6$ & $-38,0$ \\
\hline $15 / 01$ a $24 / 03$ & $-277,2$ & $-273,2$ & $-275,8$ & 9,82 & 27,75 & 19,97 & $-27,2$ & $-75,8$ & $-55,1$ \\
\hline $25 / 03$ a $25 / 05$ & 40,7 & 40,0 & 36,1 & 0,25 & 39,70 & 18,75 & 0,1 & 15,9 & 6,8 \\
\hline $26 / 05$ a $31 / 07$ & 76,6 & 72,1 & 69,4 & 0,09 & 37,73 & 28,02 & 0,1 & 27,2 & 19,4 \\
\hline $01 / 08$ a $02 / 10$ & 80,3 & 92,5 & 96,4 & 0,23 & 9,11 & 8,08 & 0,2 & 8,4 & 7,8 \\
\hline $03 / 10$ a $25 / 11$ & $-93,2$ & $-103,1$ & $-108,3$ & 3,22 & 2,25 & 14,69 & $-3,0$ & $-2,3$ & $-15,9$ \\
\hline $26 / 11$ a $25 / 12$ & $-100,1$ & $-73,1$ & $-40,6$ & 0,11 & 0,45 & 2,50 & $-0,1$ & $-0,3$ & $-1,0$ \\
\hline \multirow[t]{2}{*}{ Total } & $-646,1$ & $-628,2$ & $-599,6$ & - & - & - & $-133,1$ & $-142,5$ & $-76,0$ \\
\hline & \multicolumn{9}{|c|}{ Testemunha } \\
\hline $13 / 11$ a $14 / 01$ & $-372,5$ & $-381,8$ & $-381,3$ & 2,75 & 2,74 & 1,47 & $-10,2$ & $-10,5$ & $-5,6$ \\
\hline $15 / 01$ a $24 / 03$ & $-282,4$ & $-278,9$ & $-276,1$ & 0,02 & 0,01 & n.d." & $-0,1$ & - & - \\
\hline $25 / 03$ a $25 / 05$ & 43,7 & 43,7 & 42,8 & 0,01 & n.d. & n.d. & - & - & - \\
\hline $26 / 05$ a $31 / 07$ & 81,6 & 77,3 & 73,6 & n.d. & 0,04 & 0,01 & - & - & - \\
\hline $01 / 08$ a $02 / 10$ & 74,6 & 85,6 & 86,5 & n.d. & n.d. & n.d. & - & - & - \\
\hline $03 / 10$ a $25 / 11$ & $-92,8$ & $-103,3$ & $-112,3$ & 0,21 & n.d. & n.d. & $-0,2$ & - & - \\
\hline $26 / 11$ a $25 / 12$ & $-114,0$ & $-82,8$ & $-54,6$ & n.d. & n.d. & n.d. & - & - & - \\
\hline \multirow[t]{2}{*}{ Total } & $-661,8$ & $-640,2$ & $-621,4$ & - & - & - & $-10,5$ & $-10,5$ & $-5,6$ \\
\hline & \multicolumn{9}{|c|}{ Lodo de Esgoto dose A } \\
\hline $13 / 11$ a $14 / 01$ & $-375,1$ & $-388,1$ & $-397,5$ & 41,17 & 54,15 & 36,27 & $-154,4$ & $-210,2$ & $-144,2$ \\
\hline $15 / 01$ a $24 / 03$ & $-292,9$ & $-290,2$ & $-289,5$ & 7,76 & 46,59 & 48,10 & $-22,7$ & $-135,2$ & $-139,3$ \\
\hline $25 / 03$ a $25 / 05$ & 41,0 & 38,2 & 42,2 & 8,29 & 9,45 & 39,33 & 3,4 & 3,6 & 16,6 \\
\hline $26 / 05$ a $31 / 07$ & 95,7 & 93,5 & 84,5 & 6,32 & 4,44 & 31,90 & 6,0 & 4,2 & 27,0 \\
\hline $01 / 08$ a $02 / 10$ & 72,6 & 94,4 & 107,0 & 6,90 & 8,38 & 24,15 & 5,0 & 7,9 & 25,8 \\
\hline $03 / 10$ a $25 / 11$ & $-94,0$ & $-113,8$ & $-132,9$ & 28,63 & 4,86 & 15,62 & $-26,9$ & $-5,5$ & $-20,8$ \\
\hline $26 / 11$ a $25 / 12$ & $-114,2$ & $-83,9$ & $-19,8$ & 12,31 & 4,73 & 7,68 & $-14,1$ & $-4,0$ & $-1,5$ \\
\hline \multirow[t]{2}{*}{ Total } & $-666,9$ & $-649,9$ & $-606,0$ & - & - & - & $-203,7$ & $-339,2$ & $-236,4$ \\
\hline & \multicolumn{9}{|c|}{ Lodo de Esgoto dose B } \\
\hline $13 / 11$ a $14 / 01$ & $-380,1$ & $-394,9$ & $-407,3$ & 59,98 & 77,72 & 64,16 & $-228,0$ & $-306,9$ & $-261,3$ \\
\hline $15 / 01$ a $24 / 03$ & $-288,7$ & $-280,3$ & $-283,0$ & 29,21 & 14,74 & 37,65 & $-84,3$ & $-41,3$ & $-106,6$ \\
\hline $25 / 03$ a $25 / 05$ & 38,5 & 33,3 & 34,3 & 22,25 & 17,18 & 40,95 & 8,6 & 5,7 & 14,0 \\
\hline $26 / 05$ a $31 / 07$ & 95,7 & 91,6 & 85,5 & 28,08 & 21,45 & 37,40 & 26,9 & 19,6 & 32,0 \\
\hline $01 / 08$ a $02 / 10$ & 80,8 & 100,0 & 121,9 & 9,02 & 13,48 & 26,95 & 7,3 & 13,5 & 32,9 \\
\hline $03 / 10$ a $25 / 11$ & $-97,5$ & $-117,8$ & $-161,2$ & 38,67 & 19,39 & 52,48 & $-37,7$ & $-22,8$ & $-84,6$ \\
\hline $26 / 11$ a $25 / 12$ & $-111,8$ & $-70,4$ & $-25,1$ & 48,24 & 31,49 & 9,75 & $-53,9$ & $-22,2$ & $-2,4$ \\
\hline \multirow[t]{2}{*}{ Total } & $-663,1$ & $-638,5$ & $-634,9$ & - & - & - & $-361,1$ & $-354,4$ & $-376,0$ \\
\hline & \multicolumn{9}{|c|}{ Lodo de Esgoto dose C } \\
\hline $13 / 11$ a $14 / 01$ & $-382,8$ & $-399,8$ & $-408,6$ & 137,87 & 123,68 & 124,52 & $-527,7$ & $-494,5$ & $-508,8$ \\
\hline $15 / 01$ a $24 / 03$ & $-300,5$ & $-299,4$ & -303.3 & 68,34 & 107,80 & 85,50 & $-205,4$ & $-322,8$ & $-259,3$ \\
\hline $25 / 03$ a $25 / 05$ & 50,5 & 51,3 & 51,2 & 38,18 & 85,88 & 103,90 & 19,3 & 44,1 & 53,2 \\
\hline $26 / 05$ a $31 / 07$ & 89,5 & 86,2 & 81,3 & 32,66 & 113,54 & 89,14 & 29,2 & 97,9 & 72,5 \\
\hline $01 / 08$ a $02 / 10$ & 88,4 & 109,1 & 126,3 & 108,49 & 65,62 & 77,50 & 95,9 & 71,6 & 97,9 \\
\hline $03 / 10$ a $25 / 11$ & $-103,3$ & $-123,2$ & $-163,3$ & 129,47 & 92,35 & 66,19 & $-133,7$ & $-113,8$ & $-108,1$ \\
\hline $26 / 11$ a $25 / 12$ & $-105,7$ & $-57,6$ & 3,4 & 115,64 & 127,46 & 47,40 & $-122,2$ & $-73,4$ & 1,6 \\
\hline Total & -663.9 & $-633,4$ & -613.0 & & & & $-844,6$ & $-790,9$ & $-651,0$ \\
\hline
\end{tabular}

* n.d. - não detectado - abaixo do limite de determinação do método analítico empregado. 
As quantidades de $\mathrm{N}-\mathrm{NO}_{3}{ }^{-}$movimentadas nos tratamentos com lodo de esgoto, em todas as camadas de solo, foram crescentes em função das doses aplicadas. Embora tenham sido observados movimentos ascendentes de $\mathrm{N}_{-} \mathrm{NO}_{3}{ }^{-}$no $3^{\circ}, 4^{\circ}$ e $5^{\circ}$ período, o balanço final de perdas apontou para a camada $0-0,9 \mathrm{~m}$, respectivamente nas doses A, B e C de lodo de esgoto, lixiviações de $236,4,376,0$ e $651,0 \mathrm{~kg} \mathrm{ha}^{-1}$, correspondentes a 29,23 e $27 \%$ do N-total aplicado no segundo ano agrícola, através do resíduo. Ressalta-se que, embora essas porcentagens sejam relativamente baixas, elas representam acréscimos consideráveis de nitrogênio inorgânico no solo.

Jones \& Hinesly (1988) encontraram perdas de $\mathrm{N}^{-\mathrm{NO}_{3}}{ }^{-}$, para camadas inferiores a $0,9 \mathrm{~m}$, de 79 e $31 \mathrm{~kg} \mathrm{ha}^{-1}$ respectivamente para $\circ 1^{0}$ e $2^{0}$ ano de experimentação, o que representou aproximadamente, 24 e $9 \%$ do $\mathrm{N}$ total adicionado anualmente ao solo, via fertilizantes minerais. Devido a disposição de lodo de esgoto, eles verificaram perdas de 663 e $371 \mathrm{~kg} \mathrm{ha}^{-1}$ para os referidos anos experimentais, o que representou aproximadamente, 29 e $11 \%$ das quantidades totais de $\mathrm{N}$ aplicadas anualmente. Segundo os autores, a maior e menor quantidade de perdas foi determinada pelo volume de chuvas ocorrido em cada ano.

É importante salientar que, apesar da primeira aplicação de lodo de esgoto (ano agrícola 1996/97) ter sido realizada 400 dias antes da segunda (ano agrícola 1997/98), é possível que as perdas estimadas de $\mathrm{N}_{-} \mathrm{NO}_{3}{ }^{-}$estejam influenciadas por efeitos residuais da primeira aplicação. Além disso, tendo em vista que as precipitações ocorridas no período de estudo foram acima da média, acredita-se que os padrões de lixiviação ocorridos tenham representado um potencial máximo. Por outro lado, é preciso considerar que a ocorrência de perdas de nitrogênio por volatilização muitas vezes é significativa em solos tratados com lodo de esgoto (Kelling et al., 1977; Shepherd et al. 1996), especialmente no presente trabalho onde o resíduo utilizado apresentava $\mathrm{pH}>8,0$ e foi exposto, após aplicação ao solo, a um período de pré-secagem de \pm 7 dias.

Devido a ameaça que representam para a qualidade das águas subterrâneas, as quantidades de $\mathrm{N}^{-\mathrm{NO}_{3}}{ }^{-}$movimentadas através da camada de $0-0,9 \mathrm{~m}$ realçam a necessidade de se combinar as taxas de fornecimento do nitrogênio pelo lodo de esgoto com a capacidade de absorção das diversas culturas agrícolas. Salienta-se que as doses 
de lodo empregadas neste estudo foram obviamente excessivas no entanto, é importante lembrar que estas foram definidas, com base nos critérios da USEPA (1993), para verificar a possivel ocorrência e severidade de efeitos causados por metais pesados.

Pela comparação dos resultados fica demonstrado que, na definição das taxas de aplicação do lodo de esgoto, ao menos a curto prazo, a presença do nitrogênio é um fator mais limitante do que a dos metais pesados. Esta observação também está de acordo com os resultados obtidos por Anjos (1999).

Os resultados obtidos para a movimentação de $\mathrm{N}^{-N_{4}}{ }_{4}{ }^{+}$(Tabela 23) mostraram que as perdas do elemento sob esta forma foi insignificante quando comparada à forma nítrica. Tal comparação revela, para os tratamentos com lodo de esgoto, que do total de nitrogênio lixiviado, a forma $\mathrm{NH}_{4}{ }^{+}$representou menos de $0,6 \%$. De acordo com Victória et al. (1992) e Hue (1995) a baixa mobilidade do $\mathrm{N}_{-} \mathrm{NH}_{4}{ }^{+}$pode ser atribuída a possibilidade de sua adsorção ao complexo de troca iônica do solo, fixação no solo pela inclusão entre as lâminas dos minerais de argila 2:1 e a perdas por volatilização da $\mathrm{NH}_{3}$. No entanto, os autores salientaram que em solos bem drenados com o predomínio de condições aeróbias, o N-NH${ }_{4}^{+}$é rapidamente oxidado a $\mathrm{N}_{-} \mathrm{NO}_{3}{ }^{-}$através das reações de nitrificação sendo esta, provavelmente, a principal razão das baixas perdas de $\mathrm{N}_{-} \mathrm{NH}_{4}{ }^{+}$.

As estimativas realizadas neste trabalho teriam sido mais exatas caso tivesse sido possível um maior número de amostragens de solução do solo. No decorrer dos trabalhos surgiram alguns problemas no funcionamento dos extratores de solução sendo o de maior relevância, vazamentos discretos na junção entre o tubo coletor de solução e a rolha de borracha. A dificuldade para a identificação imediata do problema tornou a realização das duas primeiras amostragens de solução do solo muito difíceis e demoradas, pois o aparelho não mantinha a suç̧ão aplicada por tempo suficientemente longo. Somente na terceira amostragem, em fevereiro/98, suspeitou-se da possibilidade de vazamento nesta junção, ainda que os testes em laboratório não o acusavam. Surgiu a idéia de lubrificar a rolha de borracha com vaselina, o que permitiu uma vedação excepcionalmente melhor e facilitou muito a coleta, pois o aparelho passou a manter a sucção aplicada por dezenas de horas. Solução extremamente simples, que infelizmente não foi encontrada descrita na literatura pertinente, e que só surgiu após vários transtomos e ter causado pelo menos a perda de uma amostragem. Apesar disto, diante da ordem de grandeza dos resultados, os objetivos do trabalho foram alcançados. 


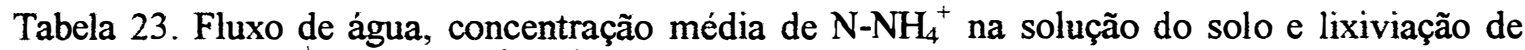
$\mathrm{N}-\mathrm{NH}_{4}^{+}$nas camadas de $0-0,3,0-0,6$ e $0-0,9 \mathrm{~m}$ para os tratamentos que compõem o experimento com lodo de esgoto.

\begin{tabular}{|c|c|c|c|c|c|c|c|c|c|}
\hline \multirow[b]{2}{*}{ Período } & \multicolumn{3}{|c|}{ Fluxo de água } & \multicolumn{3}{|c|}{ Conc. média de $\mathrm{N}-\mathrm{NH}_{4}^{+}$} & \multicolumn{3}{|c|}{ Lixiviação de $\mathrm{N}-\mathrm{NH}_{4}^{+}$} \\
\hline & $90,0,3$ & $\begin{array}{r}\mathbf{q}_{00,6} \\
-\mathrm{mm}\end{array}$ & $q_{0,0,9}$ & $\mathrm{C}_{0,3}$ & $\begin{array}{c}C_{0,6} \\
\mathrm{ng} \mathrm{L}^{-1}\end{array}$ & $\mathbf{C}_{0,9}$ & $\mathbf{L}_{0-0,3}$ & $\begin{array}{l}\mathrm{L}_{0,0,6} \\
\mathrm{~g} \mathrm{ha}\end{array}$ & Loo,9 \\
\hline & \multicolumn{9}{|c|}{ Adubação Mineral } \\
\hline $13 / 11$ a $14 / 01$ & $-373,2$ & $-383,4$ & $-376,8$ & 0,48 & 0,06 & 0,11 & $-1,79$ & $-0,2$ & $-0,4$ \\
\hline $15 / 01$ a $24 / 03$ & $-277,2$ & $-273,2$ & $-275,8$ & n.d. & n.d. & n.d. ${ }^{*}$ & - & - & - \\
\hline $25 / 03$ a $25 / 05$ & 40,7 & 40,0 & 36,1 & n.d. & n.d. & n.d. & - & - & - \\
\hline $26 / 05$ a $31 / 07$ & 76,6 & 72,1 & 69,4 & n.d. & n.d. & n.d. & - & - & - \\
\hline $01 / 08$ a $02 / 10$ & 80,3 & 92,5 & 96,4 & n.d. & 0,03 & 0,03 & - & - & - \\
\hline $03 / 10$ a $25 / 11$ & $-93,2$ & $-103,1$ & $-108,3$ & 0,01 & n.d. & n.d. & - & - & - \\
\hline $26 / 11$ a $25 / 12$ & $-100,1$ & $-73,1$ & $-40,6$ & n.d. & n.d. & n.d. & - & - & - \\
\hline \multirow[t]{2}{*}{ Total } & $-646,1$ & $-628,2$ & $-599,6$ & - & - & - & $-1,79$ & $-0,2$ & $-0,4$ \\
\hline & \multicolumn{9}{|c|}{ Testemunha } \\
\hline $13 / 11$ a $14 / 01$ & $-372,5$ & $-381,8$ & $-381,3$ & n.d. & 0,31 & n.d. & - & $-1,2$ & - \\
\hline $15 / 01$ a $24 / 03$ & $-282,4$ & $-278,9$ & $-276,1$ & n.d. & n.d. & n.d. & - & - & - \\
\hline $25 / 03$ a $25 / 05$ & 43,7 & 43,7 & 42,8 & n.d. & n.d. & n.d. & - & - & - \\
\hline $26 / 05$ a $31 / 07$ & 81,6 & 77,3 & 73,6 & n.d. & 0,03 & n.d. & - & - & - \\
\hline $01 / 08$ a 02/10 & 74,6 & 85,6 & 86,5 & n.d. & 0,02 & 0,02 & - & $=$ & - \\
\hline $03 / 10$ a $25 / 11$ & $-92,8$ & $-103,3$ & $-112,3$ & n.d. & 0,01 & n.d. & - & - & - \\
\hline $26 / 11$ a $25 / 12$ & $-114,0$ & $-82,8$ & $-54,6$ & n.d. & n.d. & n.d. & - & - & - \\
\hline \multirow[t]{2}{*}{ Total } & $-661,8$ & $-640,2$ & $-621,4$ & - & - & - & - & $-1,2$ & - \\
\hline & \multicolumn{9}{|c|}{ Lodo de Esgoto dose $A$} \\
\hline $13 / 11$ a $14 / 01$ & $-375,1$ & $-388,1$ & $-397,5$ & 0,42 & 0,08 & 0,06 & $-1,6$ & $-0,3$ & $-0,2$ \\
\hline $15 / 01$ a $24 / 03$ & $-292,9$ & $-290,2$ & $-289,5$ & n.d. & 0,06 & n.d. & - & $-0,2$ & - \\
\hline $25 / 03$ a $25 / 05$ & 41,0 & 38,2 & 42,2 & n.d. & 0,14 & 0,26 & - & 0,1 & 0,1 \\
\hline $26 / 05$ a $31 / 07$ & 95,7 & 93,5 & 84,5 & 0,28 & 0,25 & 0,54 & 0,3 & 0,2 & 0,5 \\
\hline $01 / 08$ a $02 / 10$ & 72,6 & 94,4 & 107,0 & 0,21 & 0,11 & 0,03 & 0,2 & 0,1 & - \\
\hline $03 / 10$ a $25 / 11$ & $-94,0$ & $-113,8$ & $-132,9$ & 0,13 & 0,08 & n.d. & $-0,1$ & $-0,1$ & - \\
\hline $26 / 11$ a $25 / 12$ & $-114,2$ & $-83,9$ & $-19,8$ & n.d. & 0,03 & n.d. & - & - & - \\
\hline \multirow[t]{2}{*}{ Total } & $-666,9$ & $-649,9$ & $-606,0$ & $=$ & - & - & $-1,2$ & $-0,2$ & 0,4 \\
\hline & \multicolumn{9}{|c|}{ Lodo de Esgoto dose B } \\
\hline $13 / 11$ a $14 / 01$ & $-380,1$ & $-394,9$ & $-407,3$ & 0,24 & 0,22 & 0,07 & $-0,9$ & $-0,9$ & $-0,3$ \\
\hline $15 / 01$ a $24 / 03$ & $-288,7$ & $-280,3$ & $-283,0$ & n.d. & n.d. & n.d. & - & - & - \\
\hline $25 / 03$ a $25 / 05$ & 38,5 & 33,3 & 34,3 & n.d. & 0,45 & 0,07 & - & 0,1 & - \\
\hline $26 / 05$ a $31 / 07$ & 95,7 & 91,6 & 85,5 & 0,01 & 0,43 & 0,56 & - & 0,4 & 0,5 \\
\hline $01 / 08$ a 02/10 & 80,8 & 100,0 & 121,9 & 0,22 & 0,22 & 0,15 & 0,2 & 0,2 & 0,2 \\
\hline $03 / 10$ a $25 / 11$ & $-97,5$ & $-117,8$ & $-161,2$ & 0,25 & 0,10 & 0,04 & $-0,2$ & $-0,1$ & $-0,1$ \\
\hline $26 / 11$ a $25 / 12$ & $-111,8$ & $-70,4$ & $-25,1$ & 0,06 & 0,09 & 0,04 & $-0,1$ & $-0,1$ & - \\
\hline \multirow[t]{2}{*}{ Total } & $-663,1$ & $-638,5$ & $-634,9$ & - & - & - & $-1,0$ & $-0,4$ & $\mathbf{0 , 3}$ \\
\hline & \multicolumn{9}{|c|}{ Lodo de Esgoto dose C } \\
\hline $13 / 11$ a $14 / 01$ & $-382,8$ & $-399,8$ & $-408,6$ & 0,90 & 0,69 & 1,12 & $-3,4$ & $-2,8$ & $-4,6$ \\
\hline $15 / 01$ a $24 / 03$ & $-300,5$ & $-299,4$ & $-303,3$ & 0,05 & 0,03 & 0,03 & $-0,2$ & $-0,1$ & $-0,1$ \\
\hline $25 / 03$ a $25 / 05$ & 50,5 & 51,3 & 51,2 & 0,03 & 0,05 & 0,25 & - & - & 0,1 \\
\hline $26 / 05$ a $31 / 07$ & 89,5 & 86,2 & 81,3 & 0,34 & 0,31 & 0,41 & 0,3 & 0,3 & 0,3 \\
\hline $01 / 08$ a $02 / 10$ & 88,4 & 109,1 & 126,3 & 0,26 & 0,11 & 0,20 & 0,2 & 0,1 & 0,3 \\
\hline $03 / 10$ a $25 / 11$ & $-103,3$ & $-123,2$ & $-163,3$ & 0,22 & 0,26 & 0,13 & $-0,2$ & $-0,3$ & $-0,2$ \\
\hline $26 / 11$ a $25 / 12$ & $-105,7$ & $-57,6$ & 3,4 & 0,32 & 0,14 & 0,05 & $-0,3$ & $-0,1$ & - \\
\hline Total & $-663,9$ & $-633,4$ & -613.0 & - & - & - & $-3,6$ & $-2,9$ & $-4,2$ \\
\hline
\end{tabular}




\subsubsection{Acúmulo de nitrogênio no solo}

As concentrações de $\mathrm{N}$-total, $\mathrm{N}$-orgânico e $\mathrm{N}-\mathrm{NO}_{3}{ }^{-}+\mathrm{N}^{-} \mathrm{NH}_{4}{ }^{+}$nas amostras de solo coletadas em profundidade, ao final dos anos agrícolas 1996/97 e 1997/98, são apresentadas na Figura 18.

Para ambos os anos agrícolas, nos tratamentos testemunha e adubação mineral, as concentrações das várias formas de nitrogênio foram praticamente iguais dentro de cada camada de solo analisada. Os teores de nitrogênio encontrados para estes tratamentos, nas camadas de $0-0,3,0,3-0,6$ e $0,6-0,9 \mathrm{~m}$ foram respectivamente, em média, de 609,7, 549,6 e 454,1 $\mathrm{mg} \mathrm{kg}^{-1}$ para N-total; 599,9, 543,8 e 447,1 $\mathrm{mg} \mathrm{kg}^{-1}$ para $\mathrm{N}$-orgânico; $11,1,6,1$ e 5,9 $\mathrm{mg} \mathrm{kg}^{-1}$ para $\mathrm{N}-\mathrm{NO}_{3}{ }^{-}+\mathrm{N}-\mathrm{NH}_{4}{ }^{+}$. Na camada $0,9-1,2 \mathrm{~m}$, ano agrícola 1997/98, os teores médios encontrados para as respectivas formas de nitrogênio foram: $362,5,361,9$ e $1,2 \mathrm{mg} \mathrm{kg}^{-1}$. De maneira geral, estes resultados demonstraram que a forma orgânica de nitrogênio foi predominante em todas as camadas de solo e que seus valores foram decrescentes em profundidade. No tratamento com adubação mineral os resultados sugeriram ainda, que todo o nitrogênio aplicado foi eliminado do sistema, seja devido a absorção pela cultura ou pela lixiviação para profundidades maiores que $1,2 \mathrm{~m}$.

Os teores de nitrogênio no solo foram influenciados significativamente pela interação entre tratamentos com lodo de esgoto e profundidades de amostragem (Apêndice 2). Na camada $0-0,3 \mathrm{~m}$, verifica-se que as aplicações do resíduo proporcionaram, ao final dos dois anos agrícolas, aumentos nos teores de $\mathrm{N}$-total, $\mathrm{N}$-orgânico e $\mathrm{N}-\mathrm{NO}_{3}{ }^{-}+\mathrm{N}-\mathrm{NH}_{4}^{+}$. Considerando-se que as formas orgânicas de nitrogênio representaram mais de $96 \%$ do $\mathrm{N}$-total, na discussão dos resultados será dada ênfase ao $\mathrm{N}$-orgânico em detrimento do $\mathrm{N}$-total.

Os teores de N-orgânico apresentaram na referida camada de solo, um comportamento crescente e linear em função das doses de lodo de esgoto $\left(R^{2}=0,88^{* *} \mathrm{e}\right.$ $0,98^{* *}$, respectivamente para 1996/97 e 1997/98). Ao final do primeiro ano agrícola, os teores médios de $\mathrm{N}$-orgânico encontrados no solo para as doses $\mathrm{A}, \mathrm{B}$ e $\mathrm{C}$ de lodo de esgoto foram respectivamente, $738,2,739,6$ e $828,7 \mathrm{mg} \mathrm{kg}^{-1}$, os quais apresentaram acréscimos de 23, 23,3 e 38,1\% em relação a testemunha absoluta. Para 1997/98, tais 
teores foram respectivamente, $798,9,853,7$ e $908,9 \mathrm{mg} \mathrm{kg}^{-1}$, cerca de $33,2,42,3$ e $51,5 \%$ de acréscimos em relação a testemunha. Comparando-se os teores determinados nos dois anos agrícolas, verifica-se que após a segunda aplicação do lodo de esgoto houveram incrementos nos tratamentos com as respectivas doses, de $8,2,15,4$ e $9,6 \%$ o que evidencia o potencial de acúmulo do N-orgânico por ocasião de aplicações sucessivas do resíduo. Esse resultados são concordantes Inman et al. (1982), os quais verificaram que apesar das elevadas concentrações de $\mathrm{N}_{-} \mathrm{NO}_{3}{ }^{-}$a $1,0 \mathrm{~m}$ de profundidade, doses de lodo de esgoto de 150 e $300 \mathrm{Mg} \mathrm{ha}^{-1}$ (base seca) proporcionaram, mesmo ao final de 30 meses da aplicação, quando comparado com a testemunha, aumentos de duas a três vezes nos teores de $\mathrm{N}$-orgânico do solo

A mineralização do nitrogênio é um processo lento (Victoria et al., 1992) e dependendo das condições de ambiente e da origem do lodo de esgoto, ela pode apresentar taxas inferiores a $100 \%$ por longos períodos de tempo (Lindemann \& Cardenas, 1984; Chae \& Tabatabai, 1986). Neste contexto, é importante ressaltar que aplicações anuais e sucessivas desse resíduo, até mesmo em doses menores, podem levar ao acúmulo de N-orgânico no solo, tornando com o decorrer do tempo, mesmo com baixas taxas de mineralização, quantitativamente significativas a presença de $\mathrm{N}^{-\mathrm{NO}_{3}}{ }^{-}$no solo e portanto, sujeito à lixiviação. Isto posto, são imprescindíveis estudos a longo prazo, através do monitoramento das camadas subsuperficiais do solo, que busquem definir taxas, freqüência e épocas de aplicação do lodo de esgoto bem como, estratégias de manejo baseadas na limitação do número de aplicações sucessivas e possíveis períodos de pousio, necessários para que o solo volte à suas condições originais, no que diz respeito aos teores de nitrogênio. Acredita-se que somente desta forma é que será possível a disposição desses resíduos em solos agrícolas, com risco mínimo à qualidade do ambiente.

Nas camadas 0,3-0,6 e 0,6-0,9 m para os dois anos agrícolas e a 0,9-1,2 m para 1997/98 não foram verificados incrementos significativos de $\mathrm{N}$-orgânico em função da aplicação do lodo de esgoto, o que evidencia a pouca ou nenhuma movimentação desta forma de nitrogênio, pelo perfil do solo. 
Ano agrícola 1996/97
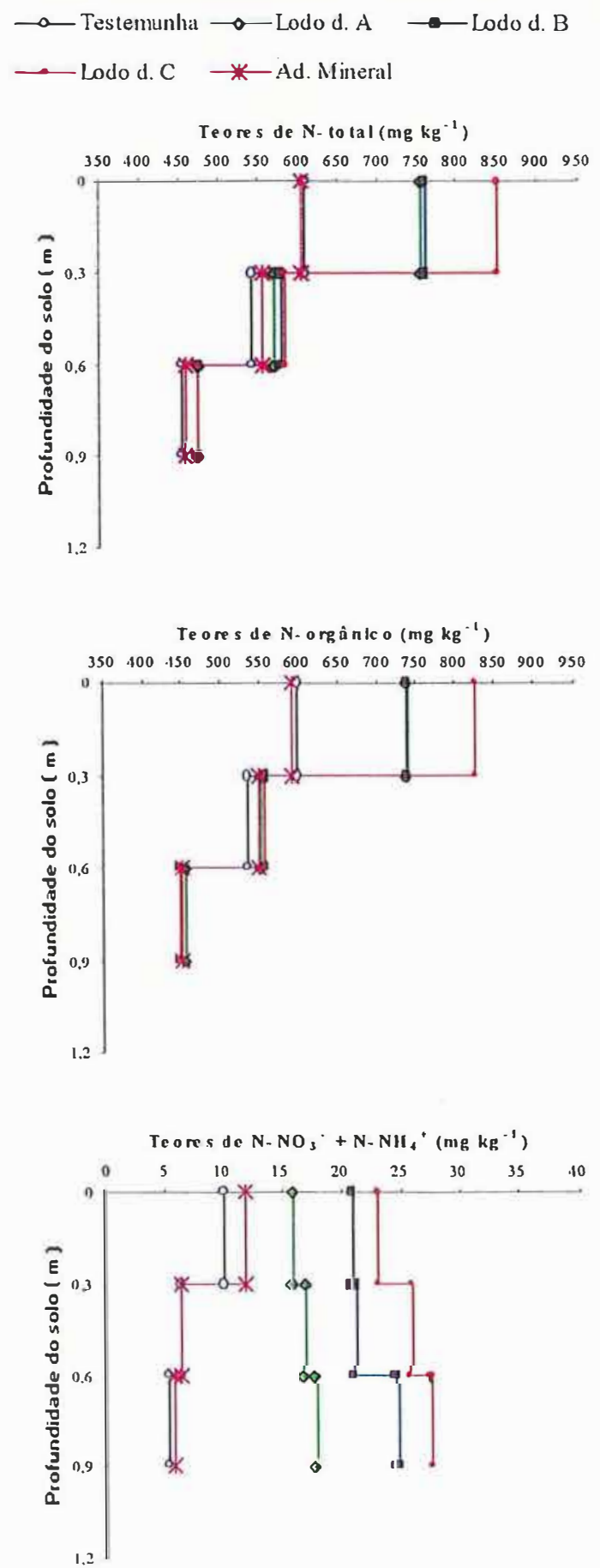

\section{Ano agrícola 1997/98}
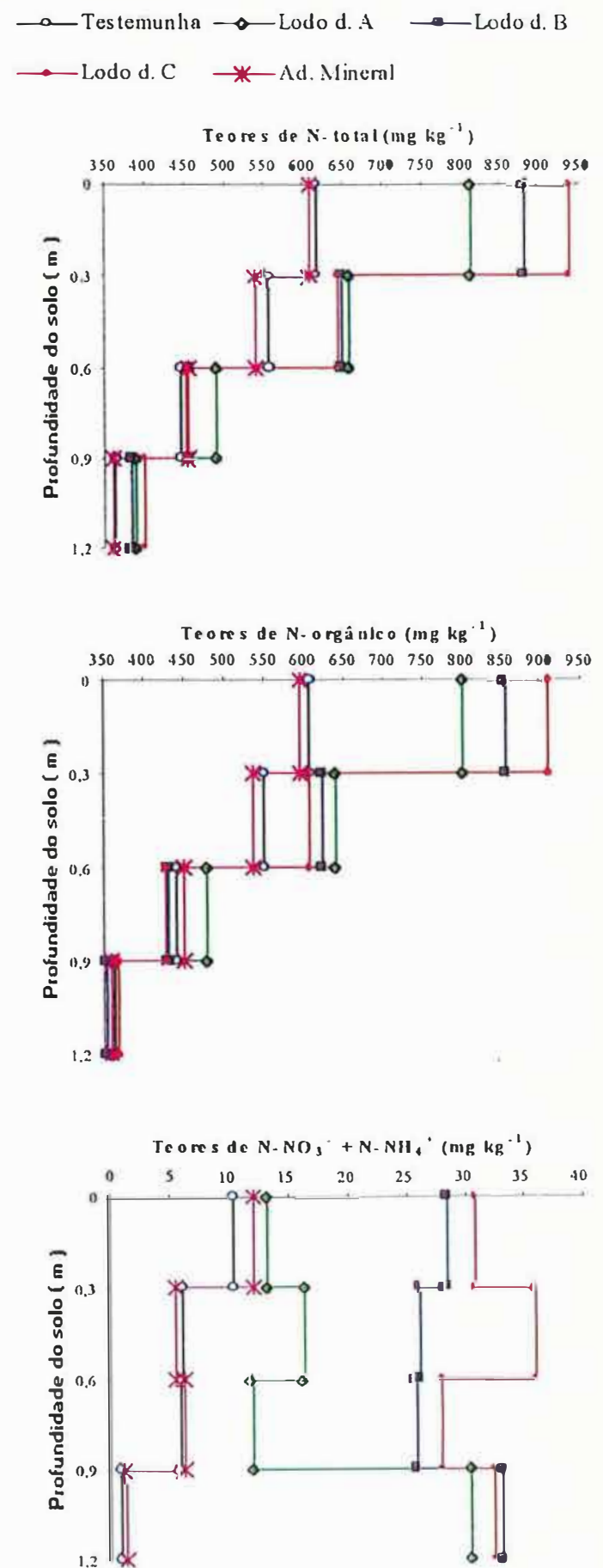

Figura 18. Teores de N-total, N-orgânico e $\mathrm{N}-\mathrm{NO}_{3}{ }^{-}+\mathrm{N}_{-} \mathrm{NH}_{4}{ }^{+}$determinados no solo, em profundidade,ao final dos anos agrícolas 1996/97 e 1997/98, no experimento com lodo de esgoto. 
Por outro lado, confirmando as observações feitas através das análises de solução, os acrécimos nos teores de $\mathrm{N}_{-} \mathrm{NO}_{3}{ }^{-}+\mathrm{N}^{-} \mathrm{NH}_{4}{ }^{+}$nas várias camadas do solo, ao final dos dois anos agrícolas, evidenciaram a intensa movimentação dessas formas nitrogenadas. Em todas as camadas, tanto para 1996/97 como para 1997/98, foram observados, em função das aplicações do lodo de esgoto, aumentos lineares nos teores de nitrogênio inorgânico. Para a camada 0,9 - 1,2 m, ano agrícola 1997/98, verifica-se para as doses $\mathrm{A}, \mathrm{B}$ e $\mathrm{C}$ do resíduo, teores médios de respectivamente, 30,3, 33,3 e $32,4 \mathrm{mg} \mathrm{kg}^{-1}$, os quais significaram em média, 26,7 vezes a concentração de $\mathrm{N} \mathrm{NO}_{3}{ }^{-}+\mathrm{N}-\mathrm{NH}_{4}{ }^{+}$no tratamento testemunha. Mais uma vez, é importante salientar que tais acréscimos foram observados numa camada bem abaixo da zona de absorção radicular das plantas de cana-de-açúcar representando quantidades de nitrogênio perdidas para o sistema agrícola e portanto, com potencial poluente. 


\subsection{Composto de lixo}

\subsubsection{Produtividade da cana-de-açúcar}

Os valores de produtividade obtidos para a cana-de-açúcar nos anos agrícolas de 1996/97 e 1997/98 são apresentados na Figura 19. Para a "cana-planta", ano agrícola 1996/97, as baixas produtividades observadas em todos os tratamentos podem ser explicadas da mesma forma que para o experimento com lodo de esgoto (4.1.1).

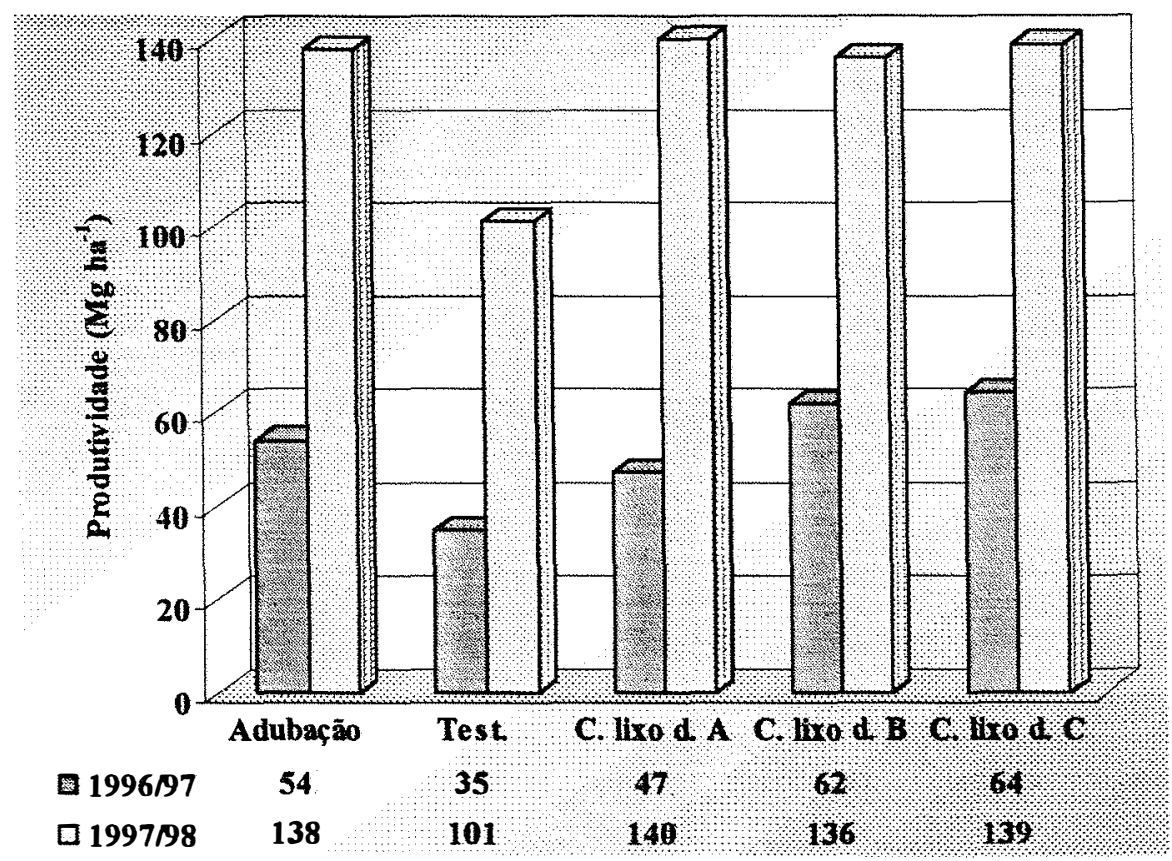

Figura 19. Produtividades da cana-de-açúcar $\left(\mathrm{Mg} \mathrm{ha}^{-1}\right)$ nos anos agrícolas 1996/97 e 1997/98 para o experimento com composto de lixo.

A análise estatística dos dados revela um comportamento linear, crescente e significativo $\left(\mathrm{R}^{2}=0,94^{* *}\right)$ da produtividade da cultura, em função das doses de composto de lixo. A comparação por contraste entre o tratamento calagem + adubação mineral e a média entre as doses $\mathrm{A}, \mathrm{B}$ e $\mathrm{C}$ não mostrou diferenças entre resíduo $\mathrm{e}$ adubação convencional. $\mathrm{O}$ macronutriente adicionado em menor quantidade via composto de lixo foi o fósforo $\left(33,65\right.$ e $98 \mathrm{~kg} \mathrm{ha}^{-1}$ de P-total respectivamente para as doses $\mathrm{A}, \mathrm{B}$ e $\mathrm{C}$ ) no entanto, considerando-se a produtividade para o tratamento com adubação mineral, não foram verificadas evidencias de que tal nutriente tenha sido limitante para o crescimento da cultura. 
As produtividades obtidas para a primeira soqueira, ano agrícola de 1997/98, foram superiores a "cana-planta". De maneira geral, as principais razões para este aumento de produtividade foram: tempo de crescimento (12 meses) e a quantidade e melhor distribuição das chuvas (Figura 11) em relação as fases de crescimento da cultura.

Para as produtividades da primeira soqueira, verificou-se um efeito quadrático $\left(\mathrm{R}^{2}=0,88^{* *}\right)$ em função das doses do resíduo. Os tratamentos com doses $\mathrm{A}, \mathrm{B}$ e $\mathrm{C}$ do composto de lixo apresentaram produtividades em média, $38 \%$ superiores a testemunha absoluta o que pode ser atribuido ao efeito residual da primeira aplicação somado aos efeitos da segunda aplicação do composto.

A capacidade do composto de lixo em proporcionar aumentos de produtividades em culturas tem sido atribuida, por diversos autores, ao aumento da fitodisponibilidade de macronutrientes assim como a elevação do $\mathrm{pH}$ e redução da acidez potencial dos solos (Mazur et al., 1983a; Mazur et al., 1983b; Peixoto et al., 1987; Ferreira \& Cruz, 1992; Trindade et al. 1996).

A produtividade média para doses $\mathrm{A}, \mathrm{B}$ e $\mathrm{C}$ de composto, quando comparada pela análise de contraste com o tratamento calagem + adubação mineral, não revelou diferença significativa. Desta forma, verifica-se que até mesmo a menor dose de composto de lixo (24 $\mathrm{Mg} \mathrm{ha}^{-1}$ ), sem nenhum tipo de complementação mineral, foi o suficiente para obtenção de um desempenho igual a fertilização mineral convencional. No entanto, para culturas de alface Cravo (1995) obteve melhores resultados em tratamentos que associavam doses de composto de lixo de até $120 \mathrm{Mg} \mathrm{ha}^{-1}$ (base seca) com fertilizantes minerais e calcário. Já Abreu Junior (1999) trabalhando com a cultura do arroz, obteve produtividades semelhantes ao tratamento com fertilizantes minerais e calcário, apenas quando doses de $60 \mathrm{Mg} \mathrm{ha}^{-1}$ (base seca) de composto de lixo foram associadas com fertilizantes. Estas variações são esperadas uma vez que, a composição do composto de lixo varia amplamente com sua origem (Xin et al., 1992) e além disso, existem variações na resposta de cada espécie vegetal em função do tipo de solo em que tais espécies são cultivadas. 


\subsubsection{Carbono orgânico}

Os teores de carbono orgânico do solo apresentaram em todas as épocas de amostragem, nos dois anos agrícolas, aumentos lineares em função das doses aplicadas de composto de lixo (Tabela 24). Tomando-se como base a testemunha absoluta verifica-se que, 360 dias após a incorporação do resíduo no ano agrícola 1996/97, houveram aumentos de 8,16 e $22 \%$ nos teores de carbono proporcionados respectivamente, pelas doses de 20,40 e $60 \mathrm{Mg} \mathrm{ha}^{-1}$. Aos 360 dias após a incorporação da segunda aplicação, ano agrícola 1997/98, foram verificados aumentos de 18, 29 e $55 \%$ respectivamente para as doses de 24,48 e $72 \mathrm{Mg} \mathrm{ha}^{-1}$, cerca de 17,19 e $36 \%$ de acúmulo em relação aos teores de carbono observados, nos mesmos tratamentos, ao final do ano anterior.

A análise conjunta dos dados revela que o composto de lixo foi capaz de proporcionar aumentos significativos nos teores de carbono do solo, sugerindo a possibilidade de incrementos crescentes em função de aplicações sucessivas do resíduo. O potencial deste resíduo em incrementar os teores de carbono orgânico de solos também foi verificado em estudos conduzidos em regiões sob clima temperado. Hortenstine \& Rothwell (1972) verificaram aumentos de 41 e $169 \%$ nos teores de carbono orgânico de um solo degradado por mineração, após 24 meses da aplicação de 35 e $70 \mathrm{Mg} \mathrm{ha}^{-1}$ (base seca) de composto de lixo. Acréscimos de 31,5\% foram verificados por Bengtson \& Cornette (1973) após 28 meses da aplicação de $44 \mathrm{Mg} \mathrm{ha}^{-1}$ (base seca) do resíduo (relação $\mathrm{C} / \mathrm{N}=66$ ). De forma concordante, Giusquiani et al. (1995) obtiveram acréscimos de 23, 40 e $55 \%$ após 4 anos de aplicações anuais sucessivas de 10,30 e $90 \mathrm{Mg} \mathrm{ha}^{-1}$ (base seca, relação $\mathrm{C} / \mathrm{N}=14$ ).

Trabalhando com diversos solos tropicais, Abreu Junior (1999) observou incrementos nos teores de carbono orgânico 90 dias após aplicação de $60 \mathrm{Mg} \mathrm{ha}^{-1}$ (base seca) de composto de lixo (relação $\mathrm{C} / \mathrm{N} \approx 19$ ). Para 21 tipos diferentes de solos ácidos os incrementos de carbono variaram entre 4 e $35 \%$ e para 5 tipos de solos alcalinos esses valores variaram entre 8,6 e $34 \%$. Os dados apresentados pelo autor sugeriram que existe uma variação no potencial de cada solo para promover a degradação da carga orgânica do resíduo, desta forma é possível que em alguns tipos de 
solos tropicais, os efeitos do composto de lixo sobre o carbono orgânico do solo sejam efềmeros caso não haja uma freqüência adequada de aplicações.

Tabela 24. Teores de Carbono orgânico do solo $\left(\mathrm{g} \mathrm{kg}^{-1}\right)$ determinados para doses de composto de lixo em diversas épocas de amostragem, dentro dos anos agrícolas 1996/97 e 1997/98.

\section{Ano agrícola 1996/97}

\begin{tabular}{|c|c|c|c|c|c|c|}
\hline \multirow[t]{2}{*}{$\operatorname{Dias}^{1}$} & \multicolumn{4}{|c|}{ Doses de composto de lixo ( $\left.\mathrm{Mg} \mathrm{ha}^{-1}\right)$} & \multicolumn{2}{|c|}{ Temno de Regressão $\left(\mathrm{R}^{2}\right)$} \\
\hline & 0 & 20 & 40 & 60 & Linear & Quadrático \\
\hline 0 & 7,16 & 9,44 & 10,96 & 12,20 & $0,98^{* *}$ & ns \\
\hline 30 & 7,09 & 8,68 & 10,00 & 10,39 & $0,94^{*-}$ & ns \\
\hline 60 & 6,94 & 8,13 & 8,98 & 9,51 & $0,97^{* *}$ & ns \\
\hline 90 & 7,58 & 9,02 & 9,97 & 11,18 & $0,99^{* *}$ & ns \\
\hline 150 & 8,74 & 9,76 & 10,93 & 11,87 & $0,99^{* *}$ & ns \\
\hline 210 & 8,39 & 9,01 & 9,78 & 11,18 & $0,96^{* 2}$ & ns \\
\hline 270 & 8,86 & 9,63 & 10,18 & 10,73 & $0,99^{*}$ & ns \\
\hline 360 & 8,86 & 9,59 & 10,29 & 10,78 & $0,99^{*}$ & ns \\
\hline \multicolumn{7}{|c|}{$\begin{array}{c}\text { Termo de } \\
\text { Regressão }\left(\mathrm{R}^{2}\right)\end{array}$} \\
\hline Linear & $0,79^{* *}$ & $0,27^{* *}$ & ns & ns & - & - \\
\hline Quadrático & $0,85^{*}$ & ns & ns & ns & - & - \\
\hline
\end{tabular}

Ano agrícola 1997/98

Dias Doses de composto de lixo ( $\left.\mathrm{Mg} \mathrm{ha} \mathrm{h}^{-1}\right)$

0

$\begin{array}{rr}0 & 8,57 \\ 30 & 8,86 \\ 60 & 8,72 \\ 90 & 8,87 \\ 150 & 8,98 \\ 210 & 8,99 \\ 270 & 9,42 \\ 360 & 9,48\end{array}$

Termo de Regressão $\left(\mathrm{R}^{2}\right)$

\section{Linear} Quadrático
24

11,50

11,90

11,21

11,51

10,75

11,06

11,37

11,23

48

13,68

13,43

13,68

12,53

11,83

12,29

12,46

12,22
72

16,16

15,00

14,99

15,43

15,75

15,51

14,82

14,70
Termo de Regressão $\left(\mathrm{R}^{2}\right)$

Linear Quadrático

$\begin{array}{ll}0,99^{* *} & \text { ns } \\ 0,97^{* *} & \text { ns } \\ 0,98^{* *} & \text { ns } \\ 0,97^{* *} & \text { ns } \\ 0,93^{* *} & \text { ns } \\ 0,97^{* *} & \text { ns } \\ 0,98^{* *} & \text { ns } \\ 0,97^{* *} & \text { ns }\end{array}$

Dias após a incorporação do composto de lixo;

*, ${ }^{* *}$, ns Indicam respectivamente, que os termos de regressão linear ou quadrática foram significativos a $P \leq 0,05$, $\mathrm{P} \leq 0,01$ ou não significativos pelo teste $\mathrm{F}$. 
Os teores de carbono orgânico foram influenciados significativamente pela interação entre tratamentos e épocas de amostragem do solo. Esta interação por sua vez, ocorreu devido as mesmas razões comentadas para o lodo de esgoto (4.1.2).

A análise de variância para gradiente de carbono apontou, para os dois anos agrícolas, efeitos significativos de doses e épocas de amostragem, não havendo interação entre estes fatores. Desta forma, obteve-se um comportamento médio válido para as três doses do resíduo.

De maneira geral, para os dois anos agrícolas, verificou-se que o decréscimo do carbono orgânico aplicado ao solo através do composto de lixo, ajustou-se a um modelo de cinética de primeira ordem (Figura 20). Com base neste modelo matemático, pode-se inferir que o composto de lixo teria apresentado uma fase inicial de degradação mais rápida seguida por outras de estabilização progressiva. A maior velocidade de degradação no período inicial seria explicada pelo ataque microbiano àquelas substâncias orgânicas mais facilmente degradáveis, como proteínas, aminoácidos e carboidratos ao passo que para a fase final, a menor velocidade de degradação seria atribuída às substâncias mais recalcitrantes, essencialmente complexos lignino-celulósicos. Levi-Minzi et al. (1990) e Barreto (1995) observaram este mesmo comportamento para composto de lixo, em ensaios de respirometria conduzidos em condições de laboratório.

O valor médio estimado para a constante de velocidade no ano agrícola 1996/97 foi superior àquele estimado no ano agrícola seguinte. Esta diferença refletiu diretamente sobre as taxas globais de decréscimo do carbono orgânico do solo nos períodos estudados.

Para o primeiro ano agrícola a taxa média de decréscimo foi estimada em $66 \%$ a qual poderia ser considerada como uma estimativa da taxa de degradação do composto de lixo. Da mesma forma que o lodo de esgoto, é importante salientar que neste ano, o revolvimento do solo pelas operações de cultivo mecânico estimularam a degradação do carbono orgânico. 


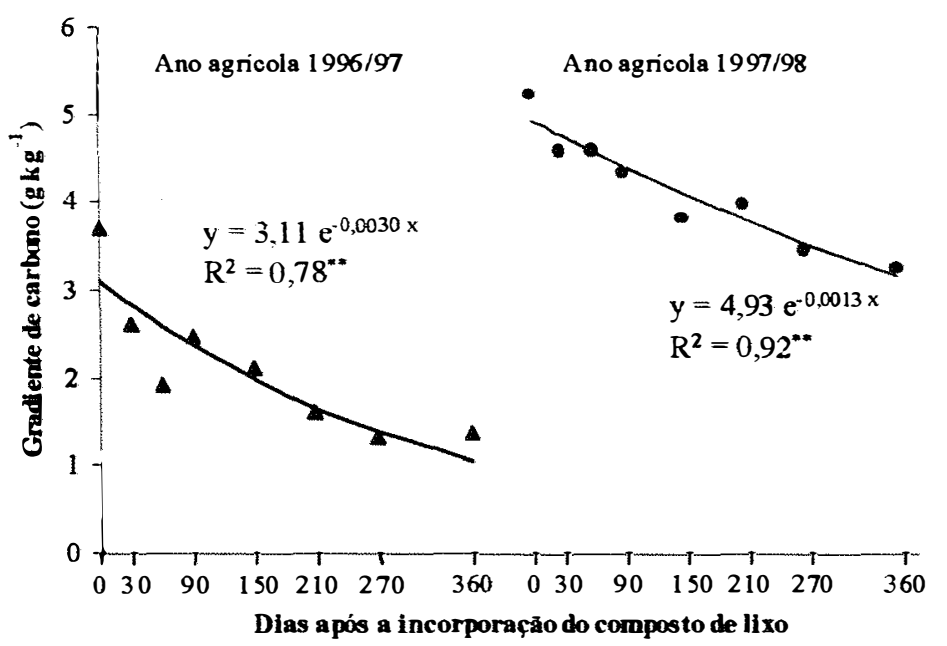

Figura 20. Decréscimo do carbono orgânico adicionado ao solo via composto de lixo, nos anos agrícolas 1996/97 e 1997/98, ajustado a um modelo de cinética de primeira ordem. ("* significativo a $\mathrm{P} \leq 0,01$ pelo teste $\mathrm{F}$ )

Para o ano agrícola 1997/98, a taxa média de decréscimo do carbono foi estimada em $37 \%$. Entretanto, não é possível afirmar com base nos dados, que houve uma queda na taxa de degradação do composto de lixo pois, nessa taxa foi incluído o carbono recalcitrante acumulado no solo devido a primeira aplicação. Por outro lado, sabe-se que a degradação do composto de lixo em solos é reduzida drasticamente a medida que aumenta seu grau de maturação (Bernal et al., 1998; Pascual et al. 1998a; Pascual et al., 1998b). Neste contexto, considerando-se que no presente trabalho a remessa de composto de lixo utilizada no ano agrícola 1997/98 apresentou um grau de maturação mais avançado do que o composto aplicado em 1996/97(verificar relações $\mathrm{C} / \mathrm{N}$ na Tabela 3), é possível que isto tenha contribuído para a menor taxa de decréscimo observada após a segunda aplicação. Além do mais nenhuma operação mecânica que revolvesse o solo foi executada neste ano, após a incorporação do resíduo.

As taxas de decréscimo do carbono encontradas no presente trabalho podem estar superestimadas, o que teria ocorrido pelas mesmas razões atribuídas ao experimento com lodo de esgoto (4.1.2).

Nas condições em que foi realizado o presente trabalho, considerando-se as taxas e a freqüência de aplicações do resíduo, evidenciou-se que parte do carbono 
orgânico presente no composto de lixo foi resistente a degradação. Estes resultados são concordantes com estudos realizados em condições controladas de laboratório, os quais evidenciaram a relativa resistência a degradação no solo, da carga orgânica de compostos de lixo. Levi-Minzi et al. (1990) obtiveram taxas máximas de degradação de 7 e $5 \%$, em 21 dias de incubação de doses equivalentes a 0,5 e $2 \%$ em peso seco, abaixo por exemplo, das taxas de 50 e $45 \%$ obtidas para cama de frango. Esses autores apontaram o composto de lixo como um resíduo de grande potencial para aumentar e manter teores elevados de carbono orgânico em solos. Barreto (1995) verificou taxas de 15 e $14 \%$ para composto de lixo aplicado respectivamente, em doses de 4 e $8 \mathrm{Mg} \mathrm{ha}^{-1}$ (base seca), equivalentes em carbono orgânico. Após 230 dias de incubação, Hadas \& Portnoy (1997) encontraram taxas de 13 a $15 \%$ para doses equivalentes a $5 \%$ em peso seco.

Considerando-se as evidencias do acúmulo de carbono orgânico no solo, algumas alterações em suas propriedades químicas e físicas são esperadas (Clapp et al., 1986 e Metzger \& Yaron, 1987). Neste contexto, estudando algumas propriedades físicas do Latossolo Vermelho-Amarelo da área experimental, Marciano (1999) verificou após a segunda aplicação de composto de lixo, alterações na densidade do solo, na porosidade total e na condutividade hidráulica determinada para a faixa de potencial mátrico de 0 a $1 \mathrm{kPa}$.

\subsubsection{Condutividade elétrica e $\mathrm{pH}$}

A condutividade elétrica do solo foi influenciada significativamente, nos dois anos agrícolas, pela interação entre tratamentos com composto de lixo e épocas de amostragem (Tabela 25).

De maneira geral, verifica-se que o composto de lixo aumentou a condutividade elétrica do solo. No ano agrícola 1996/97, foram observados aumentos lineares até 210 dias após a incorporação do resíduo. Para o ano seguinte, após a segunda aplicação, tais aumentos foram observados até 270 dias. De forma semelhante ao que foi comentado para o lodo de esgoto, pequenas diferenças no comportamento da condutividade elétrica do solo, entre épocas e anos agrícolas, devem estar relacionadas com a dinâmica da 
degradação da carga orgânica do composto de lixo e principalmente com a distribuição das chuvas durante o período experimental.

Tabela 25. Condutividade elétrica do solo $\left(\mu \mathrm{Sm}^{-1}\right)$ determinada, na camada de $0-0,2 \mathrm{~m}$, para doses de composto de lixo em diversas épocas de amostragem, dentro dos anos agrícolas 1996/97 e 1997/98.

\begin{tabular}{|c|c|c|c|c|c|c|}
\hline \multirow{3}{*}{ Dias $^{1}$} & \multicolumn{4}{|c|}{ Ano agrícola 1996/97 } & \multirow{2}{*}{\multicolumn{2}{|c|}{ Termo de Regressão $\left(\mathrm{R}^{2}\right)$}} \\
\hline & \multicolumn{4}{|c|}{ Doses de composto de lixo $\left(\mathrm{Mg} \mathrm{ha}^{-1}\right)$} & & \\
\hline & 0 & 20 & 40 & 60 & Linear & Quadrático \\
\hline 30 & 101,6 & 152,1 & 426,3 & 445,8 & $0,88^{* *}$ & ns \\
\hline 60 & 79,4 & 138,8 & 149,0 & 252,5 & $0,90^{* *}$ & ns \\
\hline 90 & 115,4 & 203,9 & 289,8 & 331,2 & $0,98^{* *}$ & ns \\
\hline 150 & 107,0 & 152,0 & 165,9 & 282,8 & $0,87^{* *}$ & ns \\
\hline 210 & 116,9 & 150,7 & 191,1 & 211,5 & $0,99^{*}$ & ns \\
\hline 270 & 62,9 & 86,1 & 104,7 & 115,3 & ns & ns \\
\hline 360 & 73,9 & 110,0 & 113,8 & 138,9 & ns & ns \\
\hline \multicolumn{7}{|l|}{$\begin{array}{c}\text { Termo de } \\
\text { Regressão }\left(\mathrm{R}^{2}\right)\end{array}$} \\
\hline Linear & ns & $0,43^{*}$ & $0,50^{* *}$ & $0,75^{* *}$ & - & - \\
\hline \multirow[t]{2}{*}{ Quadrático } & ns & ns & $0,59^{* *}$ & $0,79^{*}$ & - & - \\
\hline & \multicolumn{4}{|c|}{ Ano agrícola 1997/98 } & & \\
\hline \multirow[t]{2}{*}{ Dias } & \multicolumn{4}{|c|}{ Doses de composto de lixo $\left(\mathrm{Mg} \mathrm{ha}^{-1}\right)$} & \multicolumn{2}{|c|}{ Termo de Regressão $\left(\mathrm{R}^{2}\right)$} \\
\hline & 0 & 24 & 48 & 72 & Linear & Quadrático \\
\hline 30 & 127,3 & 202,8 & 301,8 & 401,8 & $0,99^{* *}$ & ns \\
\hline 60 & 79,7 & 161,1 & 300,5 & 239,8 & $0,70^{* *}$ & $0,88^{*}$ \\
\hline 90 & 89,8 & 199,0 & 281,2 & 392,5 & $0,99^{* *}$ & ns \\
\hline 150 & 92,2 & 199,0 & 242,0 & 401,6 & $0,95^{* *}$ & ns \\
\hline 210 & 61,8 & 125,1 & 233,9 & 245,8 & $0,93^{* *}$ & ns \\
\hline 270 & 80,0 & 162,2 & 184,0 & 237,1 & $0,95^{* *}$ & ns \\
\hline 360 & 70,8 & 141,6 & 143,6 & 139,8 & ns & ns \\
\hline \multicolumn{7}{|c|}{$\begin{array}{c}\text { Termo de } \\
\text { Regressão }\left(\mathrm{R}^{2}\right)\end{array}$} \\
\hline Linear & ns & $0,43^{* *}$ & $0,98^{* *}$ & $0,56^{* *}$ & - & - \\
\hline Quadrático & ns & ns & ns & $0,62^{* *}$ & - & - \\
\hline
\end{tabular}

Tias após a incorporação do composto de lixo;

*, ${ }^{* *}$, ns Indicam respectivamente, que os termos de regressão linear ou quadrática foram significativos a $\mathrm{P} \leq 0,05$,

$\mathrm{P} \leq 0,01$ ou não significativo pelo teste $\mathrm{F}$.

Os maiores acréscimos observados para esta variável foram, no ano agrícola 1996/97, aos 30 dias após a incorporação do composto de lixo e no ano agrícola 1997/98, aos 150 dias. Para o primeiro ano, nas parcelas tratadas com a dose $\mathrm{C}$ do 
resíduo, o acréscimo na condutividade elétrica foi de 339\% em relação a testemunha. Em 1997/98, tal acréscimo foi da ordem de 336\%. Hortenstine \& Rothwell (1972), Hortenstine \& Rothwell (1973) e Abreu Junior (1999) também observaram em seus estudos, o potencial do composto de lixo em aumentar a condutividade elétrica de solos porém, trabalhando com doses de composto que variaram de 0 a $128 \mathrm{Mgha}^{-1}$ (base seca), todos os autores relataram que não houveram efeitos salinos prejudiciais às culturas de aveia, sorgo granífero e arroz.

Tendo em vista a composição química do composto de lixo (Tabela 3), pode se inferir que os aumentos na condutividade elétrica do solo foram devidos a degradação da carga orgânica do resíduo com a conseqüente solubilização predominante de íons $\mathrm{NH}_{4}{ }^{+}$, $\mathrm{NO}_{3}{ }^{-}, \mathrm{Ca}^{2+}, \mathrm{Na}^{+}, \mathrm{K}^{+}, \mathrm{SO}_{4}{ }^{2-}$ e $\mathrm{Mg}^{2+}$.

O comportamento da condutividade elétrica dentro das doses de composto, no decorrer das amostragens, apresentou para os dois anos agrícolas, uma tendência significativa de queda em seus valores a medida em que aumentou o tempo da incorporação do resíduo (Tabela 25). Este decréscimo na concentração salina da superficie do solo provavelmente é devido a lavagem de íons solúveis ou em suspensão, proporcionada pelo movimento descendente da água de precipitações pluviométricas. Estas observações são concordantes com àquelas feitas por Epstein et al. (1976) e Harding et al. (1985) em solos tratados com elevadas doses de lodo de esgoto.

A hipótese da lixiviação de íons é comprovada pelas determinações realizadas, em amostras de solo coletadas em profundidade, 360 dias após a incorporação do resíduo em cada ano agrícola (Tabela 26). Com base nestes dados, verifica-se que as doses crescentes de composto de lixo proporcionaram de maneira geral, aumentos significativos da condutividade elétrica até $0,8 \mathrm{~m}$ de profundidade, evidenciando a lixiviação de íons pelo perfil do solo. Comparando-se os valores de condutividade elétrica em profundidade, observa-se que ao final dos dois anos agrícolas os maiores valores ocorreram nas camadas superficiais de $0-0,2$ e 0,2-0,4 m. Para as camadas de 0,4-0,6 e 0,6-0,8 $\mathrm{m}$ as médias observadas foram menores no entanto, considerando-se a ordem de grandeza dos valores obtidos dentro de doses, comparados com a testemunha absoluta, sugere-se que a movimentação de íons para as camadas abaixo de 0,8 m poderia ter ocorrido. 
Tabela 26. Condutividade elétrica do solo $\left(\mu \mathrm{S} \mathrm{cm}^{-1}\right)$ determinada nas camadas de $0-0,2$, $0,2-0,4,0,4-0,6$ e $0,6-0,8 \mathrm{~m}$, aos 360 dias após incorporação de doses de composto de lixo nos anos agrícolas 1996/97 e 1997/98.

\begin{tabular}{|c|c|c|c|c|c|c|c|}
\hline \multirow{2}{*}{$\begin{array}{l}\text { Profundidade } \\
(\mathrm{m}) \\
\end{array}$} & \multicolumn{4}{|c|}{$\begin{array}{c}\text { Ano agrícola 1996/97 } \\
\text { Doses de composto de lixo }\left(\mathrm{Mg} \mathrm{ha}^{-\mathrm{l}}\right)\end{array}$} & \multicolumn{2}{|c|}{ Termo de Regressão $\left(\mathrm{R}^{2}\right)$} & \multirow{2}{*}{$\begin{array}{l}\text { Tukey para } \\
\text { medias de prof. }\end{array}$} \\
\hline & 0 & 20 & 40 & 60 & Linear & Quadrático & \\
\hline $0-0,2$ & 73,9 & 110,0 & 113,8 & 139,0 & - & - & $109,2 \mathrm{a}$ \\
\hline $0,2-0,4$ & 73,8 & 90,0 & 102,8 & 115,9 & - & - & $95,6 \mathrm{ab}$ \\
\hline $0,4-0,6$ & 68,8 & 76,9 & 82,6 & 99,4 & - & - & 81,9 bc \\
\hline $0,6-0,8$ & 61,2 & 65,0 & 80,2 & 94,1 & - & - & 75,1 \\
\hline $\begin{array}{l}\text { Regressão para níveis } \\
\text { de tratamentos }\end{array}$ & 69,9 & 83,6 & 97,3 & 111,1 & $0,99^{* *}$ & ns & \\
\hline
\end{tabular}

\section{Ano agrícola 1997/98}

Profundidade

Doses de composto de lixo (Mg ha $\left.{ }^{-1}\right)$ Termo de Regressão $\left(R^{2}\right)$

Tukey para 0

24

48

72
Linear

Quadrático medias de prof.

$$
\begin{array}{r}
0-0,2 \\
0,2-0,4 \\
0,4-0,6 \\
0,6-0,8
\end{array}
$$

70,8

141,6

143,6

140,5

54,1

113,8

132,1

142,2

46,5

93,3

119,1

133,3

53,7

85,2

104,9

105,8

-

108,5

124,9

130,4

$0,83^{* *}$

$\begin{array}{rr}- & 124,1 \mathrm{a} \\ - & 110,5 \mathrm{ab} \\ - & 98,0 \mathrm{bc} \\ - & 87,4 \mathrm{c}\end{array}$

Regressão para níveis

56,3

de tratamentos

\footnotetext{
**, ns Indicam respectivamente, que os termos de regressão linear ou quadrática foram significativos a $\mathrm{P} \leq 0,01$ ou não significativos pelo teste $F$;

Médias seguidas por letras distintas, em colunas, diferem entre si a $\mathrm{P} \leq 0,05$ pelo teste de Tukey - D.M.S. $5 \%=17,0$ (ano agrícola 1996/97) D.M.S. 5\% = 13,9 (ano agrícola 1997/98).
}

A possibilidade de acúmulo de sais não foi evidenciada na camada de incorporação do resíduo, em decorrência de sua segunda aplicação. Quando são comparados, em todas as épocas de amostragem, os dados de condutividade elétrica entre os dois anos agrícolas, verifica-se que os mesmos se apresentaram muito próximos (Tabela 25). Porém, como foi comentado para o lodo de esgoto, é preciso salientar que a não ocorrência de efeito cumulativo pode ser devida ao fato de que no ano agrícola 1997/98, houveram precipitações acumuladas em $1655 \mathrm{~mm}$ ao passo que, no ano anterior estas foram acumuladas em $1480 \mathrm{~mm}$. Considerando-se a média local de $1275 \mathrm{~mm}$ anuais (período de retorno de 82 anos) verifica-se também que as quantidades de chuvas ocorridas no período experimental foram atípicas. 
Diante do comportamento da condutividade elétrica do solo no decorrer do experimento e da ordem de grandeza alcançada pelos seus valores, acredita-se que nas taxas e freqüência em que foram aplicados o composto de lixo, não serão observados efeitos salinos a pelo menos médio prazo. No entanto, como existem variações nesses efeitos em função do solo (Abreu Junior, 1999) e do regime pluviométrico de cada região, é recomendável que a disposição de composto de lixo em solos seja monitorada com relação a esta variável.

Os efeitos da aplicação do composto de lixo sobre o $\mathrm{pH}$ do solo são apresentados na Tabela 27. Nos dois anos agrícolas foi verificada interação significativa entre tratamentos e épocas de aplicação. Em 1996/97, em todas as épocas de amostragem do solo, o resíduo proporcionou aumentos lineares significativos para a variável $\mathrm{pH}$ do solo. No ano seguinte, tais aumentos apresentaram efeitos quadráticos em função das doses aplicadas, especialmente nas três últimas amostragens.

Para o primeiro ano agrícola, o valor $\mathrm{pH}$ apresentou acréscimos médios, em relação a testemunha, de 0,5, 0,6 e 1,1 unidades respectivamente para as doses de 20, 40 e $60 \mathrm{Mg} \mathrm{ha}^{-1}$ de composto de lixo. Em 1997/98 esses acréscimos foram de 1,3, 1,6 e 2,1 unidades, observados após a reaplicação de 24,48 e $72 \mathrm{Mg} \mathrm{ha}^{-1}$ do resíduo. Considerando-se as doses $\mathrm{A}, \mathrm{B}$ e $\mathrm{C}$, os acréscimos de $\mathrm{pH}$ em decorrência da segunda aplicação foram de $0,8,1,0$ e 1,1 unidades. Assim, verifica-se que a reaplicação do resíduo proporcionou aumentos compatíveis com àqueles do primeiro ano, o que sugere um efeito crescente sobre o $\mathrm{pH}$, por ocasião de aplicações sucessivas do resíduo.

Aumentos no valor $\mathrm{pH}$ de solos em decorrência da aplicação de composto de lixo foram observados por Hortenstine \& Rothwell (1972), Bengtson \& Cornette (1973), Mazur et al. (1983b), Maynard \& Hill (1994), Trindade et al. (1996) e Abreu Junior (1999). 
Tabela 27. Valores $\mathrm{pH}$ do solo determinados para o doses de composto de lixo em diversas épocas de amostragem, dentro dos anos agrícolas 1996/97 e $1997 / 98$.

Ano agrícola 1996/97

\begin{tabular}{|c|c|c|c|c|c|c|}
\hline \multirow[t]{2}{*}{$\operatorname{Dias}^{1}$} & \multicolumn{4}{|c|}{ Doses de composto de lixo ( $\mathrm{Mg}$ ha $\left.{ }^{-1}\right)$} & \multicolumn{2}{|c|}{ Termo de Regressão $\left(\mathrm{R}^{2}\right)$} \\
\hline & 0 & 20 & 40 & 60 & Linear & Quadrático \\
\hline 30 & 4,3 & 4,7 & 5,1 & 5,5 & $0,99^{* *}$ & ns \\
\hline 60 & 4,2 & 4,6 & 5,0 & 5,2 & $0,99^{* *}$ & ns \\
\hline 90 & 4,2 & 5,0 & 5,1 & 5,6 & $0,91^{* *}$ & ns \\
\hline 150 & 4,3 & 4,7 & 4,7 & 5,0 & $0,92^{*}$ & ns \\
\hline 210 & 4,2 & 4,6 & 4,7 & 5,2 & $0,94^{* *}$ & ns \\
\hline 270 & 4,2 & 4,6 & 4,4 & 5,0 & 0,69 * & $0,99^{* *}$ \\
\hline 360 & 4,1 & 4,5 & 4,5 & 5,0 & $0,88^{* *}$ & ns \\
\hline \multicolumn{7}{|c|}{$\begin{array}{c}\text { Termo de } \\
\text { Regressão }\left(\mathrm{R}^{2}\right)\end{array}$} \\
\hline Linear & ns & $0,27^{*}$ & $0,82^{* *}$ & $0,58^{* *}$ & - & - \\
\hline Quadrático & ns & ns & $0,88^{*}$ & ns & - & - \\
\hline
\end{tabular}

Ano agrícola 1997/98

Dias Doses de composto de lixo $\left(\mathrm{Mg} \mathrm{ha}^{-1}\right)$ Termo de Regressão $\left(\mathrm{R}^{2}\right)$

\begin{tabular}{|c|c|c|c|c|c|c|}
\hline & 0 & 24 & 48 & 72 & Linear & Quadrático \\
\hline 30 & 4,3 & 5,7 & 5,5 & 6,5 & $0,81^{* *}$ & ns \\
\hline 60 & 4,3 & 5,3 & 5,9 & 5,8 & $0,77^{* *}$ & $0,99^{* *}$ \\
\hline 90 & 4,2 & 5,3 & 5,5 & 6,2 & $0,93^{* *}$ & ns \\
\hline 150 & 4,2 & 5,4 & 5,6 & 6,4 & $0,93^{* *}$ & ns \\
\hline 210 & 4,2 & 5,7 & 5,9 & 6,3 & $0,86^{* *}$ & $0,96^{* *}$ \\
\hline 270 & 4,2 & 5,6 & 5,8 & 6,2 & $0,86^{* *}$ & $0,95^{*}$ \\
\hline 360 & 4,1 & 5,7 & 6,1 & 6,4 & $0,85^{* *}$ & $0,98^{* *}$ \\
\hline \multicolumn{7}{|c|}{$\begin{array}{c}\text { Termo de } \\
\text { Regressão }\left(\mathrm{R}^{2}\right)\end{array}$} \\
\hline Linear & ns & ns & $0,44^{* *}$ & ns & - & - \\
\hline Quadrático & ns & ns & ns & ns & - & - \\
\hline
\end{tabular}

Tias após a incorporação do composto de lixo;

${ }^{*},{ }^{* *}$, ns Indicam respectivamente, que os termos de regressão linear ou quadrática foram significativos a $\mathrm{P} \leq 0,05$, $P \leq 0,01$ ou não significativo pelo teste $F$.

O poder de neutralização exercido pelo resíduo, certamente está relacionado com o comportamento de sua carga orgânica no solo. Neste sentido, são válidas algumas explicações que determinados autores propuseram para os fenômenos envolvidos na ação neutralizante de diferentes resíduos orgânicos. Hoyt \& Tumer (1975) atribuíram a elevação do pH de um solo ácido, a ação complexante de substâncias orgânicas 
derivadas da decomposição de resíduos de alfafa, sobre o alumínio presente na solução do solo. Mattiazzo \& Glória (1987) explicaram, num estudo com vinhaça, que esses efeitos são devidos a produção de íons $\mathrm{OH}^{`}$ quando o oxigênio da solução do solo atua como receptor final de elétrons derivados da oxidação microbiana do carbono orgânico do resíduo. Para Hue (1992), resíduos orgânicos geram íons OH no solo através de dois processos: pela troca de ligantes entre ânions orgânicos (p.e. tartarato e ftalato) e terminais hidroxilas de óxidos de $\mathrm{Fe}$ e $\mathrm{Al}$; pela redução de óxidos de $\mathrm{Fe}$ e $\mathrm{Al}$ (predominantemente goethita) que deve ocorrer em ambiente rico em elétrons derivados da rápida oxidação do carbono orgânico dos resíduos.

Quando se considera o comportamento do $\mathrm{pH}$, dentro de cada dose aplicada, no decorrer das várias épocas de amostragem do solo verifica-se, para 1996/97, que houveram decréscimos naqueles valores. No ano seguinte, tais decréscimos não foram observados para nenhuma das doses. Provavelmente a diminuição do $\mathrm{pH}$ no ano de 1996/97 seja explicada pela maior taxa de decréscimo do carbono orgânico associado aos processos naturais de acidificação do solo. Já no ano agrícola 1997/98, os maiores teores de carbono orgânico do solo somados a sua menor taxa de decréscimo, provavelmente conferiram um efeito tampão ao mesmo. De forma concordante, Harding et al. (1985) observaram que a aplicação de lodo de esgoto (sem cal) foi capaz de aumentar e manter o $\mathrm{pH}$ do solo até 5 anos depois, efeito atribuído ao poder de tamponamento proporcionado pela lenta e contínua degradação de sua carga orgânica.

Avaliações de $\mathrm{pH}$ em amostras de solos coletadas em profundidade, ao final de cada ano agrícola, são apresentadas na Tabela 28. Observa-se para o ano 1996/97, aumentos lineares significativos de $\mathrm{pH}$ até a profundidade de $0,4 \mathrm{~m}$. De maneira geral, dentro de cada dose aplicada, os valores de $\mathrm{pH}$ observados até $0,4 \mathrm{~m}$ foram significativamente maiores do que àqueles das camadas de 0,4 a $0,8 \mathrm{~m}$. Para o ano agrícola 1997/98 não foram observados aumentos de $\mathrm{pH}$ nas camadas abaixo de 0,2 m. É possivel que no primeiro ano a alteração de $\mathrm{pH}$ em profundidade tenha ocorrido devido a maior taxa de degradação do composto de lixo. Dessa forma, uma quantidade maior de substâncias orgânicas solúveis, com potencial neutralizante, estariam passiveis de lixiviação. 
Tabela 28. Valores pH do solo determinados nas camadas de $0-0,2,0,2-0,4,0,4-0,6$ e $0,6-0,8 \mathrm{~m}$, aos 360 dias após incorporação de doses de composto de lixo nos anos agrícolas 1996/97 e 1997/98.

\section{Ano agrícola 1996/97}

Profundidade

Doses de composto de lixo ( $\left.\mathrm{Mg} \mathrm{ha}^{-1}\right)$

Termo de Regressão $\left(\mathrm{R}^{2}\right)$

\begin{tabular}{rccccccc}
\multicolumn{1}{c}{$\mathrm{m})$} & 0 & 20 & 40 & 60 & Linear & Quadrático \\
\hline $0-0,2$ & $4,1 \mathrm{a}$ & $4,5 \mathrm{a}$ & $4,5 \mathrm{a}$ & $5,0 \mathrm{a}$ & $0,88^{* *}$ & $\mathrm{~ns}$ \\
$0,2-0,4$ & $4,2 \mathrm{a}$ & $4,6 \mathrm{a}$ & $4,5 \mathrm{a}$ & 4,6 & $\mathrm{~b}$ & $0,70^{*}$ & $\mathrm{~ns}$ \\
$0,4-0,6$ & $4,2 \mathrm{a}$ & $4,2 \mathrm{~b}$ & $4,3 \mathrm{ab}$ & 4,2 & $\mathrm{c}$ & $\mathrm{ns}$ & $\mathrm{ns}$ \\
$0,6-0,8$ & $4,2 \mathrm{a}$ & $4,1 \mathrm{~b}$ & $4,2 \mathrm{~b}$ & 4,2 & $\mathrm{c}$ & $\mathrm{ns}$ & $\mathrm{ns}$
\end{tabular}

Ano agrícola 1997/98

Profundidade Doses de composto de lixo $\left(\mathrm{Mg} \mathrm{ha}^{-1}\right)$

Termo de Regressão $\left(\mathrm{R}^{2}\right)$

\begin{tabular}{|c|c|c|c|c|c|}
\hline 0 & 24 & 48 & 72 & Linear & Quadrátic \\
\hline & 5,7 a & 6,1 a & $6.4 \mathrm{a}$ & $0,85^{* *}$ & $0,98^{* *}$ \\
\hline a & $4,2 \quad b$ & $4,2 \quad b$ & $4,2 \quad b$ & ns & ns \\
\hline a & 4,2 & 4,1 & 4,2 & ns & ns \\
\hline a & 4,1 & 4,1 & 4,1 & ns & ns \\
\hline
\end{tabular}

\footnotetext{
*, **, ns Indicam respectivamente, que os termos de regressão linear ou quadrática foram significativos a $\mathrm{P} \leq 0,05$, $\mathrm{P} \leq 0,01$ ou não significativo pelo teste $\mathrm{F}$;
}

Médias seguidas por letras distintas, em colunas, diferem entre si a $\mathrm{P} \leq 0,05$ pelo teste de Tukey - D.M.S. $5 \%=0,27$ (ano agrícola 1996/97), D.M.S. 5\%=0,20 (ano agrícola 1997/98).

\subsubsection{Capacidade de troca de cátions}

$\mathrm{Na}$ análise de variância da CTC foram verificados, para os dois anos agrícolas, efeitos significativos de doses de composto de lixo e épocas de amostragem do solo porém, não houve interação entre estes fatores (Apêndice 2). O aumento da CTC em função das doses do resíduo seguiu, dentro de todas as amostragens de 1996/97, um comportamento linear $\left(R^{2}=0,95^{* *}\right)$ ao passo que para 1997/98, tal comportamento foi quadrático $\left(\mathrm{R}^{2}=0,99^{* *}\right)$.

Para o ano agrícola 1996/97 foi verificado através da análise de regressão, uma tendência quadrática decrescente e significativa $\left(R^{2}=0,85^{* *}\right)$ nos valores da variável em função das épocas de amostragem do solo. Dessa forma, conforme pode ser observado na Figura 21, os valores de CTC, máximos e mínimos, encontrados para as doses A, B e $\mathrm{C}$ de composto de lixo foram respectivamente, 37,57 e 34,44, 39,64 e 36,85, 41,66 e $37,26 \mathrm{mmol}_{\mathrm{c}} \mathrm{kg}^{-1}$. Comparando-se os valores mínimos de CTC, verificados aos 360 dias após a incorporação do resíduo, com a testemunha absoluta observa-se que o composto 
de lixo promoveu ao final deste ano nas respectivas doses, acréscimos líquidos de 2,73, 5,14 e $5,55 \mathrm{mmol}_{\mathrm{c}} \mathrm{kg}^{-1}$.

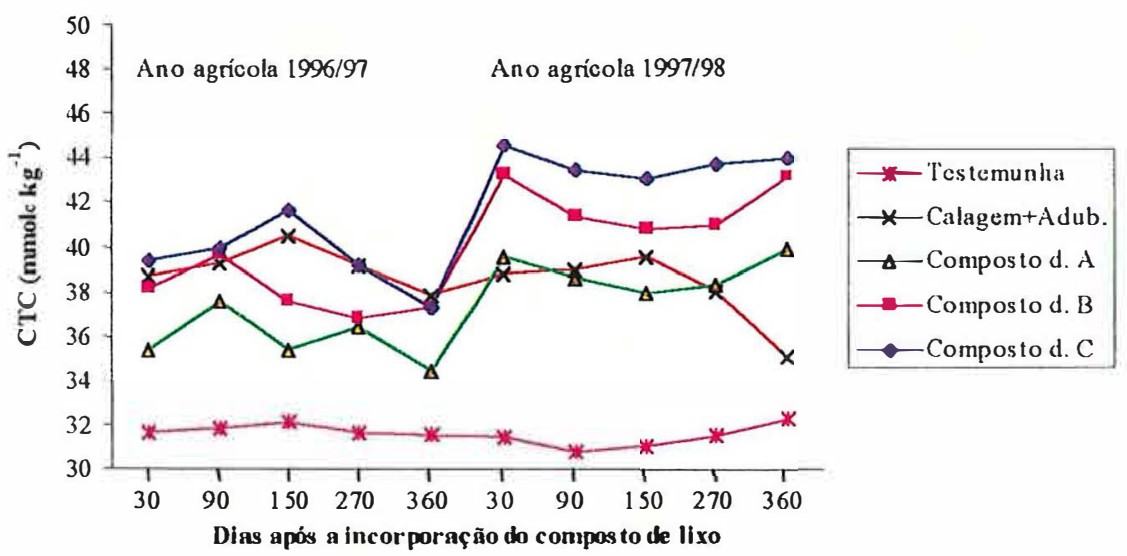

Figura 21. Capacidade de troca de cátions do solo no decorrer dos anos agrícolas 1996/97 e 1997/98 para o tratamentos com doses de composto de lixo e calagem + adubação mineral.

Após a segunda aplicação do composto, ano agrícola 1997/98, embora tenha sido verificado um comportamento quadrático da variável em função das épocas de amostragem, este não apontou decréscimos expressivos na CTC, considerando-se o ano agrícola como um todo (Figura 21). Dessa forma, os valores médios determinados para as doses $\mathrm{A}, \mathrm{B}$ e $\mathrm{C}$ foram respectivamente de 38,88 $\pm 0,38,41,93 \pm 0,54$ e $43,77 \pm 0,26 \mathrm{mmol}_{\mathrm{c}} \mathrm{kg}^{-1}$ os quais significaram, quando comparados com a testemunha, acréscimos de 7,62 $\pm 0,32,10,67 \pm 0,48$ e 12,51 $\pm 0,21 \mathrm{mmol}_{\mathrm{c}} \mathrm{kg}^{-1}$.

A comparação dos resultados obtidos nos dois anos agrícolas evidencia uma tendência crescente da variável em função da segunda aplicação do resíduo, sugerindo que por ocasião de aplicações sucessivas, outros acréscimos na CTC do solo devam ser verificados.

Aumentos na CTC de solos devido a aplicação de compostos de lixo também foram verificados por diversos autores entre eles Hortenstine \& Rothwell (1972), Bengtson \& Cornette (1973), Giusquiani et al. (1995) e Abreu Junior (1999).

Um outro aspecto importante a ser considerado diz respeito a CTC a pH 7,0 do próprio composto de lixo (Tabela 3). Estimativas de acréscimos a CTC do solo, realizadas em função desses valores, da taxa de aplicação do resíduo e da densidade do 
solo na camada de incorporação revelam acréscimos potenciais respectivamente, para as doses A, B e C, ao redor de 1,1, 2,2 e 3,3 $\mathrm{mmol}_{\mathrm{c}} \mathrm{kg}^{-1}$ em 1996/97 e 2,1, 4,2 e $6,3 \mathrm{mmol}_{\mathrm{c}} \mathrm{kg}^{-1}$ em 1997/98. Assim, mesmo não havendo semelhança entre os acréscimos estimados e os determinados, é fato que ambos apresentaram tendências crescentes em função das doses aplicadas. Portanto, considerando que a CTC a pH 7,0 do composto de lixo é devida essencialmente a sua carga orgânica, é provável que seus efeitos sobre a CTC a pH atual do solo seja resultado da interação entre os ganhos de C-orgânico proporcionados ao mesmo e as alterações no $\mathrm{pH}$ devidas a esta prática.

Esta hipótese é comprovada pelas correlações estabelecidas entre CTC e pH e CTC e C-orgânico do solo (Figura 22), onde são verificados coeficientes significativos e praticamente iguais para as correlações estabelecidas, seja para os anos agrícolas analisados separadamente ou em conjunto. Neste caso, fica evidenciado que a geração de cargas negativas no solo se deu por uma interação íntima entre a matéria orgânica do composto de lixo e seus efeitos sobre o pH do solo. Tais resultados são concordantes com àqueles obtidos por Rodella et al. (1995) e Rodella (1996). Em ambos os trabalhos, os autores verificaram que o efeito de diversos resíduos orgânicos sobre a CTC a pH atual de solos sob clima tropical, está diretamente relacionado com os efeitos desses resíduos sobre o pH desses solos. Evidenciaram que resíduos orgânicos com elevada CTC a pH 7,0, mas que não conferiram, quando aplicados aos solos, aumentos sobre o $\mathrm{pH}$, não ofereceram contribuição alguma a $\mathrm{CTC}$ a pH atual desses solos.

Embora os resultados comprovem a intima relação entre CTC, $\mathrm{pH}$ e carbono orgânico do solo, não se pode afirmar que os aumentos verificados na CTC sejam exclusivamente devidos a carga orgânica do composto de lixo. Um indicativo disto é dado pelos resultados apresentados pelo tratamento com calagem, o qual apresentou valores médios de CTC, durante os dois anos agrícolas, de $38,62 \pm 0,45 \mathrm{mmol}_{\mathrm{c}} \mathrm{kg}^{-1}$ representando um acréscimo em relação a testemunha, de 7,06 $\pm 0,52 \mathrm{mmol}_{\mathrm{c}} \mathrm{kg}^{-1}$ (Figura 21). Considerando-se que o valor médio de $\mathrm{pH}$ nos dois anos foi de 5,2 nos tratamentos com calagem e de 4,2 nas testemunhas, verifica-se que apenas a elevação do pH do solo foi capaz de aumentar sua CTC. No ano agrícola 1996/97, os valores observados para doses de composto de lixo foram relativamente próximos ao valor médio proporcionado pela calagem. Portanto, é possível que o efeito neutralizante do composto de lixo também esteja gerando cargas da mesma forma que a simples calagem. 


\section{Ano agrícola 1996/97}
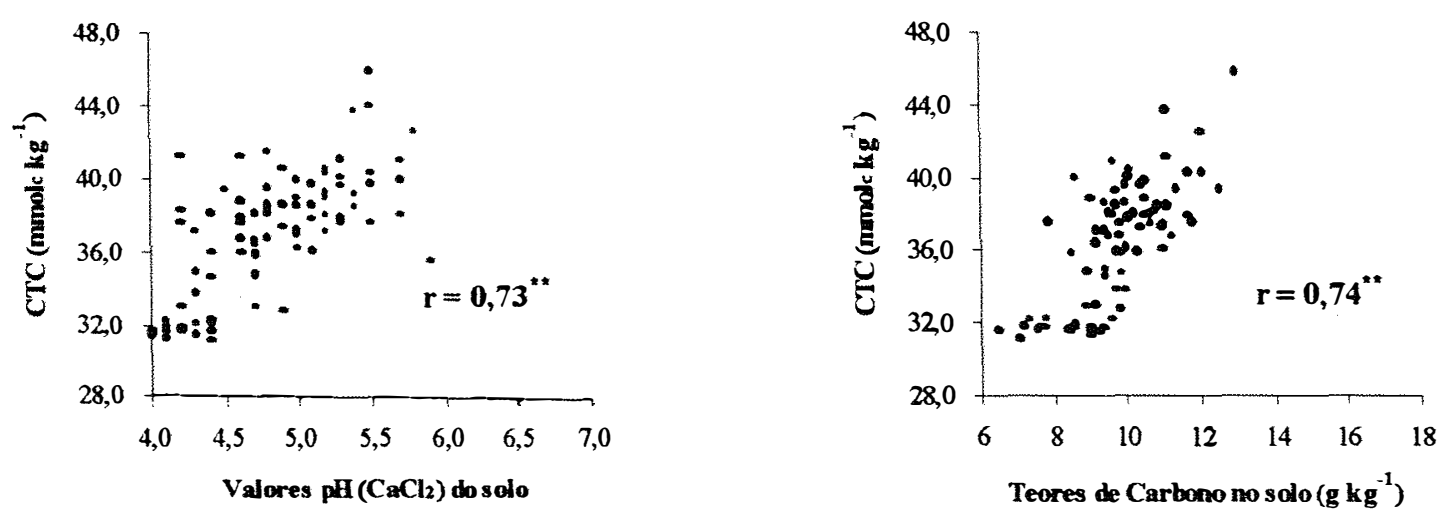

Ano agrícola 1997/98
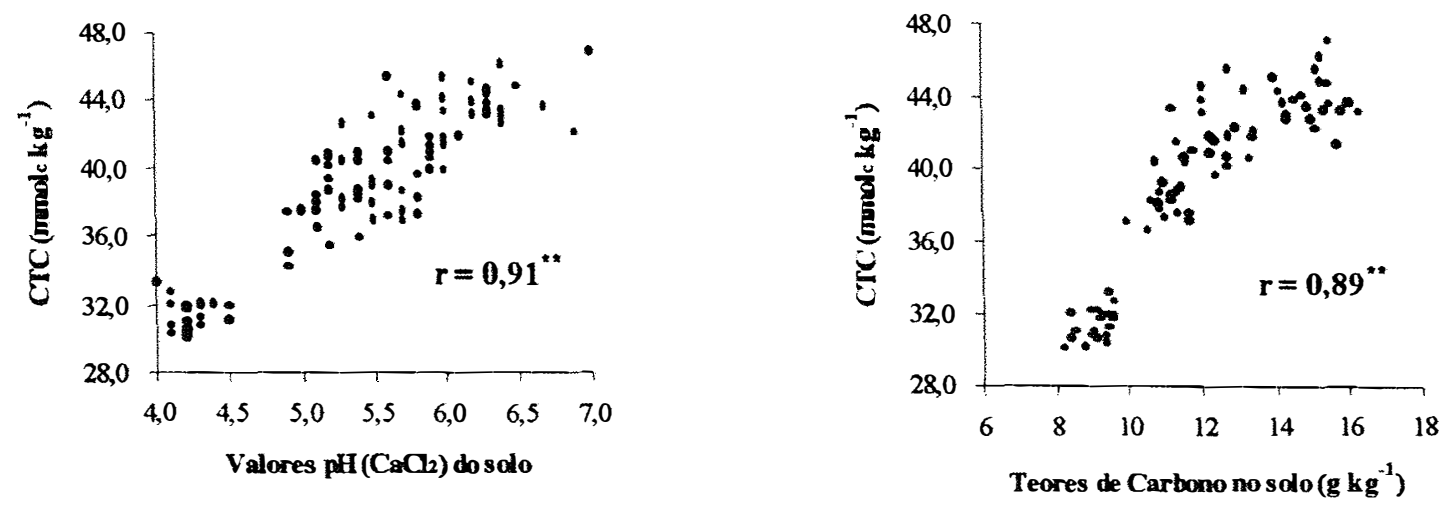

Anos agrícolas 1996/97 e 1997/98
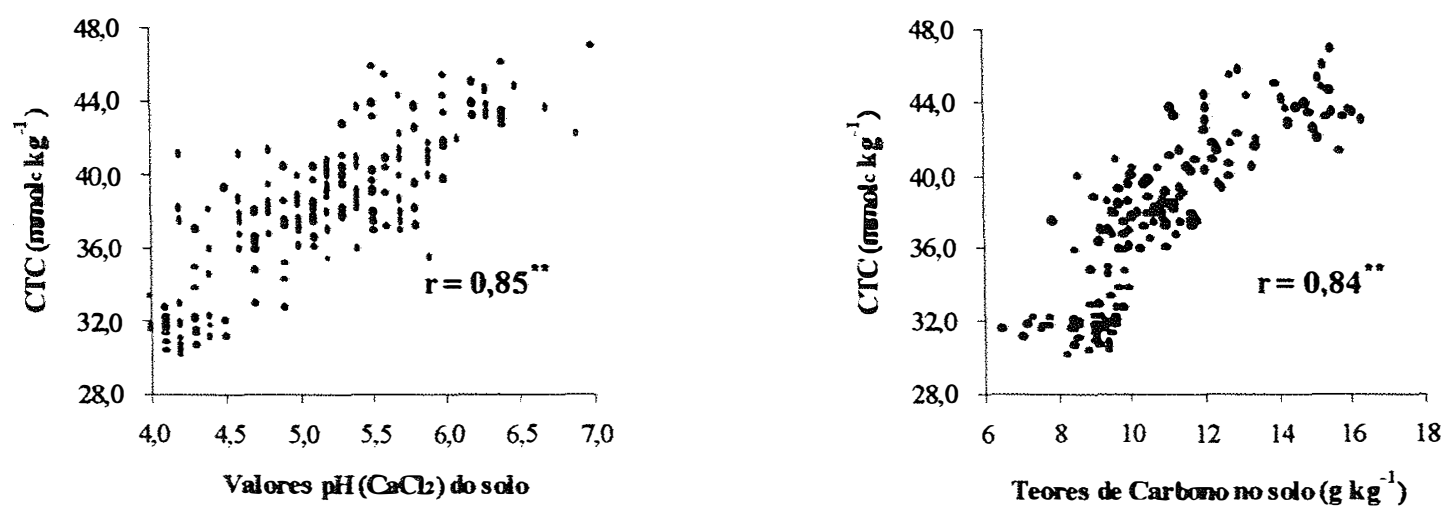

Figura 22. Relações entre CTC e pH, CTC e teores de carbono orgânico do solo no experimento com composto de lixo. ("* Coeficientes de correlação significativos a $\mathrm{P} \leq 0,01$ pelo teste $\mathrm{t})$. 
É importante salientar que a observação desses fenômenos só foi possível devido ao fato da CTC ter sido determinada ao $\mathrm{pH}$ atual do solo. Determinações realizadas com soluções alcalinas tamponadas ou por soma de bases certamente iriam mascarar esses resultados.

De maneira geral, o decréscimo da CTC verificado para as doses A, B e C do composto de lixo no transcorrer de 1996/97, poderia ser explicado pelo decréscimo do carbono orgânico e pH do solo. Por outro lado, em 1997/98 a não ocorrência deste efeito pode ser atribuída a menor taxa de decréscimo do carbono orgânico e principalmente pela manutenção do valores $\mathrm{pH}$ (Tabelas 24 e 27).

\subsubsection{Metais pesados}

\subsubsection{Acúmulo de metais pesados no solo e nas plantas}

A disposição de doses crescentes de composto de lixo proporcionou, nos dois anos agrícolas, acréscimos significativos nos teores totais de $\mathrm{Cu}$ e $\mathrm{Zn}$ presentes no solo (Tabela 29). Para o $\mathrm{Cr}$, esses acréscimos foram detectados apenas em 1997/98. Os maiores teores acumulados de $\mathrm{Cu}$ e $\mathrm{Zn}$ se explicam pelas suas concentrações no resíduo. Ao final de 1996/97 e 1997/98, foram observados para o $\mathrm{Cu}$, acréscimos médios em relação a testemunha, variando da menor para a maior taxa de aplicação, respectivamente de 12 a $25 \%$ e 27 a $88 \%$. No caso do $Z n$, esses acréscimos variaram respectivamente de 12 a $72 \%$ e de 72 a $156 \%$. Os teores de $\mathrm{Cr}$ apresentaram aumentos em 1997/98, que variaram de 12 a 25\%. Dessa forma, pela comparação desses valores evidencia-se o potencial de acúmulo dos metais no solo, por ocasião de aplicações sucessivas do composto de lixo.

Os elementos $\mathrm{Cd}$, $\mathrm{Ni}$ e $\mathrm{Pb}$ não foram detectados por apresentarem-se em concentrações abaixo do limite de determinação do método analítico. Ressalta-se que esses limites foram os mesmos utilizados para o experimento com lodo de esgoto (4.1.5.1). O elemento $\mathrm{Cd}$ não foi detectado nem mesmo no composto de lixo, por outro lado para $\mathrm{Ni}$ e $\mathrm{Pb}$, com base nas quantidades adicionadas através do resíduo (Tabela 30), é possível inferir que suas concentrações acumuladas no solo estariam variando respectivamente, entre 0,5 e $1,5 \mathrm{mg} \mathrm{kg}^{-1}$ e 2,5 e $7,5 \mathrm{mg} \mathrm{kg}^{-1}$. 
Tabela 29. Teores totais de $\mathrm{Cu}, \mathrm{Cr}$ e $\mathrm{Zn}$ recuperados do solo na camada $0-0,2 \mathrm{~m}$, nos anos agrícolas 1996/97 e 1997/98, para os tratamentos com doses de composto de lixo.

\begin{tabular}{|c|c|c|c|c|c|c|}
\hline \multirow[t]{2}{*}{ Ano agrícola } & \multicolumn{4}{|c|}{ Doses de Composto de $\operatorname{Lixo}^{1}\left(\mathrm{Mg} \mathrm{ha}^{-1}\right)$} & \multicolumn{2}{|c|}{ Termo de Regressão $\left(\mathrm{R}^{2}\right)$} \\
\hline & 0 & $20(24)$ & $40(48)$ & $60(72)$ & Linear & Quadrático \\
\hline & \multicolumn{4}{|c|}{ Cobre $\left(\mathrm{mg} \mathrm{kg}^{-1}\right)$} & & \\
\hline $1996 / 97$ & 17,86 & 20,05 & 22,38 & 22,33 & $0,88^{* *}$ & ns \\
\hline \multirow[t]{2}{*}{$1997 / 98$} & 16,87 & 21,42 & 26,74 & 31,65 & $0,99^{* *}$ & ns \\
\hline & \multicolumn{4}{|c|}{ Cromo (mg kg-1) } & & \\
\hline $1996 / 97$ & 16,57 & 17,72 & 17,47 & 17,63 & ns & ns \\
\hline \multirow[t]{2}{*}{$1997 / 98$} & 15,55 & 17,48 & 19,47 & 19,48 & $0,89^{*}$ & ns \\
\hline & \multicolumn{4}{|c|}{ Zinco ( $\left.\mathrm{mg} \mathrm{kg}^{-1}\right)$} & & \\
\hline $1996 / 97$ & 21,14 & 23,64 & 31,42 & 36,34 & $0,97^{* *}$ & ns \\
\hline $1997 / 98$ & 20,19 & 34,78 & 45,91 & 51,64 & $0,97^{* *}$ & $0,99^{* *}$ \\
\hline
\end{tabular}

'Doses entre parênteses referem-se ao ano agrícola 1997/98;

${ }^{*},{ }^{* *},{ }^{\text {ns }}$ Indicam respectivamente, que os termos de regressão linear ou quadrática foram significativos a $\mathrm{P} \leq 0,05$, $P \leq 0,01$ ou não significativo pelo teste $F$;

De maneira geral, a possibilidade de aumentos nos teores de $\mathrm{Cd}, \mathrm{Cu}, \mathrm{Cr}, \mathrm{Ni}, \mathrm{Pb}$ e $\mathrm{Zn}$ em solos tratados com composto de lixo, foi verificada por diversos autores (Hortenstine \& Rothwell, 1972; Bengtson \& Cornette, 1973; Cravo, 1995; Abreu Junior, 1999). Trindade et al. (1996) observaram acréscimos nos teores totais de $\mathrm{Cd}, \mathrm{Cu}, \mathrm{Pb}$ e $\mathrm{Zn}$ devido a aplicação de até $60 \mathrm{Mg} \mathrm{ha}^{-1}$ (base seca) de composto de lixo. Resultados semelhantes para Fe, Mn, Ni e $\mathrm{Zn}$ foram obtidos por Alves et al. (1999) em solos tratados com até $100 \mathrm{Mg} \mathrm{ha}^{-1}$ (base seca) do resíduo.

Considerando-se os teores totais de $\mathrm{Cu}, \mathrm{Cr}$ e $\mathrm{Zn}$ acumulados nos tratamentos com doses A, B e C de composto de lixo, ao final de 1997/98, verifica-se que os mesmos estão bem abaixo dos teores considerados críticos em solos pela USEPA (40 CFR Part 503) e pelas Diretrizes da Comunidade Européia (Hall, 1998). Contudo, tendo como base os teores médios teóricos dos vários metais pesados incrementados no solo através do composto de lixo utilizado (Tabela 30 ), estima-se que o $\mathrm{Pb}$ seria $\mathrm{o}$ primeiro metal a atingir os limites críticos estabelecidos pela USEPA (180 mg kg-1 $)$, o que levaria de 48 a 145 anos no caso de taxas de aplicações anuais e sucessivas variando em média, entre 66 e $22 \mathrm{Mg} \mathrm{ha}^{-1}$ (base seca). De acordo com as Diretrizes da Comunidade Européia, que são mais restritivas, estima-se que o $\mathrm{Cu}$ seria o primeiro metal a atingir o limite crítico $\left(210 \mathrm{mg} \mathrm{kg}^{-1}\right)$, o que levaria de 26 a 78 anos para as mesmas taxas e freqüências de aplicações citadas anteriormente. 
Tabela 30. Quantidades de metais pesados adicionadas ao solo $\left(\mathrm{mg} \mathrm{kg}^{-1}\right)$, na camada de $0-0,2 \mathrm{~m}$, pela aplicação de composto de lixo nos anos agrícolas 1996/97 e $1997 / 98$ e os valores acumulados no período ${ }^{1}$.

\begin{tabular}{|c|c|c|c|c|c|c|c|c|c|}
\hline \multirow{3}{*}{ Metal } & \multicolumn{9}{|c|}{ Doses de Composto de Lixo $\left(\mathrm{Mg} \mathrm{ha}^{-1}\right)$} \\
\hline & \multicolumn{3}{|c|}{ Ano agrícola 1996/97 } & \multicolumn{3}{|c|}{ Ano agrícola 1997/98 } & \multicolumn{3}{|c|}{ Valores acumulados } \\
\hline & 20 & 40 & 60 & 24 & 48 & 72 & 48 & 88 & 132 \\
\hline Cádmio & - & - & - & - & - & - & - & - & - \\
\hline Cobre & 1,69 & 3,38 & 5,07 & 3,67 & 7,35 & 11,02 & 5,36 & 10,73 & 16,09 \\
\hline Cromo & 0,31 & 0,63 & 0,94 & 0,74 & 1,48 & 2,22 & 1,05 & 2,11 & 3,16 \\
\hline Níquel & 0,20 & 0,40 & 0,60 & 0,31 & 0,62 & 0,93 & 0,51 & 1,02 & 1,53 \\
\hline Chumbo & 0,70 & 1,39 & 2,09 & 1,79 & 3,57 & 5,36 & 2,49 & 4,96 & 7,45 \\
\hline Zinco & 2,94 & 5,88 & 8,82 & 4,52 & 9,04 & 13,57 & 7,46 & 14,92 & 22,39 \\
\hline
\end{tabular}

TValores calculados com base no teor do metal presente no resíduo, com a dose aplicada e considerando a camada de incorporação no solo $(0-0,2 \mathrm{~m})$ cuja densidade de $1316 \mathrm{~kg} \mathrm{~m}^{-3}$ foi determinada por Marciano (1999).

Estimativas realizadas por Cravo (1995), com base nas concentrações médias dos diversos metais pesados verificados em amostras de compostos de lixo urbano brasileiros, demonstraram que aplicações anuais e sucessivas de $60 \mathrm{Mg} \mathrm{ha}^{-1}$ (base seca) do resíduo levariam, de acordo com os critérios adotados pelo Canadá e àqueles preconizados pela USEPA (40 CFR Part 503), de 6 a 21 anos para atingir os limites críticos de contaminação dos solos por $\mathrm{Pb}$. Neste contexto, o autor salientou que são grandes as possibilidades da existência no Brasil, de áreas contaminadas pelo elemento, essencialmente nas periferias das grandes cidades onde se cultivam, por mais de 20 anos, hortaliças com o emprego de composto de lixo. É preciso lembrar porém, que essas afirmações foram feitas com base em legislações de outros países, cuja pertinência nas condições ambientais brasileiras é desconhecida.

Diante do exposto, para se evitar os possiveis problemas decorrentes da contaminação dos solos por metais pesados, salienta-se a necessidade do monitoramento periódico dos teores desses elementos em áreas que são tratadas com composto de lixo. Paralelamente a isto, são indispensáveis a realização de pesquisas de longo prazo para a avaliação dos critérios preconizados pelas agências internacionais de proteção ambiental e principalmente, para gerar informações essenciais à elaboração de normas adequadas para as condições tropicais brasileiras. 
Quanto a absorção dos metais pesados pelas plantas de cana-de-açúcar, a exemplo do que ocorreu no experimento com lodo de esgoto, não foram detectados, nas amostras de folhas " +1 ", colmo e caldo, a presença dos metais $\mathrm{Cd}, \mathrm{Cr}, \mathrm{Ni}$ e $\mathrm{Pb}$. Todavia, é possivel assegurar que, caso as plantas tenham absorvido tais elementos, essas teriam apresentado concentrações abaixo dos mesmos limites de determinação apresentados para as amostras obtidas nos tratamentos com lodo de esgoto (4.1.5.1).

De acordo com Chang et al. (1987), as quantidades absorvidas de metais pesados pelas plantas geralmente não ultrapassam $1 \%$ do total acumulado no solo, sendo esta absorção não proporcional aos teores totais presentes. Isto posto, é provável que no período experimental considerado, o composto de lixo não tenha causado incremento algum na absorção de $\mathrm{Cd}, \mathrm{Cr}, \mathrm{Ni} \mathrm{e} \mathrm{Pb}$, haja visto que os acréscimos promovidos no solo pelas doses do resíduo foram pequenos (Tabela 30). Além disso, os teores de carbono orgânico, óxidos de $\mathrm{Fe}$ e $\mathrm{Al}$ e valores de $\mathrm{pH}$ do solo, foram favoráveis às reações de precipitação, complexação e adsorção que atuariam no sentido de reduzir a disponibilidade desses elementos às plantas (Kabata-Pendias \& Pendias, 1984; Adriano, 1986).

Cravo (1995) verificou que os teores de $\mathrm{Cd}$ e $\mathrm{Pb}$ presentes na matéria seca de folhas de alface aumentaram com a aplicação de doses crescentes de composto de lixo $\left(0,20,40\right.$ e $80 \mathrm{Mg} \mathrm{ha}^{-1}$ - base seca). Os teores observados para estes metais variaram, da testemunha para a maior dose, respectivamente de 1,65 a $4,56 \mathrm{mg} \mathrm{kg}^{-1}$ e de 19,82 a $42,25 \mathrm{mg} \mathrm{kg}^{-1}$. Com relação aos metais $\mathrm{Cr}$ e $\mathrm{Ni}$, o autor não verificou efeitos da aplicação do resíduo. Abreu Junior (1999), trabalhando com um Latossolo Vermelho-Amarelo tratado com $60 \mathrm{Mg} \mathrm{ha}^{-1}$ (base seca) de composto de lixo com e sem calagem, verificou teores médios de $\mathrm{Cd}$, na matéria seca da parte aérea de plantas de arroz cultivadas nos tratamentos com aplicação do resíduo sem calagem $\left(\mathrm{pH}_{\left(\mathrm{CaCl}_{2}\right)}=5,4\right)$, de $0,13 \mathrm{mg} \mathrm{kg}^{-1}$ ao passo que nos tratamentos com composto de lixo +

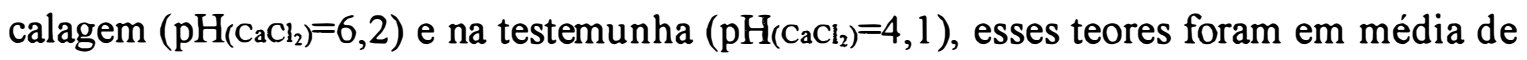
$0,05 \mathrm{mg} \mathrm{kg}^{-1}$. Para $\mathrm{Cr}$, Ni e Pb não houveram efeitos da aplicação do composto de lixo, sendo que os teores desses elementos na parte aérea da cultura foram em média, para todos tratamentos, respectivamente de $0,41,0,70$ e $0,50 \mathrm{mg} \mathrm{kg}^{-1}$. 
Os teores de $\mathrm{Cu}$ variaram, nas diversas amostras analisadas, respectivamente para os anos agrícolas 1996/97 e 1997/98, entre os seguintes valores (Figura 23): folhas “+1" - 5,04 a 6,72 mg kg-1, 4,59 a 4,99 mg kg-1, colmo - 2,20 a 3,04 mg kg-1, 1,81 a $2,70 \mathrm{mg} \mathrm{kg}^{-1}$; caldo - 0,17 a $0,41 \mathrm{mg} \mathrm{kg}^{-1}, 0,41$ a $0,86 \mathrm{mg} \mathrm{kg}^{-1}$. Para o $\mathrm{Zn}$, os intervalos de variação observados foram (Figura 24): folha "+1" - 13,58 a 20,01 mg kg-1, 13,40 a $17,83 \mathrm{mg} \mathrm{kg}^{-1}$; colmo - 4,16 a $9,91 \mathrm{mg} \mathrm{kg}^{-1}, 5,23$ a $10,88 \mathrm{mg} \mathrm{kg}^{-1}$; caldo 0,50 a $1,03 \mathrm{mg} \mathrm{kg}^{-1}, 1,07$ a $2,10 \mathrm{mg} \mathrm{kg}^{-1}$.

De acordo com Sobral \& Weber (1983), os teores de micronutrientes nas diversas partes das plantas de cana-de-açúcar variam em função da variedade, de "cana-planta" para "cana-soca", com a idade das plantas e com o tipo de solo onde é cultivada. No entanto, considerando apenas como uma referência os dados apresentados para teores de $\mathrm{Cu}$ (Orlando Filho et al., 1980a) e teores de $\mathrm{Zn}$ (Orlando Filho et al., 1980b) obtidos para a variedade CB41-76, cultivadas em diversos tipos de solo e avaliadas em várias idades, pode-se afirmar que os teores obtidos no presente trabalho, nos colmos e na folha " +1 ", ocorreram dentro das variações encontradas por estes autores.

Os efeitos da disposição de composto de lixo sobre a absorção de $\mathrm{Cu}$ e $\mathrm{Zn}$ pelas plantas de cana-de-açúcar foram avaliados através de relações estabelecidas entre os teores determinados nas diferentes amostras de plantas e os teores totais recuperados do solo, para todos os tratamentos estabelecidos (Figuras 23 e 24). À estas relações foram dadas o mesmo tratamento matemático empregado aos resultados do experimento com lodo de esgoto, buscando evidentemente, explicar os fenômenos ocorridos.

Na Figura 23, observa-se para os dois anos agrícolas que, embora a aplicação de doses crescentes de composto de lixo tenha incrementado os teores totais de $\mathrm{Cu}$ no solo, nenhum efeito sobre os teores acumulados nas amostras de folhas " +1 ", no colmo e no caldo foram evidenciados. Esses resultados sugerem que o $\mathrm{Cu}$ adicionado através do resíduo não foi prontamente disponível às plantas, o que pode ser explicado pela grande afinidade deste metal com ligantes orgânicos, formando complexos pouco solúveis (Adriano, 1986). De forma concordante, Cravo (1995) não verificou aumentos nos teores de $\mathrm{Cu}$ em plantas de alface cultivadas logo após a aplicação do composto de lixo, observações feitas também por Abreu Junior (1999), para plantas de arroz cultivadas em diversos solos ácidos. 
Ano agrícola 1996/97
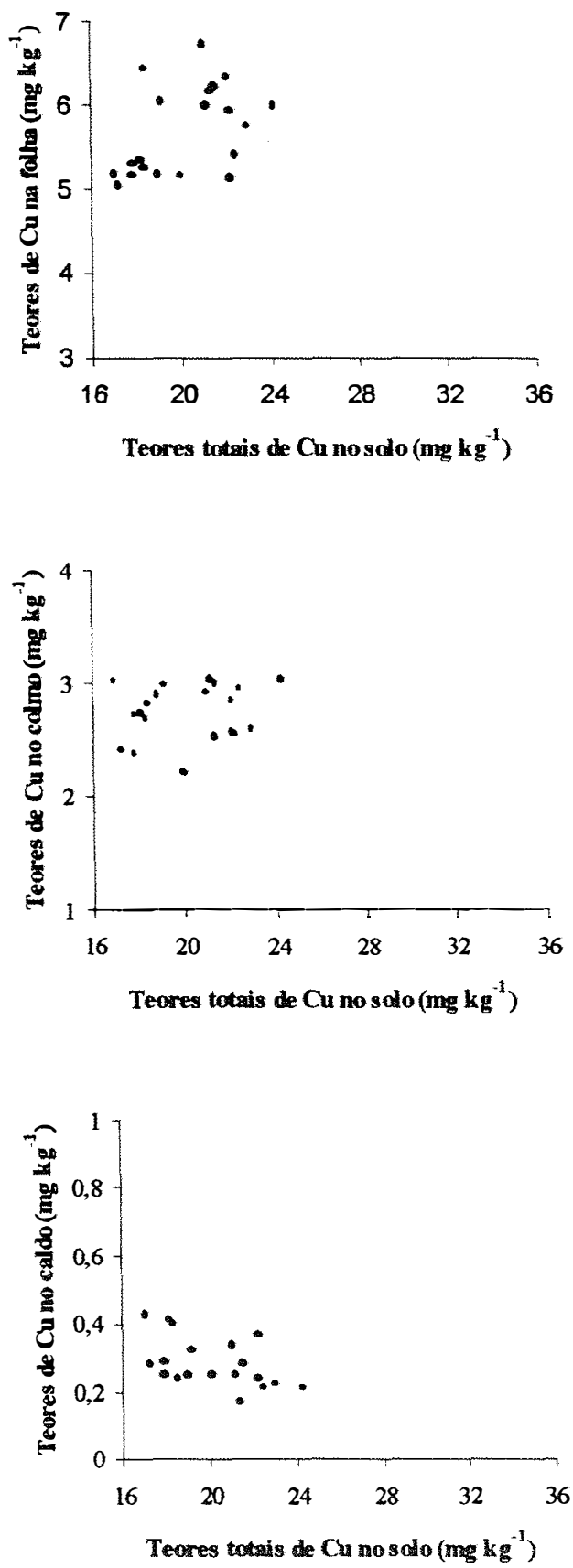

Ano agrícola 1997/98
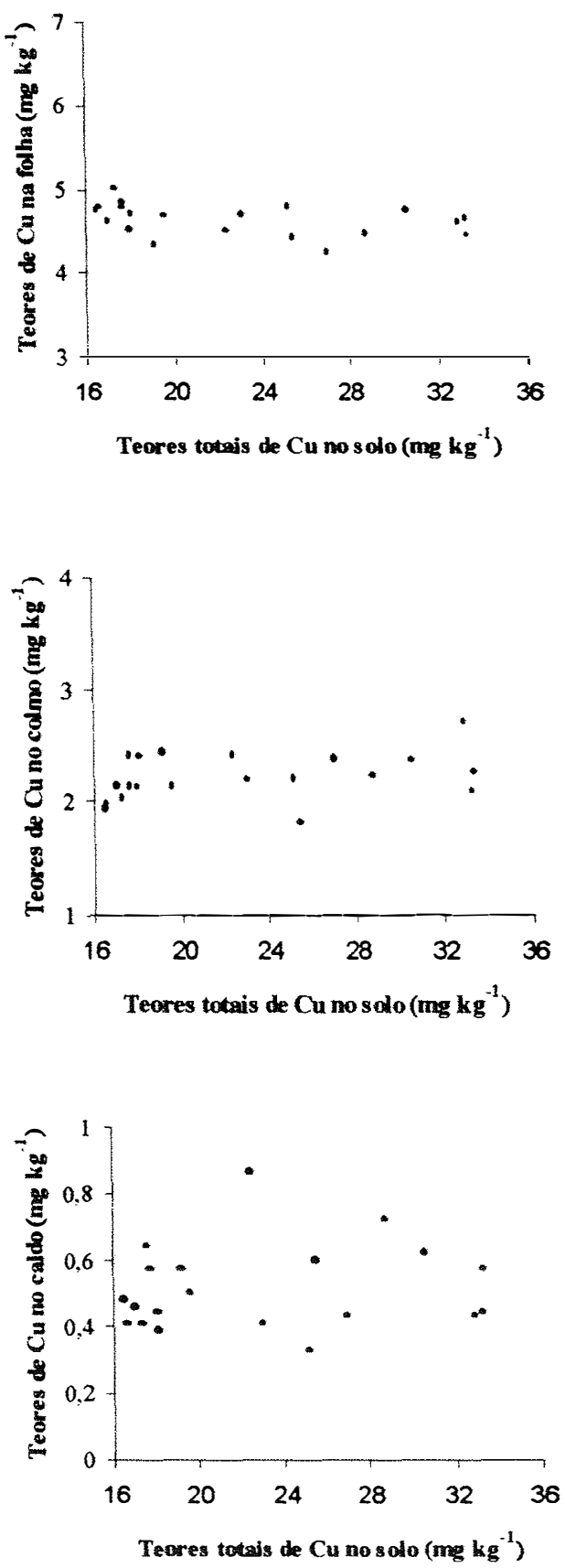

Figura 23. Relações entre teores de cobre nas amostras de folha, colmo e caldo da cana-de-açúcar e teores totais determinados no solo no experimento com composto de lixo. 
Ano agrícola 1996/97

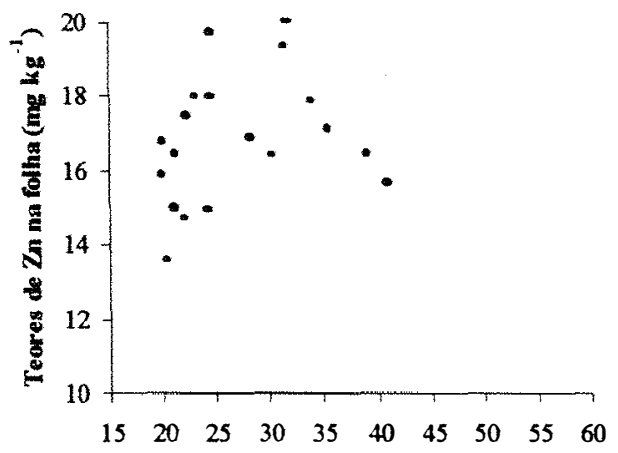

Teores totais de $\mathrm{Zn}$ no solo $\left(\mathrm{mg} \mathrm{kg}^{-1}\right)$

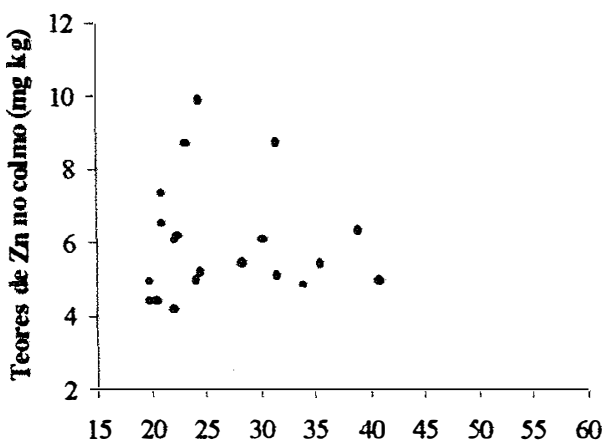

Teores totais de $\mathrm{Zn}$ no solo (mg $\mathrm{kg}$ )

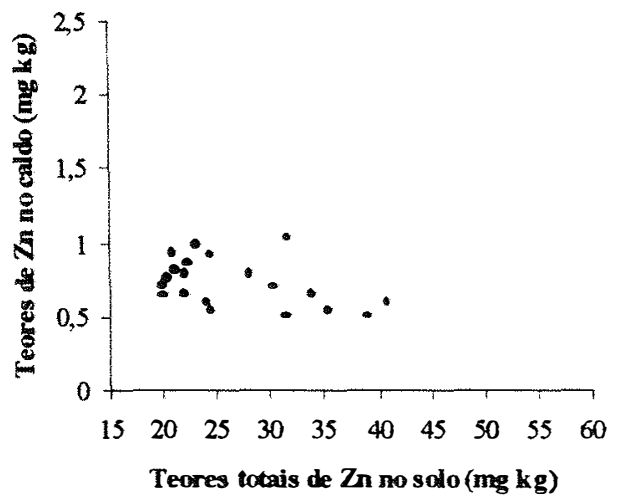

Ano agrícola 1997/98
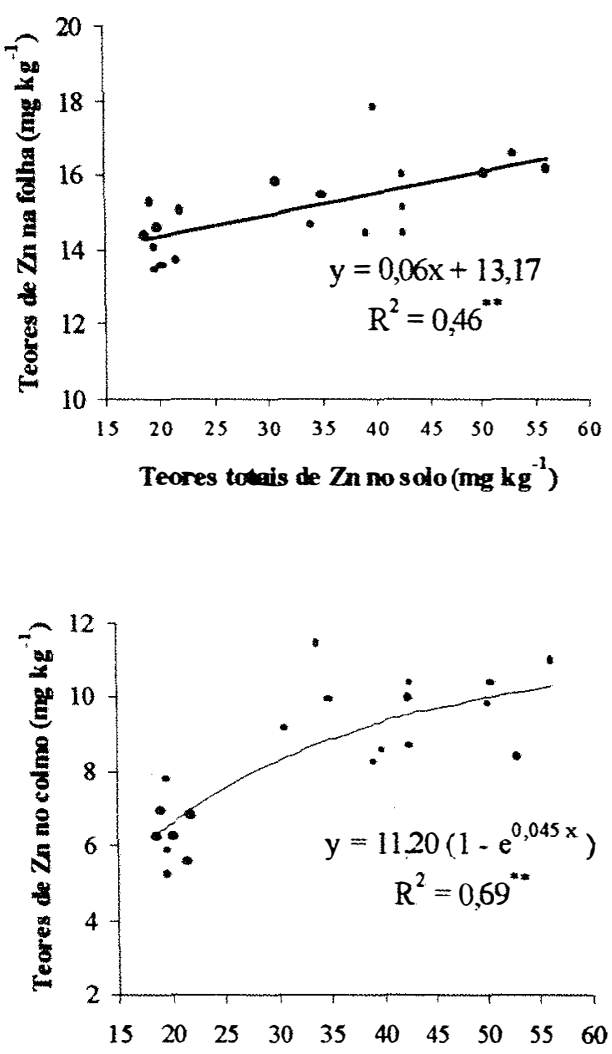

Teores totais de $\mathrm{Zn}$ no solo (mg $\mathrm{kg}^{-1}$ )

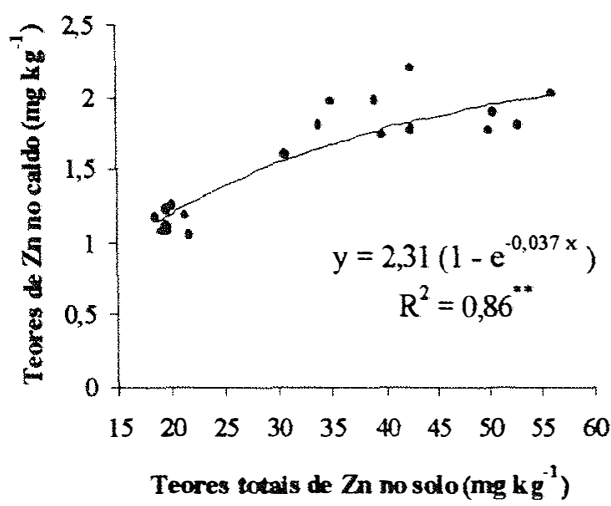

Figura 24. Relações entre teores de zinco nas amostras de folha, colmo e caldo da cana-de-açúcar e teores totais determinados no solo no experimento com composto de lixo. ("* Modelo ajustado significativo a $\mathrm{P} \leq 0,01$ pelo teste $\mathrm{F}$ ) 
Com relação ao Zn, observa-se na Figura 24 para o ano agrícola 1996/97, que a exemplo do $\mathrm{Cu}$, não ocorreram efeitos significativos sobre seu acúmulo nas amostras de plantas em função dos acréscimos dos teores totais presentes no solo. Para este primeiro ano porém, os resultados podem ter sido influenciados pela antecipação da coleta das amostras ( $\approx 11$ meses), pelo pouco desenvolvimento da cultura e também pelas maiores diferenças de produtividade entre os tratamentos (4.2.1).

Em 1997/98, ao contrário do primeiro ano agrícola, foram observados efeitos significativos dos acréscimos de $\mathrm{Zn}$ no solo, sobre seu acúmulo nas amostras de folhas " +1 ", colmo e caldo. Dessa forma, para as amostras de folhas " +1 " foi observado um efeito linear crescente enquanto que, nas amostras de colmo e caldo verificaram-se comportamentos assintóticos. Nas amostras de colmo, o ajuste matemático sugeriu uma concentração platô estimada em $11,20 \mathrm{mg} \mathrm{kg}^{-1}$ o que significa em média, $4,55 \mathrm{mg} \mathrm{kg}^{-1}$ acima dos teores obtidos nos tratamentos sem composto de lixo (tratamentos 1 e 2). No caldo a concentração platô estimada foi de $2,31 \mathrm{mg} \mathrm{kg}^{-1}$, cerca de $1,10 \mathrm{mg} \mathrm{kg}^{-1}$ maior que as testemunhas.

$\mathrm{Na}$ cultura da alface, Cravo (1995) não verificou incrementos no acúmulo de $\mathrm{Zn}$ devido a aplicação de doses crescentes de composto de lixo de até $120 \mathrm{Mg} \mathrm{ha}^{-1}$. Por outro lado, em solos tratados com lodo de esgoto, respostas do tipo platô foram encontradas para o $\mathrm{Zn}$ acumulado em plantas de trigo (Barbarick te al., 1995) e em plantas de milho (Logan et al., 1997).

Os resultados obtidos para metais pesados sugerem de maneira geral que, a curto prazo, o emprego de composto de lixo nas taxas e freqüência de aplicações utilizadas no presente trabalho, não deverão acarretar problemas, no que concerne ao acúmulo de metais pesados, à cultura da cana-de-açúcar. Da mesma forma que para o lodo de esgoto, as maiores dúvidas as quais geram inseguranças, estão ligadas aos efeitos a longo prazo que por ventura venham a ocorrer devidos a esta prática, essencialmente após o cessamento das aplicações.

Conforme comentado anteriormente, as teorias propostas para explicar o comportamento das plantas frente ao acúmulo de metais pesados no solo (Corey et al., 1987; McBride, 1995) necessitam de estudos mais aprofundados para 
serem comprovadas cientificamente. Neste sentido, os grandes desafios estão relacionados com a variabilidade de comportamento entre as diversas espécies vegetais, assim como os chamados fatores de confundimento, como o $\mathrm{pH}$ e teores de C-orgânico do solo (Logan et al., 1997), fatores estes fortemente influenciados pela aplicação do composto de lixo.

\subsubsection{Mobilidade de metais pesados no solo}

Os teores dos metais $\mathrm{Cd}^{2+}, \mathrm{Cr}, \mathrm{Cu}^{2+}, \mathrm{Ni}^{2+}, \mathrm{Pb}^{2+}$ e $\mathrm{Zn}^{2+}$ avaliados em todas as amostras de solução do solo, coletadas nas profundidades de 0,3, 0,6 e 0,9 m, estiveram abaixo dos limites de determinação analítica utilizados para o experimento com lodo de esgoto (4.1.5.2). Neste contexto, devem ser ponderadas as mesmas observações feitas em 4.1.5.2, quanto ao método de obtenção das amostras de solução do solo e aos valores de $\mathrm{pH}$ determinados nas mesmas.

Informações da literatura demonstraram que as concentrações de metais pesados em águas lixiviadas através de substratos a base de composto de lixo, são extremamente baixas, o que dificulta sobremaneira sua detecção. Sawhney et al. (1994) estudaram através de um experimento em vasos de $2 \mathrm{~L}$, o potencial de lixiviação de metais pesados devido a utilização, em substratos para cultivo de plantas ornamentais, de composto de lixo em doses equivalentes a 0, 25, 50 e $100 \%$ em volume, utilizando uma mistura $(\mathrm{pH}=6,5)$ de turfa, sílica e calcário como material de enchimento. As concentrações de $\mathrm{Cd}, \mathrm{Cr}, \mathrm{Cu}, \mathrm{Ni}, \mathrm{Pb}$ e $\mathrm{Zn}$ nos lixiviados aumentaram com a proporção utilizada do resíduo, mas decresceram no decorrer das lixiviações. Os maiores teores foram encontrados nas amostras coletadas nas duas primeiras semanas os quais foram atribuídos às formas solúveis ou trocáveis de metais presente no composto de lixo. Foram verificados respectivamente, entre as doses de 0 a $100 \%$, as seguintes variações: 0,25 a $0,82 \mu \mathrm{g} \mathrm{L}^{-1}$ de Cd, 1,6 a 5,0 $\mu \mathrm{gL}^{-1}$ de $\mathrm{Cr}, 12$ a $125 \mu \mathrm{g} \mathrm{L}^{-1}$ de $\mathrm{Cu}, 13$ a $31 \mu \mathrm{g} \mathrm{L}^{-1}$ de $\mathrm{Ni}, 1,9$ a $17 \mu \mathrm{g} \mathrm{L}^{-1}$ de $\mathrm{Pb}$ e 54 a $219 \mu \mathrm{g} \mathrm{L}^{-1}$ de $\mathrm{Zn}$. Convém salientar que estes valores estiveram abaixo daqueles estabelecidos para água potável pela USEPA (40 CFR Part 503, 1993) ou seja, $\leq 5 \mu \mathrm{g} \mathrm{L}^{-1}$ de $\mathrm{Cd}, \leq 50 \mu \mathrm{g} \mathrm{L}^{-1}$ de $\mathrm{Cr}, \leq 1300 \mu \mathrm{g} \mathrm{L}^{-1}$ de Cu , 
$\leq 100 \mu \mathrm{g} \mathrm{L}^{-1}$ de Ni, $\leq 20 \mu \mathrm{g} \mathrm{L}^{-1}$ de $\mathrm{Pb}$. Para o $\mathrm{Zn}$ não são estabelecidos valores críticos.

De maneira conclusiva, os autores sugeriram que o transporte de metais pesados para águas de subsuperficie, através de solos agrícolas tratados com composto de lixo, pode ser considerado desprezivel porque as ínfimas quantidades de metais lixiviadas do composto deverão ter sua mobilidade atenuada nas camadas do subsolo.

Nas amostras de solo coletadas em profundidade, não foram detectados os metais $\mathrm{Cd}$, $\mathrm{Ni}$ e $\mathrm{Pb}$ por estarem abaixo dos limites de determinação analítica apresentados em 4.1.5.1. Porém é preciso considerar que as concentrações desses metais no solo, proporcionadas pela aplicação do resíduo, teriam sido baixas (Tabela 30) e portanto, de difícil avaliação num experimento em condições de campo.

Os teores totais de $\mathrm{Cu}, \mathrm{Cr}$ e $\mathrm{Zn}$ determinados nas diversas camadas de solo, ao final dos anos agrícolas 1996/97 e 1997/98, são apresentados na Tabela 31. Para os metais $\mathrm{Cu}$ e $\mathrm{Cr}$, verifica-se que a aplicação de doses crescentes de composto de lixo não proporcionou incrementos nos teores das camadas de solo abaixo de $0-0,2 \mathrm{~m}$, em ambos os anos agrícolas. De maneira geral, comparando-se dentro de cada tratamento em profundidade, os teores médios de $\mathrm{Cu}$ e $\mathrm{Cr}$, observa-se que a ocorrência natural desses metais nas camadas de 0,4-0,6 e 0,6-0,8 m se deu na maioria dos casos, em concentrações iguais ou maiores do que nas camadas onde foram incorporadas doses do resíduo. Diante dessas observações é possível afirmar que não houveram evidências da mobilidade do $\mathrm{Cu}$ e do $\mathrm{Cr}$ ao final dos dois anos experimentais.

A imobilidade do $\mathrm{Cu}$ também foi observada por Williams et al. (1987), Dowdy et al. (1991) e Chino et al. (1992) em solos tratados com elevadas doses de lodo de esgoto. Para o $\mathrm{Cr}$, resultados semelhantes foram verificados por Williams et al. (1987) e Bertoncini (1997). Algumas possíveis explicações para imobilidade desses elementos são dadas em 4.1.5.2.

Com relação ao Zn, verifica-se na Tabela 31 para o ano agrícola 1996/97, que os teores totais no solo aumentaram linearmente, em função das doses de composto de lixo, até a camada de 0,2-0,4 m. Em 1997/98, esses aumentos foram observados até a camada de $0,4-0,6 \mathrm{~m}$, evidenciando uma progressão dos teores em profundidade, com as aplicações sucessivas do resíduo. 
Tabela 31. Teores totais de $\mathrm{Cu}, \mathrm{Cr}$ e $\mathrm{Zn}$ determinados no solo, nas várias profundidades, em função da disposição de doses crescentes de composto de lixo nos anos agrícolas 1996/97 e 1997/98.

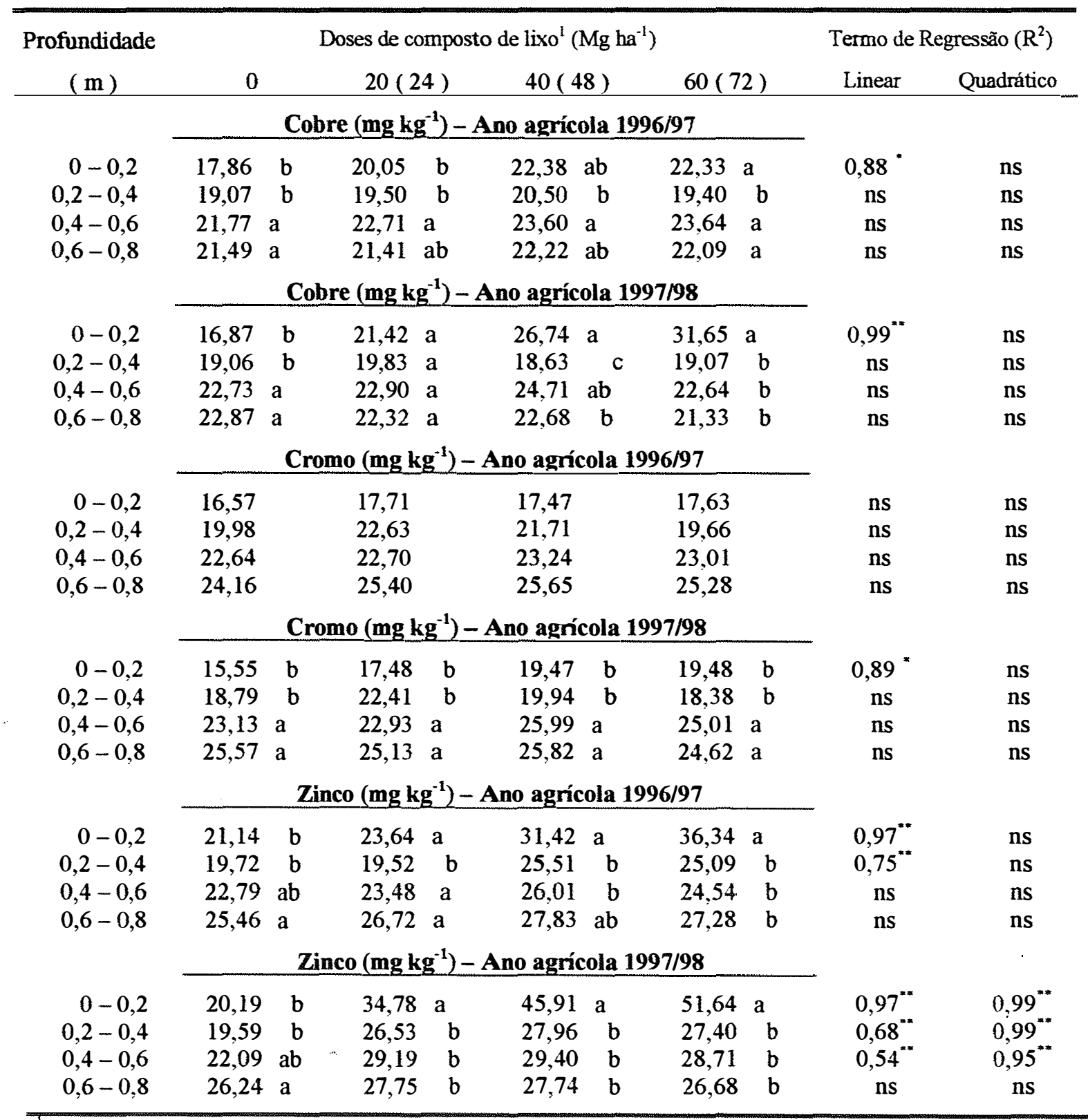

'Doses entre parènteses referem-se ao ano agrícola 1997/98;

${ }^{*},^{* *}$, ns Indicam respectivamente, que os termos de regressão linear ou quadrática foram significativos a $\mathrm{P} \leq 0,05$, $\mathrm{P} \leq 0,01$ ou não significativo pelo teste $\mathrm{F}$;

Para cada metal, dentro de cada ano agrícola, médias seguidas por letras distintas, em colunas, diferem entre si a $\mathrm{P} \leq 0,05$ pelo teste de Tukey - D.M.S. $5 \% \mathrm{Cu} 1=2,11 ; \mathrm{Cu} 2=3,33$; $\mathrm{Cr} 2=3,47 ; \mathrm{Zn} 1=3,69 ; \mathrm{Zn} 2=4,66$. 
Comparando-se os teores de $\mathrm{Zn}$ entre camadas do solo, dentro das doses $\mathrm{A}$, B e C do resíduo, observa-se que os maiores valores foram determinados na camada de incorporação e que abaixo de $0,2 \mathrm{~m}$, os teores foram praticamente iguais. Dessa forma, embora tenham sido observados aumentos nos teores naturais de $\mathrm{Zn}$ do solo em função da profundidade de coleta das amostras, pode-se verificar para o ano agrícola 1997/98, que os acréscimos nos teores de $\mathrm{Zn}$ das camadas de 0,2 - 0,4 e 0,4-0,6 m, devidos a aplicação de composto de lixo, giraram respectivamente, em torno de 39 e $32 \%$ quando comparados com a testemunha. Isto posto, verifica-se que a movimentação do $\mathrm{Zn}$ pelo perfil do solo foi um fato evidente.

Neste contexto, todas as considerações feitas, com base na literatura, para os resultados verificados no experimento com lodo de esgoto são válidas no presente caso porém, é necessário fazer uma ressalva. Além do $\mathrm{Zn}$ ser o metal adicionado ao solo em maior quantidade, é importante salientar que sua lixiviação pode ter sido favorecida pela maior presença de formas trocáveis ou solúveis devidas essencialmente, a ocorrência de acidez no solo, principalmente no primeiro ano agrícola (Tabela 27).

\subsubsection{Avaliação da fitodisponibilidade de metais pesados}

De maneira semelhante ao experimento com lodo de esgoto, as quantidades de $\mathrm{Cd}, \mathrm{Cr}$ e $\mathrm{Pb}$ extraídas pelas soluções de DTPA-TEA, $\mathrm{HCl} 0,1 \mathrm{~mol} \mathrm{~L}^{-1}$ e Mehlich-3 estiveram, nos dois anos agrícolas, abaixo dos limites de determinação do método analítico utilizado (4.1.5.3).

Cravo (1995) verificou que a solução de Mehlich-3, usada como extrator para metais pesados num solo arenoso tratado com doses crescentes de composto de lixo de até $120 \mathrm{Mg} \mathrm{ha}^{-1}$ (base seca), extraiu quantidades de $\mathrm{Cd} \leq 0,13 \mathrm{mg} \mathrm{kg}^{-1}$, de $\mathrm{Cr} \leq 0,97 \mathrm{mg} \mathrm{kg}^{-1}$ e de $\mathrm{Pb} \leq 6,05 \mathrm{mg} \mathrm{kg}^{-1}$. Em amostras de solo argiloso o autor observou teores de $\mathrm{Cd}$ e $\mathrm{Pb}$ semelhantes ao solo arenoso no entanto, não foi detectada a presença de Cr. Abreu Junior (1999) observou, num Latossolo Vermelho-Amarelo tratado com composto de lixo (60 $\mathrm{Mg} \mathrm{ha}^{-1}$ - base seca), teores de $\mathrm{Cd}, \mathrm{Cr}$ e $\mathrm{Pb}$, avaliados por DTPA-TEA, respectivamente $\leq 0,06 \mathrm{mg} \mathrm{kg}^{-1}, \leq 0,23 \mathrm{mg} \mathrm{kg}^{-1} \mathrm{e} \leq 1,30 \mathrm{mg} \mathrm{kg}^{-1}$. 
$\mathrm{Na}$ Tabela 32 são apresentados os teores de $\mathrm{Cu}, \mathrm{Ni}$ e $\mathrm{Zn}$ avaliados pelas soluções extratoras nos anos agrícolas 1996/97 e 1997/98. Considerando-se as quantidades aplicadas acumuladas desses metais no solo ao final do segundo ano (Tabela 30), é possível estimar que a extração média de $\mathrm{Cu}$, nos tratamentos com doses A, B e C de composto de lixo foi de 27,31 e $38 \%$ respectivamente para os extratores DTPA-TEA, $\mathrm{HCl} \mathrm{0,1} \mathrm{mol} \mathrm{L}{ }^{-1}$ e Mehlich-3; para o $\mathrm{Zn}$ tais valores foram de 32,45 e $63 \%$ enquanto que para o $\mathrm{Ni}$ foram verificados valores de 37 e $82 \%$ respectivamente para os extratores DTPA-TEA e $\mathrm{HCl} 0,1 \mathrm{~mol} \mathrm{~L}^{-1}$. Diante do exposto, com relação a capacidade de extração dos métodos, verifica-se que, a exemplo do experimento com lodo de esgoto, os métodos que empregaram soluções ácidas extraíram quantidades maiores que DTPA-TEA.

Tabela 32. Teores de $\mathrm{Cu}, \mathrm{Ni}$ e $\mathrm{Zn}$ avaliados no solo pelos extratores DTPA-TEA, $\mathrm{HCl}$ 0,1 mol L ${ }^{-1}$ e Mehlich-3, nos anos agrícolas 1996/97 e 1997/98, para o experimento com composto de lixo.

\begin{tabular}{|c|c|c|c|c|c|c|c|}
\hline \multirow[t]{2}{*}{ Ano Agrícola } & \multirow[t]{2}{*}{ Extrator } & \multicolumn{4}{|c|}{ Doses de composto de lixo $\left(\mathrm{Mg} \mathrm{ha}^{-1}\right)$} & \multicolumn{2}{|c|}{ Termo de Regressão $\left(R^{2}\right)$} \\
\hline & & 0 & $20(24)$ & $40(48)$ & $60(72)$ & Linear & Quadrático \\
\hline & & \multicolumn{4}{|c|}{ Cobre (mg kg ${ }^{-1}$ ) } & & \\
\hline $1996 / 97$ & DTPA-TEA & 0,70 & 1,41 & 1,17 & 1,72 & $0,71^{* *}$ & ns \\
\hline $1997 / 98$ & DTPA-TEA & 0,85 & 2,68 & 3,69 & 4,58 & $0,96^{* *}$ & ns \\
\hline $1996 / 97$ & $\mathrm{HCl} 0,1 \mathrm{~mol} \mathrm{~L}^{-1}$ & 0,90 & 1,84 & 2,00 & 2,35 & $0,88^{* *}$ & ns \\
\hline $1997 / 98$ & $\mathrm{HCl} 0,1 \mathrm{~mol} \mathrm{~L}^{-1}$ & 0,98 & 3,01 & 4,21 & 4,79 & $0,94^{* *}$ & ns \\
\hline $1996 / 97$ & Mehlich 3 & 1,22 & 1,85 & 1,90 & 3,13 & $0,87^{2 \pi}$ & ns \\
\hline \multirow[t]{2}{*}{$1997 / 98$} & Mehlich 3 & 1,18 & 3,65 & 5,03 & 6,43 & $0,98^{* *}$ & ns \\
\hline & & \multicolumn{4}{|c|}{ Níquel $\left(\mathrm{mg} \mathrm{kg}^{-1}\right)$} & & \\
\hline $1996 / 97$ & DTPA-TEA & n.d. ${ }^{2}$ & n.d. & n.d. & n.d. & - & - \\
\hline $1997 / 98$ & DTPA-TEA & n.d. & 0,33 & 0,26 & 0,37 & ns & - \\
\hline $1996 / 97$ & $\mathrm{HCl} 0,1 \mathrm{~mol} \mathrm{~L}^{-1}$ & n.d. & n.d. & n.d. & n.d. & - & - \\
\hline \multirow[t]{2}{*}{$1997 / 98$} & $\mathrm{HCl} 0,1 \mathrm{~mol} \mathrm{~L}^{-1}$ & n.d. & 0,59 & 0,70 & 0,96 & ns & - \\
\hline & & \multicolumn{4}{|c|}{ Zinco ( $\left.\mathrm{mg} \mathrm{kg}^{-1}\right)$} & & \\
\hline $1996 / 97$ & DTPA-TEA & 0,62 & 1,70 & 1,28 & 2,62 & $0,74^{* *}$ & ns \\
\hline $1997 / 98$ & DTPA-TEA & 0,77 & 3,79 & 5,25 & 6,70 & $0,96 *$ & ns \\
\hline $1996 / 97$ & $\mathrm{HCl} 0,1 \mathrm{~mol} \mathrm{~L}^{-1}$ & 0,94 & 2,09 & 2,45 & 4,66 & $0,91^{* *}$ & ns \\
\hline $1997 / 98$ & $\mathrm{HCl} 0,1 \mathrm{~mol} \mathrm{~L}^{-1}$ & 0,90 & 4,48 & 7,20 & 11,21 & $0,99^{* *}$ & ns \\
\hline $1996 / 97$ & Mehlich 3 & 1,25 & 2,55 & 2,98 & 5.15 & $0,93^{* *}$ & ns \\
\hline $1997 / 98$ & Mehlich 3 & 1,23 & 7,90 & 8,68 & 12,60 & $0,91^{* *}$ & ns \\
\hline
\end{tabular}

'Doses entre parênteses referem-se ao ano agrícola 1997/98;

${ }^{2}$ n.d. - não detectado, valor abaixo do limite de determinação do método analítico. $0,20,0,50$ e $1,00 \mathrm{mg} \mathrm{kg}^{-1}$ na amostra, respectivamente para os extratores DTPA-TEA, $\mathrm{HCl} 0,1 \mathrm{~mol} \mathrm{~L}^{-1}$ e Mehlich 3;

*, * ${ }^{\text {ns }}$ Indicam respectivamente, que os termos de regressão linear ou quadrática foram significativos a $P \leq 0,05, P \leq 0,01$ ou não significativos pelo teste $F$; 
As quantidades removidas de $\mathrm{Cu}$ e $\mathrm{Zn}$ pelas várias soluções extratoras, nos dois anos agrícolas, foram crescentes e lineares em função das doses aplicadas de composto de lixo, sugerindo que a fitodisponibilidade desses elementos também seria supostamente crescente. Para o Ni este comportamento não foi evidenciado. De forma geral, as quantidades extraídas ocorreram em concordância com os teores presentes no resíduo e com as taxas de aplicação do mesmo ou seja, $\mathrm{Zn}>\mathrm{Cu}>\mathrm{Ni}$.

Tabela 33. Coeficientes de correlação linear simples para os teores avaliados de $\mathrm{Cu}, \mathrm{Ni}$ e $\mathrm{Zn}$ entre os extratores água régia, DTPA-TEA, $\mathrm{HCl} 0,1 \mathrm{~mol} \mathrm{~L}^{-1}$ e Mehlich-3 (M-3), nos anos agrícolas de 1996/97 e 1997/98, para o experimento com composto de lixo.

\begin{tabular}{|c|c|c|c|c|c|c|c|c|c|}
\hline \multirow[t]{2}{*}{ Extrator } & \multicolumn{3}{|c|}{ Cobre } & \multicolumn{3}{|c|}{ Níquel } & \multicolumn{3}{|c|}{ Zinco } \\
\hline & DTPA & $\mathrm{HCl}$ & M-3 & DTPA & $\mathrm{HCl}$ & M-3 & DTPA & $\mathrm{HCl}$ & M-3 \\
\hline
\end{tabular}

Ano agrícola 1996/97 (considerando os tratamentos 1, 6, 7, 8 e 9)

$\begin{array}{lccccccccc}\text { água régia } & 0,68^{* *} & 0,82^{* *} & 0,77^{* *} & - & - & - & 0,79^{* *} & 0,92^{* *} & 0,92^{* *} \\ \text { DTPA } & - & 0,95^{* *} & 0,83^{* *} & - & - & - & - & 0,86^{* *} & 0,87^{* *} \\ \text { HCl } & - & - & 0,91 * & - & - & - & - & - & 0,99^{* *}\end{array}$

Ano agrícola 1996/97 (considerando os tratamentos 7, 8 e 9)

$\begin{array}{lccccccccc}\text { água régia } & 0,16^{\text {ns }} & 0,53^{\text {ns }} & 0,63^{*} & - & - & - & 0,60 & 0,85^{* *} & 0,85^{* *} \\ \text { DTPA } & - & 0,88^{* *} & 0,74^{* *} & - & - & - & - & 0,72^{* *} & 0,74^{* *} \\ \text { HCl } & - & - & 0,88^{* *} & - & - & - & - & - & 0,98^{* *}\end{array}$

Ano agrícola 1997/98 (considerando os tratamentos 1, 6, 7, 8 e 9)

$\begin{array}{lccccccccc}\text { água régia } & 0,96^{* *} & 0,94^{* *} & 0,96^{* *} & - & - & - & 0,98^{* *} & 0,96^{* *} & 0,96^{* *} \\ \text { DTPA } & - & 0,97^{* *} & 0,99^{* *} & - & - & - & - & 0,96^{* *} & 0,97^{* *} \\ \mathrm{HCl} & - & - & 0,98^{* *} & - & - & - & - & - & 0,95^{* *}\end{array}$

Ano agrícola 1997/98 (considerando os tratamentos 7, 8 e 9)

\begin{tabular}{|c|c|c|c|c|c|c|c|c|c|}
\hline água régia & $0,98^{* *}$ & $0,88^{* *}$ & $0,95^{* *}$ & $=$ & - & - & $0,93^{* *}$ & $0,89^{* *}$ & $0,80^{\prime \prime=}$ \\
\hline DTPA & - & $0,88^{* *}$ & $0,96^{* *}$ & - & $0,36^{\mathrm{ns}}$ & - & - & $0,88^{* *}$ & $0,86^{* *}$ \\
\hline $\mathrm{HCl}$ & - & - & $093^{* *}$ & - & - & . & - & - & $0,89^{* *}$ \\
\hline
\end{tabular}

pelo Indicam respectivamente, que as correlações foram significativas a $\mathrm{P} \leq 0,05, \mathrm{P} \leq 0,01$ ou não significativas
pelo teste

Apesar das diferenças na capacidade de extração das soluções empregadas, verifica-se, de maneira geral, correlações significativas entre os métodos, incluindo a "água régia", para os elementos $\mathrm{Cu}$ e $\mathrm{Zn}$ (Tabela 33). Exceção feita apenas para o ano agrícola 1996/97, quando foram considerados teores de $\mathrm{Cu}$ avaliados pela "água régia" nos tratamentos 7,8 e 9 (doses $\mathrm{A}, \mathrm{B}$ e $\mathrm{C}$ do resíduo). Todavia, pode-se considerar que as 
soluções empregadas forneceram indicações semelhantes para $\mathrm{Cu}$ e $\mathrm{Zn}$ enquanto que para $\mathrm{Ni}$, os resultados não permitiram nenhuma conclusão haja visto que, na maioria dos casos, não foram realizadas correlações pois os teores possivelmente removidos, estiveram abaixo do limite de determinação do método analítico utilizado.

$\mathrm{Na}$ Tabela 34 são apresentados os coeficientes de correlação linear obtidos entre as concentrações de $\mathrm{Cu}$ e $\mathrm{Zn}$ no solo e nas amostras de folha " +1 ", colmo e caldo das plantas de cana-de-açúcar, considerando todos os tratamentos empregados.

Tabela 34. Correlações lineares entre a concentração de cobre e zinco nas plantas de cana-de-açúcar e os teores avaliados no solo pelos vários extratores químicos, considerando todos os tratamentos do experimento com composto de lixo.

\begin{tabular}{|c|c|c|c|c|}
\hline Metais pesados & água-régia & DTPA-TEA & $\mathrm{HCl} 0,1 \mathrm{~mol} \mathrm{~L}^{-1}$ & Mehlich-3 \\
\hline & \multicolumn{4}{|c|}{ Ano agrícola 1996/97 } \\
\hline & \multicolumn{4}{|c|}{ Folha “+1" } \\
\hline Cobre & $0,50^{\circ}$ & $0,54^{*}$ & $0,59^{* *}$ & $0,41^{\mathrm{ns}}$ \\
\hline \multirow[t]{2}{*}{ Zinco } & $0,24^{\mathrm{ns}}$ & $0,34^{\mathrm{ns}}$ & $0,35^{\mathrm{ns}}$ & $0,36^{\mathrm{ns}}$ \\
\hline & \multicolumn{4}{|c|}{ Colmo } \\
\hline Cobre & $0,20^{\mathrm{ns}}$ & $0,53^{*}$ & $0,51^{*}$ & $0,48^{*}$ \\
\hline \multirow[t]{2}{*}{ Zinco } & $-0,04^{\text {ns }}$ & $-0,03^{\text {ns }}$ & $-0,06^{\mathrm{ns}}$ & $-0,08^{n s}$ \\
\hline & \multicolumn{4}{|c|}{ Caldo } \\
\hline \multirow{4}{*}{$\begin{array}{l}\text { Cobre } \\
\text { Zinco }\end{array}$} & $-0,52^{*}$ & $-0,46^{*}$ & $0,47^{*}$ & $-0,42^{\text {ns }}$ \\
\hline & $-0,42^{\mathrm{ns}}$ & $-0,29^{\mathrm{ns}}$ & $-0,39^{n s}$ & $-0,38^{\text {ns }}$ \\
\hline & \multicolumn{4}{|c|}{ Ano agrícola 1997/98 } \\
\hline & \multicolumn{4}{|c|}{ Folha "+1" } \\
\hline Cobre & $-0,35^{\mathrm{ns}}$ & $-0,49^{*}$ & $-0,54^{*}$ & $-0,52^{*}$ \\
\hline \multirow[t]{2}{*}{ Zinco } & $0,68^{* *}$ & $0,66^{* *}$ & $0,68^{* *}$ & $0,67^{* *}$ \\
\hline & \multicolumn{4}{|c|}{ Colmo } \\
\hline Cobre & $0,31^{\mathrm{ns}}$ & $0,30^{\mathrm{ns}}$ & $0,30^{\mathrm{ns}}$ & $0,30^{\mathrm{ns}}$ \\
\hline \multirow[t]{2}{*}{ Zinco } & $0,75^{* *}$ & $0,71^{\prime * *}$ & $0,70^{* *}$ & $0,75^{* *}$ \\
\hline & \multicolumn{4}{|c|}{ Caldo } \\
\hline Cobre & $0,09^{n s}$ & $0,17^{\mathrm{ns}}$ & $0,19^{\mathrm{ns}}$ & $0,21^{\mathrm{ns}}$ \\
\hline Zinco & $0,87^{\text {***}}$ & $0,86^{3 *}$ & $0,82^{* *}$ & $0,88^{* *}$ \\
\hline
\end{tabular}

${ }^{n s}$ Indicam respectivamente, que as correlações foram significativas a $\mathrm{P} \leq 0,01 \mathrm{e}$ não significativas pelo teste $\mathrm{t}$. 
No ano agrícola 1996/97 foram verificadas correlações significativas entre os teores de $\mathrm{Cu}$ presentes na folha " +1 " e teores do solo avaliados pela "água régia" e pelas soluções de DTPA-TEA e $\mathrm{HCl} 0,1 \mathrm{~mol} \mathrm{~L}^{-1}$. Quando foram consideradas as amostras de colmo, ocorreram correlações significativas com os extratores DTPA-TEA,

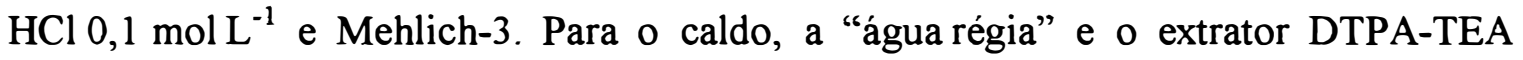
correlacionaram-se de forma significativa e negativa ao passo que a solução de $\mathrm{HCl}$ 0,1 $\mathrm{mol} \mathrm{L}^{-1}$ apresentou correlação positiva. Por outro lado, no ano agrícola 1997/98 o elemento $\mathrm{Cu}$ só apresentou correlações significativas quando foram considerados como índice, os teores presentes nas amostras de folha " +1 ". Neste caso as correlações foram negativas e ocorreram com as soluções de DTPA-TEA, $\mathrm{HCl} 0,1 \mathrm{~mol} \mathrm{~L}^{-1}$ e Mehlich-3. De qualquer forma, convém ressaltar que todos os coeficientes obtidos para $\mathrm{Cu}$ foram baixos $(\mathrm{r}<0,60)$ o que provavelmente foi influenciado pela falta de resposta das plantas aos aumentos nos teores de $\mathrm{Cu}$ do solo, proporcionados pela aplicação de doses crescentes de composto de lixo (Figura 23).

Para o elemento Zn, no ano agrícola 1996/97, nenhuma solução extratora foi eficiente na avaliação de sua disponibilidade às plantas. Este fato provavelmente ocorreu devido a falta de resposta das plantas aos acréscimos de $\mathrm{Zn}$ no solo o que pode ter sido influenciada pelas diferenças de crescimento da cultura entre os vários tratamentos e pela colheita antecipada. Já no ano agrícola 1997/98, todos os extratores foram eficientes na avaliação da fitodisponibilidade de $\mathrm{Zn}$ uma vez que, foram observados efeitos significativos dos tratamentos sobre os teores presentes nas diversas amostras das plantas da cana-de-açúcar.

Pelas mesmas razões comentadas no experimento com lodo de esgoto (4.1.5.3), procederam-se correlações entre os teores recuperados do solo, somente nos tratamentos 7, 8 e 9, e os teores presentes nas amostras de plantas cultivadas nestes tratamentos (Tabela 35).

Neste caso, nos dois anos agrícolas, todos os extratores foram ineficientes para avaliar a disponibilidade de $\mathrm{Cu}$ através das diversas amostras da cultura. A não ocorrência de correlações significativas foi devida a falta de resposta das plantas aos acréscimos de $\mathrm{Cu}$ no solo proporcionados pelas aplicações do composto de lixo, enquanto que as soluções extratoras removeram quantidades lineares e crescentes em função das taxas de aplicação. 
Tabela 35. Correlações lineares entre a concentração de cobre e zinco nas plantas de cana-de-açúcar e os teores avaliados no solo pelos vários extratores químicos, considerando apenas os tratamentos com doses $\mathrm{A}, \mathrm{B}$ e $\mathrm{C}$ de composto de lixo.

\begin{tabular}{|c|c|c|c|c|}
\hline Metais pesados & água-régia & DTPA-TEA & $\mathrm{HCl} 0,1 \mathrm{~mol} \mathrm{~L}^{-1}$ & Mehlich-3 \\
\hline & \multicolumn{4}{|c|}{ Ano agrícola 1996/97 } \\
\hline & \multicolumn{4}{|c|}{ Folha " $+1 "$} \\
\hline Cobre & $-0,35^{\text {ns }}$ & $-0,18^{\mathrm{ns}}$ & $-0,14^{\mathrm{ns}}$ & $-0,16^{\mathrm{ns}}$ \\
\hline \multirow[t]{2}{*}{ Zinco } & $-0,45^{\mathrm{ns}}$ & $-0,26^{\text {ns }}$ & $-0,30^{\mathrm{ns}}$ & $-0,33^{\text {ns }}$ \\
\hline & \multicolumn{4}{|c|}{ Colmo } \\
\hline Cobre & $-0,14^{\mathrm{ns}}$ & $0,54^{n s}$ & $0,51^{\mathrm{ns}}$ & $0,49^{\text {ns }}$ \\
\hline \multirow[t]{2}{*}{ Zinco } & $-0,42^{n s}$ & $-0,41^{\mathrm{ns}}$ & $-0,50^{\mathrm{ns}}$ & $-0,59^{*}$ \\
\hline & \multicolumn{4}{|c|}{ Caldo } \\
\hline Cobre & $-0,30^{n s}$ & $-0,30^{\mathrm{ns}}$ & $-0,29^{\mathrm{ns}}$ & $-0,26^{\mathrm{ns}}$ \\
\hline \multirow[t]{3}{*}{ Zinco } & $-0,55^{\mathrm{ns}}$ & $-0,31^{n s}$ & $-0,62^{*}$ & $-0,62^{*}$ \\
\hline & \multicolumn{4}{|c|}{ Ano agrícola 1997/98 } \\
\hline & \multicolumn{4}{|c|}{ Folha " +1 " } \\
\hline Cobre & $0,20^{\mathrm{ns}}$ & $0,11^{\mathrm{ns}}$ & $-0,07^{\mathrm{ns}}$ & $-0,02^{\text {ns }}$ \\
\hline \multirow[t]{2}{*}{ Zinco } & $0,34^{\mathrm{ns}}$ & $0,29^{n s}$ & $0,39^{\text {ns }}$ & $0,27^{\mathrm{ns}}$ \\
\hline & \multicolumn{4}{|c|}{ Colmo } \\
\hline Cobre & $0,15^{\mathrm{ns}}$ & $0,09^{\text {ns }}$ & $0,11^{\mathrm{ns}}$ & $0,11^{\mathrm{ns}}$ \\
\hline \multirow[t]{2}{*}{ Zinco } & $-0,05^{\mathrm{ns}}$ & $-0,19^{\text {ns }}$ & $0,03^{\text {ns }}$ & $-0,22^{\mathrm{ns}}$ \\
\hline & \multicolumn{4}{|c|}{ Caldo } \\
\hline Cobre & $-0,01^{\text {ns }}$ & $0,12^{\mathrm{ns}}$ & $0,15^{\mathrm{ns}}$ & $0,20^{\mathrm{ns}}$ \\
\hline Zinco & $0,24^{\mathrm{ns}}$ & $0,29^{n s}$ & $0,31^{\text {ns }}$ & $0,20^{\text {ns }}$ \\
\hline
\end{tabular}

\footnotetext{
, ${ }^{\text {ns }}$ Indicam respectivamente, que as correlações foram significativas a $\mathrm{P} \leq 0,05$ e não significativas pelo teste $t$.
}

Para o $\mathrm{Zn}$, no ano agrícola 1996/97 foram verificadas correlações significativas e negativas apenas para as amostras de colmo, quando o extrator utilizado foi Mehlich-3 e nas amostras de caldo, para os extratores $\mathrm{HCl} 0,1 \mathrm{~mol} \mathrm{~L}^{-1}$ e Mehlich-3. No entanto, estes resultados devem ser desconsiderados tendo em vista que, quando considerado todos os tratamentos, tais correlações não foram significativas. Em 1997/98 nenhuma das soluções extratoras foi eficiente para avaliar a disponibilidade de $\mathrm{Zn}$ através das amostras de plantas utilizadas. Certamente este fato esteve relacionado ao 
comportamento assintótico observado para as concentrações do elemento, essencialmente nas amostras de colmo e caldo.

Resultados controvertidos também foram observados por Cravo (1995) utilizando-se do extrator Mehlich-3. O autor verificou que a significância ou não das correlações entre os teores de $\mathrm{Cu}$ e $\mathrm{Zn}$ no solo e o absorvido por plantas de alface variou em função da origem do composto de lixo, do tipo de solo e do número de cultivos seqüenciais, sugerindo a impossibilidade de padronização do método para situações generalizadas. Abreu Junior (1999), em solos tratados com composto de lixo, encontraram correlações significativas, porém com baixos coeficientes de correlação ( $r \leq 0,63$ ), entre os teores de $\mathrm{Cu}$ e $\mathrm{Zn}$ presentes na parte aérea de plantas de arroz e àqueles avaliados pelas soluções de DTPA-TEA e Mehlich-3.

Conforme foi comentado para o experimento com lodo de esgoto, os resultados aqui observados devem ser vistos com reservas, principalmente devido aos valores de $\mathrm{pH}$ e carbono orgânico do solo verificados nos tratamentos com composto de lixo. Dessa forma, é necessário conhecer a disponibilidade destes elementos na hipótese da interrupção da aplicação do resíduo, onde ocorrerá a degradação deste carbono orgânico e o aumento natural da acidez. Deve-se considerar também o comportamento característico de cada espécie vegetal, quanto ao acúmulo de metais pesados, quando cultivadas em solos tratados com tais resíduos.

\subsubsection{Nitrogênio}

\subsubsection{Lixiviação de nitrato e amônio}

Os componentes do balanço hídrico e a estimativa do fluxo de água $(q)$ nos tratamentos com composto de lixo são apresentados na Tabela 36. A exemplo do que ocorreu nos tratamentos com lodo de esgoto, pode-se observar de maneira geral, dentro de cada período e profundidade, que os valores estimados para fluxo de água foram próximos entre os tratamentos adubação mineral, testemunha e doses de composto de lixo. Fluxos descendentes ocorreram nos períodos compreendidos entre $13 / 11 / 1997$ e $24 / 03 / 98$ e entre $03 / 10$ e $25 / 12 / 98$ enquanto que de $25 / 03$ a 02/10/98 foram verificados fluxos ascendentes. 


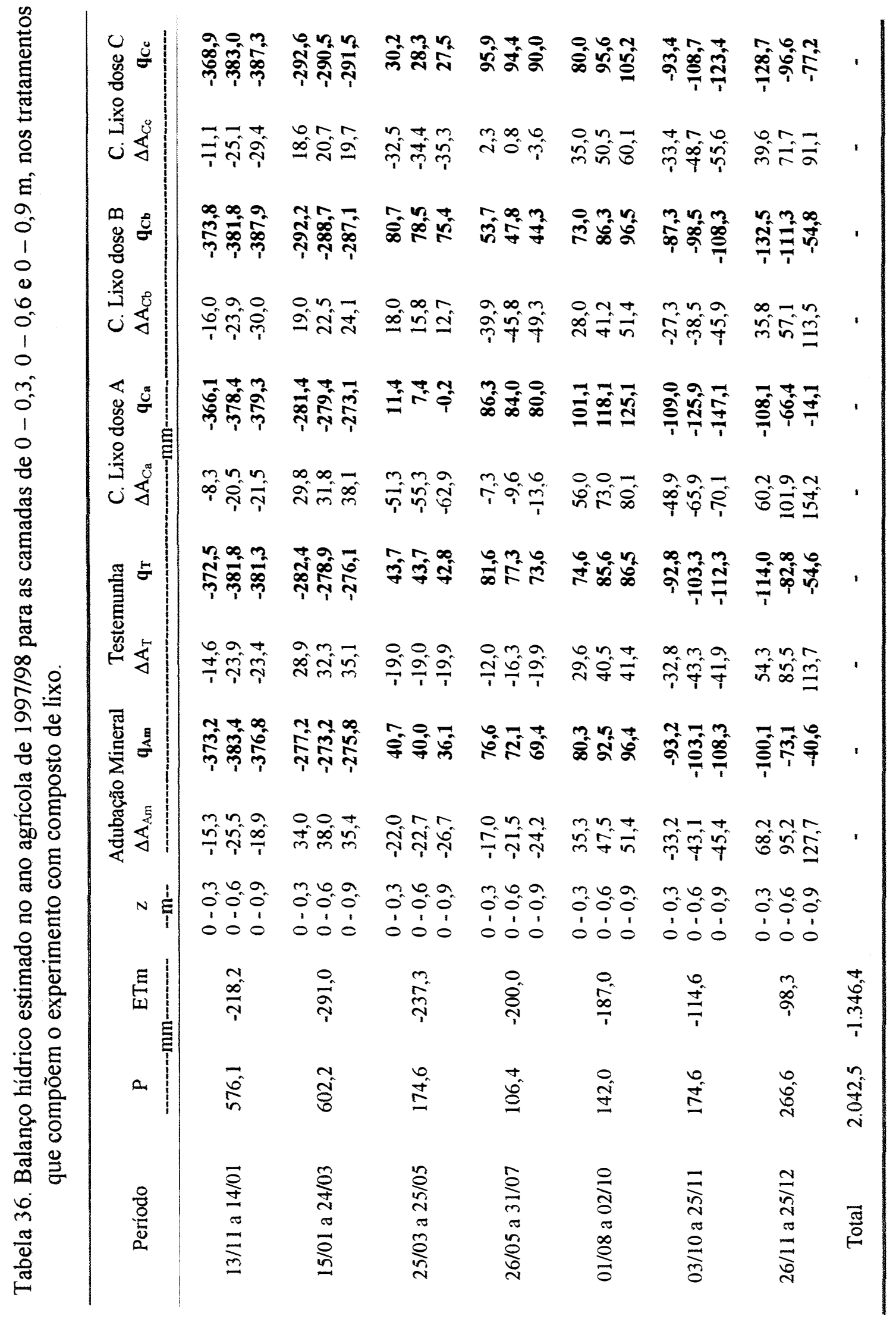


As concentrações de $\mathrm{N}_{-} \mathrm{NO}_{3}{ }^{-}$nas amostras de solução do solo, coletadas nas profundidades de $0,3,0,6$ e $0,9 \mathrm{~m}$, durante todo o período experimental, são apresentadas na Figura 25. Verifica-se em todas as profundidades aumentos nas concentrações de $\mathrm{N}^{-\mathrm{NO}_{3}}{ }^{-}$em função das doses crescentes de composto de lixo o que é explicado evidentemente, pelas quantidades proporcionais de $\mathrm{N}$-total aplicadas via resíduo. Variações em função das épocas de amostragem provavelmente estão relacionadas com a mineralização do $\mathrm{N}$-orgânico do resíduo, com a percolação das águas das chuvas e a ação do sistema radicular das plantas de cana-de-açúcar na absorção do nitrogênio.

$\mathrm{Na}$ profundidade de $0,3 \mathrm{~m}$, as concentrações de $\mathrm{N}^{-\mathrm{NO}_{3}}{ }^{-}$para os tratamentos com doses $\mathrm{A}, \mathrm{B}$ e $\mathrm{C}$ de composto de lixo variaram respectivamente, durante todo o período de monitoramento, entre os seguintes valores médios (desvio padrão): $0,70(0,18)$ a $31,13(16,03) \mathrm{mg} \mathrm{L}^{-1}, 1,8(0,85)$ a $24,28(9,53) \mathrm{mg} \mathrm{L}^{-1}$ e $11,88(2,23)$ a $52,55(13,61) \mathrm{mg} \mathrm{L}^{-1}$. Para as doses A e B, as maiores concentrações médias foram observadas na $7^{\underline{a}}$ amostragem de solução do solo enquanto que para a dose $C$, estas foram observadas na $3^{\underline{a}}$ e $4^{\underline{a}}$ amostragens. Sabe-se que a mineralização do nitrogênio contido nestes compostos orgânicos é altamente dependente de sua relação $\mathrm{C} / \mathrm{N}$ (Stratton et al., 1995) e que estas reações predominam em situações onde o material está devidamente maturado com uma conseqüente relação $\mathrm{C} / \mathrm{N}$ baixa $(<15)$ (Hue, 1995).

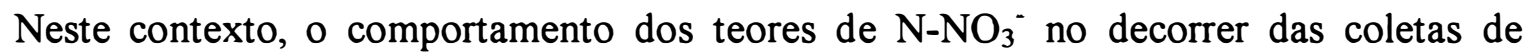
amostras sugere que a mineralização do $\mathrm{N}$-orgânico presente no composto de lixo, tenha ocorrido lentamente, já que as maiores concentrações não foram observadas nas primeiras amostragens e a relação $\mathrm{C} / \mathrm{N}$ do resíduo no momento da aplicação era $>22$.

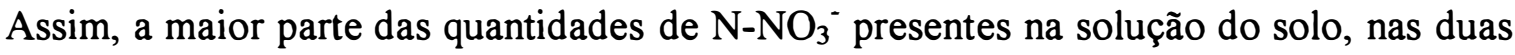
primeiras amostragens, poderia ser atribuída ao $\mathrm{N}$-inorgânico adicionado via resíduo (Tabela 4). Por outro lado, é preciso considerar que nos períodos em que foram realizadas as duas primeiras amostragens, houveram registros de grandes quantidades de chuvas (Tabela 36) e coincidiu com estágio de crescimento exponencial das plantas de cana-de-açúcar, os quais poderiam ter influenciado fortemente as concentrações de $\mathrm{N}-\mathrm{NO}_{3}{ }^{-}$no sentido de diminuí-las na camada superficial, devido a prováveis lixiviações e absorção pelas plantas. 

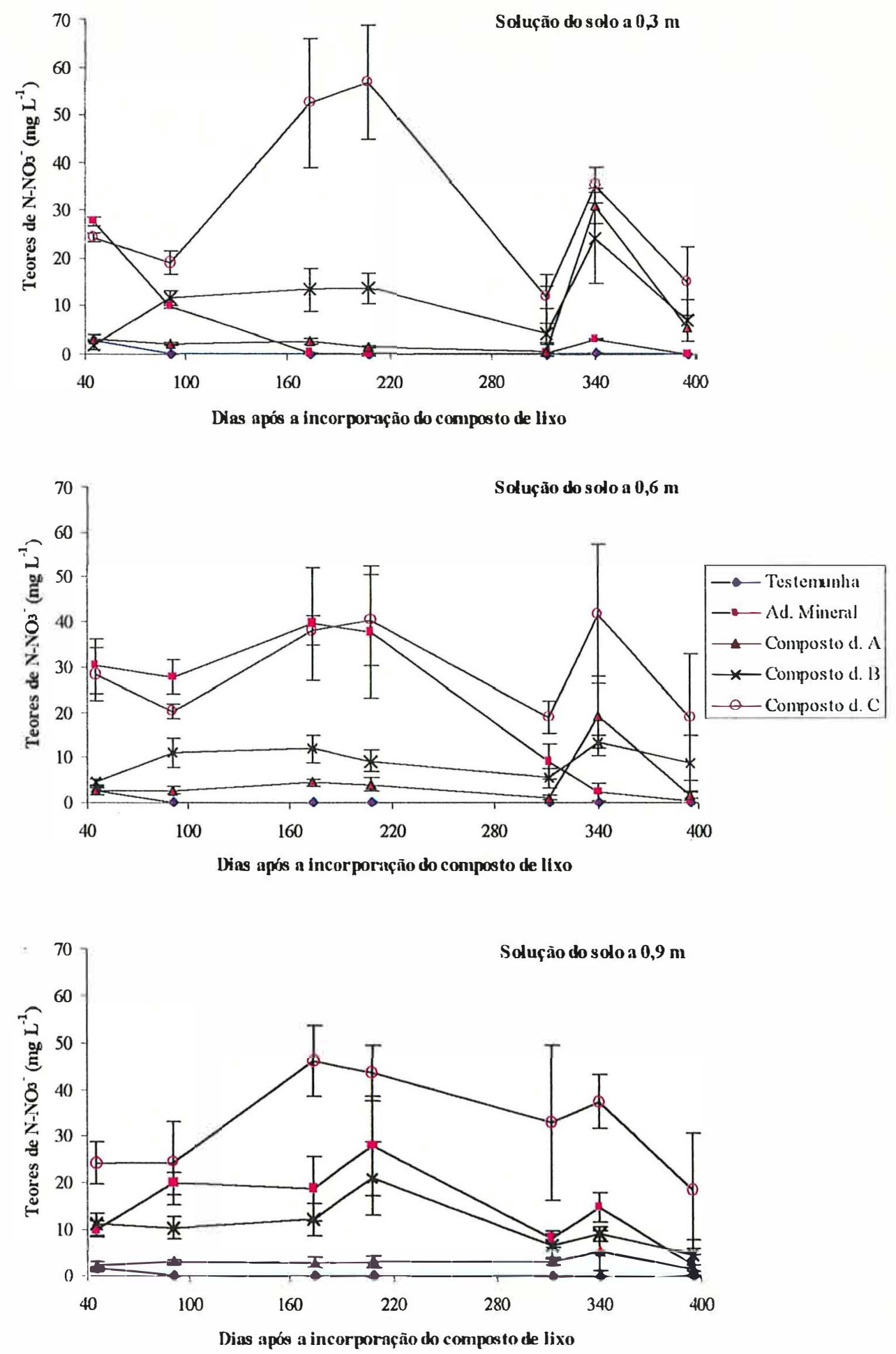

Figura 25. Concentração média e desvio padrão de $\mathrm{N}_{-} \mathrm{NO}_{3}{ }^{-}$na solução do solo determinados a 0,3,0,6 e 0,9 m de profundidade, para os tratamentos com doses de comp. de lixo e ad. mineral, no decorrer do ano agrícola 1997/98. 
As determinações de $\mathrm{N}^{-\mathrm{NO}_{3}}{ }^{-}$nas profundidades 0,6 e $0,9 \mathrm{~m}$ denunciaram a movimentação do nitrogênio em profundidade. As concentrações verificadas a $0,6 \mathrm{~m}$ não apresentaram, em função das épocas de amostragem, um comportamento crescente ou decrescente definido; estas por sua vez variaram respectivamente, nos tratamentos com doses A, B e C do resíduo, entre os seguintes valores: 1,05 a 19,24 $\mathrm{mg} \mathrm{L}^{-1}, 4,44$ a $13,39 \mathrm{mg} \mathrm{L}^{-1}$ e 18,76 a $41,80 \mathrm{mg} \mathrm{L}^{-1}$.

$\mathrm{Na}$ profundidade $0,9 \mathrm{~m}$, as concentrações verificadas durante o período experimental, na dose A de composto de lixo, apresentaram um comportamento com pequena variação no tempo, oscilando entre 1,45 e $5,45 \mathrm{mg} \mathrm{L}^{-1}$. Na dose $\mathrm{B}$, os teores de $\mathrm{N}^{-\mathrm{NO}_{3}}{ }^{-}$variaram de 10,51 a $20,93 \mathrm{mg} \mathrm{L}^{-1}$ da $1^{\underline{a}}$ a $4^{\underline{a}}$ amostragem e reduziram-se para menos de $9,02 \mathrm{mg} \mathrm{L}^{-1}$ nas demais coletas. Para a dose $\mathrm{C}$, nas primeiras quatro amostragens tais teores variaram entre 24,31 e $46,25 \mathrm{mg} \mathrm{L}^{-1}$ caindo para $18,76 \mathrm{mg} \mathrm{L}^{-1}$ na $7^{\mathrm{a}}$ amostragem.

Considerando-se que o $\mathrm{N}_{-} \mathrm{NO}_{3}^{-}$, presente a $0,9 \mathrm{~m}$ de profundidade, está praticamente fora do alcance das raizes absorventes das plantas de cana-de-açúcar e que o limite máximo para qualidade da água potável, estabelecido pela OMS, é de $10 \mathrm{mg} \mathrm{L}^{-1}$ (Muchovej \& Rechcigl, 1995) verifica-se que a disposição de composto de lixo nas doses $\mathrm{B}$ e $\mathrm{C}$ representaram um relativo potencial de contaminação das águas subterrâneas. Por outro lado, com base nos referidos padrões, aplicações anuais de até $24 \mathrm{Mg} \mathrm{ha}^{-1}$ não apresentaram, quanto ao potencial para lixiviação de nitrogênio inorgânico, riscos ao ambiente.

As quantidades lixiviadas de $\mathrm{N}-\mathrm{NO}_{3}{ }^{-}$, nas camadas do solo de $0-0,3,0-0,6 \mathrm{e}$ $0-0,9 \mathrm{~m}$, para os tratamentos com composto de lixo, encontram-se na Tabela 37. De maneira geral, as maiores perdas por lixiviação ocorreram nos dois primeiros períodos de avaliação (13/11/1997 a 14/01/98 e 15/01 a 24/03/98) chegando a representar em algumas situações, mais de $70 \%$ dos totais lixiviados. Embora as maiores concentrações de $\mathrm{N}_{-} \mathrm{NO}_{3}{ }^{-}$não tenham sido observadas nestes períodos, foram neles que se verificaram os maiores fluxos descendentes de água. 
Tabela 37. Fluxo de água, concentração média de $\mathrm{N}_{-} \mathrm{NO}_{3}{ }^{\cdot}$ na solução do solo e lixiviação de $\mathrm{N}-\mathrm{NO}_{3}{ }^{-}$nas camadas de $0-0,3,0-0,6$ e $0-0,9 \mathrm{~m}$ para os tratarnentos que compõem o experimento com composto de lixo.

\begin{tabular}{|c|c|c|c|c|c|c|c|c|c|}
\hline \multirow[b]{2}{*}{ Período } & \multicolumn{3}{|c|}{ Fluxo de água } & \multicolumn{3}{|c|}{ Conc. média de $\mathrm{N}-\mathrm{NO}_{3}^{-}$} & \multicolumn{3}{|c|}{ Lixiviação de $\mathrm{N}-\mathrm{NO}_{3}{ }^{-}$} \\
\hline & $q_{0,0,3}$ & $\begin{array}{r}9_{00,6} \\
-\mathbf{m m} \\
\end{array}$ & qa-0,9 & $\mathrm{C}_{0,3}$ & $\begin{array}{c}\mathrm{C}_{0,6} \\
\mathrm{mg} \mathrm{L}^{-1}\end{array}$ & $\mathbf{C}_{0,9}$ & $\mathbf{L}_{0,0,3}$ & $\begin{array}{c}\mathrm{L}_{0,0,6} \\
-\mathrm{kg} \mathrm{ha}^{-1}\end{array}$ & $\mathbf{L}_{0,0,9}$ \\
\hline & \multicolumn{9}{|c|}{ Adubação Mineral } \\
\hline $13 / 11$ a $14 / 01$ & $-373,2$ & $-383,4$ & $-376,8$ & 27,66 & 30,16 & 10,08 & $-103,2$ & $-115,6$ & $-38,0$ \\
\hline $15 / 01$ a $24 / 03$ & $-277,2$ & $-273,2$ & $-275,8$ & 9,82 & 27,75 & 19,97 & $-27,2$ & $-75,8$ & $-55,1$ \\
\hline $25 / 03$ a $25 / 05$ & 40,7 & 40,0 & 36,1 & 0,25 & 39,70 & 18,75 & 0,1 & 15,9 & 6,8 \\
\hline $26 / 05$ a $31 / 07$ & 76,6 & 72,1 & 69,4 & 0,09 & 37,73 & 28,02 & 0,1 & 27,2 & 19,4 \\
\hline $01 / 08$ a 02/10 & 80,3 & 92,5 & 96,4 & 0,23 & 9,11 & 8,08 & 0,2 & 8,4 & 7,8 \\
\hline $03 / 10$ a $25 / 11$ & $-93,2$ & $-103,1$ & $-108,3$ & 3,22 & 2,25 & 14,69 & $-3,0$ & $-2,3$ & $-15,9$ \\
\hline $26 / 11$ a $25 / 12$ & $-100,1$ & $-73,1$ & $-40,6$ & 0,11 & 0,45 & 2,50 & $-0,1$ & $-0,3$ & $-1,0$ \\
\hline \multirow[t]{2}{*}{ Total } & $-646,1$ & $-628,2$ & $-599,6$ & - & - & - & $-133,1$ & $-142,5$ & $-76,0$ \\
\hline & \multicolumn{9}{|c|}{ Testemunha } \\
\hline $13 / 11$ a $14 / 01$ & $-372,5$ & $-381,8$ & $-381,3$ & 2,75 & 2,74 & 1,47 & $-10,2$ & $-10,5$ & $-5,6$ \\
\hline $15 / 01$ a $24 / 03$ & $-282,4$ & $-278,9$ & $-276,1$ & 0,02 & 0,01 & n.d. ${ }^{*}$ & $-0,1$ & - & - \\
\hline $25 / 03$ a $25 / 05$ & 43,7 & 43,7 & 42,8 & 0,01 & n.d. & n.d. & - & - & - \\
\hline $26 / 05$ a $31 / 07$ & 81,6 & 77,3 & 73,6 & n.d. & 0,04 & 0,01 & - & - & - \\
\hline $01 / 08$ a $02 / 10$ & 74,6 & 85,6 & 86,5 & n.d. & n.d. & n.d. & - & - & - \\
\hline $03 / 10$ a $25 / 11$ & $-92,8$ & $-103,3$ & $-112,3$ & 0,21 & n.d. & n.d. & $-0,2$ & - & - \\
\hline $26 / 11$ a $25 / 12$ & $-114,0$ & $-82,8$ & $-54,6$ & n.d. & n.d. & nd. & - & - & - \\
\hline \multirow[t]{2}{*}{ Total } & $-661,8$ & $-640,2$ & $-621,4$ & - & - & - & $-10,5$ & $-10,5$ & $-5,6$ \\
\hline & \multicolumn{9}{|c|}{ Composto de Lixo dose A } \\
\hline $13 / 11$ a $14 / 01$ & $-366,1$ & $-378,4$ & $-379,3$ & 3,08 & 2,64 & 2,20 & $-11,3$ & $-10,0$ & $-8,3$ \\
\hline $15 / 01$ a $24 / 03$ & $-281,4$ & $-279,4$ & $-273,1$ & 2,25 & 2,72 & 3,02 & $-6,3$ & $-7,6$ & $-8,2$ \\
\hline $25 / 03$ a $25 / 05$ & 11,4 & 7,4 & $-0,2$ & 2,63 & 4,51 & 2,95 & 0,3 & 0,3 & - \\
\hline $26 / 05$ a $31 / 07$ & 86,3 & 84,0 & 80,0 & 1,59 & 3,98 & 3,06 & 1,4 & 3,3 & 2,4 \\
\hline $01 / 08$ a $02 / 10$ & 101,1 & 118,1 & 125,1 & 0,70 & 1,05 & 3,07 & 0,7 & 1,2 & 3,8 \\
\hline $03 / 10$ a $25 / 11$ & $-109,0$ & $-125,9$ & $-147,1$ & 31,13 & 19,24 & 5,45 & $-33,9$ & $-24,2$ & $-8,0$ \\
\hline $26 / 11$ a $25 / 12$ & $-108,1$ & $-66,4$ & $-14,1$ & 5,57 & 1,63 & 1,42 & $-6,0$ & $-1,1$ & $-0,2$ \\
\hline \multirow[t]{2}{*}{ Total } & $-665,8$ & $-640,6$ & $-608,7$ & - & - & - & $-\mathbf{5 5 , 1}$ & $-38,1$ & $-18,5$ \\
\hline & \multicolumn{9}{|c|}{ Composto de lixo dose $B$} \\
\hline $13 / 11$ a $14 / 01$ & $-373,8$ & $-381,8$ & $-387,9$ & 1,80 & 4,44 & 11,16 & $-6,7$ & $-16,9$ & $-43,3$ \\
\hline $15 / 01$ a $24 / 03$ & $-292,2$ & $-288,7$ & $-287,1$ & 11,69 & 11,19 & 10,51 & $-34,2$ & $-32,3$ & $-30,2$ \\
\hline $25 / 03$ a $25 / 05$ & 80,7 & 78,5 & 75,4 & 13,38 & 11,93 & 12,25 & 10,8 & 9,4 & 9,2 \\
\hline $26 / 05$ a $31 / 07$ & 53,7 & 47,8 & 44,3 & 13,72 & 9,21 & 20,93 & 7,4 & 4,4 & 9,3 \\
\hline $01 / 08$ a $02 / 10$ & 73,0 & 86,3 & 96,5 & 4,38 & 5,46 & 6,68 & 3,2 & 4,7 & 6,4 \\
\hline $03 / 10$ a $25 / 11$ & $-87,3$ & $-98,5$ & $-108,3$ & 24,28 & 13,39 & 9,02 & $-21,2$ & $-13,2$ & $-9,8$ \\
\hline $26 / 11$ a $25 / 12$ & $-132,5$ & $-111,3$ & $-54,8$ & 7,08 & 8,82 & 4,63 & $-9,4$ & $-9,8$ & $-2,5$ \\
\hline \multirow[t]{2}{*}{ Total } & $-678,4$ & $-667,7$ & $-621,9$ & - & $=$ & - & $-50,1$ & $-53,7$ & $-60,9$ \\
\hline & \multicolumn{9}{|c|}{ Composto de Lixo dose C } \\
\hline $13 / 11$ a $14 / 01$ & $-368,9$ & $-383,0$ & $-387,3$ & 24,26 & 28,25 & 24,31 & $-89,5$ & $-108,2$ & $-94,2$ \\
\hline $15 / 01$ a $24 / 03$ & $-292,6$ & $-290,5$ & $-291,5$ & 19,03 & 20,19 & 24,39 & $-55,7$ & $-58,7$ & $-71,1$ \\
\hline $25 / 03$ a $25 / 05$ & 30,2 & 28,3 & 27,5 & 52,55 & 38,03 & 46,25 & 15,9 & 10,8 & 12,7 \\
\hline $26 / 05$ a $31 / 07$ & 95,9 & 94,4 & 90,0 & 56,87 & 40,43 & 43,56 & 54,5 & 38,2 & 39,2 \\
\hline $01 / 08$ a $02 / 10$ & 80,0 & 95,6 & 105,2 & 11,88 & 18,76 & 32,96 & 9,5 & 17,9 & 34,7 \\
\hline $03 / 10$ a $25 / 11$ & $-93,4$ & $-108,7$ & $-123,4$ & 35,33 & 41,80 & 37,47 & $-33,0$ & $-45,4$ & $-46,2$ \\
\hline $26 / 11$ a $25 / 12$ & $-128,7$ & $-96,6$ & $-77,2$ & 15,15 & 18,87 & 18,46 & $-19,5$ & $-18,2$ & $-14,2$ \\
\hline Total & -677.5 & -660.5 & -656.7 & - & - & - & $-117,8$ & $-163,6$ & $-139,1$ \\
\hline
\end{tabular}


Os movimentos de $\mathrm{N}^{-\mathrm{NO}_{3}}{ }^{-}$nas camadas do solo foram crescentes em função das doses aplicadas de composto de lixo. Apesar dos fluxos ascendentes de nitrogênio observados no $3^{\circ}, 4^{\circ}$ e $5^{\circ}$ período, o balanço final de perdas apontou para a camada de $0-0,9 \mathrm{~m}$, respectivamente nas doses $\mathrm{A}, \mathrm{B}$ e $\mathrm{C}$ do resíduo, lixiviações de 18,5, 60,9 e $139,1 \mathrm{~kg} \mathrm{ha}^{-1}$, correspondentes a 4,2, 9,1 e $14,6 \%$ do $\mathrm{N}$-total aplicado no segundo ano agrícola, considerando-se as perdas naturais do solo (testemunha absoluta). Conforme comentado para os tratamentos com lodo de esgoto, é importante ressaltar que essas perdas de $\mathrm{N}_{-} \mathrm{NO}_{3}{ }^{-}$podem estar influenciadas por possíveis efeitos residuais da primeira aplicação (ano agrícola 1996/97), embora esta tenha sido feita a 400 dias antes da segunda. Outro aspecto a ser lembrado é que o volume atípico de chuvas ocorrido no período experimental, pode ter expressado um potencial máximo de lixiviação.

Tendo em vista que as doses A e B de composto de lixo proporcionaram produtividades equiparáveis a adubação mineral e que as perdas estimadas de $\mathrm{N}-\mathrm{NO}_{3}$, devidas ao resíduo, foram menores do que a proporcionada pela adubação convencional, sugere-se que a utilização de fertilizantes minerais pode oferecer maiores riscos de poluição por nitratos do que as referidas doses do composto.

No entanto, a exemplo de outros resíduos orgânicos, é importante considerar na utilização agrícola do composto de lixo, sua taxa de mineralização de nitrogênio e a capacidade de absorção da cultura instalada sem portanto, desconsiderar o monitoramento deste elemento no solo, visando em última instância, a disposição segura destes resíduos.

As quantidades de $\mathrm{N}-\mathrm{NH}_{4}^{+}$movimentadas nas camadas do solo são apresentadas na Tabela 38. Pelas mesmas razões atribuídas aos tratamentos com lodo de esgoto, verificou-se que as lixiviações de formas amoniacais foram equivalentes, nos tratamentos com composto de lixo, a menos de $7,0 \%$ dos totais lixiviados, o que diante da ordem de grandeza dos valores, teve pouca representatividade. 
Tabela 38. Fluxo de água, concentração média de $\mathrm{N}_{-} \mathrm{NH}_{4}{ }^{+}$na solução do solo e lixiviação de $\mathrm{N}-\mathrm{NH}_{4}^{+}$nas camadas de $0-0,3,0-0,6$ e $0-0,9 \mathrm{~m}$ para os tratamentos que compõem o experimento com composto de lixo.

\begin{tabular}{|c|c|c|c|c|c|c|c|c|c|}
\hline \multirow[b]{2}{*}{ Período } & \multicolumn{3}{|c|}{ Fluxo da água } & \multicolumn{3}{|c|}{ Conc. média de $\mathrm{N}-\mathrm{NH}_{4}^{+}$} & \multicolumn{3}{|c|}{ Lixiviação de $\mathrm{N}-\mathrm{NH}_{4}^{+}$} \\
\hline & $q_{0-0,3}$ & $\begin{array}{c}\mathbf{q}_{0-0,6} \\
-\mathbf{m m}\end{array}$ & $\mathbf{q}_{0-0,9}$ & $\mathrm{C}_{0,3}$ & $\begin{array}{c}C_{0,6} \\
\operatorname{ng~} L^{-1}\end{array}$ & $\mathrm{C}_{0,9}$ & $L_{0,0,3}$ & $\begin{array}{l}\mathrm{L}_{0,0,6} \\
\mathrm{~kg} \mathrm{ha}^{-1}\end{array}$ & $\mathbf{L}_{0,9}$ \\
\hline & \multicolumn{9}{|c|}{ Adubação Mineral } \\
\hline $13 / 11$ a $14 / 01$ & $-373,2$ & $-383,4$ & $-376,8$ & 0,48 & 0,06 & 0,11 & $-1,79$ & $-0,2$ & $-0,4$ \\
\hline $15 / 01$ a $24 / 03$ & $-277,2$ & $-273,2$ & $-275,8$ & n.d. & n.d. & n.d." & - & $=$ & - \\
\hline $25 / 03$ a $25 / 05$ & 40,7 & 40,0 & 36,1 & n.d. & n.d. & n.d. & - & - & - \\
\hline $26 / 05$ a $31 / 07$ & 76,6 & 72,1 & 69,4 & n.d. & n.d. & n.d. & - & - & - \\
\hline $01 / 08$ a $02 / 10$ & 80,3 & 92,5 & 96,4 & n.d. & 0,03 & 0,03 & - & - & - \\
\hline $03 / 10$ a $25 / 11$ & $-93,2$ & $-103,1$ & $-108,3$ & 0,01 & n.d. & n.d. & - & - & - \\
\hline $26 / 11$ a $25 / 12$ & $-100,1$ & $-73,1$ & $-40,6$ & n.d. & n.d. & n.d. & - & - & - \\
\hline \multirow[t]{2}{*}{ Total } & $-646,1$ & $-628,2$ & $-599,6$ & - & - & - & $-1,79$ & $-0,2$ & $-0,4$ \\
\hline & \multicolumn{9}{|c|}{ Testemunha } \\
\hline $13 / 11$ a $14 / 01$ & $-372,5$ & $-381,8$ & $-381,3$ & n.d. & 0,31 & n.d. & - & $-1,2$ & - \\
\hline $15 / 01$ a $24 / 03$ & $-282,4$ & $-278,9$ & $-276,1$ & n.d. & n.d. & n.d. & - & - & - \\
\hline $25 / 03$ a $25 / 05$ & 43,7 & 43,7 & 42,8 & n.d. & n.d. & n.d. & - & - & - \\
\hline $26 / 05$ a $31 / 07$ & 81,6 & 77,3 & 73,6 & n.d. & 0,03 & n.d. & - & - & - \\
\hline $01 / 08$ a $02 / 10$ & 74,6 & 85,6 & 86,5 & n.d. & 0,02 & 0,02 & - & - & - \\
\hline $03 / 10$ a $25 / 11$ & $-92,8$ & $-103,3$ & $-112,3$ & n.d. & 0,01 & n.d. & - & - & - \\
\hline $26 / 11$ a $25 / 12$ & $-114,0$ & $-82,8$ & $-54,6$ & n.d. & n.d. & n.d. & - & - & - \\
\hline \multirow[t]{2}{*}{ Total } & $-661,8$ & $-640,2$ & $-621,4$ & - & - & - & - & $-1,2$ & - \\
\hline & \multicolumn{9}{|c|}{ Composto de Lixo dose $A$} \\
\hline $13 / 11$ a $14 / 01$ & $-366,1$ & $-378,4$ & $-379,3$ & 0,05 & 0,41 & 0,41 & $-0,2$ & $-1,6$ & $-1,6$ \\
\hline $15 / 01$ a $24 / 03$ & $-281,4$ & $-279,4$ & $-273,1$ & nd. & n.d. & n.d. & - & - & - \\
\hline $25 / 03$ a $25 / 05$ & 11,4 & 7,4 & $-0,2$ & n.d. & 0,04 & 0,17 & - & - & - \\
\hline $26 / 05$ a $31 / 07$ & 86,3 & 84,0 & 80,0 & 0,21 & n.d. & 0,25 & 0,2 & - & 0,2 \\
\hline $01 / 08$ a $02 / 10$ & 101,1 & 118,1 & 125,1 & 0,26 & 0,16 & 0,10 & 0,3 & 0,2 & 0,1 \\
\hline $03 / 10$ a $25 / 11$ & $-109,0$ & $-125,9$ & $-147,1$ & 0,30 & 0,23 & 0,06 & $-0,3$ & $-0,3$ & $-0,1$ \\
\hline $26 / 11$ a $25 / 12$ & $-108,1$ & $-66,4$ & $-14,1$ & 0,06 & 0,02 & n.d. & $-0,1$ & - & - \\
\hline \multirow[t]{2}{*}{ Total } & $-665,8$ & $-640,6$ & $-608,7$ & - & - & - & $-0,1$ & $-1,7$ & $-1,4$ \\
\hline & \multicolumn{9}{|c|}{ Composto de lixo dose $B$} \\
\hline $13 / 11$ a $14 / 01$ & $-373,8$ & $-381,8$ & $-387,9$ & 0,26 & n.d. & n.d. & $-1,0$ & - & - \\
\hline $15 / 01$ a $24 / 03$ & $-292,2$ & $-288,7$ & $-287,1$ & n.d. & n.d. & n.d. & - & - & - \\
\hline $25 / 03$ a $25 / 05$ & 80,7 & 78,5 & 75,4 & n.d. & n.d. & 0,39 & - & - & 0,3 \\
\hline $26 / 05$ a $31 / 07$ & 53,7 & 47,8 & 44,3 & 0,28 & n.d. & 0,12 & 0,2 & - & 0,1 \\
\hline $01 / 08$ a $02 / 10$ & 73,0 & 86,3 & 96,5 & 0,29 & 0,35 & 0,20 & 0,2 & 0,3 & 0,2 \\
\hline $03 / 10$ a $25 / 11$ & $-87,3$ & $-98,5$ & $-108,3$ & 0,33 & 0,26 & 0,11 & $-0,3$ & $-0,3$ & $-0,1$ \\
\hline $26 / 11$ a $25 / 12$ & $-132,5$ & $-111,3$ & $-54,8$ & 0,04 & 0,03 & 0,02 & $-0,1$ & - & - \\
\hline \multirow[t]{2}{*}{ Total } & $-678,4$ & $-667,7$ & $-621,9$ & - & - & - & $-1,0$ & - & 0,5 \\
\hline & \multicolumn{9}{|c|}{ Composto de Lixo dose $C$} \\
\hline $13 / 11$ a $14 / 01$ & $-368,9$ & $-383,0$ & $-387,3$ & 1,08 & 0,11 & 0,62 & $-4,0$ & $-0,4$ & $-2,4$ \\
\hline $15 / 01$ a $24 / 03$ & $-292,6$ & $-290,5$ & $-291,5$ & n.d. & n.d. & n.d. & - & - & - \\
\hline $25 / 03$ a $25 / 05$ & 30,2 & 28,3 & 27,5 & 0,54 & 0,54 & 0,51 & 0,2 & 0,2 & 0,1 \\
\hline $26 / 05$ a $31 / 07$ & 95,9 & 94,4 & 90,0 & 0,10 & n.d. & 0,06 & 0,1 & - & 0,1 \\
\hline $01 / 08$ a $02 / 10$ & 80,0 & 95,6 & 105,2 & 0,54 & 0,38 & 0,37 & 0,4 & 0,4 & 0,1 \\
\hline $03 / 10$ a $25 / 11$ & $-93,4$ & $-108,7$ & $-123,4$ & 0,52 & 0,44 & 0,19 & $-0,5$ & $-0,5$ & $-0,2$ \\
\hline $26 / 11$ a $25 / 12$ & $-128,7$ & $-96,6$ & $-77,2$ & 0,11 & 0,03 & 0,03 & $-0,1$ & - & - \\
\hline Total & -677.5 & $-660,5$ & -656.7 & - & - & - & $-3,9$ & $-0,3$ & $-2,3$ \\
\hline
\end{tabular}

*n.d. - não detectado - abaixo do limite de determinação do método analitico empregado. 


\subsubsection{Acúmulo de nitrogênio no solo}

As concentrações de $\mathrm{N}$-total, $\mathrm{N}$-orgânico e $\mathrm{N}-\mathrm{NO}_{3}{ }^{-}+\mathrm{N}-\mathrm{NH}_{4}{ }^{+}$nas amostras de solo coletadas em profundidade, para os tratamentos com composto de lixo, em ambos os anos agrícolas, são apresentadas na Figura 26. De maneira geral, os teores de nitrogênio foram influenciados significativamente pela interação entre tratamentos e profundidades de amostragem (Apêndice 2).

As formas orgânicas corresponderam a mais de $98 \%$ do $\mathrm{N}$-total determinado no solo. Ao final de 1996/97, na camada de 0 - 0,3 m, observou-se um comportamento quadrático $\left(\mathrm{R}^{2}=0,99^{* *}\right)$ nos teores de $\mathrm{N}$-orgânico, em função das doses de composto de lixo. Os teores médios apresentados nos tratamentos com doses A, B e C foram respectivamente, $708,9,746,1$ e $769,1 \mathrm{mg} \mathrm{kg}^{-1}$, os quais representaram aumentos de $18,1,24,4$ e $28,2 \%$ em relação a testemunha absoluta. Em 1997/98, esses teores apresentaram um comportamento linear crescente $\left(\mathrm{R}^{2}=0,87^{* *}\right)$ com as doses $\mathrm{A}, \mathrm{B}$ e C do resíduo, onde foram verificados os seguintes teores médios: 737,2, 805,7 e $815,2 \mathrm{mg} \mathrm{kg}^{-1}$, correspondentes a acréscimos de $22,9,34,3$ e $35,9 \%$ em relação a testemunha.

A comparação entre os teores médios determinados ao final dos dois anos agrícolas revela, que por ocasião da segunda aplicação de composto de lixo, houveram incrementos de 4,8 e $6 \%$ em função das doses aplicadas. No entanto, é preciso considerar que estes incrementos poderiam ser maiores haja visto que, em 1997/98 foram verificados aumentos lineares significativos de N-orgânico na camada de 0,3-0,6 m, sugerindo lixiviação de compostos nitrogenados orgânicos e solúveis. De qualquer maneira, os resultados apontam para uma tendência de acúmulo de N-orgânico, em função das disposições sucessivas do resíduo no solo. A implicação imediata deste fato é que mesmo para a dose $\mathrm{A}$, onde não houveram indícios de potencial poluente por nitratos, na possibilidade de um número maior de aplicações, as quantidades mineralizadas e passíveis de lixiviação oriundas do $\mathrm{N}$-orgânico acumulado, podem passar a ser significativamente maiores e preocupantes do ponto de vista ambiental. 
Ano agrícola 1996/97

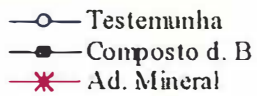

Teores de N-total (mg kg ${ }^{-1}$ )

$\begin{array}{lllllllllllll}350 & 100 & 450 & 500 & 550 & 600 & 650 & 700 & 750 & 800 & 850 & 900 & 950\end{array}$

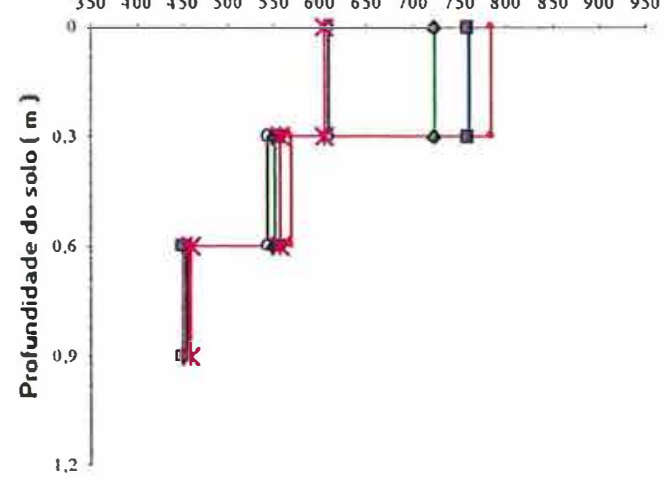

Teores de N-orgìnlco ( $\mathrm{mg} \mathrm{kg}{ }^{-1}$ )

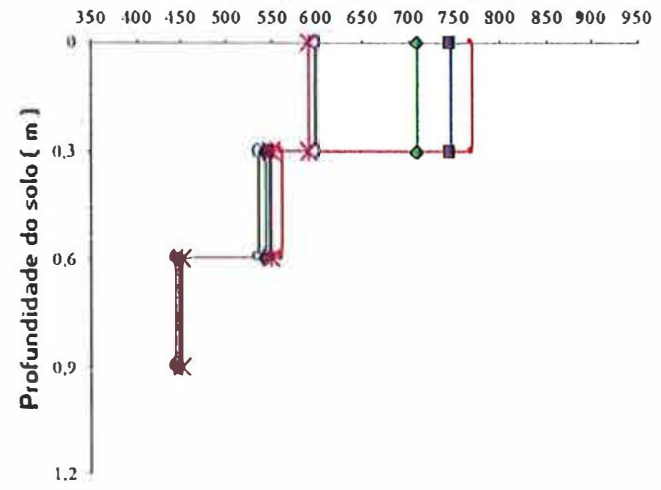

Teores de N- $\mathrm{NO}_{3}{ }^{+}+\mathrm{N}-\mathrm{NII}{ }^{+}\left(\mathrm{mg} \mathrm{kg}^{-1}\right)$

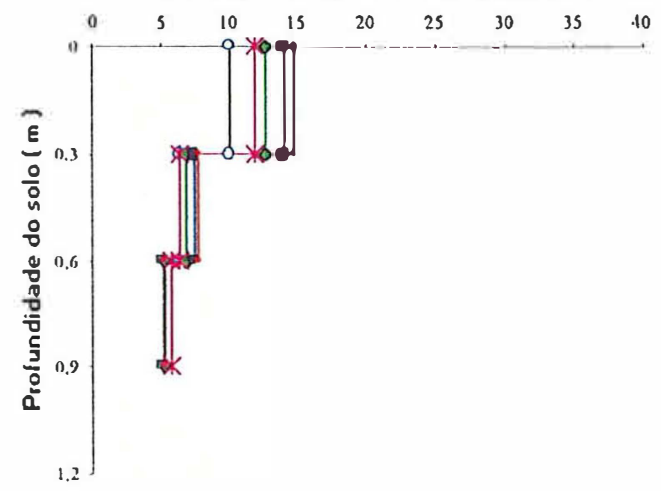

\section{Ano agrícola 1997/98} $\longrightarrow$ Testemunha
$\rightarrow$ Composto d. B Composto d. A
$\rightarrow$ Ad. Mineral

Teores de $\mathrm{N}$ - total (mg kg ${ }^{-1}$ )

$\begin{array}{lllllllllllll}350 & 400 & 450 & 500 & 550 & 600 & 650 & 700 & 750 & 800 & 850 & 900 & 950\end{array}$

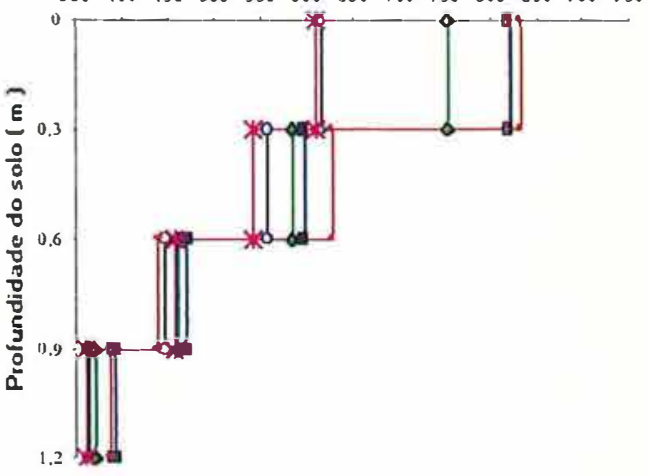

Teores de $\mathrm{N}$ - orgà nic o $\left(\mathrm{mg} \mathrm{kg}^{-1}\right)$

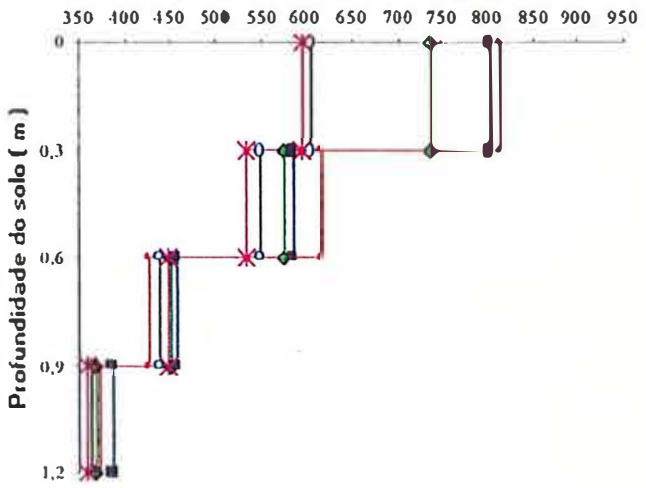

Teoros de N- $\mathrm{NO}_{3}{ }^{-}+\mathrm{N}-\mathrm{NH}_{4}{ }^{\circ}\left(\mathrm{mg} \mathrm{kg}^{-1}\right)$

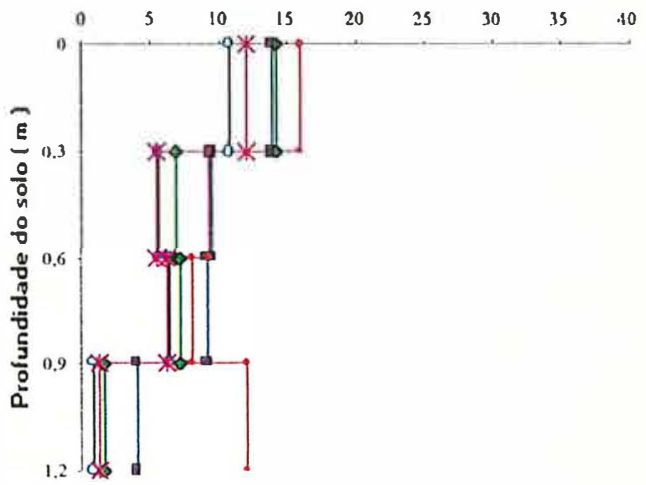

Figura 26. Teores de $\mathrm{N}$-total, N-orgânico e $\mathrm{N}-\mathrm{NO}_{3}{ }^{-}+\mathrm{N}^{-} \mathrm{NH}_{4}{ }^{+}$determinados no solo, em profundidade, ao final dos anos agrícolas 1996/97 e 1997/98, no experimento com composto de lixo. 
Informações relacionadas por Cravo (1995) dão conta de que, em diversas regiões hortícolas localizadas na periferia de médias e grandes cidades, usam-se habitualmente taxas anuais de 40 a $60 \mathrm{Mg} \mathrm{ha}^{-1}$ (base seca) de composto de lixo e outros resíduos orgânicos. $\mathrm{O}$ autor cita por exemplo que, somente na grande São Paulo, há indícios de que tal prática é realizada a mais de 20 anos. Isto posto, com base nas informações obtidas neste trabalho, é provável que nas citadas áreas agrícolas venham

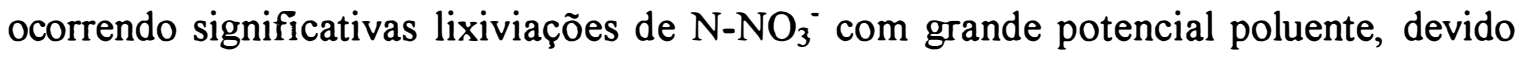
essencialmente a três particularidades dos chamados cinturões verdes, à saber: cultivo intenso durante o ano todo; localização geográfica normalmente em áreas de baixadas, próximas a cursos d'água e conseqüentemente com lençol freático pouco profundo; prática intensiva da irrigação. De qualquer forma, acredita-se que estas áreas mereçam um estudo a este respeito.

Confirmando as tendências observadas através das análises da solução, os teores de $\mathrm{N}_{-} \mathrm{NO}_{3}{ }^{-}+\mathrm{N}_{-} \mathrm{NH}_{4}{ }^{+}$determinados nas várias camadas de solo, ao final dos dois anos agrícolas, comprovaram a movimentação dessas formas nitrogenadas. Nas camadas de $0-0,3$ e 0,3-0,6 m, ao final de 1996/97, assim como todas as camadas de solo avaliadas ao final de 1997/98, apresentaram aumentos lineares significativos nos teores de nitrogênio inorgânico, em função da aplicação de composto de lixo. Para a camada de 0,9-1,2 m, no segundo ano agrícola, verifica-se para as doses $\mathrm{A}, \mathrm{B}$ e $\mathrm{C}$ do resíduo, teores médios de respectivamente, 1,$7 ; 4,0$ e $12,1 \mathrm{mg} \mathrm{kg}^{-1}$, significando no tratamento com a maior dose, em média 12 vezes a concentração na testemunha. Cabe lembrar que neste caso, essas quantidades estão praticamente perdidas para o sistema agrícola representado aqui, pela zona radicular absorvente das plantas de cana-de-açúcar. Por outro lado, estas informações reforçam a afirmativa de que doses de até $24 \mathrm{Mg}^{-1} \mathrm{a}^{-1}$ não ofereceram riscos ao ambiente, quanto a variável avaliada. 


\section{APRECIAÇÃO GERAL DOS RESULTADOS OBTIDOS}

- As elevadas doses de lodo de esgoto não proporcionaram efeitos deletérios à produtividade da cana-de-açúcar. $\mathrm{Na} 1^{\underline{a}}$ soqueira, tanto os tratamentos com lodo de esgoto quanto àqueles com composto de lixo foram superiores a testemunha absoluta porém, não revelaram diferenças significativas em relação ao tratamento calagem + adubação mineral;

- A disposição de doses crescentes de lodo de esgoto e de composto de lixo promoveram, em ambos os anos agrícolas, aumentos lineares nos teores de carbono orgânico do solo;

- Os decréscimos de carbono orgânico determinados no decorrer dos dois anos agrícolas, tanto nos tratamentos com lodo de esgoto quanto naqueles com composto de lixo, ajustaram-se a um modelo de cinética de primeira ordem. Houveram reduções nas taxas de decréscimos por ocasião da segunda aplicação dos resíduos, evidenciando o acúmulo de carbono orgânico no solo devido a aplicações sucessivas;

- As disposições de doses crescentes de lodo de esgoto e de composto de lixo promoveram, em ambos os anos agrícolas, aumentos na condutividade elétrica do solo porém, não houveram indícios de efeitos cumulativos sobre esta variável em decorrência da segunda aplicação dos resíduos. Nos tratamentos com lodo de esgoto, tais aumentos causaram maiores preocupações em virtude de sua ordem de grandeza;

- Ficou evidenciada a estreita relação entre o comportamento, em função do tempo, da condutividade elétrica na camada de incorporação dos resíduos, a ocorrência de chuvas e a lixiviação de sais, demonstrada pelos aumentos na variável nas camadas 
subsuperficiais do solo. No caso do lodo de esgoto, tais aumentos indicaram que, dependendo das condições climáticas, no caso de fluxos ascendentes da água do solo, existe um risco potencial de salinização;

- Houveram aumentos no pH do solo em função das disposições de doses crescentes de ambos os resíduos. Nos tratamentos com lodo de esgoto, por ocasião da segunda aplicação, os acréscimos foram menores do que os proporcionados em 1996/97, evidenciando o poder de tamponamento do solo; foram verificados efeitos sobre o $\mathrm{pH}$ até a profundidade de $0,8 \mathrm{~m}$. Nos tratamentos com composto de lixo, os efeitos sobre o pH do solo se restringiram a camada de incorporação;

- O lodo de esgoto e o composto de lixo atuaram no sentido de aumentar a capacidade de troca de cátions do solo. Nos tratamentos com lodo de esgoto porém, não foram verificados aumentos proporcionais às doses aplicadas e nem devidos a segunda aplicação do resíduo. As alterações na CTC foram melhor explicadas pelas variações no $\mathrm{pH}$ em detrimento dos acréscimos de carbono orgânico no solo. Para os tratamentos com composto de lixo, os aumentos de CTC foram proporcionais as doses aplicadas, havendo incrementos devidos a segunda aplicação. Neste caso, as alterações na CTC foram explicadas tanto pelos aumentos no pH quanto nos teores de C-orgânico do solo;

- Ao final de 1997/98, nos tratamentos com lodo de esgoto, foram detectados acúmulos de $\mathrm{Cu}, \mathrm{Cr}$, Ni e $\mathrm{Zn}$ na camada de solo de 0-0,2 m. Nos tratamentos com composto de lixo tais acúmulos foram detectados apenas para $\mathrm{Cu}, \mathrm{Cr}$ e $\mathrm{Zn}$;

- Os teores totais de $\mathrm{Cu}, \mathrm{Cr}$ e $\mathrm{Zn}$ acumulados no solo devido as disposições sucessivas de composto de lixo não excederam os limites críticos estabelecidos para solos, pela USEPA - 40CFR - Part 503 (1993) e pelas Diretrizes da Comunidade Européia;

- Para ambos os anos agrícolas, tanto nos tratamentos com lodo de esgoto quanto com composto de lixo, os possíveis teores absorvidos de $\mathrm{Cd}, \mathrm{Cr}, \mathrm{Ni}$ e $\mathrm{Pb}$ estiveram abaixo dos limites de determinação do método analítico empregado. Porém, para as 
amostras de caldo é possível assegurar que caso houvesse a presença de $\mathrm{Cd}, \mathrm{Cr}$ e $\mathrm{Ni}$, essas seriam extremamente baixas;

- Os incrementos nos teores de $\mathrm{Cu}$ e $\mathrm{Zn}$, na maioria das amostras de plantas de cana-de-açúcar, seguiram um comportamento assintótico em função dos acréscimos desses metais no solo, proporcionados pelas doses crescentes de lodo de esgoto;

- Nos tratamentos com composto de lixo não foram verificados efeitos sobre a absorção de $\mathrm{Cu}$ em ambos os anos agrícolas. Para o $\mathrm{Zn}$, no ano agrícola 1997/98, foi verificado efeito linear nas amostras de folha "+1", e comportamento assintótico para as amostras de colmo e caldo;

- Tanto nos tratamentos com lodo de esgoto quanto com composto de lixo, não foram encontrados teores de $\mathrm{Cu}$ e $\mathrm{Zn}$ nas amostras de plantas, superiores aos limites normais de variação encontrados na literatura;

- Não houveram evidências da mobilidade dos metais $\mathrm{Cu}$ e $\mathrm{Cr}$, ao final dos dois anos agrícolas, para os tratamentos com os resíduos. Por outro lado, o $\mathrm{Zn}$ se mostrou um elemento móvel no perfil do solo, sendo encontrado ao final de 1997/98, incrementos significativos até a camada de $0,4-0,6 \mathrm{~m}$, tanto nos tratamentos com lodo de esgoto quanto com composto de lixo;

- As soluções (de ácidas ( $\mathrm{HCl}$ 0,1 $\mathrm{mol} \mathrm{L}^{-1}$ e Mehlich-3) apresentaram, quando comparadas com a solução de DTPA-TEA, maior capacidade de extração de $\mathrm{Cu}, \mathrm{Ni}$ e $\mathrm{Zn}$ nos tratamentos com lodo de esgoto e de $\mathrm{Cu}$ e $\mathrm{Zn}$, nos tratamentos com composto de lixo. Todas as soluções extratoras utilizadas, inclusive a "água-régia", forneceram indicações semelhantes quanto a disponibilidade de $\mathrm{Cu}$ e $\mathrm{Zn}$;

- Nos tratamentos com lodo de esgoto, quando foram considerados nas análises de correlação os tratamentos testemunha e calagem + adubação mineral, todos os extratores químicos foram eficientes na avaliação da fitodisponibilidade de $\mathrm{Cu}$ e $\mathrm{Zn}$. Quando foram consideradas apenas as doses A, B e C do resíduo, os extratores 
apresentaram eficiência somente para o $\mathrm{Zn}$ determinado nas amostras de colmo e caldo, coletadas no ano agrícola 1997/98;

- Nos tratamentos com composto de lixo, considerando as correlações para as doses A, B e C, nenhuma solução extratora foi eficiente na avaliação da fitodisponibilidade de $\mathrm{Cu}$ e $\mathrm{Zn}$, em todas as amostras de plantas utilizadas;

- O método instrumental de análise, espectrometria de absorção atômica com chama convencional ar/acetileno, não foi adequado nas condições deste estudo, para as determinações dos metais $\mathrm{Cd}, \mathrm{Cr}, \mathrm{Ni}$ e $\mathrm{Pb}$ na maioria das amostras tendo em vista que, apesar do preparo de extratos mais concentrados, os limites de determinação analítica foram relativamente elevados;

- Os tratamentos calagem + adubação mineral, doses de lodo de esgoto e doses de composto de lixo proporcionaram, na solução do solo a $0,9 \mathrm{~m}$ de profundidade, aumentos na concentração de $\mathrm{N}-\mathrm{NO}_{3}{ }^{-}$;

- Nos tratamentos com doses A, B e C de lodo de esgoto e B e C de composto de lixo foram observadas predominantemente, durante todo o período experimental, a $0,9 \mathrm{~m}$ de profundidade, concentrações de $\mathrm{N}^{-\mathrm{NO}_{3}}{ }^{-}$maiores do que o padrão de qualidade para águas potáveis estabelecidos pela Organização Mundial da Saúde $\left(10 \mathrm{mg} \mathrm{L}^{-1}\right)$, evidenciando o potencial para contaminação de aqüíferos subterrâneos;

- Nas condições do experimento, doses anuais de até $24 \mathrm{Mg} \mathrm{ha}^{-1}$ (base seca) de composto de lixo, não ofereceram riscos de contaminação de aqüiferos tendo como base o critério estabelecido pela OMS;

- Disposições sucessivas de lodo de esgoto e composto de lixo contribuíram para o acúmulo de $\mathrm{N}$-orgânico na camada de $0-0,3 \mathrm{~m}$. Estas formas de nitrogênio são potencialmente mineralizáveis e passíveis de lixiviação;

- No ano agrícola 1997/98, tanto nos tratamentos com lodo de esgoto quanto com composto de lixo, incrementos nas concentrações de $\mathrm{N}_{-} \mathrm{NO}_{3}{ }^{-}+\mathrm{N}_{-} \mathrm{NH}_{4}{ }^{+}$, no solo, evidenciaram a intensa movimentação do nitrogênio até $1,2 \mathrm{~m}$ de profundidade; 


\section{CONCLUSÕES}

Tendo em vista os resultados obtidos pode-se concluir que, nas condições do experimento com lodo de esgoto, não foi possivel julgar a pertinência dos critérios, para metais pesados, preconizados pela USEPA - 40 CFR - Part 503 (1993). Os resultados apontaram para a necessidade de estudos a longo prazo como o principal caminho para obtenção de respostas conclusivas. Por outro lado, a lixiviação de $\mathrm{N}-\mathrm{NO}_{3}{ }^{-}$, verificada em profundidades de até $1,2 \mathrm{~m}$, foi o efeito de maior severidade, podendo conduzir à contaminação do ambiente. Dessa forma, pelo menos a curto prazo, o nitrogênio deve ser o fator mais restritivo quando da definição das taxas e freqüências de disposições, tanto do lodo de esgoto quanto do composto de lixo. 


\section{Anexo}

\section{Dificuldades surgidas na realização do experimento}

Estes comentários objetivaram essencialmente tornar pública uma série de dificuldades e imprevistos que surgiram por ocasião da realização do experimento de campo que deu origem a esta tese de doutorado. Faz-se votos de que estas informações venham a ser úteis para jovens pesquisadores, mestrandos ou doutorandos, que porventura planejem experimentos de semelhantes dimensões.

Para a realização do experimento foram necessárias, no primeiro ano, aproximadamente $25 \mathrm{Mg}$ de lodo de esgoto e $10 \mathrm{Mg}$ de composto de lixo. Para o segundo ano, estas quantidades foram aproximadamente $25 \mathrm{Mg}$ de lodo de esgoto e $12 \mathrm{Mg}$ de composto de lixo. Estas elevadas quantidades de resíduos significaram, para cada ano experimental, a necessidade de dois caminhões de lodo de esgoto e um caminhão de composto de lixo. O primeiro imprevisto surgiu por ocasião do transporte destes resíduos, uma vez que a maioria das empresas consultadas na época, se negaram a realizar o serviço devido a natureza dos materiais.

Não menos importante foi a grande demanda por mão-de-obra. Apesar de terem sido previstos recursos financeiros que acreditava-se suficientes, não imaginava-se que as operações de transporte e distribuição dos resíduos às parcelas seriam tão dispendiosas. Essas operações chegaram a ocupar oito trabalhadores por três dias, sendo pelo menos $75 \%$ do tempo ocupado na manipulação do lodo de esgoto. Este material apresenta consistência pastosa, o que o fez aderir às ferramentas, reduzindo o rendimento da operação. Convém salientar que essas informações não foram encontradas em nenhum trabalho realizado com tal resíduo.

$\mathrm{O}$ controle químico de plantas daninhas, em pré-emergência, não foi eficiente nas parcelas tratadas, provavelmente pelo efeito da adsorção das moléculas do herbicida à matéria orgânica dos resíduos. Houve, portanto, a necessidade de mais mão-de-obra 
para a realização de capina manual. Operações como cultivo, amostragens de solo em profundidade e colheita da cana-crua, também demandaram expressiva mão-de-obra. Tudo isso, evidentemente, a custos diferenciados em virtude da natureza dos materiais manipulados.

Com relação à incorporação dos resíduos, a consistência do lodo de esgoto, por si só, iria torná-la difícil e desuniforme em função de sua adesão aos implementos e aos pneus do trator. Além desta dificuldade intrínseca ao lodo de esgoto utilizado, a constante ocorrência de chuvas naquela ocasião impediram sua incorporação imediata. Assim, depois de distribuido nas parcelas, o material permaneceu na superfície do solo por alguns dias, ficando exposto às condições atmosféricas. Ainda que não tenha sido planejada, esta exposição levou à desidratação do lodo, tornando-o facilmente pulverizável e possibilitando a sua incorporação ao solo de forma relativamente homogênea.

Experimentos de campo podem não obedecer rigorosamente a um cronograma de execução. Principalmente no primeiro ano, devido à ocorrência de chuvas intensas por dias seguidos, o planejamento teve de ser refeito, pois máquinas agrícolas e homens não tinham condições de trabalho.

A primeira aplicação e incorporação dos resíduos às parcelas foi realizada no início de outubro/96, sendo que a seguir estava prevista a instalação de extratores de solução do solo para os estudos de lixiviação. Entretanto, os recursos necessários para aquisição dos referidos extratores só foram liberados pela agência financiadora do projeto no final de dezembro/96 e, consequentemente, os equipamentos, feitos sob encomenda, só ficaram prontos na segunda quinzena de janeiro/97, cerca de 100 dias da incorporação dos resíduos. Esse atraso no início das avaliações, associado às constantes chuvas ocorridas no período, prejudicariam sobremaneira as estimativas de lixiviação de metais pesados e nitrogênio inorgânico, o que resultou na não instalação dos equipamentos neste primeiro ano de experimentação. A instalação desses equipamentos foi efetuada apenas após a segunda aplicação e incorporação dos resíduos, e convém salientar a morosidade da operação devido à fragilidade da cápsula porosa dos extratores. Somando-se a isto, ocorreram alguns problemas no funcionamento dos aparelhos cujas soluções só surgiram após vários transtornos e ter causado pelo menos, a 
perda de uma amostragem de solução do solo. Como lição, a maior delas se traduz pela impossibilidade de prevermos todos os problemas possíveis de ocorrer. Assim sendo, jamais se deve partir para grandes experimentos sem a necessária familiaridade com os equipamentos e/ou materiais a serem utilizados. Os aspectos positivos ficaram por conta das experiências adquiridas.

Situações curiosas e inusitadas também ocorreram. Quem poderia imaginar que problemas sociais, que infelizmente são uma constante em nosso país, poderiam trazer um desconforto a mais para os responsáveis pela condução do experimento? Um grupo de aproximadamente 180 familias, organizados através do "Movimento dos Sem Teto", foram alocados pela Prefeitura Municipal de Piracicaba em um prédio da extinta Usina Modelo, localizada fora do perímetro urbano, porém a menos de $1000 \mathrm{~m}$ da área experimental. Em virtude deste fato, nas proximidades da área experimental, anteriormente isolada e considerada segura, aumentou o trânsito de pessoas (principalmente crianças e adolescentes) aumentando também os riscos de incêndio acidental na cana-de-açúcar e os riscos de que pessoas não informadas tivessem contato com o mercúrio metálico dos aparelhos extratores de solução do solo e tensiômetros. Outro fato curioso ficou por conta da ocorrência de rituais religiosos afro-brasileiros (a popular "macumba") nas proximidades do experimento, aumentado ainda mais o risco de incêndios. Houve portanto, a necessidades de se colocar placas de advertência e implementar um sistema de vigilância constante para o local.

Concluindo, que fique bem claro que esses comentários não intencionaram desestimular iniciativas semelhantes àquela tomada para realização desse experimento. Intensionaram sim, alertar para que possíveis imprevistos sejam considerados no planejamento de novos experimentos, tomando maiores cuidados com prazos, recursos financeiros, humanos, operacionais e, por que não, algumas particularidades sobre métodos e equipamentos a serem empregados e local onde se instalará o experimento. Caso este seja para elaboração de dissertações ou teses, ainda que se conte com o apoio irrestrito do orientador (como no presente caso), recomenda-se uma avaliação muito cuidadosa com relação aos novos prazos para titulação impostos pelos cursos e algumas agências financiadoras. 


\section{REFERÊNCIAS BIBLIOGRÁFICAS}

ABREU, C.A.; ABREU, M.F.; RAIJ, B. van.; SANTOS, W.R. Comparação de métodos de análise para avaliar a disponibilidade de metais pesados em solos. Revista Brasileira de Ciência do Solo, v. 19, p.463-468, 1995.

ABREU JUNIOR, C.H. Propriedades químicas e disponibilidade de nutrientes e de metais em diferentes solos adubados com composto de resíduo urbano. Piracicaba, 1999. 159p. Tese (Doutorado) - Escola Superior de Agricultura "Luiz de Queiroz", Universidade de São Paulo.

ADRIANO, D.C. Trace elements in the terrestrial environment. New York: Springer-Verlag, 1986. 533p.

AGBIN, N.N.; SABEY, B.R.; MARKSTROM, D.C. Land application of sewage sludge: $\mathrm{V}$. Carbon dioxide production as influenced by sewage sludge and wood waste mixtures. Journal of Environmental Quality, v.6, n.4, p.446-451, 1977.

ALCARDE, J.C.; CHITOLINA, J.C. Determinação do nitrogênio total em solos pelo método da liga de Raney. Revista de Agricultura, v.66, n. 1, p.97-106, 1991.

ALLISON, L.E. Salinity in relation irrigation. Advances in Agronomy, v.16, p.139-178, 1964.

ALLOWAY, B.J. Heavy metals in soils. New York: John Wiley \& Sons, 1990. 339p.

ALVES, W.L.; MELO, W.J.; FERREIRA, M.E. Efeito do composto de lixo urbano em um solo arenoso e em plantas de sorgo. Revista Brasileira de Ciência do Solo, v.23, n.3, p.729-736, 1999.

ALVES, W.L.; PASSONI, A.A. Composto e vermicomposto de lixo urbano na produção de mudas de oiti (Licania tomentosa (Benth)) para arborização. Pesquisa Agropecuária Brasileira, v.32, n. 10, p.1053-1058, 1997.

AMARAL SOBRINHO, N.M.B.; VELLOSO, A.C.X.; OLIVEIRA, C. Solubilidade de metais pesados em solo tratado com resíduo siderúrgico. Revista Brasileira de Ciência do Solo, v.21, n. 1, p.9-16, 1997. 
AMARAL SOBRINHO, N.M.B.; VELLOSO, A.C.X.; COSTA, L.M.; OLIVEIRA, C. Mobilidade de metais pesados em solo tratado com resíduo siderúrgico. Revista Brasileira de Ciência do Solo, v.22, n.2, p.345-353, 1998.

ANDRADE, C.A. Nitratos e metais pesados no solo e em plantas de Eucalyptus grandis após aplicação de biossólido da ETE Barueri. Piracicaba, 1999. 65p. Dissertação (Mestrado) - Escola Superior de Agricultura "Luiz de Queiroz", Universidade de São Paulo.

ANDRÉ, E.M. Atividade biológica do solo e disponibilidade de nutrientes e metais pesados para a cultura do sorgo granífero em solo acrescido de lodo de esgoto. Jaboticabal, 1994. 123p. Monografia (Graduação) - Faculdade de Ciências Agrárias e Veterinárias, Universidade Estadual Paulista "Julio de Mesquita Filho".

ANDREOLI, C.V.; PEGORINI, E.S. Gestão de biossólidos: Situação e perspectivas. In: SEMINÁRIO SOBRE GERENCIAMENTO DE BIOSSÓLIDOS DO MERCOSUL. 1., Curitiba, 1998. Anais. Curitiba: S ANEPAR ABES, 1998. p.11-18.

ANJOS, A.R.M. dos. Lixiviação de espécies químicas em latossolos sucessivamente tratados com biossólido e disponibilidade de metais pesados para plantas de milho. Piracicaba, 1999. 191p. Tese (Doutorado) - Escola Superior de Agricultura "Luiz de Queiroz", Universidade de São Paulo.

ASCHMANN, S.G.; McINTOSH, M.S.; ANGLE, J.S.; HILL, R.L. Nitrogen movement under a hardwood forest amended with liquid wastewater sludge. Agriculture, Ecosystems and Environment, v.38, n.4, p.249-263, 1992.

BACCHI, O.O.S. Botânica da cana-de-açúcar. In: ORLANDO FILHO, J. Nutrição e adubação da cana-de -açúcar no Brasil. Piracicaba: IAA/Planalsucar, 1983. cap.2, p.25-37.

BACHE, B.W. The measurement of cation exchange capacity of soils. Journal of the Science of Food and Agriculture, v.27, p.273-280, 1976.

BACKES, M.A.; KÄMPF, A.N. Substratos à base de composto de lixo urbano para a produção de plantas ornamentais. Pesquisa Agropecuária Brasileira, v.26, n.5, p.753-758, 1991.

BARBARIKA, A.; SIKORA, L.J.; COLACICCO, D. Factors affecting the mineralization of nitrogen in sewage sludge applied soils. Journal of Environmental Quality, v.49, p.1403-1406, 1985.

BARBARICK, K.A.; IPPOLITO, J.A.; WESTFALL, D.G. Biosolids effect on phosphorus, copper, zinc, nickel, and molybdenum concentrations in dryland wheat. Journal of Environmental Quality, v.24, n.4, p.608-611, 1995. 
BARRETO, M.C.V. Degradação da fração orgânica de diferentes resíduos e efeitos em algumas propriedades químicas e fisicas de dois solos. Piracicaba, 1995. 106p. Tese (Doutorado) - Escola Superior de Agricultura "Luiz de Queiroz", Universidade de São Paulo.

BASSOI, L.H.; CARVALHO, A.M. Lixiviação de macronutrientes em um solo cultivado com milho com e sem irrigação suplementar. Revista Brasileira de Ciência do Solo, v. 16, n.3, p.283-287, 1992.

BASSOI, L.H.; REICHARDT, K. Lixiviação de nitrato em Terra Roxa estruturada latossólica cultivada com milho fertirrigado. Revista Brasileira de Ciência do Solo, v. 19, n.3, p.329-335, 1995.

BATAGLIA, O.C.; BERTON, R.S.; CAMARGO, O.A.; VALADARES, J.M.A.S. Resíduos orgânicos como fontes de nitrogênio para capim-braquiária. Revista Brasileira de Ciência do Solo, v.7, p.277-284, 1983.

BAT AGLIA, O.C.; RAIJ, B.van. Efíciência de extratores de micronutrientes na análise de solo. Revista Brasileira de Ciência do Solo, v.13, p.205-212, 1989.

BAXTER, J.C.; AGUILAR, M.; BROWN, K. Heavy metals and persistent organics at a sewage sludge disposal site. Journal of Environmental Quality, v.12, n.3, p.311$316,1983$.

BENGTSON, G.W.; CORNETTE J.J. Disposal of composted municipal waste in a plantation of young slash pine: effects on soil and trees. Journal of Environmental Quality, v.2, n.4, p.441-444, 1973.

BERNAL, M.P.; SÁNCHES-MONEDERO, M.A.; PAREDES, C.; ROIG, A. Carbon mineralization from organic wastes at different composting stages during their incubation with soil. Agriculture, Ecosystems and Environment, v.69, p.175-189, 1998.

BERTI, W.R.; JACOBS, L.W. Chemistry and phytotoxicity of soil trace elements from repeated sewage sludge applications. Journal of Environmental Quality, v.25, n.5, p.1025-1032, 1996.

BERTON, R.S.; CAMARGO, O.A.; VALADARES, J.M.A.S. Absorção de nutrientes pelo milho em resposta à adição de lodo de esgoto a cinco solos paulistas. Revista Brasileira de Ciência do solo, v. 13, n.2, p.187-192, 1989.

BERTON, R.S.; VALADARES, J.M.A.S. Potencial agrícola do composto de lixo urbano no Estado de São Paulo. O Agronômico, v.4, p.87-93, 1991. 
BERTON, R.S.; VALADARES, J.M.A.S.; CAMARGO, O.A.; BATAGLIA, O.C. Peletização do lodo de esgoto e adição de $\mathrm{CaCO}_{3}$ na produção de matéria seca e absorção de $\mathrm{Zn}, \mathrm{Cu}$ e Ni pelo milho em três latossolos. Revista Brasileira de Ciência do Solo, v.21, p.685-691, 1997.

BERTONCINI, E.I. Mobilidade de metais pesados em solos tratados com lodo de esgoto. Piracicaba, 1997. 90p. Dissertação (Mestrado) - Escola Superior de Agricultura "Luiz de Queiroz", Universidade de São Paulo.

BETTIOL, W.; CARVALHO, P.C.T. Utilização do lodo de esgoto primário e fertilizantes organomineral IPT na cultura do milho. Fertilizantes, v.4, n.1, p.14-15, 1982a.

BETTIOL, W.; CARVALHO, P.C.T. Lodo de esgoto como fertilizante para a cultura do milho (Zea mayss L.) híbrido HMDO 7974. Fertilizantes, v.4, n.1, p.9-11, 1982 b.

BETTIOL, W.; CARVALHO, P.C.T.; FRANCO, B.J.D.C. Utilização do lodo de esgoto como fertilizante. O Solo, v.75, n. 1, p.44-54, 1983.

BEVACQUA, R.F.; MELLANO, V.J. Cumulative effects of sludge compost on crop yields and soil properties. Communications in Soil Science and Plant Analysis, v.25, n.3-4, p.395-406, 1994.

BIDWELL, A.M.; DOWDY, R.H. Cadmium and zinc availability to corn following termination of sewage sludge applications. Journal of Environmental Quality, v. 16, n. 4 , p.438-442, 1987.

BRASIL. Ministério da Agricultura. Secretaria Nacional de Defesa Agropecuária. Análise de corretivos, fertilizantes e inoculantes: métodos oficiais. Brasília, 1988. $104 p$.

BRASIL. Ministério da Saúde. Divisão Nacional de Vigilância Sanitária de Alimentos. Portaria no 36 - SVS/MS, de 19 de janeiro de 1990 In: Compêndio de legislação de alimentos. São Paulo, Associação Brasileira de Indústrias de Alimentação, rev.4, v.1/A, 1990. p.711-777.

BREMNER, J.M. Inorganic forms of nitrogen In: BLACK, C.A. (Ed.) Methods of Soil Analysis: Chemical Methods. Part 2. Madison: American Society of Agronomy / Soil Science Society of America, 1965. cap.9, p.1179-1237.

CAMOBRECO, V.J.; RICHA, RDS, B.K.; STEENHUIS, T.S.; PEVERLY, J.H.; McBRIDE, M.B. Movement of heavy metals through undisturbed and homogenized soil columns. Soil Science, v. 161, p.740-750, 1996.

CANABARro, M. Cidades. Administração e Vida Comunitária, p. 5, 1995. 
CARVALHO, F.J.P.C. Efeitos do lodo de esgoto na cultura do milho (Zea mays L.). Jaboticabal, 1983. 37p. Monografia (Graduação) - Faculdade de Ciências Agrárias e Veterinárias, Universidade Estadual Paulista "Julio de Mesquita Filho".

CARVALHO, P.C.T.; BARRAL, M.F. Aplicação do lodo de 'esgoto como fertilizante. Fertilizantes, v.3, n.2, p.1-4, 1981.

CASSMAN, K.G.; MUNNS, D.N. Nitrogen mineralization as affected by soil moisture, temperature, and depth. Soil Science Society of America Journal, v.44, p.1233-1237, 1980.

CAVALLARO, N.; PADILLA, N.; VILLARRUBIA, J. Sewage sludge effects on chemical properties of acid soils. Soil Science, v.156, n.2, p.63-70, 1993.

CEEJ-CONSÓRCIO ETEP-ESTATICA-JNS. Diretrizes para implantação da desidratação mecânica nas ETEs PNM e SMG e secagem térmica na ETE SMG. Relatório do Contrato SABESP 14.002/93, Rev.3, 1996.

CENTRO NACIONAL DE REFERÊNCIA EM GESTÃO AMBIENTAL URBANA. Utilização agrícola do lodo de esgoto como fertilizante. http://www.bsi.com.br/unilivre/centro/experiencias/015.html. (04 Nov 1998).

CHAE, Y.M.; TABATABAI, M.A. Mineralization of nitrogen in soils amended with organic wastes. Journal of Environmental Quality, v. 15, p. 193-198, 1986.

CHANG, A.C.; WARNEKE, J.E.; PAGE, A.L.; LUND, L.J. Accumulation of heavy metals in sewage sludge-treated soils. Journal of Environmental Quality, v. 13, n.1, p.87-91, 1984.

CHANG, A.C.; HINESLY, T.D.; BATES, T.E.; DONER, H.E.; DOWDY, R.H.; RYAN, J.A. Effects of long term sludge application on accumulation of trace elements by crops. In: PAGE, A.L.; LOGAN, T.J.; RYAN, J.A. Land application of sludge - food chain implications. Chelsea: Lewis Publishers, 1987. cap.4, p.53-66.

CHANG, A.C.; HYUN, H.; PAGE, A.L. Cadmium uptake for swiss chard grown on composted sewage sludge treated field plots: plateau or time bomb? Journal of Environmental Quality, v.26, n. 1, p.11-19, 1997.

CHINO, M.; SHIGEKO, G.; KUMAZAWA, K.; OWA, N.; YOSHIOKA, O.; TAKECHI, N.; INANAGA, S.; INOU, H.; DE-LONG, C.; YOUSSEF, R.A. Behavior of zinc and copper in soil with long term application of sewage sludges. Soil Science and Plant Nutrition, v.38, n.1, p.159-167, 1992.

CLAPP, C.E.; STARK, S.A.; CLAY, D.E.; LARSON, W.E. Sewage sludge organic matter and soil properties. In: CHEN, Y.; AVNIMELECH, Y. (Ed.) The Role of Organic Matter in Modern Agriculture. Dordrecht: Martinus Nijhoff Publishers, 1986. cap. 10, p.209-253. 
CLEMENTS, H.F. Sugarcane crop logging and crop control: principles and practices. Hawaii: University Press of Hawaii, 1980. 520p.

COLETI, J.T. Técnica cultural de plantio. In: PARANHOS, S.B. Cana-de -Açúcar cultivo e utilização. Campinas: Fundação Cargill, 1987. cap.3, p.284-332.

COMPANHIA DE SANEAMENTO DO PARANÁ. Manual técnico para utilização agrícola de lodo de esgoto no Paraná. Curitiba: SANEPAR, 1997. 96p.

COMPANHIA DE TECNOLOGIA E SANEAMENTO AMBIENTAL. Aplicação de biossólidos em áreas agrícolas - critérios para projeto e operação. São Paulo: CETESB, 1998. 36p. (Documento não homologado)

COREY, R.B.; KING, L.D.; LUE-HING, C.; FANNING, D.S.; STREET, J.J.; WALKER, J.M. Effects of sludge properties on accumulation of trace elements by crops. In: PAGE, A.L.; LOGAN, T.J.; RYAN, J.A. Land application of sludge food chain implications. Chelsea: Lewis Publishers, 1987. cap.3, p.25-51.

CRAVO, M.S. Composto de lixo urbano como fonte de nutrientes e metais pesados para alface. Piracicaba, 1995. 148p. Tese (Doutorado) - Centro de Energia Nuclear na Agricultura, Universidade de São Paulo.

CRIPPS, R.W.; WINFREE, S.K.; REAGAN, J.L. Effects of sewage sludge application method on corn production. Communications in Soil Science and Plant Analysis, v.23, n.15-16, p.1705-1715, 1992.

CUNNINGHAM, I.D.; KEENEY, D.R.; RYAN, J.A. Yield and metal composition of crop and rye grown on sewage ammended soil. Journal of Environmental Quality, v. 4, n. 4, p. $448-454,1975$.

DANG, Y.P.; CHHABRA, R.; VERMA, K.S. Effect of $\mathrm{Cd}, \mathrm{Ni}, \mathrm{Pb}$ and $\mathrm{Zn}$ on growth and chemical composition of onion and fenugreek. Communications in Soil Science and Plant Analysis, v.21, n.9-10, p.717-735, 1990.

DA ROS, C.O.; AITA, C.; CERETTA, C.A.; FRIES, M.R. Lodo de esgoto: efeito imediato no milheto e residual na associação aveia-ervilhaca. Revista Brasileira de Ciência do Solo, v.17, p.257-261, 1993.

DAVIS, R.D.; BECKETT, P.H.T. Upper critical levels of toxic elements in plants. II. Critical levels of copper in young barley, wheat, rape, lettucce, and ryegrass, and of nickel and zinc in young barley and ryegrass. New Phytology, v.80, p.23-32, 1978.

DAVIS, R.D.; CARTON-SMITH, C.H. An investigation into the phytotoxicity of zinc, copper and nickel using sewage sludge of controlled metal content. Environmental Pollution, v.8, p.163-185, 1984. 
DEMUYNCK, M.; NYNS, E.J.; NAVEAU, H. Use of digested effluents in agriculture In: WILLIAMS, J.H.; GUIDI, G.; L'HERMITE, P. (Ed.) Long-Term Effects of Sewage Sludge and Farm Slurries Applications. London: Elsevier Applied Science Publishers, 1985, p.2-13.

DOORENBOS, J.; PRUIT, W.O. Guidelines for predicting crop water requirements. Rome: Food and Agriculture Organization of the United Nations, 1975. 179p.

DOORENBOS, J.; KASSAN, A.H.; BENTVELSEN, C.L.M.;BRANSCHEID, V.; PLUSJÉ; J.M.G.A.; SMITH, M.; UITTENBOGAARD, G.O.; VAN DER WAL, H.K. Yield response to water. Rome: Food and Agriculture Organization of the United Nations, 1979. 193p.

DOWDY, R.H.; LATTERELL, J.J.; HINESLY, T.D.; GROSSMAN, R.B.; SULLIVAN, D.L. Trace metal movement in na aeric ochraqualf following 14 years of annual sludge applications. Journal of Environmental Quality, v.20, n.1, p.119-123, 1991.

ELLIOTT, H.A.; LIBERATI, M.R.; HUANG, C.P. Competitive adsortion of heavy metals by soils. Journal of Environmental Quality, v. 15, n.3, p.214-217, 1986.

EMMERICH, W.E.; LUND, L.J.; PAGE, A.L.; CHANG, A.C. Movement of heavy metals in sewage sludge-treated soils. Journal of Environmental Quality, v. 11, n.1, p.174-178, 1982.

EPSTEIN, E.; TAYLOR, J.M.; CHANEY, R.L. Effects of sewage sludge and sludge compost applied to soil on some soil physical and chemical properties. Journal of Environmental Quality, v.5, n.4, p.422-426, 1976.

EPSTEIN, E.; KEANE, D.B.; MEISINGER, J.J.; LEGG, J.O. Mineralization of nitrogen from sewage sludge and sludge compost. Journal of Environmental Quality, v.7, n.2, p.217-221, 1978.

ESCOSTESGUY, P.A.V.; PARCHEN, C.A.P.; SELBACH, P.A. Bactérias enteropatogênicas em compostos de lixo domiciliar, solo e planta. Revista Brasileira de Ciência do Solo, v. 17, p.365-369, 1993.

ESSINGTON, M.E.; MATTIGOD, S.V. Trace element solid-phase associations in sewage sludge and sludge-amended soil. Soil Science Society of America Journal, v. 55, p.350-356, 1991.

FAGERIA, N.K. Salinidade dos solos e sua influência na cultura do arroz. In: Adubação e Nutrição Mineral da Cultura do Arroz. Rio de Janeiro: EMBRAPA/Goiânia, 1984. p.302-330. 
FASSBENDER, H.W. Química de Suelos, Com Énfasis En Suelos de América Latina. Turrialba: Instituto Interamericano de Ciências Agrícolas de la OEA, 1975. 398p.

FERREIRA, M.E.; CRUZ, M.C.P. Estudo do efeito de vermicomposto sobre a absorção de nutrientes e produção de matéria seca pelo milho e propriedades do solo. Científica, v.20, n.1, p.217-227, 1992.

FERRO NETO, A. Produção racional de composto de lixo urbano. In: SEMINÁRIO SOBRE USO DE RESIDUOS INDUSTRIAIS E URBANOS EM FLORESTAS, 1., Botucatu, 1994. Trabalhos apresentados. Botucatu: FCA/UNESP, 1994. p.1-14.

FUNDAÇÃO INSTITUTO BRASILEIRO DE GEOGRAFIA E ESTATÍSTICA. Limpeza pública e remoção de lixo. Rio de Janeiro: IBGE, 1983. 2v.

GAINES, T.P.; GAINES, S.T. Soil texture effect on nitrate leaching in soil percolates. Communications in Soil Science and Plant Analysis, v.25, n.13-14, p.2651-2670, 1994.

GALLOWAY, H.M.; JACOBS, L.M. Sewage sludge I. Characteristics and management in utilization of municipal sewage sludges on land for agricultural production. In: NORTH CENTRAL REGIONAL EXTENTION PUBLICATION, Washington, 1977, p.3-17.

GHIBERTO, P.J. Metodologias para a obtenção de parâmetros utilizados em modelos de infiltração da água no solo. Piracicaba, 1999. 79p. Dissertação (Mestrado) - Escola Superior de Agricultura "Luiz de Queiroz", Universidade de São Paulo.

GILLMAN, G.P. A proposed method for the measurement of exchange properties of highly weathered soils. Australian Journal of Soil Research, v.17, p.129-139, 1979.

GILLMAN, G.P.; SUMPTER, E.A. Modification to the compulsive exchange method for measuring exchange characteristics of soils. Australian Journal of Soil Research, v.24, p.61-66, 1986

GILMOUR, C.M.; BROADBENT, F.E.; BECK, S.M. Recycling of carbon and nitrogen through land disposal of various wastes. In: ELLIOT, L.F. (Ed.) Soil for management of organic wastes and waste waters. Madison: American Society of Agronomy, 1977, p.171-194.

GINE-ROSIAS, M.F.G. Determinação espectrofotométrica simultânea de nitrato e nitrito em águas e solos por injeção em fluxo contínuo. Piracicaba, 1979. 70p. Dissertação (Mestrado) - Escola Superior de Agricultura "Luiz de Queiroz", Universidade de São Paulo. 
GIORDANO, P.M.; MORTVEDT, J.J.; MAYS, D.A. Effect of municipal wastes on crop yields and uptake of heavy metals. Journal of Environmental Quality, v.4, n.3, p.394-399, 1975.

GIUSQUIANI, P.L.; GIGLIOTTI, G.; BUSINELLI, D. Mobility of heavy metals in urban waste-amended soils. Journal of Environmental Quality, v.21, n.3, p.330$335,1992$.

GIUSQUIANI, P.L.; PAGLIAI, M.; GIGLIOTTI, G.; BUSINELLI, D.; BENETTI, A. Urban waste compost: effects on physical, chemical, and biochemical soil properties. Journal of Environmental Quality, v.24, n.1, p.175-182, 1995.

GLÓRIA, N.A. Uso agronômico de resíduos. In: REUNIÃO BRASILEIRA DE FERTILIDADE DO SOLO E NUTRIÇÃO DE PLANTAS, 22., Piracicaba, 1992. Anais. Campinas: Fundação Cargill, 1992. p.195-212.

GROSSI, M.G.L. Avaliação da qualidade dos produtos obtidos de usina de compostagem brasileiras de lixo doméstico através da determinação de metais pesados e substâncias orgânicas tóxicas. São Paulo, 1993. 222p. Tese (Doutorado) Instituto de Química, Universidade de São Paulo.

HADAS, A.; PORTNOY, R. Rates of decomposition in soil and release of available nitrogen from cattle manure and municipal waste composts. Compost Science and Utilization, v.5, n.3, p.48-54, 1997./Resumo em CAB Abstracts on CD-ROM, 1997-98/.

HALL, J.E. Stantardising and the management of biosolids the international experience. In: SEMINÁRIO SOBRE GERENCIAMENTO DE BIOSSÓLIDOS DO MERCOSUL. 1., Curitiba, 1998. Anais. Curitiba: SANEPAR/ABES, 1998. p.113-122.

HARDING, S.A.; CLAPP, C.E.; LARSON, W.E. Nitrogen availability and uptake from field soils five years after addition of sewage sludge. Journal of Environmental Quality, v.14, n.1, p.95-100, 1985.

HELLING, C.S.; CHESTERS, G.; COREY, R.B. Contribution of organic matter and clay to soil cation-exchange capacity as affected by the $\mathrm{pH}$ of the saturating solution. Soil Science of America Proceedings, v.23, n.4, p.517-520, 1964.

HINESLY, T.D.; JONES, L.R.; ZIEGLER, E.L. Effects on corn by application of heated anaerobically digest sludge. Compost Sci., v.19, n.4, p.26-30, 1972.

HOHLA, G.N.; JONES, R.L.; HINESLY, T.D. The effect of anaerobically digested sewage sludge on organic fractions of blount silt loam. Journal of Environmental Quality, v.7, n.4, p.559-563, 1978. 
HORTENSTINE, C.C.; ROTHWELL, D.F. Use of municipal compost in reclamation of phosphate-mining sand tailings. Journal of Environmental Quality, v.1, n.4, p.415-418, 1972.

HORTENSTINE, C.C.; ROTHWELL, D.F. Pelletized municipal refuse compost as a soil amendment and nutrients source for sorghum. Journal of Environmental Quality, v.2, n.3, p.343-345, 1973.

HOYT, P.B.; TURNER, R.C. Effects of organic materials added to very acid soil on $\mathrm{pH}$, aluminium, exchangeable $\mathrm{NH}_{4}$ and crop yields. Soil Science, v.119, p.227-237, 1975.

HUE, N.V. Correcting soil acidity of a highly weathered ultisol with chicken manure and sewage sludge. Communications in Soil Science and Plant Analysis, v.23, n.3-4, p.241-264, 1992.

HUE, N.V. Sewage sludge In: RECHCIGL, J.E. (Ed.) Soil amendments and environmental quality. Boca Raton: Lewis Publishers, 1995. cap.6, p.199-247.

HSIEH, Y.P.; DOUGLAS, L.A.; MOTTO, H.L. Modeling sewage sludge decomposition in soil: 1. organic carbon transformation. Journal of Environmental Quality, v.10, n. 1, p.54-59, 1981.

HYUN, H.; CHANG, A.C.; PARKER, D.R.; PAGE, A.L. Cadmium solubility and phytoavailability in sludge-treated soil: effects of soil organic carbon. Journal of Environmental Quality, v.27, n.2, p.329-334, 1998.

INMAN, J.C.; McINTOSH, M.S.; FOSS, J.E.; WOLF, D.C. Nitrogen and phosphorus movement in compost-amended soils. Journal of Environmental Quality, v.11, n.3, p.529-532, 1982.

JENKINSON, D.S.; POWLSON, D.S. The effects of biocidal treatments on metabolism in soil-1. Fumigation of chloroform. Soil Biology and Biochemistry, v.8, n.1, p.167-177, 1976.

JONES, R.L.; HINESLY, T.D. Nitrate from sewage-sludge amended lysimeters. Environmental Pollution, v.51, n. 1, p.19-30, 1988.

KABATA-PENDIAS, A.; ADRIANO, D.C. Trace metals In: RECHCIGL, J.E. (Ed.) Soil amendments and environmental quality. Boca Raton: Lewis Publishers, 1995. cap.4, p.139-167. 
KABATA-PENDIAS, A.; PENDIAS, $\mathrm{H}$. Trace elements in soil and plants. Boca Raton: CRC Press, 1984. 315p.

KALBASI, M.G.; RACZ, J.; LOEWEN-RUDGERS, L.A. Mechanism of Zn adsortion by iron and aluminum oxides. Soil Science, v.125, p.146-150, 1978.

KELLER, C.; VÉDY, J.C. Distribution of copper and cadmium fractions in two forest soils. Journal of Environmental Quality, v.23, n.5, p.987-999, 1994.

KELLING, K.A.; WALSH, L.M.; KEENEY, D.R.; RYAN, J.A.; PETERSON, A.E. A field study of the agricultural use of sewage sludge: II. Effect on soil $\mathrm{N}$ and $\mathrm{P}$. Journal of Environmental Quality, v.6, n.4, p.345-352, 1977.

KHALEEL, R.; REDDY, K.R.; OVERCASH, M.R. Changes in soil physical properties due to organic wastes applications: a review. Journal of Environmental Quality, v.10, n.2, p.133-141, 1981.

KIEHL, E.J. Fertilizantes Orgânicos. Piracicaba: Editora Agronômica Ceres, 1985. $492 p$.

KIEKENS, L.; COTTENIE, A. Principles of investigation on the mobility and plant uptake of heavy metals. In: LESCHBER, R.; DAVIES, R.D.; L'HERMITE, P. Chemical methods for assessing bioavailability metals in sludge and soils. London: Elsevier, 1985. p.32-41.

KING, L.D.; HAJJAR, L.M. The residual effect of sewage sludge on heavy metal content of tobacco and peanut. Journal of Environmental Quality, v.19, n.4, p.738-748, 1990.

KING, L.D.; MORRIS, H.D. Land disposal of liquid sewage sludge II. The effect on soil $\mathrm{pH}$, manganese, zinc, and growth and chemical composition of rye (Cecale cereale L.). Journal of Environmental Quality, v.1, n.4, p.425-429, 1972.

KIRKHAM, M.B. Agricultural use of phosphorus in sewage sludge. Advances in Agronomy, v.35, p.129-163, 1982.

KUCHENRITHER, R.D.; McMILLAN, S.I. Preview analysis of national sludge survey. BioCycle, v.32, p.60-62, 1990.

LAMY, I.; BOURGEOIS, S.; BERMOND, A. Soil Cadmium mobility as a consequence of sewage sludge disposal. Journal of Environmental Quality, v.22, n.4, p.731$737,1993$. 
LATTERELL, J.J.; DOWDY, R.H.; LARSON, N.E. Correlation of extractable metals and uptake of snap beans grown on soil amended with sewage sludge. Journal of Environmental Quality, v.7, n.3, p.435-440, 1978.

LESCHBER, R.; DAVIES, R.D.; L'HERMITE, P. Chemical methods for assessing bioavailability metals in sludge and soils. Lodon: Elsevier, 1985. 96p.

LESLIE, R. Liquid sludges as a farm fertilizer. Compost Sci., v.11, p.24-25, 1970.

LEVI-MINZI, R.; RIFFALDI, R.; SAVIOZZI, A. Carbon mineralization in soil amended with different organic materials. Agriculture, Ecosystems and Environment, v.31, p.325-335, 1990.

LEVINE, M.B.; HALL, A.T.; BARRETT, G.W.; TAYLOR, D.H. Heavy metal concentrations during ttemyears of sludge treatment to na old-field community. Journal of Environmental Quality, v. 18, n.4, p.411-418, 1989.

LIBARDI, P.L.; REICHARDT, K. Destino de uréia aplicada a um solo tropical. Revista Brasileira de Ciência do Solo, v.2, p.40-44, 1978.

LIMA, J.S.; LICHTIG, J.; OLIVEIRA, E.; MENK, J.R.F. Composto feito de lixo pode contaminar hortaliças. Ciência Hoje, v.24, p.57-9, 1998.

LINDEMANN, W.C.; CARDENAS, M. Nitrogen mineralization potential and nitrogen transformations of sludge-amended soil. Soil Science Society of America Journal, v.48, p.1072-1077, 1984.

LINDSAY, W.L.; NORVELL, W.A. Development of a DTPA test for zinc, iron, manganese and copper. Soil Science Society of America Journal, v.42, p.421-428, 1978.

LINDSAY, W.L. Solid phase-solution equilibria in soils. In: DOWDY, R.H.; RYAN, J.A.; VOLK, V.V.; BAKER, D.E. (Ed.). Chemistry in the soil environment. Madison: American Society of Agronomy and Soil Science Society of America, 1981. cap.10, p.183-202.

LOGAN, T.J.; CHANEY, R.L. Metals. In: WORKSHOP ON UTILIZATION OF MUNICIPAL WASTEWATER AND SLUDGE ON LAND, Riverside, 1983. Proceedings. Riverside: University of California, 1983. p.235-323.

LOGAN, T.J.; LINDSAY, B.J.; GOINS, L.E.; RYAN, J.A. Field Assessment of sludge metal bioavailability to crops: sludge rate response. Journal of Environmental Quality, v.26, n.2, p.534-550, 1997. 
LOPES, A.J.R.; STAMFORD, N.P.; FIGUEIREDO, M.U.B.; BURITY, H.A.; FERRAZ, E.B. Respostas da aplicação de composto de lixo urbano, nitrogênio mineral e produtos mineralizantes na fixação de $\mathrm{N}_{2}$ e no rendimento de caupi. Revista Brasileira de Ciência do Solo, v.20, n.1, p.55-62, 1996.

LOPES, M.S. Salinidade: quais as conseqüências. Lavoura Arrozeira, v.42, n.383, p.6-10, 1989.

LORD, E.; SHEPHERD, M.A. Developments in the use of porous ceramic cups for measuring nitrate leaching. Journal of Soil Science, v.44, p.435-449, 1993.

LUDUVICE, M. Gestão de biossólidos e o mercosul. In: SEMINÁRIO SOBRE GERENCIAMENTO DE BIOSSÓLIDOS DO MERCOSUL. 1., Curitiba, 1998. Palestras. Curitiba: SANEPAR/ABES, 1998. p.9-10.

LUND, L.J.; PAGE, A.L.; NELSON, C.O. Movement of heavy metals below sewage disposal ponds. Journal of Environmental Quality, v.5, n.3, p.330-334, 1976.

MACCALA, T.M.; PETERSON, J.R.; LUE-HING, C. Properties of agricultural and municipal waste. In: ELLIOT, L.F. (Ed.) Soils for management of organic wastes and wastes waters. Madison: Soil Science Society of America, 1986. p.11-43.

MALAVOLTA, E. Elementos de nutrição mineral de plantas. São Paulo: Editora Agronômica Ceres, 1980. 251p.

MARCIANO, C.R. Incorporação de resíduos urbanos e as propriedades físico-hídricas de um Latossolo Vermelho Amarelo. Piracicaba, 1999. 93p. Tese (Doutorado) Escola Superior de Agricultura "Luiz de Queiroz", Universidade de São Paulo.

MARSCHNER, H. Mineral nutrition of higher plants. London: Academic Press, 1995. 889p.

MARQUES, M.O. Efeitos da aplicação de lodo de esgoto na produtividade e qualidade da cana-de-açúcar. Piracicaba, 1990. 164p. Tese (Doutorado) - Escola Superior de Agricultura "Luiz de Queiroz", Universidade de São Paulo.

MARQUES, M.O. Incorporação de lodo de esgoto em solo cultivado com cana-de-açúcar. Jaboticabal, 1996. 111 p. Tese (Livre Docência) - Faculdade de Ciências Agrárias e Veterinárias, Universidade Estadual Paulista "Julio de Mesquita Filho".

MATOS, A.T.; FONTES, M.P.F.; JORDÃO, C.P.; COSTA, L.M. Mobilidade e formas de retenção de metais pesados em Latossolo Vermelho Amarelo. Revista Brasileira de Ciência do Solo, v.20, p.379-386, 1996. 
MATTIAZZO, M.E.; GLÓRIA, N.A. Effect of vinasse on soil acidity. Water Science and Technology, v.19, n.7, p.1293-1296, 1987.

MAYNARD, A.A.; HILL, D.E. Impact of compost on vegetable yields. BioCycle, v.35, n.3, p.66-67,1994.

MAYS, D.A.; TERMAN, G.L.; DUGAN, J.C. Municipal compost: effects on crop yield and soil properties. Journal of Environmental Quality, v.2, n.1, p.89-92, 1973.

MAZUR N.; SANTOS, G.A.; VELLOSO, A.C.X. Efeito do composto de resíduo urbano na disponibilidade de fósforo em solos ácidos. Revista Brasileira de Ciência do Solo, v.7, n.2, p.153-156, 1983a.

MAZUR, N.; VELLOSO, A.C.X.; SANTOS, G.A. Efeito do composto de resíduo urbano no $\mathrm{pH}$ e alumínio trocável em solos ácidos. Revista Brasileira de Ciência do Solo, v.7, n.2, p.157-159, 1983 b.

McBRIDE, M.B. Toxic metal accumulation from agricultural use of sludge: are USEPA regulations protective? Journal of Environmental Quality, v. 24, n. 1, p.5-18, 1995.

McBRIDE, M.B.; RICHARDS, B.K.; STEENHUIS, T.; RUSSO, J.J.; SAUVÉ, S. Mobility and solubility of toxic metals and nutrients in soil fifteen years after sludge application. Soil Science, v.162, n.7, p.487-500, 1997.

MEDALIE, L.; BOWDEN, B.; SMITH, C.T. Nutrient leaching following land application of aerobically digested municipal sewage sludge in a northern hardwood forest. Journal of Environmental Quality, v.23, n.1, p.130-138, 1994.

MEHLICH, A. Mehlich 3 soil test extractant: a modification of Mehlich 2 extractant. Communications in Soil Science and Plant Analysis, v.15, n.12, p.1409-1416, 1984.

MEIRELLES, N.M.F.; LIBARDI, P.L.; REICHARDT, K. Absorção e lixiviação de nitrogênio em cultura de feijão (Phaseolus vulgaris L.). Revista Brasileira de Ciência do Solo, v.4, p.83-88, 1980.

MELO, W.J.; MARQUES, M.O.; SANTIAGO, G.; CHELLI, R.A.; LEITE, S.A.S. Efeito de doses crescentes de lodo de esgoto sobre frações da matéria orgânica e CTC de um latossolo cultivado com cana-de-açúcar. Revista Brasileira de Ciência do Solo, v.18, p.449-455, 1994.

MELO, W.J.; MARQUES, M.O.; SILVA, F.C.; BOARETTO, A.E. Uso de resíduos sólidos urbanos na agricultura e impactos ambientais (compact disc) In: CONGRESSO BRASILEIRO DE CIÊNCIA DO SOLO, 26., Rio de Janeiro, 1997. Anais: trabalhos. Rio de Janeiro: SBCS, 1997. 
METZGER, L.; YARON, B. Influence of sludge organic matter on soil physical properties. Advances in Soil Science, v.7, p. 141-163, 1987.

MILLER, R.H. Factors affecting the decomposition of an anaerobically digested sewage sludge in soil. Journal of Environmental Quality, v.3, n.4, p.376-380, 1974.

MISSELBROOK, T.H.; SHEPHERD, M.A.; PAIN, B.F. Sewage sludge applications to grassland: influence of sludge type, time and method of application on nitrate leaching and herbage yield. Journal of Agricultural Science, v.126, p.343-352, 1996.

MORAES, J.F.V.; DYNIA, J.F. Uso de cápsulas porosas para extrair solução do solo. Pesquisa Agropecuária Brasileira, v.25, n. 10, p. 1523-1528, 1990.

MULCHI, C.L.; ADAMU, C.A.; BELL, P.F.; CHANEY, R.L. Residual heavy metal concentrations in sludge-amended coastal plain soils - I. Comparison of extractants. Communications in Soil Science and Plant Analysis, v.22, n.9-10, p.919-941, 1991.

MUCHOVEJ, R.M.C.; RECHCIGL, J.E. Nitrogen fertilizers In: RECHCIGL, J.E. (Ed.) Soil amendments and environmental quality. Boca Raton: Lewis Publishers, 1995. cap. 1, p.1-64.

NIEUWENHUIZE, J.; POLEY-VOS, C.H.; AKKER, A.H.van den ; DELFT, W.van. Comparison of microwave and conventional extraction techniques for the determination of metals in soil, sediment and sludge samples by atomic spectrometry. Analyst, v.116, p.347-351, 1991.

OLIVEIRA, F.C. Efeito da aplicação de lodo de esgoto em Latossolo Vermelho Escuro textura média e em sorgo granifero. Jaboticabal, 1992. 99p. Monografia (Graduação) - Faculdade de Ciências Agrárias e Veterinárias, Universidade Estadual Paulista "Julio de Mesquita Filho".

OLIVEIRA, F.C. Metais pesados e formas nitrogenadas em solos tratados com lodo de esgoto. Piracicaba, 1995. 106p. Dissertação (Mestrado) - Escola Superior de Agricultura "Luiz de Queiroz", Universidade de São Paulo.

ORLANDO FILHO, J.; ZAMBELLO JUNIOR, E.; HAAG, H.P. Influência do solo na absorção de cobre pela cana-de-açúcar, variedade CB 41-76 em função da idade. In: CONGRESSO NACIONAL DA SOCIEDADE DE TÉCNICOS AÇÚCAREIROS DO BRASIL, 1., Maceió, 1979. Anais: trabalhos. Maceió, 1980a.

ORLANDO FILHO, J.; ZAMBELLO JUNIOR, E.; HAAG, H.P. Absorção e remoção de zinco pela cana-de-açúcar, variedade $C B$ 41-76, em três solos no Estado de São Paulo. Brasil Açúcareiro,v.96, n.2, p.21-30, 1980b. 
PAGE, A.L.; LOGAN, T.J.; RYAN, J.A. Land application of sludge - food chain implications. Chelsea: Lewis Publishers, 1987. 168p.

PAGLIAI, M.; GUIDI,G.; LAMARCA, M.; GIACHETTI, M.; LUCAMANTE, G. Effects of sewage sludge and composts on soil porosity and aggregation. Journal of Environmental Quality, v.10, n.4, p.556-561, 1981.

PASCUAL, J.A.; HERNANDEZ, T.; GARCIA, C.; GARCIA, A. Changes in the organic matter mineralization rates of na arid soil after amendment with organic wastes. Arid Soil Research and Rehabilitation, v.12, n.1, p.63-72, 1998a. /Resumo em CAB Abstracts on CD-ROM, v.3A, 1998-99/.

PASCUAL, J.A.; HERNANDEZ, T.; GARCIA, C.; AYUSO, M. Carbon mineralization in na arid soil amended with organic wastes of varying degrees of stability. Communications in Soil Science and Plant Analysis, v.29, n.7-8, p.835-846, 1998 b.

PEARSON, R.G. Hard and soft acids and bases. Journal of America Chemistry Society, v.85, p.3533-3539, 1963.

PEIXOTO, R.T.G.; FRANCO, A.A.; ALMEIDA, D.L. Efeito do lixo urbano compostado com fosfato natural na nodulação, crescimento e absorção de fósforo em feijoeiro. Pesquisa Agropecuária Brasileira, v.22, n.11-12, p.1117-1132, 1987.

PEREIRA NETO, J.T. Monitoramento da eliminação de organismos patogênicos durante a compostagem do lixo urbano e lodo de esgoto pelo sistema de pilhas estáticas aeradas. Engenharia Sanitária, v.27, n.2, p.148-152, 1988.

PIETZ, R.I.; CARLSON, C.R.; PETERSON JÚNIOR， J.R.; ZENZ， D.R.; LUE-HING, C. Application of sewage sludge and other amendments to coal refuse material: III. Effects on percolate water composition. Journal of Environmental Quality, v.18, p.174-179, 1989.

RAIJ, B.van; QUAGGIO, J.A.; CANTARELLA, H.; FERREIRA, M.E.; LOPES, A.S.; BATAGLIA, O.C. Análise química do solo para fins de fertilidade. Campinas: Fundação Cargill, 1987. 170p.

RAIJ, B. van. Fertilidade do solo e adubação. São Paulo: Editora Agronômica Ceres, 1991. 343p.

RAIJ, B.van.; CANTARELLA, H.; QUAGGIO, J.A.; FURLANI, A.M.C. Recomendações de adubação e calagem para o Estado de São Paulo. Campinas: IAC, 1996. 285p. 
RAPPAPORT, B.D.; MARTENS, D.C.; RENEAU JUNIOR, R.B.; SIMPSON, T.W. Metal availability in sludge-amended soils with elevated metal levels. Journal of Environmental Quality, v.17, n.1, p.42-47, 1988.

RYAN, J.A.; KEENEY, D.R.; WALSH, L.M. Nitrogen transformations and availability of na anaerobically digested sewage sludge in soil. Journal of Environmental Quality, v.2, p.489-492, 1973.

REED, B.E.; CARRIERE, P.E.; MATSUMOTO, M.R. Applying sludge on agricultural land. BioCycle, v.32, n.7, p.58-60, 1991.

REED, S.T.; MARTENS, D.C. Copper and Zinc. In: SPARKS, D.L. (Ed.) Methods of Soil Analysis: Chemical Methods. Part 3. Madison: American Society of Agronomy / Soil Science Society of America, 1996. cap.26, p.703-722.

REICHARDT, K.; LIBARDI, P.L.; MEIRELLES, N.M.F.; FERREYRA, F.F.H.; ZAGATTO, E.A.G.; MATSUI, E. Extração e análise de nitratos em solução de solo. Revista Brasileira de Ciência do Solo, v.1, p.130-132, 1977.

REICHARDT, K.; LIBARDI, P.L.; VICTÓRIA, R.L.; VIEGAS, G.P. Dinâmica do nitrogênio num solo cultivado com milho. Revista Brasileira de Ciência do Solo, v.3, p.17-20, 1979.

RIBEIRO, A.C.; TUCUNANGO SARABIA, W.A. Avaliação de extratores para zinco e boro disponiveis em latossolos do triângulo mineiro. Revista Brasileira de Ciência do Solo, v.8, p.85-89, 1984.

RITTER, W.F.; EASTBURN, R.P. Leaching of heavy metals from sewage sludge through coastal plain soils. Communication in Soil Science and Plant Analysis, v.9, n.9, p.785-798, 1978.

ROCA, J.; POMARES, F. Prediction of available heavy metals by six chemical extractants in a sewage sludge-amended soil. Communications in Soil Science and Plant Analysis, v.22, n. 19-20, p.2129-2136, 1991.

RODELLA, A.A.; FISCHER, K.R.; ALCARDE, J.C. Cation exchange capacity of na acid soil as influenced by different sources of organic matter. Communications in Soil Science and Plant Analysis, v.26, n. 17-18, 1995.

RODELLA, A.A. Métodos de avaliação de materiais orgânicos e efeitos de sua incorporação ao solo sobre a mobilização de macronutrientes. Piracicaba, 1996. 148p. Tese (Livre Docência) - Escola Superior de Agricultura "Luiz de Queiroz", Universidade de São Paulo. 
RODELLA, A.A.; ALCARDE, J.C. Avaliação de materiais orgânicos empregados como fertilizantes. Scientia Agrícola, v. 51, n.3, 556-562, 1994.

RODELLA, A.A.; ALCARDE, J.C. Legislação sobre micronutrientes e metais pesados In: SIMPÓSIO SOBRE MICRONUTRIENTES E ELEMENTOS TÓXICOS NA AGRICULTURA, 1., Jaboticabal, 1999. Palestras apresentadas. Jaboticabal: FCAV/UNESP, 1999. (No prelo)

ROSS, S.M. Toxic metals in soil-plant-systems. New York: John Wiley \& Sons, 1994. $469 \mathrm{p}$.

SABEY, B.R.; AGBIN, N.N.; MARKSTROM, D.C. Land application of sewage sludge. Journal of Environmental Quality, v.6, n. 1, p.52-58, 1977.

SAWHNEY, B.L.; BUGBEE, G.J.; STILWELL, D.E. Leachability of heavy metals from growth media containing source-separated municipal solid waste compost. Journal of Environmental Quality, v.23, p.718-722, 1994.

SANTOS, H.F. Aplicação do lodo de estações de tratamento de esgotos em solos agrícolas. Revista D.A.E., v.32, n.122, p.31-40, 1979.

SANTOS, H.F.; TSUTIYA, M.T. Aproveitamento e disposição do lodo de estações de tratamento de esgotos do Estado de São Paulo. (mimeografado, sem data).

SAS INSTITUTE INC. SAS-Statistical analysis system (software). Cary: SAS Institute Inc., 1998.

SETZER, J. Atlas climático e ecológico do Estado de São Paulo. São Paulo: Comissão Interestadual da Bacia Paraná-Uruguai, 1966. 61p.

SHEPHERD, M.A. Factors affecting nitrate leaching from sewage sludges applied to a sandy soil in arable agriculture. Agriculture, Ecosystems and Environment, v.58, n.2-3, p.171-185, 1996.

SIDLE, R.C.; KARDOS, L.T. Nitrate leaching in sludge-treated forest soil. Soil Science Society of America Journal, v.43, p.278-282, 1979.

SILVA, F.C. Uso agronômico de lodo de esgoto: efeitos em fertilidade do solo e qualidade da cana-de-açúcar. Piracicaba, 1995. 170p. Tese (Doutorado) - Escola Superior de Agricultura "Luiz de Queiroz", Universidade de São Paulo.

SIMEONI, L.A.; BARBARICK, K.A.; SABEY, B.R. Effect of small-scale composting of sewage sludge on heavy metal availability to plants. Journal of Environmental Quality, v.13, n.2, p.264-268, 1984. 
SINGH, B.R.; NARWAL, R.P. Plant availability of heavy metals in a sludge-treated soil: II. Metal extractability compared with plant metal uptake. Journal of Environmental Quality, v.13, n.3, p.344-349, 1984.

SINGH, R.N.; KEEFER, R.F. Uptake of nickel and cadmium by vegetables grown on soil amended with different sewage sludges. Agriculture, Ecosystems and Environment, v.25, p.27-38, 1989.

SLOAN, J.J.; BASTA, N.T. Remediation of acid soils by using alkaline biosolids. Journal of Environmental Quality, v.24, n. 6, p. 1097-1103, 1995.

SMILDE, K.W.; VAN-LUIT, B.; VAN-DRIEL, W. The adsorption by soil and extracting by plants of applied zinc and cadmium. Plant and Soil, v. 143, p.233-238, 1992.

SOMMERS, L.E.; NELSON, D.W.; YOST, K.J. Variable nature of chemical composition of sewage sludges. Journal of Environmental Quality, v.5, n.3, p.303-306, 1976.

SOMMERS, L.E. Chemical composition of sewage sludges and analysis of their potential use as fertilizers. Journal of Environmental Quality, v.6, n.2, p.225-232, 1977.

SOBRAL, F.A.; WEBER, H. Nutrição mineral da cana-de-açúcar (micronutrientes). In: ORLANDO FILHO, J. Nutrição e adubação da cana-de-açúcar no Brasil. Piracicaba: Planalsucar, 1983. cap.5, p.103-122.

SOCCOL, V.T. Aspectos sanitários do lodo de esgoto. In: SEMINÁRIO SOBRE GERENCIAMENTO DE BIOSSÓlIDOS DO MERCOSUL. 1., Curitiba, 1998. Palestras. Curitiba: SANEPAR/ABES, 1998. p.65-72.

SOMMERS, L.; VOLK, V.V.; GIORDANO, P.M.; SOPPER, W.E.; BASTIAN, R. Effects of soil properties on accumulation of trace elements by crops. In: PAGE, A.L.; LOGAN, T.J.; RYAN, J.A. Land application of sludge - food chain implications. Chelsea: Lewis Publishers, 1987. cap.2, p.5-24.

SPIRONELLO, A.; RAIJ, B.van.; PENATTI, C.P.; CANTARELLA, H.; MORELLI, J.L.; ORLANDO FILHO, J.; LANDELL, M.G.A.; ROSSETO, R.; Cana-de-açúcar. In: RAIJ, B.van.; CANTARELlA, H.; QUAGGIO, J.A.; FURLANI, A.M.C. (Ed.) Recomendações de adubação e calagem para o Estado de São Paulo. Campinas: IAC, 1996. p.237-239.

SPOSITO, G.; LUND, L.J.; CHANG, A.C. Trace metal chemistry in arid-zone field soil amended with sewage sludge: I. Fractionation of $\mathrm{Ni}, \mathrm{Cu}, \mathrm{Zn}, \mathrm{Cd}$ and $\mathrm{Pb}$ in solid phases. Soil Science Society of America Journal, v.46, p. 260-264, 1982. 
STARK, S.A.; CLAPP, C.E. Residual nitrogen availability from soils treated with sewage sludge in a field experiment. Journal of Environmental Quality, v.9, n.3, p.505-512, 1980.

STOTZKY, G. Microbial respiration In: BLACK, C.A. (Ed) Methods of soil analysis: chemical and microbiological properties. part 2. Madison: American Society of Agronomy, 1965. cap. 113, p.1550-1572.

STRATTON, M.L.; BARKER, A.V.; RECHCIGL, J.E. Compost In: RECHCIGL, J.E. (Ed.) Soil amendments and environmental quality. Boca Raton: Lewis Publishers, 1995. cap.7, p.249-310.

SUAREZ, D.L. Prediction of $\mathrm{pH}$ errors in soil: water extractors due to degassing. Soil Science Society of America Journal, v.51, p.64-67, 1987.

SUMNER, M.E.; MILLER, W.P. Cation exchange capacity and exchange coefficients In: SPARKS, D.L. (Ed.) Methods of Soil Analysis: Chemical Methods. Part 3. Madison: American Society of Agronomy / Soil Science Society of America, 1996. cap.40, p.1201-1230.

TAYLOR, R.W.; XIU, H.; MEHADI, A.A.; SHUFORD, J.W.; TADESSE, W. Fractionation of residual cadmium, copper, nickel, lead, and zinc in previously sludge-amended soil. Communications in Soil Science and Plant Analysis, v.26, n. 13-14, p.2193-2204, 1995.

TERRY, R.E.; NELSON, D.W.; SOMMERS, L.E. Carbon cycling during sewage sludge decomposition in soils. Soil Science Society of America Journal, v.43, p.494-499, 1979a.

TERRY, R.E.; NELSON, D.W.; SOMMERS, L.E. Decomposition of anaerobically digested sewage sludge as affected by soil environmental conditions. Journal Environmental Quality, v.8, n.3, p.342-347, 1979b.

TESTER, C.F.; SIKORA, L.J.; TAYLOR, J.M.; PARR, J.F. Decomposition of sewage sludge compost in soil: I. $\mathrm{C}$ and $\mathrm{N}$ transformation. Journal of Environmental Quality, v.6, n.4, p.459-463, 1977.

TESTER, C.F. Organic amendment effects on physical and chemical properties of sandy soil. Soil Science Society of America Journal, v.54, p.827-831, 1990.

TRINDADE, A.V.; VILDOSO, C.I.A.; MUCHOVEJ, R.M.C.; COSTA, L.M. Interação de composto de lixo urbano e fungos micorrizicos na nutrição e crescimento do milho. Revista Brasileira de Ciência do Solo, v.20, n.2, p.199-208, 1996. 
USEPA (United States Environmental Protection Agency). Title 40 CFR - Part 503. Final rules: Standards for the use or disposal of sewage sludge. Federal Register, v.58, n.32, p.9387-9415, 1993.

VAN-LOON, J.C. Selected methods of trace metal analysis: biological and environmental samples. New York: John Wiley \& Sons, 1985. p.289-291.

VANZOLINI, S. Incorporação de calcário, lodo de esgoto e vinhaça na cultura do sorgo granifero (Sorghum bicolor (L.) Moench) em Areia Quartzosa, em condições de casa de vegetação. Jaboticabal, 1994. 114p. Monografia (Graduação) - Faculdade de Ciências Agrárias e Veterinárias, Universidade Estadual Paulista "Julio de Mesquita Filho".

VICTORIA, R.L.; PICCOLO, M.C.; VARGAS, A.A.T. O ciclo do nitrogênio In: CARDOSO, E.J.B.N.; TSAI, S.M.; NEVES, M.C.P. (Ed.) Microbiologia do Solo. Campinas: Sociedade Brasileira de Ciência do Solo, 1992. cap.8, p. 105-120.

WALKLEY, A.; BLACK, I.A. An examination of the Degtjareff method for determining soil organic matter and a proposed modification of the chromic acid titration method. Soil Science, v.37, p.29-38, 1934.

WALLACE, A. Additive, protective, and synergistic effects on plants with excess trace elements. Soil Science, v.133, p.319-323, 1982.

WALLACE, A.; BERRY, W.L. Dose-response curves for zinc, cadmium, and nickel in combinations of one, two or three. Soil Science, v.147, p.401-410, 1989.

WALLACE, A.; WALLACE, G. A. A possible flaw in EPA's 1993 new sludge rule due heavy metal interactions. Communications in Soil Science and Plant Analysis, v. 25, n. 1-2, p.129-135, 1994.

WEAR, J.I.; SOMMER, A.L. Acid-extractable zinc of soils in relation to the occurrence of zinc-deficiency symptoms in corn: A method of analysis. Soil Science Society of America Proceedings, v.12, p.143-144, 1948.

WELCH, J.E.; LUND, L.J. Zinc movement in sewage-sludge-treated soil as influenced by soil properties, irrigation water quality, and soil moisture level. Soil Science, v. 147, n.3, p.208-214, 1989.

WILLIAMS, D.E.; VLAMIS, J.; PUKITE, A.H.; COREY, J.E. Trace element accumulation, movement, and distribution in the soil profile from massive applications of sewage sludge. Soil Science, v.129, n.2, p.119-132, 1980. 
WILLIAMS, D.E.; VLAMIS, J.; PUKITE, A.H.; COREY, J.E. Metal movement in sludge-treated soils after six years of sludge addition: 1. Cadmiun, copper, lead, and zinc. Soil Science, v.137, n.5, p.351-359, 1984.

WILLIAMS, D.E.; VLAMIS, J.; PUKITE, A.H.; COREY, J.E. Metal movement in sludge-amended soils: a nine-year study. Soil Science, v.143, n.2, p.124-131, 1987.

WILLIAMS, S. (Ed.) Official methods of soil analysis of the Association of Official Analytical Chemists. 14.Ed. Arlington, AOAC, 1984. 1141p.

XIN, T.H.; TRAINA, S.J.; LOGAN, T.J. Chemical properties of municipal solid waste compost. Journal of Environmental Quality, v.21, n.3, p.318-329, 1992.

ZONTA, E.P.; MACHADO, A.A.; SILVEIRA JUNIOR, P. Sistemas de análise estatística para microcomputadores: manual de utilização. Pelotas, 1987. 145p. 


\section{APÊNDICE 1}

Precipitação pluviométrica $(\mathrm{mm})$ registrada próximo a área experimental no decorrer do ano de 1996.

\begin{tabular}{|c|c|c|c|c|c|c|}
\hline \multirow[b]{2}{*}{ Dia } & \multicolumn{6}{|c|}{ Meses } \\
\hline & Jul. & Ago. & Set. & Out. & Nov. & Dez. \\
\hline 01 & - & - & 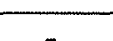 & - & 120 & - \\
\hline 02 & - & - & 5,2 & - & 7,2 & 5,0 \\
\hline 03 & 1,8 & - & 8,0 & 51,4 & 20,4 & - \\
\hline 04 & - & - & 31,4 & 17,2 & 4,2 & 0,6 \\
\hline 05 & - & - & 6,2 & - & - & 9,2 \\
\hline 06 & - & - & 5,0 & - & - & 1,4 \\
\hline 07 & - & - & - & 16,6 & - & 0,2 \\
\hline 08 & - & - & - & - & - & 5,0 \\
\hline 09 & - & - & 23,6 & - & - & - \\
\hline 10 & - & 10,2 & 19,2 & - & - & - \\
\hline 11 & - & 2,6 & 37,9 & 30,0 & - & 22,2 \\
\hline 12 & - & 0,4 & - & - & - & 3,2 \\
\hline 13 & - & - & - & 47,8 & 6,4 & 6,8 \\
\hline 14 & - & - & - & 38,8 & 4,0 & 0,8 \\
\hline 15 & - & 8,9 & - & - & 12,8 & - \\
\hline 16 & - & - & - & - & 58,4 & - \\
\hline 17 & - & - & 7,2 & - & 0,8 & 43,2 \\
\hline 18 & - & - & - & - & 47,8 & 10,8 \\
\hline 19 & - & - & - & - & - & - \\
\hline 20 & - & - & - & 4,6 & 39,8 & 3,4 \\
\hline 21 & - & - & - & 18,0 & 49,0 & 3,0 \\
\hline 22 & - & - & - & - & 0,8 & 32,8 \\
\hline 23 & - & - & - & - & - & - \\
\hline 24 & - & - & - & - & - & - \\
\hline 25 & - & - & 3,4 & - & - & - \\
\hline 26 & - & - & 0,4 & 20,0 & - & 4,0 \\
\hline 27 & - & - & - & 1,4 & - & 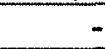 \\
\hline 28 & 1,0 & - & - & 9,2 & - & 16,4 \\
\hline 29 & - & - & - & - & - & 6,8 \\
\hline 30 & - & - & - & - & - & 6,4 \\
\hline 31 & - & - & - & - & - & 2,2 \\
\hline Total & 2,8 & 22,1 & 147,5 & 255,0 & 263,6 & 183,4 \\
\hline
\end{tabular}

Total do período: $874,4 \mathrm{~mm}$ 
Precipitação pluviométrica $(\mathrm{mm})$ registrada próximo a área experimental no decorrer do ano de 1997.

\begin{tabular}{|c|c|c|c|c|c|c|c|c|c|c|c|c|}
\hline & \multicolumn{12}{|c|}{ Meses } \\
\hline Dia & Jan. & Fev. & Mar. & Abr. & Mai. & Jun. & Jul. & Ago. & Set. & Out. & Nov. & Dez. \\
\hline 01 & - & 38,8 & - & 22,2 & - & - & - & - & - & 0,2 & - & - \\
\hline 02 & - & 2,0 & - & - & - & - & - & - & - & 16,8 & 42,6 & 6,2 \\
\hline 03 & - & 17,4 & - & 4,4 & - & - & - & - & - & - & - & 11,8 \\
\hline 04 & - & 1,2 & 3,6 & - & - & 3,4 & - & - & - & - & - & 19,6 \\
\hline 05 & - & - & 3,0 & - & - & 54,0 & - & - & - & - & - & 8,6 \\
\hline 06 & - & - & 14,8 & - & - & 27,8 & - & - & 0,2 & - & - & - \\
\hline 07 & - & - & - & - & - & - & - & - & - & 5,8 & 4,4 & - \\
\hline 08 & 3,2 & - & - & - & - & - & - & 1,4 & - & - & - & 32,4 \\
\hline 09 & 18,6 & - & - & - & - & - & - & - & - & - & - & - \\
\hline 10 & 1,6 & - & - & - & - & - & - & - & - & - & - & - \\
\hline 11 & 28,2 & - & - & - & - & - & - & - & 0,2 & - & - & - \\
\hline 12 & 8,0 & - & - & - & - & 12,6 & - & - & - & - & 4,8 & - \\
\hline 13 & 17,8 & - & - & - & - & - & - & - & - & - & - & - \\
\hline 14 & 4,0 & - & 24,8 & - & - & - & - & - & 15,8 & - & 9,4 & 1,2 \\
\hline 15 & 2,1 & 15,0 & - & - & - & 16,8 & - & - & 29,8 & - & 20,8 & 22,4 \\
\hline 16 & 1,0 & 5,4 & 2,2 & 24,8 & - & 10,6 & - & - & 2,2 & 1,6 & 2,6 & 3,2 \\
\hline 17 & - & 38,8 & - & - & 0,4 & - & - & - & - & 3,6 & 43,4 & - \\
\hline 18 & 13,6 & 14,0 & - & - & - & $=$ & - & - & - & - & 28,8 & - \\
\hline 19 & - & - & - & - & - & - & - & - & - & 1,8 & 48,8 & - \\
\hline 20 & 40,8 & - & 0,1 & - & - & - & - & - & - & - & - & - \\
\hline 21 & 14,6 & 0,4 & - & 2,2 & - & 12,2 & 6,8 & - & 29,4 & 22,8 & - & - \\
\hline 22 & 0,2 & - & - & - & - & - & 14,8 & - & 0,4 & - & 9,4 & 4,4 \\
\hline 23 & 23,2 & - & - & - & 5,8 & - & - & - & - & - & - & - \\
\hline 24 & 21,4 & - & - & - & - & - & - & 13,6 & - & $=$ & 8,8 & - \\
\hline 25 & 59,2 & - & - & - & 42,6 & - & - & - & 0,2 & - & 74,6 & 111,4 \\
\hline 26 & 2,0 & - & - & - & 1,0 & - & - & - & 23,8 & 6,8 & - & 8,6 \\
\hline 27 & 23,0 & $=$ & - & - & - & - & - & - & - & 7,4 & 26,4 & - \\
\hline 28 & 48,6 & - & - & - & - & - & - & - & - & - & 34,8 & - \\
\hline 29 & 22,4 & $=$ & - & - & 11,8 & - & - & - & - & - & 0,3 & 2,2 \\
\hline 30 & - & - & - & - & - & - & - & - & 17,6 & - & - & - \\
\hline 31 & 13,0 & - & - & - & - & - & - & - & - & 1,8 & - & 8,6 \\
\hline Total & 366,5 & 133,0 & 48,5 & 53,6 & 61,6 & 137,4 & 21,6 & 15,0 & 119,6 & 68,6 & 359,9 & 240,6 \\
\hline
\end{tabular}

Total do ano: $1.625,9 \mathrm{~mm}$ 
Precipitação pluviométrica $(\mathrm{mm})$ registrada próximo a área experimental no decorrer do ano de 1998.

\begin{tabular}{|c|c|c|c|c|c|c|c|c|c|c|c|c|}
\hline & \multicolumn{12}{|c|}{ Meses } \\
\hline Dia & Jan. & Fev. & Mar. & Abr. & Mai. & Jun. & Jul. & Ago. & Set. & Out. & Nov. & Dez. \\
\hline & & & & & & & & & & & & \\
\hline 01 & - & - & - & 7,2 & - & - & - & - & - & 0,2 & - & - \\
\hline 02 & - & 4,8 & 0,2 & 2,6 & - & - & - & - & - & - & - & - \\
\hline 03 & - & - & 11,2 & - & - & - & - & 7,8 & - & - & - & - \\
\hline 04 & - & - & 9,2 & - & 18,4 & - & - & - & - & 7,6 & - & - \\
\hline 05 & - & 37,8 & 4,0 & - & 27,0 & - & - & 3,8 & - & - & - & 34,4 \\
\hline 06 & - & 9,8 & - & - & - & - & - & 5,2 & 8,0 & 22,0 & - & 48,2 \\
\hline 07 & - & - & - & - & - & - & - & - & - & - & - & - \\
\hline 08 & 5,2 & - & - & 2,6 & - & - & - & - & 8,2 & 23,0 & - & - \\
\hline 09 & 10,8 & - & - & 25,2 & - & - & 6,6 & 0,4 & 26,4 & 25,6 & - & - \\
\hline 10 & 2,8 & - & - & 2,2 & - & - & - & 3,6 & - & - & - & 30,2 \\
\hline 11 & - & 9,2 & - & - & - & - & - & - & - & - & 2,4 & 40,4 \\
\hline 12 & - & 21,8 & 10,2 & - & - & - & - & - & - & 23,4 & - & 16,8 \\
\hline 13 & 9,6 & 7,4 & - & - & - & - & - & - & - & - & - & - \\
\hline 14 & - & 49,2 & - & - & - & - & - & 9,2 & - & - & 14,0 & - \\
\hline 15 & - & 1,8 & - & - & - & - & - & - & - & - & - & 15,8 \\
\hline 16 & 15,6 & 135,8 & - & - & 0,8 & - & - & - & - & - & - & 17,8 \\
\hline 17 & 2,6 & 6,4 & - & 8,0 & 4,0 & - & - & - & - & 29,0 & - & 6,2 \\
\hline 18 & 34,0 & - & - & 9,2 & - & - & - & - & - & 2,0 & - & 0,2 \\
\hline 19 & - & 0,6 & - & - & - & 17,2 & - & - & 49,4 & - & - & - \\
\hline 20 & - & - & - & - & - & - & 9,2 & - & - & - & - & - \\
\hline 21 & - & 24,6 & - & - & - & - & - & - & 2,8 & - & - & - \\
\hline 22 & - & - & 40,8 & - & - & - & - & - & - & - & - & 0,4 \\
\hline 23 & - & - & 19,0 & - & - & - & - & - & - & - & - & 10,2 \\
\hline 24 & - & - & - & - & - & - & - & - & - & - & - & 33,6 \\
\hline 25 & 9,2 & 68,0 & - & - & - & 6,6 & - & - & - & - & - & 5,6 \\
\hline 26 & 9,4 & - & - & - & - & - & - & - & - & 5,4 & - & 5,6 \\
\hline 27 & - & 34,6 & - & 0,8 & 16,4 & - & - & - & - & 10,4 & 6,8 & - \\
\hline 28 & - & 15,4 & - & 7,8 & 13,0 & - & - & - & 10,6 & 3,4 & - & 7,8 \\
\hline 29 & 9,6 & - & 32,6 & 11,2 & - & - & - & - & 3,0 & 2,4 & - & 24,2 \\
\hline 30 & - & - & 10,4 & 4,6 & 37,4 & - & - & - & 3,4 & - & - & 0,8 \\
\hline 31 & - & - & - & - & - & - & - & - & - & 4,0 & - & - \\
\hline Total & 108,8 & 427,2 & 137,6 & 81,4 & 117,0 & 23,8 & 15,8 & 30,0 & 111,8 & 158,4 & 23,2 & 298,2 \\
\hline
\end{tabular}

Total do ano: $1.533,2 \mathrm{~mm}$ 


\section{APÊNDICE 2}

Desdobramento dos graus de liberdade de tratamentos em contraste ortogonal de interesse e teste $\mathrm{F}$ considerando-se cada experimento dentro de cada ano agrícola, para a variável produtividade da cana-de-açúcar.

\begin{tabular}{|c|c|c|c|c|c|}
\hline \multirow{3}{*}{ Causas da variação } & \multirow{3}{*}{ G.L. } & \multicolumn{4}{|c|}{ Q.M. } \\
\hline & & \multicolumn{2}{|c|}{ Lodo de esgoto } & \multicolumn{2}{|c|}{ Composto de lixo } \\
\hline & & $1996 / 97$ & $1997 / 98$ & $1996 / 97$ & $1997 / 98$ \\
\hline Blocos & 3 & - & - &..- & - \\
\hline Tratamentos & 4 & $315,9500^{* *}$ & $956,0000^{* *}$ & $559,3250^{* *}$ & $1148,8000^{* *}$ \\
\hline C.+Ad. M. x Doses A, B e C & 1 & $481,3333^{* * *}$ & $75,0000^{\text {ns }}$ & $36,7500^{\text {ns }}$ & $0,3333^{\mathrm{ns}}$ \\
\hline Resíduo & 12 & 23,0167 & 80,8000 & 20,7250 & 71,2000 \\
\hline C.V.(\%) & & 11,25 & 7,05 & 8,70 & 6,46 \\
\hline
\end{tabular}

significativo, pelo teste $\mathrm{F}$ a $1 \%(\mathrm{P} \leq 0,01)$;

${ }^{\text {ns }}$ não significativo pelo teste $\mathrm{F}$, considerando-se como n.m.s. $5 \%$.

Análise de variância e teste $\mathrm{F}$, considerando-se doses dos resíduos em cada experimento dentro de cada ano agrícola, para a variável carbono orgânico.

\begin{tabular}{lccccc}
\hline & \multirow{3}{*}{ G.L. } & \multicolumn{2}{c}{ Lodo de esgoto } & \multicolumn{2}{c}{ Composto de lixo } \\
\cline { 3 - 6 } Causas da variação & & $1996 / 97$ & $1997 / 98$ & $1996 / 97$ & $1997 / 98$ \\
\hline Blocos & 3 & - & - & - & - \\
Tratamentos & 3 & $41,1504^{* *}$ & $155,7097^{* *}$ & $54,2928^{* *}$ & $224,4107^{* *}$ \\
Resíduo (A) & 9 & 0,3205 & 0,8146 & 0,8728 & 1,0764 \\
\hline Parcelas & 15 & - & - & - & - \\
Épocas de amostragem & 7 & $6,4791^{* * *}$ & $1,8779^{* *}$ & $5,8828^{* *}$ & $3,1609^{* *}$ \\
Trat. X Épocas de amostragem & 21 & $1,2097^{* *}$ & $0,7885^{*}$ & $0,8932^{* *}$ & $1,0764^{*}$ \\
Resíduo (B) & 84 & 0,2309 & 0,4127 & 0,3311 & 0,4808 \\
\hline C.V (\%) (A) & & 2,12 & 2,73 & 3,46 & 3,03 \\
C.V.(\%) (B) & & 5,09 & 5,50 & 6,02 & 5,73 \\
\hline
\end{tabular}

\footnotetext{
"significativo, pelo teste $\mathrm{F}$ a $1 \%(\mathrm{P} \leq 0,01)$

significativo pelo teste $\mathrm{F}$ a $5 \%(\mathrm{P} \leq 0,05)$;

${ }^{n s}$ não significativo pelo teste $F$, considerando-se como n.m.s. $\mathbf{5 \%}$.
} 
Análise de variância e teste $\mathrm{F}$, considerando-se apenas as doses $\mathrm{A}, \mathrm{B}$ e $\mathrm{C}$ dos resíduos em cada experimento dentro de cada ano agrícola, para a variável gradiente de carbono.

\begin{tabular}{lrrrrr}
\hline \multirow{2}{*}{ Causas da variação } & \multirow{2}{*}{ G.L. } & \multicolumn{2}{c}{ Lodo de esgoto } & \multicolumn{2}{c}{ Composto de lixo } \\
& & $1996 / 97$ & $1997 / 98$ & $1996 / 97$ & $1997 / 98$ \\
\hline Blocos & 3 & - & - & & - \\
Tratamentos & 2 & $14,3137^{* *}$ & $79,5934^{* *}$ & $26,5749^{* *}$ & $130,6199^{* *}$ \\
Resíduo (A) & 6 & 0,4109 & 1,0510 & 0,8728 & 0,6423 \\
\hline Parcelas & 11 & - & - & - & - \\
Épocas de amostragem & 7 & $6,2991^{* *}$ & $6,2983^{* *}$ & $7,5368^{* *}$ & $5,1303^{* *}$ \\
Trat. x Épocas de amostragem & 14 & $1,0260^{* *}$ & $0,4040^{\text {ns }}$ & $0,3977^{\text {ns }}$ & $0,9936^{\text {ns }}$ \\
Resíduo (B) & 63 & 0,2945 & 0,6561 & 0,4139 & 0,7095 \\
\hline C.V (\%) (A) & & 11,40 & 10,12 & 15,24 & 6,84 \\
C.V.(\%) (B) & & 27,30 & 22,61 & 30,08 & 20,33 \\
\hline
\end{tabular}

significativo, pelo teste $\mathrm{F}$ a $1 \%(\mathrm{P} \leq 0,01)$;

${ }^{\text {ns }}$ não significativo pelo teste $F$, considerando-se como n.m.s. $5 \%$.

Análise de variância e teste $\mathrm{F}$, considerando-se doses dos resíduos em cada experimento dentro de cada ano agrícola, para a variável condutividade elétrica.

\begin{tabular}{lrrrrr}
\hline & & \multicolumn{3}{c}{ Q.M. } \\
\cline { 3 - 6 } Causas da variação & G.L. & \multicolumn{2}{c}{ Lodo de esgoto } & \multicolumn{2}{c}{ Composto de lixo } \\
& & $1996 / 97$ & $1997 / 98$ & $1996 / 97$ & $1997 / 98$ \\
\hline Blocos & 3 & - & - & - & - \\
Tratamentos & 3 & $1668492,2^{* *}$ & $1268666,4^{* *}$ & $138233,24^{* *}$ & $227841,86^{* *}$ \\
Resíduo (A) & 9 & 3224,27 & 9751,11 & 3052,92 & 3222,80 \\
\hline Parcelas & 15 & - & - & - & - \\
Épocas de amostragem & 6 & $722404,98^{* *}$ & $193853,58^{* *}$ & $71140,98^{* *}$ & $37996,97^{* *}$ \\
Trat. x Épocas de amostragem & 18 & $77433,61^{* *}$ & $22512,54^{* *}$ & $13689,05^{* *}$ & $8482,09^{* *}$ \\
Resíduo (B) & 72 & 5332,22 & 3038,49 & 2057,44 & 1225,01 \\
\hline C.V (\%) (A) & & 4,76 & 10,10 & 12,00 & 10,85 \\
C.V.(\%) (B) & & 16,21 & 14,92 & 26,07 & 17,69 \\
\hline
\end{tabular}

\footnotetext{
significativo, pelo teste F a $1 \%(\mathrm{P} \leq 0,01)$;

${ }^{\text {ns }}$ não significativo pelo teste $F$, considerando-se como n.m.s. $5 \%$.
} 
Análise de variância e teste $\mathrm{F}$, considerando-se doses dos resíduos em cada experimento dentro de cada ano agrícola, para a variável condutividade elétrica avaliada em profundidade.

\begin{tabular}{|c|c|c|c|c|c|}
\hline \multirow{3}{*}{ Causas da variação } & \multirow{3}{*}{ G.L. } & \multicolumn{4}{|c|}{ Q.M. } \\
\hline & & \multicolumn{2}{|c|}{ Lodo de esgoto } & \multicolumn{2}{|c|}{ Composto de lixo } \\
\hline & & $1996 / 97$ & $1997 / 98$ & $1996 / 97$ & $1997 / 98$ \\
\hline Blocos & 3 & - & - & - & - \\
\hline Tratamentos & 3 & $153075,24^{* *}$ & $266756,77^{*}$ & $5087,65^{* *}$ & $18299,08^{* *}$ \\
\hline Resíduo (A) & 9 & 4750,78 & 2365,26 & 365,92 & 269,93 \\
\hline Parcelas & 15 & - & - & - & - \\
\hline Profundidade da amostra & 3 & $56525,09^{* *}$ & $27274,76^{* *}$ & $3651,19^{* *}$ & $4026,29 *$ \\
\hline Trat. x Prof. da amostra & 9 & $7029,79^{* *}$ & $5928,63^{* *}$ & $218,45^{\mathrm{ns}}$ & $394,81^{\mathrm{ns}}$ \\
\hline Resíduo (B) & 36 & 1101,08 & 1346,97 & 317,88 & 213,01 \\
\hline C.V $(\%)(A)$ & & 16,45 & 11,59 & 10,57 & 7,82 \\
\hline C.V.(\%) (B) & & 15,84 & 17,50 & 19,70 & 13,89 \\
\hline
\end{tabular}

significativo, pelo teste $\mathrm{F}$ a $1 \%(\mathrm{P} \leq 0,01)$;

* significativo pelo teste $\mathrm{F}$ a $5 \%(\mathrm{P} \leq 0,05)$;

${ }^{\text {ns }}$ não significativo pelo teste $\mathrm{F}$, considerando-se como n.m.s. $5 \%$.

Análise de variância e teste $\mathrm{F}$, considerando-se doses dos resíduos em cada experimento dentro de cada ano agrícola, para a variável $\mathrm{pH}$.

\begin{tabular}{lccccc}
\hline & & \multicolumn{3}{c}{ Q.M. } \\
\cline { 3 - 6 } Causas da variação & G.L. & \multicolumn{2}{c}{ Lodo de esgoto } & \multicolumn{2}{c}{ Composto de lixo } \\
& & $1996 / 97$ & $1997 / 98$ & $1996 / 97$ & $1997 / 98$ \\
\hline Blocos & 3 & - & - & - & - \\
Tratamentos & 3 & $41,8389^{* *}$ & $58,9791^{* *}$ & $4,7602^{* *}$ & $20,5017^{* *}$ \\
Resíduo (A) & 9 & 0,0904 & 0,1581 & 0,1130 & 0,0895 \\
\hline Parcelas & 15 & - & - & - & - \\
Épocas de amostragem & 6 & $0,4599^{* *}$ & $0,2020^{* *}$ & $0,4659^{* *}$ & $0,1464^{\text {ns }}$ \\
Trat. x Épocas de amostragem & 18 & $0,2133^{* *}$ & $0,0541^{\text {ns }}$ & $0,0725^{* *}$ & $0,1338^{*}$ \\
Resíduo (B) & 72 & 0,0648 & 0,0414 & 0,0254 & 0,0667 \\
\hline C.V (\%) (A) & & 1,91 & 2,36 & 2,70 & 2,08 \\
C.V.(\%) (B) & & 4,27 & 3,19 & 3,39 & 4,75 \\
\hline
\end{tabular}

\footnotetext{
significativo, pelo teste $\mathrm{F}$ a $1 \%(\mathrm{P} \leq 0,01)$

significativo pelo teste $\mathrm{F}$ a $5 \%(\mathrm{P} \leq 0,05)$;

${ }^{n s}$ não significativo pelo teste $F$, considerando-se como n.m.s. $5 \%$.
} 
Análise de variância e teste $\mathrm{F}$, considerando-se doses dos resíduos em cada experimento dentro de cada ano agrícola, para a variável $\mathrm{pH}$ avaliada em profundidade.

\begin{tabular}{lccccc}
\hline & & \multicolumn{3}{c}{ Q.M. } \\
\cline { 3 - 6 } Causas da variação & G.L. & \multicolumn{2}{c}{ Lodo de esgoto } & \multicolumn{2}{c}{ Composto de lixo } \\
& & $1996 / 97$ & $1997 / 98$ & $1996 / 97$ & $1997 / 98$ \\
\hline Blocos & 3 & - & - & - & - \\
Tratamentos & 3 & $4,5247^{* *}$ & $4,3593^{* *}$ & $0,2960^{* *}$ & $1,1496^{* *}$ \\
Resíduo (A) & 9 & 0,1720 & 0,0276 & 0,0414 & 0,0303 \\
\hline Parcelas & 15 & - & - & $-* *$ & - \\
Profundidade da amostra & 3 & $8,4989^{* * *}$ & $17,4277^{* *}$ & $0,5310^{* *}$ & $8,0433^{* * *}$ \\
Trat. x Prof. da amostra & 9 & $1,2058^{* *}$ & $1,9109^{* *}$ & $0,1409^{* * *}$ & $0,9290^{* *}$ \\
Resíduo (B) & 36 & 0,0779 & 0,0231 & 0,0206 & 0,0106 \\
\hline C.V (\%) (A) & & 4,20 & 1,72 & 2,34 & 1,94 \\
C.V.(\%) (B) & & 5,66 & 3,15 & 3,31 & 2,30 \\
\hline
\end{tabular}

significativo, pelo teste $\mathrm{F}$ a $1 \%(\mathrm{P} \leq 0,01)$;

${ }^{\text {ns }}$ não significativo pelo teste $F$, considerando-se como n.m.s. $5 \%$.

Análise de variância e teste $\mathrm{F}$, considerando-se doses dos resíduos em cada experimento dentro de cada ano agrícola, para a variável CTC.

\begin{tabular}{lccccc}
\hline & & \multicolumn{5}{c}{ Q.M. } \\
\cline { 3 - 6 } Causas da variação & G.L. & \multicolumn{2}{c}{ Lodo de esgoto } & \multicolumn{2}{c}{ Composto de lixo } \\
& & $1996 / 97$ & $1997 / 98$ & $1996 / 97$ & $1997 / 98$ \\
\hline Blocos & 3 & & - & - & - \\
Tratamentos & 3 & $834,3487^{* *}$ & $914,3802^{* *}$ & $227,2173^{* *}$ & $608,7032^{* *}$ \\
Resíduo (A) & 9 & 0,8950 & 1,5727 & 3,4497 & 3,9726 \\
\hline Parcelas & 15 & - & - & - & - \\
Épocas de amostragem & 4 & $4,4795^{* *}$ & $4,6127^{* *}$ & $10,1919^{* *}$ & $7,7243^{* *}$ \\
Trat. x Épocas de amostragem & 12 & $0,8148^{\text {ns }}$ & $0,2505^{\text {ns }}$ & $3,4252^{\text {ns }}$ & $0,9506^{\text {ns }}$ \\
Resíduo (B) & 48 & 0,8974 & 0,3852 & 1,7525 & 1,9676 \\
\hline C.V (\%) (A) & & 1,02 & 1,36 & 2,29 & 2,29 \\
C.V.(\%) (B) & & 2,29 & 1,50 & 3,65 & 3,60 \\
\hline
\end{tabular}

\footnotetext{
significativo, pelo teste $\mathrm{F}$ a $1 \%(\mathrm{P} \leq 0,01)$;

${ }^{n s}$ não significativo pelo teste $F$, considerando-se como n.m.s. $5 \%$.
} 
Análise de variância e teste $\mathrm{F}$, considerando-se doses dos resíduos em cada experimento dentro de cada ano agrícola, para os toores totais de cobre no solo avaliados em profundidade.

\begin{tabular}{lccccc}
\hline & & \multicolumn{5}{c}{ Q.M. } \\
\cline { 3 - 6 } Causas da variação & G.L. & \multicolumn{2}{c}{ Lodo de esgoto } & \multicolumn{2}{c}{ Composto de lixo } \\
& & $1996 / 97$ & $1997 / 98$ & $1996 / 97$ & $1997 / 98$ \\
\hline Blocos & 3 & - & - & - & - \\
Tratamentos & 3 & $45,0899^{* *}$ & $142,2188^{* *}$ & $13,5013^{* *}$ & $29,4378^{* *}$ \\
Resíduo (A) & 9 & 3,9147 & 5,1362 & 6,0999 & 2,9060 \\
\hline Parcelas & 15 & - & - & - & - \\
Profundidade da amostra & 3 & $38,0008^{* *}$ & $311,0133^{* *}$ & $28,5594^{* *}$ & $93,5963^{* * *}$ \\
Trat. X Prof. da amostra & 9 & $42,6885^{* *}$ & $129,7517^{* *}$ & 3,1897 & $48,7024^{* *}$ \\
Resíduo (B) & 36 & 1,6275 & 6,5850 & 1,2231 & 3,0482 \\
\hline C.V (\%) (A) & & 4,53 & 4,66 & 5,83 & 3,86 \\
C.V.(\%) (B) & & 5,85 & 10,56 & 5,22 & 7,90 \\
\hline \hline
\end{tabular}

\footnotetext{
significativo, pelo teste F a $1 \%(\mathrm{P} \leq 0,01)$;

* significativo pelo teste $\mathrm{F}$ a $5 \%(\mathrm{P} \leq 0,05)$;

${ }^{\text {ns }}$ não significativo pelo teste $\mathrm{F}$, considerando-se como n.m.s. $5 \%$.
}

Análise de variância e teste $\mathrm{F}$, considerando-se doses dos resíduos em cada experimento dentro de cada ano agrícola, para os teores totais de cromo no solo avaliados em profundidade.

\begin{tabular}{lccccc}
\hline \multirow{2}{*}{ Causas da variação } & G.L. & \multicolumn{2}{c}{ Lodo de esgoto } & \multicolumn{2}{c}{ Q.M. } \\
\cline { 5 - 7 } & & $1996 / 97$ & $1997 / 98$ & $1996 / 97$ & $1997 / 98$ \\
\hline Blocos & 3 & - & - & - & - \\
Tratamentos & 3 & $29,3732^{*}$ & $48,8492^{* *}$ & $5,6632^{*}$ & $11,5406^{\text {ns }}$ \\
Resíduo (A) & 9 & 5,9278 & 1,7557 & 1,0594 & 5,2582 \\
\hline Parcelas & 15 & - & - & - & - \\
Profundidade da amostra & 3 & $56,9257^{* *}$ & $59,9292^{* *}$ & $173,4644^{* *}$ & $191,3249^{* *}$ \\
Trat. x Prof. da amostra & 9 & $16,5693^{* *}$ & $30,6587^{* *}$ & $1,8342^{\text {ns }}$ & $9,7948^{* *}$ \\
Resíduo (B) & 36 & 4,3228 & 3,2808 & 4,1592 & 3,3077 \\
\hline C.V (\%) (A) & & 5,43 & 2,91 & 2,38 & 5,24 \\
C.V.(\%) (B) & & 9,27 & 7,95 & 9,45 & 8,31 \\
\hline \hline
\end{tabular}

\footnotetext{
significativo, pelo teste F a $1 \%(\mathrm{P} \leq 0,01)$;

- significativo pelo teste $\mathrm{F}$ a $5 \%(\mathrm{P} \leq 0,05)$;

${ }^{n s}$ não significativo pelo teste $F$, considerando-se como n.m.s. $5 \%$.
} 
Análise de variância e teste $\mathrm{F}$, considerando-se doses dos resíduos em cada experimento dentro de cada ano agrícola, para os teores totais de zinco no solo avaliados em profundidade.

\begin{tabular}{lccccc}
\hline & & \multicolumn{3}{c}{ Q.M. } \\
\cline { 3 - 6 } Causas da variação & G.L. & \multicolumn{2}{c}{ Lodo de esgoto } & \multicolumn{2}{c}{ Composto de lixo } \\
& & $1996 / 97$ & $1997 / 98$ & $1996 / 97$ & $1997 / 98$ \\
\hline Blocos & 3 & - & - & - & - \\
Tratamentos & 3 & $266,2928^{* *}$ & $1878,4496^{* *}$ & $148,0144^{* *}$ & $444,3667^{* *}$ \\
Resíduo (A) & 9 & 20,1857 & 21,3466 & 3,4954 & 5,0607 \\
\hline Parcelas & 15 & - & $-*$ & - & - \\
Profundidade da amostra & 3 & $370,3378^{* *}$ & $4400,3489^{* *}$ & $104,4325^{* *}$ & $543,3189^{* * *}$ \\
Trat. x Prof. da amostra & 9 & $69,0643^{* *}$ & $938,0570^{* *}$ & $34,5271^{* *}$ & $145,4947^{* *}$ \\
Resíduo (B) & 36 & 7,7937 & 33,1387 & 3,7510 & 5,9831 \\
\hline C.V (\%) (A) & & 7,92 & 6,36 & 3,68 & 3,82 \\
C.V.(\%) (B) & & 9,84 & 15,84 & 7,62 & 8,30 \\
\hline \hline
\end{tabular}

"significativo, pelo teste $\mathrm{F}$ a $1 \%(\mathrm{P} \leq 0,01)$;

${ }^{\text {ns }}$ não significativo pelo teste $\mathrm{F}$, considerando-se como n.m.s. 5\%.

Análise de variância e teste $\mathrm{F}$, considerando-se doses dos resíduos em cada experimento dentro do ano agrícola 1996/97, para os teores de nitrogênio-total, nitrogênio orgânico e nitrogênio inorgânico $\left(\mathrm{N}_{-} \mathrm{NO}_{3}{ }^{-}+\mathrm{N}-\mathrm{NH}_{4}{ }^{+}\right)$no solo avaliados em profundidade.

\begin{tabular}{|c|c|c|c|c|c|c|c|}
\hline \multirow{3}{*}{ Causas da variação } & \multirow{3}{*}{ G.L. } & \multicolumn{6}{|c|}{ Q.M. } \\
\hline & & \multicolumn{2}{|c|}{ N-total } & \multicolumn{2}{|c|}{ N-orgânico } & \multicolumn{2}{|c|}{$\left(\mathrm{N}-\mathrm{NO}_{3}^{-}+\mathrm{N}-\mathrm{NH}_{4}^{+}\right)$} \\
\hline & & L.esgoto & C.lixo & L.esgoto & C.lixo & L.esgoto & C.lixo \\
\hline Blocos & 3 & - & - & - & - & - & - \\
\hline Tratamentos & 3 & $18767,6^{* *}$ & $9890,1^{* *}$ & $14286,1^{* *}$ & $9294,7^{* *}$ & $766,17^{* * *}$ & $9,72^{* *}$ \\
\hline Resíduo (A) & 9 & 384,1 & 491,7 & $6+4,8$ & 503,3 & 3,55 & 0,14 \\
\hline Parcelas & 15 & - & - & - & - & - & - \\
\hline Profundidade da amostra & 2 & $292446,1^{* *}$ & $286230,9^{* *}$ & $310045,4^{* *}$ & $269697,4^{* *}$ & $9,56^{*}$ & $249,74^{* 2}$ \\
\hline Trat. $x$ Prof. da amostra & 6 & $8240,3^{* *}$ & $7232,3^{* *}$ & $11028,4^{* *}$ & $6893,1^{* *}$ & $19,43^{* *}$ & $4,70^{* n}$ \\
\hline Resíduo (B) & 24 & 598,3 & 723,5 & 628,4 & 733,3 & 2,59 & 0,57 \\
\hline C.V $(\%)(A)$ & & 1,91 & 2,22 & 2,54 & 2,28 & 6,04 & 2,53 \\
\hline C.V.(\%) (B) & & 4,13 & 4,67 & 4,34 & 4,77 & 8,94 & 8,94 \\
\hline
\end{tabular}

\footnotetext{
significativo, pelo teste $\mathrm{F}$ a $\mathrm{l} \%(\mathrm{P} \leq 0,01)$

- significarivo pelo teste $\mathrm{F}$ a $5 \%(\mathrm{P} \leq 0,05)$;

${ }^{n s}$ não significativo pelo teste $\mathrm{F}$, considerando-se como n.m.s. $5 \%$.
} 